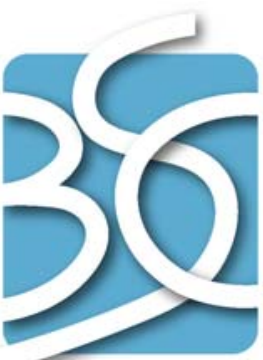

BECHTEL SAIC COMPANYLC
QA: QA

MDL-NBS-HS-000006 REV 02

October 2004
NOTICE OF OPEN CHANGE DOCUMENTS - THIS DOCUMENT IS IMPACTED BY THE LISTED CHANGE DOCUMENT AND CANNOT BE USED WITHOUT IT.

1) ACN-001, DATED 06/27/2005

\title{
UZ Flow Models and Submodels
}

Prepared for:

U.S. Department of Energy

Office of Civilian Radioactive Waste Management

Office of Repository Development

1551 Hillshire Drive

Las Vegas, Nevada 89134-6321

Prepared by:

Bechtel SAIC Company, LLC

1180 Town Center Drive

Las Vegas, Nevada 89144

Under Contract Number

DE-AC28-01RW12101 


\section{DISCLAIMER}

This report was prepared as an account of work sponsored by an agency of the United States Government. Neither the United States Government nor any agency thereof, nor any of their employees, nor any of their contractors, subcontractors or their employees, makes any warranty, express or implied, or assumes any legal liability or responsibility for the accuracy, completeness, or any third party's use or the results of such use of any information, apparatus, product, or process disclosed, or represents that its use would not infringe privately owned rights. Reference herein to any specific commercial product, process, or service by trade name, trademark, manufacturer, or otherwise, does not necessarily constitute or imply its endorsement, recommendation, or favoring by the United States Government or any agency thereof or its contractors or subcontractors. The views and opinions of authors expressed herein do not necessarily state or reflect those of the United States Government or any agency thereof. 
QA: QA

UZ Flow Models and Submodels

MDL-NBS-HS-000006 REV 02

October 2004 
2. Type of Mathemadcal Madel

Procas Modal

Atostrection Modes

System Model

Describe Invended Use of Moder

The purpose of this report is to document tho unsaturatied zone (UZ) fintid flow and golure transpors models and gulomodels as well as the flow fields generaned usilting the UZ flaw moldel of Yuta Mountain (UTZ Model), Nevadr.

\section{Tille}

UZ Flost Models and Subrondeis

4. - Dt fincluding Rey. No. Happlitoblet.

MDiLANBS-HS-000006 REVIO2:

5. Totel Appendicies

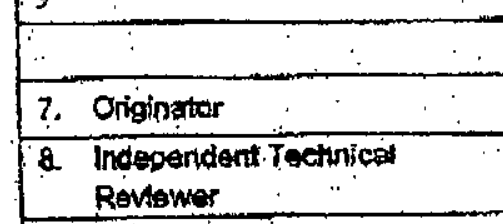

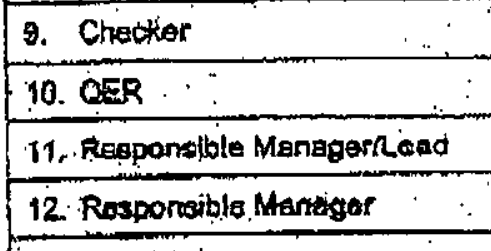

13. Remarks

Block6. One CD-ROM- "Files at Apperidix C for Mocel Repor MDI-NBS-HS-000006 REVO2." is included with Appendex C and suberitred with this report.

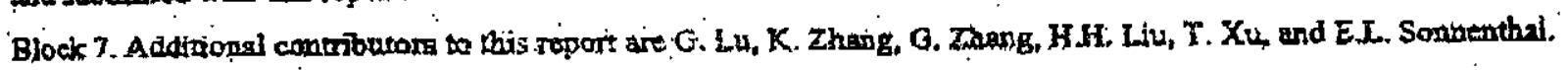

5. No. of Fages in Each Appendix

A-12, B-4,C-24, 1 CD, D-4, E-6, F-24, G-18, H-12, 1-14

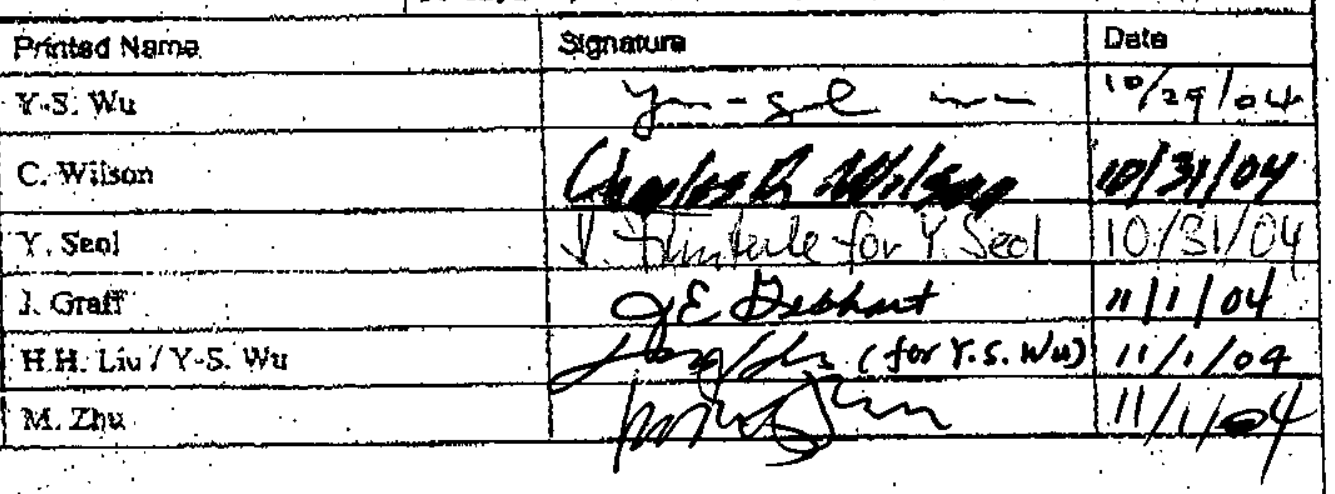

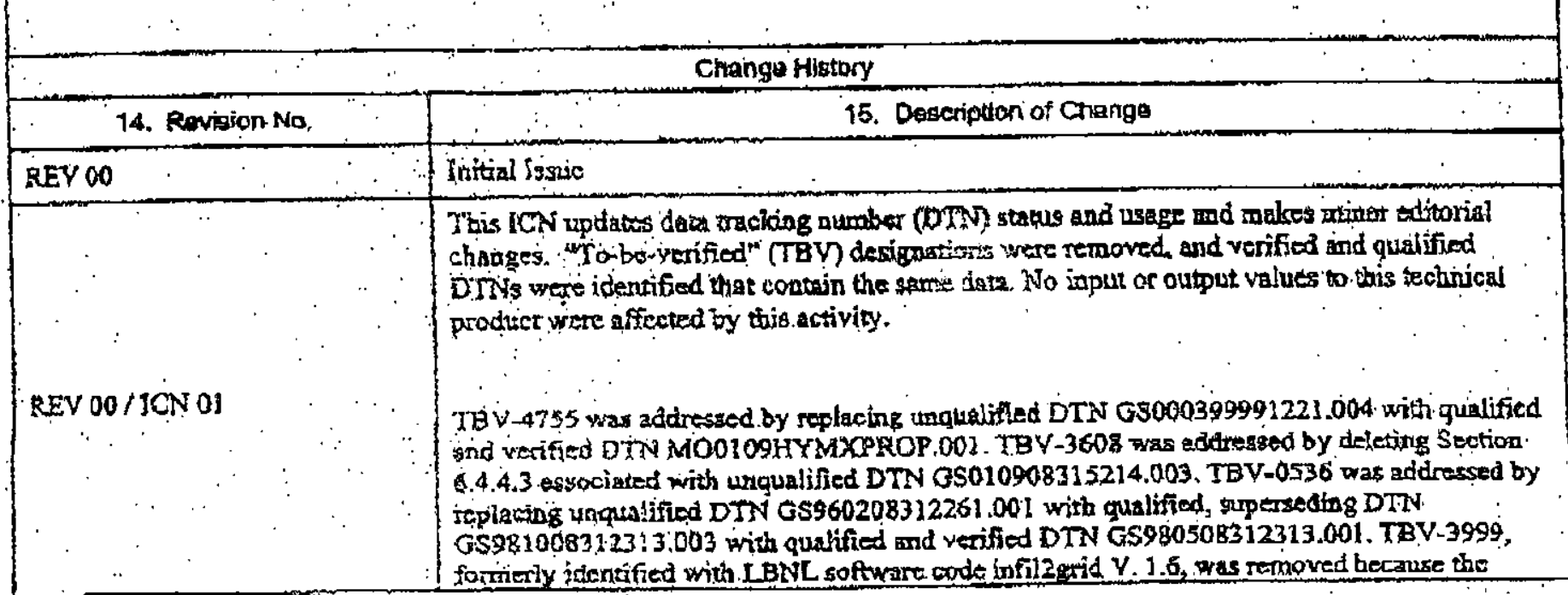




\begin{tabular}{|c|c|}
\hline & $\begin{array}{l}\text { associated software is now qualified. The input status of DTNs GS960908312231.004, } \\
\text { GS980408312232.001, and GS980908312242.036 was corrected to N/A - Corroborative } \\
\text { Information to reflect actual use of data in the report. Reference to input transmittals } \\
\text { MOL.19991027.0149, MOL.19991014.0102, MOL.20000118.0092 and MOL.19991213.0041 } \\
\text { was removed and replaced with DTN citations MO0109HYMXPROP.001, } \\
\text { GS000399991221.003, GS950308312231.002 and GS960808312231.004, respectively. } \\
\text { Table 3-1 was changed to identify the correct operational systems used in preparing the AMR. } \\
\text { Section 6.4.3.3 was determined to be unnecessary and was deleted along with the associated } \\
\text { Figure 6-32. Seven DTNs (LB991121233129.001 through LB991121233129.007) were } \\
\text { removed from Table 4-1 and Section } 8.3 \text { and inserted into Section } 8.4 \text { because they are actually } \\
\text { technical product outputs of this AMR. Incomplete reference citations in Section 8.1, 8.3, and } \\
\text { 8.4 were updated. } \\
\text { A printout of the Document Input Reference System (DIRS) sheets for this AMR, formerly } \\
\text { presented in Attachment I, has been replaced with a reference to the YMP electronic DIRS } \\
\text { database. } \\
\text { Attachment III of this technical product contains documentation of single use software routines } \\
\text { that were qualified under procedure AP-SI.1Q, Software Management, prior to the release of } \\
\text { Rev. } 3 \text { of said procedure. As the scope of the ICN did not involve a change to the routine } \\
\text { codes, and they have not been used to develop additional quality affecting information in this } \\
\text { technical product, these single use software routines will remain documented herein, in } \\
\text { accordance with AP-SI.1Q prior to release of Rev. 3. } \\
\text { These changes made in this ICN are identified by change bars. This ICN affects Sections 1, 2, } \\
\text { 3, 4, 6, 8, and Attachment I. Only the footer was changed in Attachment II and a footer with } \\
\text { page numbers was added to Attachment III. This ICN affects pages 17, 19, 21, 24-27, 41, 45, } \\
\text { 53, 54-55, 68, 73, 75, 77, 81, 83, 85, 88, 90, 102, 104-405, 125, 128-129, 142-144, 149, 152, } \\
\text { 159, 160-164, 166-170, I-1. }\end{array}$ \\
\hline REV 01 & $\begin{array}{l}\text { The entire model documentation was revised. Side bars are not used because the changes were } \\
\text { too extensive to use Step 5.9d)1) per AP-SIII.10Q, Rev. 1/ICN } 2 \text {. }\end{array}$ \\
\hline REV 01 ERRATA 001 & Response to CR-1357 \\
\hline REV 02 & $\begin{array}{l}\text { Increased transparency in response to the regulatory-focused evaluation performed by the } \\
\text { Regulatory Integration Team. Entire model documentation was revised. Side bars are not used } \\
\text { because the changes were too extensive to use Step 5.8f)1) per AP-SIII.10Q, REV 02, ICN } 07 \text {. }\end{array}$ \\
\hline
\end{tabular}




\section{CONTENTS}

Page

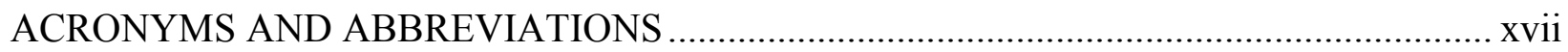

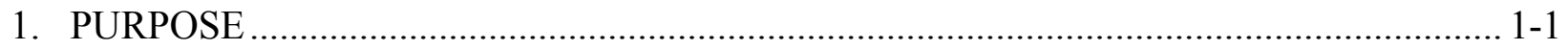

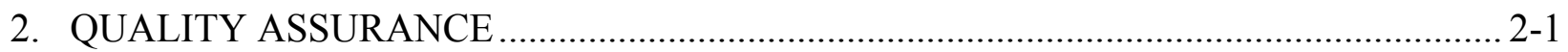

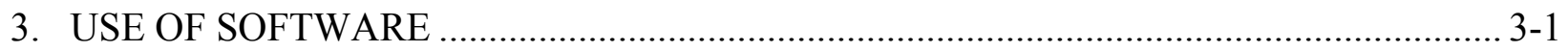

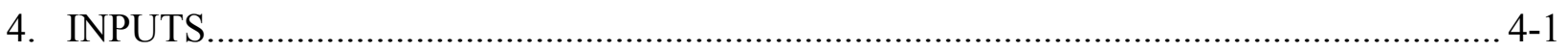

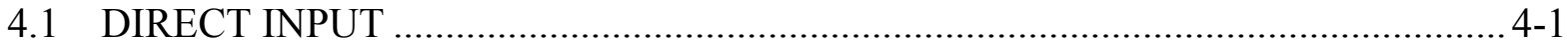

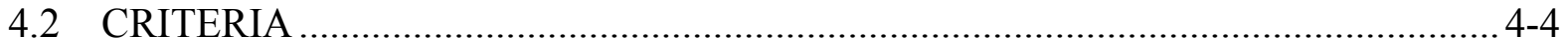

4.3 CODES, STANDARDS, AND REGULATIONS ................................................. 4-7

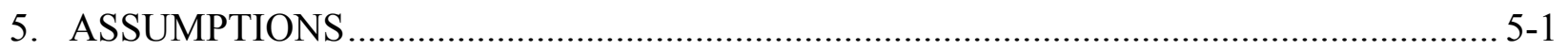

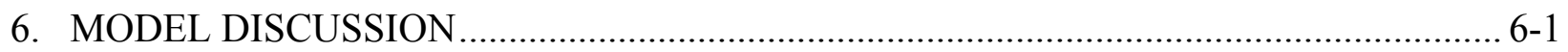

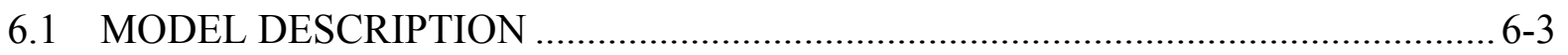

6.1.1 Geological Model and Numerical Grids .................................................. 6-3

6.1.2 Numerical Codes and Modeling Approach ……............................................. 6-7

6.1.3 Model Boundary Conditions................................................................. 6-11

6.1.4 Infiltration Scenarios...................................................................... 6-12

6.1.5 Model Parameters and Rock Properties..................................................... 6-16

6.2 THREE-DIMENSIONAL UZ FLOW MODEL CALIBRATION............................. 6-16

6.2.1 Calibration Data ..................................................................................... 6-17

6.2.2 Conceptual Models of UZ Flow .......................................................... 6-18

6.2.2.1 Capillary Barriers ..................................................................... 6-19

6.2.2.2 Perched Water ......................................................................... 6-19

6.2.3 Parameter Adjustment....................................................................... 6-20

6.2.4 Numerical Treatment and Solution Convergence......................................... 6-25

6.2.5 Simulation Scenarios, Results, and Analyses ........................................... 6-26

6.2.6 Features, Events, and Processes.................................................................. 6-31

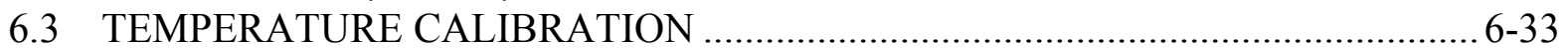

6.3.1 Three-Dimensional Thermal Model Grid .................................................. 6-33

6.3.2 Top Boundary Temperature.................................................................. 6-34

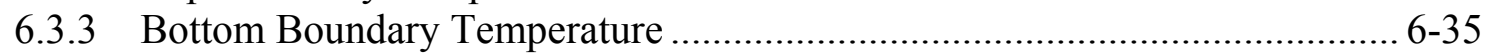

6.3.4 Calibration of Ambient Temperatures ...................................................... 6-35

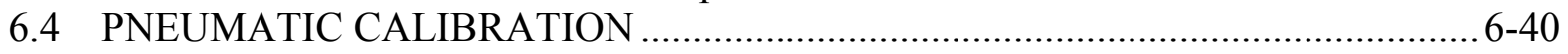

6.4.1 Model Parameters and Boundary Conditions ……....................................... 6-40

6.4.2 Modeling Approach and Calibration ...................................................... 6-40

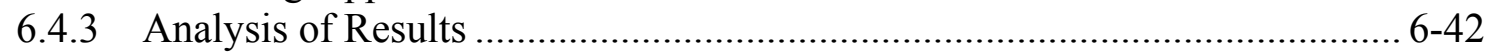

6.5 ANALYSIS AND MODELING OF PORE-WATER CHEMICAL DATA............... 6-43

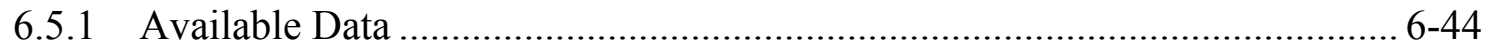




\section{CONTENTS (Continued)}

Page

6.5.1.1 Pore-Water Chemical Concentration Data .................................... 6-44

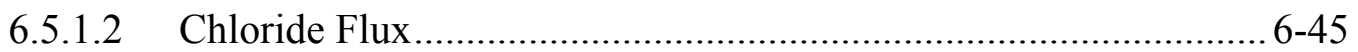

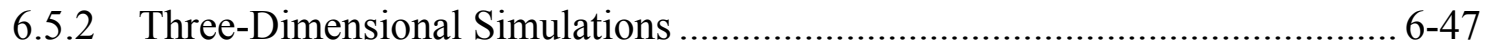

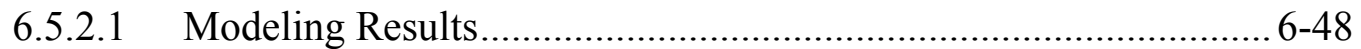

6.5.2.2 Alternative Model......................................................................... 6-48

6.6 FLOW PATTERN ANALYSIS OF TSPA-LA THREE-DIMENSIONAL FLOW

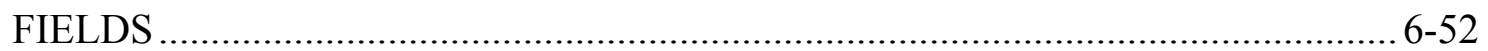

6.6.1 Simulation Scenarios ………………………..................................... 6-52

6.6.2 UZ Alternative Flow Model Results..................................................... 6-53

6.6.3 Flow Fields and Analyses ....................................................................... 6-54

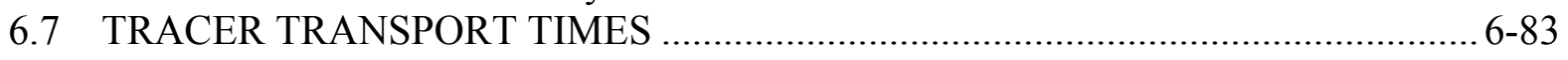

6.7.1 Methodology and Transport Parameters........................................................ 6-83

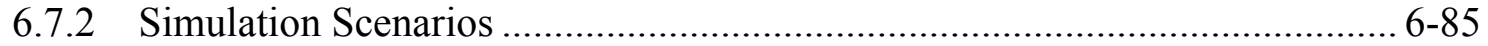

6.7.3 Simulation Results and Analyses.............................................................. 6-86

6.8 SENSITIVITY ANALYSES OF ACTIVE FRACTURE PARAMETER AND

FRACTURE POROSITY ………………………............................................. 6-97

6.8.1 Sensitivity Analyses of Flow Field with Respect to the Active Fracture

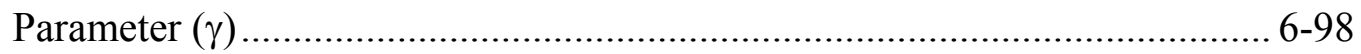

6.8.1.1 Liquid Saturation and Potential ....................................................... 6-99

6.8.1.2 Percolation Flux through Repository Layers................................ 6-101

6.8.2 Sensitivity Analyses of Transport............................................................ 6-101

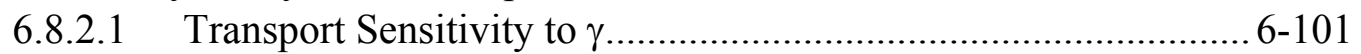

6.8.2.2 Transport Sensitivity to Fracture Porosity................................... 6-103

6.9 UNCERTAINTIES AND ALTERNATIVE MODELS ……………………........... 6-104

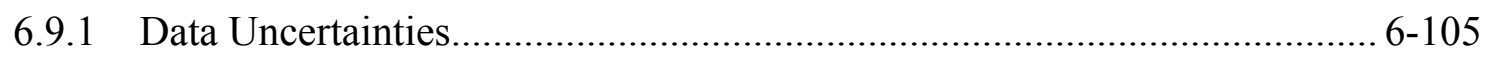

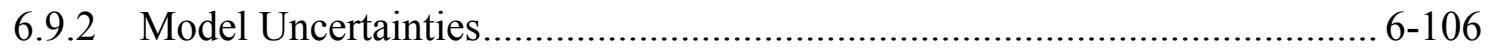

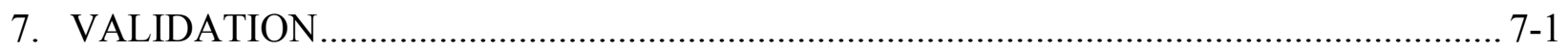

7.1 CONFIDENCE BUILDING DURING MODEL DEVELOPMENT ............................. 7-4

7.2 VALIDATION USING ECRB WATER-POTENTIAL MEASUREMENTS .............. 7-5

7.3 VALIDATION USING PERCHED-WATER DATA AT WT-24 ............................... 7-7

7.4 THREE-DIMENSIONAL PNEUMATIC MODEL PREDICTION ………................ 7-9

7.5 MODEL VALIDATION WITH ${ }^{14} \mathrm{C}$ DATA.........................................................

7.6 MODELING ANALYSIS OF ALCOVE 8/NICHE 3 FAULT TESTS ..................... 7-15

7.6.1 Field Observations ...............................................................................

7.6.2 Numerical Model ................................................................................

7.6.3 Model Simulations and Discussions ........................................................... 7-22

7.6.3.1 Calibration of Seepage-Rate Data and the Average

Water-Travel-Velocity Data.......................................................... 7-22

7.6.3.2 Effects of Matrix Diffusion ........................................................... 7-27

7.6.3.3 Implication for Radionuclide Transport in the Yucca Mountain UZ ……………………….................................... 7-31

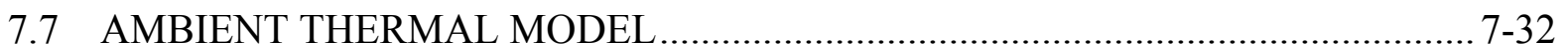




\section{CONTENTS (Continued)}

\begin{tabular}{|c|c|c|c|}
\hline & & & Page \\
\hline 7.8 & VALIL & DATION & USING CHLORIDE MEASUREMENTS ALONG ESF.............. \\
\hline & CALC & CITE MOD & OEL RESULTS \\
\hline & 7.9 .1 & Introduc & tion \\
\hline & 7.9.2 & Calcite $\mathrm{P}$ & recipitation Mechanisms \\
\hline & 7.9.3 & Reactive & -Transport Model \\
\hline & 7.9.4 & Hydroge & 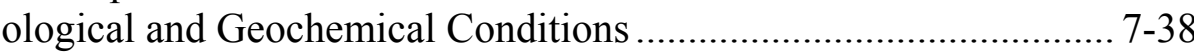 \\
\hline & & 7.9.4.1 & 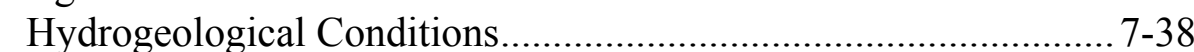 \\
\hline & & 7.9.4.2 & Geochemical Model \\
\hline & & 7.9.4.3 & Simulation Setup \\
\hline & 7.9 .5 & Results a & 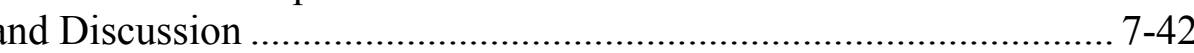 \\
\hline & & 7.9.5.1 & 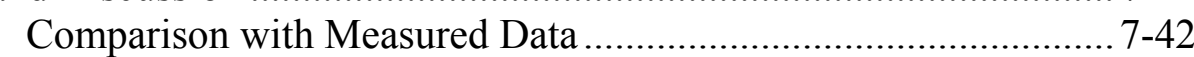 \\
\hline & & 7.9.5.2 & Calcite Precipitation in Fractures and Matrix........................... \\
\hline & & 7.9.5.3 & Spatial Variation in Calcite Deposition ................................ \\
\hline & 7.9.6 & Conclud & ing Remarks........ \\
\hline & MODE & EL VALII & DATION USING STRONTIUM GEOCHEMISTRY AND \\
\hline & ISOTO & OPIC RAT & IIOS \\
\hline & 7.10 .1 & Backgro & 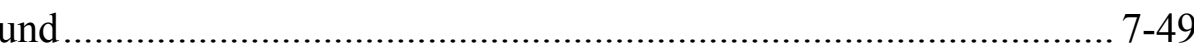 \\
\hline & 7.10 .2 & $\begin{array}{l}\text { Validatic } \\
\text { on Corro }\end{array}$ & $\begin{array}{l}\text { of of Conceptual and Numerical Models of UZ Transport Based } \\
\text { borative Information from Published Works............................ 7-49 }\end{array}$ \\
\hline & 7.10 .3 & Model fo & 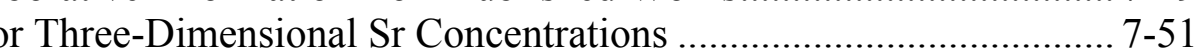 \\
\hline & REPRF & ESENTA & TION OF THE UZ FLOW FIELDS WITH A HIGHER \\
\hline & WATE & ER TABL & Е . \\
\hline & & MARY OF & \\
\hline
\end{tabular}

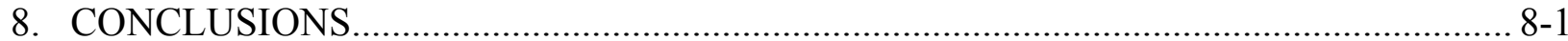

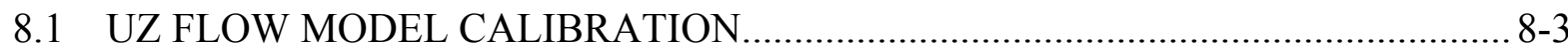

8.2 GEOTHERMAL MODEL CALIBRATION ....................................................... 8-4

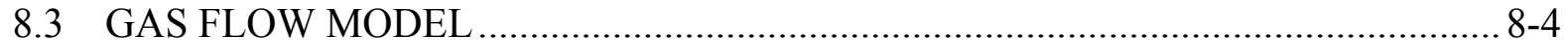

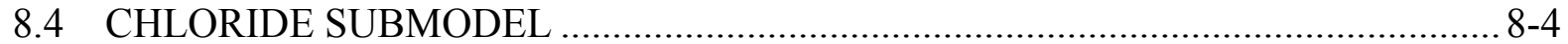

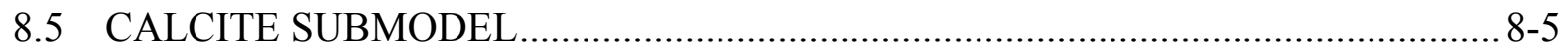

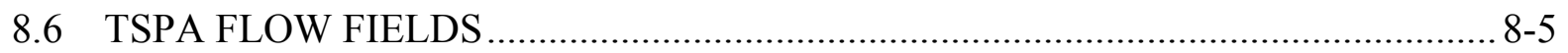

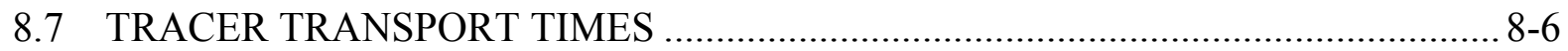

8.8 SENSITIVITY ANALYSIS OF ACTIVE-FRACTURE-MODEL PARAMETER ..... 8-7

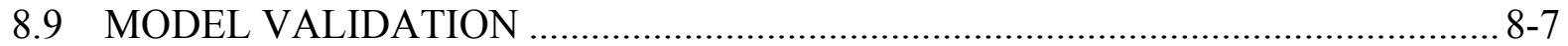

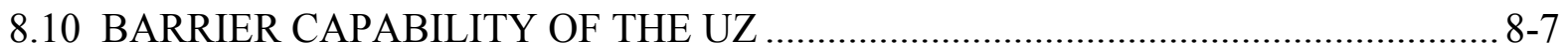

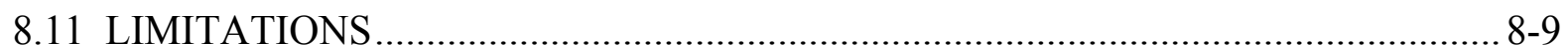

8.12 HOW ACCEPTANCE CRITERIA ARE ADDRESSED .......................................... 8-9

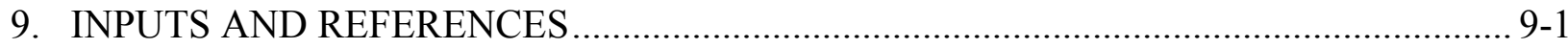

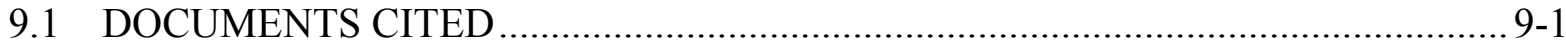

9.2 CODES, STANDARDS, REGULATIONS, AND PROCEDURES.......................... 9-13

9.3 SOURCE DATA, LISTED BY DATA TRACKING NUMBER …..........................9-13

9.4 OUTPUT DATA, LISTED BY DATA TRACKING NUMBER ……………..........9-20 


\section{CONTENTS (Continued)}

Page

9.5 SOFTWARE CODES

APPENDIX A - CALIBRATED PARAMETER SETS, COMBINING ONE-DIMENSIONAL INVERSIONS AND THREE-DIMENSIONAL PERCHED-WATER AND CHLORIDE-TRANSPORT MODELING USED IN GENERATING THE NINE FLOW FIELDS, AND TRACER TRANSPORT TIMES

APPENDIX B - LOCATION COORDINATES AND SURFACE ELEVATIONS OF SELECTED BOREHOLES USED IN MODEL CALIBRATION AND STUDIES

APPENDIX C - COMPUTATIONS IN INPUT DATA PREPARATIONS AND SIMULATION RESULT ANALYSES

APPENDIX D - PAINTBRUSH NONWELDED HYDROGEOLOGIC UNIT/TOPOPAH SPRING WELDED HYDROGEOLOGIC UNIT (PTn/TSw) FLUX AND FLOW-FIELD CONVERSION. D-1

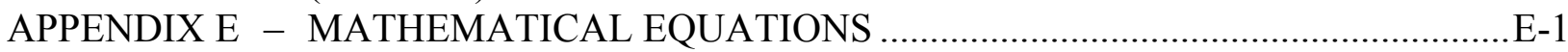
APPENDIX F - JUSTIFICATION OF THE USE OF PARAMETER SETS FOR MODELING FUTURE CLIMATE CONDITION F-1

APPENDIX G - JUSTIFICATION OF LATERAL FLOW AND SPATIAL SMOOTHING AND TEMPORAL DAMPING EFFECTS IN THE PAINTBRUSH NONWELDED HYDROGEOLOGIC UNIT G-1

APPENDIX $\mathrm{H}-{ }^{36} \mathrm{CL}$ STUDIES AT YUCCA MOUNTAIN $\mathrm{H}-1$ APPENDIX I - EVALUATION OF THE NEW INFILTRATION MAP 


\section{FIGURES}

6.1-1. Plan View of the Three-Dimensional UZ TSPA-LA Model Grid, Showing the Model Domain, Faults Incorporated, Repository Layout, and Several Borehole Locations

6.1-2. Plan View of Net Infiltration Distributed over the Three-Dimensional UZ TSPA-LA Model Grid for the Present-Day (Base-Case) Mean Infiltration Scenario.

6.1-3. Plan View of Net Infiltration Distributed over the Three-Dimensional UZ TSPA-LA Model Grid for the Monsoon Mean Infiltration Scenario

6.1-4. Plan View of Net Infiltration Distributed over the Three-Dimensional UZ TSPA-LA Model Grid for the Glacial-transition Mean Infiltration Scenario

6.2-1. Schematic Showing the Conceptualized Flow Processes and Effects of Capillary Barriers, Major Faults, and Perched-Water Zones within a Typical Cross Section of the UZ Flow Model Domain in the East-West Direction.

6.2-2. Comparison to the Simulated and Observed Matrix Liquid Saturations and Perched-Water Elevations for Borehole UZ-14, Using the Results of the Simulations with Three Mean Infiltration Rates.

6.2-3. Comparison to the Simulated and Observed Matrix Liquid Saturations and Perched-Water Elevations for Borehole SD-12, Using the Results of the Simulations with Three Mean Infiltration Rates

6.2-4. Comparison to the Simulated and Averaged Observed Water Potentials and Perched-Water Elevations for Borehole SD-12, Using the Results of the Simulations with Three Mean Infiltration Rates.

6.3-1. Plan View of the Three-Dimensional Thermal Model Grid, Showing the Model Domain, Faults Incorporated, Several Borehole Locations, and TH Model Boundaries

6.3-2. Comparisons between Measured and Modeled Ambient Temperature Profiles for the Five Boreholes under the Present-Day Mean Infiltration Rate.

6.3-3. Ambient Temperature Distributions at the Water Table for the Present-Day Mean Infiltration Scenario

6.3-4. Temperature Distributions at the Mountain Surface, the Top Model Boundary for the Present-Day Mean Infiltration Scenario

6.4-1. Comparison of Simulated and Observed Gas Pressure at Borehole SD-7 during a 60-Day Period

6.4-2. Comparison of Simulated and Observed Gas Pressure at Borehole SD-12 during the First 30-Day Period.

6.5-1. Chloride Concentration (mg/L) Profiles at Borehole USW NRG-6 for Present Recharge with Mean, Upper, and Lower Bounds and Glacial Recharge

6.5-2. Chloride Concentration (mg/L) Profiles at Borehole USW UZ-14 for Present Recharge with Mean, Upper, and Lower Bounds and Glacial Recharges.

6.5-3. Chloride Concentration (mg/L) Profiles at Borehole USW SD-9 for Present Recharge with Mean, Upper, and Lower Bounds and Glacial Recharge 6-51

6.5-4. Chloride Concentration (mg/L) Profiles at the ECRB for Present Recharge with Mean, Upper, and Lower Bounds $6-52$

6.6-1. Simulated Percolation Fluxes at the Repository Horizon under the Present-Day, Mean Infiltration Scenario Using the Results of Simulation preq mA. 6-56 


\section{FIGURES (Continued)}

Page

6.6-2. Simulated Percolation Fluxes at the Repository Horizon under the Monsoon, Mean Infiltration Scenario Using the Results of Simulation monq mA.

6.6-3. Simulated Percolation Fluxes at the Repository Horizon under the Glacial-transition Mean Infiltration Scenario Using the Results of Simulation glaq $\mathrm{mA}$.

6.6-4. Simulated Percolation Fluxes at the Water Table under the Present-Day, Lower-Bound Infiltration Scenario Using the Results of Simulating the Base-Case Model: preq 1A

6.6-5. Simulated Percolation Fluxes at the Water Table under the Present-Day, Lower-Bound Infiltration Scenario Using the Results of Simulating the Alternative Model: preq $1 \mathrm{~B}$

6.6-6. Simulated Percolation Fluxes at the Water Table under the Present-Day, Mean Infiltration Scenario Using the Results of Simulating the Base-Case Model: preq $\mathrm{mA}$

6.6-7. Simulated Percolation Fluxes at the Water Table under the Present-Day, Mean Infiltration Scenario Using the Results of Simulating the Alternative Model: preq $\mathrm{mB}$.....

6.6-8. Simulated Percolation Fluxes at the Water Table under the Present-Day, Upper-Bound Infiltration Scenario Using the Results of Simulating the Base-Case Model: preq uA

6.6-9. Simulated Percolation Fluxes at the Water Table under the Present-Day, Upper-Bound Infiltration Scenario Using the Results of Simulating the Alternative Model: preq_uB

6.6-10. Simulated Percolation Fluxes at the Water Table under the Monsoon, LowerBound Infiltration Scenario Using the Results of Simulating the Base-Case Model: monq 1A

6.6-11. Simulated Percolation Fluxes at the Water Table under the Monsoon, LowerBound Infiltration Scenario Using the Results of Simulating the Alternative Model: monq $1 \mathrm{~B}$

6.6-12. Simulated Percolation Fluxes at the Water Table under the Monsoon, Mean Infiltration Scenario Using the Results of Simulating the Base-Case Model: monq $\mathrm{mA}$

6.6-13. Simulated Percolation Fluxes at the Water Table under the Monsoon, Mean Infiltration Scenario Using the Results of Simulating the Alternative Model: monq $\mathrm{mB}$

6.6-14. Simulated Percolation Fluxes at the Water Table under the Monsoon, Upper-Bound Infiltration Scenario Using the Results of Simulating the Base-Case Model: monq u.....

6.6-15. Simulated Percolation Fluxes at the Water Table under the Monsoon, Upper-Bound Infiltration Scenario Using the Results of Simulating the Alternative Model: monq uB

6.6-16. Simulated Percolation Fluxes at the Water Table under the Glacial-transition, Lower-Bound Infiltration Scenario Using the Results of Simulating the Base-Case Model: glaq 1A 


\section{FIGURES (Continued)}

Page

6.6-17. Simulated Percolation Fluxes at the Water Table under the Glacial-transition, Lower-Bound Infiltration Scenario Using the Results of Simulating the

Alternative Model: glaq 1B

6.6-18. Simulated Percolation Fluxes at the Water Table under the Glacial-transition, Mean Infiltration Scenario Using the Results of Simulating the Base-Case Model: glaq $\mathrm{mA}$

6.6-19. Simulated Percolation Fluxes at the Water Table under the Glacial-transition, Mean Infiltration Scenario Using the Results of Simulating the Alternative Model: glaq_mB

6.6-20. Simulated Percolation Fluxes at the Water Table under the Glacial-transition, Upper-Bound Infiltration Scenario Using the Results of Simulating the Base-Case Model: glaq uA

6.6-21. Simulated Percolation Fluxes at the Water Table under the Glacial-transition, Upper-Bound Infiltration Scenario Using the Results of Simulating the Alternative Model: glaq uB

6.6-22. Areal Frequency and Distribution of Simulated Percolation Fluxes within the Repository Domain Normalized to the Three Mean Infiltration Rates: (a) Present Day, (b) Monsoon, and (c) Glacial-transition

6.6-23. Cumulative Flux Distribution and Range as Functions of Normalized Percolation Flux within the Repository from the 18 Flow Fields

6.7-1. Simulated Breakthrough Curves of Cumulative Tracer Mass Arriving at the Water Table, after Release from Fractures in the Repository, Using the Base-Case Flow Fields with the Nine Infiltration Scenarios of Present-Day, Monsoon, and Glacial-Transition Climates for Nonadsorbing and Adsorbing Tracers

6.7-2. Simulated Breakthrough Curves of Cumulative Tracer Mass Arriving at the Water Table, after Release from Fractures in the Repository, Using the Alternative Flow Fields with the Nine Infiltration Scenarios of Present-Day, Monsoon, and Glacial-Transition Climates for Nonadsorbing and Adsorbing Tracers

6.7-3. Comparison of Simulated Breakthrough Curves of Cumulative Tracer Mass Arriving at the Water Table, after Release from Fractures and Matrix Blocks in the Repository, Using the Base-Case and Alternative Flow Fields under the Present-Day Mean Infiltration Flow Fields for Nonadsorbing and Adsorbing Tracers.

6.7-4. Correlation of Average Infiltration Rates and Tracer Transport Times at 50 Percent Mass Breakthrough for the 36 Tracer-Fracture-Release Simulation Scenarios

6.7-5. Simulated Cumulative, Normalized Mass Arrival Contours of a Conservative Tracer at the Water Table after 1,000 Years, Indicating Potential Breakthrough Locations at the Time, Using the Present- Day, Mean Infiltration Scenario.

6.7-6. Simulated Cumulative, Normalized Mass Arrival Contours of a Reactive Tracer at the Water Table after 1,000 Years, Indicating Potential Breakthrough Locations at the Time, Using the Present-Day, Mean Infiltration Scenario. 


\section{FIGURES (Continued)}

Page

6.7-7. Simulated Cumulative, Normalized Mass Arrival Contours of a Conservative Tracer at the Water Table after 1,000,000 Years, Indicating Potential Breakthrough Locations at the Time, Using the Present-Day, Mean Infiltration Scenario

6.7-8. Simulated Cumulative, Normalized Mass Arrival Contours of a Reactive Tracer at the Water Table after 1,000,000 Years, Indicating Potential Breakthrough Locations at the Time, Using the Present-Day, Mean Infiltration Scenario

6.8-1. Comparison of (a) Simulated Matrix Liquid Saturation and (b) Water Potential Using Calibrated Hydraulic Properties (Solid Line) with That Obtained Using Smaller (Half) $\gamma$ of TSw Units (Dashed Line) for Borehole USW SD-6

6.8-2. Comparison of (a) Simulated Matrix Liquid Saturation and (b) Water Potentials Using Calibrated Hydraulic Properties (Solid Line) with that Obtained Using Smaller (Half) $\gamma$ of Under Repository Units (Dashed Line) for Borehole USW SD-6

6.8-3. Comparison of a Simulated Breakthrough Curve of Relative Tracer Mass at the Groundwater Table Obtained for the Base Case (Using Calibrated Rock Hydraulic Properties, Red Solid Line), a Case Using the Smaller $\gamma$ of TSw Units (Blue Dash Line), and Another Case Using the Smaller $\gamma$ of All Units below the Repository (Green Dash Line).

6.8-4. Comparison of Simulated Breakthrough Curve of Relative Tracer Mass at the Groundwater Table Obtained for the Base Case (Using Calibrated Rock Hydraulic Properties, Red Solid Line), and a Case Using a Smaller (1/10) Fracture Porosity (Blue Dash Line).

7.2-1. Comparison of Predicted and Measured Water Potential along ECRB Using the Present-Day, Mean Infiltration Rates (preq_mA).

7.3-1. Comparison of Predicted and Measured Matrix Water Potentials and Perched-Water Elevations at Borehole WT-24 Using the Present-Day Mean Infiltration Rate (preq_mA)

7.4-1. Comparison of Three-Dimensional Pneumatic Prediction to Observation Data from Borehole UZ-7a.

7.4-2. Comparison of Three-Dimensional Pneumatic Prediction to Observation Data from Borehole SD-12

7.5-1. Simulated Groundwater Age for UZ-1 Borehole Compared to the Measured ${ }^{14} \mathrm{C}$ Age

7.5-2. Simulated Groundwater Age for SD-12 Borehole Compared to the Measured ${ }^{14} \mathrm{C}$ Age.

7.6-1. Infiltration Rate as a Function of Time

7.6-2. Total Seepage Rate as a Function of Time

7.6-3. Water Travel Velocity Data for Boreholes 9 and 10 .......................................... 7-19

7.6-4. Observed Flux-Average Breakthrough Curve .... $7-20$

7.6-5. Cross-Sectional Schematic of the Three-Dimensional Numerical Grid Used for Modeling Studies of Alcove 8/Niche 3 


\section{FIGURES (Continued)}

7.6-6. A Comparison between Simulated Seepage Rates as a Function of Time (Run \#1) and Field Observations

7.6-7. A Comparison among Calculated Water Travel Velocities from Two Calibration Runs and the Velocity Data Observed from the Fault Test

7.6-8. A Comparison between Simulated Seepage Rates as a Function of Time (Run \#2) and Field Observations

7.6-9. Comparisons between Simulated Breakthrough Curves at the Niche for Two Different Fault-Matrix Interface Areas and the Observed Data

7.6-10. Comparisons between Simulated Breakthrough Curves (Considering Dispersion) at the Niche for the Increased Fault-Matrix Interface Areas and the Observed Data.... 7-31

7.7-1. Comparison of Simulated and Observed Temperature Profiles for Borehole H-5 ........ 7-33

7.7-2. Comparison of Simulated and Observed Temperature Profiles for Borehole H-4 ........ 7-33

7.7-3. Comparison of Simulated and Observed Temperature Profiles for Borehole WT-18

7.8-1. Comparison of Chloride Concentration (mg/L) Profiles under Present-Day Recharges with Mean, Upper, and Lower Bounds and Glacial-transition Recharge at the ESF...

7.9-1. Modeled Steady-State Water Saturations for the WT-24 Column Using Infiltration Rates: 2, 5.92, and $20 \mathrm{~mm} /$ year ..

7.9-2. Modeled Temperature Profiles in Borehole WT-24 as a Function of Depth for Three Infiltration Rates.

7.9-3. Simulated Total (Fracture Plus Matrix) Calcite Abundances (in ppmV or $10^{-6}$ Volume Fraction) in the WT-24 Column for Different Infiltration Rates after 10 Million Years: (a) Extended-Case Geochemical System, (b) Base-Case Geochemical System.

7.9-4. Modeled Calcite Abundances (in ppmV or 10-6 Volume Fraction) in Fractures and in the Matrix after 10 Million Years for Differing Infiltration Rates Using the Extended-Case Geochemical System

7.9-5. Modeled Calcite Abundances (in ppmV or $10^{-6}$ Volume Fraction) in Fractures and in the Matrix for (a) the Extended-Case and (b) Base-Case Geochemical Systems...... 7-45

7.9-6. Changes in Calcite Volume Fraction (ppmV) vs. Infiltration Rates for tsw4 Layer (at an Elevation of 1,126 m) for (a) the Extended-Case and (b) Base-Case Geochemical Systems .....

7.9-7. Calcite Abundances (in ppmV or $10^{-6}$ Volume Fraction) with Depth in Boreholes WT-24 and SD-6.

7.9-8. Geometric Means of Calcite Abundances with Depth for Boreholes WT-24 and SD-6.

7.10-1. Comparison of Measured and Modeled Sr Concentrations as a Function of Elevation for the Surface-Based Boreholes (a) SD-9 and (b) SD-12 $7-52$

7.10-2. Measured and Modeled Sr Concentrations in Pore Waters Extracted from Cores Taken in the ECRB 7-53 
INTENTIONALLY LEFT BLANK 


\section{TABLES}

Page

3-1. Qualified Software Used in This Report............................................................. 3-1

4.1-1. Input Data Source and Data Tracking Numbers ........................................................ 4-2

4.2-1. Project Requirements and Yucca Mountain Review Plan, Final Report (YMRP)

Acceptance Criteria Applicable to This Report .......................................................... 4-4

6-1. Scientific Notebooks Used in Model-Development Documentation............................ 6-2

6.1-1. GFM2000 Lithostratigraphy, UZ Model Layer, and Hydrogeological Unit Correlation Used in the UZ Flow Model and Submodels............................................. 6-3

6.1-2. Infiltration Rates (mm/year) Averaged over the UZ Model Domain .......................... 6-12

6.2-1. Borehole Data Used for Three-Dimensional Flow Model Calibration......................... 6-17

6.2-2. Calibrated PTn Fracture-Matrix Parameters for the Present-Day, Mean Infiltration

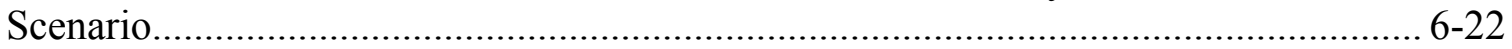

6.2-3. Calibrated PTn Fracture-Matrix Parameters for the Present-Day, Upper-Bound Mean Infiltration Scenario

6.2-4. Calibrated PTn Fracture-Matrix Parameters for the Present-Day, Lower-Bound Mean Infiltration Scenario

6.2-5. Calibrated Parameters of Perched-Water Conceptual Model for the Present-Day, Base-Case Infiltration Scenario

6.2-6. Calibrated Parameters of Perched-Water Conceptual Model for the Present-Day, Upper-Bound Infiltration Scenario

6.2-7. Calibrated Parameters of Perched-Water Conceptual Model for the Present-Day, Lower-Bound Infiltration Scenario

6.2-8. Calibrated TSw Fracture Permeability for the Present-Day, Mean Infiltration Scenario.

6.2-9. Nine UZ Flow Simulation Scenarios: Data Files, Parameter Sets, and Infiltration Maps for the UZ Model Calibrations.

6.2-10. Mass-Balance Results for Nine Flow Simulations

6.2-11. FEPs Addressed in This Report

6.3-1. Temperature Boreholes and Corresponding Element Columns of the Thermal Model Grid.

6.4-1. Observation Data and Corresponding Grid Columns of Boreholes SD-7 and SD-

12 Used in the Pneumatic Calibration

6.5-1. Chloride Data Sources

6.5-2. Present-Day and Glacial Infiltration Fluxes at Different Scenarios (Averaged over Model Domain, mm/year).

6.6-1. Nine Simulation Scenarios of Alternative UZ Flow, Data Files, Parameter Sets, and Infiltration Maps for the UZ Flow Fields

6.6-2. Mass-Balance Results for Nine Simulations of Alternative Flow Model..... 6-53 


\section{TABLES (Continued)}

Page

6.6-3. Comparison of the Water Flux through Matrix, Fractures of Non-fault Zones, and Faults as a Percentage of the Total Flux over the Entire Model Domain and within the Repository Footprint at Three Different Horizons (1) at the TCw/PTn Interface, (2) at the Repository Level, and (3) at the Water for the Nine Base-Case Flow Fields

6.6-4. Comparison of the Water Flux through Matrix, Fractures of Non-fault Zones, and Faults as a Percentage of the Total Flux over the Entire Model Domain and within the Repository Footprint at Three Different Horizons (1) at the TCw/PTn Interface, (2) at the Repository Level, and (3) at the Water for the Nine Alternative Flow Fields

6.7-1. $\mathrm{K}_{\mathrm{d}}$ Values Used for Reactive Tracer Transport in Different Hydrogeologic Units 6-84

6.7-2. Transport Simulation Scenarios: Data Files and Corresponding Nine Base-Case Flow Fields with Nine Infiltration Rates

6.7-3. Transport Simulation Scenarios: Data Files and Corresponding Nine Alternative Fields with Nine Infiltration Rates.

6.7-4. Tracer Transport Times at 10 Percent and 50 Percent Mass Breakthrough Times for 18 Transport Simulation Scenarios, Corresponding to the Nine Base-Case Flow Fields with Nine Infiltration Rates

6.7-5. Tracer Transport Times at 10 Percent and 50 Percent Mass Breakthrough Times for 14 Transport Simulation Scenarios, Corresponding to the Nine Alternative Flow Fields with Nine Infiltration Rates

6.8-1. The $\gamma$ Values Used in Flow Simulations for Sensitivity Analyses

6.8-2. Relative Changes of Fracture Flux in Response to the Changes in $\gamma$ 6-101

7.4-1. Observation Sensors in Borehole USW UZ-7a .................................................... 7-9

7.6-1. Uncalibrated Rock Properties ............................................................................. 7-23

7.6-2. Rock Properties Calibrated from Seepage Rate Data (Run \#1)................................ 7-25

7.6-3. Rock Properties Calibrated from Both Seepage Rate and Water Travel Velocity Data (Run \#2).

7.9-1. Hydrogeologic Units, Model Layers, and Hydrogeological Properties for the Yucca Mountain Unsaturated Zone Flow and Transport Model, as Given by the Calibrated Properties Model

7.9-2. Water and Gas Chemistry Used for Initial and Boundary Conditions of the Reaction-Transport Simulations $7-40$

8-1. Output Data and Data Tracking Numbers $8-2$

8-2. Percentage of Net Infiltration over Net Recharge after Evapotranspiration for Present-Day/Modern Climates over the Model Domain) $8-8$ 


\section{ACRONYMS AND ABBREVIATIONS}

AFM active fracture model

BSC Bechtel SAIC Company, LLC

CHn Calico Hills nonwelded hydrogeologic unit

ECRB Enhanced Characterization of Repository Block

ESF Exploratory Studies Facility

FEP Feature, Event, and Process

FEHM finite element heat and mass

LA license application

MINC multiple interacting continua

PTn Paintbrush nonwelded hydrogeologic unit

QA quality assurance

QARD Quality Assurance Requirements and Description

SR site recommendation

SZ saturated zone

TCw Tiva Canyon welded hydrogeologic unit

TDMS Technical Data Management System

TSPA total system performance assessment

TSw Topopah Spring welded hydrogeologic unit

TWP Technical Work Plan

USGS United States Geological Survey

UZ unsaturated zone

UZ model unsaturated zone flow models and submodels

YMP Yucca Mountain Project

YMRP Yucca Mountain Review Plan, Final Report 


\section{INTENTIONALLY LEFT BLANK}




\section{PURPOSE}

The purpose of this report is to document the unsaturated zone (UZ) flow models and submodels, as well as the flow fields that have been generated using the UZ flow model(s) of Yucca Mountain, Nevada. In this report, the term UZ model refers to the UZ flow model and the several submodels, which include tracer transport, temperature or ambient geothermal, pneumatic or gas flow, and geochemistry (chloride, calcite, and strontium) submodels. The term UZ flow model refers to the three-dimensional models used for calibration and simulation of UZ flow fields. This work was planned in the Technical Work Plan (TWP) for: Unsaturated Zone Flow Analysis and Model Report Integration (BSC 2004 [DIRS 169654], Section 1.2.7). The table of included Features, Events, and Processes (FEPs), Table 6.2-11, is different from the list of included FEPs assigned to this report in the Technical Work Plan for: Unsaturated Zone Flow Analysis and Model Report Integration (BSC 2004 [DIRS 169654], Table 2.1.5-1), as discussed in Section 6.2.6.

The UZ model has revised, updated, and enhanced the previous UZ model (BSC 2001 [DIRS 158726]) by incorporating the repository design with new grids, recalibration of property sets, and more comprehensive validation effort. The flow fields describe fracture-fracture, matrix-matrix, and fracture-matrix liquid flow rates, and their spatial distributions as well as moisture conditions in the UZ system. These three-dimensional UZ flow fields are used directly by Total System Performance Assessment (TSPA). The model and submodels evaluate important hydrogeologic processes in the UZ as well as geochemistry and geothermal conditions. These provide the necessary framework to test hypotheses of flow and transport at different scales, and predict flow and transport behavior under a variety of climatic conditions. In addition, the limitations of the UZ model are discussed in Section 8.11.

This model report relies on many direct inputs, as listed in Section 4, and other data sources. The required information and data sources are taken primarily from following reports: a conceptual model from Conceptual Model and Numerical Approaches for Unsaturated Zone Flow and Transport (BSC 2004 [DIRS 170035]); numerical grids from Development of Numerical Grids for UZ Flow and Transport Modeling (BSC 2004 [DIRS 169855]); fracture and matrix rock property data described in Analysis of Hydrologic Properties Data (BSC 2004 [DIRS 170038]) and in Calibrated Properties Model (BSC 2004 [DIRS 169857]); geological and mineralogical models of Geologic Framework Model (GFM2000) (BSC 2004 [DIRS 170029]) and Mineralogic Model (MM3.0) Report (BSC 2004 [DIRS 170031]); and future climate reports of Future Climate Analysis (BSC 2004 [DIRS 170002]); and infiltration rates from Simulation of Net Infiltration for Present-Day and Potential Future Climates (BSC 2004 [DIRS 170007])

The base-case three-dimensional flow fields are generated using the UZ flow model in this report. The flow fields are developed for nine spatially varying maps representing the mean, lower, and upper bounds of estimated net infiltration rates for the present-day climate and two projected future climates (monsoon and glacial-transition). This results in a total of nine base-case flow fields. In addition, nine alternative flow fields were also generated to assess the importance of lateral diversion in the Paintbrush nonwelded hydrogeologic unit (PTn). These flow fields have been submitted to the Technical Data Management System (TDMS) for TSPA 
activities. In particular, this report supports activities and investigations in a number of other model reports, including

- Ventilation Model and Analysis Report

- Multiscale Thermohydrologic Model

- Advection Versus Diffusion in the Invert

- EBS Radionuclide Transport Abstraction

- Seepage Model for PA Including Drift Collapse

- Seepage Calibration Model and Seepage Testing Data

- Mountain-Scale Coupled Processes (TH/THC/THM)

- Radionuclide Transport Models Under Ambient Conditions

- Drift-Scale Coupled Processes (DST and TH Seepage) Models

- Drift-Scale Radionuclide Transport

- Drift Scale THM Model

- Abstraction of Drift Seepage

- Particle Tracking Model and Abstraction of Transport Process

- Saturated Zone Flow

- Transport Model Abstraction

- Total System Performance Assessment (TSPA) Model/Analysis for the License Application.

The UZ flow models and submodels documented in this report include the UZ flow model(s), ambient thermal submodel, chloride submodel, calcite submodel, and strontium submodel. The UZ flow model is used for generating three-dimensional UZ flow fields, estimating current and future UZ conditions, and studying tracer-transport behavior. The ambient thermal or temperature submodel characterizes ambient geothermal conditions with temperature data for use in the UZ model and provides the boundary and initial condition for the mountain-scale coupled processes thermal-hydrologic (TH) model. The pneumatic data are used for additional calibration of the three-dimensional UZ flow model. The chloride submodel examines the spatial and temporal variations in chloride chemistry and the results are compared with pore-water concentrations measured in samples from boreholes, the Exploratory Studies Facility (ESF), and the Enhanced Characterization of Repository Block (ECRB) Cross-Drift. Modeling calcite deposition can be used to constrain hydrological parameters such as the infiltration-percolation flux. The calcite modeling also provides additional evidence for validation of the UZ model. In addition, the strontium submodel incorporates the effects of rate-limited dissolution and precipitation on the concentration of a solute, in addition to dispersion, radioactive decay, and linear equilibrium adsorption. The primary objectives of developing the UZ flow model and its submodels are:

- To integrate all the available field data and conceptual knowledge of the UZ system into a single, comprehensive, and calibrated three-dimensional model for simulating the ambient hydrological, thermal, and geochemical conditions, and for predicting system responses to future climate conditions.

- To quantify the flow of moisture, heat, and gas through the UZ under present-day and predicted future climate scenarios. 
- To perform detailed studies of perched water, percolation through the PTn, flow patterns through Calico Hills nonwelded $(\mathrm{CHn})$ zeolitic units, and pore-water chemical and calcite analyses.

- To predict the migration of potential radionuclide releases after waste emplacement.

- To contribute model parameters and boundary conditions for drift seepage and other modeling studies.

- To provide TSPA and Repository Design with a scientifically defensible and credible model of relevant UZ flow processes. 


\section{INTENTIONALLY LEFT BLANK}




\section{QUALITY ASSURANCE}

Development of this report and the supporting modeling activities have been determined to be subject to the Yucca Mountain Project's (YMP's) quality assurance (QA) program, as indicated in Technical Work Plan for: Unsaturated Zone Flow Analysis and Model Report Integration, TWP-MGR-HS-000001 (BSC 2004 [DIRS 169654], Section 8.1). Approved QA procedures identified in the TWP (BSC 2004 [DIRS 169654], Section 4) have been used to conduct and document the activities described in this report. The report was prepared under AP-SIII.10Q, Models. The TWP also identifies the methods used to control the electronic management of data (BSC 2004 [DIRS 169654], Section 8.4) during the modeling and documentation activities.

This report examines the properties of natural barriers that are classified in the Q-List (BSC 2004 [DIRS 168361]) as "Safety Category" because they are important to waste isolation, as defined in AP-2.22Q, Classification Analyses and Maintenance of the Q-List. The report contributes to the analysis and modeling data used to support TSPA. The conclusions of this report do not affect the repository design or engineered features important to safety, as defined in AP-2.22Q. 


\section{INTENTIONALLY LEFT BLANK}




\section{USE OF SOFTWARE}

The software and routines used in the modeling study of this report are listed in Table 3-1. These codes are appropriate for the intended application and were used strictly within the range of validation. These codes were obtained from Software Configuration Management in accordance with LP-SI.11Q-BSC, Software Management. All qualified software used in this report have been run on the OS Platform Version Numbers consistent with those listed in the Software Baseline Report readily available through the Software Configuration Management.

Table 3-1. Qualified Software Used in This Report

\begin{tabular}{|l|c|c|c|}
\hline \multicolumn{1}{|c|}{$\begin{array}{c}\text { Software Name, } \\
\text { Codes }\end{array}$} & Version & $\begin{array}{c}\text { Software Tracking } \\
\text { Number (STN) }\end{array}$ & $\begin{array}{c}\text { DIRS Reference } \\
\text { Number }\end{array}$ \\
\hline TOUGH2 & 1.4 & $10007-1.4-01$ & [DIRS 146496] \\
\hline T2R3D & 1.4 & $10006-1.4-00$ & [DIRS 146654] \\
\hline TOUGHREACT & 3.0 & $10396-3.0-00$ & [DIRS 161256] \\
\hline TOUGH2 & 1.6 & $10007-1.6-01$ & [DIRS 161491] \\
\hline infil2grid & 1.7 & $10077-1.7-00$ & [DIRS 154793] \\
\hline 2kgrid8.for & 1.0 & $10503-1.0-00$ & [DIRS 154787] \\
\hline bot_sum.f & 1.0 & $10349-1.0-00$ & [DIRS 153471] \\
\hline vf_con.for & 1.0 & $10466-1.0-00$ & [DIRS 154345] \\
\hline WINGRIDDER & 2.0 & $10024-2.0-00$ & [DIRS 154785] \\
\hline TOPTEMP_V0.f & 1.0 & $10224-1.0-00$ & [DIRS 147030] \\
\hline GET_TEMP_V0.f & 1.0 & $10222-1.0-00$ & [DIRS 147027] \\
\hline TBgas3D & 2.0 & $10882-2.0-00$ & [DIRS 160107] \\
\hline iTOUGH2 & 4.0 & $10003-4.0-00$ & [DIRS 139918] \\
\hline Bkread.f & 1.0 & $10894-1.0-00$ & [DIRS 162143] \\
\hline Smesh.f & 1.0 & $10896-1.0-00$ & [DIRS 162142] \\
\hline flow-con & 1.0 & $10993-1.0-00$ & [DIRS 163162] \\
\hline T2FEHM & 4.0 & $10997-4.0-00$ & [DIRS 163161] \\
\hline WTRISE & 2.0 & $10537-2.0-00$ & [DIRS 163453] \\
\hline ITOUGH2 & 5.0 & $10003-5.0-00$ & [DIRS 160106] \\
\hline
\end{tabular}

DIRS=Document Input Reference System

The use of the codes listed in Table 3-1 is documented in Section 6 and in the supporting scientific notebooks identified in Table 6-1. These codes and routines have been qualified under LP-SI.11Q-BSC, Software Management. The software code TOUGH2 V1.4 (LBNL 2000 [DIRS 146496]) is used to generate flow fields (Section 6) and to conduct model calibrations (Sections 6.2 and 6.3). Also, TOUGH2 V1.4 (LBNL 2000 [DIRS 146496]) is used to simulate three-dimensional gas flow (Section 6) and for geothermal calibrations. T2R3D V1.4 (LBNL 1999 [DIRS 146654]) is used for tracer transport simulations, tracer transport travel-time estimates (Section 6.8), and modeling pore-water chemistry (Section 6.5). TOUGHREACT V3.0 (LBNL [DIRS 161256] 2002) is used for conducting calcite studies (Section 7.9). TOUGH2 V1.6 (LBNL 2003 [DIRS 161491]) is used to simulate three-dimensional UZ flow (Appendix $\mathrm{I}^{1}$ ) for sensitivity analyses of a new infiltration map. WINGRIDDER V2.0 (LBNL 2002 [DIRS 154785]) is used to generate a three-dimensional thermal model grid (Section 6.3).

${ }^{1}$ Appendices A, B, C, D, E, F, G, and H are referred to elsewhere in this report. 
The infil2grid V1.7 software (LBNL 2002 [DIRS 154793]) is used to apply infiltration maps onto the grids used for simulating flow and transport (Section 6). ITOUGH2 V4.0 (LBNL 1999 [DIRS 139918]) is used for modeling Alcove 8/Niche 3 fault tests; while ITOUGH2 V5.0 (LBNL 2002 [DIRS 160106]) is used in fault property calibration in Appendix F.

Standard spreadsheet (Microsoft Excel 97 and Microsoft Excel 2002) and plotting programs (Tecplot V9.0) are also used but are exempt from software qualification requirements of LP-SI.11Q-BSC. Details and procedures for calculations using Excel and its standard functions in postprocessing and flow field extraction are provided in Appendix C. The infil2grid V1.7 software (LBNL 2002 [DIRS 154793]) is used, not V1.6 (LBNL 1999 [DIRS 134754]), because infil2grid V1.7 (LBNL 2002 [DIRS 154793]) can handle eight-character grid element names, while infil2grid V1.6 (LBNL 1999 [DIRS 134754]) cannot. For the same reason, 2kgrid8.for V1.0 (LBNL 2002 [DIRS 154787]) is also used to generate dual-permeability grids with eight-character element names.

The three-dimensional UZ flow fields are generated using a dual-permeability model with extra global fracture-matrix connections, which cannot be directly used by the finite element heat and mass (FEHM) code in TSPA calculations. Therefore, the TOUGH2 flow fields are converted using the routine: flow-con V1.0 (LBNL 2003 [DIRS 163162]) into flow fields on the dual-permeability mesh that does not have the extra fracture-matrix connections. These output flow field files of flow-con v1.0 are then used as input files to the routine: T2FEHM V4.0 (LBNL 2003 [DIRS 163161]), which converts TOUGH2 files in format of "flow9.dat" into files readable to FEHM.

The software WTRISE V2.0 (LBNL 2003 [DIRS 163453] is used in Section 6.6 .3 to handle the case for a higher future water table.

These software, mainly the TOUGH2 family of codes (TOUGH2, iTOUGH2, T2R3D, and TOUGHREACT), are selected to use in this model report because of their generalized capability in handling UZ flow and transport in fractured rock. There are no limitations in outputs in these software's within the range of use for modeling unsaturated flow and transport through fractured, porous rock. 


\section{INPUTS}

This section provides documentation for data (Table 4.1-1) used as direct inputs to this report. The Q-status of all input and a description of the data are shown in the Document Input Reference System database. The inputs to the modeling activities described in this report are obtained from the TDMS and include the following:

- Stratigraphy data from borehole logs

- Infiltration maps

- Calibrated fracture and matrix properties

- Geochemistry data from the ESF, the ECRB, and boreholes

- UZ model grids

- Temperature data for boreholes

- Pneumatic-pressure data

- Locations and elevations of perched water in boreholes

- Uncalibrated fracture properties

- Water-potential data

- Matrix liquid-saturation data

- Residual and satiated saturations.

\subsection{DIRECT INPUT}

The key input data used in the UZ flow model and its submodel development include the following (See Table 4.1-1):

- Fracture properties (frequency, permeability, van Genuchten $\alpha$ and $m$ parameters, porosity, and interface area per unit volume rock) for each UZ model layer

- Matrix properties (porosity, permeability, and the van Genuchten $\alpha$ and $m$ parameters) for each UZ model layer

- Thermal and transport properties (grain density, wet and dry thermal conductivity, grain specific heat, and tortuosity coefficients) for each UZ model layer

- Fault properties (fracture parameters) for each major hydrogeologic unit as defined by Table 6.1-1 (Note that matrix properties in faults are the same as the adjacent matrix blocks of nonfault zones).

The calibrated parameter sets also include an estimate for each model layer of the active-fracture parameter, $\gamma$, that accounts for the reduction in interaction between matrix and fracture flow resulting from flow fingering and channelization (Liu et al. 1998 [DIRS 105729]). Uncertainty in the input data and parameters are addressed in Section 6.9. Specific input data sets and associated data tracking numbers (DTN) are listed in Table 4.1-1. 
Table 4.1-1. Input Data Source and Data Tracking Numbers

\begin{tabular}{|c|c|c|c|c|}
\hline \multirow[b]{2}{*}{ Current DTN } & \multicolumn{3}{|c|}{ Location in this report } & \multirow[b]{2}{*}{ Description/Remarks } \\
\hline & Text & Figure & Table & \\
\hline $\begin{array}{l}\text { LB03023DKMGRID.001 } \\
\text { [DIRS 162354] }\end{array}$ & & $6.1-1$ & & $\begin{array}{l}\text { Three-dimensional } \\
\text { TSPA-LA model grid }\end{array}$ \\
\hline $\begin{array}{l}\text { GS000308311221.005 } \\
\text { [DIRS 147613] }\end{array}$ & $\begin{array}{l}\text { 6.1.4, } 6.5 \\
6.5 .1 .2 \\
6.8 .1,7.2\end{array}$ & $\begin{array}{l}\text { Figures } 6.1-2 \text {, } \\
6.1-3,6.1-4\end{array}$ & $\begin{array}{l}\text { Tables 6.1-2, } \\
6.2-9,6.5-2 \\
6.6-1,6.7-2 \\
6.7-3 \\
\end{array}$ & Net infiltration maps \\
\hline $\begin{array}{l}\text { LB02091DSSCP3I.002 } \\
\text { [DIRS 161433] }\end{array}$ & $\begin{array}{l}6.1 .5,6.2 \\
6.4 .1\end{array}$ & & & $\begin{array}{l}\text { One-dimensional site } \\
\text { scale calibrated } \\
\text { properties }\end{array}$ \\
\hline $\begin{array}{l}\text { LB02092DSSCFPR.002 } \\
\text { [DIRS 162128] }\end{array}$ & $\begin{array}{l}\text { 6.1.5, 6.2 } \\
6.3 .4,6.4 .1 \\
7.2\end{array}$ & & & $\begin{array}{l}\text { Two-dimensional site } \\
\text { scale calibrated fault } \\
\text { properties }\end{array}$ \\
\hline $\begin{array}{l}\text { LB0205REVUZPRP.001 } \\
\text { [DIRS 159525] }\end{array}$ & 6.2 .3 & & & Fracture properties \\
\hline $\begin{array}{l}\text { LB991121233129.001 } \\
\text { [DIRS 147328] }^{\mathrm{a}}\end{array}$ & 6.2 & & Table 6.2-2 & $\begin{array}{l}\text { PTn fracture-matrix } \\
\text { parameters (for } \\
\text { present-day, mean } \\
\text { infiltration) }\end{array}$ \\
\hline $\begin{array}{l}\text { LB991121233129.003 } \\
\text { [DIRS 147335] }^{\mathrm{a}}\end{array}$ & 6.2 & & Table 6.2-3 & $\begin{array}{l}\text { PTn fracture-matrix } \\
\text { parameters (for } \\
\text { present-day, } \\
\text { upper-bound infiltration) }\end{array}$ \\
\hline $\begin{array}{l}\text { LB991121233129.005 } \\
\text { [DIRS 147346] }^{\mathrm{a}}\end{array}$ & 6.2 & & Table 6.2-4 & $\begin{array}{l}\text { PTn fracture-matrix } \\
\text { parameters (for present- } \\
\text { day, lower-bound } \\
\text { infiltration) }\end{array}$ \\
\hline $\begin{array}{l}\text { GS950208312232.003 } \\
\text { [DIRS 105572] }\end{array}$ & $6.3 .2,6.3 .3$ & & & $\begin{array}{l}\text { Surface temperature for } \\
\text { Boreholes NRG-6 and } \\
\text { NRG-7a }\end{array}$ \\
\hline $\begin{array}{l}\text { GS970808312232.005 } \\
\text { [DIRS 105978], } \\
\text { GS971108312232.007 } \\
\text { [DIRS 105980] }\end{array}$ & 6.3 .3 & Figure 6.3-2 & & $\begin{array}{l}\text { Temperature data in } \\
\text { Boreholes NRG-7a, } \\
\text { SD-12 UZ\#4, UZ\#5, and } \\
\text { UZ-7a }\end{array}$ \\
\hline $\begin{array}{l}\text { GS031208312232.003 } \\
\text { [DIRS 171287] }\end{array}$ & $6.3 .2,6.3 .3$ & $\begin{array}{l}\text { Figure 6.2-4, } \\
\text { Figure 6.3-2 }\end{array}$ & Table 6.2-1 & $\begin{array}{l}\text { In situ water potential } \\
\text { measurement and } \\
\text { temperature data in } \\
\text { Boreholes NRG-6, } \\
\text { NRG-7a, SD-12 UZ\#4, } \\
\text { UZ\#5, and UZ-7a }\end{array}$ \\
\hline $\begin{array}{l}\text { LB0210THRMLPRP.001 } \\
\text { [DIRS 160799] }^{\mathrm{b}}\end{array}$ & $\begin{array}{l}\text { 6.3.4, 6.4.1, } \\
6.7 .1 \\
\end{array}$ & & & Thermal properties \\
\hline $\begin{array}{l}\text { LB0302AMRU0035.001 } \\
\text { [DIRS 162378] }\end{array}$ & 6.4 .1 & & & $\begin{array}{l}\text { Measured atmospheric } \\
\text { barometric pressure }\end{array}$ \\
\hline $\begin{array}{l}\text { GS960808312232.004 } \\
\text { [DIRS 105974] } \\
\text { GS970108312232.002 } \\
\text { [DIRS 105975] }\end{array}$ & 6.3 .3 & Figure 6.3-2 & & $\begin{array}{l}\text { Temperature data in } \\
\text { Boreholes NRG-6, } \\
\text { NRG-7a, SD-12 UZ\#4, } \\
\text { UZ\#5, and UZ-7a }\end{array}$ \\
\hline $\begin{array}{l}\text { LB991091233129.001 } \\
\text { [DIRS 125868] }^{\mathrm{C}}\end{array}$ & $6.4 .1,6.4 .2$ & $\begin{array}{l}\text { Figures } 6.2-4, \\
6.4-1,6.4-2, \\
7.4-2\end{array}$ & Table 6.4-1 & $\begin{array}{l}\text { Pneumatic pressure } \\
\text { data used for calibration }\end{array}$ \\
\hline
\end{tabular}


Table 4.1-1. Input Data Source and Data Tracking Numbers (Continued)

\begin{tabular}{|c|c|c|c|c|}
\hline \multirow[b]{2}{*}{ Current DTN } & \multicolumn{3}{|c|}{ Location in this report } & \multirow[b]{2}{*}{ Description/Remarks } \\
\hline & Text & Figure & Table & \\
\hline $\begin{array}{l}\text { LB02092DSSCFPR.001 } \\
\text { [DIRS 162422] }\end{array}$ & $6.4 .1,6.4 .2$ & Figure 7.4-1 & Table 7.4-1 & $\begin{array}{l}\text { Pneumatic pressure data } \\
\text { used for calibration }\end{array}$ \\
\hline $\begin{array}{l}\text { LA0003JC831362.001 } \\
\text { [DIRS 149557] }^{\mathrm{d}}\end{array}$ & $\begin{array}{l}6.7 .1 \\
6.8 .2 .1\end{array}$ & & & $\begin{array}{l}\text { Diffusion coefficients for } \\
\text { conservative and active } \\
\text { components }\end{array}$ \\
\hline $\begin{array}{l}\text { LA0010JC831341.001 [DIRS 162476] } \\
\text { LA0010JC831341.002 [DIRS 153321] } \\
\text { LA0010JC831341.003 [DIRS 153322] } \\
\text { LA0010JC831341.004 [DIRS 153323] } \\
\text { LA0010JC831341.005 [DIRS 153320] } \\
\text { LA0010JC831341.006 [DIRS 153318] } \\
\text { LA0010JC831341.007 [DIRS 153319] }\end{array}$ & 6.7 .1 & & Table 6.7-1 & Sorption coefficients \\
\hline $\begin{array}{l}\text { MO0109HYMXPROP.001 } \\
\text { [DIRS 155989] } \\
\text { GS980808312242.014 } \\
\text { [DIRS 106748] } \\
\text { LB0208UZDSCPMI.001 } \\
\text { [DIRS 161285] } \\
\text { SNT02110894001.002 } \\
\text { [DIRS 105067] } \\
\text { GS960308312312.005 } \\
\text { [DIRS 107230] } \\
\text { GS980708312242.010 } \\
\text { [DIRS 106752] } \\
\text { GS980508312313.001 } \\
\text { [DIRS 109746] }\end{array}$ & 6.2 & & Table 6.2-1 & $\begin{array}{l}\text { Matrix saturation, water } \\
\text { potential, or perched } \\
\text { water elevation data used } \\
\text { for calibration }\end{array}$ \\
\hline
\end{tabular}

Output: DTN: LB03013DSSCP3I.001 and DTN: LB0303THERMESH.001 are the output DTNs.

NOTE: these two DTNs are source DTNs for DTN: LB0303THERMSIM.001 and DTN: LB0303GASFLW3D.001 as well.

${ }^{a}$ DTNs: LB991121233129.001 (DIRS 147328), LB991121233129.003 [DIRS 147335], LB991121233129.005 (DIRS 147346) from historic technical product outputs are suitable for their intended use within this report because (1) these data were originated from a reliable source, (2) these data were generated by a qualified organization, Lawrence Berkeley National Laboratory, and (3) these data have been used in previous analyses of UZ flow and transport (i.e., they are pertinent to the properties of interest).

${ }^{\mathrm{b}}$ Note that several parameters, such as matrix porosity and thermal conductivities in a few units, of DTN: LB0210THRMLPRP.001 (DIRS 160799) has been updated in a different DTN. The DTN: LB0210THRMLPRP.001 (DIRS 160799) is still suitable for their intended use within this report, because these updated parameters have little impact on steady-state heat flow simulations and a recent sensitivity analysis (BSC 2004 [DIRS 169866]) has shown the insignificant effects of the updated parameters on simulation results under thermal loading conditions.

${ }^{c}$ DTN: LB991091233129.001 (DIRS 125868) from historic technical product outputs is suitable for its intended use in this report because (1) the measured pressure data of this data tracking number were measurements originated from a reliable source and have not been changed, and (2) the data set has been used in previous model calibration of UZ flow analyses.

d DTN: LA0003JC831362.001 (DIRS 149557) from the product output of a cancelled document is suitable for its intended use in this report because (1) the diffusion coefficient data of this data tracking number were originated from a reliable source, (2) these data were generated by a qualified organization, Los Alamos National Laboratory, and (3) the data have been used in the previous modeling analyses of UZ flow and transport.

DTN=data tracking number; LA=license application; PTn=Paintbrush nonwelded hydrogeologic unit; TSPA=total system performance assessment 
This report documents the flow models and submodels in the UZ model. It utilizes properties from two related UZ parameter reports of the Calibrated Properties Model (BSC 2004 [DIRS 169857]) and the Analysis of Hydrologic Properties Data (BSC 2004 [DIRS 170038]). The input and output files for the model runs presented in this report are listed in Tables 6.2-9, 6.6-1, 6.7-2, and 6.7-3, and some of the model input fracture and matrix parameters are given in Appendix A. The data used as direct input for the UZ flow model and UZ flow fields are all qualified in accordance with the requirements of Quality Assurance Requirements Description (QARD). The model input data are available, qualified data except some borehole temperature data used as corroboration for thermal model validation (Section 7.7) and sorption coefficient $\left(\mathrm{K}_{\mathrm{d}}\right)$ data used for $\mathrm{Sr}$ model validation (Section 7.10). The qualified data are appropriate for this study because they represent fracture and matrix properties calibrated for the UZ at Yucca Mountain. The appropriateness of the data is also discussed in Sections 6 and 7 where they are used for modeling and validation efforts.

\subsection{CRITERIA}

Technical requirements to be satisfied by performance assessment (PA) are based on 10 CFR 63.114 (DIRS 156605) (Requirements for Performance Assessment) and 10 CFR 63.115 (DIRS 156605) (Requirements for Multiple Barriers). They are identified in the Yucca Mountain Project Requirements Document (Canori and Leitner 2003 [DIRS 166275]). The acceptance criteria that will be used by the U.S. Nuclear Regulatory Commission to determine whether the technical requirements have been met are identified in the Yucca Mountain Review Plan, Final Report (YMRP) (NRC 2003 [DIRS 163274]). The pertinent requirements and acceptance criteria for this report are summarized in Table 4.2-1.

Table 4.2-1. Project Requirements and Yucca Mountain Review Plan, Final Report (YMRP) Acceptance Criteria Applicable to This Report

\begin{tabular}{|c|l|c|c|}
\hline $\begin{array}{c}\text { Requirement } \\
\text { Number }^{\mathrm{a}}\end{array}$ & \multicolumn{1}{|c|}{ Requirement Title $^{\mathrm{a}}$} & 10 CFR 63 Link & \multicolumn{1}{c|}{ YMRP Acceptance Criteria } \\
\hline PRD-002/T-015 & $\begin{array}{l}\text { Requirements for } \\
\text { Performance Assessment }\end{array}$ & 10 CFR 63.114(a-c) & $\begin{array}{l}\text { Criteria 1 to 4 for Flow Paths in the } \\
\text { Unsaturated Zone }\end{array}$ \\
\hline
\end{tabular}

a From Canori and Leitner 2003 (DIRS 166275).

b From NRC (2003 [DIRS 163274], Section 2.2.1.3.6.3).

YMRP $=$ Yucca Mountain Review Plan, Final Report

The acceptance criteria identified in Section 2.2.1.3.6 of the YMRP (NRC 2003 [DIRS 163274]) are included below. In cases where subsidiary criteria are listed in the YMRP for a given criterion, only the subsidiary criteria addressed by this model report are listed below. Where a subcriterion includes several components, only some of those components may be addressed. How these components are addressed is summarized in Section 8.12 of this report.

\section{Acceptance Criteria from Section 2.2.1.3.6, Flow Paths in the Unsaturated Zone}

\section{Acceptance Criterion 1, System Description and Model Integration Are Adequate:}

(1) The total system performance assessment adequately incorporates, or bounds, important design features, physical phenomena, and couplings, and uses consistent and appropriate assumptions throughout the flow paths in the 
unsaturated zone abstraction process. Couplings include thermal-hydrologicmechanical-chemical effects, as appropriate;

(2) The aspects of geology, hydrology, geochemistry, physical phenomena, and couplings that may affect flow paths in the unsaturated zone are adequately considered. Conditions and assumptions in the abstraction of flow paths in the unsaturated zone are readily identified and consistent with the body of data presented in the description.

(3) The abstraction of flow paths in the unsaturated zone uses assumptions, technical bases, data, and models that are appropriate and consistent with other related U.S. Department of Energy abstractions. For example, the assumptions used for flow paths in the unsaturated zone are consistent with the abstractions of quantity and chemistry of water contacting waste packages and waste forms, climate and infiltration, and flow paths in the saturated zone (Sections 2.2.1.3.3, 2.2.1.3.5, and 2.2.1.3.8 of the Yucca Mountain Review Plan, respectively). The descriptions and technical bases are transparent and traceable to site and design data;

(4) The bases and justification for modeling assumptions and approximations of radionuclide transport in the unsaturated zone are consistent with those used in model abstractions for flow paths in the unsaturated zone and thermal-hydrologic-mechanical-chemical effects;

(6) Adequate spatial and temporal variability of model parameters and boundary conditions are employed in process-level models to estimate flow paths in the unsaturated zone, percolation flux, and seepage flux.

(7) Average parameter estimates used in process-level models are representative of the temporal and spatial discretizations considered in the model.

(8) Reduction in unsaturated zone transport distances, after a climate-induced water table rise, is considered; and

(9) Guidance in NUREG-1297 and NUREG-1298 (Altman et al. 1988 [DIRS 103597 and DIRS 103750]), or other acceptable approaches for peer review and data qualification is followed.

\section{Acceptance Criterion 2, Data Are Sufficient for Model Justification:}

(1) Hydrological and thermal-hydrological-mechanical-chemical values used in the license application are adequately justified. Adequate descriptions of how the data were used, interpreted, and appropriately synthesized into the parameters are provided.

(2) The data on the geology, hydrology, and geochemistry of the unsaturated zone, are collected using acceptable techniques; 
(3) Estimates of deep-percolation flux rates constitute an upper bound, or are based on a technically defensible unsaturated zone flow model that reasonably represents the physical system. The flow model is calibrated, using site-specific hydrologic, geologic, and geochemical data. Deep-percolation flux is estimated, using the appropriate spatial and temporal variability of model parameters, and boundary conditions that consider climate-induced change in soil depths and vegetation.

(6) Accepted and well-documented procedures are used to construct and calibrate numerical models.

(7) Reasonably complete process-level conceptual and mathematical models are used in the analyses. In particular: (i) mathematical models are provided that are consistent with conceptual models and site characteristics; and (ii) the robustness of results from different mathematical models is compared.

\section{Acceptance Criterion 3, Data Uncertainty Is Characterized and Propagated through the Model Abstraction:}

(1) Models use parameter values, assumed ranges, probability distributions, and bounding assumptions that are technically defensible, reasonably account for uncertainties and variabilities, and do not result in an under-representation of the risk estimate.

(4) The initial conditions, boundary conditions, and computational domain used in sensitivity analyses and/or similar analyses are consistent with available data. Parameter values are consistent with the initial and boundary conditions and the assumptions of the conceptual models for the Yucca Mountain site.

(5) Coupled processes are adequately represented; and

(6) Uncertainties in the characteristics of the natural system and engineered materials are considered.

\section{Acceptance Criterion 4, Model Uncertainty Is Characterized and Propagated through the Model Abstraction:}

(1) Alternative modeling approaches of features, events, and processes, consistent with available data and current scientific understanding, are investigated. The results and limitations are appropriately considered in the abstraction.

(3) Consideration of conceptual model uncertainty is consistent with available site characterization data, laboratory experiments, field measurements, natural analog information and process-level modeling studies; and the treatment of conceptual model uncertainty does not result in an underrepresentation of the risk estimate. 


\subsection{CODES, STANDARDS, AND REGULATIONS}

No codes, standards, or regulations, other than those identified in the Project Requirements Documents (Canori and Leitner 2003 [DIRS 166275], Table 2-3) and determined to be applicable in Table 4.2-1, were used in this model report. 


\section{INTENTIONALLY LEFT BLANK}




\section{ASSUMPTIONS}

Assumptions are listed in this section only if they are necessitated by lack of data in the development of the UZ flow model and its submodels. Several approximations and idealizations are used for model development, such as selection of hydrogeological conceptual models, use of numerical modeling approaches, and specification of model boundary conditions. These are discussed and justified as appropriate in Section 6. In particular, the methodological premises used for specific modeling studies are more appropriately discussed in the context of the modeling methodologies in Section 6.

This section presents the rationale and justification for assumptions, discusses whether further confirmation is needed, and references the sections in the report where these assumptions are used. The assumptions used in developing the UZ flow models and submodels includes:

1. In the UZ flow model, faults are assumed to be vertical or inclined 30-m-wide zones, crossing the entire $\mathrm{UZ}$ thickness from the surface to the water table. This assumption is used for the three-dimensional UZ flow model (Sections 6.1, 6.2, 6.5, 6.6, and 6.7) and three-dimensional ambient thermal model (Sections 6.3 and 6.4) of this report.

Basis: This assumption is consistent with the assumptions and approximations used in designing the three-dimensional UZ model grid (BSC 2004 [DIRS 169855]). Considering the large-scale averaging with the three-dimensional mountain-scale UZ model in which horizontal grid spacings are typically on the order of $100 \mathrm{~m}$, a $30 \mathrm{~m}$ width is compatible with spatial discretization of 100-m lateral spacing in the adjacent, nonfault gridblocks. Note that impact of fault widths or cross-sectional areas on results of steady-state flow simulation in the UZ is equivalent to that of variation in fault permeability. The sensitivity modeling analysis (BSC 2004 [DIRS 170012]) showed that three-orders-of-magnitude variations in fault transmissivity had very small impact on UZ flow and tracer transport from the repository to the water table. Therefore, this assumption is considered adequate and requires no further confirmation.

2. In describing the top temperature boundary condition, the ambient thermal model (Section 6.3) assumes that the average surface temperature is a linear function of surface elevation. Therefore, the entire temperatures on the top model boundary can be determined using the linear equation whose coefficients are estimated using average annual temperature data measured from two boreholes.

Basis: The surface temperature is controlled by the local atmosphere condition, while variations in the mean atmospheric temperature are dependent primarily on elevation, which are handled as linear functions of elevation. More importantly, the model calibration of Section 6.3 shows that the ambient thermal model with such description of a linear function for the top boundary temperatures can match field observed borehole temperature data well. Therefore, this assumption is considered reasonable and adequate and requires no further confirmation. 


\section{INTENTIONALLY LEFT BLANK}




\section{MODEL DISCUSSION}

As outlined in Section 1, this report documents the development and results of the UZ flow model and the temperature and geochemistry submodels. This section consists of the following:

- Model description (Section 6.1)

- Three-dimensional UZ flow model calibrations (Section 6.2)

- Ambient geothermal model (Section 6.3)

- Gas flow analysis and pneumatic calibration (Section 6.4)

- Geochemical submodel for chloride (Section 6.5)

- Flow patterns and analysis of three-dimensional flow fields (Section 6.6)

- Tracer transport (Section 6.7)

- Sensitivity analysis of active fracture model (AFM) parameters (Section 6.8)

- Model uncertainties and alternative models (Section 6.9).

The UZ flow model, temperature model, and geochemistry submodels have all been developed to simulate past, present, and future hydrological, geothermal, and geochemical conditions in the UZ of Yucca Mountain. In the last decade, Yucca Mountain has been studied extensively, and many types of data have been collected. These data have been used in developing conceptual and numerical models for investigating the hydrological, geothermal, and geochemical behavior of the site. These models simulate ambient, steady-state UZ flow conditions and perform predictive studies of changes in the mountain caused by climatic, thermal, and geochemical perturbations. The comprehensive model that integrates pertinent data from the UZ at Yucca Mountain is the three-dimensional site-scale UZ model, developed over the past decade [as documented e.g., in "Overview of Scientific Investigations at Yucca Mountain-The Potential Repository for High-Level Nuclear Waste.” Journal of Contaminant Hydrology by Bodvarsson et al. (1999 [DIRS 120055]); Wu et al. (1999 [DIRS 117161]; 2002 [DIRS 160195])]. Model development described in this report results from the continued modeling investigations and field studies of flow and transport behavior in the UZ system of Yucca Mountain.

The UZ model is a process model developed according to the Technical Work Plan for: Unsaturated Zone Flow Analysis and Model Report Integration (BSC 2004 [DIRS 169654], Section 1.2.7) and for support of the LA. The TSPA-LA will use the UZ flow model results to provide input to other models such as ambient and thermal drift-scale models, the mountain-scale thermal-hydrological model, and the UZ radionuclide transport model. The UZ flow model and its submodels evaluate features and processes that are important to the performance of the repository, all of which contribute to the TSPA-LA, such as:

- The spatially distributed values of the percolation flux at the repository horizon

- The components of fracture and matrix flow at and below the repository horizon

- The flow diversion in the PTn

- The perched-water zones and associated flow barriers

- The probable flow paths from the repository to the water table 
- Tracer transport times and paths from the repository to the water table, and breakthrough curves and areas of tracers at the water table.

In developing the UZ model, the main objective has been placed on preparing a defensible and credible UZ model for Yucca Mountain to evaluate it as an underground radioactive waste repository. Major activities, as identified in this report, include updated model calibration studies of three-dimensional UZ flow, effects of PTn and perched water, geochemistry, geothermal conditions, estimates of tracer transport times and radionuclide transport, and intensive model validation efforts.

Other activities have involved generating 18 three-dimensional flow fields (Sections 6.2 and 6.7) to evaluate the uncertainties and sensitivity of the UZ model relative to fracture-matrix parameters and infiltration rates over the mountain by using six sets of model parameters and nine infiltration scenarios. A total of 18 flow fields (nine base cases and nine alternatives) have been submitted to the TDMS as output DTNs. The nine base case flow fields are provided for use in TSPA calculations of radionuclide transport through the UZ system, and for other activities such as drift seepage abstraction. The other nine alternatives show the results of using an alternative conceptual model (Sections 6.5, 6.6, and 6.7).

The scientific notebooks (with relevant page numbers) used for modeling and validation activities described in this report are listed in Table 6-1.

FEPs included through this report are discussed in Section 6.2.6 and in Table 6.2-11.

Table 6-1. Scientific Notebooks Used in Model-Development Documentation

\begin{tabular}{|c|c|c|c|}
\hline $\begin{array}{l}\text { LBNL Scientific } \\
\text { Notebook ID }\end{array}$ & $\begin{array}{c}\text { M\&O Scientific } \\
\text { Notebook ID }\end{array}$ & Relevant Pages & Citation \\
\hline YMP-LBNL-YSW-3 & SN-LBNL-SCI-199-V1 & pp. 65 to 70,81 to 278 & $\begin{array}{l}\text { Wang } 2003 \\
\text { [DIRS 162417] }\end{array}$ \\
\hline YMP-LBNL-YSW-KZ-1 & SN-LBNL-SCI-202-V1 & pp. 68 to 97,105 to 111 & $\begin{array}{l}\text { Wang } 2003 \\
\text { [DIRS 162417] }\end{array}$ \\
\hline YMP-LBNL-ELS-GL-1 & SN-LBNL-SCI-219-V1 & pp. 74 to 83,120 to 150 & $\begin{array}{l}\text { Wang } 2003 \\
\text { [DIRS 162417] }\end{array}$ \\
\hline YMP-LBNL-HHL-GZ-1 & SN-LBNL-SCI-227-V1 & pp. 87,89 to 119 & $\begin{array}{l}\text { Wang } 2003 \\
\text { [DIRS 162417] }\end{array}$ \\
\hline YMP-LBNL-GSB-TX-1 & SN-LBNL-SCI-160-V1 & pp. 89 to 92 & $\begin{array}{l}\text { Wang } 2003 \\
\text { [DIRS 162417] }\end{array}$ \\
\hline YMP-LBNL-GSB-HHL-3 & SN-LBNL-SCI-215-V1 & pp. 107 to 119 & $\begin{array}{l}\text { Wang } 2003 \\
\text { [DIRS 162417] }\end{array}$ \\
\hline YMP-LBNL-UZ-ELS-1 & SN-LBNL-SCI-170-V1 & pp. 42 to 44 & $\begin{array}{l}\text { Wang } 2003 \\
\text { [DIRS 162417] }\end{array}$ \\
\hline YMP-LBNL-YSW-3.1 & SN-LBNL-SCI-199-V2 & pp. 7 to 28,145 to 173 & $\begin{array}{l}\text { Wang } 2003 \\
\text { [DIRS 162417] }\end{array}$ \\
\hline
\end{tabular}

ID=identification; LBNL=Lawrence Berkeley National Laboratory; M\&O=management and operating contractor 


\subsection{MODEL DESCRIPTION}

The conceptual and numerical models used for the modeling studies are documented in this report as well as in the report Conceptual Model and Numerical Approaches for Unsaturated Zone Flow and Transport (BSC 2004 [DIRS 170035]). The conceptual and numerical models are presented in this section so that a complete discussion of the models can be made.

\subsubsection{Geological Model and Numerical Grids}

The geological model used for developing the UZ flow model and its submodels is the geological framework model (GFM2000; DTN: MO0012MWDGFM02.002 [DIRS 153777]). The development and features of the three-dimensional model grids are documented in the report entitled Development of Numerical Grids for UZ Flow and Transport Modeling (BSC 2004 [DIRS 169855]). Table 6.1-1 lists the geological units/layers for different hydrogeologic units and the associated UZ model numerical grid-layer information. These geologic formations have been organized into layered hydrogeologic units based primarily on the degree of welding (Montazer and Wilson 1984 [DIRS 100161]). These are the Tiva Canyon welded hydrogeologic unit (TCw), the PTn, the Topopah Spring welded unit (TSw), the $\mathrm{CHn}$, and the Crater Flat undifferentiated unit.

Table 6.1-1. GFM2000 Lithostratigraphy, UZ Model Layer, and Hydrogeological Unit Correlation Used in the UZ Flow Model and Submodels

\begin{tabular}{|c|c|c|c|}
\hline $\begin{array}{c}\text { Major Unit } \\
\text { (Modified from Montazer } \\
\text { and Wilson 1984 } \\
\text { [DIRS 100161]) } \\
\end{array}$ & $\begin{array}{c}\text { Lithostratigraphic } \\
\text { Nomenclature } \\
\text { (BSC 2004 [DIRS 170029]) }\end{array}$ & $\begin{array}{l}\text { UZ Model Grid } \\
\text { Unit/Layer } \\
\text { (BSC 2004 }^{\mathrm{a}} \\
\text { [DIRS 169855]) }\end{array}$ & $\begin{array}{c}\text { Hydrogeological Unit }^{\text {b }} \\
\text { (Flint 1998 } \\
\text { [DIRS 100033]) } \\
\end{array}$ \\
\hline \multirow{5}{*}{$\begin{array}{l}\text { Tiva Canyon welded } \\
\text { (TCw) }\end{array}$} & Tpcr & tcw11 & CCR, CUC \\
\hline & Трср & \multirow[t]{2}{*}{ tcw12 } & \multirow[t]{2}{*}{ CUL, CW } \\
\hline & TpcLD & & \\
\hline & Tpcpv3 & \multirow[t]{2}{*}{ tcw13 } & \multirow[t]{2}{*}{ CMW } \\
\hline & Tpcpv2 & & \\
\hline \multirow{10}{*}{$\begin{array}{l}\text { Paintbrush nonwelded } \\
\text { (PTn) }\end{array}$} & Tpcpv1 & ptn21 & CNW \\
\hline & Tpbt4 & \multirow[t]{2}{*}{ ptn22 } & \multirow[t]{2}{*}{ BT4 } \\
\hline & \multirow[t]{3}{*}{ Tpy (Yucca) } & & \\
\hline & & ptn23 & TPY \\
\hline & & \multirow[t]{2}{*}{ ptn24 } & \multirow[t]{2}{*}{ ВT3 } \\
\hline & Tpbt3 & & \\
\hline & Tpp (Pah) & ptn25 & TPP \\
\hline & Tpbt2 & \multirow[t]{3}{*}{ ptn26 } & \multirow[t]{3}{*}{ BT2 } \\
\hline & Tptrv3 & & \\
\hline & Tptrv2 & & \\
\hline
\end{tabular}


Table 6.1-1. GFM2000 Lithostratigraphy, UZ Model Layer, and Hydrogeological Unit Correlation Used in the UZ Flow Model and Submodels (Continued)

\begin{tabular}{|c|c|c|c|}
\hline $\begin{array}{l}\text { Major Unit } \\
\text { (Modified from Montazer } \\
\text { and Wilson 1984 } \\
\text { [DIRS 100161]) }\end{array}$ & $\begin{array}{c}\text { Lithostratigraphic } \\
\text { Nomenclature } \\
\text { (BSC 2004 [DIRS 170029]) }\end{array}$ & $\begin{array}{l}\text { UZ Model Grid } \\
\text { Unit/Layer }{ }^{\text {a }} \\
\text { (BSC 2004 } \\
\text { [DIRS 169855]) }\end{array}$ & $\begin{array}{c}\text { Hydrogeological Unit }^{\text {b }} \\
\text { (Flint 1998 } \\
\text { [DIRS 100033]) } \\
\end{array}$ \\
\hline \multirow{4}{*}{$\begin{array}{l}\text { Topopah Spring welded } \\
\text { (TSw) }\end{array}$} & Tptrv1 & \multirow[t]{2}{*}{ tsw31 } & \multirow[t]{2}{*}{$\mathrm{TC}$} \\
\hline & \multirow[t]{2}{*}{ Tptrn } & & \\
\hline & & tsw32 & TR \\
\hline & Tptrl, Tptf & tsw33 & TUL \\
\hline \multirow{7}{*}{$\begin{array}{l}\text { Topopah Spring welded } \\
\text { (TSw) (Continued) }\end{array}$} & Tptpul, RHHtop & & \\
\hline & Tptpmn & tsw34 & TMN \\
\hline & Tptpll & tsw35 & TLL \\
\hline & \multirow[t]{2}{*}{ Tptpln } & tsw36 & $\begin{array}{l}\text { TM2 (upper } 2 / 3 \text { of } \\
\text { Tptpln) }\end{array}$ \\
\hline & & tsw37 & $\begin{array}{l}\text { TM1 (lower } 1 / 3 \text { of } \\
\text { Tptpln) }\end{array}$ \\
\hline & Tptpv3 & tsw38 & PV3 \\
\hline & Tptpv2 & tsw39 (vit, zeo) & PV2 \\
\hline \multirow{14}{*}{$\begin{array}{l}\text { Calico Hills nonwelded } \\
(\mathrm{CHn})\end{array}$} & Tptpv1 & \multirow[t]{2}{*}{ ch1 (vit, zeo) } & BT1 or \\
\hline & Tpbt1 & & BT1a (altered) \\
\hline & \multirow{4}{*}{$\begin{array}{l}\text { Tac } \\
\text { (Calico) }\end{array}$} & ch2 (vit, zeo) & \multirow{4}{*}{$\begin{array}{l}\mathrm{CHV} \text { (vitric) } \\
\text { or } \\
\mathrm{CHZ} \text { (zeolitic) }\end{array}$} \\
\hline & & ch3 (vit, zeo) & \\
\hline & & ch4 (vit, zeo) & \\
\hline & & ch5 (vit, zeo) & \\
\hline & Tacbt (Calicobt) & ch6 (vit, zeo) & BT \\
\hline & Tcpuv (Prowuv) & $\mathrm{pp} 4$ & PP4 (zeolitic) \\
\hline & Tcpuc (Prowuc) & pp3 & PP3 (devitrified) \\
\hline & Tcpmd (Prowmd) & pp2 & PP2 (devitrified) \\
\hline & Tcplc (Prowlc) & & \\
\hline & Tcplv (Prowlv) & pp1 & PP1 (zeolitic) \\
\hline & Tcpbt (Prowbt) & & \\
\hline & Tcbuv (Bullfroguv) & & \\
\hline
\end{tabular}


Table 6.1-1. GFM2000 Lithostratigraphy, UZ Model Layer, and Hydrogeological Unit Correlation Used in the UZ Flow Model and Submodels (Continued)

\begin{tabular}{|c|c|c|c|}
\hline $\begin{array}{c}\text { Major Unit } \\
\text { (Modified from Montazer } \\
\text { and Wilson 1984 } \\
\text { [DIRS 100161]) } \\
\end{array}$ & $\begin{array}{c}\text { Lithostratigraphic } \\
\text { Nomenclature } \\
\text { (BSC 2004 [DIRS 170029]) }\end{array}$ & $\begin{array}{l}\text { UZ Model Grid } \\
\text { Unit/Layer }^{a} \\
\text { (BSC 2004 }^{\text {a }} \\
\text { [DIRS 169855]) }\end{array}$ & $\begin{array}{c}\text { Hydrogeological Unit }^{\text {b }} \\
\text { (Flint } 1998 \\
\text { [DIRS 100033]) }\end{array}$ \\
\hline \multirow{11}{*}{$\begin{array}{l}\text { Crater Flat undifferentiated } \\
\text { (CFu) }\end{array}$} & Tcbuc (Bullfroguc) & \multirow[t]{3}{*}{ bf3 } & \multirow[t]{3}{*}{ BF3 (welded) } \\
\hline & Tcbmd (Bullfrogmd) & & \\
\hline & Tcblc (Bullfroglc) & & \\
\hline & Tcblv (Bullfroglv) & \multirow[t]{3}{*}{ bf2 } & \multirow[t]{3}{*}{ BF2 (nonwelded) } \\
\hline & Tcbbt (Bullfrogbt) & & \\
\hline & Tctuv (Tramuv) & & \\
\hline & Tctuc (Tramuc) & \multirow[t]{3}{*}{$\operatorname{tr} 3$} & \multirow[t]{3}{*}{ Not Available } \\
\hline & Tctmd (Trammd) & & \\
\hline & Tctlc (Tramlc) & & \\
\hline & Tctlv (Tramlv) & \multirow[t]{2}{*}{$\operatorname{tr} 2$} & \multirow[t]{2}{*}{ Not Available } \\
\hline & Tctbt (Trambt) and below & & \\
\hline
\end{tabular}

${ }^{a}$ Defined by the rock material type, represented by the code name, for grid layers or blocks belonging to the same rock unit.

${ }^{b}$ Hydrogeologcal units or layers defined for the UZ model exclude alluvial covers. The top model boundary is at the ground surface of the mountain (or the tuff-alluvium contact in areas of significant alluvial covers).

UZ=unsaturated zone

The three-dimensional UZ model domain, as well as the numerical grid for this study, is shown in plan view in Figure 6.1-1, encompassing approximately $40 \mathrm{~km}^{2}$ of the area over the mountain. The UZ model grid, shown in Figure 6.1-1, is referred to as the TSPA-LA grid. It is primarily designed for model calibration and simulations of three-dimensional flow fields delivered for use in TSPA-LA calculations. This three-dimensional model grid uses a refined mesh in the vicinity of the repository, located near the center of the model domain, covering the region from the Solitario Canyon fault to Ghost Dance fault in the west-east direction, and from borehole G-3 in the south to beyond Sever Wash fault in the north. Also shown in Figure 6.1-1 are the locations of several boreholes used in model calibrations and analyses. The model domain is selected to focus on the study area of the repository and to investigate the effects of different infiltration scenarios and major faults on moisture flow around and below the repository. In the model grid, faults are represented in the model by vertical or inclined 30-m-wide zones (Section 5).

The three-dimensional numerical model grid, as shown for its plan view in Figure 6.1-1, has 2,042 mesh columns of both fracture and matrix continua and an average of 59 computational grid layers in the vertical direction, resulting in 245,506 gridblocks and 989,375 connections in a dual-permeability grid. 


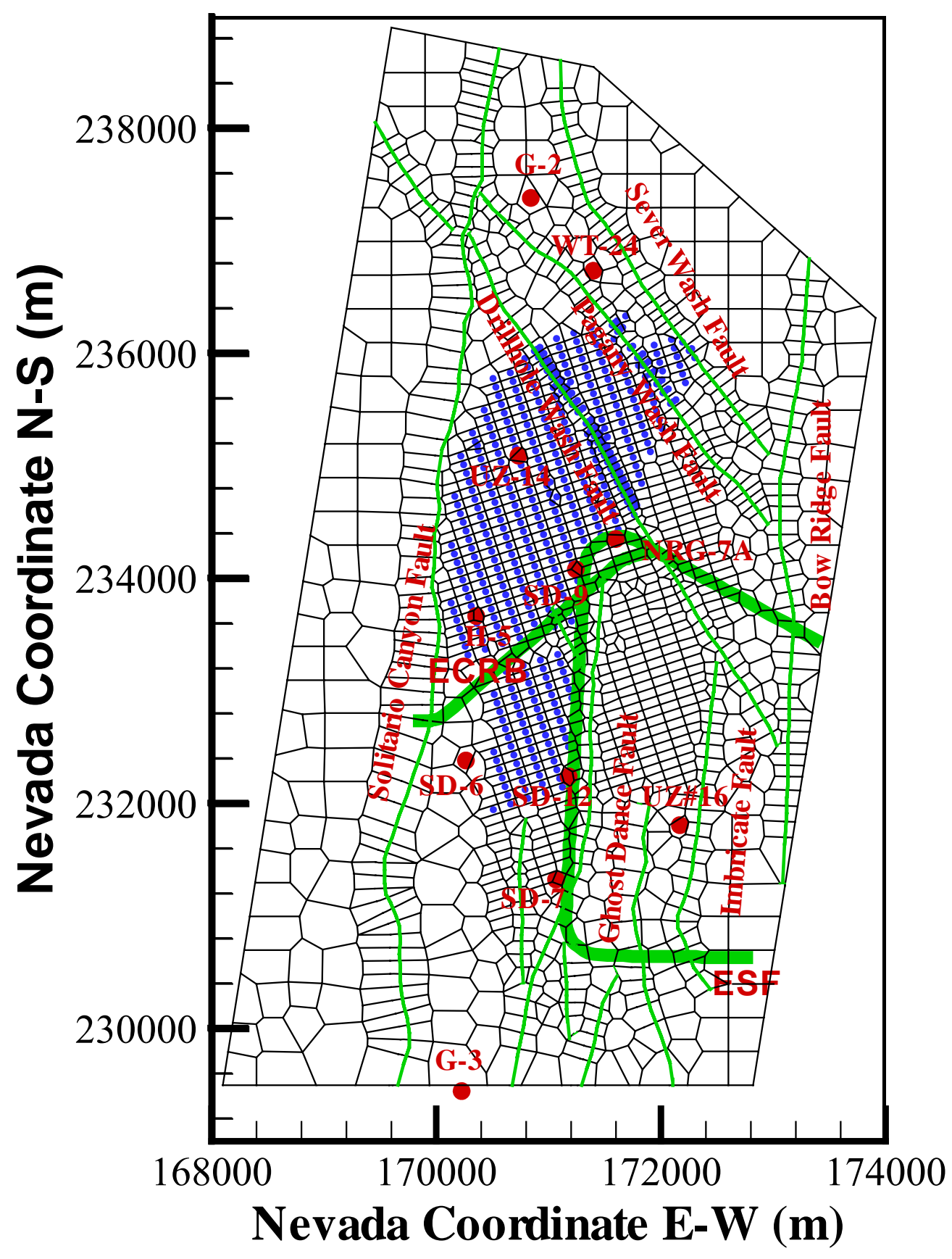

\begin{tabular}{|lll|}
\hline LEGEND & & \\
\hline \multirow{2}{*}{ Repository Blocks } & & Faults \\
& Tunnel & Borehole \\
\hline
\end{tabular}

Source DTN: LB03023DKMGRID.001 [DIRS 162354].

Figure 6.1-1. Plan View of the Three-Dimensional UZ TSPA-LA Model Grid, Showing the Model Domain, Faults Incorporated, Repository Layout, and Several Borehole Locations 


\subsubsection{Numerical Codes and Modeling Approach}

The model calibration and simulation results presented in this report were carried out mainly using TOUGH2 V1.4 (LBNL 2000 [DIRS 146496]) and T2R3D V1.4 (LBNL 1999 [DIRS 146654]), as summarized in Section 3. The single active liquid-phase flow module (EOS9) of the TOUGH2 code was used to calibrate the UZ flow model and several submodels and to generate three-dimensional TSPA-LA flow fields. For gas flow simulation and temperature calibration, the TOUGH2 V1.4 (LBNL 2000 [DIRS 146496]) EOS3 module was used. Tracer transport and chloride studies were performed using the decoupled module of T2R3D V1.4 (LBNL 1999 [DIRS 146654]) with flow fields generated by the EOS9 module. TOUGH2 V1.4 (LBNL 2000 [DIRS 146496]) and T2R3D V1.4 (LBNL 1999 [DIRS 146654]) were selected because they have been baselined through the YMP QA procedure LP-SI.11Q-BSC for modeling flow and transport in heterogeneous fractured rock (e.g., BSC 2001 [DIRS 158726]; Wu et al. 2002 [DIRS 160195]). No other numerical codes could be used for this work, either because they were not qualified and baselined for use at the time of preparing this report, or because they did not have the generalized capability of handling fractured rock with both local and global fracture-matrix interaction, which was needed in modeling studies of this report.

To model flow and transport processes in the UZ system at Yucca Mountain, mathematical models or governing equations are needed to describe the physical processes quantitatively. The physical processes associated with flow and transport in porous media are governed by the fundamental conservation laws (i.e., conservation of mass, momentum, and energy), which govern the behavior of fluid flow, chemical migration, and heat transfer through fractured porous media. The macroscopic continuum approach has been most commonly used in practical applications (Bear 1972 [DIRS 156269]). In this approach, the physical laws governing flow of several fluids, transport of multicomponents, and heat transfer in porous media are represented mathematically on the macroscopic level by a set of partial differential or integral equations. Fluid and heat flow and chemical-transport processes in fracture and matrix systems in the UZ are described using a macroscopic, dual-permeability continuum approach.

In addition to the conservation or continuity equations of mass and thermal energy in fracture and matrix systems, specific relationships or mechanisms are needed that describe how fluid flow, solute/tracer transport, and heat transfer occur in porous and fractured media. The following specific constitutive laws act as such mechanisms by governing local fluid flow, component transport, and heat-transfer processes in porous and fractured media:

1. The governing equation for isothermal, unsaturated liquid flow is the Richards equation (Richards 1931 [DIRS 104252]; Pruess et al. 1999 [DIRS 160778], Equation A-17, p. 146), based on the conservation of mass and Darcy's law (Bear 1972 [DIRS 156269]) with flux driven by gravity and capillary pressure gradient. The unsaturated flux is equal to unsaturated hydraulic conductivity times the driving gradient. The hydraulic conductivity is proportional to effective permeability and fluid density, and inversely proportional to fluid viscosity. The rock and fluid properties are treated as constants under isothermal conditions. The effective permeability (relative permeability times absolute permeability or saturated permeability) is related to both water content (saturation times porosity) and capillary pressure, as described by the van Genuchten model (1980 [DIRS 100610]). The 
governing equations for unsaturated flow under isothermal conditions are given in Appendix E.

The UZ flow model and its submodels adopt the dual-continuum approach for modeling flows through both fractures and the matrix. The Richards equation is applied to both fracture continuum and matrix continuum for unsaturated flow under isothermal condition. The fluid exchange between fracture continuum and matrix continuum is the fracture-matrix interaction, which is simulated by the dual-permeability concept, and is further modified by an AFM (Liu et al. 1998 [DIRS 105729]) in the UZ flow model.

The AFM was developed within the context of the dual-continuum approach (Liu et al. 1998 [DIRS 105729]). It is based on the reasoning that, because of the fingering flow, only a portion of fractures in a connected, unsaturated fracture network contribute to liquid water flow, while other fractures are simply bypassed. The portion of the connected fractures that actively conduct water are called active fractures. In other words, the AFM uses a combination of the continuum approach and a simple filtering concept to model fracture flow. Inactive fractures are filtered out in modeling fracture-matrix interaction and flow in the fracture continuum.

Darcy's law and the van Genuchten model can be generalized for multiphase flows under nonisothermal conditions. The governing equations for both gas- and liquid-flows and temperature are based on conservation of mass of fluid phases, and on conservation of energy for conductive and convective heat transfer processes, respectively. The full set of equations of nonisothermal, two-phase flows of gas and water in both fractures and matrix are presented in the report by Pruess et al. (1999 [DIRS 160778], Appendix A).

In solving the above equations, a number of variables are known and given as input to the UZ flow model. Some of those variables are treated as constants - for example, fluid viscosity under isothermal conditions. Others are provided as known parameters measured either in the laboratory or in field tests, and/or further calibrated. Examples of known parameters are rock density, porosity, and absolute permeability. The input parameters are discussed Section 6.1.5. In addition, boundary conditions are needed to solve the equation (Section 6.1.3). The top boundary for the UZ flow model is subject to net infiltration from the land surface (Section 6.1.4). With these input parameters and boundary conditions, the solving of the full set of equations (Pruess et al. 1999 [DIRS 160778]) in the UZ flow model provides outputs for variables such as liquid saturation, phase pressures, capillary pressure, concentrations, and mass flux, in addition to temperatures in the thermal model.

2. The migration of dissolved mass components or chemical species within a fluid in the two-phase, fractured porous media system is governed mainly by advective, diffusive, and dispersive processes. It may also be subject to other processes such as radioactive decay, adsorption, mass exchange or partition between phases, and other chemical reactions under local thermodynamic equilibration or kinetic reactions. 
3. The generalized Fick's law (Wu and Pruess 2000 [DIRS 153972], Equations 3.1.5 to 3.1 .7$, p. 705), including hydrodynamic dispersion effects in a multiphase system, is used to evaluate diffusive and dispersive flux of chemical transport.

In both research and application, the multiphase extension of Darcy's law (Pruess et al. 1999 [DIRS 160778], Equation A-5, p. 145), the Richards equation (Richards 1931 [DIRS 104252]), and the generalized Fick's law (Wu and Pruess 2000 [DIRS 153972], pp. 704 to 707) have been used as fundamental laws that govern multiphase flow and transport processes within porous-medium and fractured rocks. These fundamental laws or correlations, based on theory, experiment, and field studies, reflect our current understanding of porous-medium physics. Note that Richards' equation is extended for use in both fracture and matrix flow, as well as interflow between fractures and matrix.

A key issue for simulating fluid and heat flow and chemical transport in the fractured porous rock of Yucca Mountain is how to handle fracture and matrix flow and interaction under multiphase, multicomponent, and isothermal or nonisothermal conditions. The available methods for treating fluid flow in fractures and the rock matrix using a numerical approach include: (1) an explicit discrete-fracture and matrix representation; (2) the dual-continuum method, including double- and multiporosity, dual-permeability, or the more general "multiple interacting continua" (MINC) method (Pruess and Narasimhan 1985 [DIRS 101707]); and (3) the generalized effective continuum method. For the work documented in this report, the dual-permeability modeling approach is applied to evaluate fluid and heat flow and chemical transport in the fracture-matrix system of the UZ system of Yucca Mountain, in which the AFM is adopted to modify fracture-matrix interface areas for flow and transport between fracture and matrix systems.

The dual-continuum conceptualization provides an appropriate representation of flow and transport processes within the UZ at Yucca Mountain (Doughty 1999 [DIRS 135997]; BSC 2004 [DIRS 170035]). It is much less demanding in computational effort or in data requirements than the discrete-fracture-modeling approach. The dual-continuum method has been shown to be able to match different types of data from Yucca Mountain and, therefore, become the main approach used in the modeling studies of the YMP (Wu et al. 1999 [DIRS 117161]; 2002 [DIRS 160195]). The dual-permeability methodology for handling fluid flow, tracer transport, and heat transfer through fractured rocks treats fracture and rock matrix flow and interaction with a multicontinuum numerical approach. It considers global flow occurring not only between fractures, but also between matrix gridblocks. In this approach, each gridblock of the primary mesh is divided into two gridblocks, one representing fracture and the other for matrix, locally connected to each other. Because of the one-block representation of fracture or matrix, the interflow between fractures and matrix has to be handled using a quasi-steady-state flow approximation, and this may limit its application in estimating the gradients of pressures, temperatures, and concentrations within the matrix. Note that the UZ flow model of this report has been developed to simulate steady-state UZ flow conditions at Yucca Mountain. Under steady-state flow conditions, however, such gradients near the matrix surfaces become minimal, and the one block matrix-fracture representation is expected to produce accurate solutions (Doughty 1999 [DIRS 135997]). 
As applied in this report, the traditional dual-permeability concept is first modified using an AFM (Liu et al. 1998 [DIRS 105729]) to represent fingering effects of liquid flow through fractures and to limit flow into the matrix system. The active fracture concept has been evaluated in the Conceptual Model and Numerical Approaches for Unsaturated Zone Flow and Transport report (BSC 2004 [DIRS 170035]) and further sensitivity analyses are provided in Section 6.8 of this report. The dual-permeability model is also modified by adding additional global fracture-matrix connections at interfaces of TCw-PTn, PTn-TSw, and boundaries of vitric-nonvitric units to better simulate fracture-matrix flow at these transitions. These additional global fracture-matrix connections do not exist in the dual-permeability model. Specifically, $\mathrm{TCw}$ fractures are vertically connected to the PTn matrix, PTn matrix to TSw fractures, and vitric matrix to nonvitric fractures, respectively, along these interfaces. Note that vitric units in the $\mathrm{CHn}$ are handled as single-porosity matrix only (i.e., the effect of fractures on flow and transport within Calico Hills vitric zones is neglected). This conceptual model is supported by observation from the tracer tests (BSC 2001 [DIRS 156609], p. 136). In addition, the previous UZ flow model (BSC 2001 [DIRS 158726]) took into account the vitric fractures, but found that the permeability of those fractures was not very different from that of the vitric matrix. Therefore, fractures in the vitric zones do not need to be treated separately from the matrix.

As an alternative modeling approach, the discrete fracture or weeps type model face extremely high uncertainties in fracture distribution data within the mountain as well as an extensive computational burden that cannot be solved currently or in the near future. On the other hand, the effective continuum method approach, although the most computationally efficient, may not capture important, nonequilibrium interaction in flow and transport between fractures and matrix in the $\mathrm{UZ}$ and, therefore, is also not appropriate for use in modeling $\mathrm{UZ}$ flow and transport.

In model calibration of moisture flow and tracer transport, ambient variably saturated flow in the UZ underlying Yucca Mountain is treated as an isothermal, steady-state flow system. This is considered to be a good approximation within the UZ below the PTn unit, because the relatively unfractured nonwelded PTn unit is expected to damp and homogenize downward-moving transient pulses arising from episodic surface infiltration events (Wu et al. 2000 [DIRS 154918]; Wu et al. 2002 [DIRS 161058]; Flint et al. 2001 [DIRS 164506]). Therefore, estimated surface net infiltration rates may effectively be described as steady-state water recharge (Section 6.1.4).

In the development of the UZ flow model and its submodels over the past decade, the steady-state nature of the flow fields and the damping of transient pulses were evaluated in different studies. Wu et al. (1999 [DIRS 117161], p. 186) referred to the early work of Wang and Narasimhan (1985 [DIRS 108835]; 1993 [DIRS 106793], Figure 7.4.7), which suggested that effects of infiltration pulses at the surface are damped by the underlying tuff units, especially the PTn. The welded tuff of the repository horizon exhibited only small changes in saturations, pressures, and potentials from steady-state values in response to the transient pulses. Pan et al. (1997 [DIRS 164181]) investigated transient flow behavior for downward water flow through sloping layers in the vadose zone, with up-slope flow developed during heavy rain, likely enhancing the downward flow. Wu et al. (2002 [DIRS 161058], p. 35-11) analyzed the capillary barrier capacities in unsaturated units and indicated that, on average, it took several thousands years for water to travel through the PTn. Both Wu et al. (2000 [DIRS 154918]; 2002 [DIRS 161058]) and Flint et al. (2003 [DIRS 163967]) analyzed the implications of capillary barrier development in subunits of the PTn for lateral diversion of flow in the PTn. Along sloping layers, strong capillary barrier capacities promote lateral diversions, even though the 
degree or scale of lateral diversion can be evaluated by comparative sensitivity studies, by detailed analysis of field data including geochemical evidences, and by long-term controlled field tests.

\subsubsection{Model Boundary Conditions}

The ground surface of the mountain (or the tuff-alluvium contact in areas of significant alluvial cover) is taken as the top model boundary; the water table is treated as the bottom model boundary. Both the top and bottom boundaries of the model are treated as Dirichlet-type conditions with specified constant, but spatially varying temperature and gas pressure. For flow simulations using the EOS9 module, only water pressure or saturation values are needed along the top and bottom model boundaries. Surface infiltration, as discussed below in Section 6.1.4, is applied using a source term in the fracture gridblocks within the second grid layer from the top. This method was adopted because the first layer is treated as a Dirichlet-type boundary with constant pressure, saturation, and temperature to represent average atmospheric conditions at the mountain.

The water table is used as the bottom model boundary, a surface where the water pressure is a fixed, single value. Within the numerical models, only one single set of model primary variables for solving Richards' equations is specified for the bottom boundary, and this is equivalent to specifying a constant saturation. For gas and/or heat flow simulations, the bottom model boundary representing the water table is subject to fixed gas pressure, equal to the atmospheric pressure at the elevation (Sections 6.3.3 and 6.4.1). Lateral boundaries, as shown in Figure 6.1-1, are treated as no-flow (closed) boundaries, which allow flow occurring only along the vertical plane. This treatment is reasonable for the eastern boundary, which is along or near the Bow Ridge fault, because high vertical permeability and lower capillary forces are expected within the faults (see fault properties estimated in the report by BSC (2004 [DIRS 169857]). For the western and northern lateral boundaries, no-lateral-flow boundaries would have little effect on moisture flow within and near the repository areas because these boundaries are separated from the repository by faults. For the southern lateral boundary, this is also true because it is far from the repository (Figure 6.1-1).

The spatially distributed values of temperatures along the top and bottom boundaries are based on field observation. This treatment is corroborated by data reported by Sass et al. (1988 [DIRS 100644]) and the calibrated temperature distribution along the water table (BSC 2001 [DIRS 158726]), and further confirmed by matching qualified temperature profiles from a number of boreholes as described in Section 6.3.

Pressure conditions at the bottom boundary of the model are based on observed gas-pressure values. The water table, which is the bottom boundary of the UZ model, is shown to be a relatively flat, stable surface in most of the model domain, increasing its elevation only in the north (BSC 2004 [DIRS 169855]). The rise in the north has little effect on flow simulation results within the model domain, because the flow is essentially determined by upstream, not downstream (water table) conditions in the UZ. In the eastern part of the site to the Solitario Canyon fault, the water table elevation of the flat portion is about $730 \mathrm{~m}$ above sea level (BSC 2004 [DIRS 169855]). The gas pressures are estimated using a pressure value of $92 \mathrm{kPa}$ at an elevation of $730 \mathrm{~m}$. Surface gas pressures are determined by running the TOUGH2 code, EOS3 module to steady-state under given temperature, bottom pressure, and surface-infiltration 
conditions. This is necessary to generate a steady state, equilibrated gas-pressure boundary to avoid artificial airflow or circulation, which may occur if nonequilibrated pressures are imposed on the ground surface and model bottom boundaries.

\subsubsection{Infiltration Scenarios}

Water entering the UZ as net infiltration from precipitation at the land surface is the major control on overall hydrological and thermal-hydrological conditions within the UZ at Yucca Mountain. Net infiltration is the ultimate source of percolation through the UZ. Water percolating downward through the UZ will be the principal means by which radionuclides may be transported from the repository to the water table.

The UZ model uses net infiltration rates as surface water recharge boundary conditions. The net infiltration rates are determined for present-day and future climate scenarios (BSC 2004 [DIRS 170002] and BSC 2004 [DIRS 170007]). A total of nine net infiltration maps (DTN: GS000308311221.005 [DIRS 147613]) are implemented with the UZ model and its submodels. These infiltration maps are documented in the report: Simulation of Net Infiltration for Present-Day and Potential Future Climates (BSC 2004 [DIRS 170007]) for infiltration and climate models. They include present-day (modern), monsoon, and glacial-transition-three climatic scenarios, each of which consists of lower-bound, mean, and upper-bound rates. The nine infiltration rates are summarized in Table 6.1-2 for their average values over the model domain. Note that the UZ model is concerned primarily with steady-state flow under each infiltration scenario, while in the climate analysis reference to future climates means climates are expected to occur sequentially over the 10,000-year compliance period: present-day, monsoon, and then glacial-transition for specific periods.

Table 6.1-2. Infiltration Rates (mm/year) Averaged over the UZ Model Domain

\begin{tabular}{|l|c|c|c|}
\hline \multicolumn{1}{|c|}{ Scenario } & Lower-Bound Infiltration & Mean Infiltration & Upper-Bound Infiltration \\
\hline Present-Day/Modern & 1.25 & 4.43 & 10.74 \\
\hline Monsoon & 4.43 & 11.83 & 19.23 \\
\hline Glacial-transition & 2.35 & 17.02 & 31.69 \\
\hline
\end{tabular}

Values averaged from DTN: GS000308311221.005 [DIRS 147613].

As shown in Table 6.1-2, the average rate over the model domain for the present-day mean infiltration with the UZ model grid is $4.43 \mathrm{~mm} / \mathrm{year}$ (Wang 2003 [DIRS 162417], SN-LBNL-SCI-199-V1, pp. 99 to 101), which is considered as a base-case infiltration scenario. The use of the lower- and upper-bound infiltration values is intended to cover the uncertainties associated with the infiltration for each climate. The two future climatic scenarios, the monsoon and glacial-transition periods, are used to account for possible climate-induced changes in precipitation and net infiltration. Note that the glacial-transition has higher infiltration rates except for the lower-bound case. The average values in Table 6.1-2 are estimated using the TSPA-LA grid, shown in Figure 6.1-1 for infiltration maps (DTN: GS000308311221.005 [DIRS 147613]), and the software routine infil2grid V1.7 (LBNL 2002 [DIRS 154793]). Net infiltration is handled in a consistent manner in this report (i.e., mapping the USGS infiltration maps to model top boundary meshes). 
A plan view of the spatial distribution in the three mean infiltration maps, as interpolated onto the TSPA-LA grid, is shown in Figures 6.1-2, 6.1-3, and 6.1-4 for the present-day, monsoon, and glacial-transition mean infiltration scenarios, respectively. The figures show similar patterns of flux distributions with the three infiltration rates, with higher infiltration rates in the northern part of the model domain and along the mountain ridge east of the Solitario Canyon fault.

\section{Present Day Infiltration (Mean)}



Source DTN: GS000308311221.005 [DIRS 147613].

Figure 6.1-2. Plan View of Net Infiltration Distributed over the Three-Dimensional UZ TSPA-LA Model Grid for the Present-Day (Base-Case) Mean Infiltration Scenario 


\section{Monsoon Infiltration (Mean)}

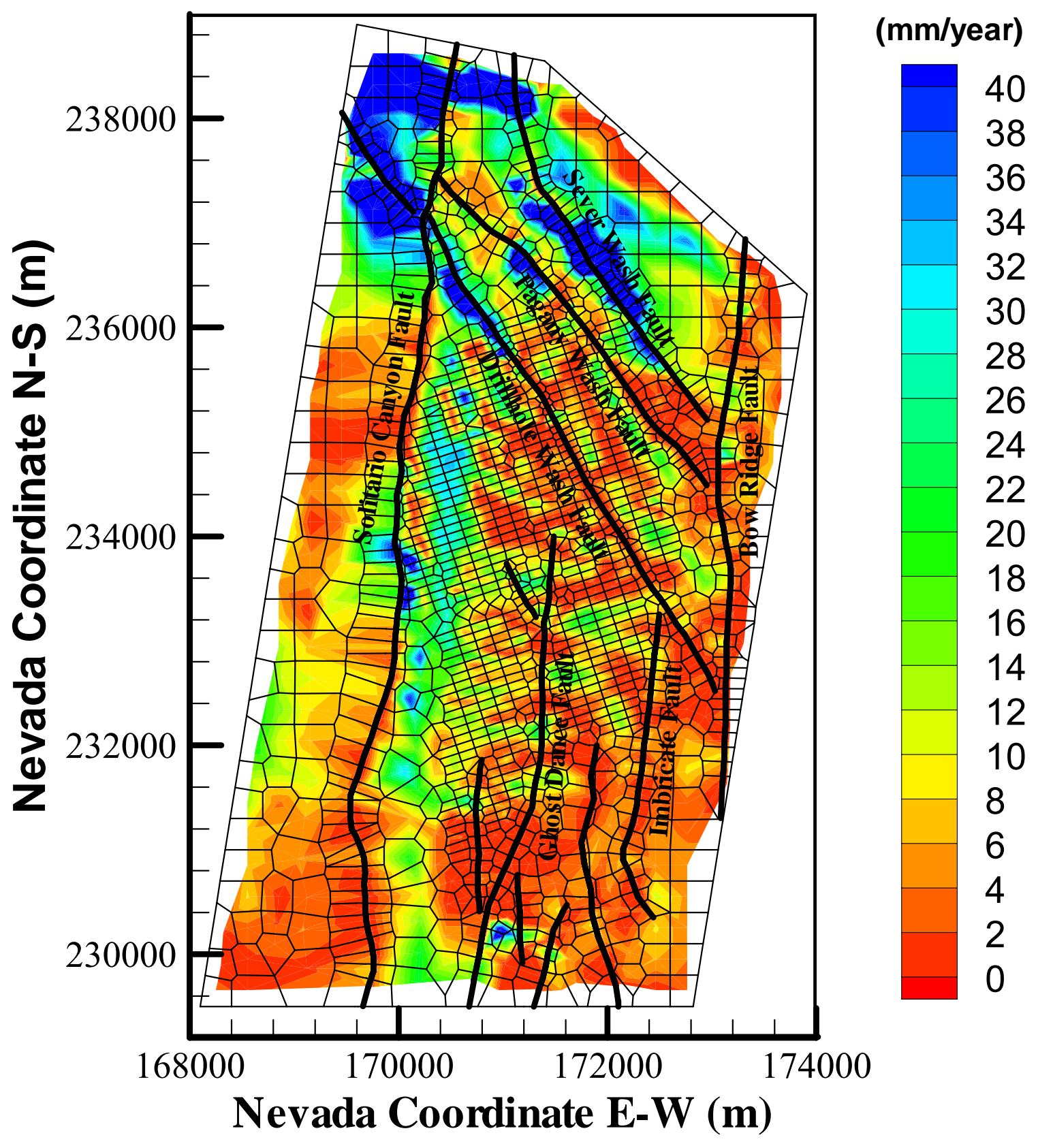

Source DTN: GS000308311221.005 [DIRS 147613].

Figure 6.1-3. Plan View of Net Infiltration Distributed over the Three-Dimensional UZ TSPA-LA Model Grid for the Monsoon Mean Infiltration Scenario 


\section{Glacial Transition Infiltration (Mean)}

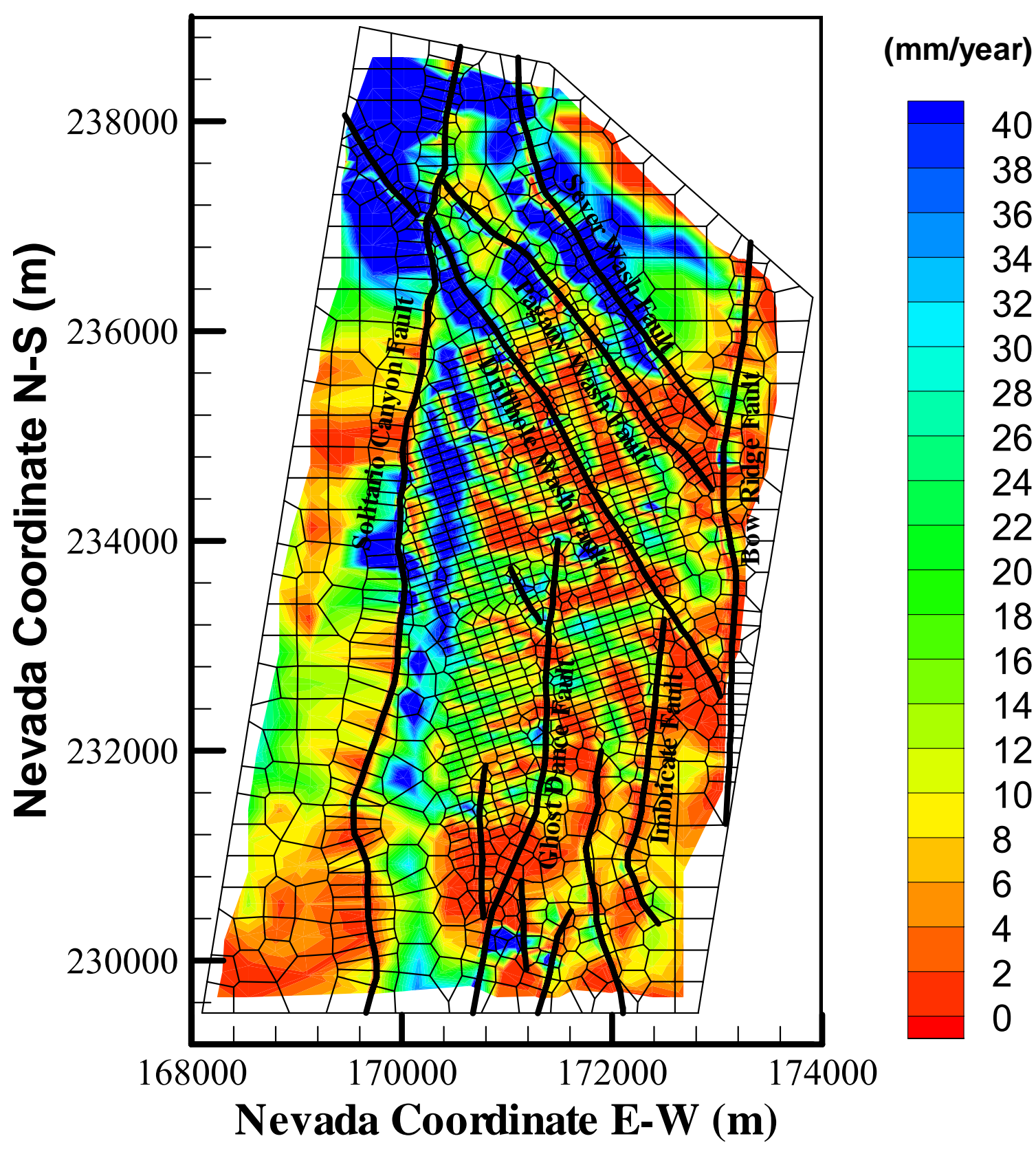

Source DTN: GS000308311221.005 [DIRS 147613].

Figure 6.1-4. Plan View of Net Infiltration Distributed over the Three-Dimensional UZ TSPA-LA Model Grid for the Glacial-transition Mean Infiltration Scenario 


\subsubsection{Model Parameters and Rock Properties}

The key input rock and fluid-flow parameters used in UZ model development are summarized in Section 4. They include (1) fracture properties (frequency, permeability, van Genuchten $\alpha$ and $m$ parameters, porosity, fracture-matrix interface area, and residual and satiated saturations) for each UZ model layer; (2) matrix properties (porosity, permeability, the van Genuchten $\alpha$ and $m$ parameters, and residual and satiated saturations) for each UZ model layer; (3) thermal and transport properties (grain density, wet and dry thermal conductivity, grain specific heat, and tortuosity coefficients) for each UZ model layer; and (4) fault properties (fracture parameters, DTN: LB02092DSSCFPR.002 [DIRS 162128]) for each of the major hydrogeologic units (Table 6.1-1). The development and estimation of these parameters are presented in the reports, Calibrated Properties Model (BSC 2004 [DIRS 169857]) (DTN: LB02091DSSCP3I.002 [DIRS 161433]) and Analysis of Hydrologic Properties Data (BSC 2004 [DIRS 170038]), as well as the calibration results of this report.

The rock-parameter specification in the three-dimensional UZ model and its submodels is, in general, uniform layer-wise (BSC 2004 [DIRS 169855]). However, certain portions of grid layers representing the $\mathrm{CHn}$ unit are partly altered from vitric to zeolitic. In these altered layers, different rock properties are specified for vitric or zeolitic zones accordingly. The UZ model treats all of the geological units, including those representing fault zones, as fracture-matrix systems using a dual-permeability approach, except the $\mathrm{CHn}$ vitric zones, which are treated as single-porosity matrix. Global fracture-matrix connections are added to those across interfaces between TCw-PTn, PTn-TSw, and vitric-nonvitric units to model transition between fracture-and matrix-dominated flow at these interfaces. In addition, the van Genuchten relative permeability and capillary pressure functions (van Genuchten 1980 [DIRS 100610]) are used to describe flow in both fractures and matrix.

In addition to fracture and matrix properties, lithophysal cavities are found in several hydrogeological layers of upper lithophysal (tsw33) and lower lithophysal (tsw35) units. These cavities, according to their local association with fractures or matrix blocks, mainly contribute storage space to fracture or matrix systems in terms of impact on flow and transport through these tuff layers. Therefore, lithophysal cavities should be included as part of fracture or matrix porosity in the UZ flow model, if incorporated. Note that the main objective of the UZ flow model is to develop three-dimensional steady-state UZ flow fields, which are independent of the values of fracture or matrix porosity used under steady-state flow condition. Therefore, the existence of these lithophysal cavities has no impact on the calibration and simulation results of the UZ flow model.

\subsection{THREE-DIMENSIONAL UZ FLOW MODEL CALIBRATION}

A critical step in developing the three-dimensional UZ flow model was to use field-measured liquid saturation, water potential, perched-water, pneumatic, and isotopic tracer data to calibrate the three-dimensional model. This is part of important iterative processes of model calibration and verification, which increase confidence in model predictions for the site conditions. A detailed model calibrating investigation is reported in Calibrated Properties Model (BSC 2004 [DIRS 169857]) using one-dimensional models for estimating model parameters with water potential, saturation, and other types of data. However, these one-dimensional models cannot 
predict whether lateral flow or perched water occurs in several hydrogeological units of the UZ below the repository level. This section documents a further model calibration effort, focusing on the three-dimensional flow patterns: perched-water calibrations using the three-dimensional model grid (Figure 6.1-1).

The three-dimensional flow model calibration is conducted using the three sets of parameters of one-dimensional site-scale calibrated properties (BSC 2004 [DIRS 169857]; DTN: LB02091DSSCP3I.002 [DIRS 161433]), two-dimensional site-scale calibrated fault properties (DTN: LB02092DSSCFPR.002 [DIRS 162128]), three present-day infiltration rates (See Table 6.1-2), and the geological model and numerical grid for calibration (BSC 2004 [DIRS 169855]). In addition, previously developed three-dimensional properties for the PTn unit (BSC 2001 [DIRS 158726]; DTNs: LB991121233129.001 [DIRS 147328]; LB991121233129.003 [DIRS 147335]; LB991121233129.005 [DIRS 147346]) are adopted for the PTn properties in this report. A permeability-barrier water-perching model is developed, as discussed in Section 6.2.2.2. In this model, rock properties are locally adjusted in several grid layers of the lower basal vitrophyre in the TSw unit and upper zeolites in the CHn unit. The objective of perched-water calibrations is (1) to match perched-water occurrences as observed at the site and (2) to investigate the effects of flow-through and bypassing of perched bodies on tracer transport.

\subsubsection{Calibration Data}

The field data used in the three-dimensional UZ flow model calibration include matrix liquid saturations, matrix water potentials, and perched-water elevations, as observed from boreholes. Table 6.2-1 shows the types of data from boreholes used in the calibration, and Figure 6.1-1 shows the locations of the boreholes and the tunnel at Yucca Mountain.

Table 6.2-1. Borehole Data Used for Three-Dimensional Flow Model Calibration

\begin{tabular}{|c|c|c|c|}
\hline Borehole & $\begin{array}{l}\text { Matrix Liquid Saturation } \\
\text { (Core) }\end{array}$ & Matrix Liquid Water Potential & $\begin{array}{l}\text { Perched Water Elevation } \\
\text { (Meters above Sea Level) }\end{array}$ \\
\hline USW NRG-7a & $\begin{array}{l}\text { MO0109HYMXPROP.001 } \\
\text { [DIRS 155989] }\end{array}$ & & $\begin{array}{l}\text { Rousseau et al. } 1997 \\
\text { [DIRS 100178] }\end{array}$ \\
\hline USW SD-6 & $\begin{array}{l}\text { GS980808312242.014 } \\
\text { [DIRS 106748] }\end{array}$ & $\begin{array}{l}\text { GS980808312242.014 } \\
\text { [DIRS 106748] }\end{array}$ & \\
\hline USW SD-7 & $\begin{array}{l}\text { MO0109HYMXPROP.001 } \\
\text { [DIRS 155989] }\end{array}$ & & $\begin{array}{l}\text { SNT02110894001.002 } \\
\text { [DIRS 105067] }\end{array}$ \\
\hline USW SD-9 & $\begin{array}{l}\text { MO0109HYMXPROP.001 } \\
\text { [DIRS 155989] }\end{array}$ & & $\begin{array}{l}\text { Rousseau et al. } 1999 \\
\text { [DIRS 102097] }\end{array}$ \\
\hline USW SD-12 & $\begin{array}{l}\text { MO0109HYMXPROP.001 } \\
\text { [DIRS 155989] }\end{array}$ & $\begin{array}{l}\text { GS031208312232.003 } \\
\text { [DIRS 171287] (in situ } \\
\text { measurement) (organized in } \\
\text { LB0208UZDSCPMI.001 } \\
\text { [DIRS 161285] and } \\
\text { MO0109HYMXPROP.001 } \\
\text { [DIRS 155989]) }\end{array}$ & $\begin{array}{l}\text { Rousseau et al. } 1997 \\
\text { [DIRS 100178] }\end{array}$ \\
\hline USW UZ-14 & $\begin{array}{l}\text { MO0109HYMXPROP.001 } \\
\text { [DIRS 155989] }\end{array}$ & & $\begin{array}{l}\text { GS960308312312.005 } \\
\text { [DIRS 107230] }\end{array}$ \\
\hline UE-25 UZ\#16 & $\begin{array}{l}\text { MO0109HYMXPROP.001 } \\
\text { [DIRS 155989] }\end{array}$ & & \\
\hline
\end{tabular}


Table 6.2-1. Borehole Data Used for Three-Dimensional Flow Model Calibration (Continued)

\begin{tabular}{|l|l|l|l|}
\hline Borehole & Matrix Liquid Saturation (Core) & Matrix Liquid Water Potential & $\begin{array}{l}\text { Perched Water Elevation } \\
\text { (Meters above Sea } \\
\text { Level) }\end{array}$ \\
\hline USW WT-24 & & $\begin{array}{l}\text { GS980708312242.010 } \\
\text { [DIRS 106752] }\end{array}$ & $\begin{array}{l}\text { GS980508312313.001 } \\
\text { [DIRS 109746] }\end{array}$ \\
\hline USW G-2 & & & $\begin{array}{l}\text { GS980508312313.001 } \\
\text { [DIRS 109746] }\end{array}$ \\
\hline
\end{tabular}

NOTE: The data in Table 6.2-1 from DTNs are used as direct input for model calibration. Data from Rousseau et al. 1997 [DIRS 100178] and Rousseau et al. 1999 [DIRS 102097] are used as indirect input for corroboration of model results.

\subsubsection{Conceptual Models of UZ Flow}

Subsurface flow and transport processes in the UZ occur in a heterogeneous system of layered, anisotropic, fractured volcanic rocks. Greater understanding of such processes has been contributed by a continuous effort of data collection and analysis as well as modeling studies (BSC 2001 [DIRS 158726]). The report entitled Conceptual Model and Numerical Approaches for Unsaturated Zone Flow and Transport (BSC 2004 [DIRS 170035]) presents a discussion of these conceptual models used in the study of UZ flow processes within this report. Figure 6.2-1 illustrates a typical geological profile along a vertical east-west transect as well as the conceptual model that characterizes potential lateral flow in the PTn unit, and the effects of faults and perched water on the UZ system.

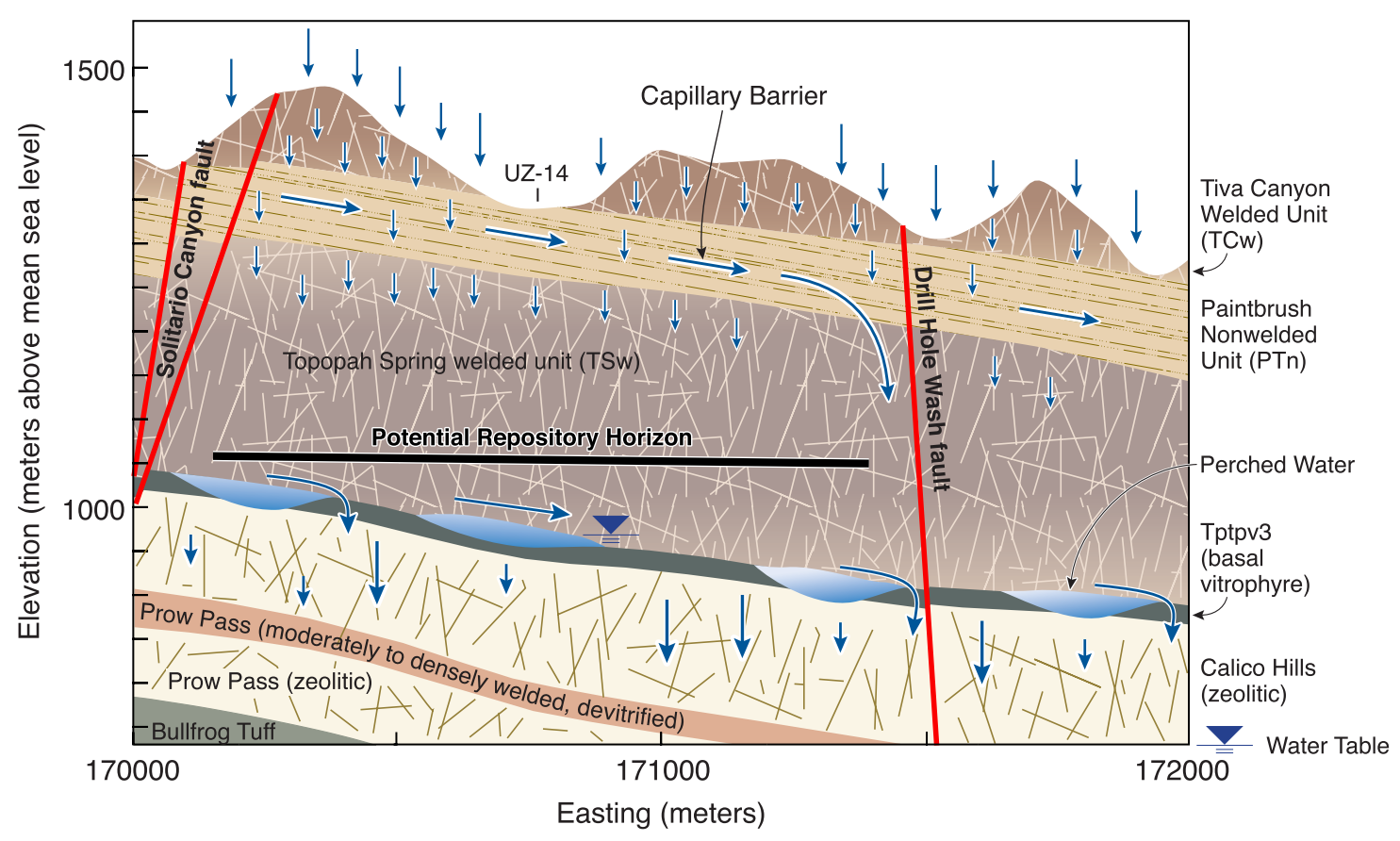

UZ03-002

Figure 6.2-1. Schematic Showing the Conceptualized Flow Processes and Effects of Capillary Barriers, Major Faults, and Perched-Water Zones within a Typical Cross Section of the UZ Flow Model Domain in the East-West Direction 
The PTn unit, as described by the current geological model, consists primarily of non- to partially welded tuffs. The dip of these layers is generally less than $10^{\circ}$ to the east or southeast. The combined thickness of the PTn layers ranges from $150 \mathrm{~m}$ in the north of the model area to $30 \mathrm{~m}$ or less, even completely missing in several areas of the south. However, the PTn unit is present over the entire repository area, where the thickness of the PTn unit ranges from approximately 30 to $60 \mathrm{~m}$ and it is even thicker to the north of the repository. The PTn unit as a whole exhibits very different hydrogeologic properties from the $\mathrm{TCw}$ and $\mathrm{TSw}$ units that bound it above and below. Both the TCw and the TSw have low porosity and intense fracturing typical of the densely welded tuffs at Yucca Mountain. In contrast, the PTn has high porosity and low fracture intensity, and its matrix system has a large capacity for storing groundwater. It has been shown to effectively damp spatial and temporal variations in percolation flux (Wu et al. 2000 [DIRS 154918], pp. 30 to 32 and 39 to 41). Therefore, water flow through the UZ is modeled to occur under steady-state conditions. Transient "fast-pathway" flow is considered to contribute insignificantly to the total flow below the PTn through the UZ (BSC 2001 [DIRS 158726], pp. 137 to 139).

\subsubsection{Capillary Barriers}

Capillary barriers were speculated to exist within the PTn unit, because of the large contrast in rock properties across the interfaces of the unit (Montazer and Wilson 1984 [DIRS 100161], pp. 26 to 30). In addition, rock-property contrasts between sublayers within the PTn unit may potentially produce capillary barriers. Characterization of groundwater flow behavior within the PTn is critically dependent on detailed knowledge of rock properties and the heterogeneity within the PTn unit. Considerable amounts of field data, obtained from tens of boreholes and hundreds of outcrop samples at the site, constrain the distribution of rock properties within the PTn unit. In general, field data indicate that the Yucca Mountain formation is more heterogeneous vertically than horizontally, so that layer-wise representations provide reasonable approximation of the complex geologic system. Calibration using this conceptual model matches different types of observation data, as further demonstrated in the following sections. However, characterizing general flow behavior within the UZ system is complicated by the presence of faults, which interrupt the lateral continuity in rock matrix properties of sloping layers.

The key conceptualizations made in the UZ flow model concerning lateral flow above the repository horizon are as follows: (1) the hydrogeological units/layers are internally homogeneous, and the material properties of each unit are continuous throughout each layer (Table 6.1-1) unless interrupted by faults; (2) ambient water flow in the system is at a steady-state condition; and (3) faults are represented by vertical or inclined columns of gridblocks having finite or small width. The flow patterns associated with capillary barriers within the PTn are studied in the following sections using this conceptual model and alternative parameters.

\subsubsection{Perched Water}

Conceptual models of perched water occurrence are of particular interest in assessing the system performance of the repository and UZ flow patterns below the repository. Waste-isolation strategies and UZ natural barrier capability depend, in part, on sorption within the zeolitic 
portions of the $\mathrm{CHn}$ and on tracer transport times between the repository horizon and the water table. Several conceptual models have been proposed for the genesis of perched water at Yucca Mountain (e.g., Wu et al. 1999 [DIRS 117167]).

Perched water may occur where percolation flux exceeds the capacity of the geologic media to transmit vertical flux in the UZ. Perched water has been encountered in a number of boreholes at Yucca Mountain, including UZ-14, SD-7, SD-9, SD-12, NRG-7a, G-2, and WT-24. These perched-water occurrences are found to be associated with low-permeability zeolites in the CHn or the densely welded basal vitrophyre (Tptpv3, Table 6.1-1) of the TSw unit. Possible mechanisms of water-perching in the UZ of Yucca Mountain may be permeability or capillary barrier effects at faults, or a combination of both.

A permeability-barrier conceptual model for perched water occurrence has been used in UZ flow modeling studies since 1996, as summarized by Wu et al. (1999 [DIRS 117167]). In this model, perched-water bodies in the vicinity of the ESF North Ramp (near Boreholes UZ- 14, SD-9, NRG-7a, G-2, and WT-24) are observed to occur above the base of the TSw, underlain by a zone of low-permeability zeolitized rock. The perched-water bodies in this northern area of the repository may be interconnected. However, the perched-water zones at Boreholes SD-7 and SD-12 are considered here as local, isolated bodies. In this conceptual model, both vertical and lateral water movement in the vicinity of the perched zones is considered to be controlled mainly by the fracture and matrix permeability distribution in these areas. The major aspects of the permeability-barrier conceptual model are: (1) no large-scale vertically connected potentially fluid-conducting fractures transect the underlying low-permeability units, (2) both vertical and horizontal permeabilities within and below the perched-water zone are small compared with permeabilities outside perching zones, and (3) sufficient percolation flux (greater than $1 \mathrm{~mm} /$ year) exists locally.

Perched-water occurrence caused by permeability barrier effects is consistent with the conceptual model that ambient conditions reflect long-term, steady-state, or transient flow through the UZ, and that perched water under steady-state flow conditions may only result from a permeability barrier. Previous modeling studies (BSC 2001 [DIRS 158726]) concluded that this conceptual water-perching model is able to match the observation data of perched water in the Yucca Mountain UZ. In the present numerical studies, the occurrence of perched water is assumed to follow the conceptual model of a permeability barrier. In other words, perched-water bodies are formed as a result of permeability barrier effects.

\subsubsection{Parameter Adjustment}

Calibrated Properties Model (BSC 2004 [DIRS 169857]) provides basic input parameter sets of fractures and matrix rocks for modeling efforts in this report. However, these properties were estimated through a series of one-dimensional model inversions, in which lateral flow, perched water, and capillary barrier effects cannot be simulated by the one-dimensional model. Use of a three-dimensional model allows further parameter adjustment to match field observation data. This section presents calibrated parameters after adjustment through a series of three-dimensional model calibrations. The adjusted parameters include fracture-matrix properties of the top TSw layer, PTn unit, and perched water zones, and fracture permeabilities in the upper TSw layers. 
In addition to estimating model parameters, these calibration studies can also be used to examine the adequacy of discretization for the three-dimensional model grid. The three-dimensional UZ TSPA-LA grid (Figure 6.1-1 for its plan view) uses finer vertical discretization than those used in the TSPA site recommendation (SR) model by BSC (2001 [DIRS 158726]), particularly, for the PTn unit and the potential perched-water layers. For example, the PTn unit consists, in general, of six hydrogeological units vertically (namely, ptn21, ptn22, ptn23, ptn24, ptn25, and ptn26; Table 6.1-1), each of which is discretized into one or several vertical grid layers with maximum thickness of 2 or $5 \mathrm{~m}$, respectively. The details of discretization are described in the Development of Numerical Grids for UZ Flow and Transport Modeling (BSC 2004 [DIRS 169855], Section 6.6).

The three-dimensional model calibration efforts were performed by starting with the three sets of calibrated parameters from the one-dimensional inversions in the report (BSC 2004 [DIRS 169857] in forward three-dimensional simulations). Then, model results were compared with the field-observed data of matrix liquid saturation, along with water-potential data, perched-water elevations, and gas pressures. In general, some model parameters from one-dimensional calibrations are found to need adjustment in order to capture three-dimensional flow behavior or match observations at the mountain. The following modifications made to the one-dimensional rock properties were found necessary: modifying the fracture $\alpha$ of the tsw31 unit, using fracture-matrix properties from the previous three-dimensional calibration, locally adjusting fracture-matrix properties for the model layers associated with perched-water occurrence, and adjusting fracture permeability for the TSw units.

When the one-dimensional calibrated fracture-matrix properties (BSC 2004 [DIRS 169857]) were used directly without any modifications as input to the three-dimensional model, significant lateral flow was predicted to occur along the top layer (tsw31) of the TSw unit under the present-day, mean infiltration scenario. This results from the limitation of a one-dimensional model; there is no evidence to support lateral flow within this layer. The three-dimensional simulation results indicated that a strong capillary barrier is formed between this tsw 31 layer and the layer below. Examination of the calibrated fracture parameters for this layer showed that such large lateral flow was artificially created by the small value of fracture $\alpha$ in tsw31, estimated by the one-dimensional inversion. The one-dimensional inverted fracture $\alpha=1.597 \times$ $10^{-5} \mathrm{~Pa}^{-1}$, which was even smaller than matrix $\alpha\left(=8.702 \times 10^{-5} \mathrm{~Pa}^{-1}\right)$ for the same layer. This was an artifact of the one-dimensional inversion model, because the top unit of the TSw was the locale of transition from matrix-dominated flow in the PTn to fracture-dominated flow in the TSw, for which a strong capillary suction is needed within the fractures. Physically, there are many larger fractures along the top layer of the TSw unit (DTN: LB0205REVUZPRP.001 [DIRS 159525]); therefore, a larger fracture $\alpha\left(=1.000 \times 10^{-4} \mathrm{~Pa}^{-1}\right)$ is used instead, leading to a good match between observed data (as discussed in Section 6.2.5) and three-dimensional models, and indicating little lateral flow in the tsw31 layer.

The second modification to the three one-dimensional inverted property sets is to replace the PTn fracture-matrix properties by those presented in Tables 6.2-2, 6.2-3, and 6.2-4, which are the corresponding parameter sets developed in previous UZ flow modeling studies (BSC 2001 [DIRS 158726], Tables II-1, II-3, and II-5). The PTn properties of Tables 6.2-2, 6.2-3, and 6.2-4 are used because these parameters provide a better match of not only liquid saturation and water-potential data, but also of observed chloride data, as discussed in the following sections. 
In Tables 6.2-2-6.2-8 as well as those in Appendix A, the symbols and notations standing for parameters are defined as: $k_{M}$ and $k_{F}$ are intrinsic permeability of matrix and fracture systems; $\alpha_{M}$ and $\alpha_{F}$ are van Genuchten $\alpha$ parameters of matrix and fracture systems; $m_{M}$ and $m_{F}$ are van Genuchten m parameters of matrix and fracture systems; and $\gamma$ is the AFM parameter.

Table 6.2-2. Calibrated PTn Fracture-Matrix Parameters for the Present-Day, Mean Infiltration Scenario

\begin{tabular}{|l|c|c|c|c|c|c|c|}
\hline Model Layer & $\begin{array}{c}\boldsymbol{k}_{M} \\
\left(\mathbf{m}^{2}\right)\end{array}$ & $\begin{array}{c}\alpha_{M} \\
(\mathbf{1} / \mathbf{P a})\end{array}$ & $\begin{array}{c}\boldsymbol{m}_{M} \\
(-)\end{array}$ & $\begin{array}{c}\boldsymbol{k}_{F} \\
\left(\mathbf{m}^{2}\right)\end{array}$ & $\begin{array}{c}\alpha_{F} \\
(\mathbf{1} / \mathbf{P a})\end{array}$ & $\begin{array}{c}\boldsymbol{m}_{\boldsymbol{F}} \\
(-)\end{array}$ & $\begin{array}{c}\gamma \\
(-)\end{array}$ \\
\hline ptn21 & $9.90 \mathrm{E}-13$ & $1.01 \mathrm{E}-5$ & 0.176 & $1.86 \mathrm{E}-12$ & $1.68 \mathrm{E}-3$ & 0.580 & 0.09 \\
\hline ptn22 & $2.65 \mathrm{E}-12$ & $1.60 \mathrm{E}-4$ & 0.326 & $2.00 \mathrm{E}-11$ & $7.68 \mathrm{E}-4$ & 0.580 & 0.09 \\
\hline ptn23 & $1.23 \mathrm{E}-13$ & $5.58 \mathrm{E}-6$ & 0.397 & $2.60 \mathrm{E}-13$ & $9.23 \mathrm{E}-4$ & 0.610 & 0.09 \\
\hline ptn24 & $7.86 \mathrm{E}-14$ & $1.53 \mathrm{E}-4$ & 0.225 & $4.67 \mathrm{E}-13$ & $3.37 \mathrm{E}-3$ & 0.623 & 0.09 \\
\hline ptn25 & $7.00 \mathrm{E}-14$ & $5.27 \mathrm{E}-5$ & 0.323 & $7.03 \mathrm{E}-13$ & $6.33 \mathrm{E}-4$ & 0.644 & 0.09 \\
\hline ptn26 & $2.21 \mathrm{E}-13$ & $2.49 \mathrm{E}-4$ & 0.285 & $4.44 \mathrm{E}-13$ & $2.79 \mathrm{E}-4$ & 0.552 & 0.09 \\
\hline
\end{tabular}

Source DTN: LB991121233129.001 [DIRS 147328].

Table 6.2-3. Calibrated PTn Fracture-Matrix Parameters for the Present-Day, Upper-Bound Mean Infiltration Scenario

\begin{tabular}{|l|c|c|c|c|c|c|c|}
\hline Model Layer & $\begin{array}{c}\boldsymbol{k}_{\mathbf{M}} \\
\left(\mathbf{m}^{2}\right)\end{array}$ & $\begin{array}{c}\alpha_{M} \\
(\mathbf{1} / \mathrm{Pa})\end{array}$ & $\begin{array}{c}\boldsymbol{m}_{M} \\
(-)\end{array}$ & $\begin{array}{c}\boldsymbol{m}_{F} \\
\left(\mathbf{m}^{2}\right)\end{array}$ & $\begin{array}{c}\alpha_{F} \\
(\mathbf{1} / \mathrm{Pa})\end{array}$ & $\begin{array}{c}\boldsymbol{m}_{F} \\
(-)\end{array}$ & $\begin{array}{c}\gamma \\
(-)\end{array}$ \\
\hline ptn21 & $1.26 \mathrm{E}-13$ & $1.84 \mathrm{E}-4$ & 0.199 & $1.00 \mathrm{E}-11$ & $2.38 \mathrm{E}-3$ & 0.611 & 0.08 \\
\hline ptn22 & $5.98 \mathrm{E}-12$ & $2.42 \mathrm{E}-5$ & 0.473 & $1.00 \mathrm{E}-11$ & $1.26 \mathrm{E}-3$ & 0.665 & 0.08 \\
\hline ptn23 & $3.43 \mathrm{E}-13$ & $4.06 \mathrm{E}-6$ & 0.407 & $1.96 \mathrm{E}-13$ & $1.25 \mathrm{E}-3$ & 0.627 & 0.08 \\
\hline ptn24 & $3.93 \mathrm{E}-13$ & $5.27 \mathrm{E}-5$ & 0.271 & $4.38 \mathrm{E}-13$ & $2.25 \mathrm{E}-3$ & 0.631 & 0.08 \\
\hline ptn25 & $1.85 \mathrm{E}-13$ & $2.95 \mathrm{E}-5$ & 0.378 & $6.14 \mathrm{E}-13$ & $1.00 \mathrm{E}-3$ & 0.637 & 0.08 \\
\hline ptn26 & $6.39 \mathrm{E}-13$ & $3.54 \mathrm{E}-4$ & 0.265 & $3.48 \mathrm{E}-13$ & $3.98 \mathrm{E}-4$ & 0.367 & 0.08 \\
\hline
\end{tabular}

Source DTN: LB991121233129.003 [DIRS 147335].

Table 6.2-4. Calibrated PTn Fracture-Matrix Parameters for the Present-Day, Lower-Bound Mean Infiltration Scenario

\begin{tabular}{|l|c|c|c|c|c|c|c|}
\hline Model Layer & $\begin{array}{c}\boldsymbol{k}_{\mathbf{M}} \\
\left(\mathbf{m}^{2}\right)\end{array}$ & $\begin{array}{c}\alpha_{M} \\
(\mathbf{1} / \mathbf{P a})\end{array}$ & $\begin{array}{c}\boldsymbol{m}_{M} \\
(-)\end{array}$ & $\begin{array}{c}\boldsymbol{k}_{F} \\
\left(\mathbf{m}^{2}\right)\end{array}$ & $\begin{array}{c}\alpha_{F} \\
(\mathbf{1} / \mathbf{P a})\end{array}$ & $\begin{array}{c}\boldsymbol{m}_{F} \\
(-)\end{array}$ & $\begin{array}{c}\gamma \\
(-)\end{array}$ \\
\hline ptn21 & $1.86 \mathrm{E}-13$ & $6.13 \mathrm{E}-5$ & 0.165 & $1.00 \mathrm{E}-11$ & $1.66 \mathrm{E}-3$ & 0.503 & 0.01 \\
\hline ptn22 & $3.27 \mathrm{E}-12$ & $1.51 \mathrm{E}-5$ & 0.390 & $1.00 \mathrm{E}-11$ & $9.39 \mathrm{E}-4$ & 0.651 & 0.01 \\
\hline ptn23 & $4.20 \mathrm{E}-13$ & $2.04 \mathrm{E}-6$ & $0.387^{\mathrm{a}}$ & $1.84 \mathrm{E}-13$ & $1.28 \mathrm{E}-3$ & 0.518 & 0.01 \\
\hline ptn24 & $3.94 \mathrm{E}-13$ & $2.32 \mathrm{E}-5$ & 0.210 & $4.31 \mathrm{E}-13$ & $2.02 \mathrm{E}-3$ & 0.594 & 0.01 \\
\hline ptn25 & $2.22 \mathrm{E}-13$ & $2.04 \mathrm{E}-5$ & 0.296 & $7.12 \mathrm{E}-13$ & $7.42 \mathrm{E}-4$ & 0.555 & 0.01 \\
\hline ptn26 & $5.43 \mathrm{E}-13$ & $1.82 \mathrm{E}-4$ & 0.264 & $3.08 \mathrm{E}-13$ & $2.00 \mathrm{E}-4$ & 0.401 & 0.01 \\
\hline
\end{tabular}

Source DTN: LB991121233129.005 [DIRS 147346].

${ }^{a}$ In output DTN, this value is 0.388 due to round off. 
For perched-water calibration, calibrated parameters of fracture and matrix permeabilities within perched zones are determined from many modeling studies with three-dimensional simulations. The perched-water conceptual model with respect to water-perching scenarios is realized and carried out by modifying the three-dimensional UZ model grid file as follows:

- The grid-layer properties of tsw38 (tswF8/tswM8), tsw39 (tswF9/tswM9), ch1z $(\operatorname{ch} 1 \mathrm{Fz} / \mathrm{ch} 1 \mathrm{Mz})$, and $\operatorname{ch} 2 \mathrm{z}(\mathrm{ch} 2 \mathrm{Fz} / \mathrm{ch} 2 \mathrm{Mz})$ are replaced by (pcF38/pcM38), (pcF39/pcM39), (pcF1z/pcM1z), and $(\mathrm{pcF} 2 \mathrm{z} / \mathrm{pcM} 2 \mathrm{z})$, respectively, where the basal vitrophyre of the TSw is underlain by zeolitic units.

- Near Borehole SD-7, properties for the gridblocks in grid columns q45, i80, i81, i84, i87, o92, and o95, over grid layers of ch5z (ch5Fz/ch5Mz), ch6z (ch6Fz/ch6Mz) and pp4 $(\mathrm{pp} 4 \mathrm{Fz} / \mathrm{pp} 4 \mathrm{Mz})$ are replaced by $(\mathrm{pcF} 5 \mathrm{z} / \mathrm{pcM} 5 \mathrm{z}),(\mathrm{pcF} 6 \mathrm{z} / \mathrm{pcM} 6 \mathrm{z})$, and $(\mathrm{pcF} 4 \mathrm{p} / \mathrm{pcM} 4 \mathrm{p})$, respectively.

- Near Borehole SD-12, properties for the gridblocks in grid columns q47, b93, b99, k61, k62 and k67, over grid layers of tsw38 (tswF8/tswM8), tsw39 (tswF9/tswM9), and ch1v (ch1Fv/ch1Mv) are replaced by (pcF38/pcM38), (pcF39/pcM39), and (pcF1z/pcM1z), respectively.

Fracture and matrix permeabilities of potential perched layers/zones, as identified above, are calibrated based on the three-dimensional model calibrated values (BSC 2001 [DIRS 158726]), and shown in Tables 6.2-5, 6.2-6, and 6.2-7. All properties except intrinsic permeabilities, van Genuchten's $\alpha$ and $m$ parameters, and residual saturations for matrix blocks within perched zones are identical to parameters estimated from the current one-dimensional inversions of the report by BSC (2004 [DIRS 169857]). The active-fracture parameter, $\gamma$, is set to zero for the perched zones, causing the fracture-matrix interface-area factor to be equivalent to liquid saturation (Liu et al. 1998 [DIRS 105729]). Tables 6.2-5, 6.2-6, and 6.2-7 present the final three sets of calibrated rock properties at zones with perched water, with base-case (mean), upper-bound, and lower-bound present-day infiltration scenarios, respectively. The modified "fracture" properties in the following three tables are close to those of the matrix, so that fractures in water perching layers are effectively removed.

Table 6.2-5. Calibrated Parameters of Perched-Water Conceptual Model for the Present-Day, Base-Case Infiltration Scenario

\begin{tabular}{|c|c|c|c|c|c|c|c|}
\hline Model Layer & $\begin{array}{c}k_{M} \\
\left(m^{2}\right)\end{array}$ & $\begin{array}{c}\alpha_{M} \\
(1 / P a)\end{array}$ & $\begin{array}{c}m_{M} \\
(-)\end{array}$ & $\begin{array}{c}k_{F} \\
\left(m^{2}\right)\end{array}$ & $\begin{array}{c}\alpha_{F} \\
(1 / P a)\end{array}$ & $\begin{array}{c}m_{F} \\
(-)\end{array}$ & $\begin{array}{c}\gamma \\
(-)\end{array}$ \\
\hline pcM38/ pcF38 & $3.00 \mathrm{E}-19$ & $6.23 \mathrm{E}-6$ & 0.286 & $3.00 \mathrm{E}-18$ & $6.23 \mathrm{E}-6$ & 0.286 & 0.00 \\
\hline pcM39/ pcF39 & $6.20 \mathrm{E}-18$ & 4.61E-6 & 0.059 & $6.20 \mathrm{E}-17$ & 4.61E-6 & 0.059 & 0.00 \\
\hline pcM1z/ pcF1z & $9.30 \mathrm{E}-20$ & 2.12E-7 & 0.349 & $9.30 \mathrm{E}-19$ & 2.12E-7 & 0.349 & 0.00 \\
\hline pcM2z/ pcF2z & $2.40 \mathrm{E}-18$ & $2.25 \mathrm{E}-6$ & 0.257 & $2.40 \mathrm{E}-17$ & $2.25 \mathrm{E}-6$ & 0.257 & 0.00 \\
\hline pcM5z/ pcF5z & $2.40 \mathrm{E}-18$ & $2.25 \mathrm{E}-6$ & 0.257 & $2.40 \mathrm{E}-18$ & $2.25 \mathrm{E}-6$ & 0.257 & 0.00 \\
\hline pcM6z/ pcF6z & 1.10E-19 & $1.56 \mathrm{E}-7$ & 0.499 & 1.10E-19 & $1.56 \mathrm{E}-7$ & 0.499 & 0.00 \\
\hline pcM4p/ pcF4p & 7.70E-19 & $4.49 \mathrm{E}-7$ & 0.474 & 7.70E-19 & $4.49 \mathrm{E}-7$ & 0.474 & 0.00 \\
\hline
\end{tabular}

Output DTN: LB03013DSSCP3I.001. 
Table 6.2-6. Calibrated Parameters of Perched-Water Conceptual Model for the Present-Day, Upper-Bound Infiltration Scenario

\begin{tabular}{|l|c|c|c|c|c|c|c|}
\hline \multicolumn{1}{|c|}{ Model Layer } & $\begin{array}{c}\boldsymbol{k}_{\mathrm{M}} \\
\left(\mathbf{m}^{2}\right)\end{array}$ & $\begin{array}{c}\alpha_{M} \\
(\mathbf{1} / \mathbf{P a})\end{array}$ & $\begin{array}{c}\boldsymbol{m}_{M} \\
(-)\end{array}$ & $\begin{array}{c}\boldsymbol{k}_{F} \\
\left(\mathbf{m}^{2}\right)\end{array}$ & $\begin{array}{c}\alpha_{F} \\
(\mathbf{1} / \mathbf{P a})\end{array}$ & $\begin{array}{c}\boldsymbol{m}_{F} \\
(-)\end{array}$ & $\begin{array}{c}\gamma \\
(-)\end{array}$ \\
\hline pcM38/ pcF38 & $3.00 \mathrm{E}-19$ & $5.58 \mathrm{E}-6$ & 0.286 & $3.00 \mathrm{E}-18$ & $5.58 \mathrm{E}-6$ & 0.286 & 0.00 \\
\hline pcM39/ pcF39 & $6.20 \mathrm{E}-18$ & $4.61 \mathrm{E}-6$ & 0.059 & $6.20 \mathrm{E}-17$ & $4.61 \mathrm{E}-6$ & 0.059 & 0.00 \\
\hline pcM1z/ pcF1z & $9.30 \mathrm{E}-20$ & $2.12 \mathrm{E}-7$ & 0.349 & $9.30 \mathrm{E}-19$ & $2.12 \mathrm{E}-7$ & 0.349 & 0.00 \\
\hline pcM2z/ pcF2z & $2.40 \mathrm{E}-18$ & $2.25 \mathrm{E}-6$ & 0.257 & $2.40 \mathrm{E}-17$ & $2.25 \mathrm{E}-6$ & 0.257 & 0.00 \\
\hline pcM5z/ pcF5z & $2.40 \mathrm{E}-18$ & $2.25 \mathrm{E}-6$ & 0.257 & $2.40 \mathrm{E}-18$ & $2.25 \mathrm{E}-6$ & 0.257 & 0.00 \\
\hline pcM6z/ pcF6z & $1.10 \mathrm{E}-19$ & $1.56 \mathrm{E}-7$ & 0.499 & $1.10 \mathrm{E}-19$ & $1.56 \mathrm{E}-7$ & 0.499 & 0.00 \\
\hline pcM4p/ pcF4p & $7.70 \mathrm{E}-19$ & $4.57 \mathrm{E}-7$ & 0.474 & $7.70 \mathrm{E}-19$ & $4.57 \mathrm{E}-7$ & 0.474 & 0.00 \\
\hline
\end{tabular}

Output DTN: LB03013DSSCP3I.001.

Table 6.2-7. Calibrated Parameters of Perched-Water Conceptual Model for the Present-Day, Lower-Bound Infiltration Scenario

\begin{tabular}{|l|c|c|c|c|c|c|c|}
\hline \multicolumn{1}{|c|}{ Model Layer } & $\begin{array}{c}\boldsymbol{k}_{\mathbf{M}} \\
\left(\mathbf{m}^{2}\right)\end{array}$ & $\begin{array}{c}\boldsymbol{\alpha}_{M} \\
(\mathbf{1} / \mathrm{Pa})\end{array}$ & $\begin{array}{c}\boldsymbol{m}_{M} \\
(-)\end{array}$ & $\begin{array}{c}\boldsymbol{k}_{F} \\
\left(\mathbf{m}^{2}\right)\end{array}$ & $\begin{array}{c}\alpha_{F} \\
(\mathbf{1} / \mathbf{P a})\end{array}$ & $\begin{array}{c}\boldsymbol{m}_{\boldsymbol{F}} \\
(-)\end{array}$ & $\begin{array}{c}\gamma \\
(-)\end{array}$ \\
\hline pcM38/ pcF38 & $3.00 \mathrm{E}-19$ & $1.43 \mathrm{E}-6$ & 0.286 & $3.00 \mathrm{E}-19$ & $1.43 \mathrm{E}-6$ & 0.286 & 0.00 \\
\hline pcM39/ pcF39 & $6.20 \mathrm{E}-18$ & $4.61 \mathrm{E}-6$ & 0.059 & $6.20 \mathrm{E}-18$ & $4.61 \mathrm{E}-6$ & 0.059 & 0.00 \\
\hline pcM1z/ pcF1z & $9.30 \mathrm{E}-20$ & $2.12 \mathrm{E}-7$ & 0.349 & $9.30 \mathrm{E}-20$ & $2.12 \mathrm{E}-7$ & 0.349 & 0.00 \\
\hline pcM2z/ pcF2z & $2.40 \mathrm{E}-18$ & $2.25 \mathrm{E}-6$ & 0.257 & $2.40 \mathrm{E}-18$ & $2.25 \mathrm{E}-6$ & 0.257 & 0.00 \\
\hline pcM5z/ pcF5z & $2.40 \mathrm{E}-18$ & $2.25 \mathrm{E}-6$ & 0.257 & $2.40 \mathrm{E}-18$ & $2.25 \mathrm{E}-6$ & 0.257 & 0.00 \\
\hline pcM6z/ pcF6z & $1.10 \mathrm{E}-19$ & $1.56 \mathrm{E}-7$ & 0.499 & $1.10 \mathrm{E}-19$ & $1.56 \mathrm{E}-7$ & 0.499 & 0.00 \\
\hline pcM4p/ pcF4p & $7.70 \mathrm{E}-19$ & $2.88 \mathrm{E}-7$ & 0.474 & $7.70 \mathrm{E}-19$ & $2.88 \mathrm{E}-7$ & 0.474 & 0.00 \\
\hline
\end{tabular}

Output DTN: LB03013DSSCP3I.001.

The fourth and last parameter adjustment is the fracture permeability in the TSw unit under the present-day, mean infiltration scenario (see Section 6.4). The present-day, mean infiltration rate is used for gas flow calibration because the pneumatic tests were conducted in a small time scale of days to years at present day conditions. This calibration described in Section 6.4 was made from three-dimensional gas flow analysis with the calibrated fracture permeability results summarized in Table 6.2-8. In this table, the fracture permeabilities of several TSw units from the one-dimensional inversion are reduced by a factor of 15 .

Table 6.2-8. Calibrated TSw Fracture Permeability for the Present-Day, Mean Infiltration Scenario

\begin{tabular}{|l|c|}
\hline \multicolumn{1}{|c|}{ Model Layer } & $\begin{array}{c}\boldsymbol{k}_{\boldsymbol{F}} \\
\left(\mathbf{m}^{2}\right)\end{array}$ \\
\hline tsw31 & $5.42 \mathrm{E}-12$ \\
\hline tsw32 & $4.72 \mathrm{E}-12$ \\
\hline tsw33 & $5.18 \mathrm{E}-12$ \\
\hline tsw34 & $2.21 \mathrm{E}-12$ \\
\hline tsw35 & $6.06 \mathrm{E}-12$ \\
\hline tsw36 & $8.99 \mathrm{E}-12$ \\
\hline tsw37 & $8.99 \mathrm{E}-12$ \\
\hline
\end{tabular}

Output DTN: LB03013DSSCP3I.001. 
The final results and calibrated parameter sets of the three-dimensional model studies are given in Tables A-1 to A-6 of Appendix A. Tables A-1, A-2, and A-3 are considered as base-case scenario parameter sets, and Tables A-4, A-5, and A- 6 are regarded as alternative property sets for use in generating the three-dimensional flow fields and estimating tracer transport times.

\subsubsection{Numerical Treatment and Solution Convergence}

Numerical modeling of large-scale three-dimensional flow and transport in the UZ beneath Yucca Mountain is mathematically challenging. The principal difficulty stems from the highly nonlinear coupling of the flow system. First, the hydrogeological system is distinctly heterogeneous on all model scales, and there are orders-of-magnitude contrasts in permeabilities across geological layers or between fracture and matrix rock. Secondly, the two-phase flow functions of relative permeability and capillary pressure for Yucca Mountain tuffs are extremely nonlinear for both fractures and matrix systems. The mathematical difficulties become even more severe when using the dual-permeability modeling approach for handling fracture-matrix interaction. In this case, flows through fractures and matrix are on very different time scales, with fracture flow being orders of magnitude faster than matrix flow. Furthermore, fracture elements have a much smaller storage space than matrix elements. In general, it takes simulation times of thousands to millions of years for the system to equilibrate. Rapid flow through fractures, plus the slow response in the matrix, makes it very difficult to obtain steady-state solutions numerically (BSC 2001 [DIRS 158726], p. 51).

For all flow simulations (this section and Section 6.7), the EOS9 module of TOUGH2 V1.4 (LBNL 2000 [DIRS 146496]) was used to solve Richards' equation in the unsaturated flow calculations. In this method, air/gas flow dynamics are ignored by using a constant gas-phase pressure in an isothermal system. This simplified single-phase, unsaturated flow solution for the three-dimensional model calibrations and TSPA flow field simulations is the most computationally efficient approach, while giving accurate results for isothermal two-phase flow. Two-phase flow problems are solved with one equation per gridblock instead of solving two or three equations, as required by the EOS3 module. Numerical tests allow one to conclude that for moisture flow and distributions at steady state, the EOS9 solutions are, in general, identical to EOS3 ("true two-phase" flow solutions) (BSC 2001 [DIRS 158726], pp. 52 to 53).

Model calibrations and flow-field simulations are both based on steady-state solutions using the EOS9 module. In each simulation, fracture, fault, and zeolitic element volumes are increased by a factor of 10,000 in the grid to overcome convergence difficulties associated with these nodes, while keeping other mesh geometric information unchanged. This approach does not affect the final solution as long as a "true" steady-state solution is obtained for a given run. The initial condition for a new scenario run is estimated using a default (uniform) initial condition or results of a previous run with a similar modeling condition. Each simulation is usually subdivided into stages. For the first-stage runs, a large convergence tolerance on the order of 10,000 or more is used to keep simulation progressing with a large time step. It has been found based on those studies that using large residual tolerance in the first stage has no effects on final, steady-state solutions as long as no oscillations or unphysical solutions occur. After running the solution to $10^{9}$ years or more with a large tolerance, the convergence tolerance is reduced to $10^{-2}$ to $10^{-3}$, and the model is run until a steady-state solution is reached. The final steady-state solutions are confirmed using a global mass-balance check, as discussed in Sections 6.2.5 and 6.6.2. 


\subsubsection{Simulation Scenarios, Results, and Analyses}

This section summarizes the three-dimensional flow model calibration scenarios performed for this report, including simulation results and analyses. The model calibrations are performed using (1) the three-dimensional TSPA-LA grid (Figure 6.1-1) and nine net infiltration maps, as discussed in Section 6.1.4; (2) the three parameter sets (Table A-1, A-2, and A-3 in Appendix A of this report); and (3) the UZ flow conceptual models of Section 6.2.2 above. Simulation results are called TSPA-LA flow simulations or base-case flow fields in this report. Simulation results with the alternative model will be discussed in Section 6.6.

Simulation Scenarios: Table 6.2-9 summarizes these nine simulation scenarios, associated parameter sets, and infiltration rates used.

Table 6.2-9. Nine UZ Flow Simulation Scenarios: Data Files, Parameter Sets, and Infiltration Maps for the UZ Model Calibrations

\begin{tabular}{|c|c|c|}
\hline $\begin{array}{l}\text { Designation/ } \\
\text { Simulation }\end{array}$ & $\begin{array}{c}\text { Parameter Set/ } \\
\text { Calibration } \\
\text { (Output DTN: LB03013DSSCP3I.001) }\end{array}$ & $\begin{array}{ll} & \begin{array}{l}\text { Infiltration Map } \\
\text { DTN: } \\
\text { GS000308311221.005 } \\
\text { [DIRS 147613] }\end{array} \\
\end{array}$ \\
\hline preq_IA & $\begin{array}{l}\text { Parameter set from Table A-3, } \\
\text { present day/modern, lower-bound infiltration }\end{array}$ & Present-day, lower-bound infiltration \\
\hline preq_mA & $\begin{array}{l}\text { Parameter set from Table A-1, } \\
\text { present day/modern, mean infiltration }\end{array}$ & Present-day, mean infiltration \\
\hline preq_uA & $\begin{array}{l}\text { Parameter set from Table A-2, } \\
\text { present day/modern, upper- bound infiltration }\end{array}$ & Present-day, upper-bound infiltration \\
\hline monq_IA & $\begin{array}{l}\text { Parameter set from Table A-3, } \\
\text { present day/modern, lower-bound infiltration }\end{array}$ & Monsoon, lower- bound infiltration \\
\hline monq_mA & $\begin{array}{l}\text { Parameter set from Table A-1, } \\
\text { present day/modern, mean infiltration }\end{array}$ & Monsoon, mean infiltration \\
\hline monq_uA & $\begin{array}{l}\text { Parameter set from Table A-2, } \\
\text { present day/modern, upper-bound infiltration }\end{array}$ & Monsoon, upper-bound infiltration \\
\hline glaq_IA & $\begin{array}{l}\text { Parameter set from Table A-3, } \\
\text { lower-bound/present-day infiltration }\end{array}$ & $\begin{array}{l}\text { Glacial-transition, lower-bound } \\
\text { infiltration }\end{array}$ \\
\hline glaq_mA & $\begin{array}{l}\text { Parameter set from Table A-1, } \\
\text { present day/modern, mean infiltration }\end{array}$ & Glacial-transition, mean infiltration \\
\hline glaq_uA & $\begin{array}{l}\text { Parameter set from Table A-2, } \\
\text { present day/modern, upper-bound infiltration }\end{array}$ & $\begin{array}{l}\text { Glacial-transition, upper-bound } \\
\text { infiltration }\end{array}$ \\
\hline
\end{tabular}

Mass Balance and Solution Convergence: Table 6.2-10 shows the mass-balance results for the nine simulation scenarios. In Table 6.2-10, "inflow" is the total infiltration rate over the entire model top boundary, representing a net water recharge rate (mass) into the system for the infiltration scenario simulated. "Outflow" is the cumulative total-flow rate out of the model and into the lower boundary representing the water table. Global mass-balance errors between inflow and outflow from the system, as shown in Table 6.2-10, are less than 0.06 percent for the nine simulations, leading to the conclusion that steady-state solutions are obtained for all the simulations. 
Table 6.2-10. Mass-Balance Results for Nine Flow Simulations

\begin{tabular}{|l|c|c|c|}
\hline $\begin{array}{c}\text { Simulation } \\
\text { Scenarios }\end{array}$ & $\begin{array}{c}\text { Inflow from infiltration } \\
(\mathbf{k g} / \mathbf{s})\end{array}$ & $\begin{array}{c}\text { Outflow to water table } \\
(\mathbf{k g} / \mathbf{s})\end{array}$ & $\begin{array}{c}\text { Relative error } \\
(\%)\end{array}$ \\
\hline preq_IA & 1.5828143 & 1.5828216 & 0.0005 \\
\hline preq_mA & 5.5922355 & 5.5908953 & 0.0240 \\
\hline preq_uA & 13.564390 & 13.556891 & 0.0553 \\
\hline monq_IA & 5.5922355 & 5.5922194 & 0.0003 \\
\hline monq_mA & 14.939317 & 14.945912 & 0.0473 \\
\hline monq_uA & 24.286298 & 24.286685 & 0.0016 \\
\hline glaq_IA & 2.9648877 & 2.9648851 & 0.0001 \\
\hline glaq_mA & 21.494950 & 21.495135 & 0.0009 \\
\hline glaq_uA & 40.024949 & 40.024915 & 0.0001 \\
\hline
\end{tabular}

Output DTN: LB03023DSSCP9I.001.

Model Calibrations and Results: As listed in Table 6.2-9, there are nine scenarios for model calibrations, sensitivity analyses, as well as flow fields, covering nine infiltration rates for three climates. The nine simulations have been calibrated against the field-observed data of perched water. In addition, the observed matrix liquid saturations and water potentials (when available) are also used to examine these modeling results. A perched-water body is defined as fully liquid saturated gridblocks with zero capillary pressure for calibration. The data source used in the calibrations are listed in Section 4-1. Note that only in situ measurement water potentials among the water-potential data are used. In this section, the simulation results are presented and discussed in terms of (1) comparisons with matrix liquid saturation, water potential, and perched water data; (2) examination of simulated perched-water bodies; and (3) examination of simulated percolation flux and fracture-matrix flow components.

All nine simulations are checked against observed saturation, water potential, and perched-water data. (See Wang 2003 [DIRS 162417], SN-LBNL-SCI-199-V1, pp. 131 to 157, 242 to 243, for detailed comparisons of the saturation and potential profiles of all boreholes evaluated by the model and for mass balance results of the simulations.) However, only a few of these comparisons are shown in the report, and Boreholes UZ-14 and SD-12 are selected to show the match between observed and modeled vertical-saturation profiles and perched-water locations for six simulations with perched-water occurrence. Matches to other borehole data are similar. Note that most borehole observation data used in this section and the following sections are given relative to depth. In plots of this report, we use elevations to show model results and comparisons. Appendix B lists the surface elevations and coordinates of selected boreholes for conversion from depth to elevation.

Here higher future infiltration scenarios of monsoon and glacial-transition are not used for model calibration against future infiltration scenarios. Instead, they are used to assess uncertainties with possible historical high infiltration in the past and its impact on the current UZ condition. In addition, such simulation results quantify the range of variation in UZ conditions that spans the range of future climates, and are not expected to match measured data well. In particular, the calibrated mean, lower and upper bound model properties have not been adjusted to match conditions generated by those high infiltration rates. 
Comparisons with Liquid Saturation, Water Potential, and Perched-Water Data: Measured matrix liquid saturation, water-saturation data and perched-water elevations are compared against three-dimensional model results from the nine simulations. Matrix liquid saturation, water potential, and perched-water data used for comparisons are taken from nine boreholes (NRG-7a, SD-6, SD-7, SD-9, SD-12, UZ-14, UZ\#16, WT-24, and G-2). The locations of these boreholes are shown in Figure 6.1-1.

The comparisons of simulated and observed matrix liquid saturations along the vertical column representing Boreholes UZ-14 and SD-12 are shown, as examples, in Figures 6.2-2 and 6.2-3 from the UZ flow models with nine infiltration scenarios. Figure 6.2-4 shows comparison with water potentials for SD-12. In general, the modeled results from the nine simulations with the UZ flow conceptual model are in reasonable agreement with the measured saturation and water-potential profiles, as shown in Figures 6.2-2, 6.2-3, and 6.2-4. It should be mentioned that the modeling results from the three lower infiltration scenarios show some differences from, or compare more poorly than, the rest of the model predictions. The differences between simulated and observed saturation data, as shown in Figures 6.2-2 and 6.2-3, are primarily caused by heterogeneity and grid coarseness.

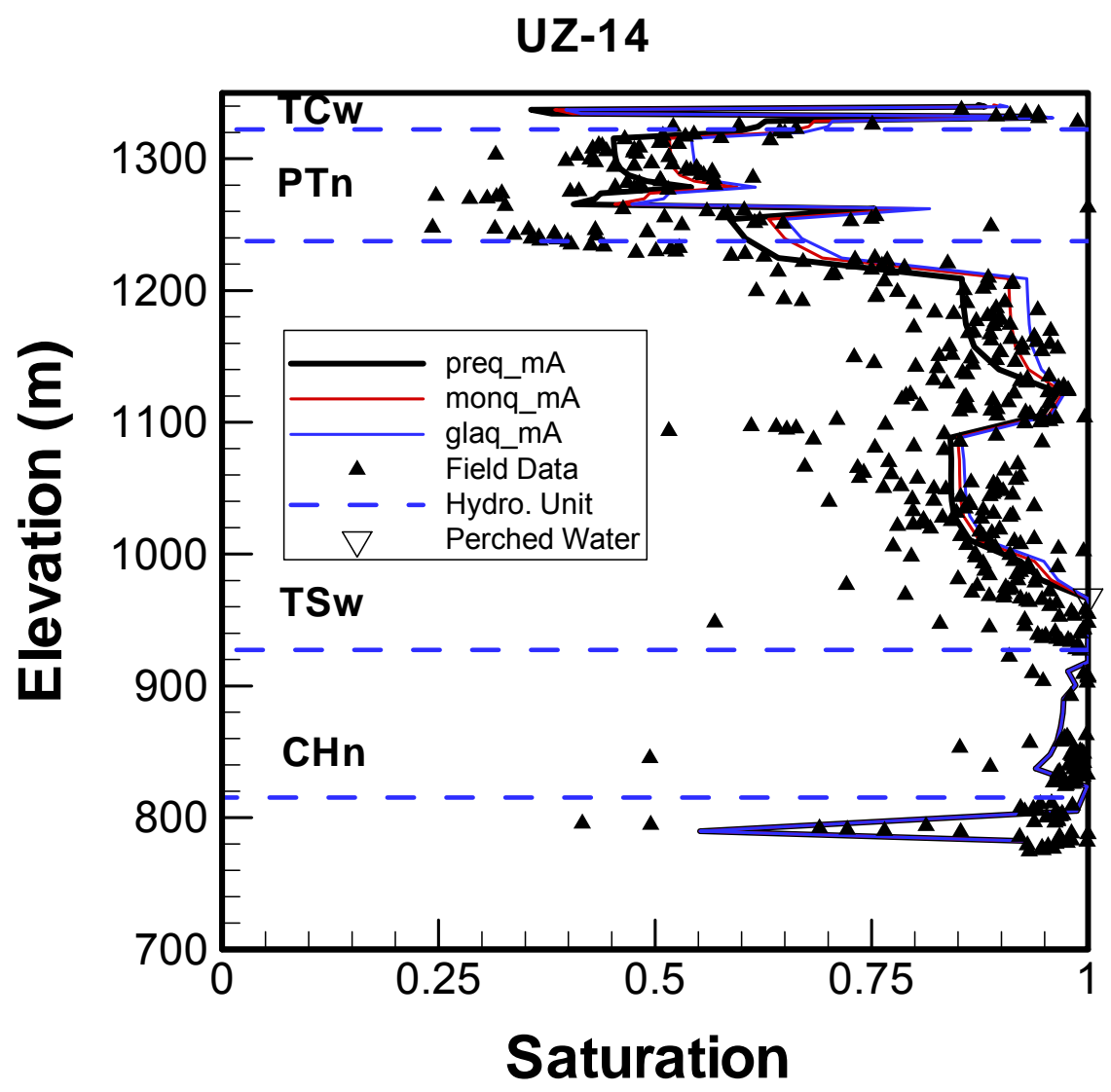

Sources: DTNs: GS960308312312.005 (DIRS 107230); MO0109HYMXPROP.001 (DIRS 155989); MO0004QGFMPICK.000 (DIRS 152554).

Output DTN: LB03023DSSCP9I.001.

Figure 6.2-2. Comparison to the Simulated and Observed Matrix Liquid Saturations and Perched-Water Elevations for Borehole UZ-14, Using the Results of the Simulations with Three Mean Infiltration Rates 


\section{SD-12}

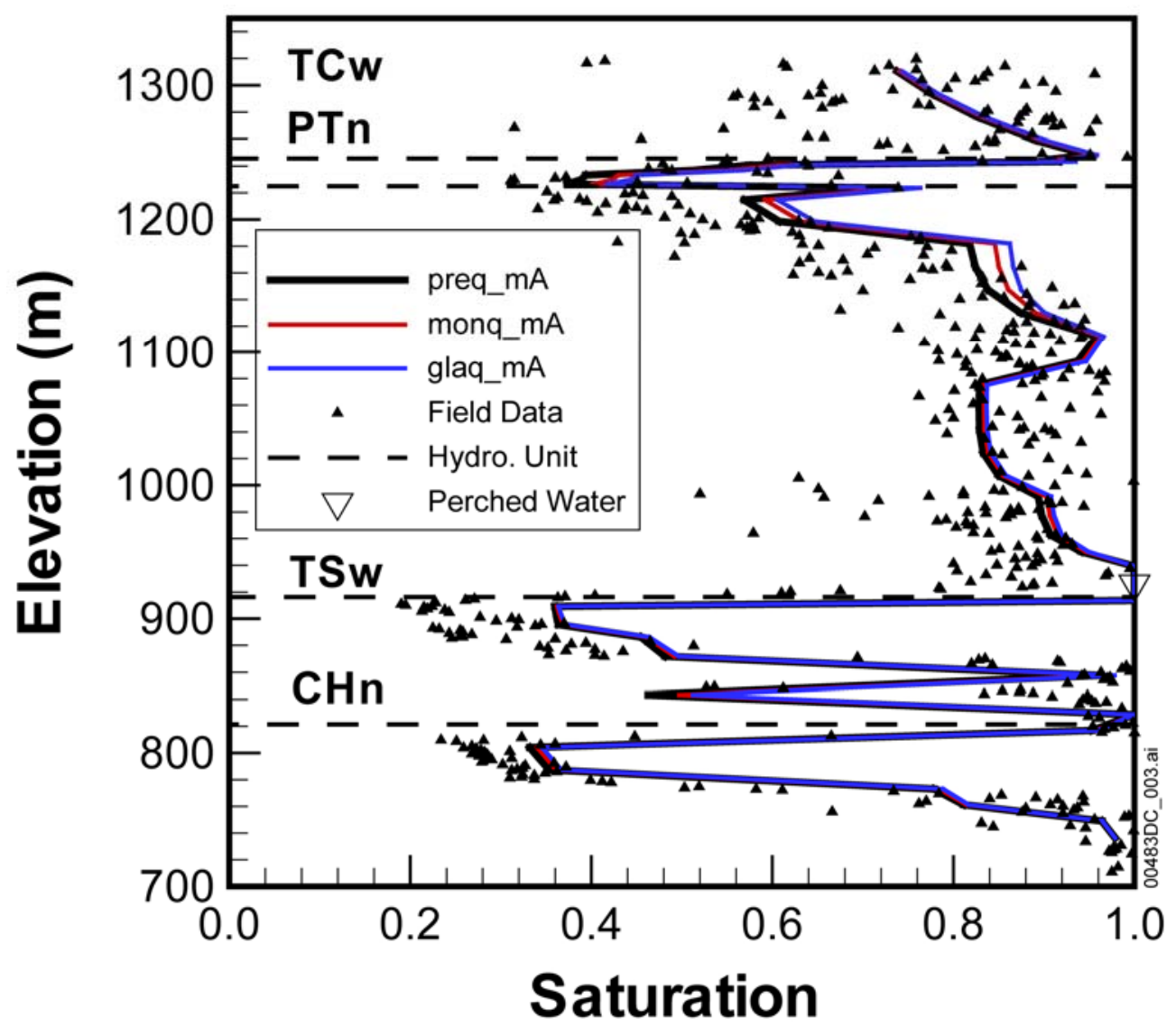

Sources: $\quad$ Rousseau et al. 1997 (DIRS 100178); DTNs: MO0109HYMXPROP.001 (DIRS 155989); MO0004QGFMPICK.000 (DIRS 152554).

Output: DTN: LB03023DSSCP9I.001.

Figure 6.2-3. Comparison to the Simulated and Observed Matrix Liquid Saturations and Perched-Water Elevations for Borehole SD-12, Using the Results of the Simulations with Three Mean Infiltration Rates 


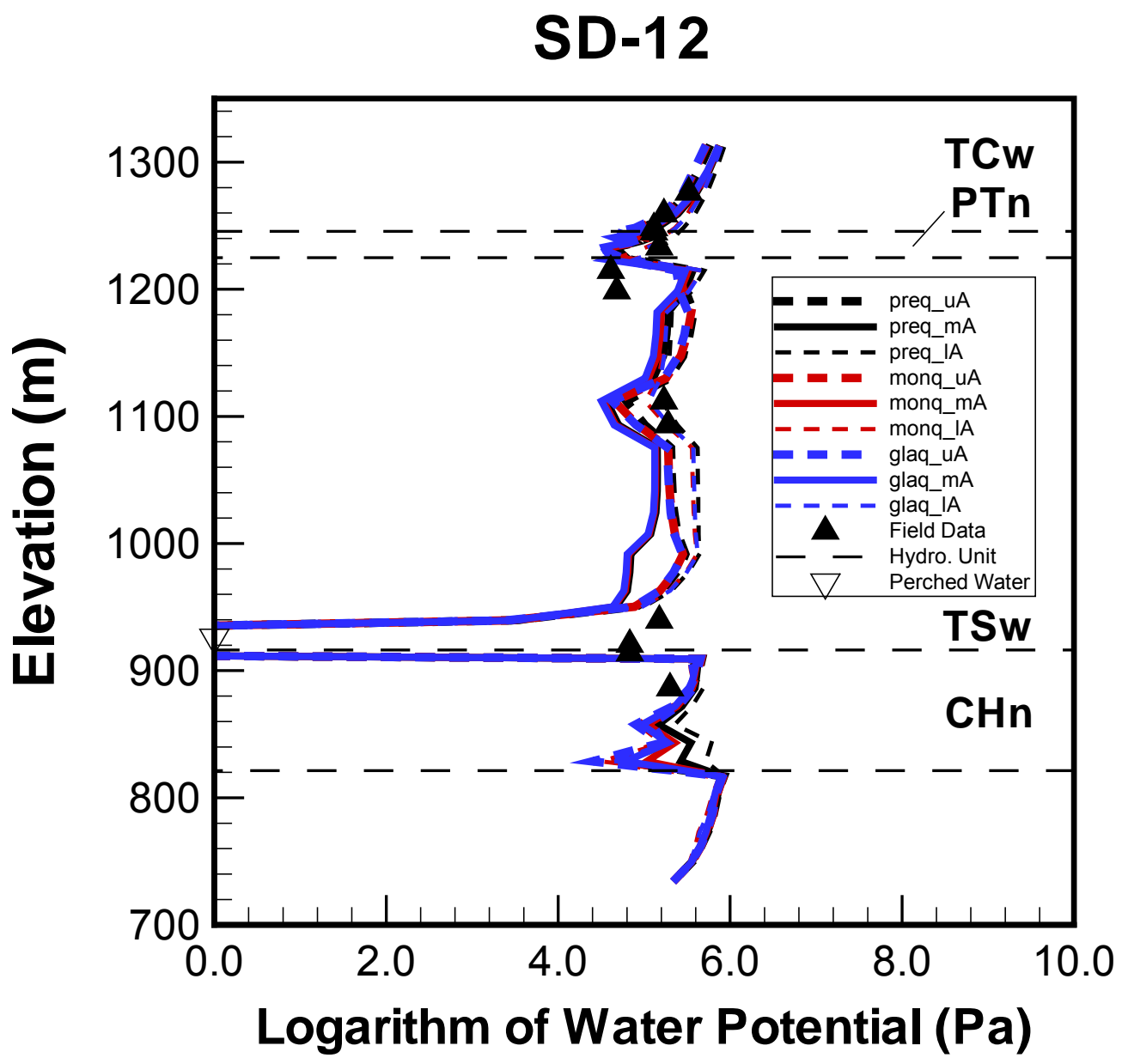

Source DTN: MO0004QGFMPICK.000 (DIRS 152554); Model Results - DTN: LB03023DSSCP9I.001.

NOTE: Field data shown in figure are from DTN: LB991091233129.001 (DIRS 125868), based on measured water potentials in DTNs: GS970808312232.005 [DIRS 105978] and GS031208312232.003 (DIRS 171287).

Figure 6.2-4. Comparison to the Simulated and Averaged Observed Water Potentials and Perched-Water Elevations for Borehole SD-12, Using the Results of the Simulations with Three Mean Infiltration Rates

Also shown in Figures 6.2-2, 6.2-3, and 6.2-4 are the perched-water elevations at the two boreholes, indicating a good agreement between observed and simulated data. In addition, each of the nine simulations has been compared to perched-water data, as observed from the seven perched-water boreholes of Table 6.2-1 (see Wang 2003 [DIRS 162417], SN-LBNL-SCI-199V1, pp. 131 to 157,242 to 243 , for detailed comparisons). The results are as follows:

- Under the present-day, monsoon, or glacial-transitional mean infiltration scenarios of the three climates (preq_mA, monq_mA, and glaq_mA, Table 6.2-9), the three-dimensional flow-simulation-results model generally matches water-perching conditions in the UZ model domain. 
- Under the present-day, monsoon, or glacial-transitional upper-bound infiltration scenarios (preq_uA, monq_uA, and glaq_uA, Table 6.2-9), the three-dimensional flow-simulation-results model generally reproduces water-perching conditions in the UZ model domain.

- Under the present-day, lower-bound infiltration scenarios (preq_1A, Table 6.2-9), the models, in general, do not match the perched-water data very well, except UZ-12 because of the low percolation fluxes at these borehole locations. While under the lower-bound monsoon or glacial-transitional infiltration scenarios (monq 1A and glaq_1A, Table 6.2-9), the flow model results match well with observed perched-water data.

Note that the high liquid saturations simulated in the areas immediately above the water table and the perched water locations, as shown in Figures 6.2-3 and 6.2-4, indicate that the model results include capillary rise in the UZ.

\subsubsection{Features, Events, and Processes}

The selected FEPs for this report (Table 6.2-11) are those taken from the LA FEP list (DTN: MO0407SEPFEPLA.000 [DIRS 170760]) that are included in the TSPA through this report. The list of FEPs in Table 6.2-11 includes two that were not listed, and omits two that were listed, in BSC (2004 [DIRS 169654], Table 2.1.5-1). This deviation from the TWP was necessary because the list in the TWP was based upon the previous revision of this report, and because of a change in the include/exclude status of two FEPs. The discussion in this and other model and analysis reports form the technical basis for evaluation of the listed FEPs. The cross-reference for each FEP the relevant section of this report is given in Table 6.2-11.

The results of this model are part of the basis for the treatment of FEPs, as discussed in the Total System Performance Assessment-License Application Methods and Approach (BSC 2002 [DIRS 160146], Section 3.2.2). The cross-reference for each FEP to the relevant sections of this report is also given in Table 6.2-11.

The results of this and other reports are used to fully document the technical basis for the include/exclude status of these FEPs for TSPA-LA. The UZ Department's documentation for the included FEPs listed in Table 6.2-11 is compiled from this and other reports, and can be found in the model abstraction reports, as described in Sections 2.1.2 and 2.4 of the TWP (BSC 2002 [DIRS 160819]), and in the FEP report, as described in Section 1.12.10 of the TWP (BSC 2002 [DIRS 160819]). Excluded FEPs are to be documented in the FEP report, as described in Section 1.12.10 of the TWP (BSC 2002 [DIRS 160819]). Complete or partial treatment of FEPs is provided herein. 
Table 6.2-11. FEPs Addressed in This Report

\begin{tabular}{|c|c|c|}
\hline $\begin{array}{l}\text { LA FEP } \\
\text { Number }\end{array}$ & FEP Name & $\begin{array}{l}\text { Section(s) Where } \\
\text { FEP Is Addressed }\end{array}$ \\
\hline 1.2.02.01.0A & Fractures & $\begin{array}{l}\text { 6.1.5, 6.2.3, 6.4, } \\
6.6 .3,6.7 .3,6.8,7.4\end{array}$ \\
\hline 1.2.02.02.0A & Faults & $\begin{array}{l}\text { 6.1.5, 6.2.2, 6.6.2, } \\
6.6 .3,6.7 .3\end{array}$ \\
\hline 1.3.01.00.0A & Climate change & $\begin{array}{l}\text { 6.1.4, 6.2.5, 6.5.1, } \\
6.6,6.7 .2,6.7 .3\end{array}$ \\
\hline 1.3.07.02.0B & Water table rise affects UZ & $6.6 .3,7.11$ \\
\hline 1.4.01.01.0A & $\begin{array}{l}\text { Climate modification } \\
\text { increases recharge }\end{array}$ & $\begin{array}{l}\text { 6.1.4, 6.2.5, 6.6.2, } \\
6.6 .3,6.7 .2,6.7 .3\end{array}$ \\
\hline 2.1.08.01.0A & $\begin{array}{l}\text { Water influx at the } \\
\text { repository }\end{array}$ & $6.6 .3,6.7 .3$ \\
\hline 2.2.03.01.0A & Stratigraphy & $6.1 .1,6.1 .2,6.2 .3$ \\
\hline 2.2.03.02.0A & $\begin{array}{l}\text { Rock properties of host } \\
\text { rock and other units }\end{array}$ & $6.1 .5,6.2 .3,6.4 .2$ \\
\hline 2.2.07.01.0A & $\begin{array}{l}\text { Locally Saturated Flow at } \\
\text { Bedrock/Alluvium Contact }\end{array}$ & $6.1 .3,6.1 .4$ \\
\hline 2.2.07.02.0A & $\begin{array}{l}\text { Unsaturated ground-water } \\
\text { flow in the geosphere }\end{array}$ & $6.2,6.6,6.7$ \\
\hline 2.2.07.03.0A & Capillary rise in the UZ & 6.2 .5 \\
\hline 2.2.07.04.0A & $\begin{array}{l}\text { Focusing of unsaturated } \\
\text { flow (fingers, weeps) }\end{array}$ & $6.1 .2,6.6 .3,6.7 .3$ \\
\hline 2.2.07.07.0A & Perched water develops & $\begin{array}{l}\text { 6.2.2.2, 6.2.3, 6.2.5, } \\
6.6 .2,6.6 .3\end{array}$ \\
\hline 2.2.07.08.0A & Fracture flow in the UZ & $6.6 .2,6.6 .3$ \\
\hline 2.2.07.09.0A & Matrix imbibition in the UZ & 6.6.2, 6.6.3, 7.6.3.2 \\
\hline 2.2.07.19.0A & $\begin{array}{l}\text { Lateral flow from Solitario } \\
\text { Canyon fault enters drift }\end{array}$ & 6.6 .3 \\
\hline 2.2.10.03.0B & $\begin{array}{l}\text { Natural geothermal effects } \\
\text { on flow in the UZ }\end{array}$ & 6.3 .4 \\
\hline 2.3.01.00.0A & $\begin{array}{l}\text { Topography and } \\
\text { Morphology }\end{array}$ & 6.1 .1 \\
\hline 2.3.11.01.0A & Precipitation & $6.1 .4,6.5 .1 .2$ \\
\hline 2.3.11.02.0A & $\begin{array}{l}\text { Surface Runoff and } \\
\text { Flooding }\end{array}$ & $6.1 .4,6.5 .1 .2$ \\
\hline 2.3.11.03.0A & Infiltration and recharge & $\begin{array}{l}\text { 6.1.4, 6.5, 6.6.1, } \\
6.7 .2\end{array}$ \\
\hline
\end{tabular}

$\mathrm{FEP}=$ feature, event, and process; $L A=$ license application; $\mathrm{UZ}=$ unsaturated zone 


\subsection{TEMPERATURE CALIBRATION}

Prior to performing thermal-hydrological $(\mathrm{TH})$ studies of the UZ system as well as repository performance studies under thermal-loading conditions, the ambient temperature, percolation, and moisture distributions are first needed to determine as TH model initial conditions. The ambient geothermal and moisture conditions serve as the initial and boundary conditions of a thermal model. This section describes a three-dimensional ambient geothermal submodel of the UZ model developed to evaluate steady-state, ambient thermal, and moisture conditions of the UZ system for use in various scale TH modeling studies. Subsequent temperature calibration then provides an independent examination of percolation fluxes simulated by the UZ flow model. This is because the ambient temperature distribution within the UZ is related to percolation fluxes or infiltration rates (Bodvarsson et al. 2003 [DIRS 162477]). By matching borehole temperature measurements, the ambient $\mathrm{TH}$ model helps to constrain infiltration rate ranges as well as fracture-matrix parameter values. Note that except this section, the rest of the 3-D model development and calibration in this model report are dealing with isothermal conditions.

\subsubsection{Three-Dimensional Thermal Model Grid}

For thermal calibration as well as the gas flow calibration described in the next section, a new three-dimensional grid (Figure 6.3-1), smaller than the TSPA-LA grid (Figure 6.1-1), is developed. This grid is designed to relax intensive computational burdens needed in thermal modeling studies using a three-dimensional dual-permeability grid. The thermal model domain is selected to focus on geothermal conditions and thermal-loading effects at and near the repository area. The model domain is considered to provide sufficient accuracy for such studies because of the small thermal impact expected in the lateral directions from the repository thermal loading.

This three-dimensional grid, featuring a smaller model domain than that of the UZ flow model (Figure 6.1-1), is referred to as the three-dimensional thermal model grid. As shown in the plan view of Figure 6.3-1, the thermal model grid domain covers approximately $20 \mathrm{~km}^{2}$ of the area. Similar to the TSPA-LA grid of Figure 6.1-1, the thermal model grid (Figure 6.3-1) also uses a refined mesh in the vicinity of the repository and includes the locations of several boreholes used in temperature calibrations and analyses. In particular, the thermal grid explicitly incorporates every repository drift by taking into account orientations, lengths, elevations, and spacings of the drifts. A grid spacing of $81 \mathrm{~m}$ is used in the direction perpendicular to drifts, such that each individual drift segment can be inserted into the three-dimensional thermal grid for thermalloading studies in a different report (BSC 2004 [DIRS 169866]), as documented in the TWP (BSC 2002 [DIRS 160819], Section 1.12.7). In the model, faults are also represented in the model by vertical or inclined 30-m wide zones.

The thermal model grid of Figure 6.3-1 consists of 980 mesh columns of both fracture and matrix continua, 86,440 gridblocks, and 343,520 connections in a dual-permeability grid. Vertically, the thermal grid has an average of 45 computational grid layers. 


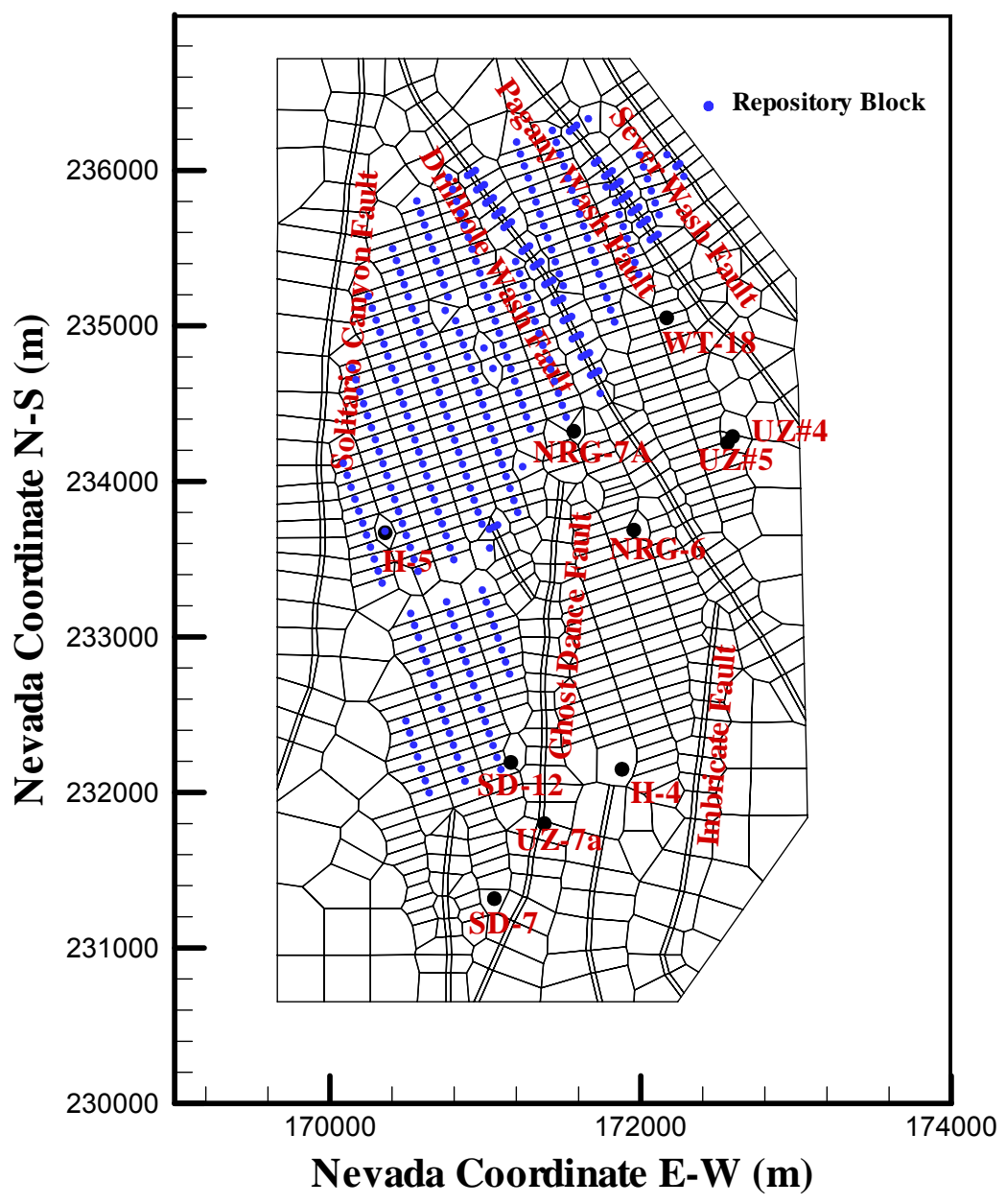

Output DTN: LB0303THERMESH.001.

Figure 6.3-1. Plan View of the Three-Dimensional Thermal Model Grid, Showing the Model Domain, Faults Incorporated, Several Borehole Locations, and TH Model Boundaries

\subsubsection{Top Boundary Temperature}

To account for variations in atmospheric temperature with surface elevations in the mountain, measured mean surface temperatures and a linear equation that correlates surface temperature with elevation are used (Section 5). The annual-average temperature was measured for near-surface sensors in Boreholes NRG-6 and NRG-7a (DTNs: GS960308312232.001 [DIRS 105573], GS951108312232.008 [DIRS 106756], and GS950208312232.003 [DIRS 105572]), with several years of continuous temperature monitoring data. The surface temperatures $\mathrm{T}_{\mathrm{s}}$ at any elevation $\mathrm{Z}$ are then computed using the routine toptemp_v0.f V1.0 (LBNL 2000 [DIRS 147030]), and are treated as constants according to the following equation (Wu et al. 1999 [DIRS 117161], Equation 4):

$$
\mathrm{T}_{\mathrm{s}}=\mathrm{T}_{\mathrm{ref}}-\lambda\left[\mathrm{Z}-\mathrm{Z}_{\mathrm{ref}}\right]
$$

where $T_{\text {ref }}$ is mean surface temperature at reference elevation $Z_{\text {ref }}$ and $\lambda$ is the dry adiabatic atmospheric lapse rate in ${ }^{\circ} \mathrm{C} / \mathrm{m}$. This lapse is $0.01^{\circ} \mathrm{C} / \mathrm{m}$ (Driscoll 1986 [DIRS 116801], p. 50). 
In this formulation, the surface reference temperature used is $18.23^{\circ} \mathrm{C}$ at an elevation of $1,231.0 \mathrm{~m}$, averaged using measured data from Borehole NRG-6. The averaged temperature measurement of NRG-7a at an elevation of $1,282.2 \mathrm{~m}$ is $17.78^{\circ} \mathrm{C}$. The calculated mean lapse rate, based on these field measurements, is $0.009^{\circ} \mathrm{C} / \mathrm{m}$.

\subsubsection{Bottom Boundary Temperature}

The initial estimates of temperature distributions at the bottom boundary of the TH were taken from the report by BSC (2001 [DIRS 158726]). For that report, an effort was made to obtain accurate bottom-temperature boundary conditions for use in thermal-hydrological simulations. Following that work, the software routine of get_temp_v0.f V1.0 (LBNL 2000 [DIRS 147027]) was used to estimate temperatures at a flat surface of an elevation of $730 \mathrm{~m}$. Because the water table is no longer flat with the current $\mathrm{UZ}$ and TH models, the actual estimates of the water table or bottom-model-boundary temperatures were interpolated between the values at $730 \mathrm{~m}$ elevation and the model surface boundary. Several nonqualified measured temperature profiles (Sass et al. 1988 [DIRS 100644]) were used as corroborative data (BSC 2001 [DIRS 158726]) for an initial guess of the water-table-boundary temperature contours. In this report, initially estimated water table temperatures are examined against the qualified temperature data in Boreholes NRG-6, NRG-7a, SD-12 UZ\#4, UZ\#5, and UZ-7a (DTN: GS950208312232.003 [DIRS 105572], DTNs: GS970808312232.005 [DIRS 105978], GS971108312232.007 [DIRS 105980], GS960808312232.004 [DIRS 105974], GS970108312232.002 [DIRS 105975], GS031208312232.003 [DIRS 171287]).

\subsubsection{Calibration of Ambient Temperatures}

The temperature profiles or geothermal gradients with the UZ system are controlled by several factors, such as formation thermal conductivity and net infiltration rates, in addition to the regional weather condition or surface temperatures. Because of the small impact of uncertainties in measured thermal conductivities on simulated heat flow, the temperature calibration may be conducted using either ambient infiltration, or model boundary temperatures, or both. In this report, the ambient net infiltration rate is fixed as the present-day, mean infiltration rate with an average value of $3.6 \mathrm{~mm} /$ year within the grid domain (Figure 6.3-1), which is averaged over a smaller model domain than the UZ flow model domain (Figure 6.1-10), resulting a smaller mean infiltration value. Temperatures are slightly adjusted from the estimated values along the top boundary only, and this results in a better match of observed borehole data. The reason behind the adjustment is, first, that insufficient temperature data was collected along these boundaries for accurate description of temperature distributions. Second, under steady-state moisture and heat flow conditions, both top and bottom boundary temperatures are spatially varying constants, which leaves room for adjusting to fit measured steady-state temperature profiles from boreholes.

The ambient temperature condition was calibrated using the three-dimensional thermal model grid of Figure 6.3-1 (Output-DTN: LB0303THERMESH.001), a dual-permeability mesh. The simulations were performed using TOUGH2 V1.4 (LBNL 2000 [DIRS 146496]) with the EOS3 module. In addition to the prescribed temperature conditions on top and bottom boundaries, the infiltration was described using the base-case, present-day, mean infiltration scenario. The model incorporated the parameter set of Table A-1 (DTN: LB03013DSSCP3I.001), the thermal 
properties (DTN: LB0210THRMLPRP.001 [DIRS 160799]), and the calibrated fault properties (DTN: LB02092DSSCFPR.002 [DIRS 162128]). Note that the thermal properties incorporated include effects of lithophysal cavities for TSw layers tsw33 and tsw 35. The simulations were run to steady state for comparisons with measured borehole temperatures.

Table 6.3-1 lists the boreholes with qualified temperature measurements and the corresponding column element names used in the three-dimensional calibration of model ambient temperature. Note that in both the three-dimensional thermal model grid and the TSPA-LA grid, each element name is 8 characters long, consisting of numbers, alphabets, or symbols. The last three characters of 8-character names are assigned to stand for a vertical column, which are determined uniquely for each vertical grid column. As shown in Table 6.3-1, Boreholes UZ\#4 and UZ\#5 are so close to each other that they fall into the same grid column. Therefore, we use only UZ\#5 for calibrations (i.e., using temperature data from 5 of 6 boreholes). The comparison between UZ\#4 and UZ\#5 is documented in the report by Wang (2003 [DIRS 162417], SN-LBNL-SCI-199-VI, pp. 219, 223). During calibration, the corresponding simulated temperature profiles for the boreholes were extracted from the TOUGH2 output and then plotted against the measurements along each borehole.

Figure 6.3-2 shows the final model calibrated results and measured temperature profiles in the five temperature boreholes. The figure shows a good match between measured and simulated temperatures using the specified boundary conditions and the present-day, mean infiltration rate. Near the ground surface in five of the boreholes, observed temperatures show significant seasonal variations. However, these seasonal changes in surface temperature have little impact on steady-state heat flow or temperature profiles in the deeper (more than $20 \mathrm{~m}$ ) UZ.

Table 6.3-1. Temperature Boreholes and Corresponding Element Columns of the Thermal Model Grid

\begin{tabular}{|l|l|}
\hline \multicolumn{1}{|c|}{ Borehole } & \multicolumn{1}{c|}{ Element Column } \\
\hline NRG-6 & h39 \\
\hline NRG-7A & h40 \\
\hline SD-12 & h44 \\
\hline UZ\#5 & h45 \\
\hline UZ-7a & h74 \\
\hline UZ\#4 & h45 \\
\hline
\end{tabular}

DTN: LB0303THERMESH.001.

Figure 6.3-3 shows the contour plot of calibrated temperature distributions at the water table or the model bottom boundary. This temperature distribution is used for thermal simulations in which the model boundary temperature is fixed at the water table. Figure 6.3-3 indicates that the average temperature at the water table ranges from $27^{\circ} \mathrm{C}$ to $33^{\circ} \mathrm{C}$, and lower temperatures are located in the north of the model domain where elevations and percolation fluxes are both higher. For the top model boundary, the estimated temperature distributions are shown in Figure 6.3-4. Based on calibration results, the ambient temperature distribution in the UZ TH model can be described to specify steady-state, mountain-scale temperature conditions. 

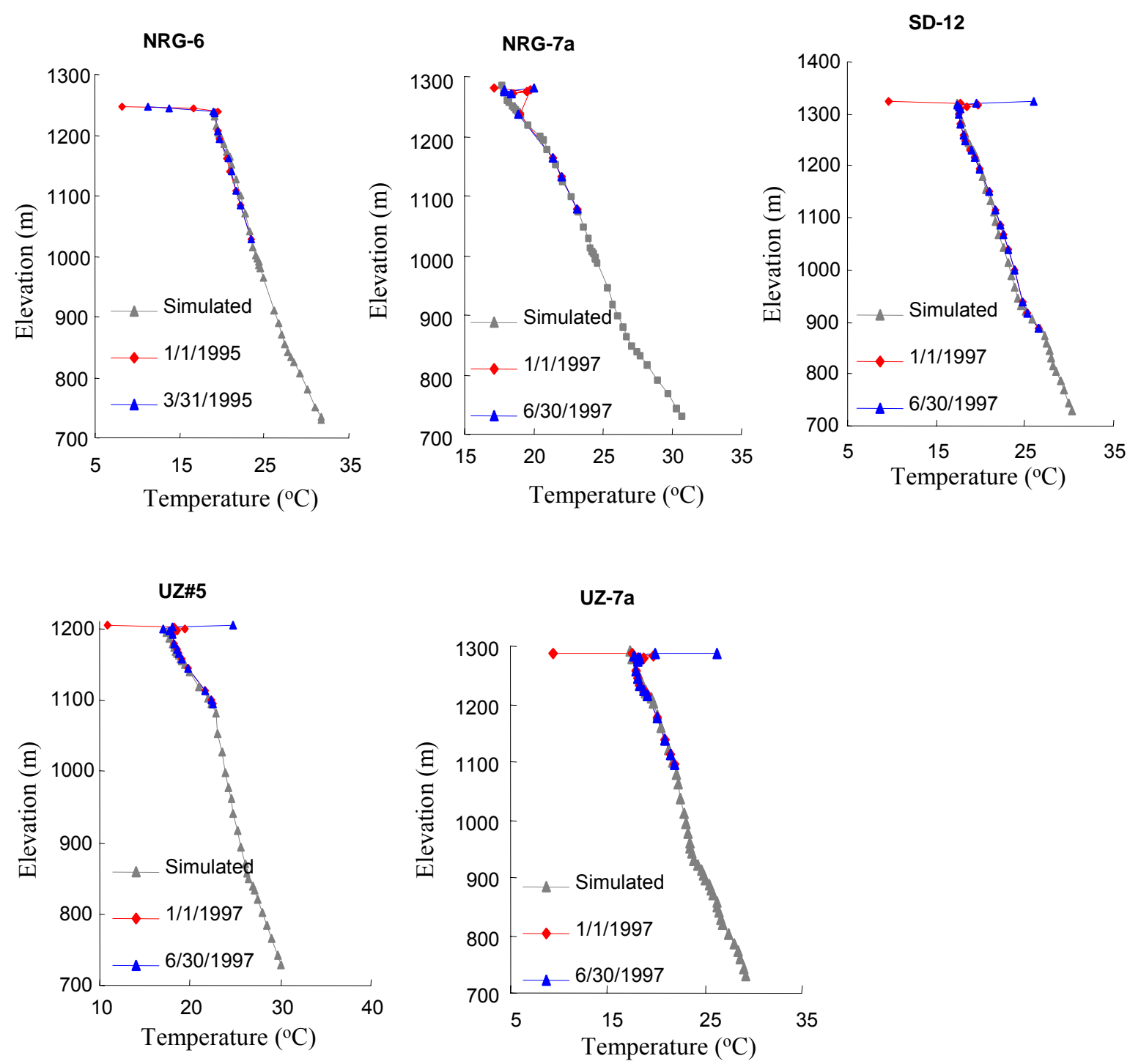

Source DTNs: GS970808312232.005 [DIRS 105978]; GS971108312232.007 [DIRS 105980]; GS960808312232.004 [DIRS 105974]; GS970108312232.002 [DIRS 105975]; GS031208312232.003 [DIRS 171287].

Output DTN: LB0303THERMSIM.001.

Figure 6.3-2. Comparisons between Measured and Modeled Ambient Temperature Profiles for the Five Boreholes under the Present-Day Mean Infiltration Rate

The UZ flow fields for ambient conditions are not sensitive to temperature distributions. For corroborative purpose, and to build confidence in the flow field representations, the temperature contours in Figure 6.3-3 were developed over the years from available data. Wu et al. (1999 [DIRS 117161], Figure 12) identified that the data sources were from 25 boreholes documented mainly in the report by Sass et al. (1988 [DIRS 100644]), and observed that, in general, the measured data matched reasonably with early three-dimensional model results (Bodvarsson et al. 1997 [DIRS 100103]; Ahlers et al. 1995 [DIRS 101180]). The majority of the early temperature data in Temperature, Thermal Conductivity, and Heat Flow Near Yucca Mountain, Nevada: Some Tectonic and Hydrologic Implications (Sass et al. 1988 [DIRS 100644]) are currently not 
qualified. In this report, six qualified data sets of temperature distributions along boreholes are shown to be consistent with the water table distribution developed from the more extensive data set, demonstrating the consistency of water temperature distribution with unsaturated processes. The same extensive data set is also the basis for saturated zone interpretation of Fridrich et al. (1994 [DIRS 100575], pp. 133 to 168). Fridrich et al. (1994 [DIRS 100575], p. 157) discussed the heat flow anomalies, upward and downward flows, and the uncertainty of ignoring unsaturated-zone processes. The consistency of different saturated zone and UZ interpretations can be further evaluated.

\section{Temperature distribution at water table}

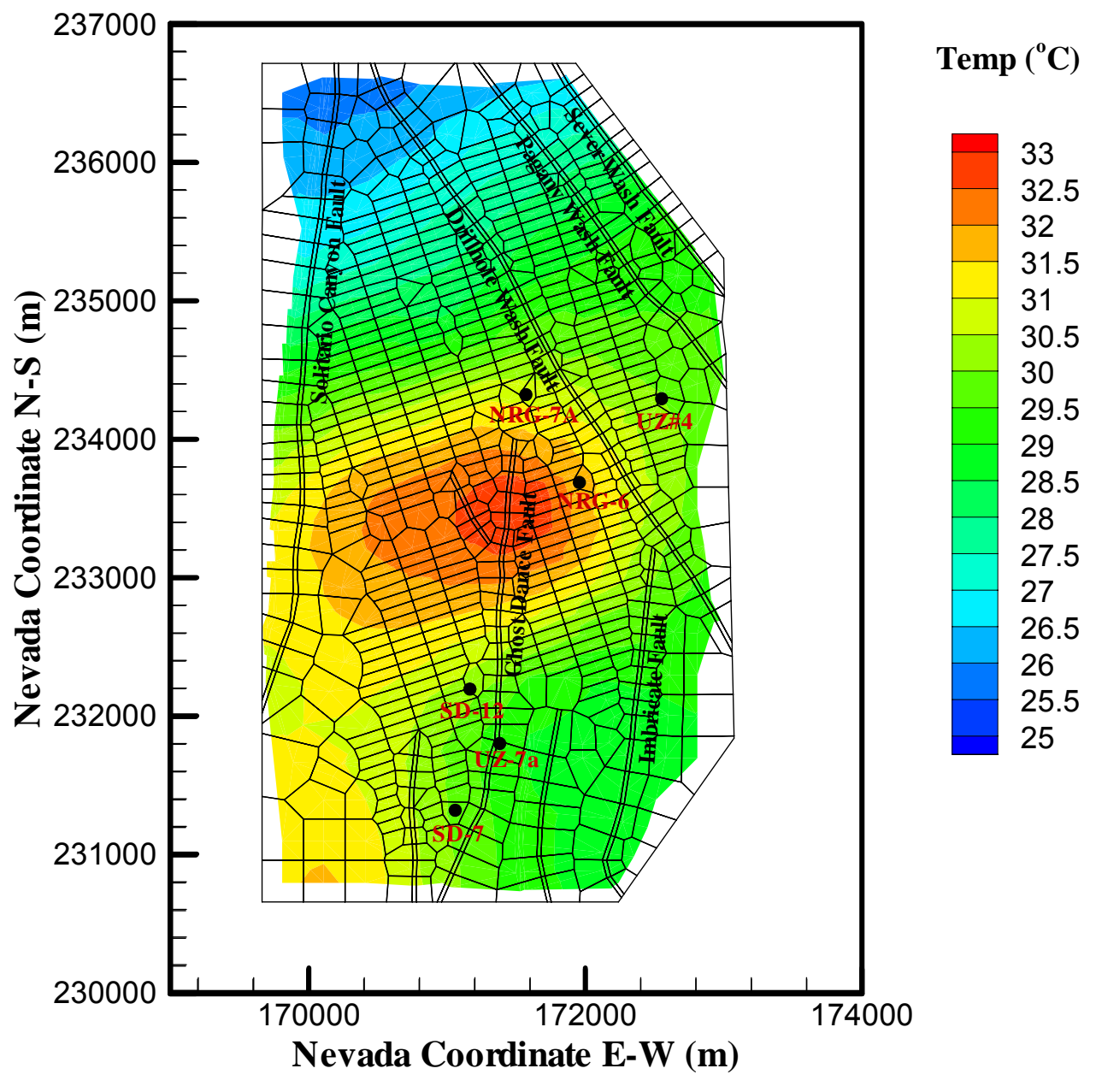

Output DTN: LB0303THERMSIM.001.

Figure 6.3-3. Ambient Temperature Distributions at the Water Table for the Present-Day Mean Infiltration Scenario 


\section{Temperature Distribution at Land surface}

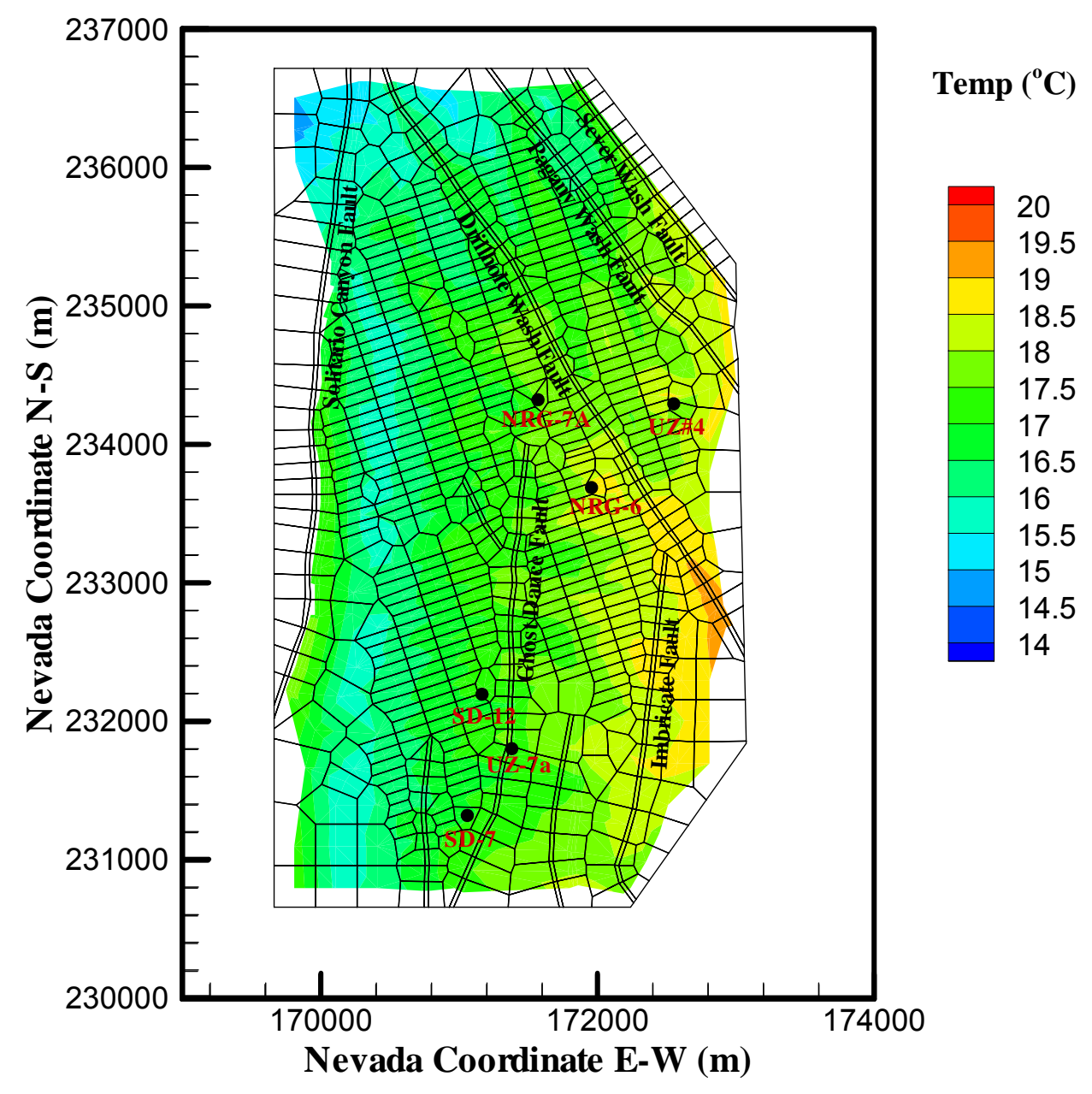

Output DTN: LB0303THERMSIM.001.

Figure 6.3-4. Temperature Distributions at the Mountain Surface, the Top Model Boundary for the Present-Day Mean Infiltration Scenario 


\subsection{PNEUMATIC CALIBRATION}

As part of the UZ model calibration effort, three-dimensional pneumatic simulations are conducted and summarized in this section. Calibration of the UZ model to pneumatic data will aid in estimates of large-scale fracture permeability for the UZ system. This is particularly useful for modeling studies of thermal loading, gas flow, and transport of gaseous phase radionuclides for the site (Ahlers et al. 1999 [DIRS 109715]). The results of these gas flow simulations are compared with field measured pneumatic data from several boreholes to re-estimate fracture permeability in several TSw layers. This section focuses on the model calibration and analysis using these pneumatic simulation results.

\subsubsection{Model Parameters and Boundary Conditions}

The three-dimensional mesh used in this gas flow simulation is the same three-dimensional thermal grid mesh (Figure 6.3-1) used for the thermal simulation. The mesh is described in Section 6.3. The grid domain covers approximately $20 \mathrm{~km}^{2}$ of the area, which is smaller than the TSPA-LA grid (Figure 6.1-1). Similar to TSPA-LA grid, this grid also uses a finer mesh in the vicinity of the repository area.

The rock properties used for current three-dimensional pneumatic prediction are initially those developed using one-dimensional models for the present-day mean infiltration scenario (BSC 2004 [DIRS 169857]; DTN: LB02091DSSCP3I.002 [DIRS 161433]) and two-dimensional site-scale calibrated fault properties (DTN: LB02092DSSCFPR.002 [DIRS 162128]). In addition, the model incorporated the parameter set of Table A-1 (DTN: LB03013DSSCP3I.001), and the thermal properties (DTN: LB0210THRMLPRP.001 [DIRS 160799]).

The present-day, mean net infiltration rate (with a value of $3.6 \mathrm{~mm} /$ year for the $\mathrm{TH}$ model grid) is used to describe the surface infiltration conditions. However, additional pneumatic boundary conditions needed on land surface are time-dependent, and are specified using the routine TBgas3D V2.0 (LBNL 2002 [DIRS 160107]), based on measured atmospheric barometric pressure data (DTN: LB0302AMRU0035.001 [DIRS 162378]). The bottom water table boundary is treated as a Dirichlet-type boundary. The pressure conditions at the bottom boundary are based on measured surface pressures for Boreholes USW SD-7 and SD-12 (DTN: LB991091233129.001 [DIRS 125868]). First, the average surface pressure and the corresponding pressure at the horizon of $730 \mathrm{~m}$ are calculated for each borehole. Then, the average of the two subsurface pressures, $92 \mathrm{kPa}$, is used to determine the pressures at the water table boundary as a function of elevation change from $730 \mathrm{~m}$. Lateral boundaries are treated as no-flow boundaries. The UZ system is set at an isothermal condition of $25^{\circ} \mathrm{C}$, the average of the surface temperature and water table temperature. The steady state solution of flow simulation for the present-day mean infiltration scenario is taken as the initial moisture condition of the current model.

\subsubsection{Modeling Approach and Calibration}

The three-dimensional pneumatic simulation is run using EOS3 module of the TOUGH2 code V1.4 (LBNL 2000 [DIRS 146496]) by neglecting the influence of liquid phase flow. The impact 
of liquid phase flow to the gas flow system is small for gas-flow simulation results. This was shown by examining the simulation results for the single-phase gas and two-phase water-gas flow, in which single-phase and two-phase flow simulations produce almost identical results in calculated gas pressures, as documented in the Scientific Notebook by Wang (2003 [DIRS 162417], SN-LBNL-SCI-202-V1, pp. 84 to 85). The simulation of gas flow by itself is implemented by using the linear relative permeability function and choosing TOUGH input parameters to force the relative permeability of liquid phase to equal 0 .

The pneumatic model was calibrated against the field-measured pneumatic data from two boreholes. The model calibration results indicated that some modification of rock properties in several TSw layers is necessary to match field observed gas pressures. In particular, it was found necessary to reduce the fracture permeability of tsw31-tsw37 subunits by a factor of 15 . The lower fracture permeability for the three-dimensional model may be attributed to the original fracture permeability being estimated from inversion of one-dimensional models with one-dimensional vertical flow paths only. In a three-dimensional model, some high flux channels, such as faults, exist, and three-dimensional gas flow is able to find these high-permeability pathways with the least resistance for three-dimensional gas flow. As a result, the fracture permeability of a three-dimensional model may be lower than that estimated by one-dimensional models. The differences for the inversion of one-dimensional, twodimensional, and three-dimensional pneumatic models for this site have been discussed by Ahlers et al. (1999 [DIRS 109715]).

The two boreholes used for calibration are USW SD-7 and SD-12. Table 6.4-1 shows the sensor elevations, files for averaged observed data (DTNs: LB991091233129.001 [DIRS 125868], and LB02092DSSCFPR.001 [DIRS 162422]), and observing-date ranges for comparison of these boreholes. The table also lists the corresponding mesh cells in the three-dimensional thermal model grid. For SD-12, data of the first 30 days are used for the calibration, and the second 30 days are compared to the prediction for validation, as discussed in Section 7.4.

Table 6.4-1. Observation Data and Corresponding Grid Columns of Boreholes SD-7 and SD-12 Used in the Pneumatic Calibration

\begin{tabular}{|c|c|c|c|}
\hline Sensor Elevation $(\mathrm{m})$ & $\begin{array}{c}\text { File for Observation } \\
\text { Data }\end{array}$ & Date Range & $\begin{array}{c}\text { Corresponding } \\
\text { Observation Cells }\end{array}$ \\
\hline \multicolumn{4}{|c|}{ Borehole USW SD-7 (LB991091233129.001 [DIRS 125868]) } \\
\hline 1271.6 & Sd7_300_zone1.txt & $4 / 5-6 / 4 / 96$ & F0003h42 \\
\hline 1256.4 & Sd7_350_zone2.txt & $4 / 5-6 / 4 / 96$ & F0008h42 \\
\hline 1241.4 & Sd7_400_zone3.txt & $4 / 5-6 / 4 / 96$ & F0010h42 \\
\hline 1119.2 & Sd7_800_zone11.txt & $4 / 5-6 / 4 / 96$ & F013Ah42 \\
\hline \multicolumn{4}{|c|}{ Borehole USW SD-12 (LB991091233129.001 [DIRS 125868]) } \\
\hline 1258.5 & Sd12_214_PT1679.txt & $12 / 1 / 95-1 / 29 / 96$ & F002Bh44 \\
\hline 1232.0 & Sd12_301_PT1667.txt & $12 / 1 / 95-1 / 29 / 96$ & F0009h44 \\
\hline 1217.1 & Sd12_350_PT1661.txt & $12 / 1 / 95-1 / 29 / 96$ & F0011h44 \\
\hline 1001.3 & Sd12_1058_PT1619.txt & $12 / 1 / 95-1 / 29 / 96$ & F014Bh44 \\
\hline
\end{tabular}




\subsubsection{Analysis of Results}

Comparisons of the model simulation results and the field measurement data for Boreholes SD-7 (60 days) and SD-12 (30 days) are shown in Figures 6.4-1 and 6.4-2, respectively. In general, the simulation results demonstrate a good match with measurement data for the two boreholes. Except in the TSw unit of SD-7, the three-dimensional simulation predicts a slightly smaller amplitude signal than the observation data. Many comparisons between model simulated pressures with and without fracture-permeability modifications against field measurements show that the calibrated three-dimensional model has improved consistently in matching observation data. Note that for Borehole SD-7, the calibrated-fracture-permeability values of the TSw unit may be even lower for a better match. This might be caused by the effect of the nearby fault on pneumatic signal propagation. In addition, slightly greater differences between simulated and observed gas pressures in the lower TSw unit may be caused by coarse-grid effects and the larger effect of heterogeneity with depth. Overall, a reduction by a factor of 15 (Table 6.2-9) for the $\mathrm{TSw}$ fracture permeability provides a better fit to observed pneumatic data for all locations and time periods.

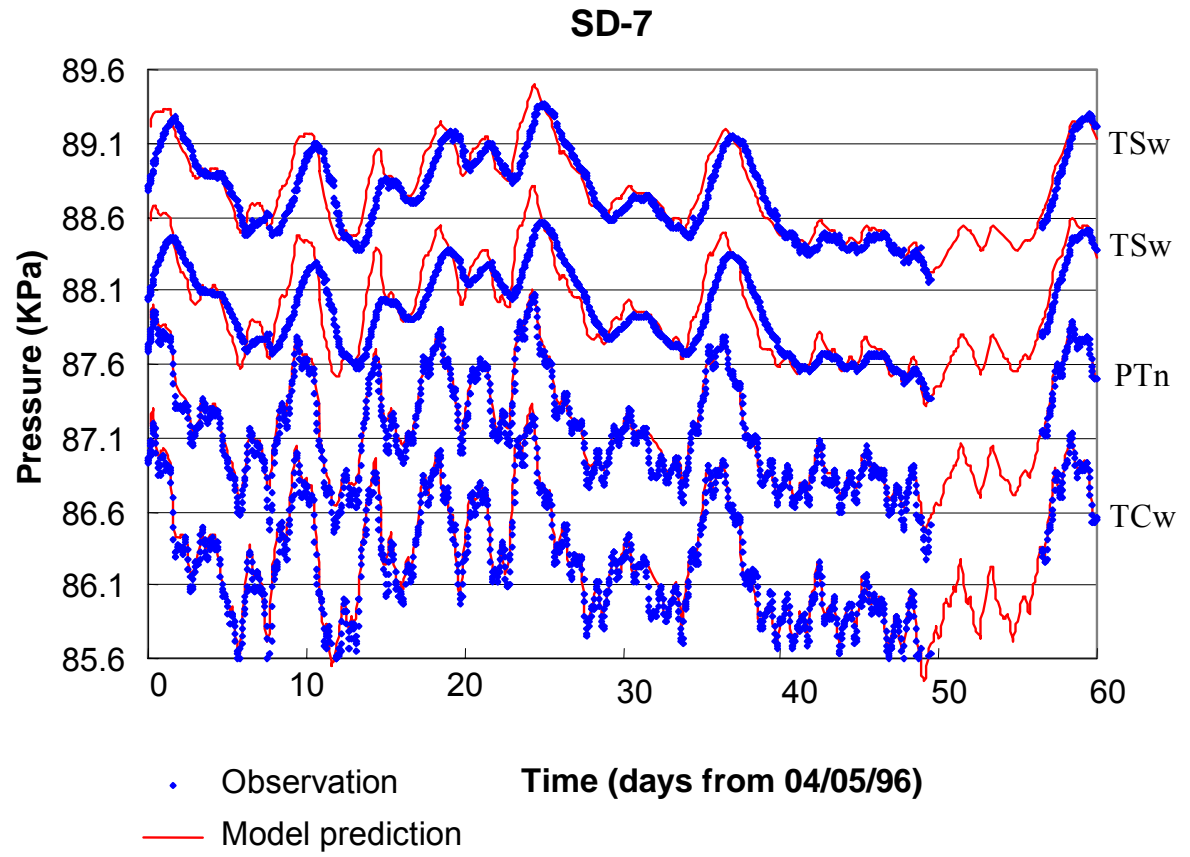

Source DTN: LB991091233129.001 (DIRS 125868).

Output DTN: LB0303GASFLW3D.001.

NOTE: Field data from DTN: LB991091233129.001 [DIRS 125868] are extracted from DTN: GS960908312261.004 (DIRS 106784). Both observations and simulations have been vertically offset for clearer display.

Figure 6.4-1. Comparison of Simulated and Observed Gas Pressure at Borehole SD-7 during a 60-Day Period 
SD-12

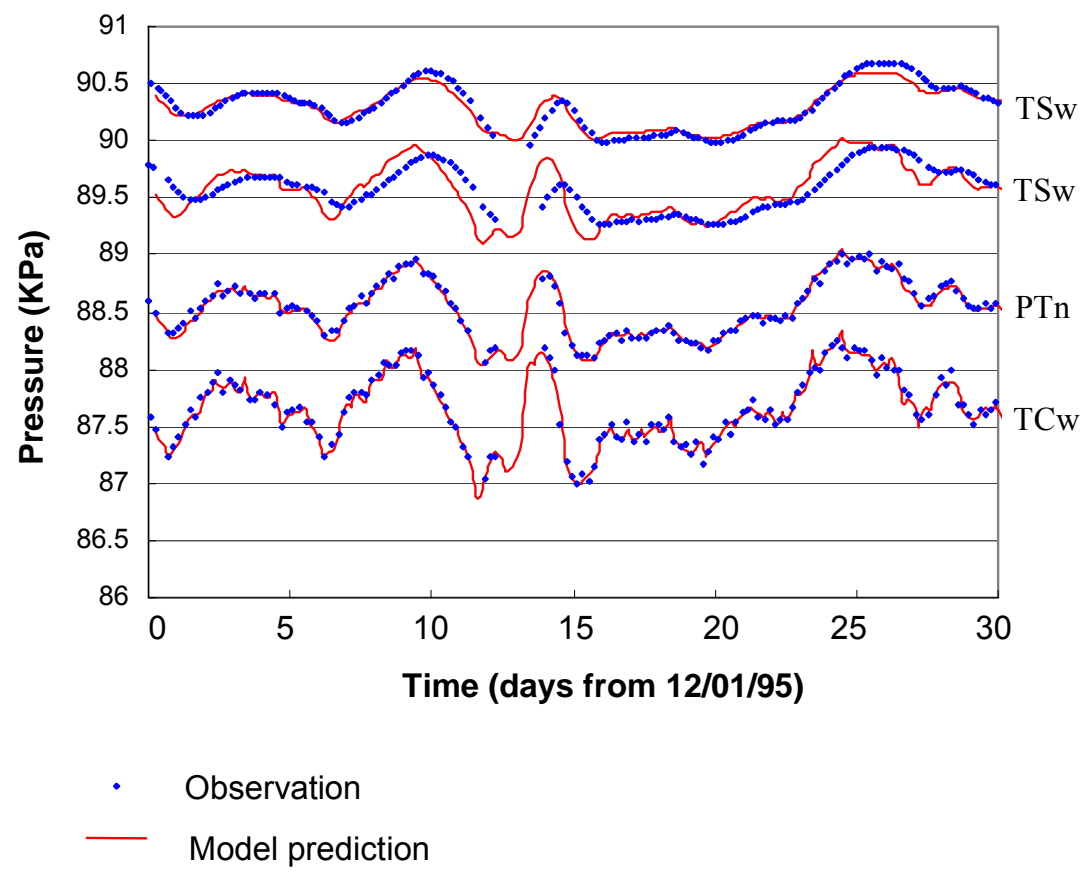

Source DTN: LB991091233129.001 (DIRS 125868).

Output DTN: LB0303GASFLW3D.001.

NOTE: Field data from DTN: LB991091233129.001 (DIRS 125868) are extracted from

DTN: GS960308312232.001 (DIRS 105573). Both observations and simulations have been vertically offset for clearer display.

Figure 6.4-2. Comparison of Simulated and Observed Gas Pressure at Borehole SD-12 during the First 30-Day Period

\subsection{ANALYSIS AND MODELING OF PORE-WATER CHEMICAL DATA}

This study consists of using geochemical data and models to evaluate the hydrological systems through assessing spatial distribution of surface net infiltration and the impact of variations in its magnitude.

The UZ system of Yucca Mountain has been the subject of intense geological, hydrological, and subsurface engineering studies. One of the main issues is to estimate the percolation flux at the nuclear waste repository. Percolation flux strongly depends on infiltration rates and their spatial distribution. Much work has been done to estimate the infiltration flux based on various evaporation models (Hevesi et al. 1992 [DIRS 116809]; Flint and Flint 1994 [DIRS 103746]). The present-day mean infiltration rate across the study area ranges from one millimeter per year to several tens of millimeters per year (Table 6.1-2, DTN: GS000308311221.005 [DIRS 147613]). The climate over the past 100,000 years has been used to estimate the possible range in infiltration rates over the next 10,000 years (Sonnenthal and Bodvarsson 1999 [DIRS 117127]). 
Geochemical data provide additional information to analyze the UZ system. Pore-water chemical concentration data are used in this section to calibrate the UZ model and to bound the infiltration flux range, flow pathways, and transport times. The distribution of chemical constituents in both liquid and solid phases of the UZ system depends on many factors, such as hydrological and geochemical processes of surface precipitation, evapotranspiration, and fracture-matrix interaction of flow and transport, large-scale mixing via lateral transport, and the history of climate changes and recharge.

The distribution of chloride in the UZ groundwater provides important data for UZ model calibration and validation. In this study, concentration data of pore-water chloride $(\mathrm{Cl})$ are analyzed and modeled by three-dimensional chemical transport simulations using the dual-permeability modeling approach. In the UZ flow model on which this chloride transport modeling was based, the base-case flow models use the property set of the PTn (Section 6.2.3) that favor lateral diversion of flow in the PTn unit, as discussed in 6.6.3. Alternative UZ flow models incorporate another property set of the PTn (Section 6.2.3, Tables A-4, A-5, and A-6) not likely to cause large-scale lateral flow.

\subsubsection{Available Data}

\subsubsection{Pore-Water Chemical Concentration Data}

Chloride transport processes were modeled in this model analysis. The chloride concentrations used in our modeling were measured from pore waters extracted from field samples. These samples were collected from eleven surface-based boreholes, the ESF, and the ECRB tunnels. The Boreholes are SD-6, SD-7, SD-9, SD-12, NRG-6, NGR-7a, UZ-14, UZ\#16, UZ-7a, WT-24, and G-2. Data for each borehole are listed in Table 6.5-1.

Table 6.5-1. Chloride Data Sources

\begin{tabular}{|l|c|}
\hline \multicolumn{1}{|c|}{ Boreholes/Facilities } & Data Tracking Number (DTN) \\
\hline SD-6 & GS981008312272.004 [DIRS 153677] A \\
& LA0002JF12213U.001 [DIRS 154760] B \\
\hline SD-7 & GS000608312271.001 [DIRS 153407] C \\
& GS970908312271.003 [DIRS 111467] D \\
& GS961108312271.002 [DIRS 121708] F \\
& GS981008312272.004 [DIRS 153677] A \\
& LA0002JF12213U.001 [DIRS 154760] B \\
& LAJF831222AQ98.011 [DIRS 145402] H \\
\hline SD-9 & GS970908312271.003 [DIRS 111467] D \\
& GS961108312271.002 [DIRS 121708] F \\
& LA0002JF12213U.001 [DIRS 154760] B \\
& LAJF831222AQ98.011 [DIRS 145402] H \\
\hline SD-12 & GS000608312271.001 [DIRS 153407] C \\
& GS970908312271.003 [DIRS 111467] D \\
& GS961108312271.002 [DIRS 121708] F \\
& GS981008312272.004 [DIRS 153677] A \\
& LA0002JF12213U.001 [DIRS 154760] B \\
\hline
\end{tabular}


Table 6.5-1. Chloride Data Sources (Continued)

\begin{tabular}{|l|l|}
\hline \multicolumn{1}{|c|}{ Boreholes/Facilities } & \multicolumn{1}{|c|}{ DTN } \\
\hline NRG-6 & GS010708312272.002 [DIRS 156375] I \\
& LA0002JF12213U.001 [DIRS 154760] B \\
& LAJF831222AQ98.011 [DIRS 145402] H \\
\hline NRG-7a & GS961108312271.002 [DIRS 121708] F \\
& GS981008312272.004 [DIRS 153677] A \\
& GS010708312272.002 [DIRS 156375] I \\
& LA0002JF12213U.001 [DIRS 154760] B \\
& LAJF831222AQ98.011 [DIRS 145402] H \\
\hline UZ-14 & GS010708312272.002 [DIRS 156375] I \\
& GS961108312271.002 [DIRS 121708] F \\
& GS990208312272.001 [DIRS 146134] J \\
& LA0002JF12213U.001 [DIRS 154760] B \\
& LAJF831222AQ98.011 [DIRS 145402] H \\
\hline UZ\#16 & GS010708312272.002 [DIRS 156375] I \\
& GS990208312272.001 [DIRS 146134] J \\
& LA0002JF12213U.001 [DIRS 154760] B \\
& LAJF831222AQ98.011 [DIRS 145402] H \\
\hline UZ-7a & LA0002JF12213U.001 [DIRS 154760] B \\
& GS981008312272.004 [DIRS 153677] A \\
\hline WT-24 & GS981008312272.004 [DIRS 153677] A \\
& LA0002JF12213U.001 [DIRS 154760] B \\
& LAJF831222AQ98.011 [DIRS 145402] H \\
\hline G-2 & LAJF831222AQ98.011 [DIRS 145402] H \\
\hline ECRB & LA9909JF831222.004 [DIRS 145598] K \\
& LA0002JF12213U.002 [DIRS 156281] L \\
\hline ESF & GS961108312261.006 [DIRS 107293] M \\
& LA0002JF12213U.002 [DIRS 156281] L \\
& LA9909JF831222.010 [DIRS 122733] N \\
\hline NOTE: & DIRS numbr a no a Pat of the DTN \\
&
\end{tabular}

NOTE: The letters following the DIRS number are not a part of the DTN number. Each letter corresponds to the identification of the same DTN in the column.

$E C R B=E n h a n c e d$ Characterization of the Repository Block; ESF=Exploratory Studies Facility

\subsubsection{Chloride Flux}

The sources contributing to the chloride in recharge waters are precipitation, run-on, and runoff. Only a small portion of these waters becomes net infiltration. The present-day mean infiltration is approximately $5 \mathrm{~mm} /$ year, while the glacial maximum infiltration rate of 28,000 years ago was about 28 mm/year (Sonnenthal and Bodvarsson 1999 [DIRS 117127], p. 148, Figure 23; Flint et al. 1996 [DIRS 100147]). In chloride modeling analysis of this section, a glacial infiltration scenario was obtained by multiplying the present-day mean infiltration rate by a factor of 5 with the same distribution pattern. This is an approximation of future infiltration under the glacial-transitional climate scenario. Based on the historical infiltration information in the past 
glacial period, the estimated infiltration rate was about 5.6 times the rate of the present-day infiltration at Yucca Mountain area, supported by relevant studies by Sonnenthal and Bodvarsson (1999 [DIRS 117127],) and Flint et al. (1996 [DIRS 100147]). Accordingly, in estimating chloride flux, we choose infiltration rates of a magnitude of 5 times those of the present-infiltration as an approximation.

Four case studies corresponding to four climate scenarios were chosen. They represent modern (or present-day) mean, modern low and modern upper bounds, and glacial mean. Their mean fluxes are listed in Table 6.5-2, calculated from four infiltration maps (DTN: GS000308311221.005 [DIRS 147613]). Also listed in the table are the notations for these infiltration scenarios. The upper-case " $\mathrm{A}$ " represents the corresponding base-case three-dimensional UZ flow model having a property set for the PTn that would allow lateral diversion. The upper-case "B" denotes an alternative model that predicts less lateral flow at the PTn (Section 6.2.3). The lower case $\mathrm{u}, \mathrm{m}$, and $\mathrm{l}$ in the notations stand for flow models of upper, mean, and lower infiltration, on which the chloride models were built. These notations are consistent with the ones used in flow models (Section 6.2). The chloride transport model uses the same flow model as the notation indicates. Chloride recharge fluxes to these transport models are calculated accordingly for these climate scenarios.

The sources of chloride recharge into the UZ includes dissolved material in rain, particulate in snow, and a contribution from windblown dusts (Tyler et al. 1996 [DIRS 108774]). Precipitation on the land surfaces would experience physical processes such as evaporation, which leaves behind $\mathrm{Cl}^{-}$in the remaining water. The chloride mass flux to the chloride transport model depends on the amount of water flux and its chloride concentration. In our modeling study, we consider the fluxes as precipitation, run-on, and runoff. Thus, the water fluxes contributing to chloride recharge can be calculated using the following equation:

$$
F=F_{\text {prec }}+F_{\text {runon }}-F_{\text {runoff }}
$$

where $F$ is net flux contributing to chloride in the recharging water (defined as net recharge in Table 6.5-2, different from the net infiltration of Table 6.1-2), $F_{\text {prec }}$ is precipitation flux, $F_{\text {runon }}$ is run-on, and $F_{\text {runoff }}$ is runoff flux. These water flux terms are eventually converted to have units of $\mathrm{kg} /\left(\mathrm{m}^{2} \cdot \mathrm{sec}\right)$ as input. The calculation of each term in $\mathrm{F}$ is performed using the routine infil2grid V1.7 (LBNL 2002 [DIRS 154793] and DTN: GS000308311221.005 [DIRS 147613]). 
Table 6.5-2. Present-Day and Glacial Infiltration Fluxes at Different Scenarios (Averaged over Model Domain, $\mathrm{mm} / \mathrm{year}$ )

\begin{tabular}{|l|l|c|c|c|c|}
\hline $\begin{array}{c}\text { Scenario } \\
\text { Notations }\end{array}$ & \multicolumn{1}{|c|}{ Scenarios } & Precipitation & Runon & Runoff & $\begin{array}{c}\text { Net Recharge Used } \\
\text { in Calculation of } \\
\text { Chloride Flux }\end{array}$ \\
\hline $\begin{array}{l}\text { preq_uA } \\
\text { preq_uB }\end{array}$ & Modern upper & 267.1 & 171.9 & 9.1 & 429.9 \\
\hline $\begin{array}{l}\text { preq_mA } \\
\text { preq_mB }\end{array}$ & Modern mean & 189.5 & 41.1 & 3.5 & 227.1 \\
\hline $\begin{array}{l}\text { preq_IA } \\
\text { preq_IB }\end{array}$ & Modern low & 185.9 & 13.6 & 1.0 & 198.5 \\
\hline glaq_mA ${ }^{\mathrm{c}}$ & Glacial mean & 316.9 & 292.0 & 14.4 & 594.5 \\
\hline
\end{tabular}

Source: $\quad$ Fluxes calculated as described in Appendix C, Section C.1.1; data from DTN: GS000308311221.005 (DIRS 147613).

${ }^{a}$ The upper-case letter $A$ in the notation denotes the base-case model property set used by the corresponding flow model that would favor lateral flow diversion, and upper-case B denotes the alternative model, in which the property set of the PTn would not likely cause flow diversion (Section 6.2.3).

${ }^{b}$ Net water flux contributing to the chloride recharge is calculated by Equation 6.5-1.

${ }^{c}$ In our modeling of the glacial scenario, a special case of the model was run for simulating 100,000 years to steady-state with glacial chloride flux and then switched to present-day mean chloride recharge for 11,600 years. The simulation is given the notation: glaq_pmA.

Surface chloride concentrations are discussed by Sonnenthal and Bodvarsson (1999 [DIRS 117127], pp. 113 to 114). The range of 0.55 to $0.73 \mathrm{mg} / \mathrm{L}$ was considered to bound the average value. Similar value was obtained by combining a mean annual precipitation of about $170 \mathrm{~mm} /$ year with a present-day chloride surface flux of $106 \mathrm{mg} /\left(\mathrm{m}^{2}\right.$-year $)$, yielding a mean chloride concentration of about $0.62 \mathrm{mg} / \mathrm{L}$ (Fabryka-Martin et al. 1997 [DIRS 100145]). A value of $0.55 \mathrm{mg} / \mathrm{L}$ (Sonnenthal and Bodvarsson 1999 [DIRS 117127]; Triay et al. 1996 [DIRS 101014]) is used in the present simulations, applied to infiltrating water in the forms of precipitation, runon, and runoff (Sonnenthal and Bodvarsson 1999 [DIRS 117127], p. 148). Then, the chloride flux is calculated using the following formula:

$$
F_{C l}=C_{C l, p} \times 10^{-6}\left(F_{\text {prec }}+F_{\text {runon }}-F_{\text {runoff }}\right)
$$

where $F_{C l}$ is chloride flux $(\mathrm{kg} / \mathrm{sec}), F_{\text {prec }}$ is precipitation flux $(\mathrm{kg}$ water $/ \mathrm{sec}), F_{\text {runon }}$ is runon $(\mathrm{kg}$ water/sec), and $F_{\text {runoff }}$ is runoff flux ( $\mathrm{kg}$ water/sec). $C_{C l, p}$ is chloride concentration in precipitation ( $\mathrm{mg} / \mathrm{kg}$ water). Actual calculations and procedures using this equation in preparing input files for chloride simulations are summarized in Appendix C, Section C.1.

\subsubsection{Three-Dimensional Simulations}

Chloride transport for the UZ hydrological system was simulated under two-phase isothermal flow conditions of water and air. A three-dimensional dual-permeability model and the T2R3D V1.4 (LBNL 1999 [DIRS 146654]) of the TOUGH2 code were employed for the simulations. The steady-state liquid-flow fields were obtained using the EOS9 module of TOUGH2 (LBNL 2000 [DIRS 146496]). Chemical distributions were then computed from transport equations using the decoupled T2R3D module (LBNL 1999 [DIRS 146654]). Flow boundary conditions, simulation grids, and the basic hydrological properties of the rock matrix and fractures are the 
same as those used in the three-dimensional UZ flow simulations of Section 6.2. Boundary conditions for chemical components were treated similarly to those for flow simulations, with mass flux described at the top boundary and no-flow and water table conditions at the lateral and bottom boundaries, respectively. The dispersivities for both fracture and matrix continua in the simulation were assumed to be zero (Sonnenthal and Bodvarsson 1999 [DIRS 117127], Section 5.3, p. 129). The same diffusion coefficient used for $\mathrm{Cl}^{-}, 2.032 \mathrm{E}-9 \mathrm{~m}^{2} / \mathrm{s}$ (Lide 2002 [DIRS 160832], pp. 5 to 96), is used for chemical ions at $25^{\circ} \mathrm{C}$, which is the average of the surface temperature and water table temperature, and dilution in water. The tortuosity was set to 0.7 for fracture and 0.2 for matrix, respectively (BSC 2001 [DIRS 158726]; Grathwohl 2000 [DIRS 141512]).

\subsubsection{Modeling Results}

The modeling results are represented in Figures 6.5-1 and 6.5-2 for Boreholes NRG-6 and UZ-14. These figures plot the chloride profiles under present-day infiltration rates of mean infiltration with lower and upper bounds. The results demonstrate that the mean infiltration case has the closest match between the calculated concentrations and the field-measured chloride data. The upper-bound case shows a moderate match; the lower-bound case shows the poorest match.

The glacial scenario yields generally lower chloride concentration than the present case, upper bound (Figures 6.5-1 and 6.5-2). A special scenario run (glaq pmA) with the glacial case was conducted (Figure 6.5-2, purple line). The model was run for 100,000 years to steady state with glacial recharge, and then was switched to present-day recharge for 11,600 years. The model yields a closer match than the glacial recharge case.

\subsubsection{Alternative Model}

In the above base case (A), the property set for the PTn would favor lateral diversion of flow within the PTn unit. The alternative model (B) uses a different property set for the PTn unit, one that does not result in large-scale PTn lateral diversion (Table 6.5-2). A comparison between the base-case model and the alternative model results are presented for Borehole USW SD-9 and the ECRB in Figures 6.5-3 and 6.5-4.

Comparative studies of chloride distributions within the UZ, simulated using the base-case and alternative flow fields, indicate consistently that the base-case flow field simulation results provide an overall better match with the observed chloride data. As discussed in Sections 6.2.5 and 6.6.3, the main difference between the base-case and alternative flow fields is whether there is large- or small-scale lateral flow within the PTn unit, and the base-case flow fields predict relatively large lateral diversion in general. These model calibration results of better matching chloride data with the larger-scale PTn lateral diversion, base-case flow fields indicate that large lateral diversion may exist in the PTn Unit. Therefore, pore-water chloride may provide key evidence for understanding flow through the PTn, which has a direct impact on chloride transport and distributions. 


\section{USW NRG-6}

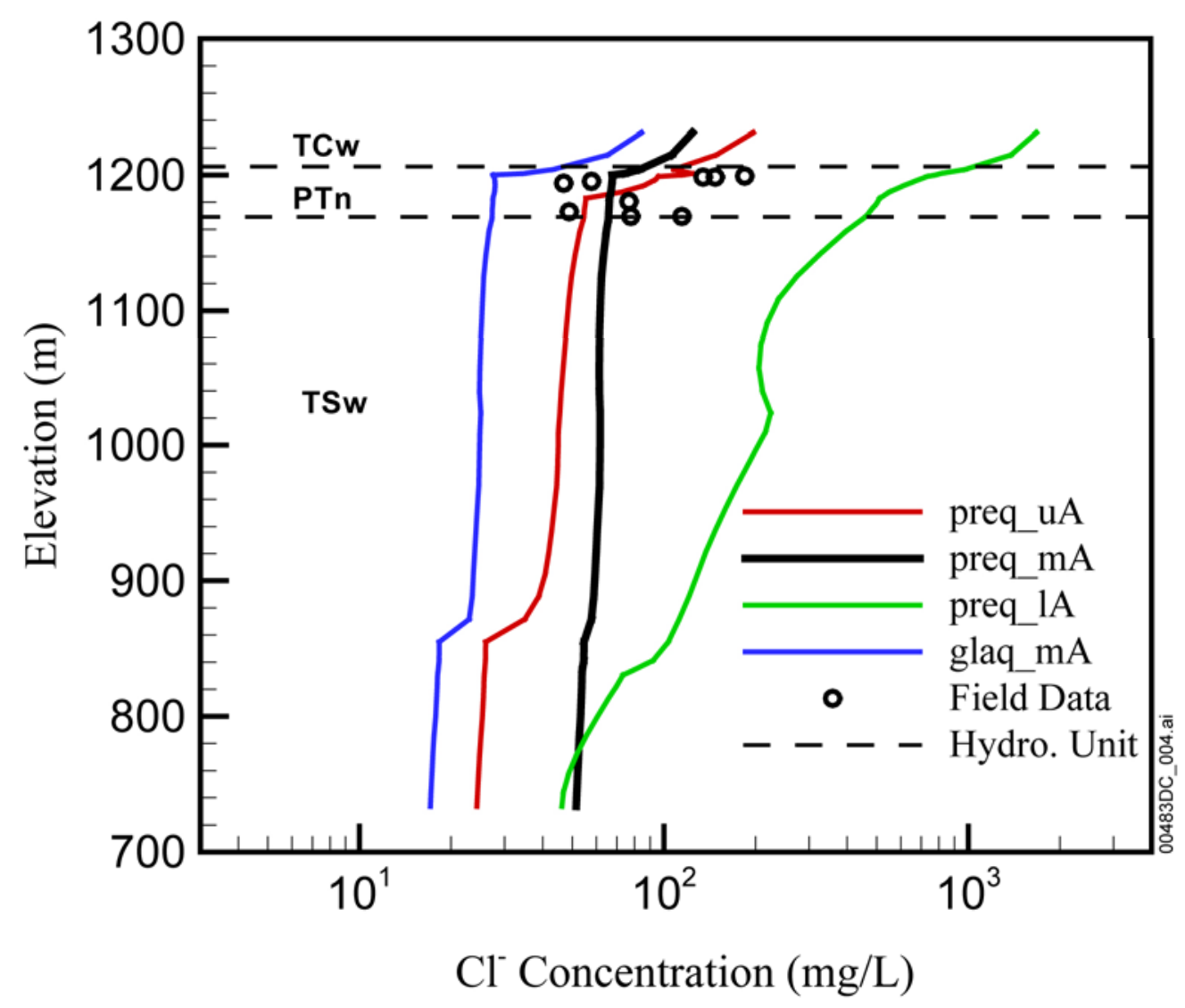

DTNs: $\quad$ GS010708312272.002 (DIRS 156375); LA0002JF12213U.001 (DIRS 154760); LAJF831222AQ98.011 (DIRS 145402).

Output DTN: LB0303CLINFL3D.001.

Figure 6.5-1. Chloride Concentration (mg/L) Profiles at Borehole USW NRG-6 for Present Recharge with Mean, Upper, and Lower Bounds and Glacial Recharge 


\section{USW UZ-14}

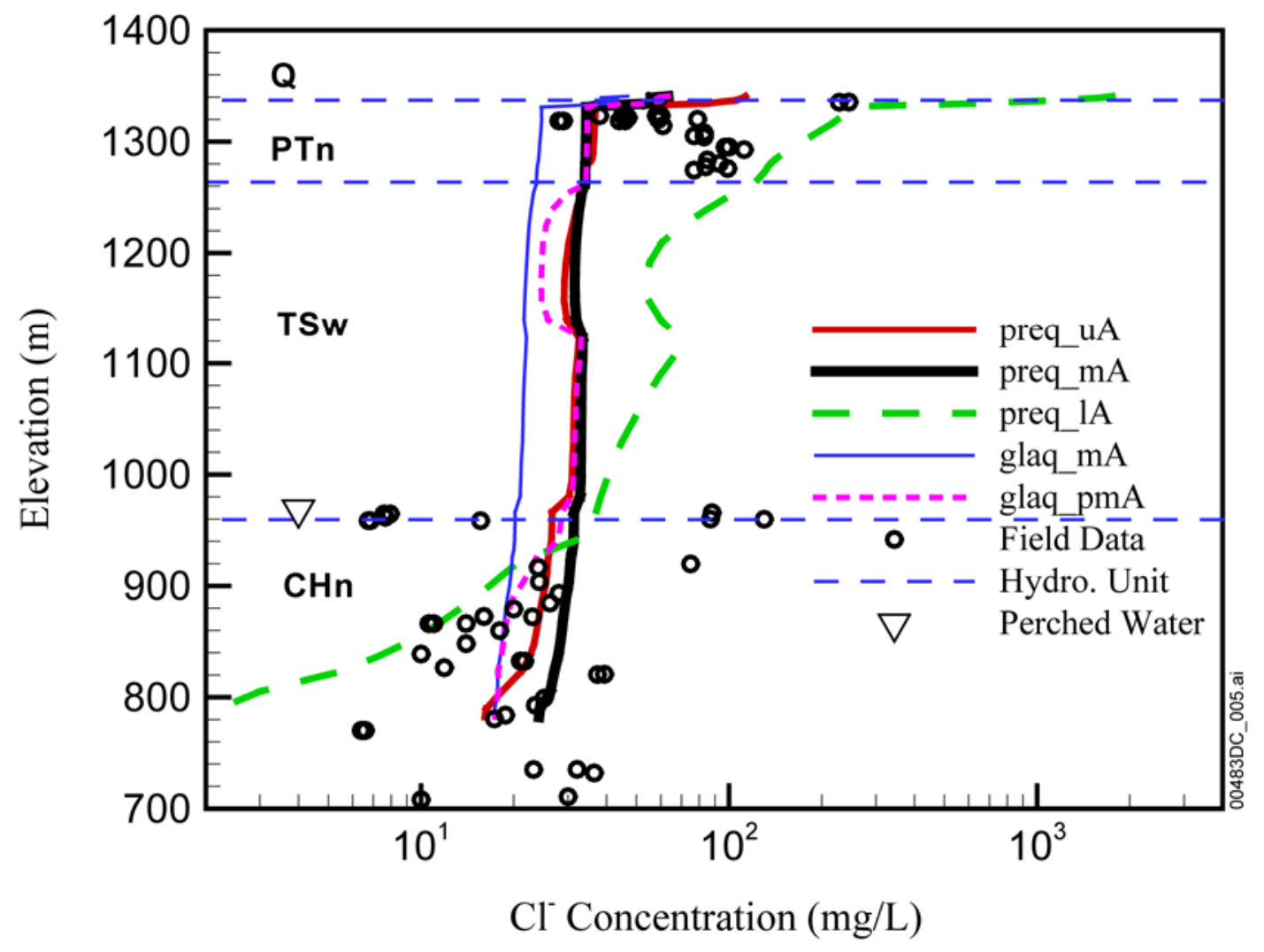

Source DTNs: GS010708312272.002 (DIRS 156375); GS961108312271.002 (DIRS 121708); GS990208312272.001 (DIRS 146134); LA0002JF12213U.001 (DIRS 154760); LAJF831222AQ98.011 (DIRS 145402).

Output DTN: LB0303CLINFL3D.001.

Figure 6.5-2. Chloride Concentration (mg/L) Profiles at Borehole USW UZ-14 for Present Recharge with Mean, Upper, and Lower Bounds and Glacial Recharges 


\section{USW SD-9}

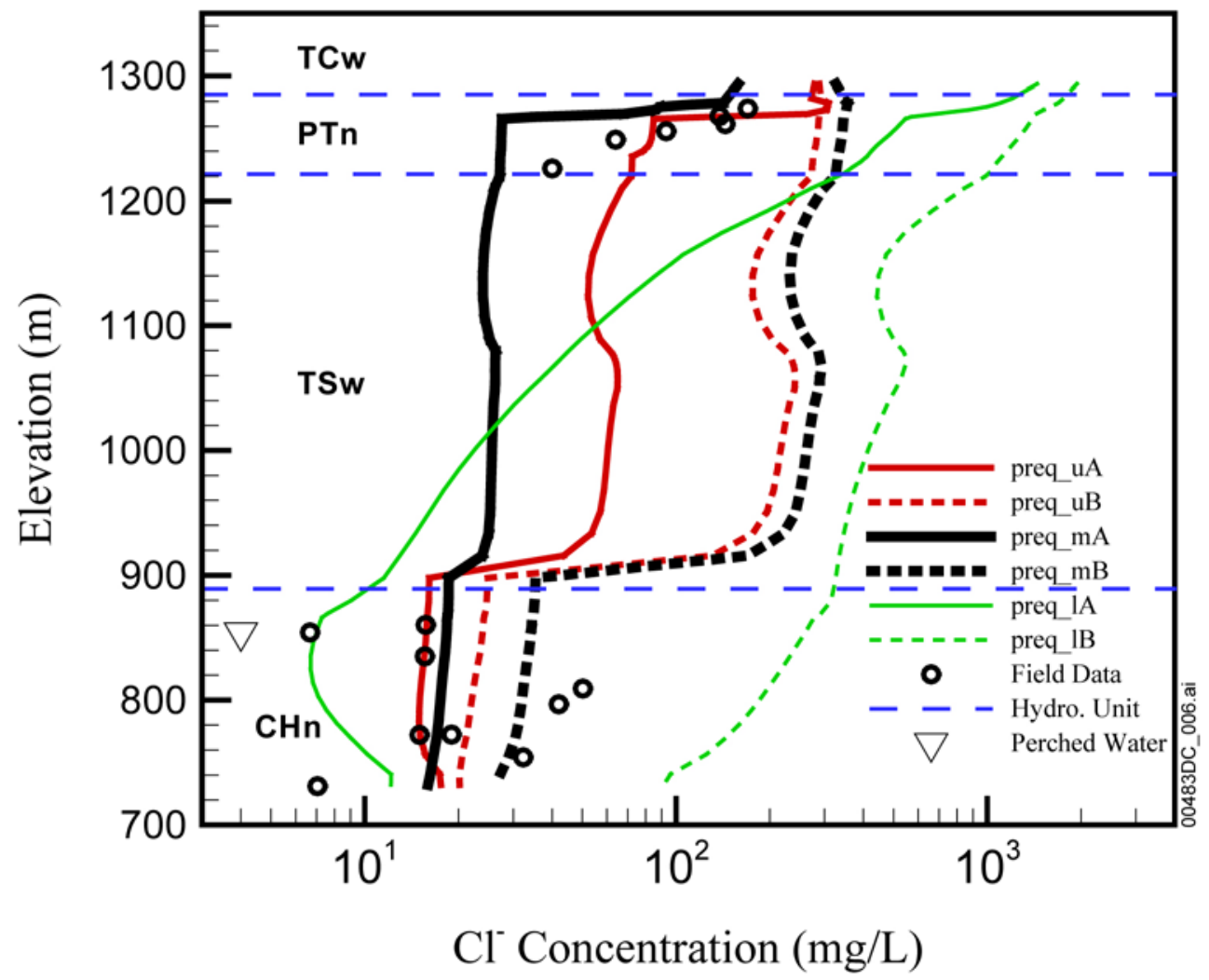

Source DTNs: GS970908312271.003 (DIRS 111467); GS961108312271.002 (DIRS 121708);

LA0002JF12213U.001 (DIRS 154760); LAJF831222AQ98.011 (DIRS 145402).

Output DTN: LB0303CLINFL3D.001.

NOTE: The upper-case letter A denotes the base-case model property set. The uppercase letter B denotes the alternative model.

Figure 6.5-3. Chloride Concentration (mg/L) Profiles at Borehole USW SD-9 for Present Recharge with Mean, Upper, and Lower Bounds and Glacial Recharge 


\section{ECRB}

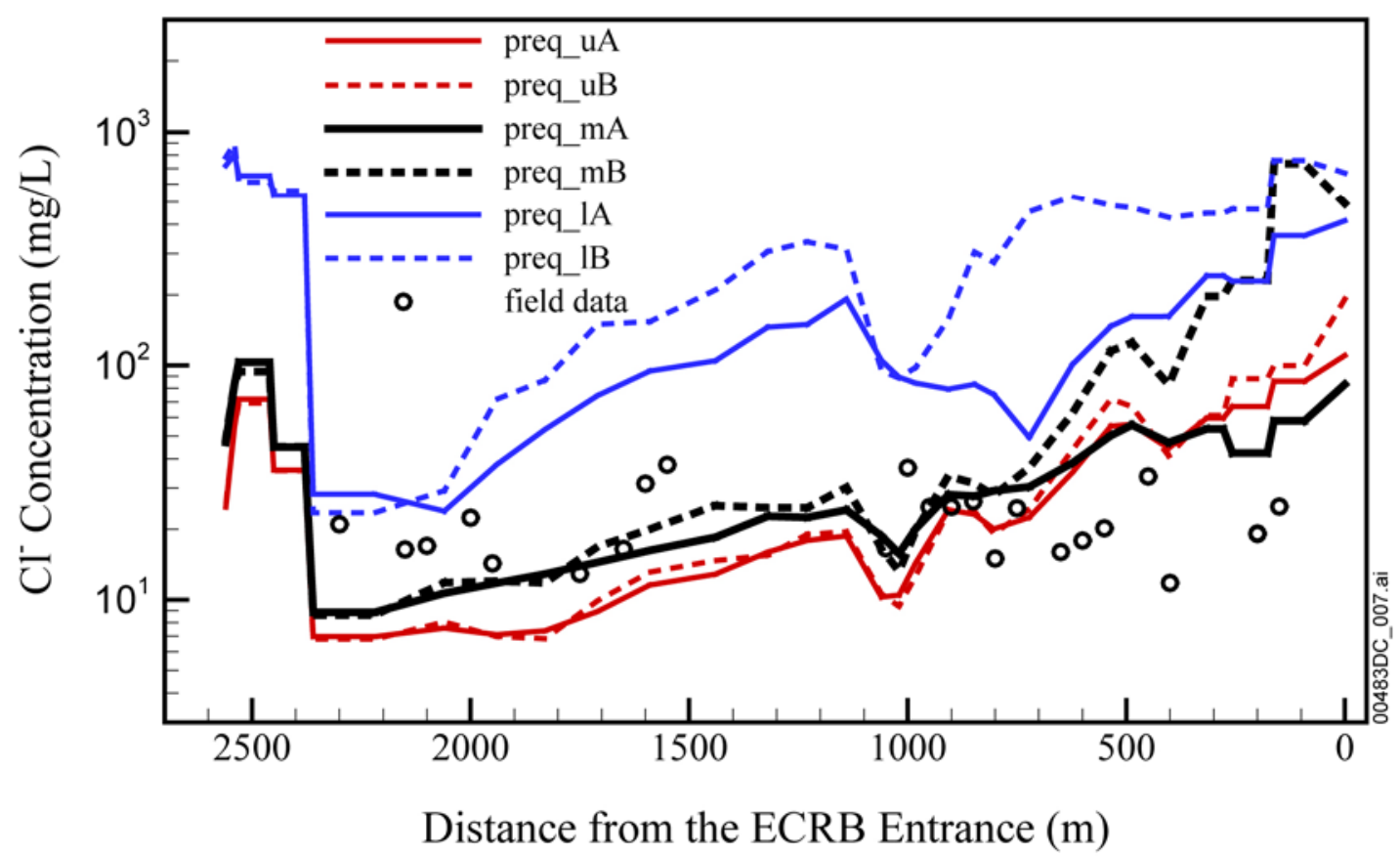

Source DTNs: LA9909JF831222.004 (DIRS 145598); LA0002JF12213U.002 (DIRS 156281).

Output DTN: LB0303CLINFL3D.001.

NOTE: The upper-case letter A denotes base-case model property set. The upper-case letter B denotes the alternative model.

Figure 6.5-4. Chloride Concentration (mg/L) Profiles at the ECRB for Present Recharge with Mean, Upper, and Lower Bounds

\subsection{FLOW PATTERN ANALYSIS OF TSPA-LA THREE-DIMENSIONAL FLOW FIELDS}

This section analyzes and summarizes the 18 flow simulation scenarios. Nine of the flow fields are the base-case flow fields of Section 6.2, as summarized in Table 6.2-9, and have been submitted to TSPA-LA for performance analyses. The remaining nine flow fields are considered as alternatives. The 18 model simulations are performed using the TSPA-LA grid (Figure 6.1-1) and nine infiltration maps, as discussed in Section 6.1, the six calibrated parameter sets in Appendix A of this report, and the UZ flow model of Section 6.2.2.

\subsubsection{Simulation Scenarios}

Table 6.6-1 summarizes the nine alternative simulation scenarios associated with parameter sets (Tables A-4, A-5, and A-6, respectively) for the nine infiltration maps. The alternative property set "B" uses different rock parameters for the PTn unit such that less lateral diversion in the PTn is expected. 
Table 6.6-1. Nine Simulation Scenarios of Alternative UZ Flow, Data Files, Parameter Sets, and Infiltration Maps for the UZ Flow Fields

\begin{tabular}{|c|c|c|}
\hline $\begin{array}{l}\text { Designation/ } \\
\text { Simulation }\end{array}$ & $\begin{array}{c}\text { Parameter Set/ } \\
\text { Calibration } \\
\text { (Output-DTN: LB03013DSSCP3I.001) }\end{array}$ & $\begin{array}{l}\text { Infiltration Map } \\
\text { (DTN: GS000308311221.005 } \\
\text { [DIRS 147613]) } \\
\end{array}$ \\
\hline preq_IB & $\begin{array}{l}\text { Parameter set from Table A-6, } \\
\text { present day/modern, lower-bound infiltration }\end{array}$ & $\begin{array}{l}\text { Present-day, lower-bound } \\
\text { infiltration }\end{array}$ \\
\hline preq_mB & $\begin{array}{l}\text { Parameter set from Table A-4, } \\
\text { present day/modern, mean infiltration }\end{array}$ & Present-day, mean infiltration \\
\hline preq_uB & $\begin{array}{l}\text { Parameter set from Table A-5, } \\
\text { upper-bound infiltration }\end{array}$ & $\begin{array}{l}\text { Present-day, upper-bound } \\
\text { infiltration }\end{array}$ \\
\hline monq_IB & $\begin{array}{l}\text { Parameter set from Table A-6, } \\
\text { present day/modern, lower-bound infiltration }\end{array}$ & Monsoon, lower-bound infiltration \\
\hline monq_mB & $\begin{array}{l}\text { Parameter set from Table A-4, } \\
\text { present day/modern, mean infiltration }\end{array}$ & Monsoon, mean infiltration \\
\hline monq_uB & $\begin{array}{l}\text { Parameter set from Table A-5, } \\
\text { present day/modern, upper-bound infiltration }\end{array}$ & Monsoon, upper- bound infiltration \\
\hline glaq_IB & $\begin{array}{l}\text { Parameter set from Table A- } 6 \text {, } \\
\text { present day/modern, lower-bound infiltration }\end{array}$ & $\begin{array}{l}\text { Glacial-transition, lower-bound } \\
\text { infiltration }\end{array}$ \\
\hline glaq_mB & $\begin{array}{l}\text { Parameter set from Table A-4, } \\
\text { present day/modern, mean infiltration }\end{array}$ & Glacial-transition, mean infiltration \\
\hline glaq_uB & $\begin{array}{l}\text { Parameter set from Table A-5, } \\
\text { present day/modern, upper-bound infiltration }\end{array}$ & $\begin{array}{l}\text { Glacial-transition, upper-bound } \\
\text { infiltration }\end{array}$ \\
\hline
\end{tabular}

As shown in Table 6.6-1, simulations with the alternative model are also carried out for the same three climatic scenarios (i.e., present-day, monsoon, and glacial-transition), and mean, lower-bound, and upper-bound infiltration rates as for the base-case simulations.

\subsubsection{UZ Alternative Flow Model Results}

Similar to the calibration simulations of the base-case flow fields, the mass-balance check has been conducted for the nine alternative model simulations. Table 6.6-2 lists the global mass-balance results for the nine alternative model simulations. Global mass-balance errors between inflow and outflow of the system for the nine flow fields, as shown in Table 6.6-2, are all smaller than 0.06 percent, indicating that solutions approximate steady-state for these cases.

Table 6.6-2. Mass-Balance Results for Nine Simulations of Alternative Flow Model

\begin{tabular}{|l|c|c|c|}
\hline $\begin{array}{c}\text { Simulation } \\
\text { Scenarios }\end{array}$ & $\begin{array}{c}\text { Inflow from Infiltration } \\
(\mathbf{k g} / \mathbf{s})\end{array}$ & $\begin{array}{c}\text { Outflow to Water Table } \\
(\mathbf{k g} / \mathbf{s})\end{array}$ & $\begin{array}{c}\text { Relative Error } \\
(\%)\end{array}$ \\
\hline preq_IB & 1.5828143 & 1.5828178 & 0.0002 \\
\hline preq_mB & 5.5922355 & 5.5951199 & 0.0516 \\
\hline preq_uB & 13.564390 & 13.568112 & 0.0274 \\
\hline monq_IB & 5.5922355 & 5.5920365 & 0.0036 \\
\hline monq_mB & 14.939317 & 14.936880 & 0.0163 \\
\hline monq_uB & 24.286298 & 24.277515 & 0.0362 \\
\hline
\end{tabular}


Table 6.6-2. Mass-Balance Results for Nine Simulations of Alternative Flow Model (Continued)

\begin{tabular}{|l|c|c|c|}
\hline $\begin{array}{c}\text { Simulation } \\
\text { Scenarios }\end{array}$ & $\begin{array}{c}\text { Inflow from Infiltration } \\
(\mathbf{k g} / \mathbf{s})\end{array}$ & $\begin{array}{c}\text { Outflow to Water Table } \\
\mathbf{( k g / s )}\end{array}$ & $\begin{array}{c}\text { Relative Error } \\
(\%)\end{array}$ \\
\hline glaq_IB & 2.9648877 & 2.9648838 & 0.0001 \\
\hline glaq_mB & 21.494950 & 21.495094 & 0.0007 \\
\hline glaq_uB & 40.024949 & 40.024939 & 0.0000 \\
\hline
\end{tabular}

DTN: LB03033DSSFF9I.001.

Alternative Model Result Examination: In addition to the nine base-case flow fields of Section 6.2.5, the nine alternative three-dimensional flow fields have also been compared against the field-observed data of matrix liquid saturation, as well as available water-potential and perched-water data. The available data used in the model checking are listed in Table 6.2-1. Overall, examination results are as follows (see Wang 2003 [DIRS 162417], SN-LBNL-SCI-199-V1, pp. 158 to 186, 243, for detailed comparisons):

- The simulation results with the nine alternative flow fields are also able to fit the available matrix liquid saturation and water potential data from the nine boreholes (Table 6.2-1) well, similarly to the base-case flow fields of Section 6.2.5, including PTn units.

- For calibrations with perched-water data, except for water-potential results for lower-bound infiltration (in SD-7 and SD-9), the six simulations with mean, lower-bound, and upper-bound present-day infiltration rates, in general, match perched-water data.

\subsubsection{Flow Fields and Analyses}

Percolation flux through the UZ is one important natural-barrier factor affecting overall repository performance in TSPA calculations. The quantity as well as the spatial and temporal variations in percolation flux will directly affect (1) the amount of water flowing into waste emplacement drifts, (2) moisture conditions and the corrosion environment of waste packages within the drifts, (3) radionuclide release from the repository, and (4) radionuclide migration from the UZ to the saturated zone. Percolation fluxes through unsaturated fractured tuffs cannot be readily measured in the field, and, thus, indirect data and model results have to be used to estimate these fluxes.

Model studies (Wu et al. 1999 [DIRS 117161] and 2002 [DIRS 160195]) indicate that the accuracy of model predictions for percolation fluxes in the UZ at Yucca Mountain depend on many factors, including (1) net infiltration rates over the surface boundary (Wu et al. 1999 [DIRS 117161], pp. 208 to 210 and Figure 13; 2002 [DIRS 160195], p. 227, Figure 6), (2) geological models and conceptualizations, (3) distribution of rock-property values for fractures and matrix, and (4) treatment of fracture-matrix flow and interaction. In this section, percolation fluxes at the repository horizon are analyzed using the 18 simulation results (Tables 6.2-9 and 6.6-1) of the UZ flow models for TSPA-LA. In the analysis, the percolation flux is defined as total vertical liquid mass flux through both fractures and matrix, and is converted to millimeter per year ( $\mathrm{mm} /$ year) per unit area using a constant water density. 
Figures 6.6-1 to 6.6-3 show examples of percolation fluxes along the repository layer for the three mean infiltration scenarios of the three climates, respectively, with the base-case flow fields. (Note: see Appendix D for relevant data compilation for the PTn/TSw interface flux.) Comparisons of the calculated repository percolation fluxes of Figures 6.6-1, 6.6-2, and 6.6-3 with those of the surface infiltration maps (Figures 6.1-2, 6.1-3, and 6.1-4, respectively), indicate that percolation fluxes at the repository are very different from surface infiltration patterns. Note that surface infiltration rates and distributions are independent of faults. Under steady-state flow condition, percolation flux and its distribution along any horizon of the model domain would be the same or very similar if there were no lateral flow occurring. The major differences in percolation flux at the repository level (Figures 6.6-1-6.6-3) are (1) flow mainly through faults in the very northern part of the model domain (with the north coordinate greater than $237,000 \mathrm{~m}$ ) and (2) flow diverted into or near faults located in the model domain. A comparison between the surface infiltration map (Figure 6.1-2) and the repository level percolation flux (Figure 6.6-1) indicates about a $500 \mathrm{~m}$ lateral flow of the high infiltration zones from south to north along the crest located to the east. This large-scale lateral flow from west to east (in general) is illustrated by "Lateral Flow Scale" on Figures 6.6-1, 6.6-2, and 6.6-3, respectively, for the three mean infiltration scenarios. Lateral flow may also occur from the Solitario Canyon fault to the east reaching the repository blocks included in the 18 flow fields, since the fault is very close to the repository (Figure 6.1-1). Note that flow redistribution in the very northern part of the model domain (far beyond the repository block) results from the repository grid layer horizon laterally intersecting the $\mathrm{CHn}$ zeolitic and perched-water zones, with major flow paths being faults. Overall, percolation results as shown in Figures 6.6-1, 6.6-2, and 6.6-3 display very different patterns from the surface infiltrations because of the substantial amount of large-scale lateral flow within the PTn unit. More analyses of the role played by the PTn unit are presented in Appendix G. The results in this section and Appendix G indicate that within the PTn unit, lateral flow has a significant impact on percolation flux distribution in the repository layer.

Simulated percolation fluxes in the repository layer, in addition to those shown in Figures 6.6-1, 6.6.2, and 6.6-3 (for three mean infiltration rates), include three lower bounds and three upper bounds of infiltration rates for the nine base-case flow fields, as well as the nine infiltration rates of the three climates with the alternative flow fields. Further examination of all nine base-case simulation results against their corresponding surface infiltration maps indicates that more significant lateral flow occurs in the PTn for lower-bound and mean infiltration scenarios than for the upper bound infiltration. A further examination of all flow fields indicates that the lower the infiltration rates, the larger the lateral flow scales [for examples, see Wang (2003 [DIRS 162417], SN-LBNL-SCI-199-V1, pp. 125, 128 to 130; SN-LBNL-SCI-199-V2, pp. 17, $24,25)]$. This is because the lower infiltration results in drier condition with stronger capillarity (Wu et al. 2002 [DIRS 161058]). On the other hand, the simulation results with the nine alternative flow fields show small lateral flow occurrence in the PTn in the area above the repository (Appendix G, Figure G-8). These results show that the flow patterns through PTn have a large impact on percolation flux distribution in the repository horizon. 
vertical flux for preq_mA at repository layer

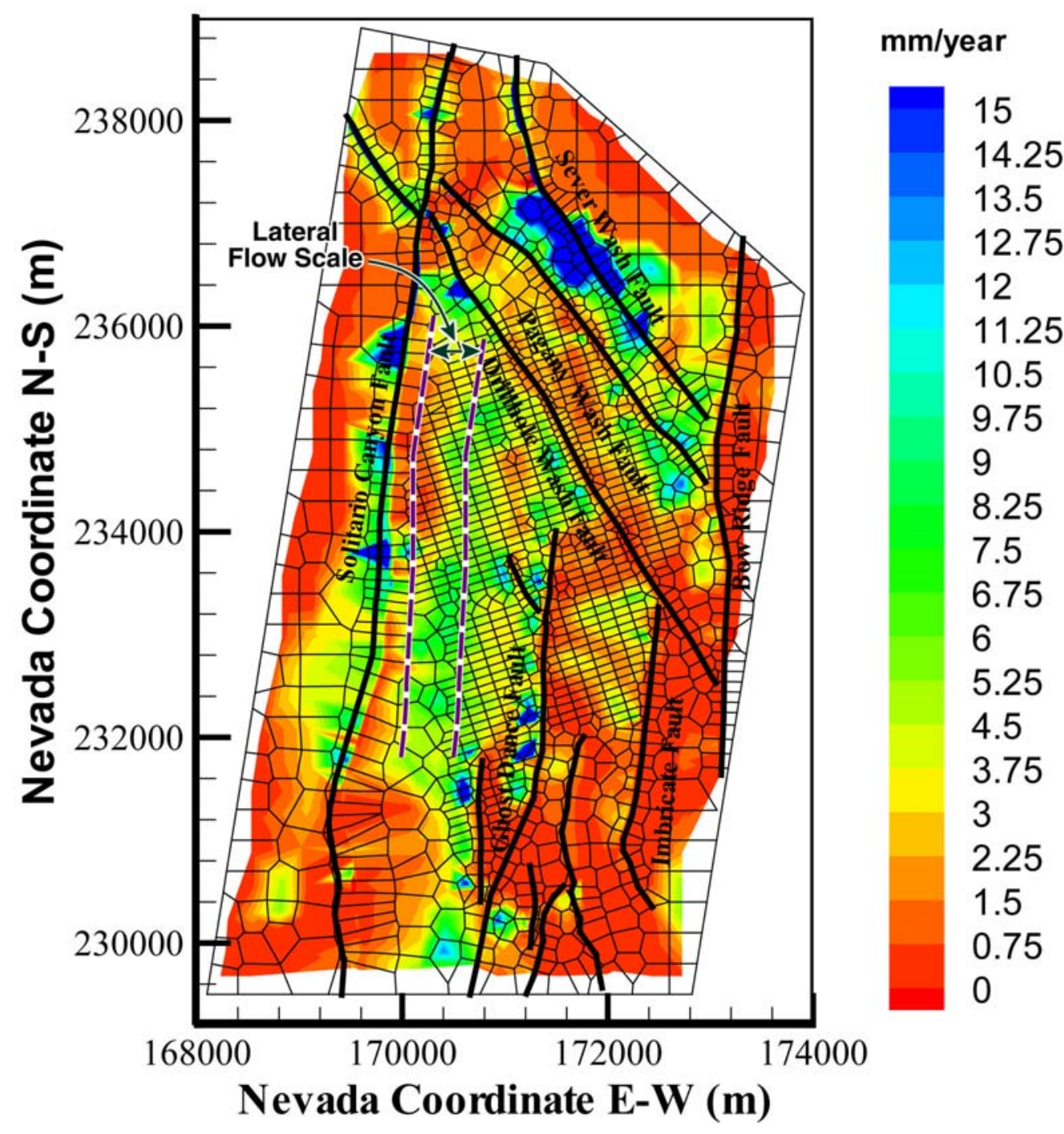

Output DTN: LB03023DSSCP9I.001.

Figure 6.6-1. Simulated Percolation Fluxes at the Repository Horizon under the Present-Day, Mean Infiltration Scenario Using the Results of Simulation preq_mA 
vertical flux for monq_mA at repository layer

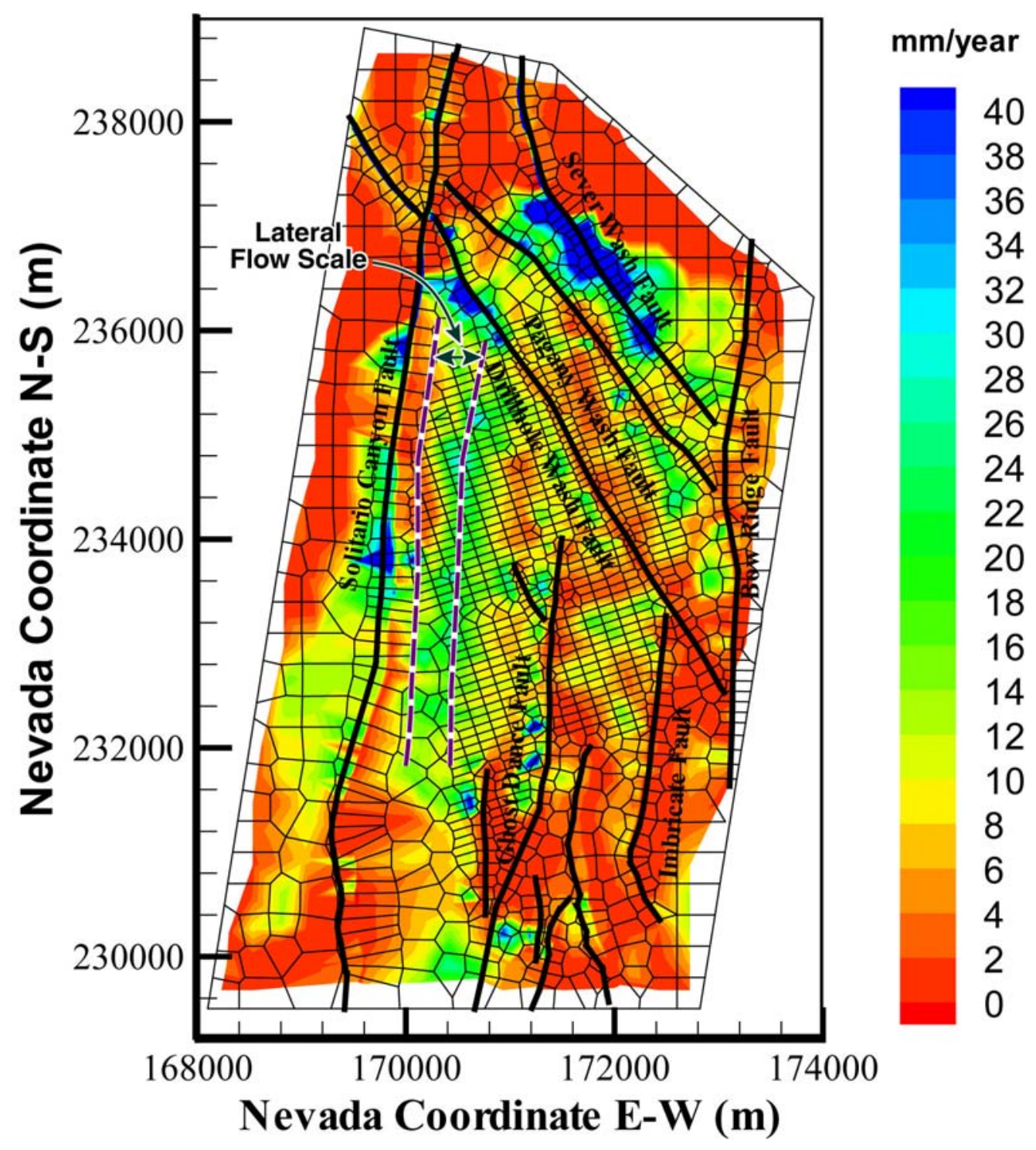

Output DTN: LB03023DSSCP9I.001.

Figure 6.6-2. Simulated Percolation Fluxes at the Repository Horizon under the Monsoon, Mean Infiltration Scenario Using the Results of Simulation monq_mA 


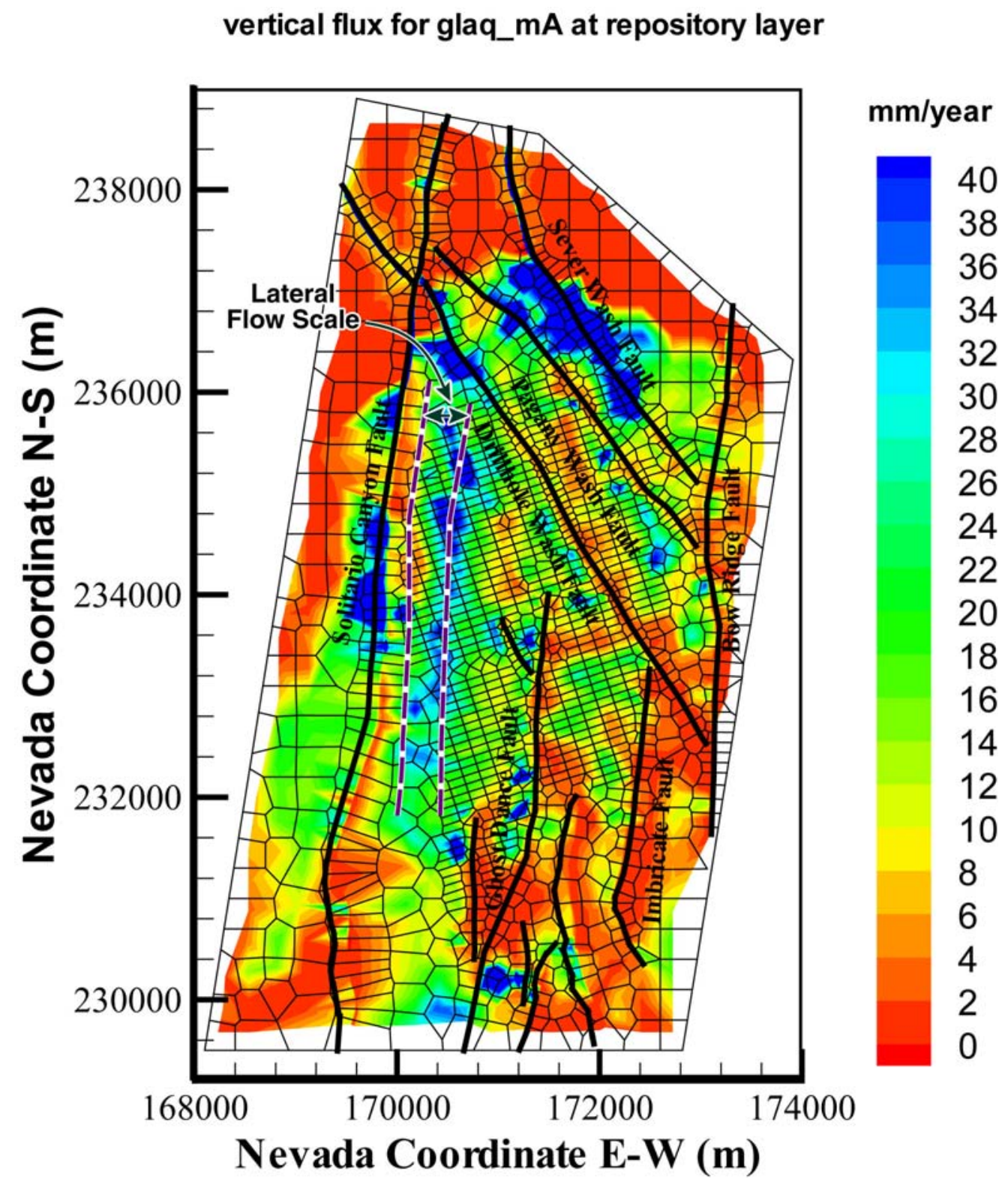

Output DTN: LB03023DSSCP9I.001.

Figure 6.6-3. Simulated Percolation Fluxes at the Repository Horizon under the Glacial-transition Mean Infiltration Scenario Using the Results of Simulation glaq_mA 
Figures 6.6-4 through 6.6-21 show the simulated percolation fluxes at the water table using the nine base-case and nine alternative flow simulations with nine infiltration scenarios of the three climates. When comparing the percolation fluxes at the repository (e.g., Figures 6.6-1, 6.6-2, and 6.6-3), as well as with themselves from the two models (e.g., Figure 6.6-4 versus Figure 6.6-5), we find the following:

- There are fewer differences in the calculated percolation fluxes for the two models at the water table than those at the repository level for the same infiltration scenarios.

- In the northern half of the domain, the base-case flow fields are very similar to the alternative ones. Because of the impact of perched water and zeolitic units, flow is mainly focused into major faults.

- In the central and southern portions of the model domain, the base-case flow fields at the water table show lateral flow of several hundreds of meters to the east in the area directly below the southern repository. This is the area where vitric zones are located within the CHn unit.

Note that all 18 flow fields are calculated using a fixed water table. These flow fields can also be used for a rising-water-table case in the future. This is because the water table is handled as a sink term in the model, and the flow at or above the water table is determined by the upstream or upper-layer conditions. Therefore, a water-rise situation can be handled by simply transecting the flow fields vertically at a new water table elevation. The software WTRISE V2.0 (LBNL 2003 [DIRS 163453]) is available to obtain those results.

As discussed in Saturated Zone Site-Scale Flow Model (BSC 2004 [DIRS 170037], Section 6.4.5) and Particle Tracking Model and Abstraction of Transport Processes (BSC 2004 [DIRS 170041], Section 6.4.9), the water table under future wetter climates is expected to rise. The elevation of $850 \mathrm{~m}$ was selected (BSC 2004 [DIRS 170041], Section 6.4.9) as a nominal water table elevation under future climates consistent with the studies documented in the report by BSC (2004 [DIRS 170037], Section 6.4.5.1). Simulations of groundwater flow under wetter, glacial climatic conditions with the saturated zone (SZ) regional-scale flow model (D'Agnese et al. 1999 [DIRS 120425]) indicate that groundwater flow paths from beneath Yucca Mountain do not change much under glacial climatic conditions (BSC 2004 [DIRS 170037], Section 6.4.5.1). However, paleohydrologic evidence suggests that at points downstream of Yucca Mountain, the water table could have been on the order of 100 to $120 \mathrm{~m}$ higher during glacial climates (Forester et al. 1996 [DIRS 100148], p. 63). The present-day water table varies from roughly 730 to 830 m (BSC 2004 [DIRS 170037], Figure 10) beneath the repository. Approximately half of the repository overlies the water table whose elevations are lower than $750 \mathrm{~m}$ (BSC 2004 [DIRS 170037], Figure 10). The effect of water table rise on UZ flow and transport is primarily an issue of a change in the transport path length between the repository and the water table, having very little effect otherwise on the UZ flow fields. This is in contrast with SZ flow models, because the water table gradient affects the driving force for SZ flow. Therefore, given the conservative estimate for future water table rise and the uncertainty associated with future water table predictions, a flat water table at $850 \mathrm{~m}$ is expected to bound the potential effects of water table rise for the purposes of UZ flow and transport. The water table elevation of $850 \mathrm{~m}$ results in a water table that is a minimum of $188 \mathrm{~m}$ below from repository waste emplacement 
drifts because all repository drifts are at elevations of $1038 \mathrm{~m}$ or higher (BSC 2003 [DIRS 161727]). The design requirement for standoff of the repository waste emplacement drifts from the water table is a minimum of $120 \mathrm{~m}$ (BSC 2003 [DIRS 165572], Section 7.1.1).

Six UZ flow fields (DTN: LB0312TSPA06FF.001) for future climates are converted by WTRISE V2.0, for accounting for a higher future water table. These future UZ flow fields are generated using the three-dimensional UZ flow fields (monq_1A, monq_mA, monq_uA, glaq 1A, glaq $\mathrm{mA}$, and glaq $\mathrm{uA}$ ) of Section 6.6.3, which have been determined using a fixed, lower water table representing the current, ambient condition. The 6 new flow fields are extracted using the WTRISE code for a rising-water-table case of $850-\mathrm{m}$ elevation in the future by transecting the 6 flow fields with the current water table vertically at a new water table elevation.

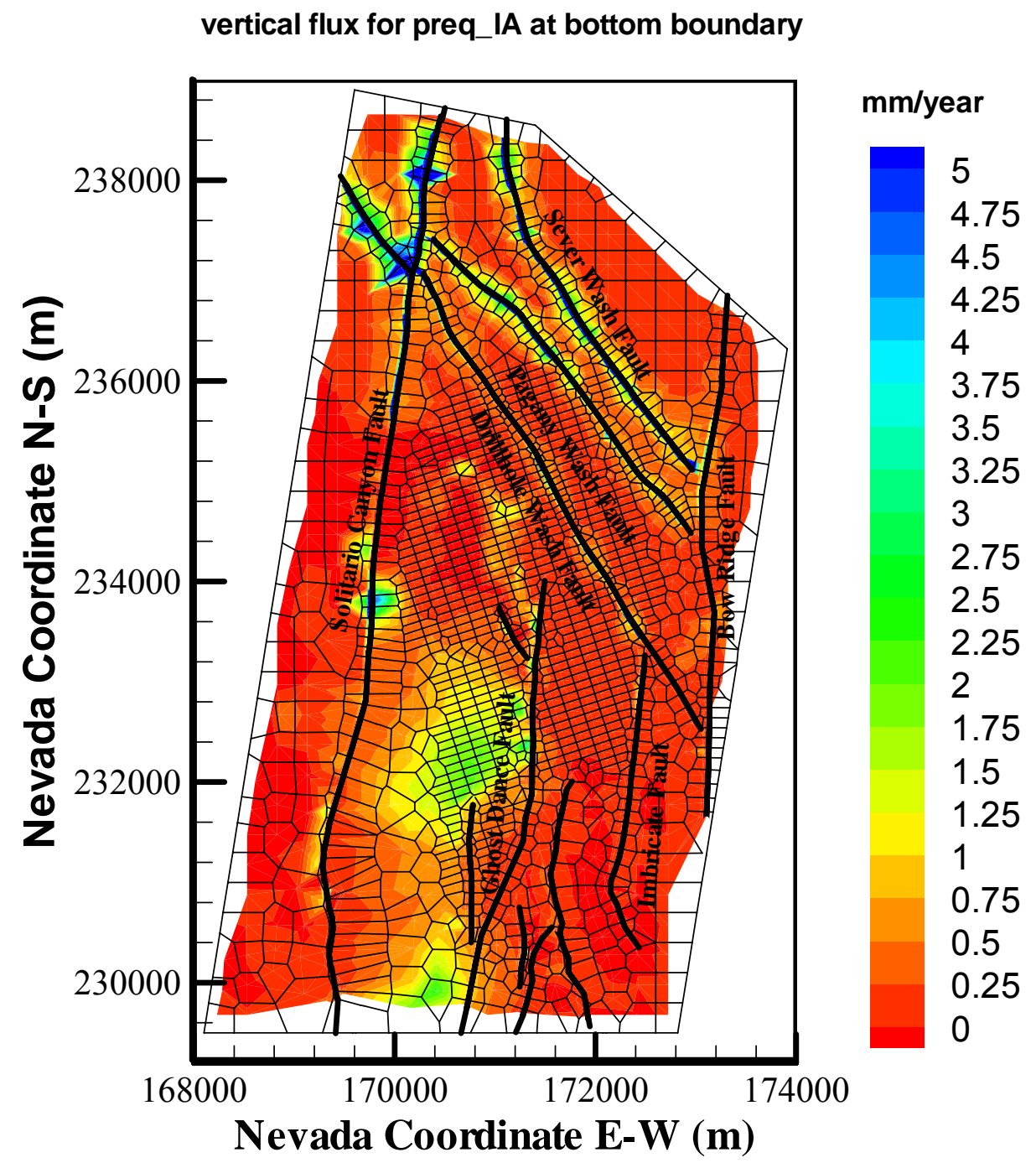

Output DTN: LB03023DSSCP9I.001.

Figure 6.6-4. Simulated Percolation Fluxes at the Water Table under the Present-Day, Lower-Bound Infiltration Scenario Using the Results of Simulating the Base-Case Model: preq_IA 


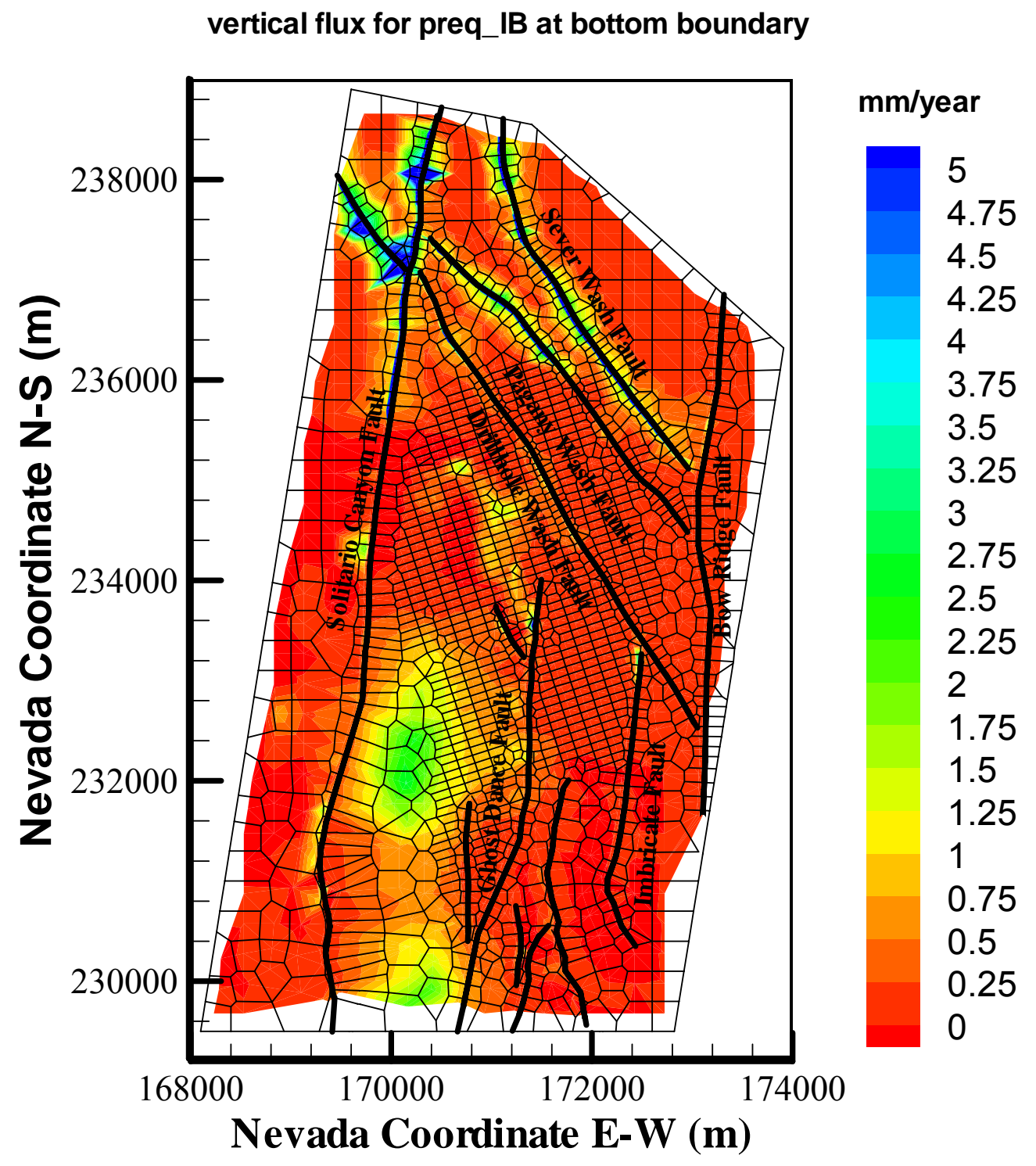

Output DTN: LB03033DSSFF9I.001.

Figure 6.6-5. Simulated Percolation Fluxes at the Water Table under the Present-Day, Lower-Bound Infiltration Scenario Using the Results of Simulating the Alternative Model: preq_IB 


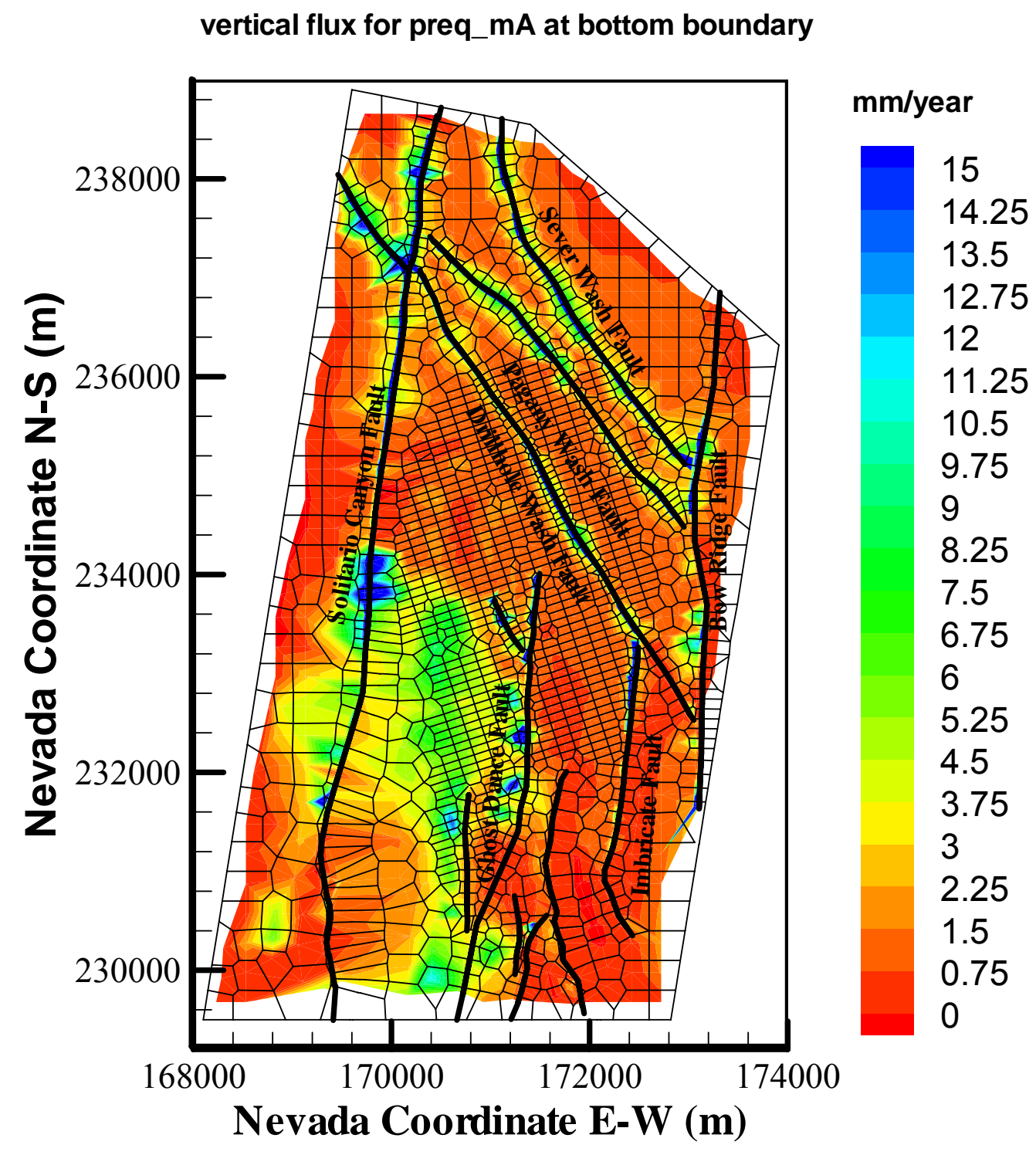

Output DTN: LB03023DSSCP9I.001.

Figure 6.6-6. Simulated Percolation Fluxes at the Water Table under the Present-Day, Mean Infiltration Scenario Using the Results of Simulating the Base-Case Model: preq_mA 


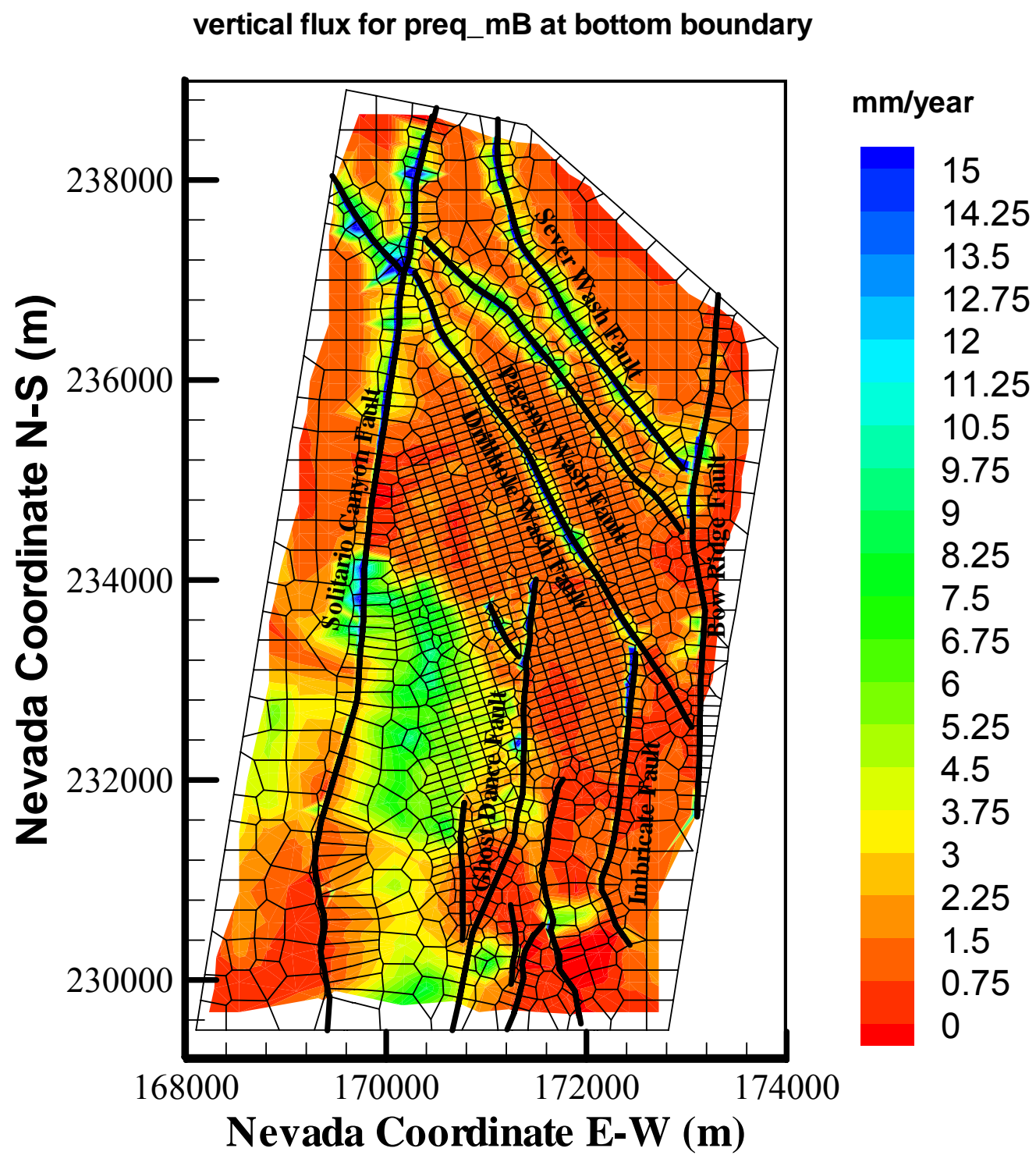

Output DTN: LB03033DSSFF9I.001.

Figure 6.6-7. Simulated Percolation Fluxes at the Water Table under the Present-Day, Mean Infiltration Scenario Using the Results of Simulating the Alternative Model: preq_mB 


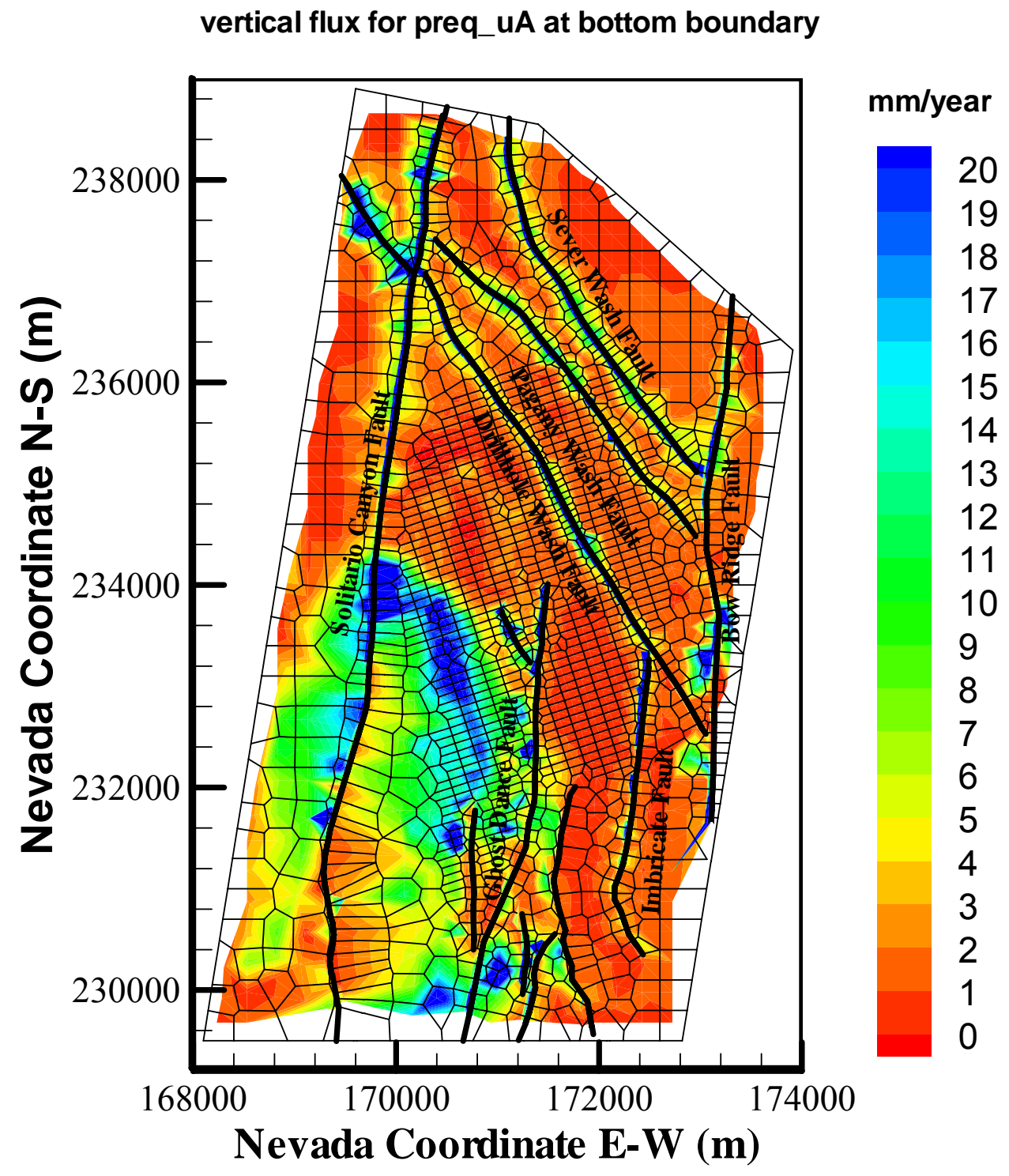

Output DTN: LB03023DSSCP9I.001.

Figure 6.6-8. Simulated Percolation Fluxes at the Water Table under the Present-Day, Upper-Bound Infiltration Scenario Using the Results of Simulating the Base-Case Model: preq_uA 


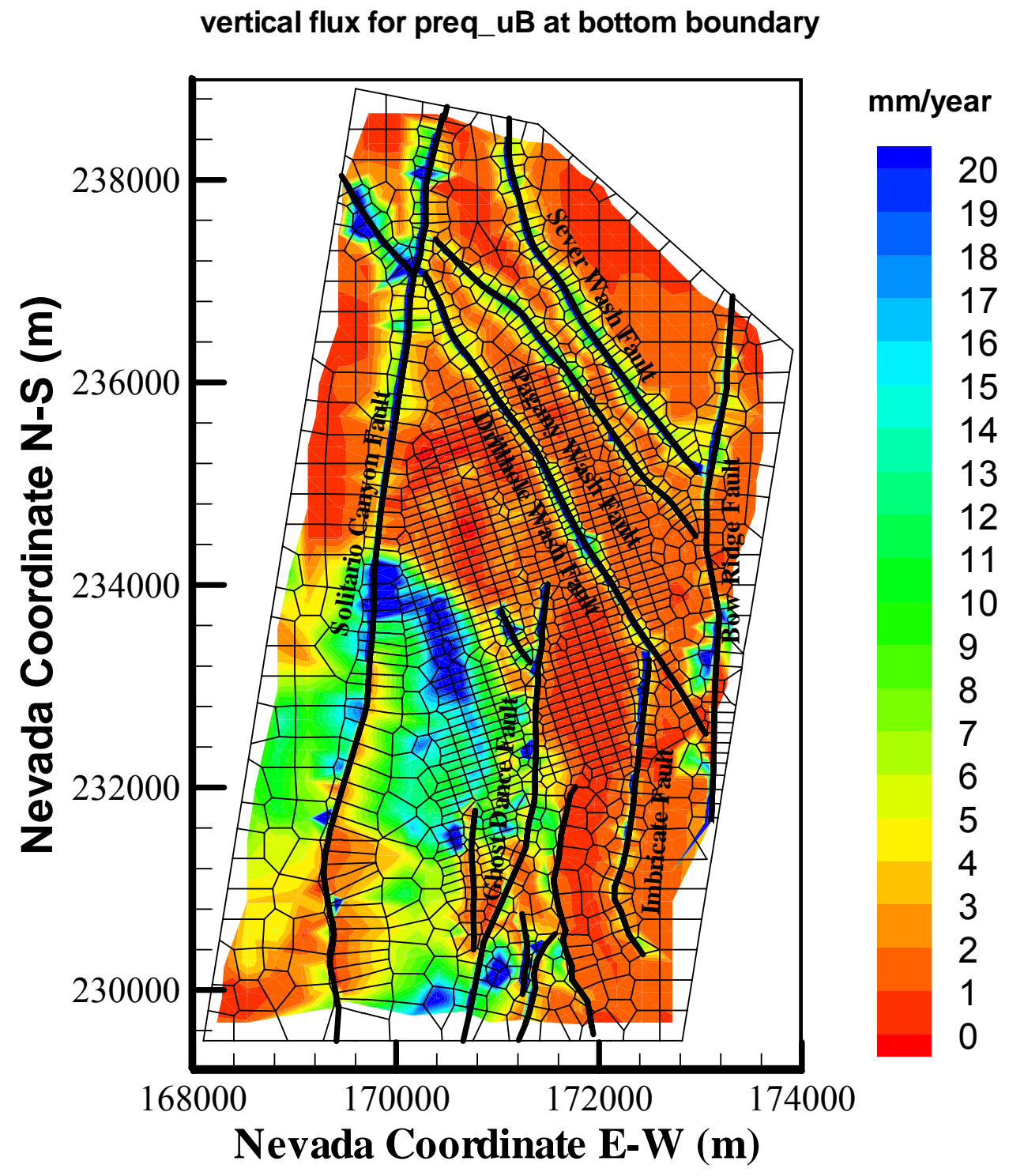

Output DTN: LB03033DSSFF9I.001.

Figure 6.6-9. Simulated Percolation Fluxes at the Water Table under the Present-Day, Upper-Bound Infiltration Scenario Using the Results of Simulating the Alternative Model: preq_uB 


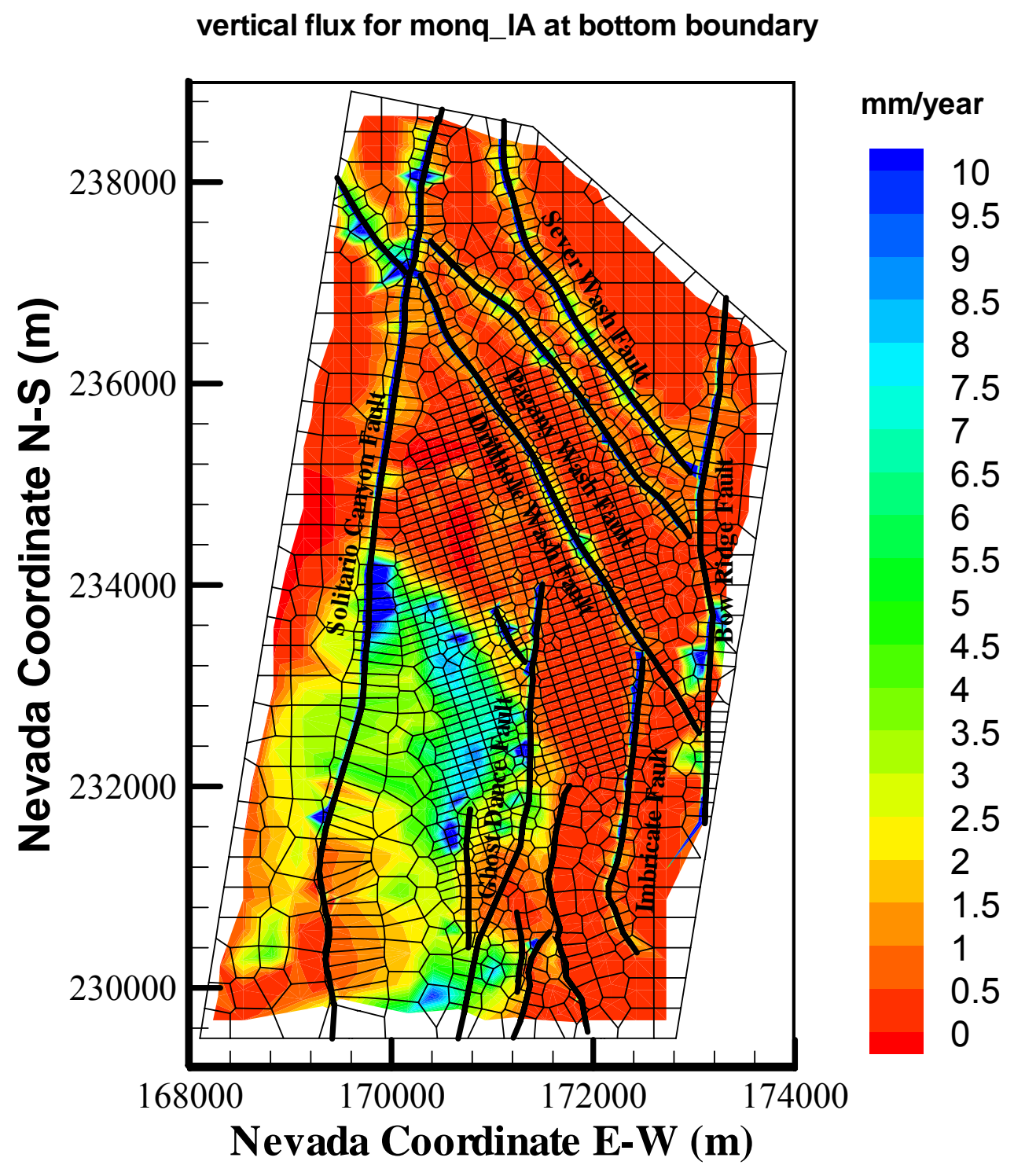

Output DTN: LB03023DSSCP9I.001.

Figure 6.6-10. Simulated Percolation Fluxes at the Water Table under the Monsoon, Lower-Bound Infiltration Scenario Using the Results of Simulating the Base-Case Model: monq_IA 


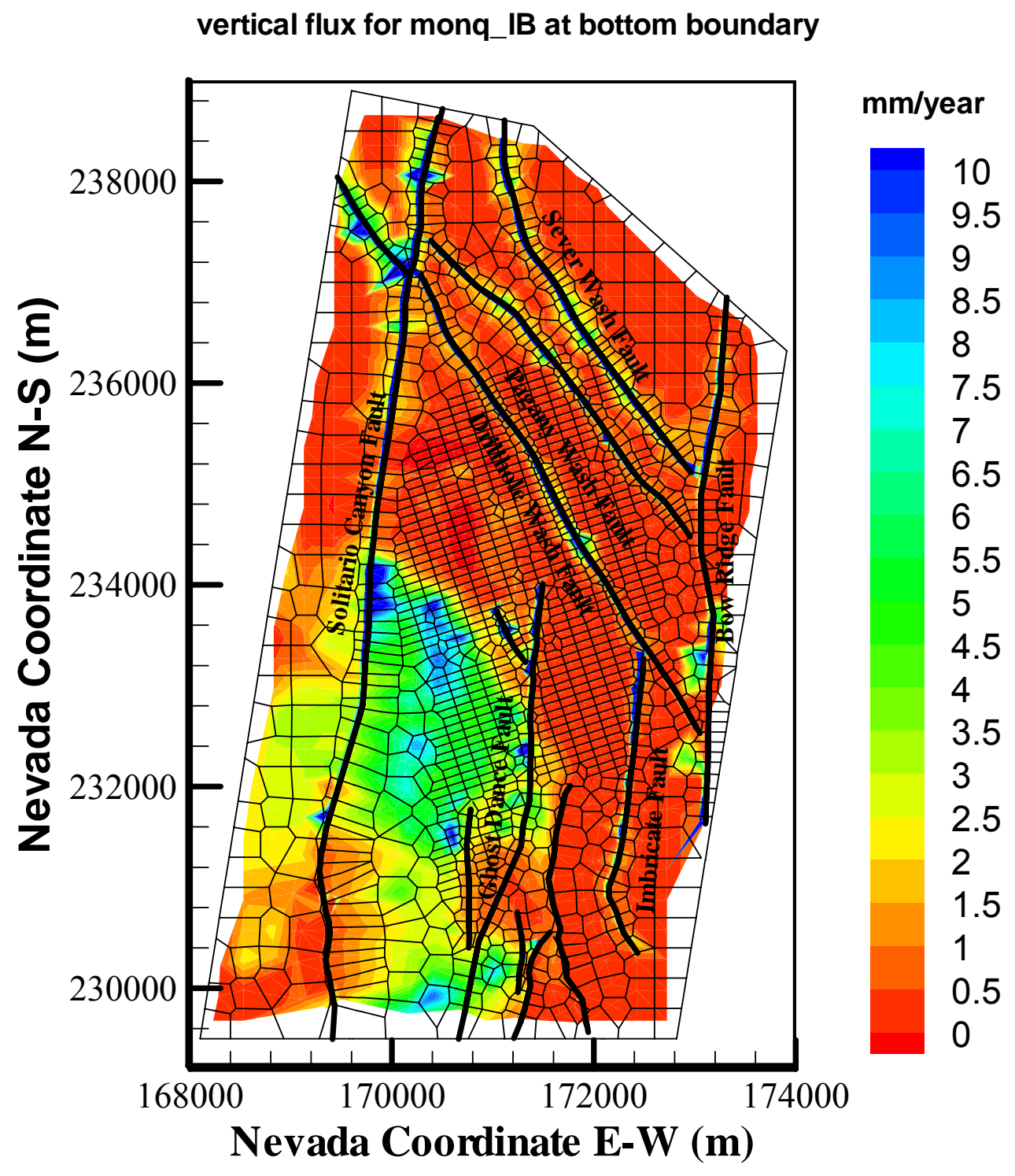

Output DTN: LB03033DSSFF9I.001.

Figure 6.6-11. Simulated Percolation Fluxes at the Water Table under the Monsoon, Lower-Bound Infiltration Scenario Using the Results of Simulating the Alternative Model: monq_IB 


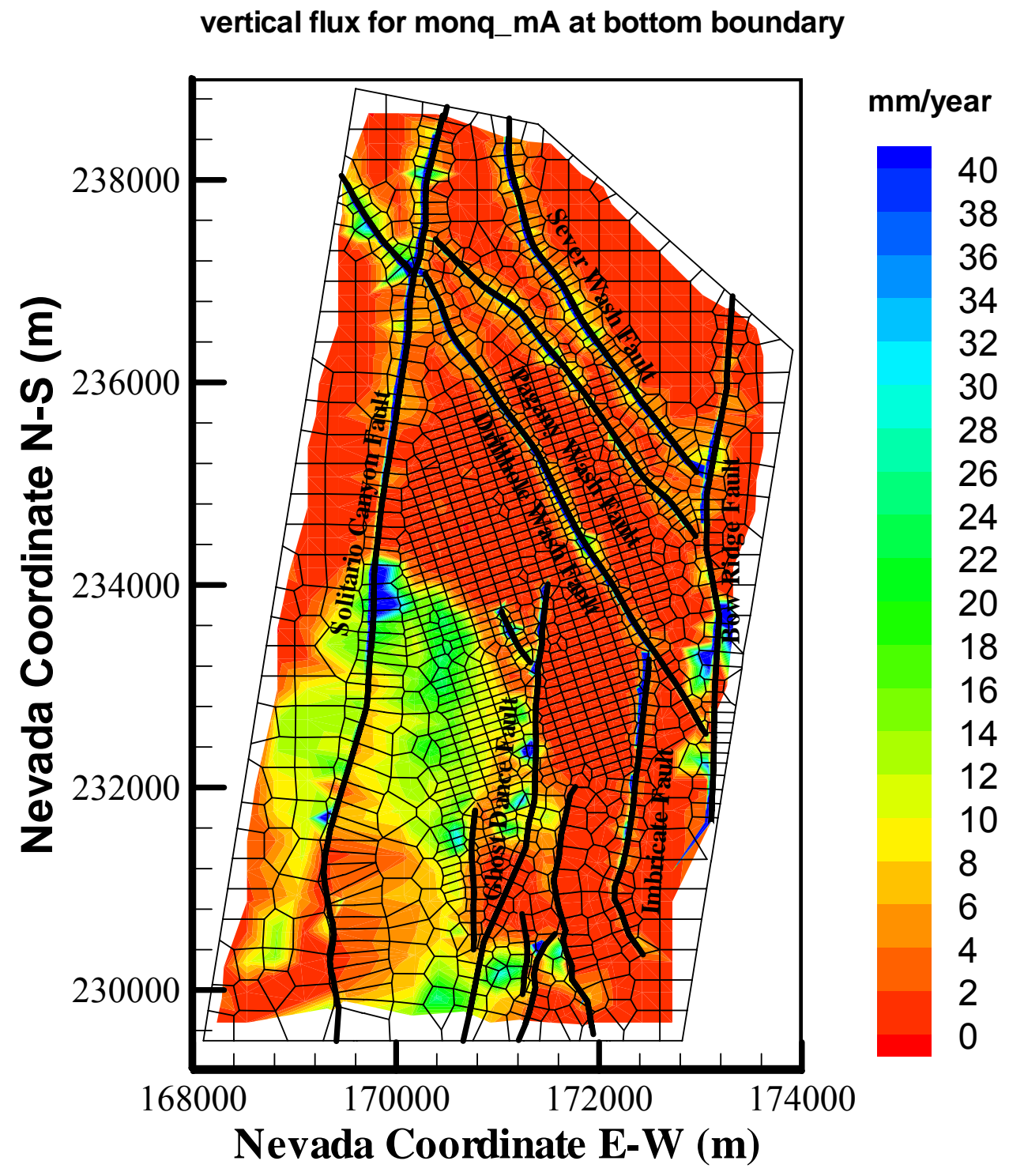

Output DTN: LB03023DSSCP9I.001.

Figure 6.6-12. Simulated Percolation Fluxes at the Water Table under the Monsoon, Mean Infiltration Scenario Using the Results of Simulating the Base-Case Model: monq_mA 


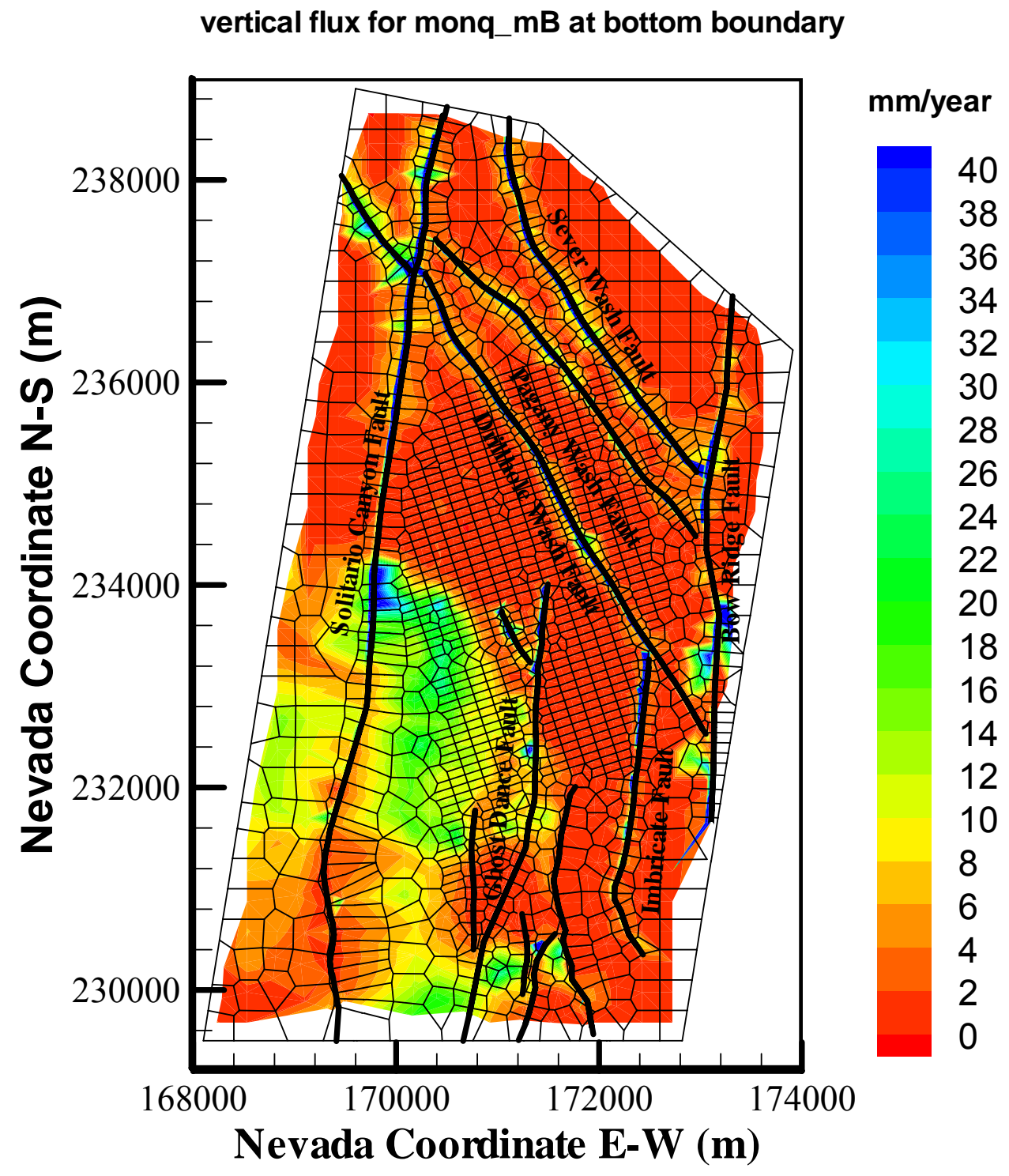

Output DTN: LB03033DSSFF9I.001.

Figure 6.6-13. Simulated Percolation Fluxes at the Water Table under the Monsoon, Mean Infiltration Scenario Using the Results of Simulating the Alternative Model: monq_mB 


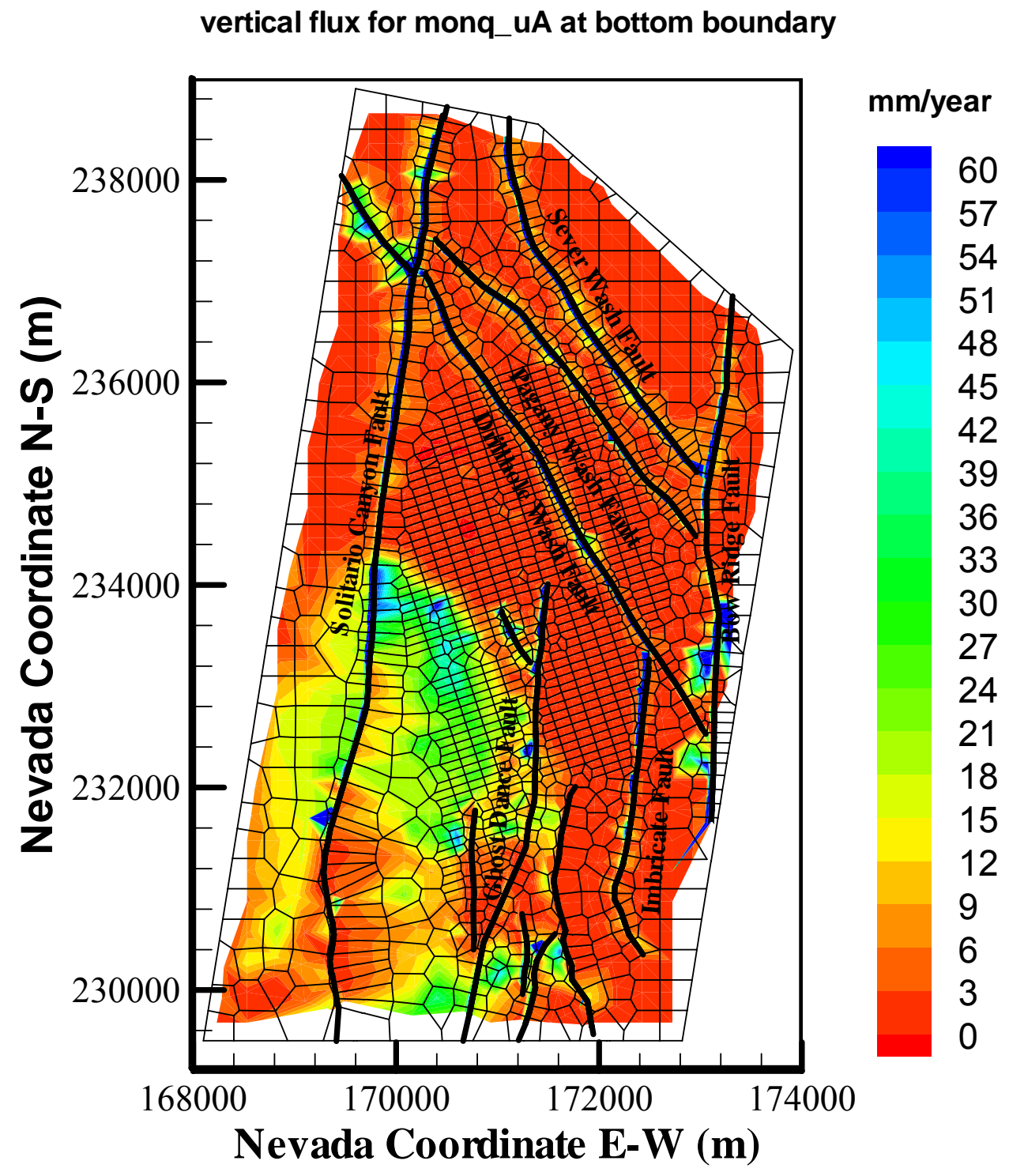

Output DTN: LB03023DSSCP9I.001.

Figure 6.6-14. Simulated Percolation Fluxes at the Water Table under the Monsoon, Upper-Bound Infiltration Scenario Using the Results of Simulating the Base-Case Model: monq_u 


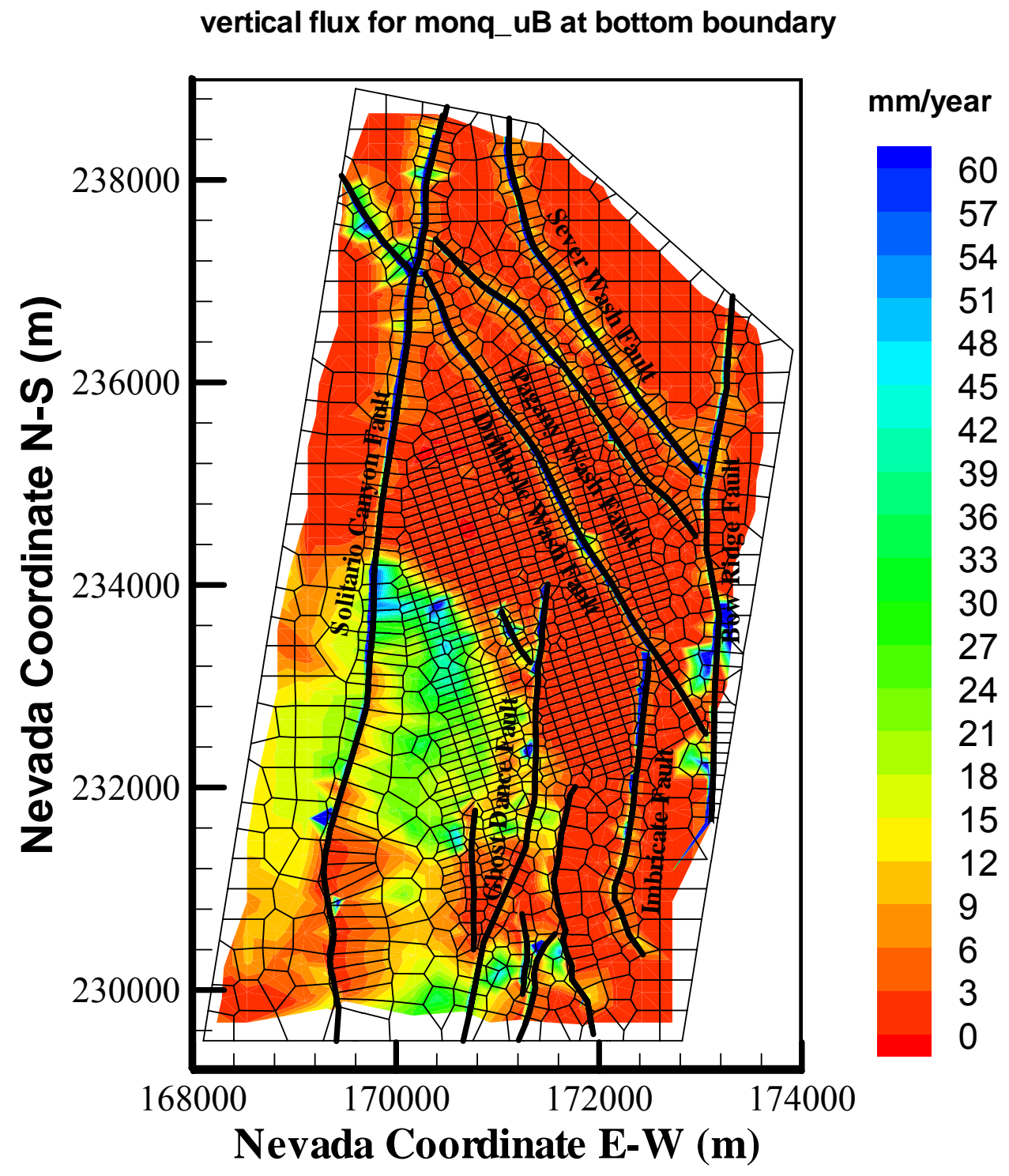

Output DTN: LB03033DSSFF9I.001.

Figure 6.6-15. Simulated Percolation Fluxes at the Water Table under the Monsoon, Upper-Bound Infiltration Scenario Using the Results of Simulating the Alternative Model: monq_uB 


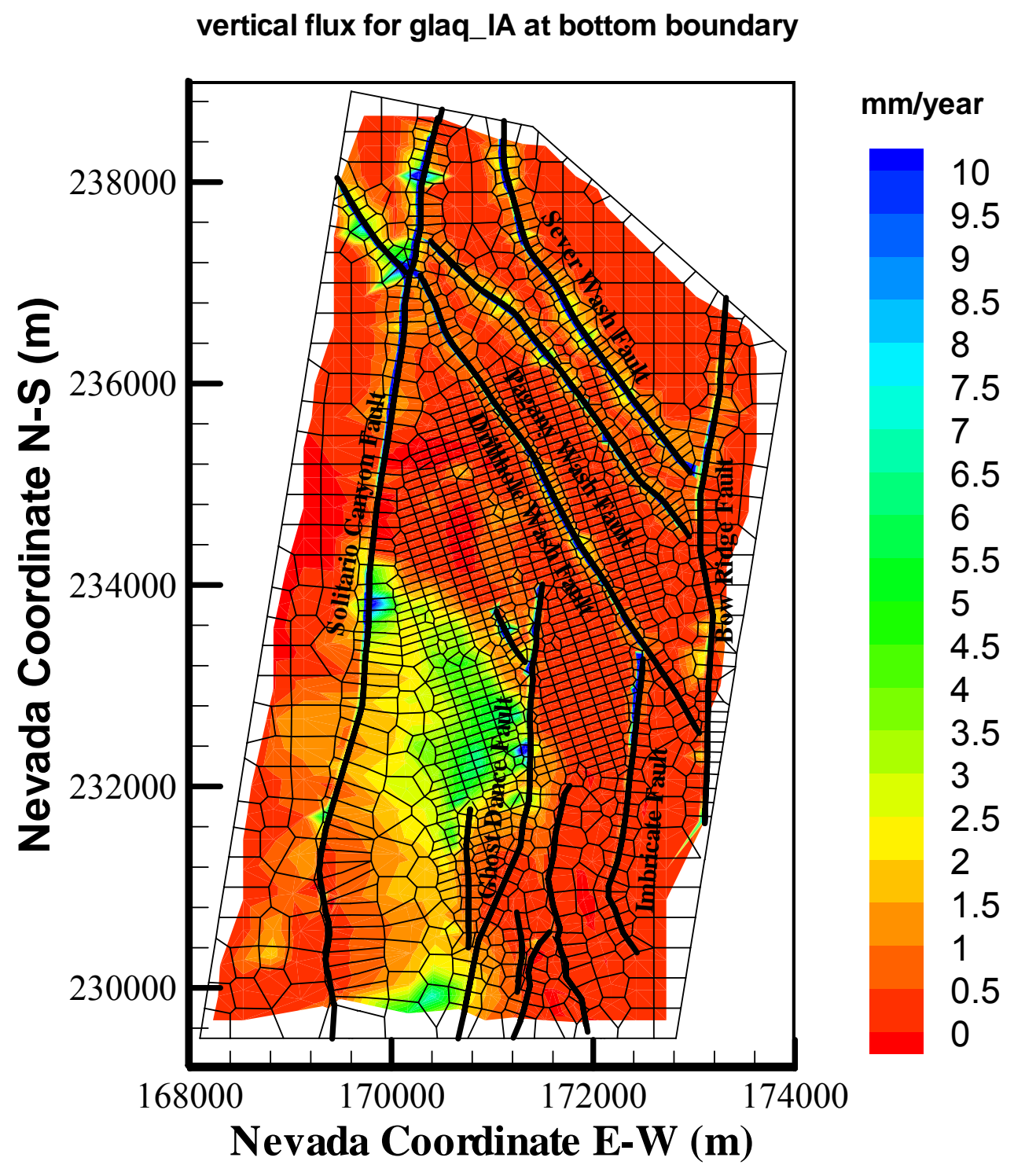

Output DTN: LB03023DSSCP9I.001.

Figure 6.6-16. Simulated Percolation Fluxes at the Water Table under the Glacial-transition, LowerBound Infiltration Scenario Using the Results of Simulating the Base-Case Model: glaq_IA 


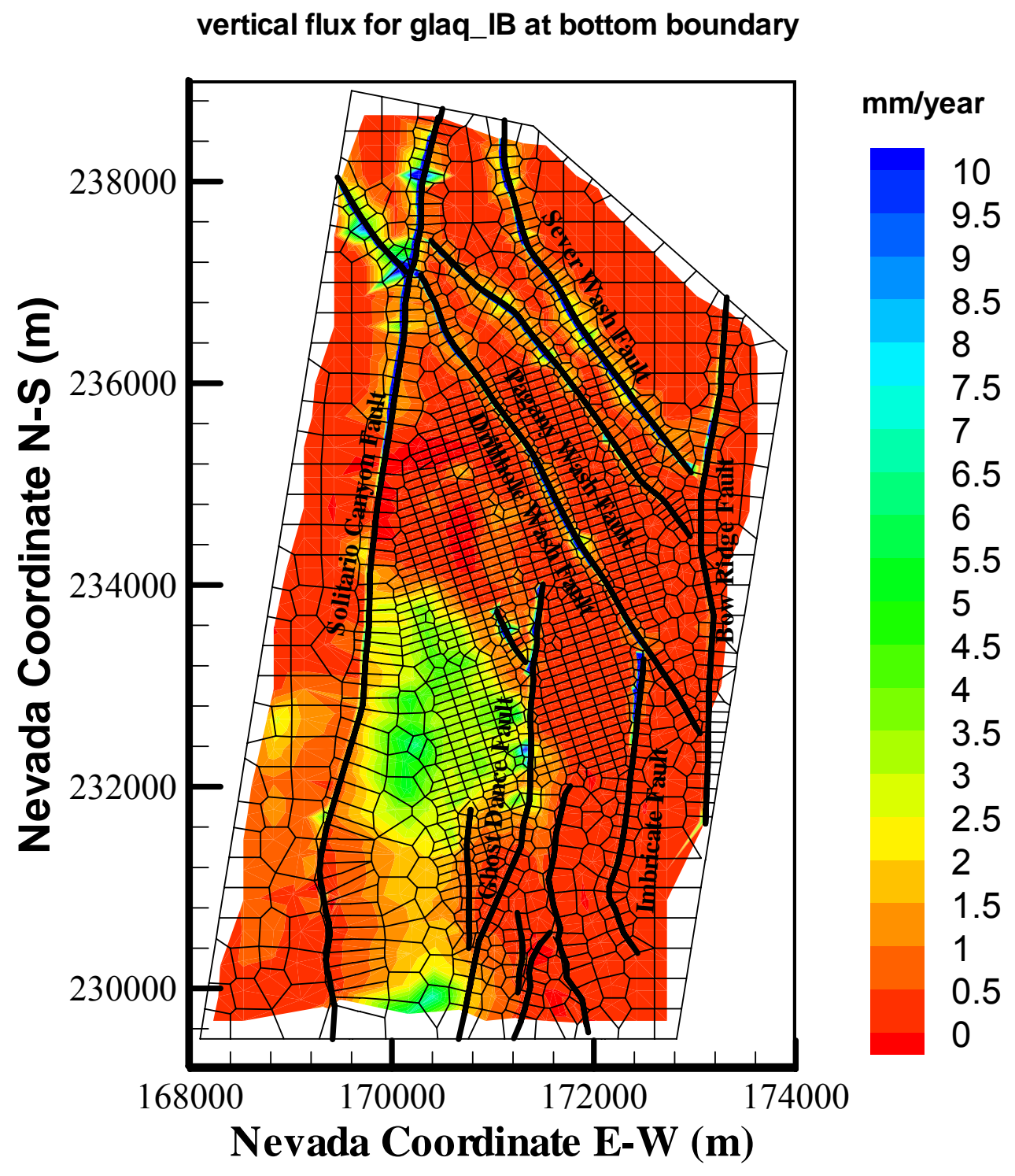

Output DTN: LB03033DSSFF9I.001.

Figure 6.6-17. Simulated Percolation Fluxes at the Water Table under the Glacial-transition, LowerBound Infiltration Scenario Using the Results of Simulating the Alternative Model: glaq_IB 


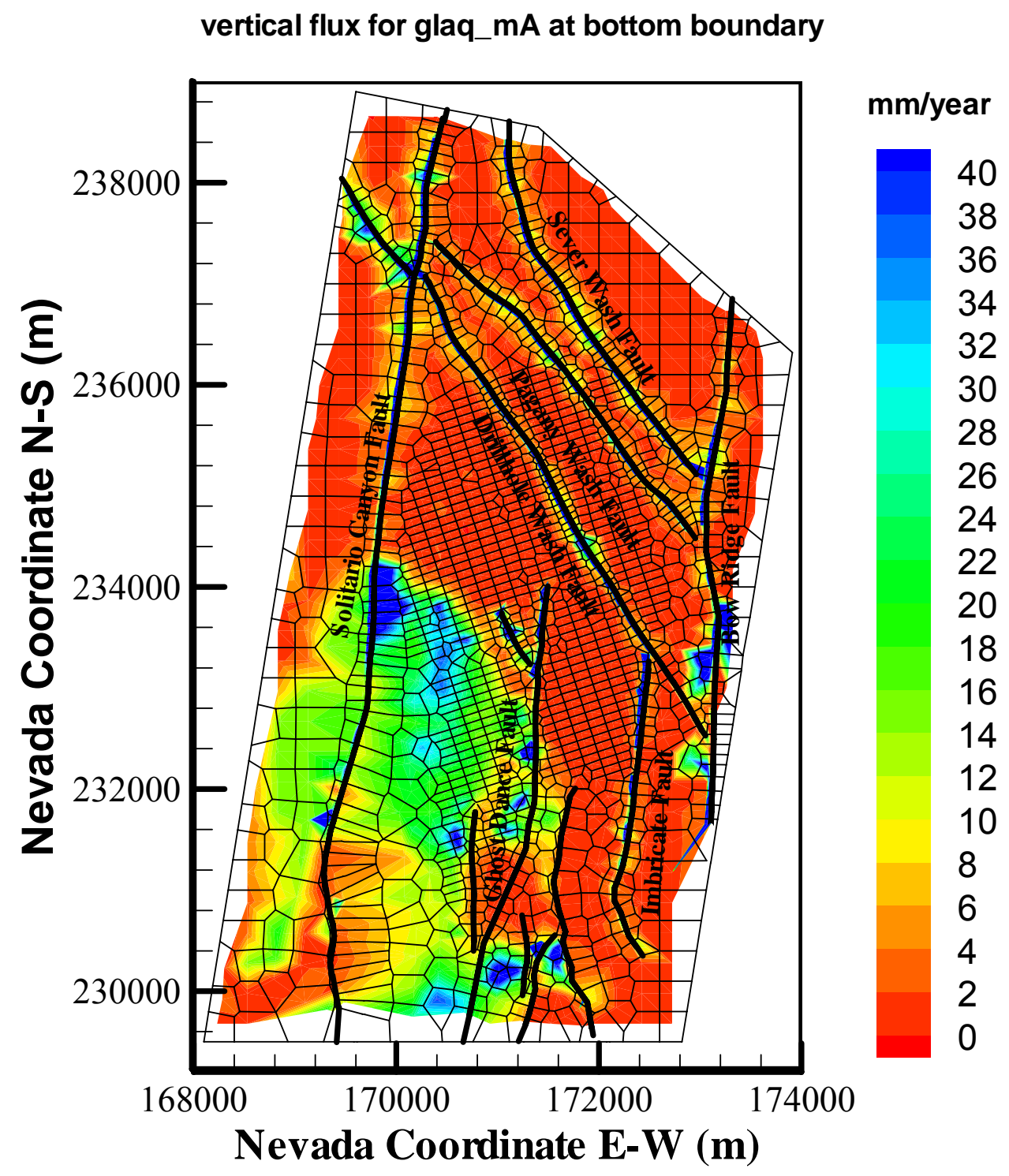

Output DTN: LB03023DSSCP9I.001.

Figure 6.6-18. Simulated Percolation Fluxes at the Water Table under the Glacial-transition, Mean Infiltration Scenario Using the Results of Simulating the Base-Case Model: glaq_mA 


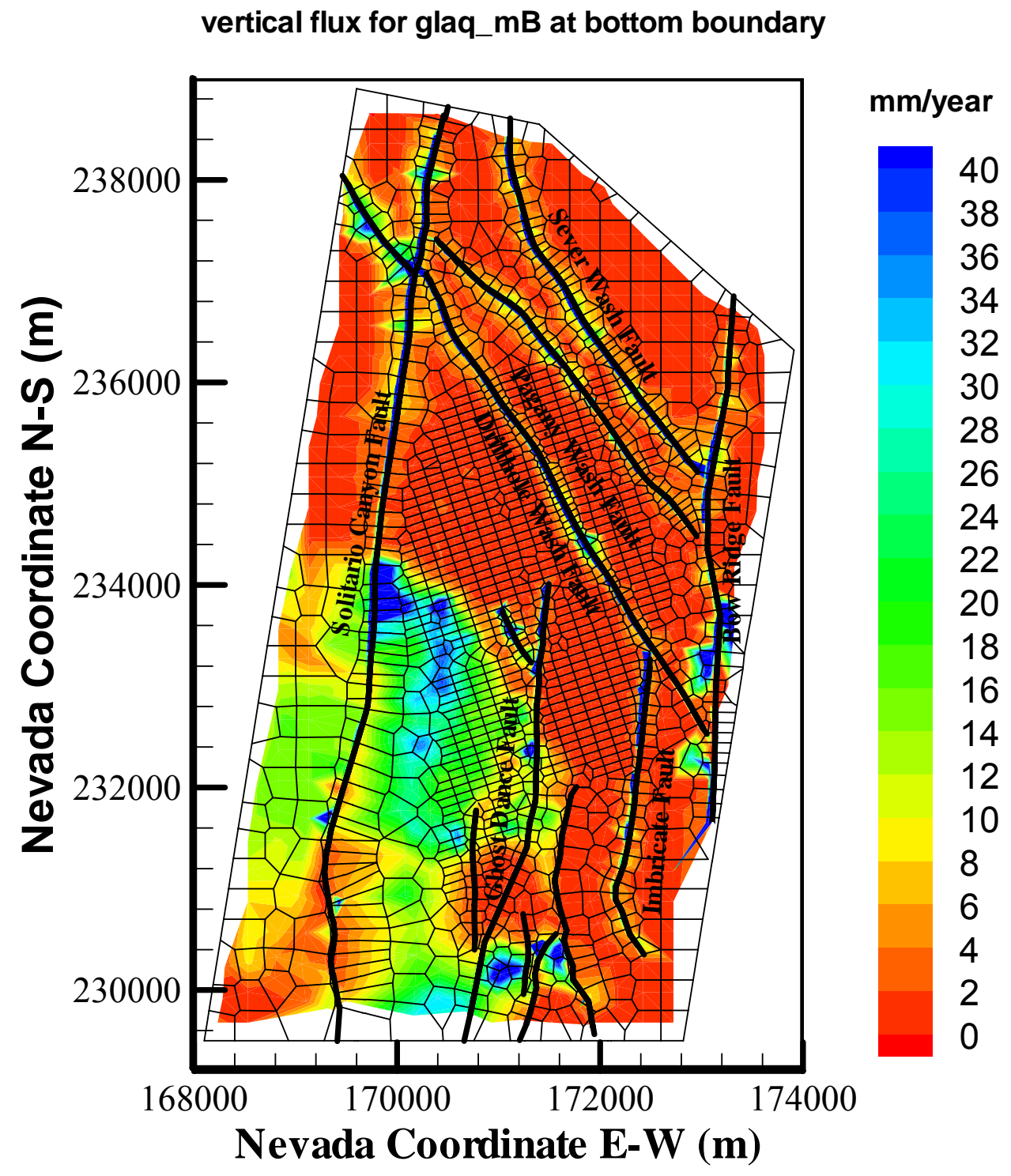

Output DTN: LB03033DSSFF9I.001.

Figure 6.6-19. Simulated Percolation Fluxes at the Water Table under the Glacial-transition, Mean Infiltration Scenario Using the Results of Simulating the Alternative Model: glaq_mB 


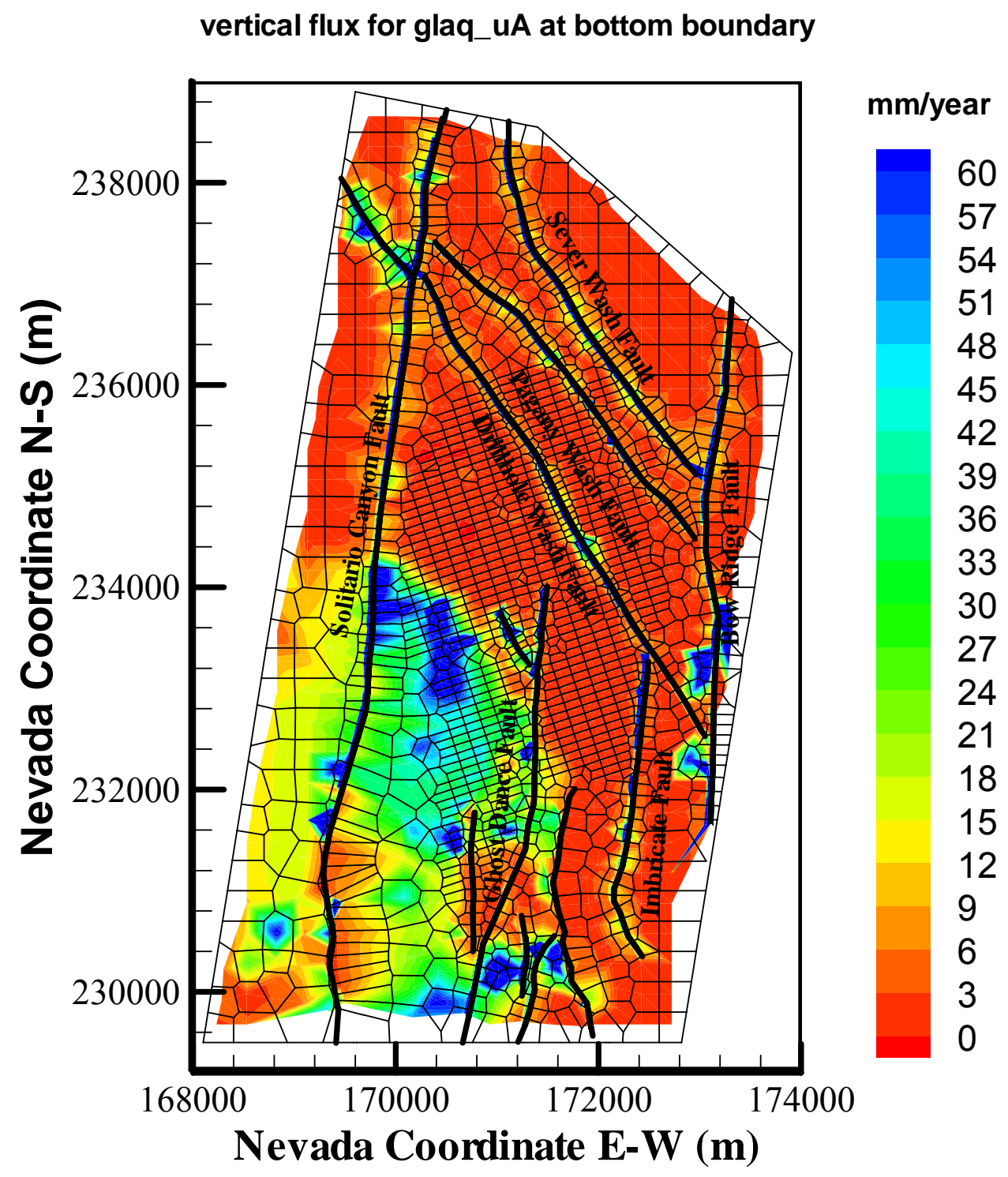

Output DTN: LB03023DSSCP9I.001.

Figure 6.6-20. Simulated Percolation Fluxes at the Water Table under the Glacial-transition, Upper-Bound Infiltration Scenario Using the Results of Simulating the Base-Case Model: glaq_uA 


\section{vertical flux for glaq_uB at bottom boundary}

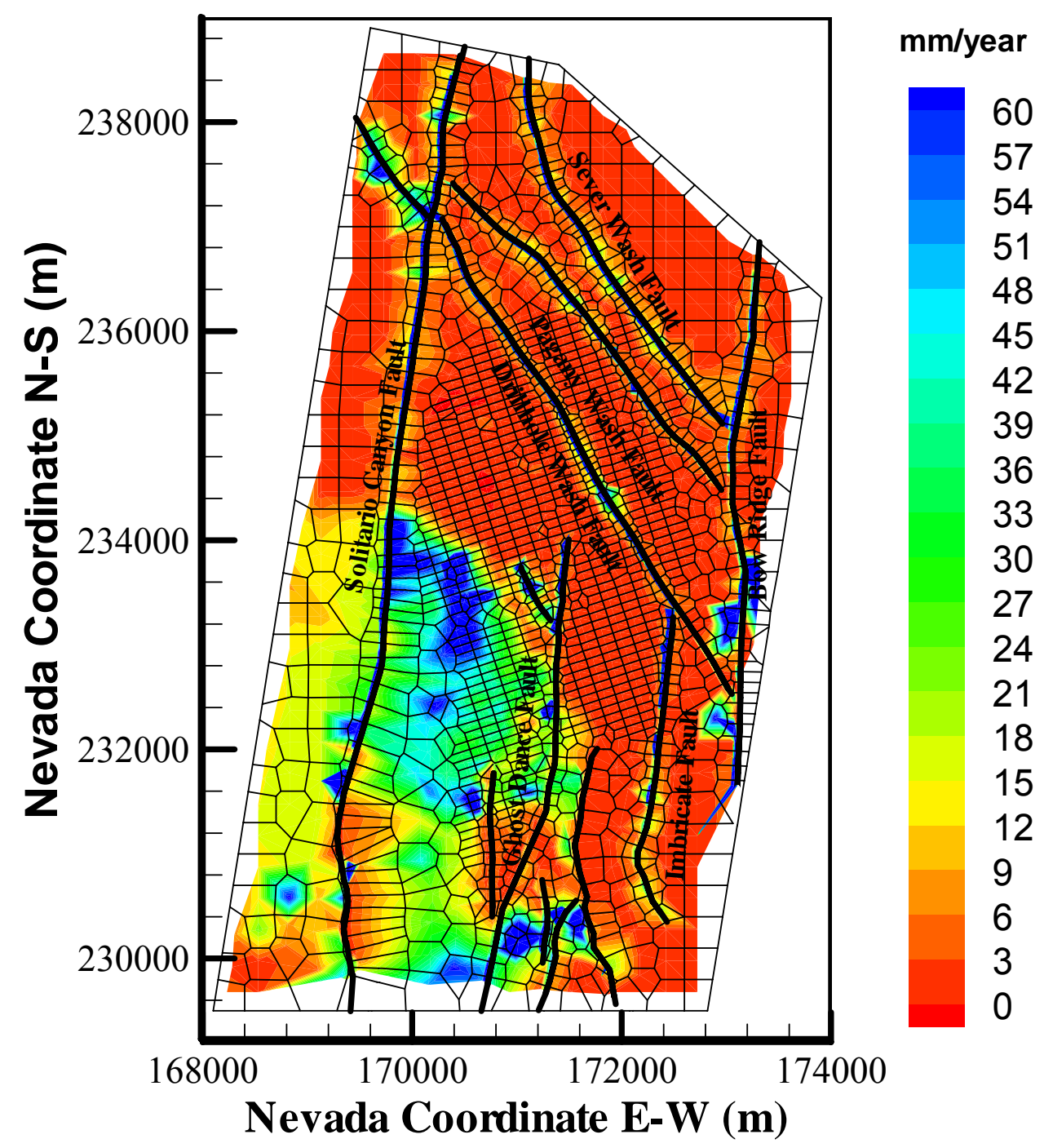

Output DTN: LB03033DSSFF9I.001.

Figure 6.6-21. Simulated Percolation Fluxes at the Water Table under the Glacial-transition, Upper-Bound Infiltration Scenario Using the Results of Simulating the Alternative Model: glaq_uB

Tables 6.6-3 and 6.6-4 list percentages of fracture-matrix flow components of non-fault zones and fault flow over the entire model domain and within the repository footprint at the three horizons of the TCw/PTn interface, the repository layer, and the water table. Fracture and matrix percentages are computed for the non-fault zones only (i.e., excluding fault flow) while fault flow percentages represent total vertical fracture-matrix flux through fault blocks over the entire model layer or the smaller region of the repository footprint at the three horizons. The three percentages sum to 100 percent, (procedures for calculating the percentages are explained in Appendix C, Section C.2). These statistics are calculated from vertical flow along each grid column, using the nine base-case and nine alternative flow fields. 
A comparison between the statistical data of the two tables (Tables 6.6-3 and 6.6-4) indicates that the two models generate similar results in terms of fracture-matrix flow components and fault flow percentage at the repository horizon over the entire model layer and within the repository footprint. This is because the two models differ only in the PTn properties (a unit above), and also because the statistics are taken from averaging an entire layer or repository domain without considering detailed spatial distributions of flow percentage. These statistics indicate that fracture flow is dominant both at the repository horizon over the entire model layer and within the repository footprint. At the repository level, fracture flow consists of more than 90 to 95 percent of the total percolation fluxes over the entire model layer, and is as high as at about 98 percent within the repository footprint. Over the entire model layer, fault flow becomes dominant at the water table, and fault flow percentage increases from about 30 to 40 percent at the repository to about 60 percent at the water table, except for the case of the present-day, lower-bound infiltration. Within the repository footprint, fault flow percentages also show significant increase from 1 percent at the repository level to about 33 to 54 percent at water table. Comparison of fault flow percentages at the $\mathrm{TCw} / \mathrm{PTn}$ interface, the repository horizon, and the water table in Tables 6.6-3 and 6.6-4 indicates that flow focusing into faults occur mainly within the lower hydrogeological CHn unit, not the PTn unit.

Note that according to the active fracture concept (Liu et al. 1998 [DIRS 105729]), not all fractures are transmitting percolation fluxes. Actual active fracture spacings (i.e., fracture flow intervals) in the flow fields are much larger than measured fracture spacings in different units.

Table 6.6-3. Comparison of the Water Flux through Matrix, Fractures of Non-fault Zones, and Faults as a Percentage of the Total Flux over the Entire Model Domain and within the Repository Footprint at Three Different Horizons (1) at the TCw/PTn Interface, (2) at the Repository Level, and (3) at the Water Table for the Nine Base-Case Flow Fields

\begin{tabular}{|l|c|c|c|c|c|c|}
\hline \multirow{2}{*}{ Simulation Designation } & \multicolumn{3}{|c|}{$\begin{array}{c}\text { Flux at TCw/PTn Interface over } \\
\text { Entire Model Domain (\%) }\end{array}$} & \multicolumn{3}{c|}{$\begin{array}{c}\text { Flux at TCw/PTn Interface within } \\
\text { Repository Footprint (\%) }\end{array}$} \\
\hline & Fracture & Matrix & Fault & Fracture & Matrix & Fault \\
\hline preq_IA & 97.38 & 0.08 & 2.54 & 98.89 & 0.13 & 0.99 \\
\hline preq_mA & 95.60 & 1.07 & 3.33 & 98.92 & 0.01 & 1.07 \\
\hline preq_uA & 95.22 & 1.14 & 3.64 & 98.56 & 0.07 & 1.37 \\
\hline monq_IA & 95.45 & 1.21 & 3.34 & 98.87 & 0.05 & 1.08 \\
\hline monq_mA & 95.20 & 1.08 & 3.72 & 98.35 & 0.01 & 1.64 \\
\hline monq_uA & 95.12 & 1.06 & 3.81 & 98.19 & 0.04 & 1.77 \\
\hline glaq_IA & 96.04 & 0.92 & 3.04 & 98.87 & 0.09 & 1.05 \\
\hline glaq_mA & 95.14 & 1.11 & 3.75 & 98.57 & 0.01 & 1.42 \\
\hline glaq_uA & 95.11 & 1.07 & 3.81 & 98.53 & 0.03 & 1.44 \\
\hline
\end{tabular}

Output DTN: LB03023DSSCP9I.001.

PTn=Paintrbush nonwelded hydrogeologic unit; TCw=Tiva Canyon welded hydrogeologic unit 
Table 6.6-3. Comparison of the Water Flux through Matrix, Fractures of Non-fault Zones, and Faults as a Percentage of the Total Flux over the Entire Model Domain and within the Repository Footprint at Three Different Horizons (1) at the TCw/PTn Interface, (2) at the Repository Level, and (3) at the Water Table for the Nine Base-Case Flow Fields (Continued)

\begin{tabular}{|c|c|c|c|c|c|c|}
\hline \multirow[t]{2}{*}{ Simulation Designation } & \multicolumn{3}{|c|}{$\begin{array}{c}\text { Flux at Entire Repository } \\
\text { Layer(\%) }\end{array}$} & \multicolumn{3}{|c|}{\begin{tabular}{|c|}
$\begin{array}{c}\text { Flux at Repository Horizon within } \\
\text { Repository Footprint (\%) }\end{array}$ \\
\end{tabular}} \\
\hline & Fracture & Matrix & Fault & Fracture & Matrix & Fault \\
\hline preq_IA & 32.94 & 8.28 & 58.78 & 94.06 & 3.47 & 2.47 \\
\hline preq_mA & 65.75 & 5.63 & 28.62 & 98.24 & 0.56 & 1.20 \\
\hline preq_uA & 66.56 & 6.03 & 27.41 & 98.23 & 0.52 & 1.24 \\
\hline monq_IA & 61.62 & 6.49 & 31.89 & 97.69 & 0.71 & 1.61 \\
\hline monq_mA & 67.92 & 5.45 & 26.63 & 98.15 & 0.24 & 1.60 \\
\hline monq_uA & 68.26 & 5.70 & 26.04 & 98.08 & 0.34 & 1.57 \\
\hline glaq_IA & 55.54 & 7.75 & 36.71 & 97.04 & 1.16 & 1.80 \\
\hline glaq_mA & 70.22 & 5.51 & 24.27 & 98.47 & 0.17 & 1.36 \\
\hline glaq_uA & 70.63 & 5.56 & 23.81 & 98.46 & 0.22 & 1.32 \\
\hline
\end{tabular}

Output DTN: LB03033DSSFF9I.001.

\begin{tabular}{|c|c|c|c|c|c|c|}
\hline \multirow[t]{2}{*}{ Simulation Designation } & \multicolumn{3}{|c|}{ Flux at Water Table (\%) } & \multicolumn{3}{|c|}{$\begin{array}{l}\text { Flux at Water Table within } \\
\text { Repository Footprint (\%) }\end{array}$} \\
\hline & Fracture & Matrix & Fault & Fracture & Matrix & Fault \\
\hline preq_IA & 7.63 & 20.58 & 71.78 & 5.71 & 56.76 & 37.53 \\
\hline preq_mA & 18.72 & 27.55 & 53.73 & 18.62 & 46.67 & 34.71 \\
\hline preq_uA & 19.71 & 19.61 & 60.68 & 20.29 & 32.06 & 47.64 \\
\hline monq_IA & 7.42 & 26.05 & 66.54 & 5.55 & 44.72 & 49.73 \\
\hline monq_mA & 13.54 & 25.40 & 61.06 & 10.09 & 41.11 & 48.80 \\
\hline monq_uA & 17.47 & 18.29 & 64.25 & 16.37 & 31.55 & 52.08 \\
\hline glaq_IA & 7.02 & 27.58 & 65.40 & 6.04 & 51.82 & 42.14 \\
\hline glaq_mA & 11.47 & 26.96 & 61.57 & 7.84 & 42.27 & 49.89 \\
\hline glaq_uA & 14.30 & 20.33 & 65.37 & 13.62 & 32.60 & 53.78 \\
\hline
\end{tabular}

Output DTN: LB03033DSSFF9I.001. 
Table 6.6-4. Comparison of the Water Flux through Matrix, Fractures of Non-fault Zones, and Faults as a Percentage of the Total Flux over the Entire Model Domain and within the Repository Footprint at Three Different Horizons (1) at the TCw/PTn Interface, (2) at the Repository Level, and (3) at the Water Table for the Nine Alternative Flow Fields

\begin{tabular}{|l|c|c|c|c|c|c|}
\hline \multirow{2}{*}{ Simulation Designation } & \multicolumn{2}{|c|}{$\begin{array}{c}\text { Flux at TCw/PTn Interface over } \\
\text { Entire Model domain (\%) }\end{array}$} & \multicolumn{2}{c|}{$\begin{array}{c}\text { Flux at TCw/PTn Interface within } \\
\text { Repository Footprint (\%) }\end{array}$} \\
\hline & Fracture & Matrix & Fault & Fracture & Matrix & Fault \\
\hline preq_IB & 97.38 & 0.07 & 2.55 & 98.86 & 0.15 & 0.99 \\
\hline preq_mB & 95.79 & 0.87 & 3.34 & 98.92 & 0.01 & 1.07 \\
\hline preq_uB & 95.32 & 1.03 & 3.64 & 98.56 & 0.07 & 1.37 \\
\hline monq_IB & 95.69 & 0.96 & 3.35 & 98.87 & 0.05 & 1.08 \\
\hline monq_mB & 95.40 & 0.88 & 3.72 & 98.35 & 0.00 & 1.64 \\
\hline monq_uB & 95.22 & 0.97 & 3.81 & 98.19 & 0.04 & 1.77 \\
\hline glaq_IB & 96.21 & 0.75 & 3.05 & 98.88 & 0.08 & 1.05 \\
\hline glaq_mB & 96.72 & 1.35 & 1.94 & 99.18 & 0.01 & 0.81 \\
\hline glaq_uB & 95.21 & 0.98 & 3.81 & 98.53 & 0.03 & 1.44 \\
\hline
\end{tabular}

Output DTN: LB03023DSSCP9I.001.

PTn=Paintrbush nonwelded hydrogeologic unit; TCw=Tiva Canyon welded hydrogeologic unit

\begin{tabular}{|l|c|c|c|c|c|c|}
\hline \multirow{2}{*}{ Simulation Designation } & \multicolumn{3}{|c|}{ Flux at Entire Repository } & \multicolumn{3}{c|}{$\begin{array}{c}\text { Flux at Repository Horizon } \\
\text { within Repository Footprint (\%) }\end{array}$} \\
\hline & Fracture & Matrix & Fault & Fracture & Matrix & Fault \\
\hline preq_IB & 25.33 & 9.01 & 65.66 & 96.22 & 3.17 & 0.62 \\
\hline preq_mB & 59.95 & 7.20 & 32.86 & 98.69 & 0.35 & 0.96 \\
\hline preq_uB & 63.19 & 6.32 & 30.49 & 98.32 & 0.48 & 1.20 \\
\hline monq_IB & 55.69 & 6.76 & 37.55 & 97.95 & 0.75 & 1.30 \\
\hline monq_mB & 65.03 & 6.17 & 28.80 & 98.25 & 0.19 & 1.55 \\
\hline monq_uB & 65.76 & 5.85 & 28.39 & 98.02 & 0.32 & 1.67 \\
\hline glaq_IB & 47.89 & 8.42 & 43.69 & 97.75 & 1.12 & 1.13 \\
\hline glaq_mB & 67.90 & 6.13 & 25.97 & 98.55 & 0.14 & 1.31 \\
\hline glaq_uB & 68.56 & 5.70 & 25.74 & 98.49 & 0.20 & 1.31 \\
\hline
\end{tabular}

Output DTN: LB03033DSSFF9I.001. 
Table 6.6-4. Comparison of the Water Flux through Matrix, Fractures of Non-fault Zones, and Faults as a Percentage of the Total Flux over the Entire Model Domain and within the Repository Footprint at Three Different Horizons (1) at the TCw/PTn Interface, (2) at the Repository Level, and (3) at the Water Table for the Nine Alternative Flow Fields (Continued)

\begin{tabular}{|l|c|c|c|c|c|c|}
\hline \multirow{2}{*}{ Simulation Designation } & \multicolumn{3}{|c|}{ Flux at Water Table (\%) } & \multicolumn{3}{c|}{$\begin{array}{c}\text { Flux at Water Table within } \\
\text { Repository Footprint (\%) }\end{array}$} \\
\hline & Fracture & Matrix & Fault & Fracture & Matrix & Fault \\
\hline preq_IB & 7.19 & 19.42 & 73.39 & 4.77 & 57.78 & 37.45 \\
\hline preq_mB & 18.21 & 28.00 & 53.79 & 18.95 & 48.16 & 32.88 \\
\hline preq_uB & 19.75 & 19.40 & 60.84 & 21.61 & 33.91 & 44.48 \\
\hline monq_IB & 7.22 & 26.11 & 66.66 & 5.68 & 47.47 & 46.85 \\
\hline monq_mB & 13.43 & 25.44 & 61.13 & 10.25 & 42.42 & 47.33 \\
\hline monq_uB & 17.68 & 18.07 & 64.25 & 17.17 & 32.94 & 49.89 \\
\hline glaq_IB & 6.62 & 27.02 & 66.36 & 6.01 & 54.95 & 39.03 \\
\hline glaq_mB & 11.44 & 27.01 & 61.55 & 7.94 & 43.62 & 48.44 \\
\hline glaq_uB & 14.33 & 20.31 & 65.36 & 14.18 & 33.77 & 52.04 \\
\hline
\end{tabular}

Output: DTN: LB03033DSSFF9I.001.

Distributions of Percolation Fluxes within the Repository: Percolation fluxes within the repository footprint can be further analyzed using a frequency distribution plot. This plot displays the average percentage of the repository area subject to a particular percolation rate. Note that the normalized flux rates are determined by normalizing an infiltration value with respect to the averaged infiltration rate for the scenario. For example, 1 for the normalized flux rate corresponds to 4.43,11.83, and $17.02 \mathrm{~mm} /$ year (Table 6.1-2), respectively, for the three mean infiltration scenarios. The information, as shown in Figure 6.6-22 (see Appendix C.2.5 for details of the calculation), is important to drift-scale modeling studies of flow and transport at drifts and flow-redistributing phenomena through the TSw. Figure 6.6-22 shows the frequency distribution of normalized percolation flux within the repository horizon for the three mean infiltration rates of the three climates.

Figure 6.6-22 indicates that the highest flux frequencies have a normalized flux of about 0.5 or less, and occur over about 30 percent of the repository area. The area with normalized percolation fluxes greater than 5 comprises less than 1 percent of the total repository area. In general, the modeling results for 18 flow fields show that the percolation flux value with highest areal frequencies is always lower than the average values of the corresponding infiltration rates.

The results of the 18 flow fields analyses, as shown in Figure 6.6-22, can be used to define a cumulative flux-frequency distribution, as shown in Figure 6.6-23 (see Appendix C.2.6 for details of the calculation). Figure 6.6-23 also presents a regression curve that incorporates the 18 flow fields. The cumulative frequency of Figure 6.6-23 can be used, for example, in selecting ambient flow boundary conditions for drift-scale modeling. The similarity in flux distribution patterns for the 18 flow fields helps to define a flux-distribution factor for seepage estimation in the TSPA-LA calculations on the scale of the site-scale UZ model, but is not recommended for use in small-scale models, such as the drift-scale seepage models. The regression curve, with the equation given on the figure, may be used to correlate cumulative flux frequency within the repository with net infiltration rates for any future climatic scenarios. For example, use of the equation with $\mathrm{x}=1,2$, and 5 gives results of 60 percent, 88 percent, and 99 percent. This indicates that 60 percent, 88 percent, and 99 percent repository blocks are subject to less than normalized fluxes of 1,2 , and 5 , respectively. This provides data for PA calculations. 

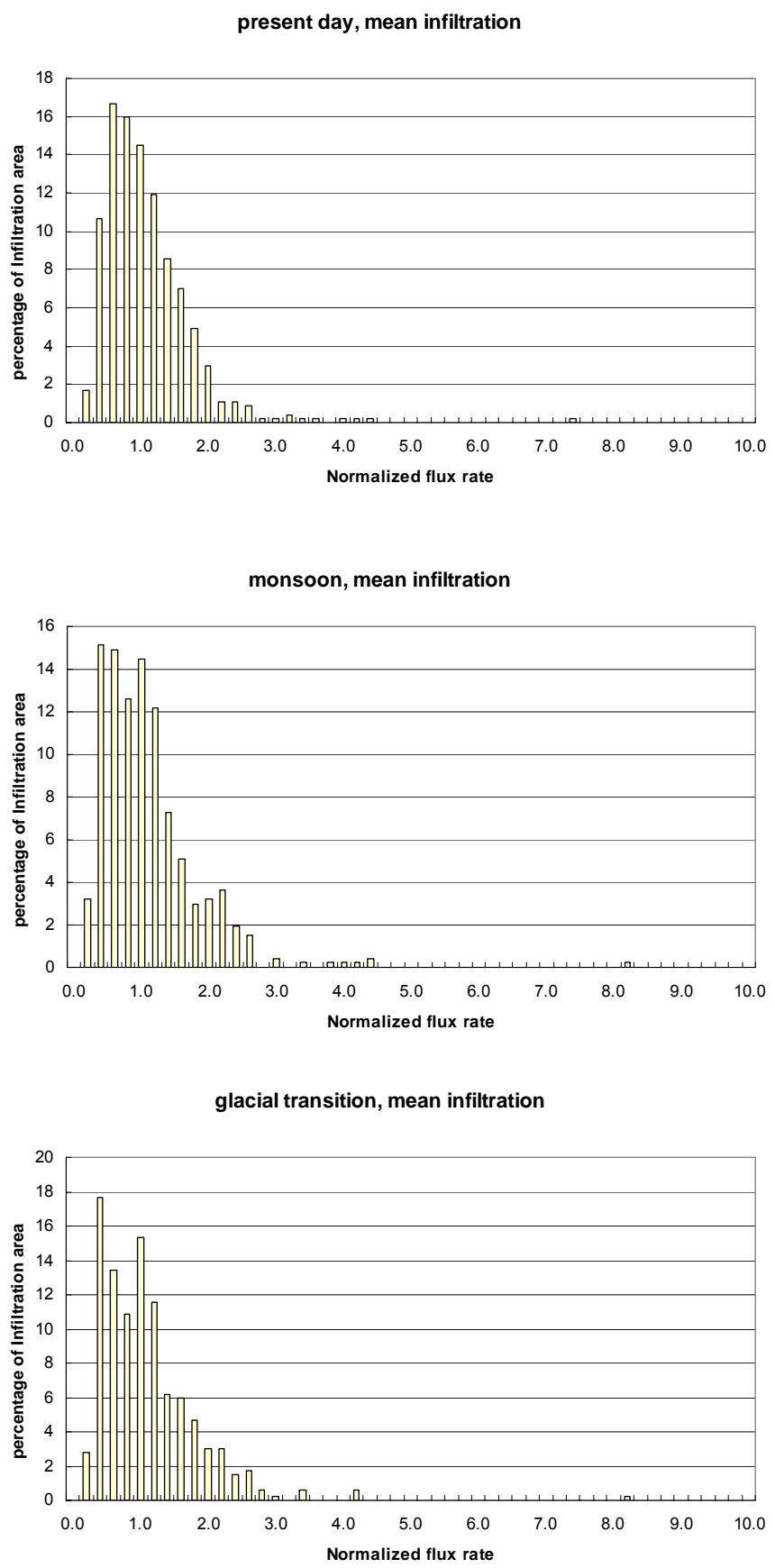

Output DTN: LB03023DSSCP9I.001.

Figure 6.6-22. Areal Frequency and Distribution of Simulated Percolation Fluxes within the Repository Domain Normalized to the Three Mean Infiltration Rates: (a) Present Day, (b) Monsoon, and (c) Glacial-transition 


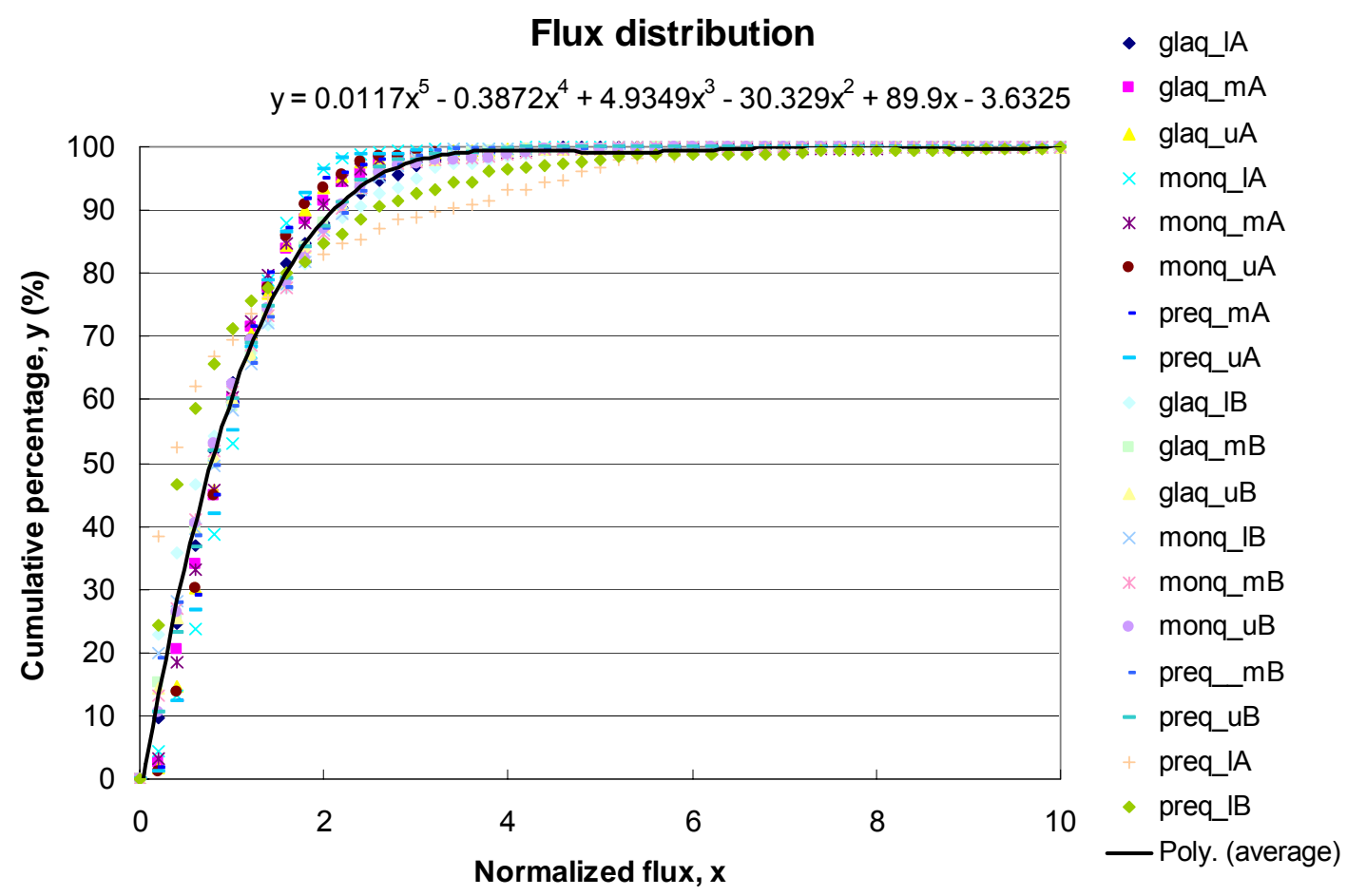

Output DTNs: LB03023DSSCP9I.001; LB03033DSSFF9I.001.

NOTE: Equation is valid for 0.05 less than $x$ less than 10 .

Figure 6.6-23. Cumulative Flux Distribution and Range as Functions of Normalized Percolation Flux within the Repository from the 18 Flow Fields

\subsection{TRACER TRANSPORT TIMES}

This section summarizes simulated tracer transport using the nine base-case UZ flow fields and the nine alternative UZ flow fields. The results present an evaluation of tracer transport processes from the repository to the water table (saturated zone), and within the mountain, including the effects of different infiltration scenarios and adsorption. Studies described in this section provide insight into UZ flow patterns and transport processes.

\subsubsection{Methodology and Transport Parameters}

Simulation results and analyses of this section are based on transport studies of conservative and reactive tracers using the T2R3D V1.4 code (LBNL 1999 [DIRS 146654]). The dual-permeability modeling approach with the three-dimensional TSPA-LA grid (Figure 6.1-1), as discussed in Section 6.1.1, is used in the transport simulations. Note that in the dual-permeability concept matrix blocks are handled as single grid cell using the fracture spacing data in each geological unit. This one-block approximation to matrix blocks for estimating fracture-matrix interaction may introduce some numerical errors for simulating transient tracer transport, when compared with the more accurate MINC discretization. However, it has been shown that the dual-continuum approach produces more conservative results than the MINC 
method in modeling tracer transport from the repository to the water table (i.e., predicting a short tracer transport time).

In the tracer transport modeling, the 18 steady-state, three-dimensional flow fields of Section 6.6 are directly used as input to the $\mathrm{T} 2 \mathrm{R} 3 \mathrm{D}$ code for modeling transport from the repository to the water table.

To assess tracer transport times from the repository to the water table, tracers are treated as conservative (nonadsorbing) and reactive (adsorbing) components transported through the UZ. In both cases, hydrodynamic/mechanical dispersion through the fracture-matrix system is ignored, because sensitivity studies indicated that mechanical dispersion has an insignificant effect on the cumulative breakthrough curves of tracers at the water table (BSC 2001 [DIRS 158726]). A constant molecular diffusion coefficient of $3.2 \times 10^{-11} \mathrm{~m}^{2} / \mathrm{s}$ is used for matrix diffusion of the conservative component, and $1.6 \times 10^{-10} \mathrm{~m}^{2} / \mathrm{s}$ is used for the reactive component (DTN: LA0003JC831362.001 [DIRS 149557]). The two diffusion coefficients are multiplied by porosity and tortuosity in the simulation to account for various units. In the case of a reactive or adsorbing tracer, several $K_{d}$ values are used, as given in Table 6.7-1, for different units. These values were selected to approximate those for neptunium $\left({ }^{237} \mathrm{~Np}\right)$ transport (DTNs: LA0010JC831341.001] [DIRS 162476]; LA0010JC831341.002

$\begin{array}{llll}\text { LA0010JC831341.003 } & \text { [DIRS 153322]; } & \text { LA0010JC831341.004 } & \text { [DIRS 153323]; } \\ \text { LA0010JC831341.005 } & \text { [DIRS 153320]; } & \text { LA0010JC831341.006 } & \text { [DIRS 153318]; }\end{array}$
LA0010JC831341.007 [DIRS 153319]). For a conservative tracer, $K_{d}$ is set to zero. These molecular diffusion coefficients and $\mathrm{K}_{\mathrm{d}}$ values are selected to represent technetium and neptunium. Model parameters such as porosity and rock grain density were taken from the thermal properties (DTN: LB0210THRMLPRP.001 [DIRS 160799]).

Transport simulations were conducted for $1,000,000$ years using nine constant infiltration rates of three climates. An initial, constant concentration source was instantaneously released from the fracture continuum gridblocks representing the repository, released at the starting time of simulation. In addition, tracer transport was also investigated with tracers initially released from the matrix continuum of the repository block under the present-day mean infiltration scenario.

Table 6.7-1. $\quad K_{d}$ Values Used for Reactive Tracer Transport in Different Hydrogeologic Units

\begin{tabular}{|l|c|}
\hline \multicolumn{1}{|c|}{ Hydrogeologic Unit } & $\left.\mathbf{K}_{\mathbf{d}} \mathbf{( c c} / \mathbf{g}\right)$ \\
\hline Zeolitic matrix in $\mathrm{CHn}$ & 4.0 \\
\hline Vitric matrix in $\mathrm{CHn}$ & 1.0 \\
\hline Matrix in TSw & 1.0 \\
\hline Fault matrix in CHn & 1.0 \\
\hline Fractures and the matrix in the rest of units & 0.0 \\
\hline
\end{tabular}

NOTE: $\quad K_{d}$ values selected from ranges in the following DTNs: LA0010JC831341.001 [DIRS 162476], LA0010JC831341.002 [DIRS 153321], LA0010JC831341.003 [DIRS 153322], LA0010JC831341.004 [DIRS 153323], LA0010JC831341.005 [DIRS 153320], LA0010JC831341.006 [DIRS 153318], and LA0010JC831341.007 [DIRS 153319].

$\mathrm{CHn}=$ Calico Hills nonwelded hydrogeologic unit; TSw=Topopah Spring welded hydrogeologic unit 


\subsubsection{Simulation Scenarios}

For each TSPA-LA flow simulation, as listed in Tables 6.2-9 and 6.6-1, there are two transport runs, one for conservative $\left(*_{-} \mathrm{tc}\right)$ and one for reactive $\left({ }^{*} \mathrm{np}\right)$ tracer transport. For most cases, tracer first releases from fracture gridblocks within the repository. Tables 6.7-2 and 6.7-3 summarize a total of $18 \times 2$ tracer-fracture-release simulation scenarios, corresponding to the 18 TSPA-LA flow fields for the nine infiltration maps of three climates, respectively. There are only four tracer-matrix-release simulations, two each for the base-case and alternative flow fields (*tcM and *npM for Tc and Np, respectively).

Table 6.7-2. Transport Simulation Scenarios: Data Files and Corresponding Nine Base-Case Flow Fields with Nine Infiltration Rates

\begin{tabular}{|c|c|c|}
\hline $\begin{array}{c}\text { Designation/ } \\
\text { Transport Simulation }\end{array}$ & $\begin{array}{l}\text { Designation/ } \\
\text { Flow Simulation } \\
\text { (Output-DTN: } \\
\text { LB03023DSSCP9I.001) } \\
\end{array}$ & $\begin{array}{c}\text { Infiltration Map } \\
\text { (DTN: } \text { GS000308311221.005 } \\
\text { [DIRS 147613] }\end{array}$ \\
\hline $\begin{array}{l}\text { preqlA_tc } \\
\text { preqIA_np }\end{array}$ & preq_IA & Present-day, lower-bound infiltration \\
\hline $\begin{array}{l}\text { preqmA_tc } \\
\text { preqmA_tcM } \\
\text { preqmA_np } \\
\text { preqmA_npM }\end{array}$ & preq_mA & Present-day, mean infiltration \\
\hline $\begin{array}{l}\text { prequA_tc } \\
\text { prequA_np }\end{array}$ & preq_uA & Present-day, upper-bound infiltration \\
\hline $\begin{array}{l}\text { monqIA_tc } \\
\text { monqIA_np }\end{array}$ & monq_IA & Monsoon, lower-bound infiltration \\
\hline $\begin{array}{l}\text { monqmA_tc } \\
\text { monqmA_np }\end{array}$ & monq_mA & Monsoon, mean infiltration \\
\hline $\begin{array}{l}\text { monquA_tc } \\
\text { monquA_np }\end{array}$ & monq_uA & Monsoon, upper-bound infiltration \\
\hline $\begin{array}{l}\text { glaqIA_tc } \\
\text { glaqIA_np }\end{array}$ & glaq_IA & $\begin{array}{l}\text { Glacial-transition, lower-bound } \\
\text { infiltration }\end{array}$ \\
\hline $\begin{array}{l}\text { glaqmA_tc } \\
\text { glaqmA_np }\end{array}$ & glaq_mA & Glacial-transition, mean infiltration \\
\hline $\begin{array}{l}\text { glaquA_tc } \\
\text { glaquA_np }\end{array}$ & glaq_uA & $\begin{array}{l}\text { Glacial-transition, upper-bound } \\
\text { infiltration }\end{array}$ \\
\hline
\end{tabular}

Output DTN: LB03033DUZTRAN.001.

a Tracer release from repository matrix blocks 
Table 6.7-3. Transport Simulation Scenarios: Data Files and Corresponding Nine Alternative Fields with Nine Infiltration Rates

\begin{tabular}{|c|c|c|}
\hline $\begin{array}{c}\text { Designation/ } \\
\text { Transport Simulation }\end{array}$ & $\begin{array}{l}\text { Designation/ } \\
\text { Flow Simulation } \\
\text { Output-DTN: } \\
\text { LB03033DSSFF9l.001 }\end{array}$ & $\begin{array}{cl}\text { Infiltration Map } \\
\text { DTN: } \\
\text { GS000308311221.005 } \\
\text { [DIRS 147613] }\end{array}$ \\
\hline $\begin{array}{l}\text { preqlB_tc } \\
\text { preqIB_np }\end{array}$ & preq_IB & Present-day, lower-bound infiltration \\
\hline $\begin{array}{l}\text { preqmB_tc } \\
\text { preqmB_tcM }^{\mathrm{a}} \\
\text { preqmB_np } \\
\text { preqmB_npM }\end{array}$ & preq_mB & Present-day, mean infiltration \\
\hline $\begin{array}{l}\text { prequB_tc } \\
\text { prequB_np }\end{array}$ & preq_uB & Present-day, upper-bound infiltration \\
\hline $\begin{array}{l}\text { monqlB_tc } \\
\text { monqlB_np }\end{array}$ & monq_IB & Monsoon, lower-bound infiltration \\
\hline $\begin{array}{l}\text { monqmB_tc } \\
\text { monqmB_np }\end{array}$ & monq_mB & Monsoon, mean infiltration \\
\hline $\begin{array}{l}\text { monquB_tc } \\
\text { monquB_np }\end{array}$ & monq_uB & Monsoon, upper-bound infiltration \\
\hline $\begin{array}{l}\text { glaqIB_tc } \\
\text { glaqlB_np }\end{array}$ & glaq_IB & $\begin{array}{l}\text { Glacial-transition, lower-bound } \\
\text { infiltration }\end{array}$ \\
\hline $\begin{array}{l}\text { glaqmB_tc } \\
\text { glaqmB_np }\end{array}$ & glaq_mB & Glacial-transition, mean infiltration \\
\hline $\begin{array}{l}\text { glaquB_tc } \\
\text { glaquB_np }\end{array}$ & glaq_uB & $\begin{array}{l}\text { Glacial-transition, upper-bound } \\
\text { infiltration }\end{array}$ \\
\hline
\end{tabular}

Output:DTN: LB03033DUZTRAN.001.

a Tracer release from repository matrix blocks

\subsubsection{Simulation Results and Analyses}

Tracer transport times (since release from the repository to the water table) may be analyzed using a cumulative fractional breakthrough curve, as shown in Figures 6.7-1, 6.7-2, and 6.7-3 for 1 million years. The fractional mass breakthrough in these figures is defined as the cumulative mass of a tracer arriving at the water table over the entire bottom model boundary over time, normalized by the total mass of the component initially introduced at the repository. In the figures, solid-line and dotted-line curves of the same color represent simulation results of conservative/nonadsorbing tracer transport and adsorbing tracer transport, respectively. The three figures show a wide range of tracer transport times with different infiltration rates and types of tracers considered in the 40 simulations (listed in Tables 6.7-2 and 6.7-3).

As indicated by Figures 6.7-1 and 6.7-2, the predominant factors in controlling tracer transport are (1) surface-infiltration rates or net water recharge; (2) adsorption effects (i.e., whether the tracer is conservative or reactive); and (3) whether it is initially released from fracture or matrix blocks in the repository. The figures also show that the base-case flow fields (Figure 6.7-1) and the alternative flow fields (Figure 6.7-2) result in very similar tracer transport times. However, 
the base-case flow scenarios generate slightly shorter transport times or more conservative results in general.

Statistics of tracer transport times of 10 percent and 50 percent mass breakthrough at the water table for the 36 simulation scenarios of tracer-fracture release plus four tracer-matrix-release scenarios are given in Tables 6.7-4 and 6.7-5, respectively. Figure 6.7-4 correlates average infiltration rates and tracer transport times at 50 percent mass breakthrough for the 36 simulation scenarios of tracer-fracture release. Figures 6.7-1, 6.7-2, 6.7-3, and 6.7-4, and the statistical data of Tables 6.7-4 and 6.7-5, show the following:

- Tracer transport times vary inversely to the average surface infiltration (net water recharge) rate over the model domain (Figure 6.7-4). When the average infiltration rate increases from 5 to 35 ( $\mathrm{mm} /$ year), average tracer transport (50 percent breakthrough) times decrease by more than one order of magnitude for both adsorbing and nonadsorbing species.

- Nonadsorbing tracers migrate (from the repository to the water table) one to two orders of magnitude faster than an adsorbing tracer under the same infiltration condition (Figure 6.7-4).

- Tracer transport times are significantly longer when tracers are initially released from repository matrix blocks instead of fractures. For conservative (i.e., nonadsorbing) transport, transport times are increased by one to two orders of magnitude (Figure 6.7-3, Tables 6.7-4 and 6.7-5). For reactive (i.e., adsorbing) tracers, the transport times are increased by more than one order of magnitude at 10 percent mass breakthrough, and by approximately two times at 50 percent breakthrough.

- A comparison of travel/transport times obtained from the nine base-case flow fields with those from the nine alternative flow fields indicates that the base-case flow fields show slightly shorter transport times (or slightly more conservative results in general) under the same infiltration scenarios. 


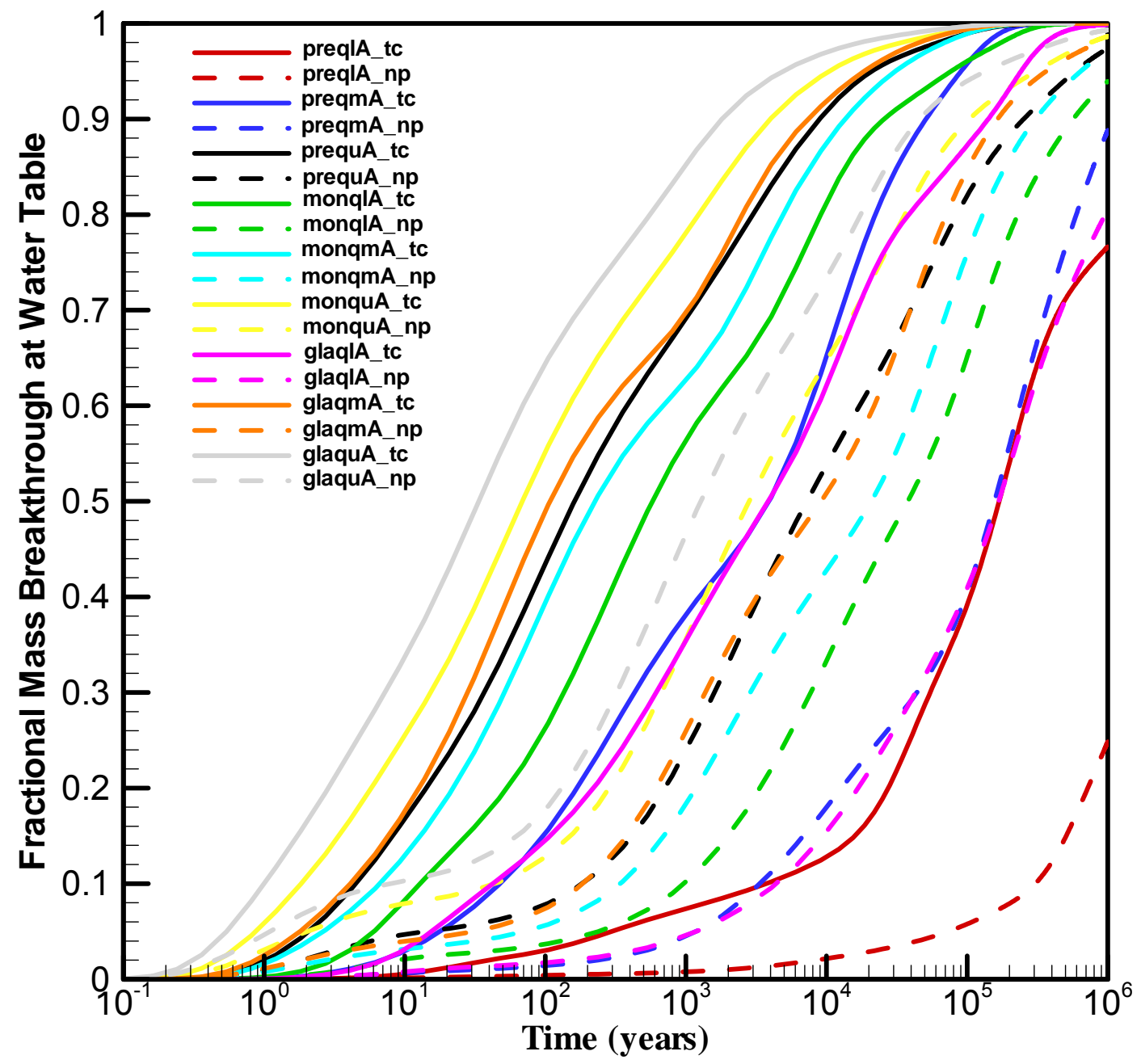

Output DTN: LB03033DUZTRAN.001.

Note: The tracer is released instantaneously from repository fracture elements at the start time of simulation.

Figure 6.7-1. Simulated Breakthrough Curves of Cumulative Tracer Mass Arriving at the Water Table, after Release from Fractures in the Repository, Using the Base-Case Flow Fields with the Nine Infiltration Scenarios of Present-Day, Monsoon, and Glacial-Transition Climates for Nonadsorbing and Adsorbing Tracers 


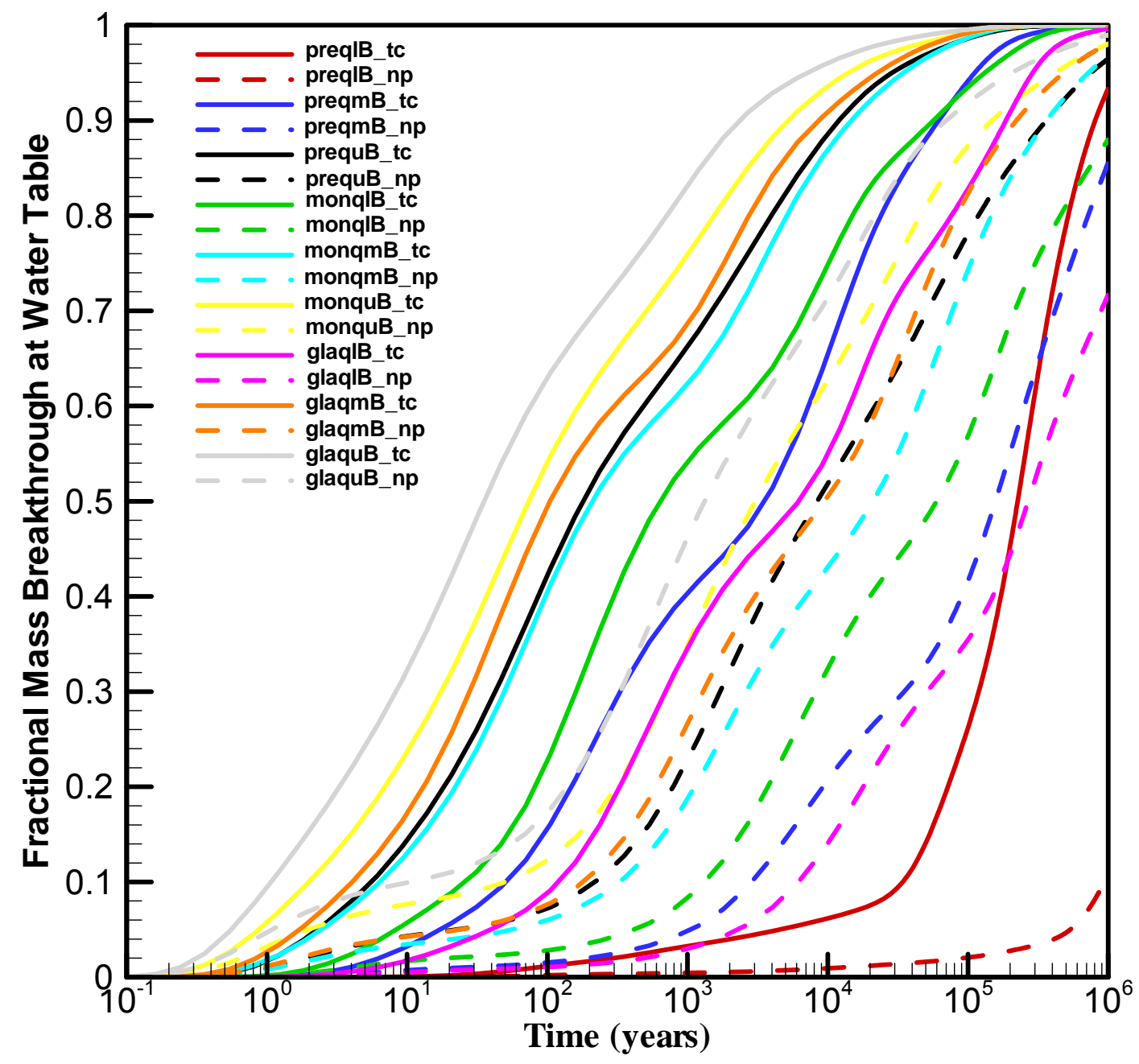

Output DTN: LB03033DUZTRAN.001.

NOTE: The tracer is released instantaneously from repository fracture elements at the start time of simulation.

Figure 6.7-2. Simulated Breakthrough Curves of Cumulative Tracer Mass Arriving at the Water Table, after Release from Fractures in the Repository, Using the Alternative Flow Fields with the Nine Infiltration Scenarios of Present-Day, Monsoon, and Glacial-Transition Climates for Nonadsorbing and Adsorbing Tracers 


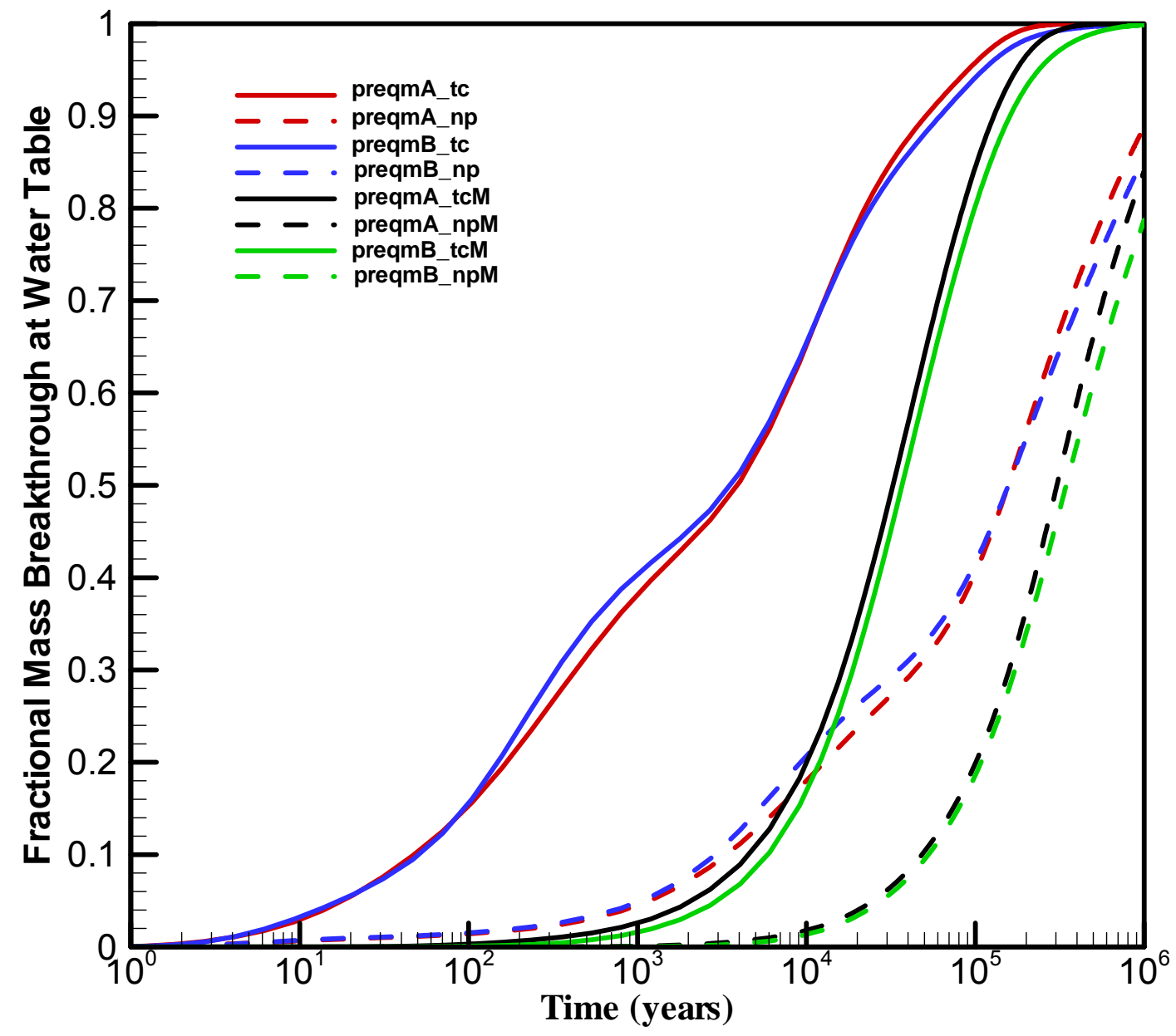

Output DTN: LB03033DUZTRAN.001.

NOTE: The tracer is released instantaneously from repository fracture or matrix elements at the start time of simulation.

Figure 6.7-3. Comparison of Simulated Breakthrough Curves of Cumulative Tracer Mass Arriving at the Water Table, after Release from Fractures and Matrix Blocks in the Repository, Using the Base-Case and Alternative Flow Fields under the Present-Day Mean Infiltration Flow Fields for Nonadsorbing and Adsorbing Tracers 
Table 6.7-4. Tracer Transport Times at 10 Percent and 50 Percent Mass Breakthrough Times for 18 Transport Simulation Scenarios, Corresponding to the Nine Base-Case Flow Fields with Nine Infiltration Rates

\begin{tabular}{|l|l|c|c|}
\hline $\begin{array}{c}\text { Designation/ } \\
\text { Transport Simulation }\end{array}$ & \multicolumn{1}{|c|}{$\begin{array}{c}\text { Types } \\
\text { of Tracer }\end{array}$} & $\begin{array}{c}\text { 10\% Breakthrough } \\
\text { Times (years) }\end{array}$ & $\begin{array}{c}\text { 50\% Breakthrough } \\
\text { Times (years) }\end{array}$ \\
\hline preqIA_tc & Nonadsorbing & 3,800 & 169,000 \\
\hline preqIA_np & Adsorbing & 305,000 & $>1,000,000$ \\
\hline preqmA_tc & Nonadsorbing & 50 & 3,900 \\
\hline preqmA_tcM ${ }^{\text {a }}$ & Nonadsorbing & 4,600 & 33,000 \\
\hline preqmA_np & Adsorbing & 3,400 & 157,000 \\
\hline preqmA_npM & Adsorbing & 48,000 & 300,000 \\
\hline prequA_tc & Nonadsorbing & 5 & 160 \\
\hline prequA_np & Adsorbing & 190 & 7,400 \\
\hline monqIA_tc & Nonadsorbing & 13 & 590 \\
\hline monqIA_np & Adsorbing & 980 & 38,000 \\
\hline monqmA_tc & Nonadsorbing & 7 & 230 \\
\hline monqmA_np & Adsorbing & 340 & 21,000 \\
\hline monquA_tc & Nonadsorbing & 2 & 69 \\
\hline monquA_np & Adsorbing & 44 & 2,800 \\
\hline glaqIA_tc & Nonadsorbing & 43 & 3,900 \\
\hline glaqIA_np & Adsorbing & 4,400 & 167,000 \\
\hline glaqmA_tc & Nonadsorbing & 4 & 110 \\
\hline glaqmA_np & Adsorbing & 187 & 9,200 \\
\hline glaquA_tc & Nonadsorbing & 1 & 34 \\
\hline glaquA_np & Adsorbing & 8 & 1,300 \\
\hline OutputDTn LB03033DUZTRAN.01. & & \\
\hline
\end{tabular}

Output DTN: LB03033DUZTRAN.001.

${ }^{a}$ Tracer release from repository matrix blocks

Table 6.7-5. Tracer Transport Times at 10 Percent and 50 Percent Mass Breakthrough Times for 14 Transport Simulation Scenarios, Corresponding to the Nine Alternative Flow Fields with Nine Infiltration Rates

\begin{tabular}{|l|l|c|c|}
\hline $\begin{array}{c}\text { Designation/ } \\
\text { Transport Simulation }\end{array}$ & \multicolumn{1}{|c|}{$\begin{array}{c}\text { Types } \\
\text { of Tracer }\end{array}$} & $\begin{array}{c}\mathbf{1 0 \%} \text { Breakthrough } \\
\text { Times (years) }\end{array}$ & $\begin{array}{c}\text { 50\% Breakthrough } \\
\text { Times (years) }\end{array}$ \\
\hline preqlB_tc & Nonadsorbing & 34,000 & $\mathbf{2 2 6 , 0 0 0}$ \\
\hline preqIB_np & Adsorbing & 940,000 & $>1,000,000$ \\
\hline preqmB_tc & Nonadsorbing & 51 & 3,600 \\
\hline preqmB_tcM & Nonadsorbing & 5,900 & 37,000 \\
\hline preqmB_np & Adsorbing & 2,900 & 157,000 \\
\hline preqmB_npM & Adsorbing & 53,000 & 345,000 \\
\hline prequB_tc & Nonadsorbing & 6 & 180 \\
\hline prequB_np & Adsorbing & 220 & 8,500 \\
\hline monqlB_tc & Nonadsorbing & 26 & 660 \\
\hline monqlB_np & Adsorbing & 1,300 & 60,000 \\
\hline monqmB_tc & Nonadsorbing & 6 & 210 \\
\hline monqmB_np & Adsorbing & 330 & 21,000 \\
\hline
\end{tabular}


Table 6.7-5. Tracer Transport Times at 10 Percent and 50 Percent Mass Breakthrough Times for 14 Transport Simulation Scenarios, Corresponding to the Nine Alternative Flow Fields with Nine Infiltration Rates (Continued)

\begin{tabular}{|c|c|c|c|}
\hline $\begin{array}{c}\text { Designation/ } \\
\text { Transport Simulation }\end{array}$ & $\begin{array}{c}\text { Types } \\
\text { of Tracer }\end{array}$ & $\begin{array}{c}10 \% \text { Breakthrough } \\
\text { Times (years) }\end{array}$ & $\begin{array}{c}50 \% \text { Breakthrough } \\
\text { Times (years) }\end{array}$ \\
\hline monquB tc & Nonadsorbing & 2 & 74 \\
\hline monuB_np & Adsorbing & 50 & 3,100 \\
\hline glaqlB_tc & Nonadsorbing & 120 & 6,200 \\
\hline glaqlB_np & Adsorbing & 6,200 & 268,000 \\
\hline glaqmB_tc & Nonadsorbing & 4 & 105 \\
\hline glaqmB_np & Adsorbing & 180 & 9,500 \\
\hline glaquB_tc & Nonadsorbing & 1 & 36 \\
\hline glaquB_np & Adsorbing & 10 & 1,350 \\
\hline
\end{tabular}

Output DTN: LB03033DUZTRAN.001.

a Tracer release from repository matrix blocks

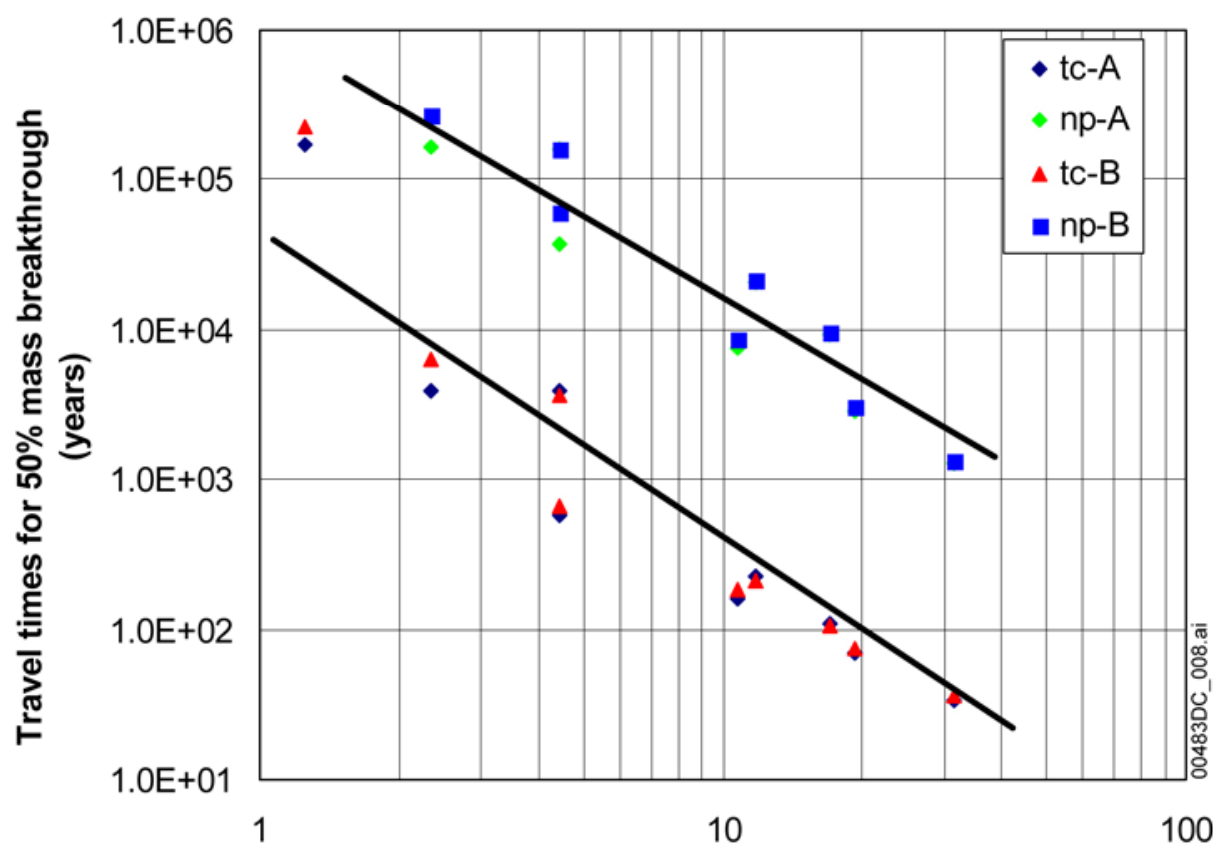

Average Infiltration Rate Over the model domain (mm/year)

Output DTN: LB03033DUZTRAN.001.

NOTE: Some pairs of points for "A" and "B" simulations are superimposed. See Tables 6.7-4 and 6.7-5.

Figure 6.7-4. Correlation of Average Infiltration Rates and Tracer Transport Times at 50 Percent Mass Breakthrough for the 36 Tracer-Fracture-Release Simulation Scenarios 
The tracer transport times, as shown in Figures 6.7-1, 6.7-2, and 6.7-3, and Tables 6.7-4 and 6.7-5, are relatively shorter than those estimated using the UZ model for TSPA-SR (BSC 2001 [DIRS 158726]) for the same infiltration rates. This is primarily because the LA repository design is close to or at several faults, such as the Drill Hole Wash fault (Figure 6.1-1), which provide fast flow pathways for tracer transport. Moreover, the current LA UZ model predicts higher fracture flow components at the repository level, e.g., fracture flow percentage is 94 percent for the case of preq mA (Table 6.6-3), compared with 84 percent of the previous SR case of pa_pchm1 (BSC 2001 [DIRS 158726], Table 6-22) for the same infiltration scenario.

The tracer-transport-simulation results can also be used to estimate potential locations or areas where radionuclides are most likely to break through along high-flux flow paths at the water table. Figures 6.7-5, 6.7-6, 6.7-7, and 6.7-8 show cumulative and normalized mass arrival contours at the water table at 1,000 and 1,000,000 years. The cumulative mass arrival is defined as cumulative mass arrived at each grid column of the water table over time, normalized by the total initial mass released at the repository. These figures present examples of breakthrough at the water table for conservative and reactive tracer transport with the present-day, mean infiltration rate.

Figures 6.7-5 and 6.7-6 compare percentage mass arrival contours of a conservative and reactive tracer, respectively, at the water table after 1,000 years, simulated using the present-day, mean infiltration of the base-case flow field (preq $\mathrm{mA}$ ). The two figures clearly indicate a significant difference from the two tracer modeling results in distributions of tracer mass arrivals along the water table. Without adsorption, in 1,000 years the conservative tracer (Tc) has a much larger area of breakthrough, covering the entire area directly below the repository footprint, spreading to the east in the north. At this time, about 40 percent of the total initial mass of conservative tracers has arrived at the water table (see Figure 6.7-3), whereas only about 2 percent of the reactive tracer $(\mathrm{Np})$ breaks through, and only along and near the major faults, owing to adsorption effects in the rock matrix.

At a later time of 1,000,000 years, Figures 6.7-7 and 6.7-8 show nearly identical mass arrival contours for the two tracers below the repository footprint. This is because $90-100$ percent of both tracers have arrived at the water table at this time, which are transported under the same flow field. The 1,000- and 1,000,000-year contours are used to illustrate the predominantly downward percolation flow patterns, early influence of faults (especially the in-block faults), and small long-term effects of slow diffusion. The flow patterns are for hypothetical nonsorbing and sorbing tracers without taking into consideration the radioactive decay, which reduce the concentrations. The 1,000- and 1,000,000-year flow pattern results can be further verified by comparing results at intermediate times between 1,000- and 1,000,000-years from radionuclide transport models using the UZ flow fields [transport models described in the report by BSC (2002 [DIRS 160819], Section 1.11)]. The information depicted in Figures 6.7-7 and 6.7-8 does not provide direct feeds to TSPA-LA; radionuclide transport is studied in detail in the downstream transport models. 


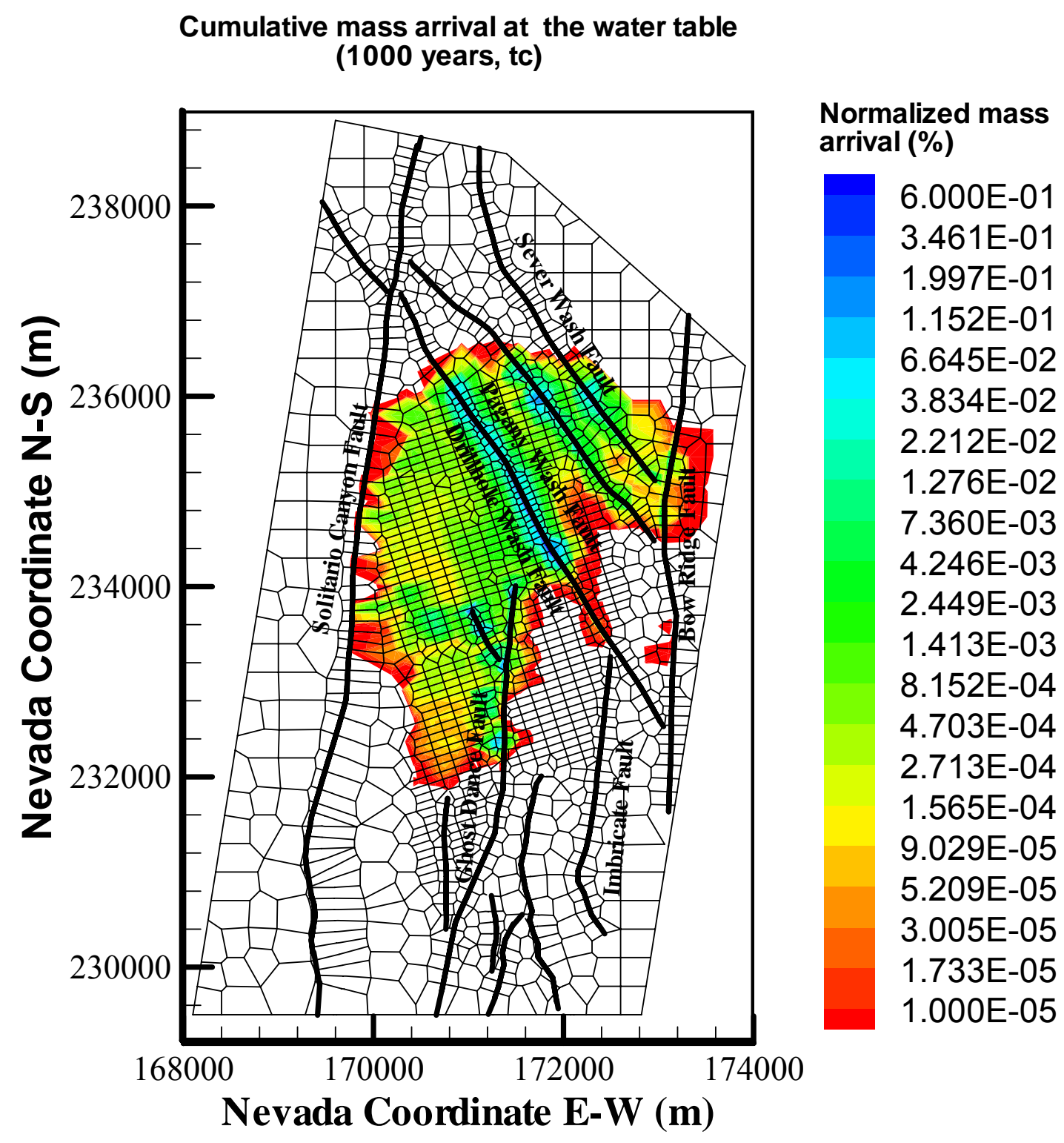

Output DTN: LB03033DUZTRAN.001.

Figure 6.7-5. Simulated Cumulative, Normalized Mass Arrival Contours of a Conservative Tracer at the Water Table after 1,000 Years, Indicating Potential Breakthrough Locations at the Time, Using the Present- Day, Mean Infiltration Scenario 


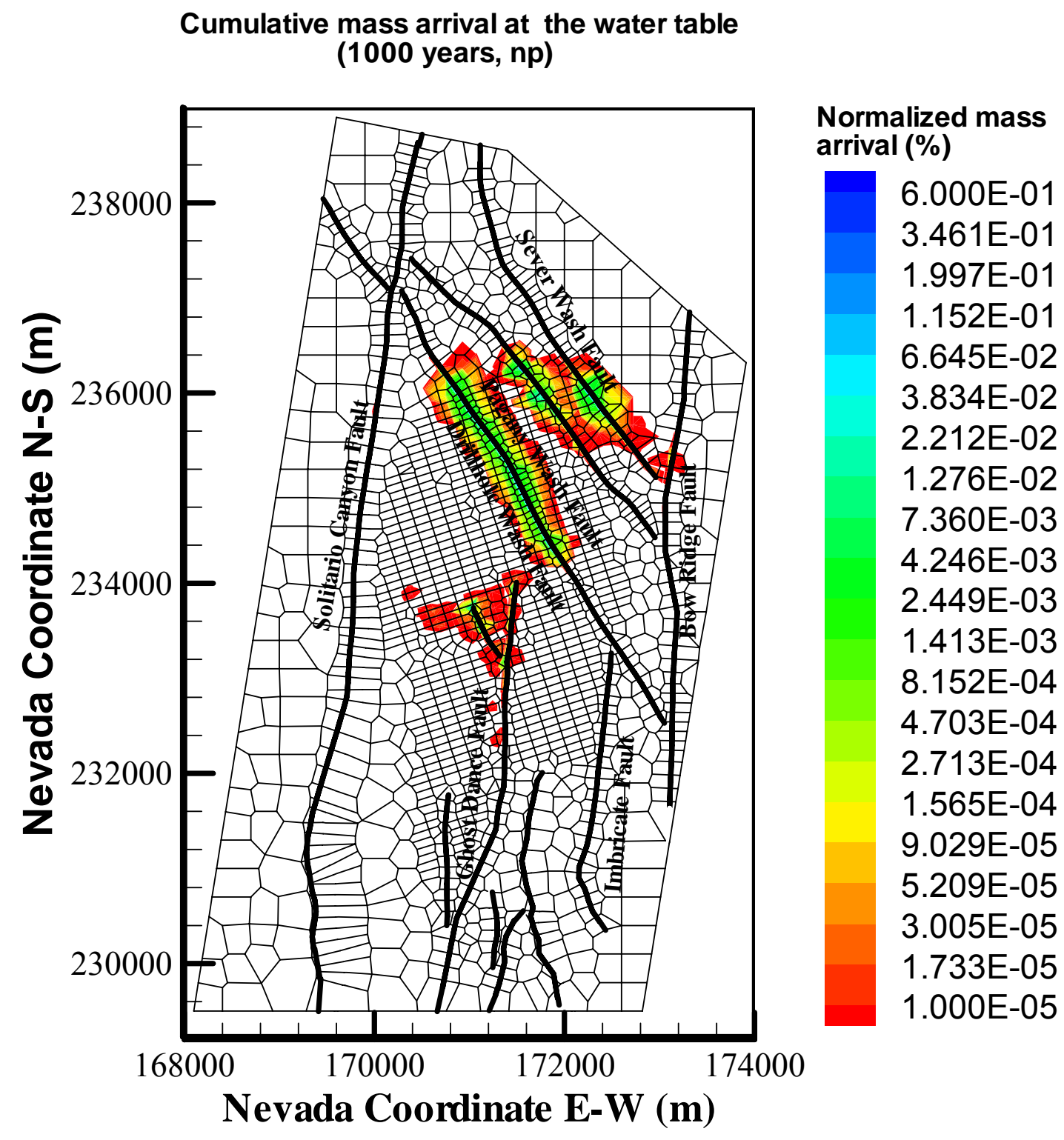

Output DTN: LB03033DUZTRAN.001.

Figure 6.7-6. Simulated Cumulative, Normalized Mass Arrival Contours of a Reactive Tracer at the Water Table after 1,000 Years, Indicating Potential Breakthrough Locations at the Time, Using the Present-Day, Mean Infiltration Scenario 


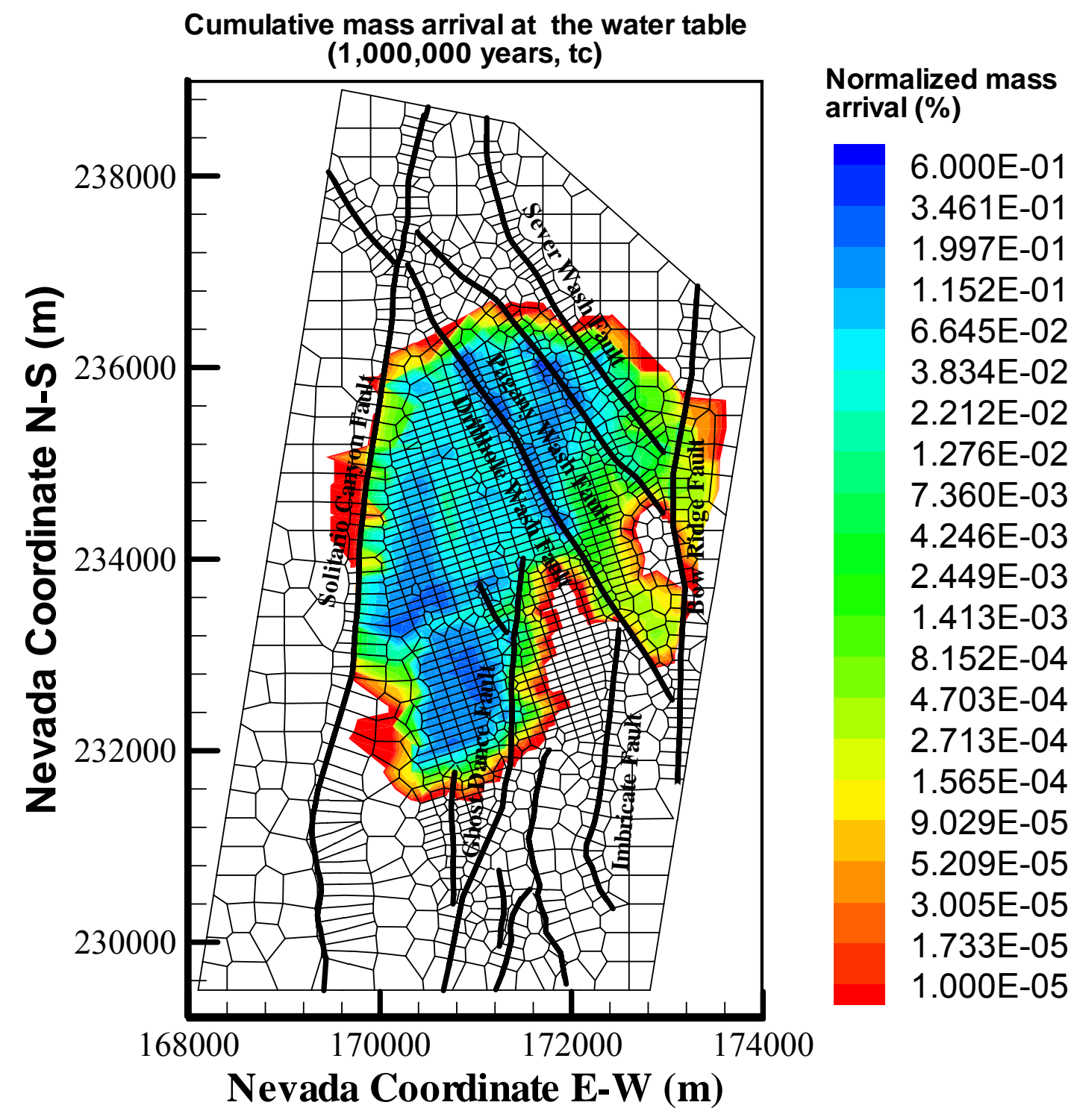

Output DTN: LB03033DUZTRAN.001.

Figure 6.7-7. Simulated Cumulative, Normalized Mass Arrival Contours of a Conservative Tracer at the Water Table after 1,000,000 Years, Indicating Potential Breakthrough Locations at the Time, Using the Present-Day, Mean Infiltration Scenario 


\section{Cumulative mass arrival at the water table $(1,000,000$ years, $n p)$}

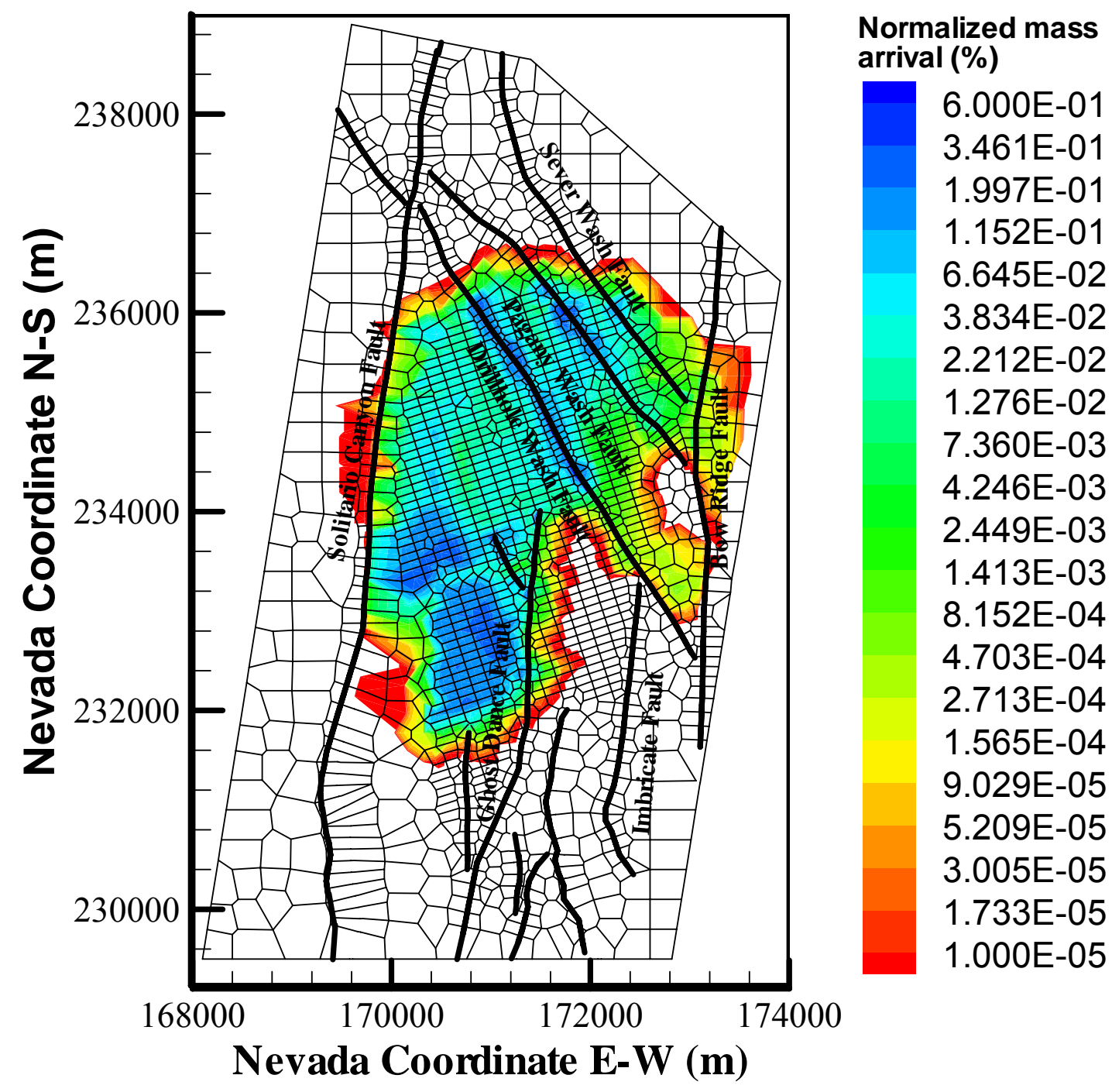

Output DTN: LB03033DUZTRAN.001.

Figure 6.7-8. Simulated Cumulative, Normalized Mass Arrival Contours of a Reactive Tracer at the Water Table after 1,000,000 Years, Indicating Potential Breakthrough Locations at the Time, Using the Present-Day, Mean Infiltration Scenario

\subsection{SENSITIVITY ANALYSES OF ACTIVE FRACTURE PARAMETER AND FRACTURE POROSITY}

In the AFM conceptualization (Liu et al. 1998 [DIRS 105729], pp. 2638 to 2641), only a portion of fracture networks are active (hydraulically conductive) under unsaturated conditions. Numerically, this active portion is defined as a function of water saturation $\mathrm{S}$ and the active fracture parameter $\gamma$ (Liu et al. 1998 [DIRS 105729], pp. 2638 to 2641). By definition, $\gamma$ ranges between 0 and 1 , with $\gamma=0$ or $S=1$ (corresponding to a saturated condition) signifying that all 
fractures are active, while $\gamma=1$ signifying the smallest active fracture portion for a given saturation.

Water flux in TSw layers of Yucca Mountain tuff is dominated mainly by fracture flow. Uncertainties in $\gamma$ impact the partition of water content and water flux between matrix and fractures of model gridblocks and, in turn, affect (possibly insignificantly) the entire flow field by determining the effective fracture permeability and the effective interface area between fracture and matrix (Liu et al. 1998 [DIRS 105729], pp. 2638 to 2641). Transport behavior may be sensitive to $\gamma$, because the determination of effective fracture-matrix interface areas by $\gamma$ will significantly impact the diffusive solute flux between fractures and matrix. This effect is in addition to the effects of changing the flow field.

As planned in the report by BSC (2002 [DIRS 160819], Section 1.10.4), the active fracture parameter, $\gamma$, was evaluated in Analysis of Hydrologic Properties Data (BSC 2004 [DIRS 170038]), using ${ }^{14} \mathrm{C}$ data. In Section 6.8 .1 of the present report, additional sensitivity studies are reported to analyze the sensitivities of simulated water saturation, water potential, and percolation flux with respect to $\gamma$.

In addition, the sensitivity of tracer transport with respect to $\gamma$ and fracture porosity are discussed in Section 6.8.2.1 and Section 6.8.2.2, respectively.

\subsubsection{Sensitivity Analyses of Flow Field with Respect to the Active Fracture Parameter $(\gamma)$}

In these analyses, we consider the $\gamma$ value of TSw units, except for tsw31, as a sensitivity analysis case and the units below the repository horizon (including the units at where the repository is located) as another sensitivity analysis case (Table 6.8-1). According to the evaluation of $\gamma$ using ${ }^{14} \mathrm{C}$ data, conducted in Analysis of Hydrologic Properties Data (BSC 2004 [DIRS 170038], pp. 78 to 82), the proper $\gamma$ value of tsw32-tsw38 ranges between 0.2-0.4. However, the calibrated values in DTN: LB0208UZDSCPMI.002 (DIRS 161243) for these units are 0.6 (tsw32-tsw33) and 0.569 (TSw34-TSw38), which are out of the proper range suggested in the report by BSC (2004 [DIRS 170038], Section 6.8). To test the impact of $\gamma$ uncertainties on flow field, we set up two three-dimensional flow simulations using $\gamma$ values different from the calibrated values (Table 6.8-1). The $\gamma$ values used in the sensitivity analyses simulations are half of the calibrated values of the respective units. For tsw32-tsw38, these values are within the suggested range. One simulation was performed using reduced $\gamma$ values of tsw32-tsw39 (Table 6.8-1, simulation ID: TSw). The simulation is focused on evaluating the impact of uncertainties in TSw units. Another simulation used the reduced $\gamma$ values of all units below the repository (Table 6.8-1, simulation ID: UnderRepo). The simulations take the input to the base case flow field simulation (Output-DTN: LB03023DSSCP9I.001, present-day mean infiltration, DTN: GS000308311221.005 [DIRS 147613]) and change the $\gamma$ values of the corresponding units (Table 6.8-1). 
Table 6.8-1. The $\gamma$ Values Used in Flow Simulations for Sensitivity Analyses

\begin{tabular}{|l|c|c|c|}
\hline \multirow{2}{*}{ Rock Units } & \multicolumn{2}{c|}{$\gamma$ Values } & UnderRepo \\
\cline { 2 - 4 } & Base Case & TSw & 0.129 \\
\hline tsw31 & 0.129 & 0.129 & 0.600 \\
\hline tsw32, tsw33 & 0.600 & 0.300 & 0.284 \\
\hline tsw34-tsw38 & 0.569 & 0.284 & 0.185 \\
\hline tsw39z & 0.370 & 0.185 & 0.125 \\
\hline tsw39v & 0.250 & 0.125 & 0.185 \\
\hline ch1z-ch6z, pp4z, pp1z, bf2z, and tr2z & 0.370 & 0.370 & 0.125 \\
\hline ch1v-ch6v & 0.250 & 0.250 & 0.100 \\
\hline pp3d, pp2d, bf3d, and tr3d & 0.199 & 0.199 & \\
\hline
\end{tabular}

Output DTN: LB0303RDTRNSNS.001.

NOTE: Base-case values are from DTN: LB0208UZDSCPMI.002 [DIRS 161243] and the same with those used in the flow field simulations.

TSw=Topopah Spring welded hydrogeologic unit

The results of these sensitivity analyses (Figure 6.8-1 and Figure 6.8-2) show that changing $\gamma$ results in only small changes in matrix liquid saturations and water potentials. The details are discussed below.

\subsubsection{Liquid Saturation and Potential}

Figure 6.8-1 shows that implementing a $\gamma$ of one half the calibrated value (used for base case present-day, mean infiltration flow field simulation, Table 6.8-1) in TSw layers leads to some small changes in the simulated matrix water saturation and water potential. The matrix liquid saturation and water potential changes in response to the changes of $\gamma$ in all units below the repository are also small (Figure 6.8-2). Thus, the saturation and water potential are not sensitive to the uncertainties in $\gamma$. In addition, the sensitivity analysis results also indicate that the change of $\gamma$ values has an insignificant effect on fracture liquid saturation and water potential. In fact, a comparison at SD-6 using the two $\gamma$ values indicates that average absolute changes in fracture saturation and capillarity pressure are only 0.004 and $230 \mathrm{~Pa}$, respectively. 


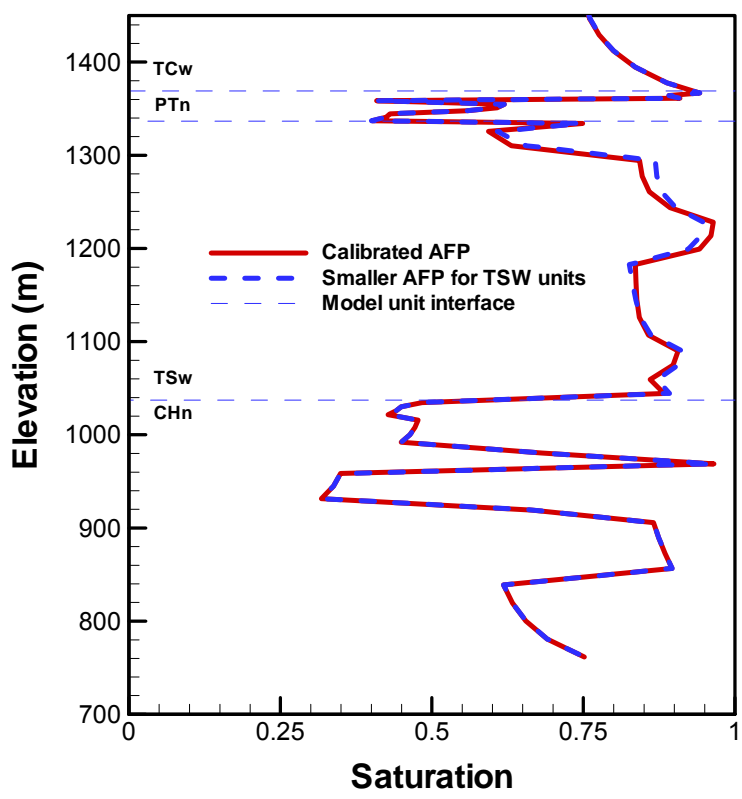

(a)

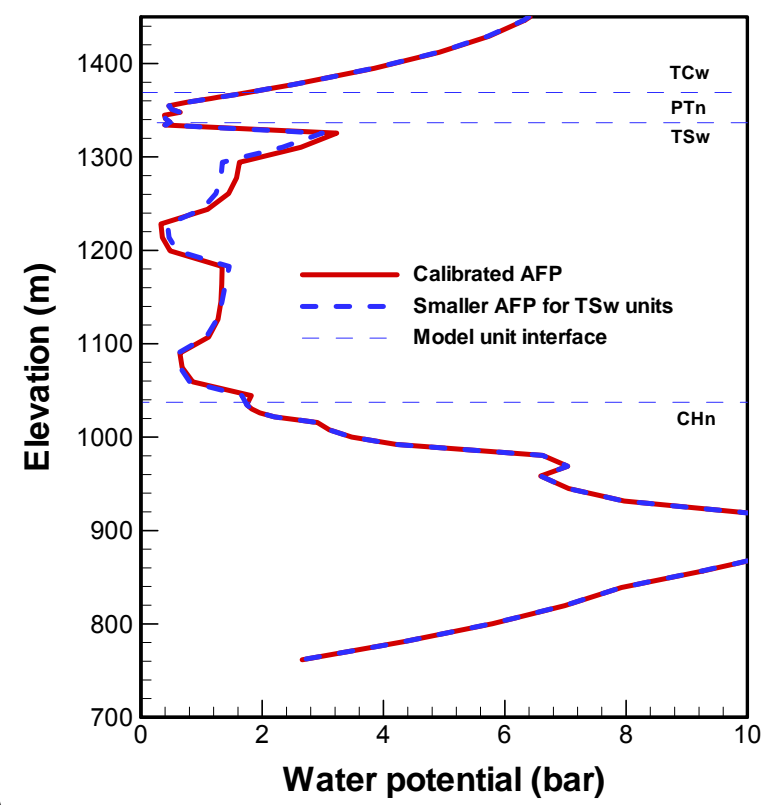

Output DTN: LB0304RDTRNSNS.001.

Figure 6.8-1. Comparison of (a) Simulated Matrix Liquid Saturation and (b) Water Potential Using Calibrated Hydraulic Properties (Solid Line) with That Obtained Using Smaller (Half) $\gamma$ of TSw Units (Dashed Line) for Borehole USW SD-6

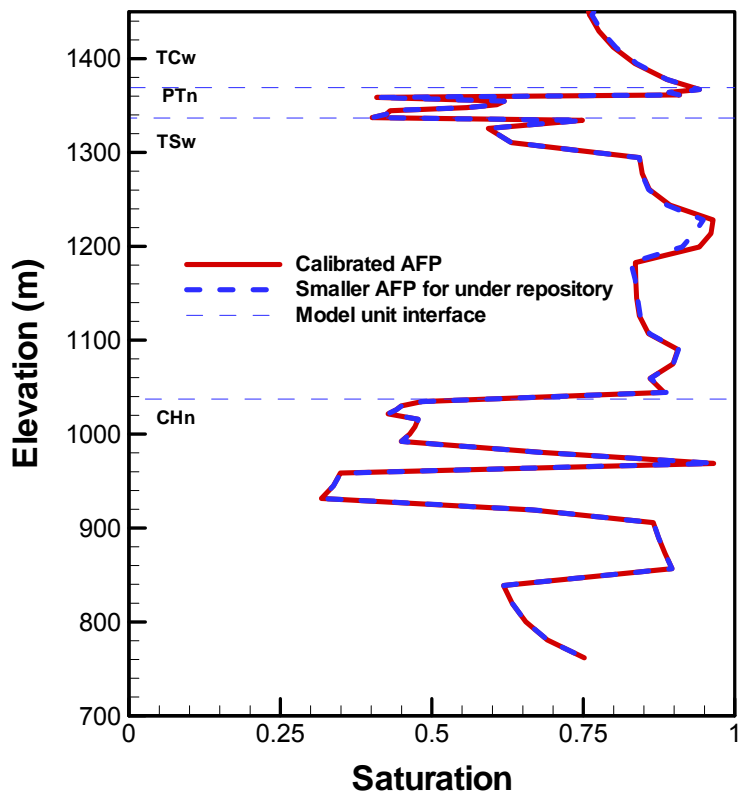

(a)

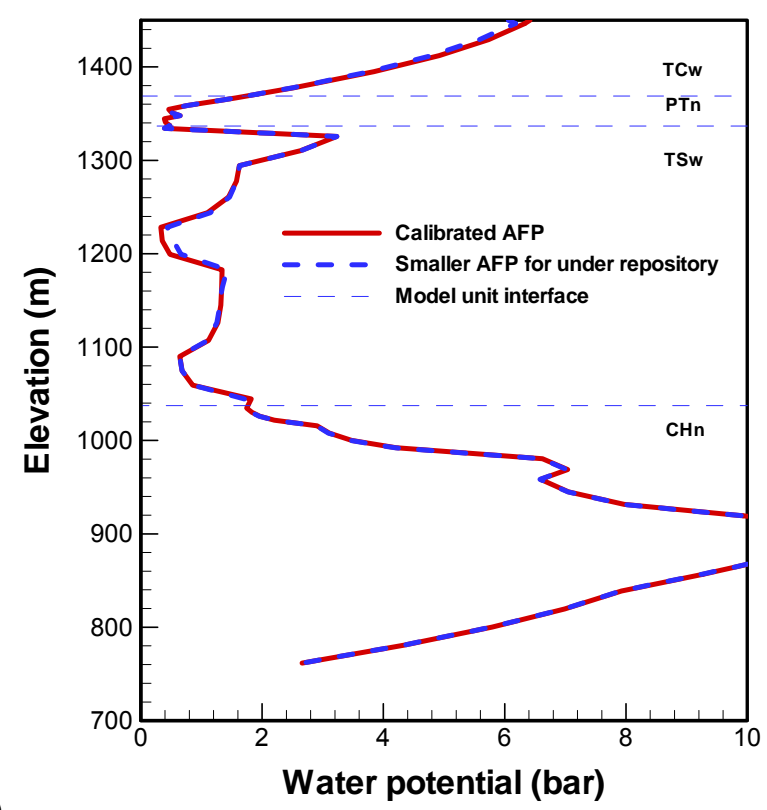

Output DTN LB0304RDTRNSNS.001.

Figure 6.8-2. Comparison of (a) Simulated Matrix Liquid Saturation and (b) Water Potentials Using Calibrated Hydraulic Properties (Solid Line) with that Obtained Using Smaller (Half) $\gamma$ of Under Repository Units (Dashed Line) for Borehole USW SD-6 


\subsubsection{Percolation Flux through Repository Layers}

As listed in Table 6.8-2, the average fracture flux change within the repository area, caused by the $\gamma$ changes in TSw layers, is -0.285 percent. The fracture fluxes, within the repository area, change -0.497 percent, on average, in response to the $\gamma$ changes in units below the repository. Average values for the entire repository layer and the water table are also listed in Table 6.8-2 (for calculation details, see Appendix C, Section C.3).

Table 6.8-2. Relative Changes of Fracture Flux in Response to the Changes in $\gamma$

\begin{tabular}{|l|c|c|c|}
\hline \multicolumn{1}{|c|}{ Simulation ID } & $\begin{array}{c}\text { Within the Repository } \\
\text { Area }\end{array}$ & Entire Repository Layer & Water Table \\
\hline TSw & $-2.85 \mathrm{E}-3$ & $1.51 \mathrm{E}-2$ & $2.48 \mathrm{E}-2$ \\
\hline UnderRepo & $-4.97 \mathrm{E}-3$ & $-2.32 \mathrm{E}-2$ & $-2.32 \mathrm{E}-2$ \\
\hline
\end{tabular}

Output DTN: LB0304RDTRNSNS.001.

NOTE: Calculation is shown in Appendix C, Section C.3.

$\mathrm{ID}=$ =identification number; TSw=Topopah Spring welded hydrogeologic unit

Therefore, considering the rather small changes in modeled saturation, water potential, and the very small change in percolation flux (on average), one can conclude that the water flow field is not significantly sensitive to $\gamma$. This may indicate that the $\gamma$ values, estimated based on flow calibrations, are not well constrained.

\subsubsection{Sensitivity Analyses of Transport}

\subsubsection{Transport Sensitivity to $\gamma$}

Solute transport through tuff is mainly carried out by advection and diffusion. Because of the small flux rate, hydraulic dispersion plays a very minor role and, therefore, is ignored in simulations. Advection is determined by water flux and thus not sensitive to $\gamma$. However, because the fracture Darcy velocity is two to three orders of magnitude larger than matrix Darcy velocity, the advective solute flux in fractures is much faster than in the matrix. This leads to a short-term concentration difference between fractures and matrix, causing significant diffusion between them. At steady-state, when the concentrations in fractures and matrix must reach equilibrium, the diffusion between fractures and the matrix will vanish. Therefore, the steady-state concentration is insensitive to $\gamma$. The short-term transport behavior may be sensitive to the changes in $\gamma$, but the long-term transport behavior will be relatively insensitive to the changes of this parameter.

Diffusion is driven by the concentration gradient and the effective diffusion coefficient of rocks. Numerically, the diffusion between fractures and matrix is calculated upon the concentration differences between matrix and fractures, the active (effective) interface area between fractures and matrix, and the fracture spacing. The active interface area between matrix and fractures is related to $\gamma$. A larger $\gamma$ defines a smaller effective interface area. Therefore, the diffusion between the matrix and fractures must be sensitive to this parameter, and the entire transport rate is affected. 
In the Yucca Mountain UZ, transport is dominated by the fracture advective flux (BSC 2004 [DIRS 164500], Section 6.1.2.4). The diffusion from fractures into matrix functions as a buffer for the advection through fractures, similar to kinetic sorption, which impedes the transport through fractures (BSC 2004 [DIRS 164500], Section 6.1.2.4).

To test the sensitivity of tracer transport to the active fracture parameter, $\gamma$, three conservative-tracer transport simulations were performed. The first simulation is the base case (or reference case), using the calibrated $\gamma$ and the base-case flow field; and the other two are for sensitivity analysis. Of these three scenarios, the second one uses a smaller $\gamma(1 / 2$ of the calibrated value) for TSw units except for tsw1, the same as the first flow-sensitivity-analysis simulation in Section 6.8.1 (simulation ID: TSw in Table 6.8-1). Note that no change is made for the $\gamma$ values of faults for this scenario. The third caser uses a smaller $\gamma(1 / 2$ of the calibrated value) for repository units, all units below the repository as well as faults, similar to the second flow-sensitivity-analysis simulation (Simulation ID: UnderRepo in Table 6.8-1, see Section 6.8.1). Simulations were performed using T2R3D V1.4 (LBNL 1999 [DIRS 146654]). The base-case flow field (using calibrated rock properties) comes from flow simulation (Output-DTN: LB03023DSSCP9I.001, see Section 6.2.5). The flow fields for two reference simulations were taken from flow sensitivity analyses (Section 6.8.1).

The transport models simulate the tracer transport processes from the repository to the groundwater table. The tracer is represented by technetium, with diffusion coefficients of $3.20 \times 10^{-11} \mathrm{~m}^{2} / \mathrm{s}(\mathrm{DTN}:$ LA0003JC831362.001 [DIRS 149557]). The cumulative relative mass of the tracer arriving at the groundwater table (breakthrough curves), obtained from simulations using different $\gamma$ values, are presented in Figure 6.8-3. The figure shows that tracer transport is relatively sensitive to $\gamma$. The base case is conservative; the differences among the cases are small after 7,000 years and become negligible after 20,000 years. With the base-case parameter, the tracer arrives at the water table faster than the two reference cases. In the base case, 20 percent of the total input mass arrives at the water table at (approximately) 150 years (Figure 6.8-3), and 50 percent of the total mass arrives at the water table at (approximately) 3,400 years (Figure 6.8-3). The two sensitivity analyses cases give similar results: 20 percent mass arrival at 1,900 years and 50 percent at (approximately) 7,100 years, (Figure 6.8-3). However, the times for 100 percent mass arrival at the groundwater table in all three cases are similar. This indicates that long-term transport behavior is not very sensitive to the change in $\gamma$. In addition, the small difference between the two scenarios of $\gamma$ changes in Figure 6.8-3 implies that $\gamma$ values in the $\mathrm{CHn}$ or in faults have insignificant impact on tracer transport from the repository to the water table.

The base-case model with the larger $\gamma$ values defines a smaller active interface area between fracture and matrix. Consequently, the buffer effect of matrix diffusion is smaller. This causes faster breakthrough of the tracer. In the two sensitivity cases, a smaller $\gamma$ defines a larger active interface area and, hence, larger buffer effects from matrix diffusion. Therefore, the overall transport is slower. In summary, this study indicates that larger $\gamma$ values give more conservative or faster tracer transport times from the repository to the water table. 


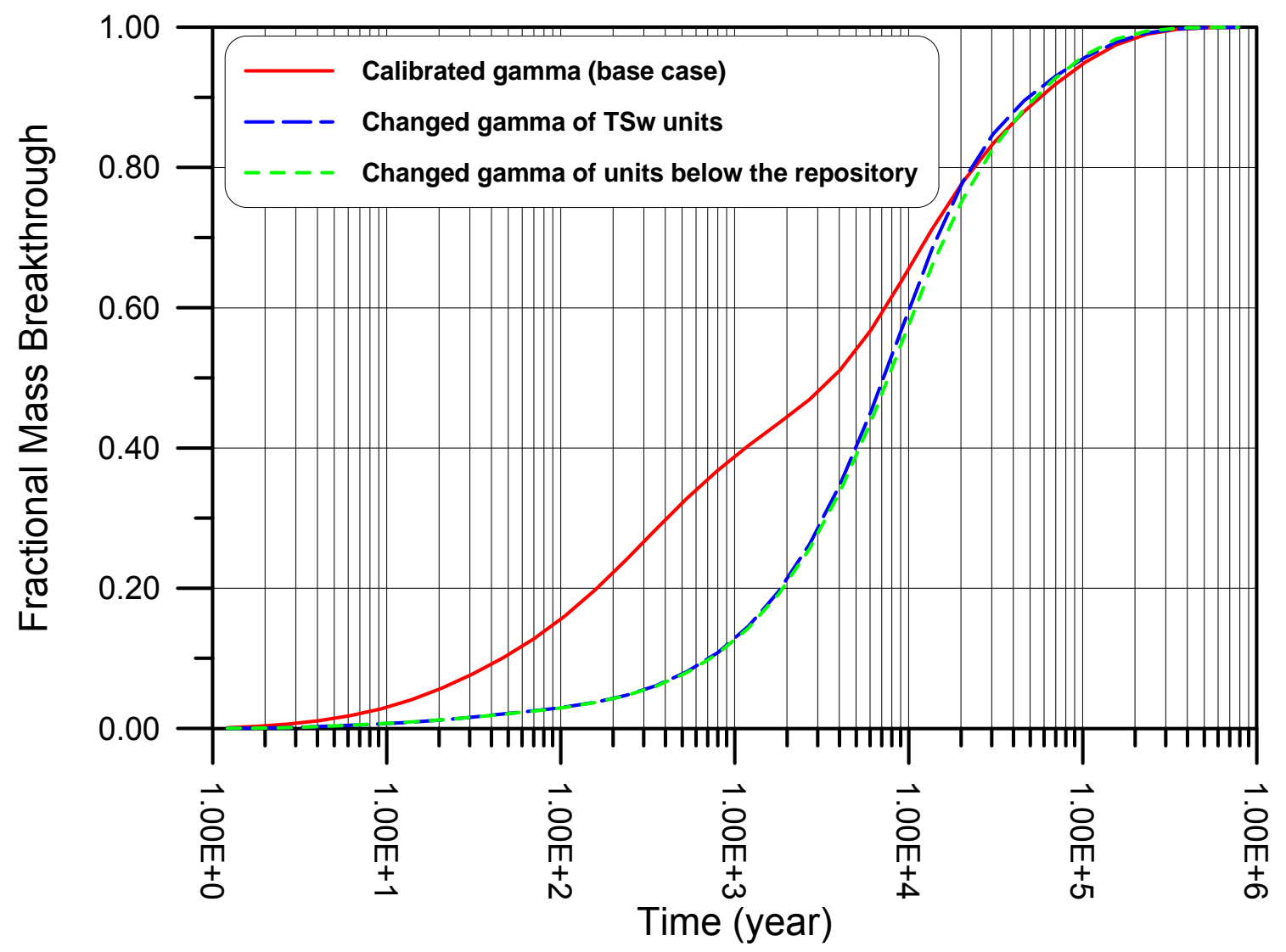

Output DTN: LB0304RDTRNSNS.001.

NOTE: The simulation is carried out under the present-day, mean infiltration rate with the tracer released instantaneously from repository fracture elements at the start time of simulation.

Figure 6.8-3. Comparison of a Simulated Breakthrough Curve of Relative Tracer Mass at the Groundwater Table Obtained for the Base Case (Using Calibrated Rock Hydraulic Properties, Red Solid Line), a Case Using the Smaller y of TSw Units (Blue Dash Line), and Another Case Using the Smaller y of All Units below the Repository (Green Dash Line)

\subsubsection{Transport Sensitivity to Fracture Porosity}

To test the sensitivity of tracer transport with respect to the uncertainties in fracture porosity, a transport simulation, using the same input data as the base-case simulation in Section 6.8.2.1 (except for fracture porosity), was performed. This simulation uses smaller fracture porosity ( $1 / 10$ of the calibrated values) for all units. However, the steady-state flow field is independent of fracture porosity, and only the changes in repository units and units below the repository may impact the early transport time of the tracer arriving at the groundwater table. Simulation results are plotted in Figure 6.8-4 and compared to the base-case results in the figure. The figure shows that the fractional mass breakthrough of the tracer arrived at the water table is larger only during the first 50 years if the fracture porosity is one order of magnitude smaller than the calibrated value. However, the accumulated breakthrough mass arrival is quite small during this period in both cases (less than 15 percent of the released mass). After 100 years, both simulation cases give similar results: almost 50 percent of the tracer mass arrives at the groundwater bottom at 3,400 years, and the two breakthrough curves are not differentiable (Figure 6.8-4). 


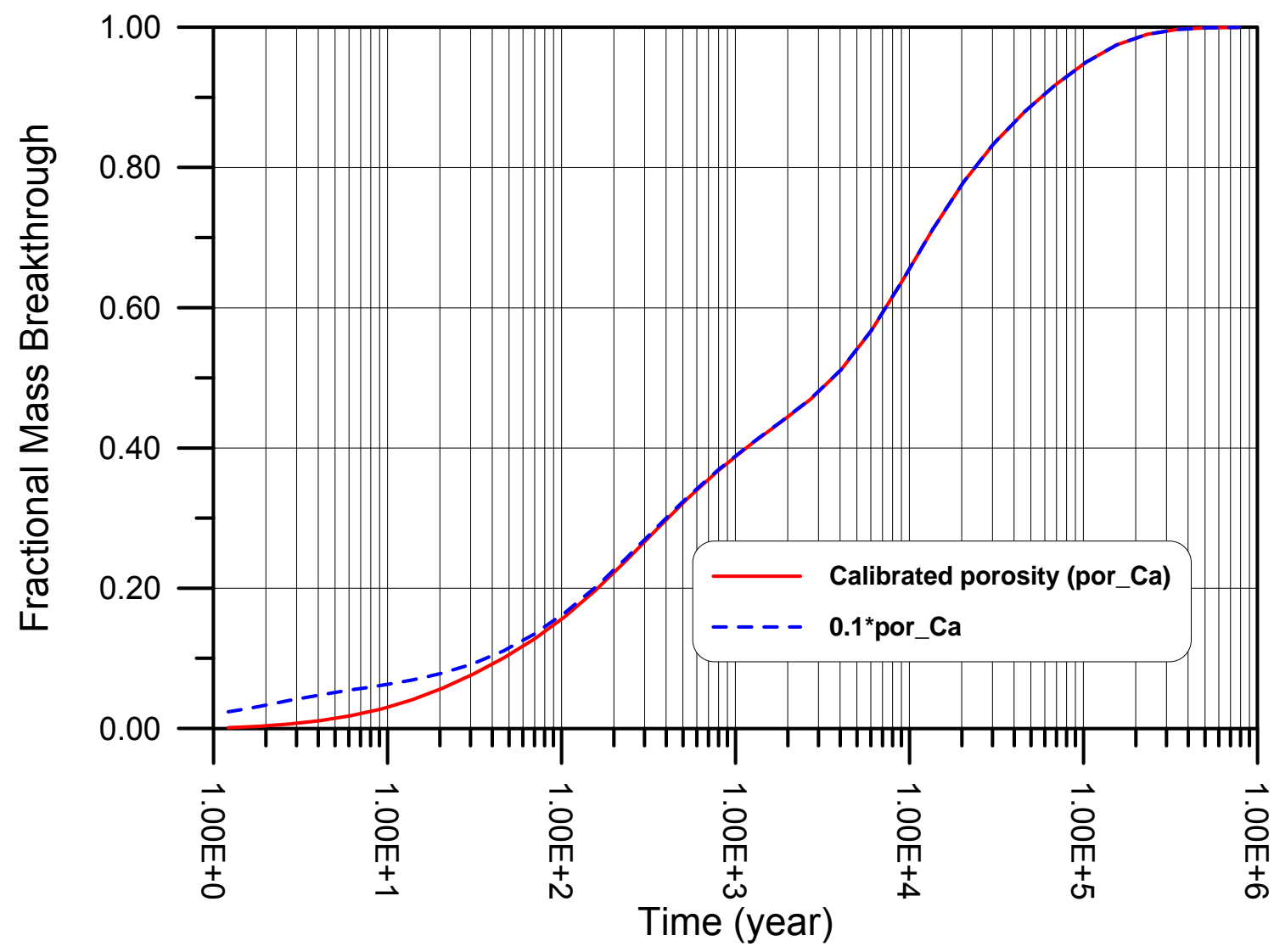

Output DTN: LB0304RDTRNSNS.001.

NOTE: The simulation is carried out under the present-day, mean infiltration rate with the tracer released instantaneously from repository fracture elements at the start time of simulation.

Figure 6.8-4. Comparison of Simulated Breakthrough Curve of Relative Tracer Mass at the Groundwater Table Obtained for the Base Case (Using Calibrated Rock Hydraulic Properties, Red Solid Line), and a Case Using a Smaller (1/10) Fracture Porosity (Blue Dash Line)

This result indicates that radionuclide transport is sensitive to fracture porosity only at the early times (less than 50 years), and in long-term evolution, transport behavior is not sensitive to this parameter. Overall, this sensitivity analysis shows that fracture porosity has an insignificant effect on tracer transport.

\subsection{UNCERTAINTIES AND ALTERNATIVE MODELS}

The calibrated model parameters of Section 6.2, as well as the 18 three-dimensional flow fields of Section 6.6, currently represent the best estimates with the UZ flow model. The validation efforts of Section 7 will further show the validity of the UZ flow model in describing the UZ hydrological, geochemical, and geothermal conditions and processes. It should be recognized, however, that some uncertainties are associated with these model parameters and output results, although they are based on qualified field-observation data, updated hydrogeological conceptual understanding, and integrated modeling studies, as documented in the model report. The sources of uncertainties arise from (1) uncertainty in observed parameters and field data; (2) uncertainty 
in estimated present-day and future climates; (3) approximations used in hydrogeological conceptual models, such as steady-state flow conditions; (4) scale-dependent heterogeneity and model input parameters in the UZ fracture-matrix system; (5) the complexity of different UZ coupled processes; and (6) the limitations of current modeling and large volume-average approaches.

Numerical model representation of a real-world hydrogeologic system involves discretization of a model volume into a large number of elements, with each element assigned the necessary attributes or properties. For the UZ models developed and used in this report, the necessary properties are known at only a relatively few locations within the model domain. Limitations of the software used to develop the UZ models at Yucca Mountain may also create a potential source of uncertainty, which is addressed in the Software Qualification per LP-SI.11Q-BSC, Software Management. These parameter, data, and model related uncertainties are discussed in this section as follows.

\subsubsection{Data Uncertainties}

To address the issue of uncertainties associated with input parameters and data, significant efforts have been made to quantify and reduce uncertainties associated with model parameters and output results in this report. A total of six sets of model input parameters are developed, with three base cases and three alternatives, which cover the effect of uncertainties in lower, mean, and upper bound infiltration rates. Uncertainties with present-day and two future climates are investigated using three bounds of infiltration (i.e., lower-bound, mean, and upper-bounds for each climate scenario). In addition, sensitivity and uncertainty with the AFM parameter, $\gamma$, is evaluated for its impact on flow and transport modeling results. The sensitivity analysis shows that the $\gamma$ value has little effect on simulated steady-state UZ percolation fluxes, but a large impact on tracer transport. Nevertheless, the $\gamma$ values used in the UZ model produce more conservative transport results.

Implementation of six model input property sets (Appendix A) for three-dimensional mountain-scale UZ flow models, combining with the nine different infiltration maps of three climates, results in 18 three-dimensional flow fields. The effects of parameter and data uncertainties on UZ flow should be sufficiently covered in the model results.

Additional sources of parameter uncertainties exist when using the hydrologic property sets, obtained by model calibration with the present-day climate for modeling studies under future climate conditions with higher infiltration rates. Uncertainties with both present-day and future climates are investigated using three climates, present day, monsoon, and glacial-transition, which combine for nine different net infiltration scenarios. In addition, a newly estimated present-day, mean infiltration scenario is studied (Appendix I), and the sensitivity analysis gives similar model predictions of UZ flow, as compared with the current present-day mean infiltration model results, in terms of moisture distribution and flux statistics. To assess the uncertainties in parameter estimates caused by applying infiltration rates and to justify the use of the parameters, calibrated using present-day infiltration rates, for simulation in future climates, a comprehensive analysis is made in Appendix F. In particular, Appendix F uses field tests with higher infiltration rates to show the appropriateness of the calibrated hydrologic properties for modeling current and future UZ flow at Yucca Mountain. 


\subsubsection{Model Uncertainties}

Model uncertainties with the UZ flow model consist mainly of hydrogeological conceptual models used, including steady-state flow approximation, layer-wise homogeneous geological layering, the role played by the PTn unit, perched water occurrence, fast-flow pathways, and effects of major faults. These uncertainties have been discussed, investigated, or quantified in this report using field observation data, modeling analyses, and other arguments. In particular, uncertainties with UZ conceptual flow models of the PTn unit are studied using two conceptual models (i.e., base-case and alternative models, and the perched water occurrence is investigated using a permeability-barrier model).

The base-case conceptual model for the PTn is selected because of its better predictions of chloride data as well as moisture data. Each of the PTn conceptual models uses three different parameter sets for lower, mean, and upper bound infiltration rates to cover the uncertainties and possible ranges with model parameters and infiltration rates. This results in nine base-case and nine alternative three-dimensional UZ flow fields. In general, the nine base-case flow fields show more lateral flow occurring within the PTn than those predicted by the alternative model. Furthermore, analyses have been done for the impact of behavior on tracer or radionuclide transport for the nine base-case and nine alternative flow fields. The results of 40 three-dimensional tracer-transport simulations show a wide range of tracer transport times from the repository to the water table, and the base-case model gives slightly more conservative estimates in general.

Uncertainty may exist in the analysis of lateral flow in the PTn unit because of the choice of study approaches. Different approaches may yield different conclusions. Flint et al. (2003 [DIRS 163967]) concluded that lateral flow may occur in the PTn on a smaller scale than indicated in Figures 6.6-1 to 6.6-3. However, their conclusion is based on a different approach from the one used in this report. First, Flint et al. (2003 [DIRS 163967]) use an analytical solution which is applicable to single-porosity porous-medium flow with two semi-infinite layers, and may not be suitable for the multilayered three-dimensional fracture-matrix system, to estimate lateral flow. Second, the analytical solution uses a Gardner's equation for relative permeability, which is different from what is used in this report. Third, Flint et al. (2003 [DIRS 163967]) present a two-dimensional modeling study without including three-dimensional effects, and also acknowledge that no one approach, analysis, or data set provided can establish whether large-scale lateral flow occurs above the repository.

Among the approximations or conceptualizations used in the UZ flow model, the steady-state or quasi-steady-state assumption is a key issue. This assumption relies on the effect of spatial and temporal damping of transient infiltration pulses when flowing through the PTn unit. Effectiveness of the PTn unit to damp episodic flow is further addressed in Appendix G. Appendix $G$ presents a detailed justification of lateral flow and spatial smoothing and temporal damping effects by the PTn unit. Using model results and corroboration with field data, Appendix $G$ demonstrates that the PTn unit is very effective in both laterally diverting percolation flux and in temporally damping episodic infiltration pulses. It shows that the steady-state flow below the PTn is a good approximation. 
The issue with chlorine-36 $\left({ }^{36} \mathrm{Cl}\right)$ is addressed in Appendix $\mathrm{H}$. In this appendix, the previous ${ }^{36} \mathrm{Cl}$ studies for the Yucca Mountain site are further reviewed and analyzed. It is concluded that only a small percentage of ${ }^{36} \mathrm{Cl}$ mass breaks through in 50 years along the repository layers. This appendix has demonstrated that the UZ flow model results are consistent with observed ${ }^{36} \mathrm{Cl}$ data.

Additional uncertainty associated with models includes different matrix porosity values and extra storage space contributed by lithophysal cavities in the hydrogeological layers of upper lithophysal (tsw33) and lower lithophysal (tsw35) units. This uncertainty with matrix porosity or lithophysal cavities should have little impact on simulation results of steady-state UZ flow. In addition, the effect of these cavities on tracer transport from the repository to the water table is expected to be small. This is because (1) the geological layers with cavities are located either higher than or at the repository horizon, and (2) cavities will remain dry and little water is expected to flow through cavities due to strong capillary barrier effects on seepages into cavities. 


\section{INTENTIONALLY LEFT BLANK}




\section{VALIDATION}

Validation activities for the UZ flow model and submodels were planned as level I validation in Technical Work Plan for: Unsaturated Zone Flow Analysis and Model Report Integration (BSC 2004 [DIRS 169654], Section 2.2.1.1). Those plans repeat the plans that were originally documented in Technical Work Plan for: Performance Assessment Unsaturated Zone (BSC 2002 [DIRS 160819], Attachment Section I-1-2), and modified in the report by BSC (2004 [DIRS 168027], Sections 7.4, 7.5, and 7.7). According to AP-2.27Q (Revision 1, ICN5, Table 1) and the technical work plan, the requirement level of validation for the UZ flow model is level I, which is considered to be appropraite for the intended use of the model. The model validation efforts include confidence building during model development and corroboration with experimental data. The additional validation activities of this section are corroboration with information published in referred journals and literature, analysis of model uncertaities, and corroboration with natural analogues. The models will be accepted as valid for their purposes through confidence building during model development of Setion 7.1 as well as through post-developemt validation efforts of corroboration with experimental data in Sections 7.2 to 7.10, if the following criteria are met:

- The water-potential data measured from ECRB are used for validation by comparing with simulation results of the UZ flow model. The criterion for the validation is that simulated water-potential values are within the range of measurements along the ECRB tunnel (BSC 2002 [DIRS 160819], Attachment Section I-1-2-1). Demonstration that this criterion was met is shown in Section 7.2.

- WT-24 perched-water elevation data is used to validate the UZ flow model. The criterion for the validation is that simulated perched elevation matches the observed value within $10 \mathrm{~m}$ (BSC 2002 [DIRS 160819], Attachment Section I-1-2-1). Demonstration that this criterion was met is shown in Section 7.3.

- The gas-flow model was calibrated against the first 30 days of pneumatic data for borehole SD-12 (Section 6.4). Pneumatic data measured in SD-12 (for the second 30 days) and UZ-7a (for all 60 days) are used for validation of the UZ flow model. The criterion for the validation is that simulated gas pressures and their patterns of variations consistently compare closely with the observed values. That is, the simulations will consistently reproduce increases and decreases resulting from changes in barometric pressure at the ground surface (BSC 2002 [DIRS 160819], Attachment Section I-1-2-1). Demonstration that this criterion was met is shown in Section 7.4.

- ${ }^{14} \mathrm{C}$ data from gas samples provide approximate $\mathrm{C}-14$ residence times for pore water. The residence times can be interpreted as tracer transport time from the ground surface to where the gas samples were collected, based on the current conceptual model for UZ flow and transport. These data are used to validate the UZ flow model. The criterion for the validation is that simulated tracer transport times (i.e., peak of the breakthrough curve at the sample-collection locations for a pulse input at the ground surface or the time for first moment of concentration) are within the range of times estimated from data in the TSw unit (BSC 2002 [DIRS 160819], Attachment Section I-1-2-1). Demonstration that this criterion was met is shown in Section 7.5. 
- Data from Alcove 8/Niche 3 flow and seepage test results are used to validate the UZ flow model. The tests involve a fault test and a large-infiltration-plot test. The fault test includes water infiltration and liquid tracer experiments. Test data from the latter test are not available in time for this report and therefore are not used here for model validation. Flow and seepage test results are used for model validation. The criterion for validation is that the predicted results for the time to reach a given concentration of a conservative tracer are within a factor of 5 of the observed times, or that explanations can be found for why the observed and simulated results deviate significantly (BSC 2002 [DIRS 160819], Attachment Section I-1-2-1). Demonstration that this criterion was met is shown in Section 7.6.

- Boreholes H-5, H-4, and WT-18 observed temperature data are used to validate the ambient thermal model of the UZ model, since no temperature measurements of ECRB specified in the TWP are available in the TDMS. The validation criterion is the same as that in TWP, i.e., to match the observed values with less than $3^{\circ} \mathrm{C}$ difference (BSC 2002 [DIRS 160819], Attachment Section I-1-2-2). Demonstration that this criterion was met is shown in Section 7.7.

- For the chloride model, simulated pore-water chloride concentrations in the ESF are compared with analysis of samples for validation of the UZ flow model. The criterion for validation is that the range of the simulated chloride concentration falls within the range of measured concentrations (BSC 2002 [DIRS 160819], Attachment Section I-1-2-3). Demonstration that this criterion was met is shown in Section 7.8.

- The calcite model is used to validate the UZ flow model with the abundance data of calcite mineral. The calcite model is validated by comparing one-dimensional simulation results with measurements. The criterion is that the simulated volume fraction of calcite coating for each UZ model layer falls within the range of measurements for that layer (BSC 2002 [DIRS 160819], Attachment Section I-1-2-4). Demonstration that this criterion was met is shown in Section 7.9.

- Borehole and ECRB strontium (Sr) concentrations are used to check the UZ flow model results using the $\mathrm{Sr}$ modeling analysis. The criterion for validation is qualitative agreement between the simulated strontium concentrations and the average of the observations at the same elevation, and agreement with the vertical trends (BSC 2002 [DIRS 160819], Attachment Section I-1-2-5). Demonstration that this criterion was met is shown in Section 7.10.

For the validation activities of this section, none of the corroborative data sets selected for use in model validation were used in model calibration and development of Section 6. In addition, there were no other similar data sets available for model validation efforts.

Corroboration with Information Published in Referred Journals and Literature. Journal publications are used to provide corroboration for our model validation. A three-dimensional UZ numerical model was developed to simulate flow and distribution of moisture, gas, and heat at Yucca Mountain (Wu et al. 1999 [DIRS 117161]). Flow and transport processes within the UZ were characterized under current and future climates (Wu et al. 2002 [DIRS 160195]). Studies 
of capillary barriers in the unsaturated rock of Yucca Mountain have also been published (Wu et al. 2002 [DIRS 161058]). The perched-water phenomena in the UZ at Yucca Mountain have been investigated (Wu et al. 1999 [DIRS 117167]). Subsurface pressure variations have been used to determine the pneumatic diffusivity of important geological features (Ahlers et al. 1999 [DIRS 109715]). Subsurface borehole temperature data were used to estimate percolation flux (Bodvarsson et al. 2003 [DIRS 162477]). Chloride measurements were used to calculate infiltration rates along the ESF (Fabryka-Martin et al. 1998 [DIRS 146355]). Chloride data, in conjunction with hydrostructural and hydrogeological features, were also used to constrain infiltration rates (Liu et al. 2003 [DIRS 162478]). In addition, chloride and strontium geochemistry were investigated using three-dimensional modeling for insights into the hydrology of the UZ (Sonnenthal and Bodvarsson 1999 [DIRS 117127]).

Analysis of Model Uncertainty. As discussed in Section 6.9, there are a number of uncertainties associated with the UZ flow model, including data, model and climate uncertainties. The existence of these uncertainties is because of uncertainties existing in measurement of parameters and field data, in estimates of present-day and future climates, in hydrogeological conceptual models and modeling approaches, and scale-dependent heterogeneity and model input parameters. These data and model related uncertainties have been discussed, investigated or evaluated in this report using field observation data, modeling sensitivity analyses, model calibration, natural analog information, and other arguments in Sections 6.2 through 6.8 and this section. These uncertainties are reasonably captured by simulation results using 6 different parameter sets and 9 infiltration maps, as discussed in Section 6.9. The effects of parameter and data uncertainties on UZ flow model results are mostly covered in the model results for the 18 three-diemnsional flow fields.

Corroboration with Natural Analogues. Note that the UZ flow model has been developed (Sections 6.1-6.8) and is validated through corroboration of field data (Section 7) under nominal scenario conditions. Applications of the UZ flow model to modeling UZ flow and transport processes under seismic and igneous disruptive scenarios, however, were demonstrated by sensitivity studies using modified fracture properties in the FEPs report (BSC 2004 [DIRS 170012]). These modeling analyses show insignificant effects of fault displacement or increase in fracture permeability and aperture on transport from the repository to the water table. Therefore, the impact of seismic or igneous activities on rock properties was excluded on the bases of low-consequence and small spatial extent arguments.

For level I validation, the validation activities for the UZ flow model include corroboration with experimental data and modeling studies using the following: (1) ECRB observation data within the ESF; (2) WT-24 perched-water data; (3) gas-flow data from Boreholes SD-12 and UZ-7a; (4) measured C-14 borehole data; and (5) Alcove 8/Niche 3 (also referred to as Niche 3107) flow and seepage test results. In addition, validation efforts are also performed for the ambient thermal model, chloride model, calcite model, and strontium model.

In these cases, simulation results of the UZ model and submodels are able to match different types of available observation data, such as water potentials, perched-water locations, temperatures, tracer concentrations, and pneumatic pressures. These efforts have provided validation of the UZ model and its submodels for their accuracy and reliability in describing 
hydrogeological, thermal, and chemical conditions, and predicting flow and transport processes in the Yucca Mountain UZ.

In addition, the key flow and transport processes pertaining to the UZ at Yucca Mountain have been investigated through natural analogues (BSC 2004 [DIRS 169218]). These analogue studies contained both literature studies and analyses. One of the important case studies was the flow experiment and tracer infiltration test in fractured media at the Box Canyon (CRWMS M\&O 2000 [DIRS 141407], Section 6.5.1.1). The field tests at the site provided calibrations of numerical models with needed in situ measured data. A consistent set of parameters was obtained from calibrating the site-wide model using the dual-permeability approach to both pneumatic and infiltration tests. The studies demonstrated that conceptual models and large-scale, volume-averaged numerical modeling approaches used for the UZ flow model at Yucca Mountain can be applied with confidence (CRWMS M\&O 2000 [DIRS 141407], Section 7). The model validation effort of this section is intended to further build confidence in the UZ flow model and submodels with regard to their ability to predict flow and transport processes in the Yucca Mountain UZ system. In particular, these model validation efforts further confirm that using uniform hydrogeologic parameter values across the lateral extent of most hydrostratigraphic units in the UZ flow model provides reasonable approximations and simulation results, because of the model capability of matching different types of data from boreholes that are considerably distance apart.

\subsection{CONFIDENCE BUILDING DURING MODEL DEVELOPMENT}

To establish the scientific basis and the accuracy of intended use, AP-SIII.10Q and AP-2.27Q require documentation of decisions or activities that are implemented to generate confidence in the model during model development, including the following:

(1) Selection of input parameters and/or input data, and a discussion of how the selection process builds confidence in the model [AP-SIII.10Q 5.3.2(b)(1) and AP-2.27Q Attachment 3 Level I (a)]

The selection of input parameters and/or input data for the UZ flow model and its submodels is discussed and presented mainly in Sections 4.1, 6.1-6.5, and Appendix A. Model calibration results in Section 6 show that these selected input parameter values or input data are reasonable to simulate flow and transport processes in the Yucca Mountain UZ.

(2) Description of calibration activities, and/or initial boundary condition runs, and/or run convergences and a discussion of how the activity or activities build confidence in the model. Inclusion of a discussion of impacts of any non- convergence runs. [AP-SIII.10Q 5.3.2(b)(2) and AP-2.27Q Attachment 3 Level 1 (e)]

Calibration activities and/or the use of initial and boundary conditions are discussed in Sections 6.1 to 6.5, resulting in the model results consistent with field measured data. No non-convergence runs occurred.

(3) Discussion of the impacts of uncertainties to model results. [AP-SIII.10Q 5.3.2(b)(3) and AP-2.27Q Attachment 3 Level 1 (d) and (f)] 
Impacts of uncertainties to model results are discussed in Section 6.9.

(4) Formulation of defensible assumptions and simplifications. [AP-2.27Q Attachment 3 Level I (b)]

As discussed in Sections 5 and 6.1.2, the development of the UZ flow model and its submodels is based on assumptions and simplifications that are accepted in the scientific community, which are supported by many scientific journal publications, as discussed above.

(5) Consistency with physical principles, such as conservation of mass, energy, and momentum. [AP-2.27Q Attachment 3 Level I (c)]

As discussed and shown in Section 6.1.2 and Appendix E, the development of the UZ flow model and its submodels is consistent with all these physical principles.

In addition, the justification for the representation of the flow fields with a higher water table is carried out using Method 2, Corroboration with Alternative Mathematical Models, as listed in AP-SIII.10Q, Section 5.4.1 (c). Demonstration that this criterion was met is shown in Section 7.11. This validation effort, even though specified in the TWP, is needed to justify the use of future flow fields.

\subsection{VALIDATION USING ECRB WATER-POTENTIAL MEASUREMENTS}

The three-dimensional site-scale UZ numerical model at Yucca Mountain has been the subject of several journal articles. In one of them, flow in the UZ was simulated in conjunction with distribution of moisture, gas, and heat (Wu et al. 1999 [DIRS 117161]). In another study, flow and transport processes within the UZ under current and future climates were characterized using a three-dimensional numerical model, which incorporates a wide variety of field data in the highly heterogeneous, unsaturated fractured porous rock (Wu et al. 2002 [DIRS 160195]). The capillary barriers in the unsaturated rock of Yucca Mountain were also studied (Wu et al. 2002 [DIRS 161058]).

An east-west cross-drift was constructed in 1997 as part of the ECRB program (see Figure 6.1-1 for the location of the ECRB tunnel). Water-potential data (DTN: GS980908312242.036 [DIRS 119820]) were collected from heat-dissipation probes installed in the tunnel wall (at a depth of $2 \mathrm{~m}$ ) along the ECRB tunnel inside the ESF. Water-potential data were collected from heat dissipation sensors that have been calibrated for matrix potential. Though the boreholes were dry drilled, the sensors were installed with wet cement. Thus, the sensors were fully saturated and surrounded with contact media to ensure good contact with rock, and equilibrated with the matrix potential of the rock. Following the equilibration, the probe would gradually dry out from ventilation effects. Since this was the first group of probes installed in the tunnel wall, no steps were taken to reduce the effects of ventilation drying in the tunnel. Extra steps, such as installing multiple doors, were taken during subsequent installation and monitoring of probes in the ECRB tunnel.

As part of the three-dimensional flow and transport modeling validation process, modeled results of water potentials were compared to field-observation data collected from the wall of the tunnel to check the accuracy of the modeling predictions. The base-case (preq mA with 
DTN: LB03023DSSCP9I.001) of the present-day, mean infiltration simulation results of the UZ flow model was selected for validation of the UZ flow model, as discussed in Section 6.2.5. Here the ' $\mathrm{m}$ ' stands for mean infiltration and " $\mathrm{A}$ " the base-case flow field with the infiltration rate specified. A complete list of modeling scenarios is in Table 6.7-1. The infiltration boundary condition is the present-day, mean infiltration rate (DTN: GS000308311221.005 [DIRS 147613]). The calibrated properties used for the three-dimensional prediction are those developed and listed in Table A-1 (Output-DTN: LB03013DSSCP3I.001), and the calibrated fault properties (DTN: LB02092DSSCFPR.002 [DIRS 162128]).

Figure 7.2-1 shows a comparison of simulated and measured matrix water potentials along the wall of the ECRB drift (note that water potential is defined as the absolute value of capillary pressure in this report). As shown in the figure, observation data are available only along part of the tunnel. Most of the observed water-potential data are distributed between $0.1\left(10^{4} \mathrm{~Pa}\right)$ and $1\left(10^{5} \mathrm{~Pa}\right)$ bars, with a maximum of 3.4 bar. The model predicted approximately 1 bar for the same section of tunnel, which is higher than most of the observed data. The predicted water potentials along the ECRB from the UZ flow model ranged between 0.30 and 1.92 bars (Figure 7.2-1) for the present-day, mean infiltration scenario (preq_mA).

The available data for field measured matrix water potentials at the ECRB were mostly distributed in a range between $0.1\left(10^{4} \mathrm{~Pa}\right)$ and $1\left(10^{5} \mathrm{~Pa}\right)$ bar. Their comparison with simulation results may have been affected by scales of measurements and model grids. This is because the model has a gridblock at the ECRB of about $100 \times 100 \times 10 \mathrm{~m}$ in $\mathrm{x}, \mathrm{y}$, and $\mathrm{z}$ directions, respectively. Thus, simulated water potentials are the results of large-scale average of tuff matrix, which is intercepted by many fractures. On the other hand, measurements were made on a much smaller, local scale on the order of a meter, thus, controlled by local heterogeneity.

Even though the data available for comparison at the ECRB drift are limited, the comparison results indicated that the UZ flow model is able to predict the range of the water-potential data from in situ measurements. Therefore, the criterion of validation is satisfied and this indicates that the model is capable of predicting the range of water potential and is reasonable for its intended use. 


\section{ECRB}

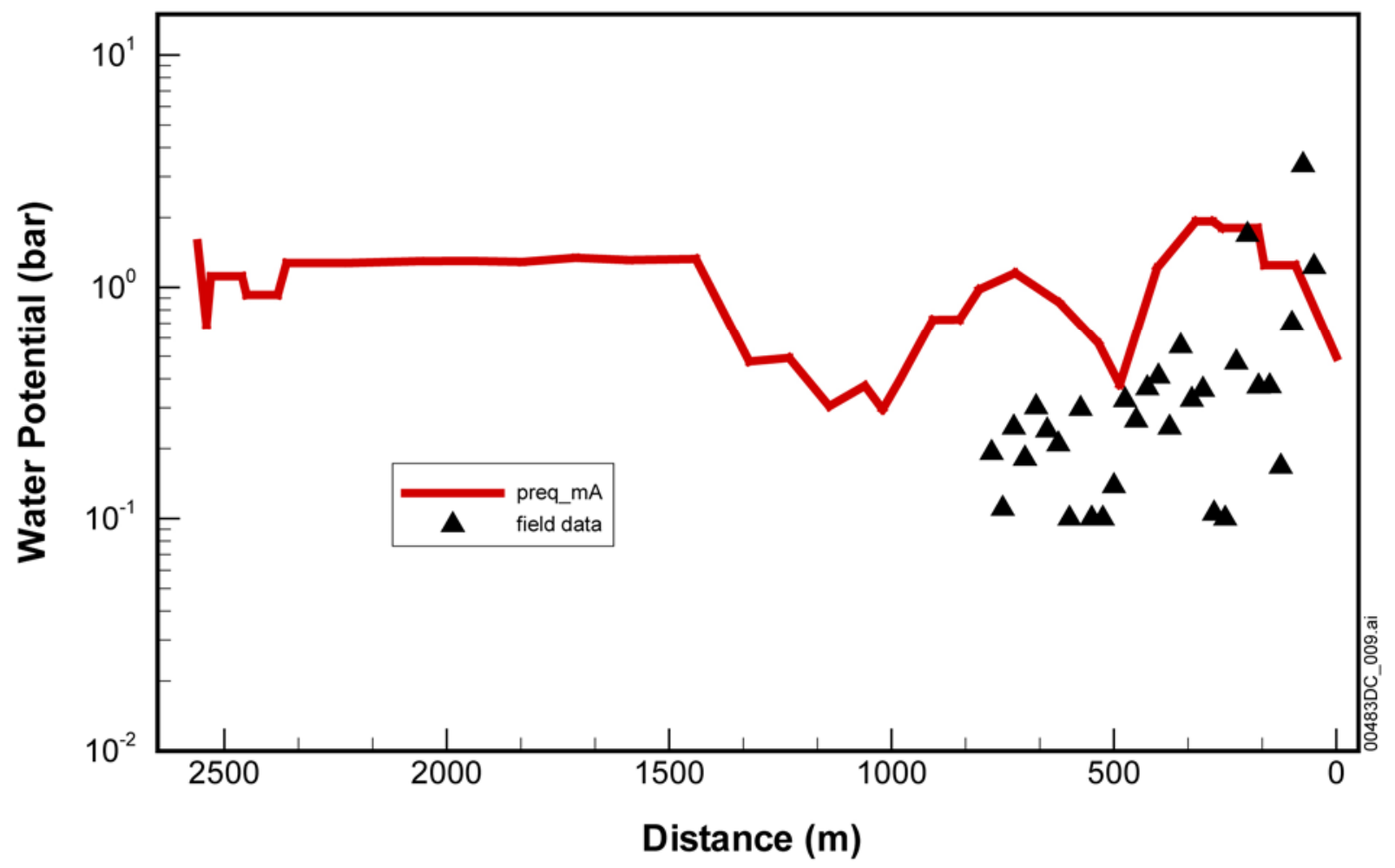

Source DTN: GS980908312242.036 (DIRS 119820).

Output DTN: LB03023DSSCP9I.001.

Figure 7.2-1. Comparison of Predicted and Measured Water Potential along ECRB Using the PresentDay, Mean Infiltration Rates (preq_mA)

\section{3ＶALIDATION USING PERCHED-WATER DATA AT WT-24}

The perched-water phenomena in the UZ at Yucca Mountain were investigated in a multiphase subsurface flow model (Wu et al. 1999 [DIRS 117167]). In that paper, the simulation results were shown to agree with the observed perched water data, including water saturation, potential profile, and perched-water elevation. In this validation, we use the field-measured perched-water data at Borehole WT-24. Borehole WT-24 was drilled in 1997 as part of the ECRB program (see Figure 6.1-1 for borehole locations). Observed saturation data were collected from the borehole (see Section 4-1 for DTNs), and perched water was detected within the basal vitrophyre of the TSw at an elevation of approximately 986.69 m (DTN: GS980508312313.001 [DIRS 109746]). As part of the model validation process, modeled results were compared to the field-observation perched-water elevation to check the accuracy of the modeled predictions.

The UZ flow model scenario (preq mA, with Output-DTN: LB03023DSSCP9I.001) of the present-day, mean infiltration rate is used for the comparison. Figure 7.3-1 shows a comparison of simulated matrix water-potential results with field measurement data at Borehole WT-24. The observed elevation of perched water is also shown in the figure. As indicated there, the field-measured data for potentials are limited to the deeper section of the borehole (mostly in the $\mathrm{CHn}$ unit). The UZ flow model prediction closely matches the field measurements of both water 
potentials and perched water elevations. Note that a simulated perched water zone is indicated by zero water potential. It should be mentioned that the field-measured perched-water elevation is only measured at one point, at the onset of a pumping test (DTN: GS980508312313.001 [DIRS 109746]). During pumping, the perched-water table was lowered by $20.66 \mathrm{~m}$ (DTN: GS980508312313.001 [DIRS 109746]). The actual perched-water zone thickness may be larger than this fluctuation of water levels. The value of $20.66 \mathrm{~m}$ is very close to the simulated perched water thickness of about $30 \mathrm{~m}$, as shown in Figure 7.3-1. Examination of simulated and observed perched water elevations show a difference of $6.55 \mathrm{~m}$. This satisfies the validation criterion of the $10 \mathrm{~m}$. Since the average grid spacing is about $10 \mathrm{~m}$ with the UZ flow model, the $10-\mathrm{m}$ criterion is sufficiently accurate in model outputs and consistent with the spatial discretization of the model.

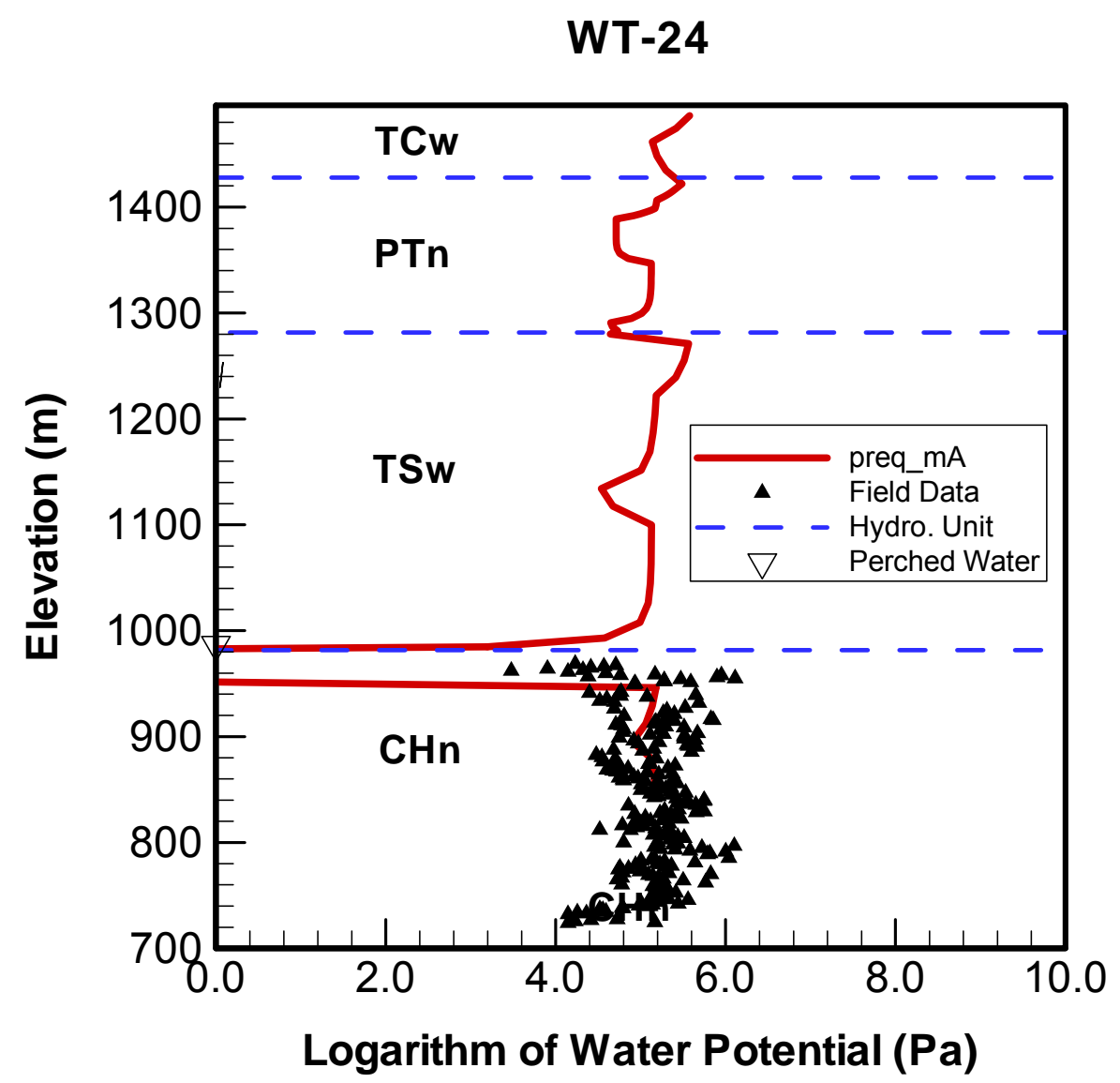

Source: DTNs: Field Water Potential Data DTN: GS980708312242.010 (DIRS 106752);

Perched Water-DTN: GS980508312313.001 (DIRS 109746).

Output DTN: LB03023DSSCP9I.001.

Figure 7.3-1. Comparison of Predicted and Measured Matrix Water Potentials and Perched-Water Elevations at Borehole WT-24 Using the Present-Day Mean Infiltration Rate (preq_mA) 


\subsection{THREE-DIMENSIONAL PNEUMATIC MODEL PREDICTION}

Subsurface gas-pressure variations have been used to determine the pneumatic diffusivity of important geological features in the unsaturated fractured tuffs. One-, two-, and three-dimensional numerical models have been used to simulate the observed subsurface pressure variations (Ahlers et al. 1999 [DIRS 109715]). For this UZ flow model validation, the same three-dimensional gas flow model, as discussed in Section 6.4, is used. Note that the gas flow model uses the same input parameters and the same conceptual hydrogeological models as the UZ flow model, and the gas flow model and the UZ flow model grids are based on the same geological framework model with similar spatial discretization scales. The model validation effort using the gas flow model is considered to provide direct validation of the UZ flow model.

Pneumatic data measured in SD-12 and UZ-7a boreholes are used for the model validation. The 60-day period of observation data from UZ-7a and the second 30-day period (immediately following the first 30 days of data used for calibration) from SD-12 are compared to the simulation predictions from the three-dimensional gas flow simulation results. The criterion for the validation is that simulated gas pressures and their pattern variations are consistent with the observed values. That is, the simulations will consistently reproduce increases and decreases resulting from changes in barometric pressure at the ground surface.

Table 7.4-1 lists the sensor locations, files for observation data, observation period, and corresponding model mesh cells for Borehole UZ-7a (the information for Borehole SD-12 is given in Table 6.4-1). Figures 7.4-1 and 7.4-2 show the comparisons of simulation results and field-measured values at these observation locations of the validation periods. UZ-7a is close to a fault; therefore, it "sees" the surface signal quickly and with little attenuation (Figure 7.4-1). The signal to SD-12 at the TSw may be affected by attenuation through the PTn. Overall, both figures show good agreement between the predicted gas pressures and observed data. The good match in Figures 7.4-1 and 7.4-2 builds confidence that the base-case infiltration-scenario calibrated properties are appropriate for gas flow simulations. The comparisons between simulated and observed gas pressures at different locations of the two boreholes, shown in the two figures, prove that simulated gas pressures and their patterns of variations are consistent with observed values. In particular, the simulations consistently reproduce increases and decreases resulting from changes in barometric pressure at the ground surface. This satisfies the validation criterion for this case and demonstrates that fracture properties used in the model are able to capture transient gas flow behavior.

Table 7.4-1. Observation Sensors in Borehole USW UZ-7a

\begin{tabular}{|l|c|c|c|}
\hline Sensor Elevation $(\mathbf{m})$ & $\begin{array}{c}\text { File for Observation } \\
\text { Data }\end{array}$ & $\begin{array}{c}\text { Corresponding } \\
\text { Observation } \\
\text { Cells }\end{array}$ \\
\hline 1243.0 & uz7a1343.prn & $12 / 1 / 95-1 / 29 / 96$ & F002Bh74 \\
\hline 1232.3 & uz7a1337.prn & $12 / 1 / 95-1 / 29 / 96$ & F0003h74 \\
\hline 1221.6 & uz7a1331.prn & $12 / 1 / 95-1 / 29 / 96$ & F0007h74 \\
\hline 1213.4 & uz7a1325.prn & $12 / 1 / 95-1 / 29 / 96$ & F0009h74 \\
\hline 1177.8 & uz7a1319.prn & $12 / 1 / 95-1 / 29 / 96$ & F011Ah74 \\
\hline
\end{tabular}

DTN: LB02092DSSCFPR.001 [DIRS 162422]. 


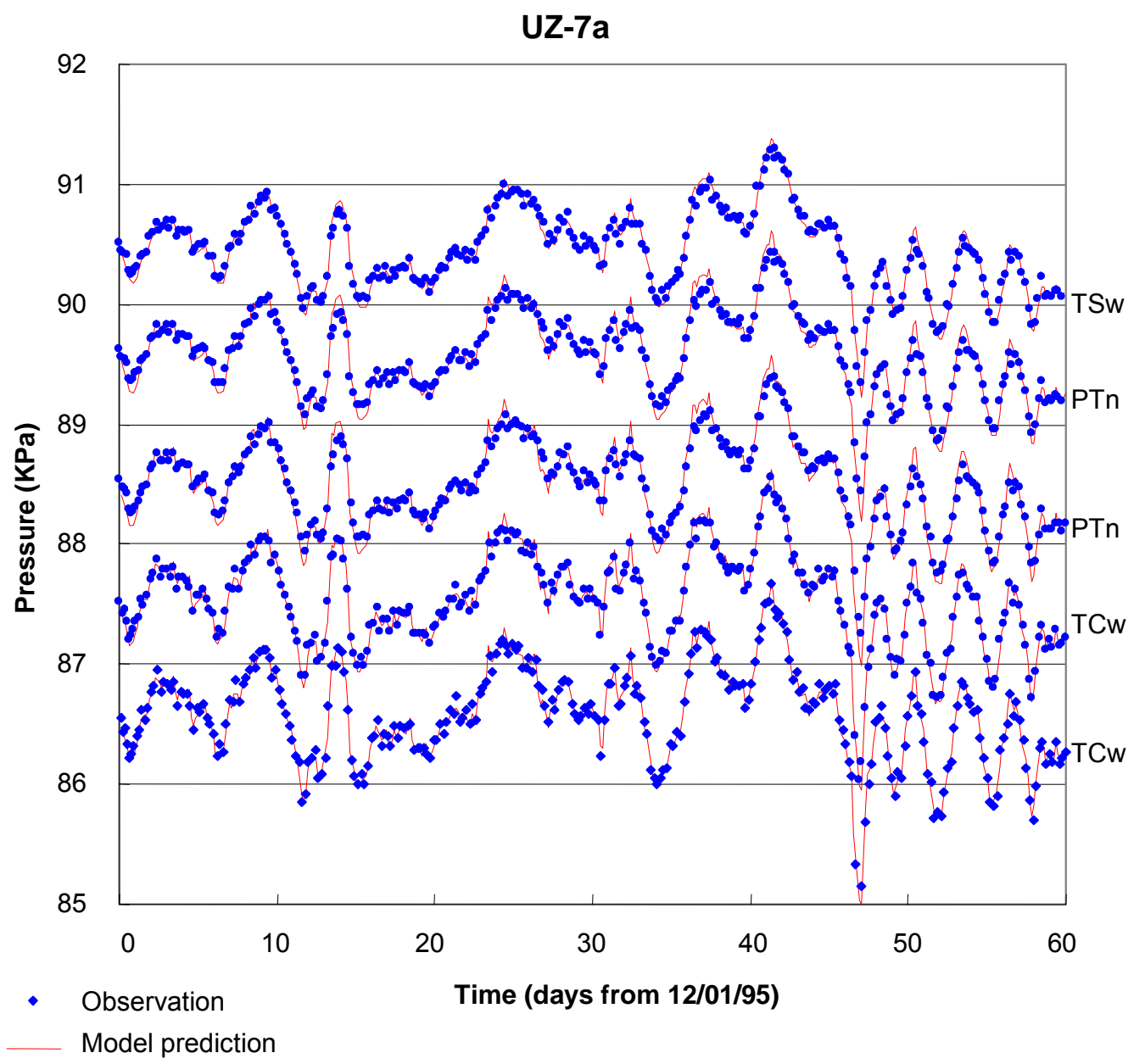

Source DTN: LB02092DSSCFPR.001 (DIRS 162422).

Output DTN: LB0303GASFLW3D.001.

NOTE: Field data from DTN: LB02092DSSCFPR.001 (DIRS 162422) are extracted from

DTN: GS960308312232.001 (DIRS 105573). Both observations and simulations have been vertically offset for clearer display.

Figure 7.4-1. Comparison of Three-Dimensional Pneumatic Prediction to Observation Data from Borehole UZ-7a 


\section{SD-12}

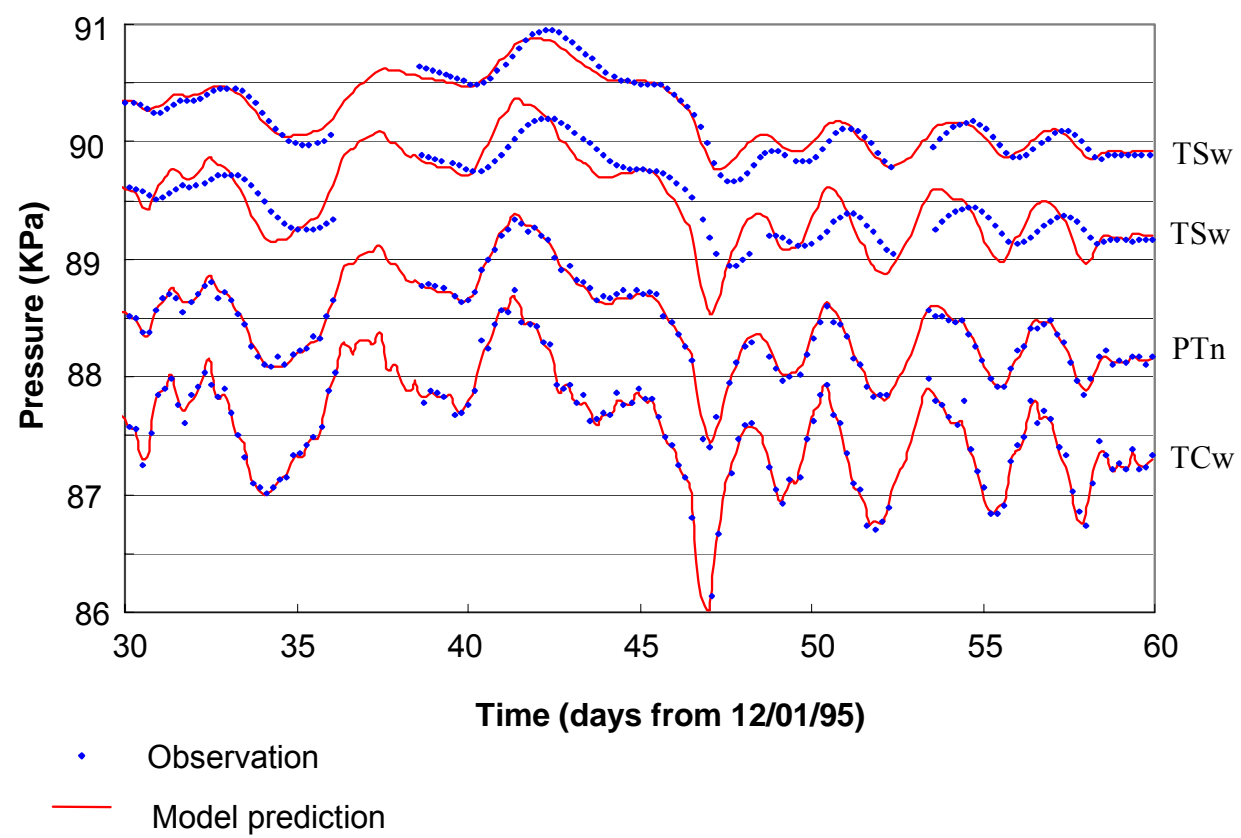

Source DTN: LB991091233129.001 (DIRS 125868).

Output DTN: LB0303GASFLW3D.001.

NOTE: $\quad$ Field data from DTN: LB991091233129.001 (DIRS 125868) are extracted from

DTN: GS960308312232.001 (DIRS 105573). Both observations and simulations have been vertically offset for clearer display.

Figure 7.4-2. Comparison of Three-Dimensional Pneumatic Prediction to Observation Data from Borehole SD-12

\subsection{MODEL VALIDATION WITH ${ }^{14}$ C DATA}

The UZ of Yucca Mountain is a quasi-steady-state flow system, subject to small infiltration and percolation rates. The matrix pore-water age corresponds to the mean transport time required for the groundwater to move from the ground surface to where it is sampled in the system. The age can be considered constant at each location in this quasi-steady-state flow system, but spatially variable. The migration of water molecules is governed by advection and diffusion, similar to solute transport (Goode 1996 [DIRS 162573]). Thus, tracer transport times (ages) can be simulated using a conservative transport model. The tracer transport time within the matrix (or matrix pore-water age) was defined as the time corresponding to a tracer concentration peak from an initial tracer pulse applied on the ground surface. If the simulated water age matches the available measured data (age) well, the transport model or the UZ flow model is considered to be validated.

In this validation effort, we estimate the groundwater age in the UZ using a tracer transport model based on the calibrated groundwater flow field of the UZ flow model (DTN: LB03023DSSCP9I.001). The simulated groundwater age is compared to available field-measured water age data $\left({ }^{14} \mathrm{C}\right)$. 
${ }^{14} \mathrm{C}$ data were collected from perched water, pore water, and gas samples from the Yucca Mountain UZ (BSC 2004 [DIRS 169734], Section 5.2.2.5.4). Pore-water ${ }^{14} \mathrm{C}$ data from boreholes at Yucca Mountain may not be representative of the pore-water residence time because of possible contamination by atmospheric ${ }^{14} \mathrm{CO}_{2}$ during borehole drilling, which may result in apparently younger residence times (Yang 2002 [DIRS 160839], Section 4.1.2; BSC 2004 [DIRS 169734], Section 5.2.2.5.4). ${ }^{14} \mathrm{C}$ data from gas samples, on the other hand, are considered to be most representative of in situ conditions (Yang 2002 [DIRS 160839], Section 4.1.2), because the borehole was closed, thus preventing exchange of ${ }^{14} \mathrm{C}$ with the atmosphere. ${ }^{14} \mathrm{C}$ is also considered as the most sensitive isotope measuring the groundwater age at the Yucca Mountain UZ due to its half-life duration, which is in the same order of magnitude as the groundwater age in the UZ, and its detectable abundance. Gas samples were collected from different kinds of boreholes, including open and instrumented surface-based boreholes. The data from the latter boreholes (USW SD-12 and USW UZ-1) are regarded as more reliable indicators of in situ matrix pore-water ages (BSC 2004 [DIRS 169734], Section 5.2.2.5.4). ${ }^{14} \mathrm{C}$ ages (BSC 2004 [DIRS 169734], Section 5.2.2.5.4) calculated using the data from these two boreholes are used for validating the UZ flow model.

Gas-phase ${ }^{14} \mathrm{C}$ ages (DTN: GS961108312271.002 [DIRS 121708] for Borehole USW SD-12 and DTN: MO0012CARB1314.000 [DIRS 153398] for Borehole USW UZ-1) are interpreted to be representative of ages of the in situ pore water. The rationale for this interpretation is provided by Yang (2002 [DIRS 160839], Section 4.1.2). The interpretation is based on the rapid exchange of gas-phase $\mathrm{CO}_{2}$ (reaching equilibrium in hours to days) with dissolved $\mathrm{CO}_{2}$ and $\mathrm{HCO}_{3}{ }^{-}$in pore water. Furthermore, the amount of carbon in an aqueous-phase reservoir is greater by orders of magnitude than carbon in the $\mathrm{CO}_{2}$ gas-phase reservoir. Consequently, the aqueous phase will dominate the gaseous phase when exchange occurs, indicating the reasonableness of the interpretation (Yang 2002 [DIRS 160839], Section 4.1.2). The continuous calcite precipitation in the UZ removes carbon from groundwater. Although ${ }^{14} \mathrm{C}$ behaves a little differently from total carbon, the effect on the carbon isotopic fraction is minor, and the calcite precipitation is considered to have an insignificant impact on the ${ }^{14} \mathrm{C}$ activity in the groundwater and gas (Codell and Murphy 1992 [DIRS 100719]). Therefore, we chose the measured gas phase ${ }^{14} \mathrm{C}$ age to be the representative age data for the matrix pore-water age of the Yucca Mountain UZ in the following model validation effort.

A three-dimensional transport model simulation was performed using T2R3D V1.4 (LBNL 1999 [DIRS 146654]) decoupled version. The three-dimensional flow field obtained with the base-case UZ flow model simulation (present day mean infiltration, DTN: LB03023DSSCP9I.001) is incorporated to simulate the matrix pore-water age in the entire model domain. The numerical grid used in this transport simulation is the same as that used in the base-case flow simulation (Figure 6.1-1). As discussed in Section 6.8, hydrodynamic dispersion was ignored because of low water percolation fluxes. Thus, the ${ }^{14} \mathrm{C}$ transport is being carried out primarily by advective and diffusive processes. An effective-diffusion-coefficient value of $1.97 \times 10^{-10} \mathrm{~m}^{2} / \mathrm{s}$ was adopted, equal to the average value of measured coefficients for tritiated water through Yucca Mountain tuffs (DTN: LA000000000034.002 [DIRS 148603]).

A tracer source was introduced as a pulse on the ground surface through fractures and observe the tracer concentration in rock matrix in the entire domain. The simulated matrix pore-water age, at a specific location, is then identified as the time required for the tracer pulse (appearing as 
concentration peaks in the UZ) to travel to that location, and is determined from the concentration breakthrough curve at the location. Then, we compare the simulated ages to the measured matrix pore water ${ }^{14} \mathrm{C}$ age. The simulated matrix pore-water age for Boreholes UZ-1 and SD-12 were plotted and compared to available measured age data $\left({ }^{14} \mathrm{C}\right.$ ) (Figures 7.5-1 [UZ-1] and 7.5-2 [SD-12]).

Figure 7.5-1 (UZ-1) and Figure 7.5-2 (SD-12) show that the simulated matrix pore-water ages (curves identified by ' $\gamma=0.6$ ' on the figures, with $\gamma$ being the active-fracture-model parameter) in the upper portion of the TSw unit are larger than the measured ${ }^{14} \mathrm{C}$ ages. This is caused mainly by the underestimated advective and diffusive solute flux between fractures and matrix along these subunits. The smaller the flux or the slower the diffusion from fractures to matrix, the older the ages for matrix pore water. As analyzed in Section 6.8, advective and diffusive fluxes are both proportional to the effective interface area between fractures and matrix and, in turn, related to the larger $\gamma$ values. The calibrated $\gamma$ values, 0.6 for tsw32 and tsw33, and 0.569 for tsw34-tsw38, were determined from inverse models of flow processes (DTN: LB0208UZDSCPMI.002 [DIRS 161243]). When compared to transport analyses, sensitivity studies (BSC 2004 [DIRS 170038], Section 6.8) indicate that a more appropriate range of $\gamma$ value for tsw32-tsw38 is between 0.2 and 0.4. A smaller $\gamma$ corresponds to a larger effective fracture-matrix interface area, leading to larger advective or diffusive flux. Therefore, another simulation was performed using $\gamma$ equal to 0.4 for tsw2 through tsw8. The simulated ages are also plotted in the same figures.

Figure 7.5-1 (UZ-1) shows that the simulated matrix pore-water ages for the upper TSw units with $\gamma=0.4$ match the measured ${ }^{14} \mathrm{C}$ ages well. Overall, simulated ages for lower TSw units in Figure 7.5-1 for bore UZ-1 are slightly younger than the measurements, but still meet the particular criterion of the UZ flow model (the simulated ages for TSw unit are also within the range of measured ${ }^{14} \mathrm{C}$ age of $\mathrm{TSw}$ units, Section 7.1). Figure 7.5-2 (SD-12) shows that the match between the simulated groundwater ages and the measurements is reasonable and meets the model validation criterion for most parts (i.e., the simulated ages for the most units and the major portion of the TSw unit are within the range of the measured ${ }^{14} \mathrm{C}$ age for borehole SD-12, Section 7.1). However, it should be mentioned that the model validation criterion is met everywhere except at the upper part of the TSw unit for $\gamma=0.6$, as shown in Figure 7.5-2. This small deviation from the TWP will have no impact on the validation result. This is because overpredicting the age in the upper TSw would be of little consequence to the intended use because this is not a zone of consequence to radionuclide transport and model predictions at and below the repository level, where radionuclide transport is important, are much better. Due to the uncertainties associated with modeling long term ${ }^{14} \mathrm{C}$ transport in the UZ, this validation shows that the UZ flow model is able to capture the general trend of long term tracer transport.

A larger gamma ( 0.6 for the TSw units) was used in the base-case UZ flow model. As demonstrated in Section 6.8 (which describes the sensitivity of UZ flow and transport processes to the gamma factor), the larger gamma gives slightly earlier breakthrough times for solute transport from the repository to the water table, and, therefore, provides more conservative results. This is because a larger gamma factor corresponds to a larger fracture pore velocity and a smaller effective fracture-matrix interface area (or a smaller degree of fracture-matrix interaction). 


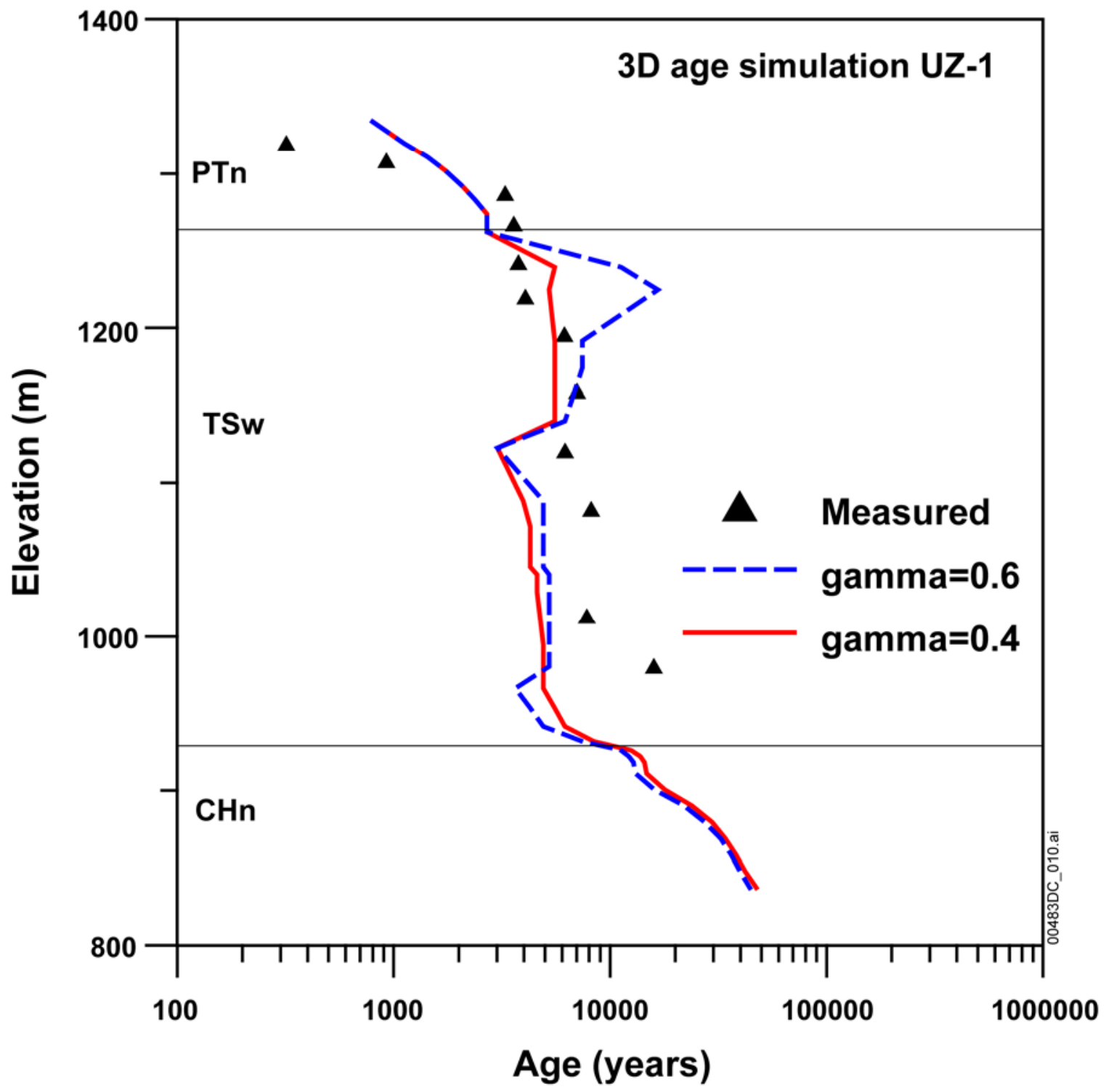

Source DTN: MO0012CARB1314.000 (DIRS 153398) and converted to ages (Wang 2003 [DIRS 162417], SN-LBNL-SCl-27-V1, p. 87).

Output DTN: LB0303C14INF3D.001.

Figure 7.5-1. Simulated Groundwater Age for UZ-1 Borehole Compared to the Measured ${ }^{14} \mathrm{C}$ Age 


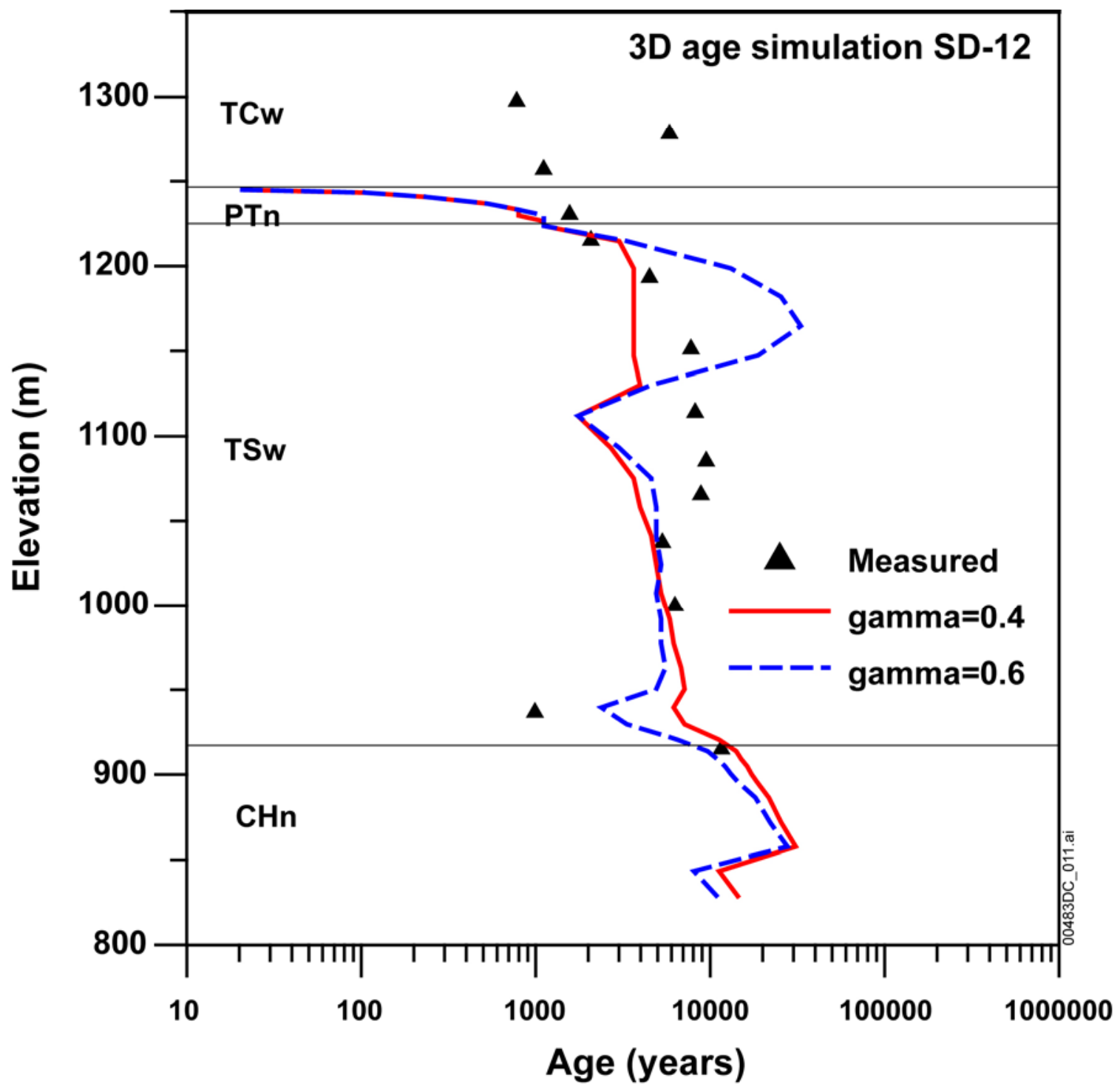

Source DTN: GS961108312271.002 (DIRS 121708) and converted to ages (Wang 2003 [DIRS 162417], SN-LBNL-SCl-227-V1, p. 87).

Output DTN: LB0303C14INF3D.001.

NOTE: Only one sample is plotted for each depth.

Figure 7.5-2. Simulated Groundwater Age for SD-12 Borehole Compared to the Measured ${ }^{14} \mathrm{C}$ Age

In summary, the comparison between simulated matrix pore-water age and observed ${ }^{14} \mathrm{C}$ ages indicates that with $\gamma=0.4$ (for UZ model layers tsw32-tsw38), the simulated tracer transport time can reasonably represent the measured ${ }^{14} \mathrm{C}$ ages of Boreholes UZ-1 and SD-12. In addition, the simulated matrix pore-water age is sensitive to the active fracture parameter, $\gamma$.

\subsection{MODELING ANALYSIS OF ALCOVE 8/NICHE 3 FAULT TESTS}

This section simulates in situ field tests of artificial infiltration along a fault at Alcove 8/Niche 3 . The fault tests caused localized saturated conditions below the test spot in an otherwise UZ. Under this field condition, test data are compared to results of simulations using the same 
conceptual model, methodology, and modeling approach as those used in the UZ flow model. This modeling activity presents a different case of validation for the UZ flow model. The results will build confidence in the UZ flow model from a different perspective (in terms of different-scale model results and field conditions).

This modeling analysis uses both model calibration and prediction. Comparisons between simulated and observed data are useful for evaluating the validity of the methodology used in the UZ flow model for capturing UZ flow and transport processes. The criterion for validation is that the predicted results for the time required for a conservative tracer to reach a given concentration (e.g., peak concentration) are within a factor of five of the observed time. (BSC 2002 [DIRS 160819], Attachment Section I-1-2-1). As demonstrated in Section 7.6.3.2 below (the discussion of modeling results), the criterion is met. This modeling activity is also documented in a Scientific Notebook by Wang (2003 [DIRS 162417], SN-LBNL-SCI-215-V1, pp. 107 to 119). Note that the modeling analysis of Alcove 8/Niche 3 fault tests has been used to validate both UZ flow and UZ transport models (BSC 2002 [DIRS 160819], Attachment Sections I-1-2-1 and I-2-1-2).

\subsubsection{Field Observations}

Infiltration rate, seepage rate, and tracer concentration data from the fault test are used to corroborate model simulations. The fault test used water and two liquid tracers. The test was carried out in the upper lithophysal and middle nonlithophysal subunits in the Yucca Mountain UZ. These geological subunits correspond to model layers tsw33 and tsw34, respectively, in the UZ model. The tsw33 has some lithophysal cavities that may intersect fractures. Liquid water, first without and then with tracers, was released at the floor of an alcove along the fault (about 5 m long (DTN: GS020508312242.001 [DIRS 162129]) within tsw33. Seepage from the fault into a niche and tracer concentrations of seeping liquid were monitored as functions of time. The niche is located within tsw34, about $20 \mathrm{~m}$ below the floor of the alcove; the interface between tsw33 and tsw34 is about $15 \mathrm{~m}$ below the floor of the alcove (DTN: LB0301N3SURDAT.001 [DIRS 162130]).

A pressure head of $2 \mathrm{~cm}$ was maintained at the infiltration plot along the fault at the alcove. The plot consists of four trenches that have different infiltration rates as a result of subsurface heterogeneity along the fault. Figure 7.6-1 shows the total infiltration rate as a function of time (DTNs: GS020508312242.001 [DIRS 162129] and GS020908312242.002 [DIRS 162141]; Wang 2003 [DIRS 162417], SN-LBNL-SCI-215-V1, p. 107). For simplicity, our model considers the uniformly distributed infiltration rate along the infiltration plot to be consistent with the uniform property distribution in the UZ model. One consideration in our modeling study is to evaluate approaches used in the site-scale model. Considerable temporal variability in the infiltration rate occurred during the test as a result of infilled materials within the fault just below the infiltration plot (Figure 7.6-1). In other words, the effective permeability of the fault just below the plot changed with time. It is also expected that most portions of the fault and the surrounding fractures away from the plot would still be unsaturated, although pressure head at the plot was positive during the test. Based on these observations, total infiltration rate (instead of a pressure head of $2 \mathrm{~cm}$ ) was used as the boundary condition in our model. 


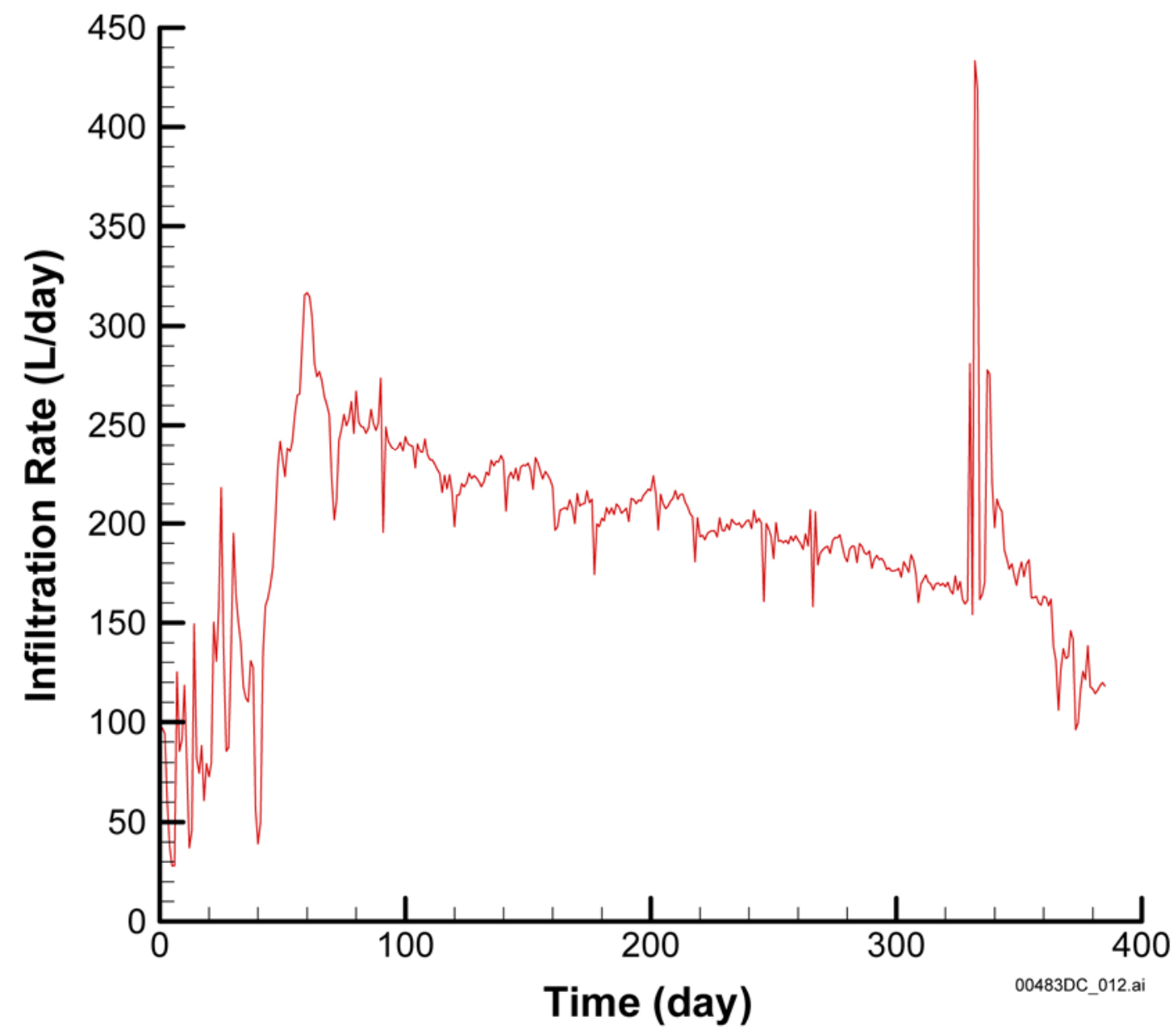

Output DTN: LB0303A8N3MDLG.001 (File: inf_sum.dat).

NOTE: Based on DTNS: GS020508312242.001 (DIRS 162129) and GS020908312242.002 (DIRS 162141).

Figure 7.6-1. Infiltration Rate as a Function of Time

Seepage from the fault into the niche was measured during the test, with a number of trays used to cover the areas where seepage might occur. Seepage was found to be highly spatially variable. The total seepage rate as a function of time is given in Figure 7.6-2 (DTN: LB0303A8N3LIQR.001 [DIRS 162570]). Several boreholes were installed around the niche. Water arrival times at these boreholes were monitored by electrical resistivity probes. Figure 7.6-3 shows average water travel velocities determined from the arrival times from two boreholes just above the ceiling of the niche (DTN: LB0303A8N3LIQR.001 [DIRS 162570]). The fault is about $2 \mathrm{~m}$ from the borehole collars in Figure 7.6-3 (DTN: LB0303A8N3LIQR.001 [DIRS 162570]). Note that relatively uniform water-travel-velocity distribution within and near the fault was observed from these two boreholes. 


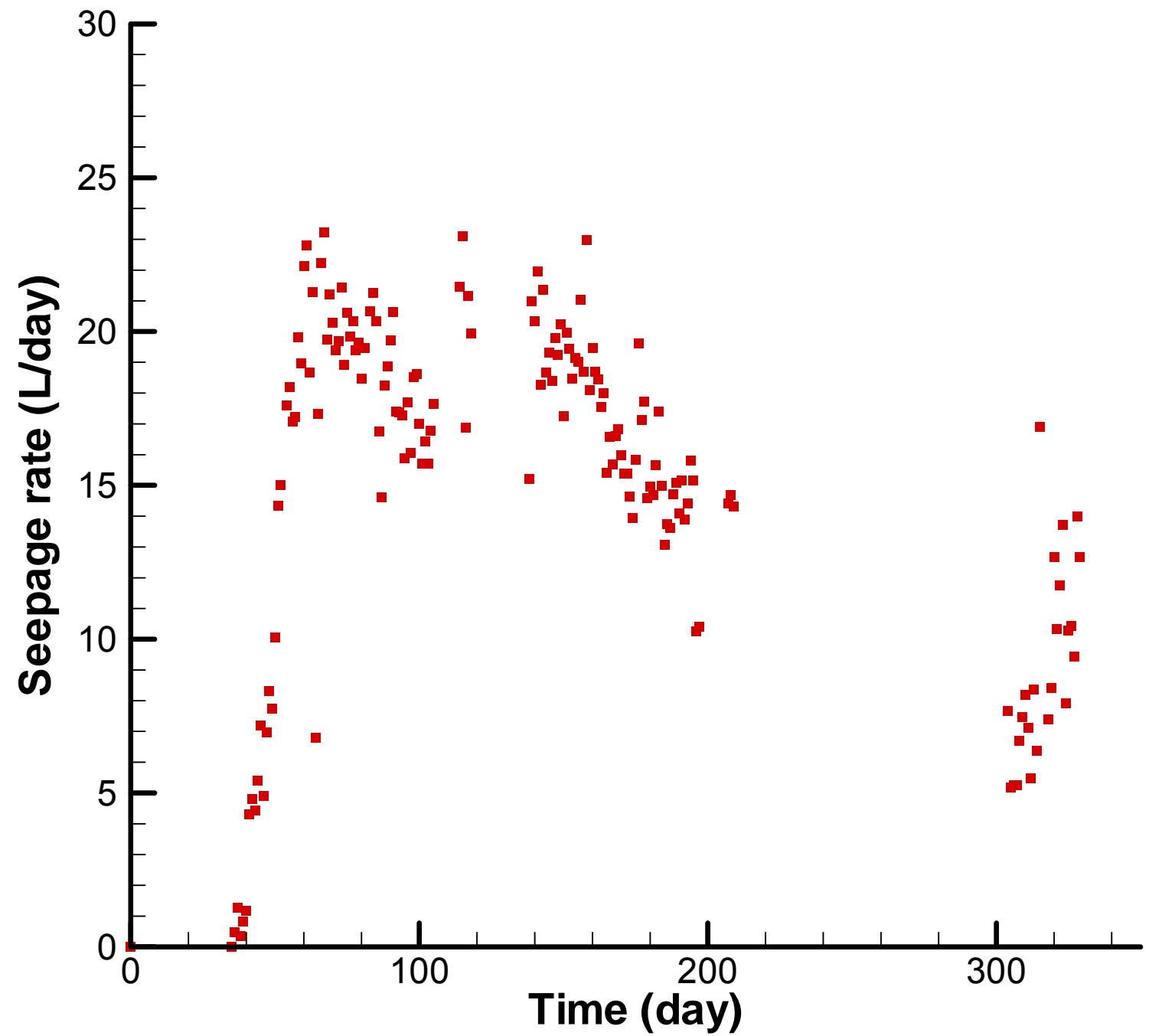

Source DTN: LB0303A8N3LIQR.001 (DIRS 162570) (file: All_seepage.xIs).

Figure 7.6-2. Total Seepage Rate as a Function of Time 


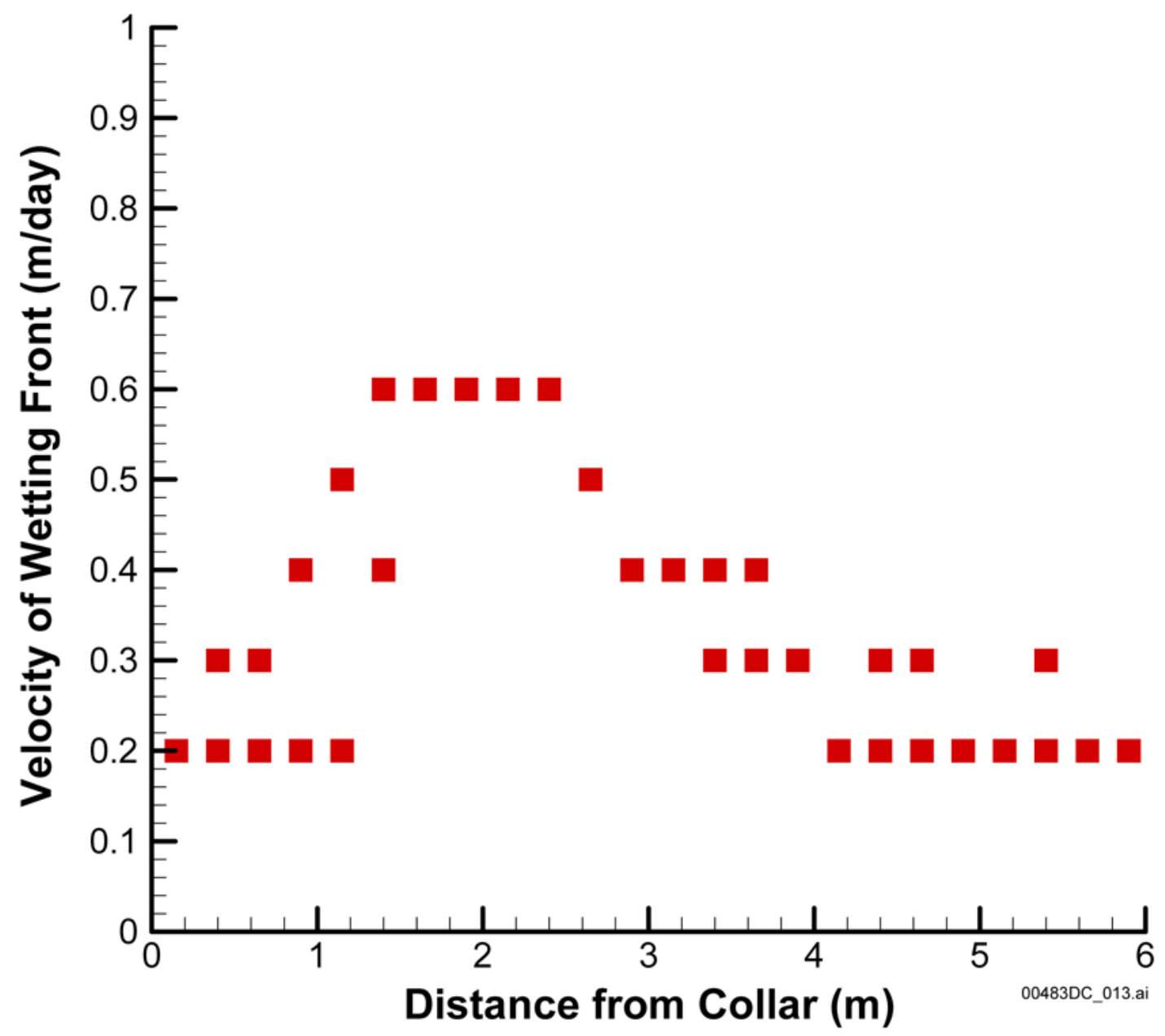

Source DTN: LB0303A8N3LIQR.001 (DIRS 162570).

NOTE: Observation boreholes are approximately perpendicular to the fault. The distance from a borehole collar (called distance from collar) to the fault is about $2 \mathrm{~m}$.

Figure 7.6-3. Water Travel Velocity Data for Boreholes 9 and 10

After 209 days, two tracers with different molecular diffusion coefficients, $\mathrm{Br}$ and pentafluorobenzoic acid, were introduced into infiltrating water at the infiltration plot. Tracer concentrations in three of the trays (at the niche) capturing seeping water from the fault were measured (DTN: LB0303A8N3LIQR.001 [DIRS 162570]). Seepage rates corresponding to these three trays were not measured during the period of tracer concentration measurement. In this study, a flux-averaged breakthrough curve (concentration as a function of time) from these trays was used to represent the average breakthrough curve for all trays at the niche where seepage was captured (Wang 2003 [DIRS 162417], SN-LBNL-SCI-215-V1, pp. 108 to 109). A constant flux value for each of the three trays was used for calculating the flux-averaged breakthrough curve shown in Figure 7.6-4. The constant flux values for the three trays were determined as the averaged value over 56 days before tracers were introduced. This flux-averaged breakthrough curve was compared with simulation results. 


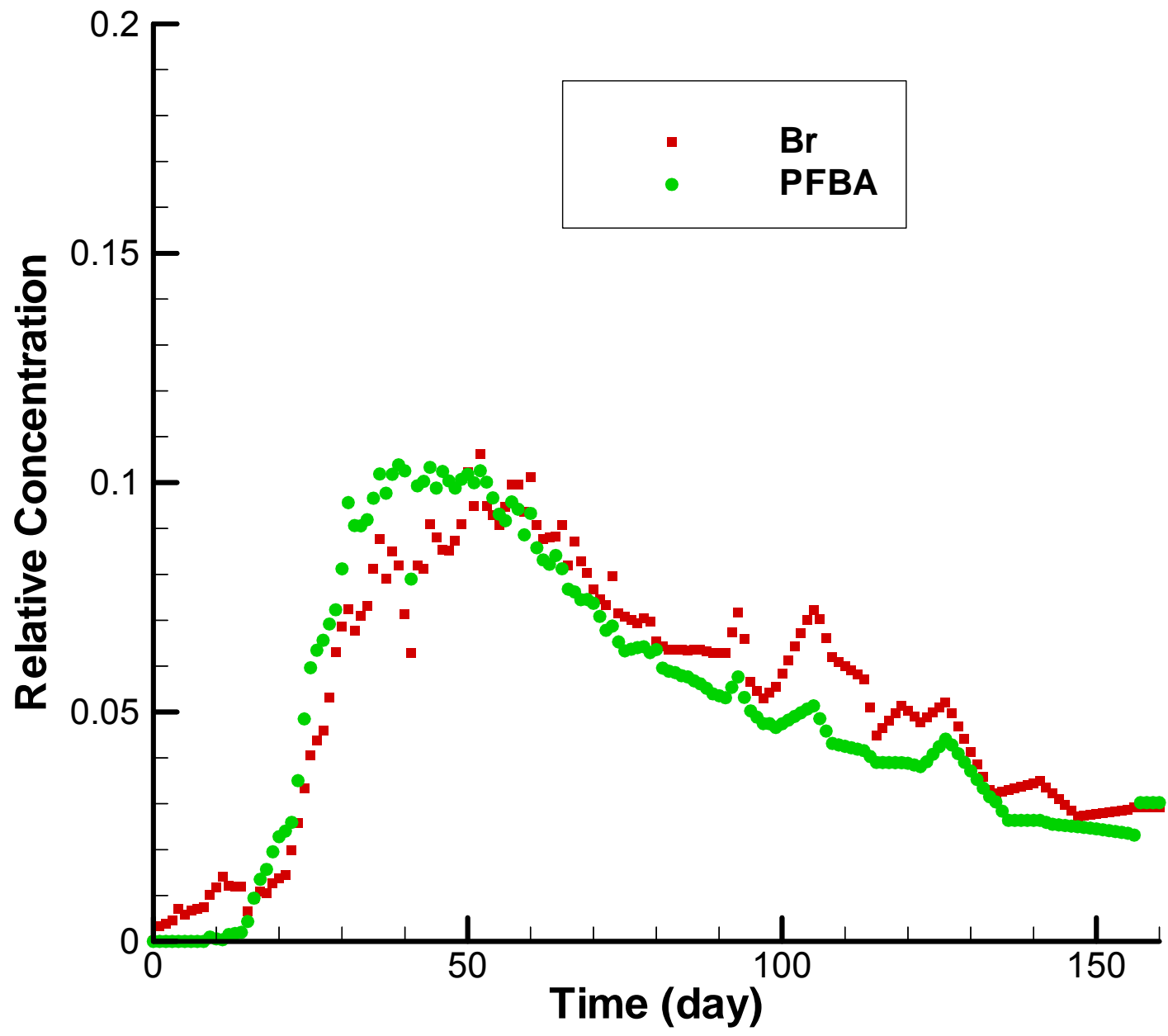

Based on Source DTN: LB0303A8N3LIQR.001 (DIRS 162570).

Output DTN: LB0303A8N3MDLG.001 (file: BTC.dat).

Source: Wang 2003 (DIRS 162417), SN-LBNL-SCI-215-V1, pp. 108 to 109.

Figure 7.6-4. Observed Flux-Average Breakthrough Curve

\subsubsection{Numerical Model}

A numerical model was developed for the fault test site to compare the simulation results with the relevant field observations. (The grid was generated with a software routine Smesh.f V1.0 (LBNL 2002 [DIRS 162142]).) While comparison results will be presented below in Section 7.6.4, in this section, the focus is on schemes used for developing the numerical model.

A three-dimensional numerical grid is constructed for simulating the fault test (Figure 7.6-5). The fault is represented as a vertical fracture, and surrounding fractured rock is approximated as a dual-continuum system (consisting of overlapped, interacting fracture and matrix continua). Global water flow and solute transport are allowed to occur in both continua. Figure 7.6-5 shows a cross section of the grid within the fault. The thickness of the grid in the direction perpendicular to fault walls is $3 \mathrm{~m}$ along each side of the fault. The fracture frequency used for generating the dual-continuum grid is 1.03 for tsw33 (determined from the fracture map at the alcove floor) and 1.72 for tsw34 (determined from the fracture map at the ceiling of the niche) 
(DTN: GS030108314224.001 [DIRS 162131]; Wang 2003 [DIRS 162417], SN-LBNL-SCI-215V1, pp. 111 to 112). As shown in Figure 7.6-5, within a cross section of the grid along the fault, the grid spacing is $10 \mathrm{~cm}$ just above the ceiling of the niche, enabling the seepage process to be accurately simulated. The grid spacings in the direction perpendicular to the fault are $0.024 \mathrm{~m}$, $0.168 \mathrm{~m}, 0.456 \mathrm{~m}, 0.756 \mathrm{~m}$, and $1.44 \mathrm{~m}$, respectively. The smallest spacing is adjacent to the fault, so that water imbibition and tracer diffusion into the fractured rock from the fault can be accurately captured. Cross sections in parallel to the fault walls have identical grid meshes (Figure 7.6-5) for different distances from the fault. The niche is represented by an opening at the bottom of the grid (Figure 7.6-5), with the geometry of the opening determined from the survey data of the niche near the fault. Note that this is only an approximation of the geometry of the test site; a three-dimensional geometry of the niche with an underground tunnel connected to the niche are difficult to incorporate into the model. However, since our main concern is flow and transport processes within the fault, this geometric representation is adequate.

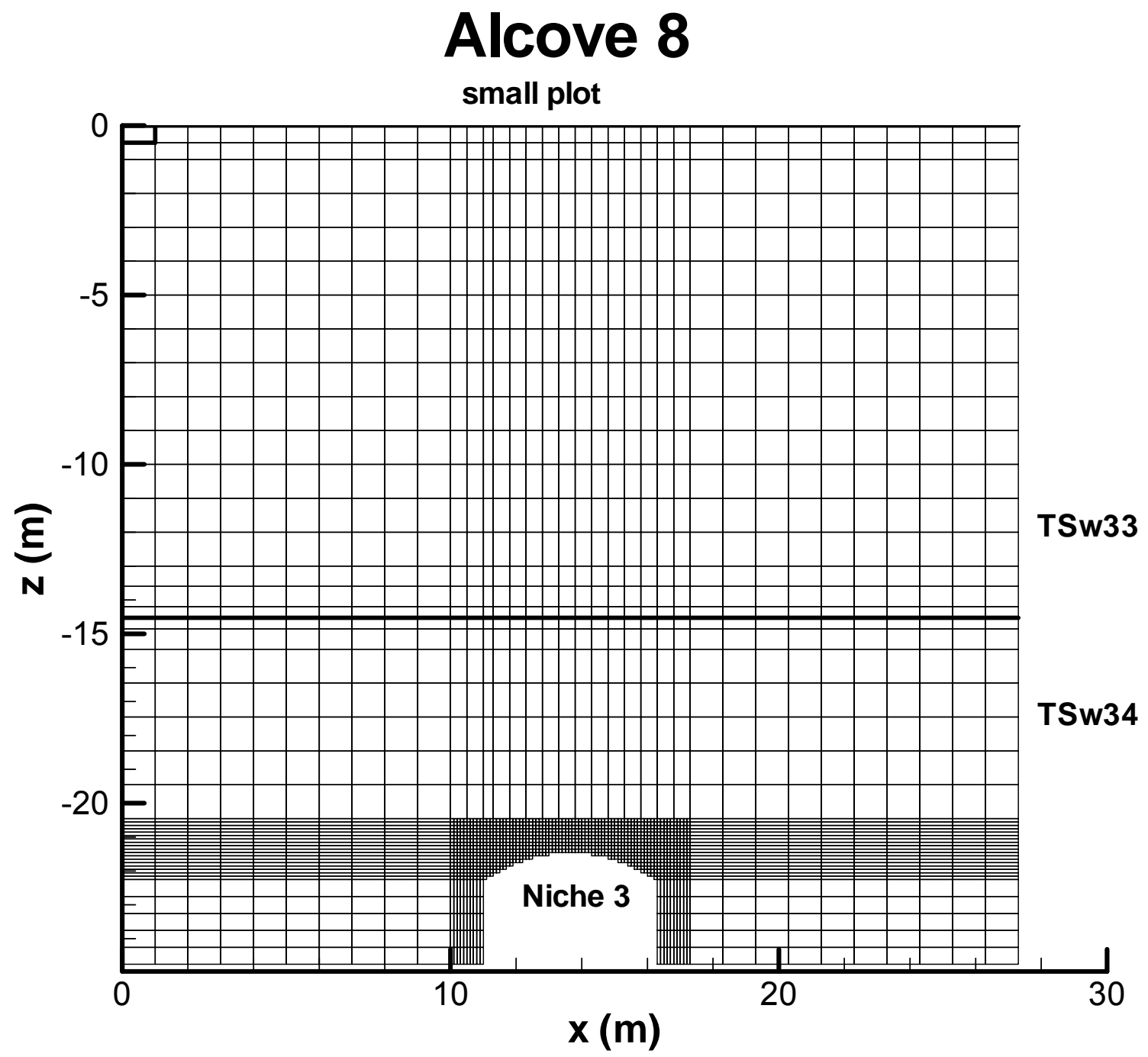

Figure 7.6-5. Cross-Sectional Schematic of the Three-Dimensional Numerical Grid Used for Modeling Studies of Alcove 8/Niche 3 
Temporally variable inflow rates are imposed on the top boundary, corresponding to the infiltration plot at the alcove floor (Figure 7.6-1). The side boundary corresponds to zero-flow conditions (in the direction perpendicular to the simulation domain). The niche wall boundary is modeled by a zero capillary-pressure condition, representing capillary barrier effects (Birkholzer et al. 1999 [DIRS 105170]). The bottom boundary was assigned a constant matrix saturation of 0.85, which is consistent with field observations under ambient conditions (Flint 1998 [DIRS 100033], p. 44, Table 7). Also based on field observations in the report by Flint (1998 [DIRS 100033], p. 44), matrix saturations are initially assigned to be 0.72 for tsw33 and 0.85 for tsw34. Other initial conditions for the rock mass within the model domain are that it is solute-free and has little water saturation (1.05E-2) in both the fractures and the fault. Rock properties used in model simulations are presented in Section 7.6.3.1.

Model calibration is performed using an inverse modeling code iTOUGH2 V4.0 (LBNL 1999 [DIRS 139918]). The model calibration is defined herein as the adjustment of rock hydraulic parameters to make simulation results match the corresponding data. The goodness of match is measured using the standard least squares approach, which minimizes the sum of the squared residuals weighted by the inverse of variance of the data. T2R3D V1.4 (LBNL 1999 [DIRS 146654]) is used for modeling tracer transport.

\subsubsection{Model Simulations and Discussions}

The numerical model was first calibrated against only the seepage and water-travel-velocity data to obtain the calibrated rock properties and the corresponding water flow field using iTOUGH2. Then, forward tracer transport simulations with different chemical transport parameters were carried out using T2R3D to evaluate the effects of matrix diffusion and other related processes on solute transport in the fault.

\subsubsection{Calibration of Seepage-Rate Data and the Average Water-Travel-Velocity Data}

Both fracture and matrix properties were assumed to be homogeneous within each geological subunit (tsw33 and tsw34). Fault properties were assumed to be the same for both units. This is based mainly on the following three considerations:

(1) Consideration of the heterogeneity within each subunit would introduce a large number of rock properties that need to be determined by more data than was available from the test site.

(2) These treatments have been used by the site-scale model of the Yucca Mountain UZ. It is of interest to examine how well this simple representation of subsurface heterogeneity can be used to model the fault test.

(3) A study by Zhou et al. (2003 [DIRS 162133]) implies that flow and transport in the Yucca Mountain UZ are mainly determined by large-scale heterogeneity, characterized by property differences between different geological units rather than by property variability within a geological unit.

Rock hydraulic properties needed as inputs into the model include fracture and matrix permeabilities, fracture and matrix porosities, fault aperture and permeabilities, van Genuchten 
(1980 [DIRS 100610]) parameters (for matrix, fractures, and the fault), and the parameter of the AFM, $\gamma$, for fractures (DTNs: LB997141233129.001 [DIRS 104055]; LB980901233124.101 [DIRS 136593]; LB990861233129.001 [DIRS 110226]; and LB990501233129.001 [DIRS 106787]; Wang 2003 [DIRS 162417], SN-LBNL-SCI-215-V1, pp. 114 to 115). Because fracture van Genuchten parameters for tsw33 and tsw34 are similar (Table 7.6.1), a simple average of these parameters was used as the corresponding parameters for the fault (Wang 2003 [DIRS 162417], SN-LBNL-SCI-215-V1, pp. 114 to 115). The averaged $\mathrm{k} / \phi$ (where $\mathrm{k}$ is fracture permeability and $\phi$ is the corresponding fracture porosity) was calculated as fault permeability. Note that because there is no matrix in the fault in our model (or $\phi=1$ ), the weighted $\mathrm{k} / \phi$ (rather than weighted $\mathrm{k}$ ) is employed for estimating fault permeability. The aperture of the fault was estimated as the average of fracture apertures of the two subunits. Note that the AFM was developed for fracture networks rather than for a single fracture. Consequently, the AFM does not apply to the fault here. In fact, most of the parameter values mentioned above and given in Table 7.6-1 are not site specific for the fault test site. These values were used as initial guesses for model calibration against the seepage rate and water-travel-velocity data observed from the fault test. Note that not all site-specific parameters are available and the initial guess of some values were necessary. This is because the initial guess does not significantly affect the final calibrated values. To reduce the number of variables in model calibration (or inverse modeling), parameters expected to significantly affect simulated tracer transport time and seepage rate were varied in the calibration, while other parameters were kept unchanged. The varied parameters were fracture and fault permeabilities, fracture porosity, fault aperture, and fracture and fault van Genuchten $\alpha$ values.

Table 7.6-1. Uncalibrated Rock Properties

\begin{tabular}{|l|l|l|l|l|l|}
\hline \multirow{2}{*}{\multicolumn{1}{c|}{ Rock property }} & \multirow{2}{*}{ Fault $^{\text {e }}$} & Fracture & Matrix & Fracture & Matrix \\
\cline { 3 - 6 } & $4.34 \mathrm{E}-11$ & $5.5 \mathrm{E}-13^{\mathrm{c}}$ & $3.08 \mathrm{E}-17^{\mathrm{a}}$ & $0.35 \mathrm{E}-13^{\mathrm{e}}$ & $4.07 \mathrm{E}-18^{\mathrm{a}}$ \\
\hline Permeability $(\mathrm{m} 2)$ & 1.00 & $6.6 \mathrm{E}-3^{\mathrm{d}}$ & $0.154^{\mathrm{a}}$ & $1 . \mathrm{E}-2^{\mathrm{d}}$ & $0.11^{\mathrm{a}}$ \\
\hline Porosity & & $1.03^{\mathrm{e}}$ & & $1.5^{\mathrm{e}}$ & \\
\hline Fracture frequency $(\mathrm{m}-1)$ & & $1.49 \mathrm{E}-3^{\mathrm{e}}$ & & $1.14 \mathrm{E}-3^{\mathrm{e}}$ & \\
\hline Fracture aperture $(\mathrm{m})$ & $1.12 \mathrm{E}-3$ & & & $0.41^{\mathrm{a}}$ & \\
\hline $\begin{array}{l}\text { Active fracture model } \\
\text { parameter } \gamma\end{array}$ & 0.0 & $0.41^{\mathrm{a}}$ & & & \\
\hline van Genuchten $\alpha(\mathrm{Pa}-1)$ & $1.0 \mathrm{E}-3$ & $11.46 \mathrm{E}-3^{\mathrm{a}}$ & $2.13 \mathrm{E}-5^{\mathrm{a}}$ & $5.16 \mathrm{E}-4^{\mathrm{a}}$ & $3.86 \mathrm{E}-6^{\mathrm{a}}$ \\
\hline van Genuchten $\mathrm{m}$ & 0.608 & $0.608^{\mathrm{a}}$ & $0.298^{\mathrm{a}}$ & $0.608^{\mathrm{a}}$ & $0.291^{\mathrm{a}}$ \\
\hline
\end{tabular}

${ }^{a}$ DTN: LB997141233129.001 (DIRS 104055).

b DTN: LB980901233124.101 (DIRS 136593).

c DTN: LB990861233129.001 (DIRS 110226).

d DTN: LB990501233129.001 (DIRS 106787).

e Wang (2003 [DIRS 162417], SN-LBNL-SCI-215-V1, pp. 114 to 115).

Infiltration-seepage processes in the fault and the surrounding fractured rock were determined by several mechanisms. Liquid water applied at the alcove floor (Figure 7.6-5) flowed first into the fault and then into fractured networks connected to the fault. Matrix imbibition occurred at interfaces between fractures and the matrix, and between the fault and the matrix. When water arrived at the intersection between the fault and the niche, it might not have immediately seeped into the niche until the capillary pressure became zero because of capillary barrier effects (Philip et al. 1989 [DIRS 105743]; Birkholzer et al. 1999 [DIRS 105170]). Such effects can divert flow away from the opening, resulting in only a portion of the water arriving at the niche ceiling 
actually seeping into the niche. Tracer transport time was determined by fracture porosity, fault aperture, and the matrix imbibition process.

Figure 7.6-6 shows a comparison between seepage-rate data and the simulation result from a model calibration (Run \#1) without considering the water-travel-velocity data. In this calibration run, fracture porosity and fault aperture were not varied. A fairly good match to the observed seepage data was obtained (Figure 7.6-6); however, water travel velocity is significantly overestimated (Figure 7.6-7). Water travel velocities were calculated from water arrival times at locations about $1 \mathrm{~m}$ above the middle of the opening in Figure 7.6-5 (Wang 2003 [DIRS 162417], SN-LBNL-SCI-215-V1, pp. 116 to 119). The transport time was defined as the time when fault or fracture saturation was increased from the initial value of $1.05 \mathrm{E}-2$ to $1.06 \mathrm{E}-2$. This comparison implies that seepage rate as a function of time may be mainly controlled by rock properties near seepage locations [influence zone of capillary barrier (Liu et al. 2002 [DIRS 160230], Section 3.3)]. On the other hand, water travel velocities are determined by rock properties from the infiltration plot to the locations where water travel velocities are monitored. Table 7.6-2 gives the calibrated properties obtained from Run \#1.

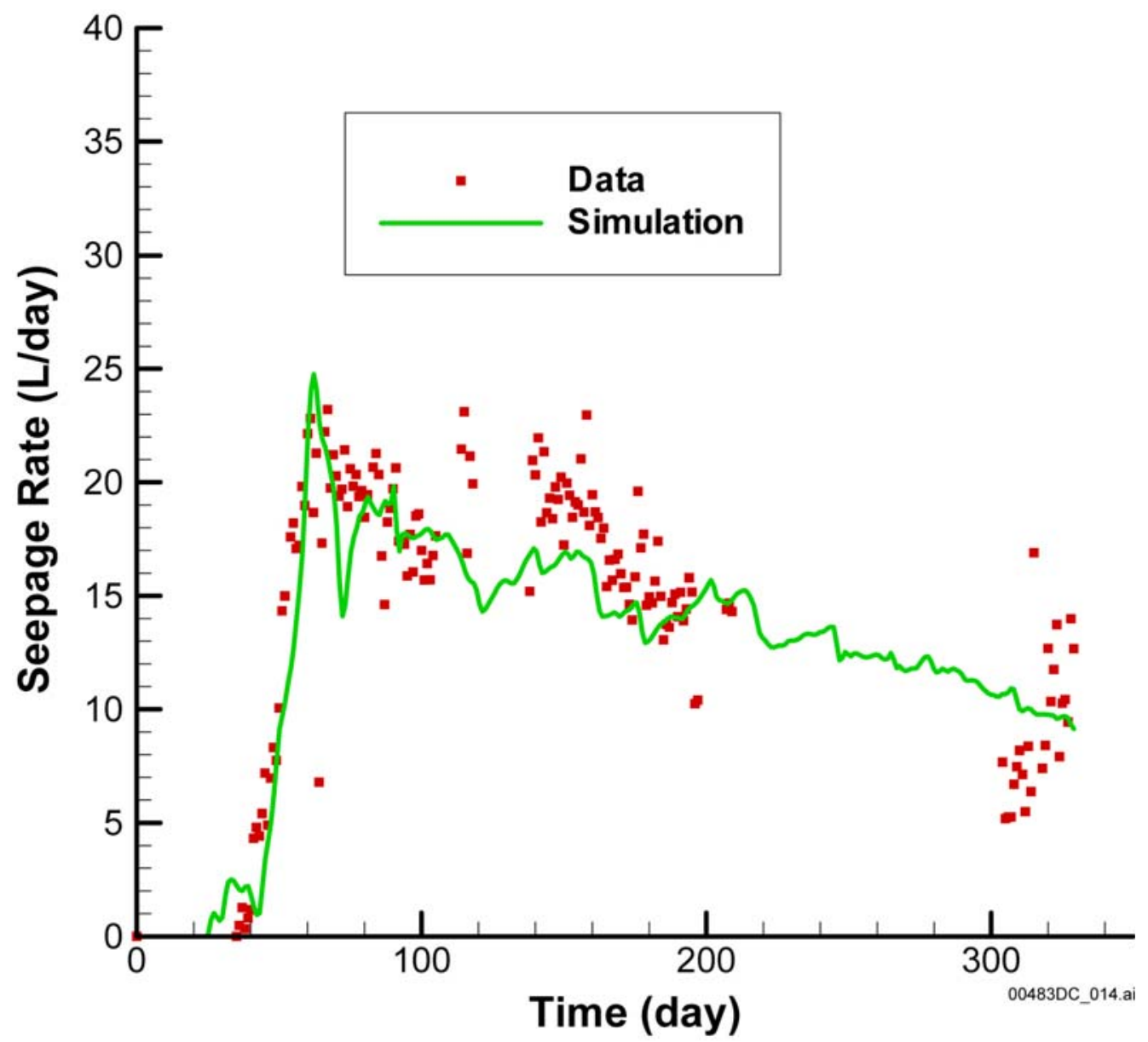

Source DTN: LB0303A8N3LIQR.001 (DIRS 162570) (file: All_seepage.dat).

Output DTN: LB0303A8N3MDLG.001 (file: Irun1i.tec).

Figure 7.6-6. A Comparison between Simulated Seepage Rates as a Function of Time (Run \#1) and Field Observations 


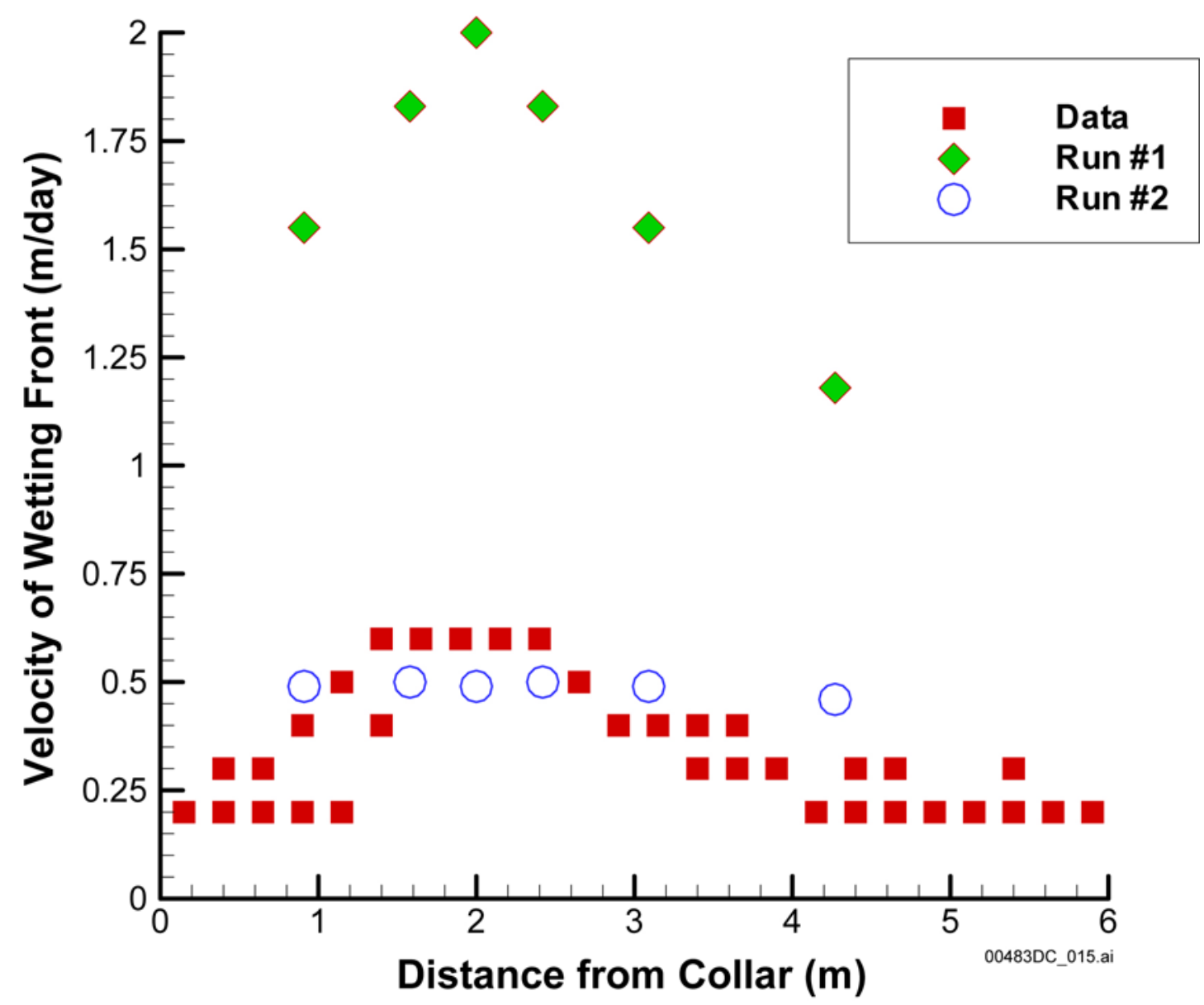

Source DTN: LB0303A8N3LIQR.001 (DIRS 162570).

Output DTN: LB0303A8N3MDLG.001 (files: WV_Irun1Ni.tec; WV_Irun4Ni.tec).

Figure 7.6-7. A Comparison among Calculated Water Travel Velocities from Two Calibration Runs and the Velocity Data Observed from the Fault Test

Table 7.6-2. Rock Properties Calibrated from Seepage Rate Data (Run \#1)

\begin{tabular}{|l|c|c|c|}
\hline \multicolumn{1}{|c|}{ Rock property } & Fault & tsw33 & tsw34 \\
\hline Fracture Permeability $\left(\mathrm{m}^{2}\right)$ & $6.67 \mathrm{E}-11$ & $8.93 \mathrm{E}-13$ & $3.16 \mathrm{E}-14$ \\
\hline Fracture van Genuchten $\alpha\left(\mathrm{Pa}^{-1}\right)$ & $1.15 \mathrm{E}-3$ & $1.67 \mathrm{E}-3$ & $4.59 \mathrm{E}-4$ \\
\hline
\end{tabular}

Source: DTN: LB0303A8N3MDLG.001 (file: Irun1i.par).

a All other rock properties are the same as those in Table 7.6.1. Rock names "tswF3", "NetF3," and "NetF4" in file Irun1i.par correspond to "Fault", "tsw33" and "tsw34", respectively, in this table. 
The overestimation of the water travel velocities may result from the following: (1) some cavities in tsw 33 are connected to fractures and might contribute to increasing the storage in the fracture continuum; (2) in reality, the fault is a zone rather than a single fracture. The effective aperture from this zone may be much larger than the assumed aperture value for the fault (Table 7.6-1). Neither of these factors was considered in Run \#1 (first calibration). Taking these factors into consideration, the new calibration (Run \#2) allowed both fault aperture and fracture porosity in tsw33 to be varied. The resultant values are $3 \mathrm{~cm}$ for fault aperture and 0.066 for fracture porosity of tsw33 (Table 7.6-3). While the actual width of the fault zone is unknown, the estimated equivalent fault aperture $(3 \mathrm{~cm})$ is used. The estimated fracture porosity is consistent with those estimated from water release tests performed in the same geological unit (BSC 2004 [DIRS 170004], Section 6.11.3.2).

Table 7.6-3. Rock Properties Calibrated from Both Seepage Rate and Water Travel Velocity Data (Run \#2)

\begin{tabular}{|l|c|c|c|}
\hline \multicolumn{1}{|c|}{ Rock property } & Fault & tsw33 & tsw34 \\
\hline Fracture Permeability $\left(\mathrm{m}^{2}\right)$ & $1.12 \mathrm{E}-10$ & $1.23 \mathrm{E}-12$ & $5.01 \mathrm{E}-13$ \\
\hline Fracture Porosity & & 0.066 & \\
\hline Fracture aperture $(\mathrm{m})$ & 0.03 & & \\
\hline Fracture van Genuchten $\alpha\left(\mathrm{Pa}^{-1}\right)$ & $1.24 \mathrm{E}-3$ & $2.19 \mathrm{E}-3$ & $1.09 \mathrm{E}-3$ \\
\hline
\end{tabular}

Source: Output DTN: LB0303A8N3MDLG.001 (file Irun4Ni.par).

NOTE: All other rock properties are the same as those in Table 7.6.1. Rock names "tswF3", "NetF3," and "NetF4" in file Irun1i.par correspond to "Fault", "tsw33," and "tsw34", respectively, in this table.

Figure 7.6-7 shows a comparison among calculated water travel velocities from two calibration runs and the velocity data observed from the fault test. The simulated water travel velocities from Run \#2 are much closer to the observed data than those from Run \#1 (especially near the fault). However, the water travel velocities away from the fault are still overestimated. One possible explanation is that matrix imbibition from fractures above the niche were underestimated because the dual-continuum approach considerably underestimates the pressure gradient near a fracture matrix interface during transient flow conditions (Pruess and Narasimhan 1985 [DIRS 101707]). While this problem can be resolved with the MINC model of the report by Pruess and Narasimhan (1985 [DIRS 101707]), the computational intensity of the inverse model problem under consideration would be significantly increased. Note that a model calibration involves a great number of forward simulation runs. Considering that (1) the transient flow effects would be considerably reduced later in the test and that (2) our focus here is on flow and transport within and near faults, simulated flow field and calibrated rock properties from Run \#2 were used for simulating tracer transport at the test site. Figure 7.6-8 also shows a comparison between simulated seepage rates as a function of time (Run \#2) and field observations. The match is reasonable. Figure 7.6-8 matches both wetting-front velocity and seepage-rate, and it is, therefore, considered a better calibration than Figure 7.6-6, which only matches the seepage rate data. Note that to give a reasonable prediction of solute transport, the water flow must be correctly modeled. 


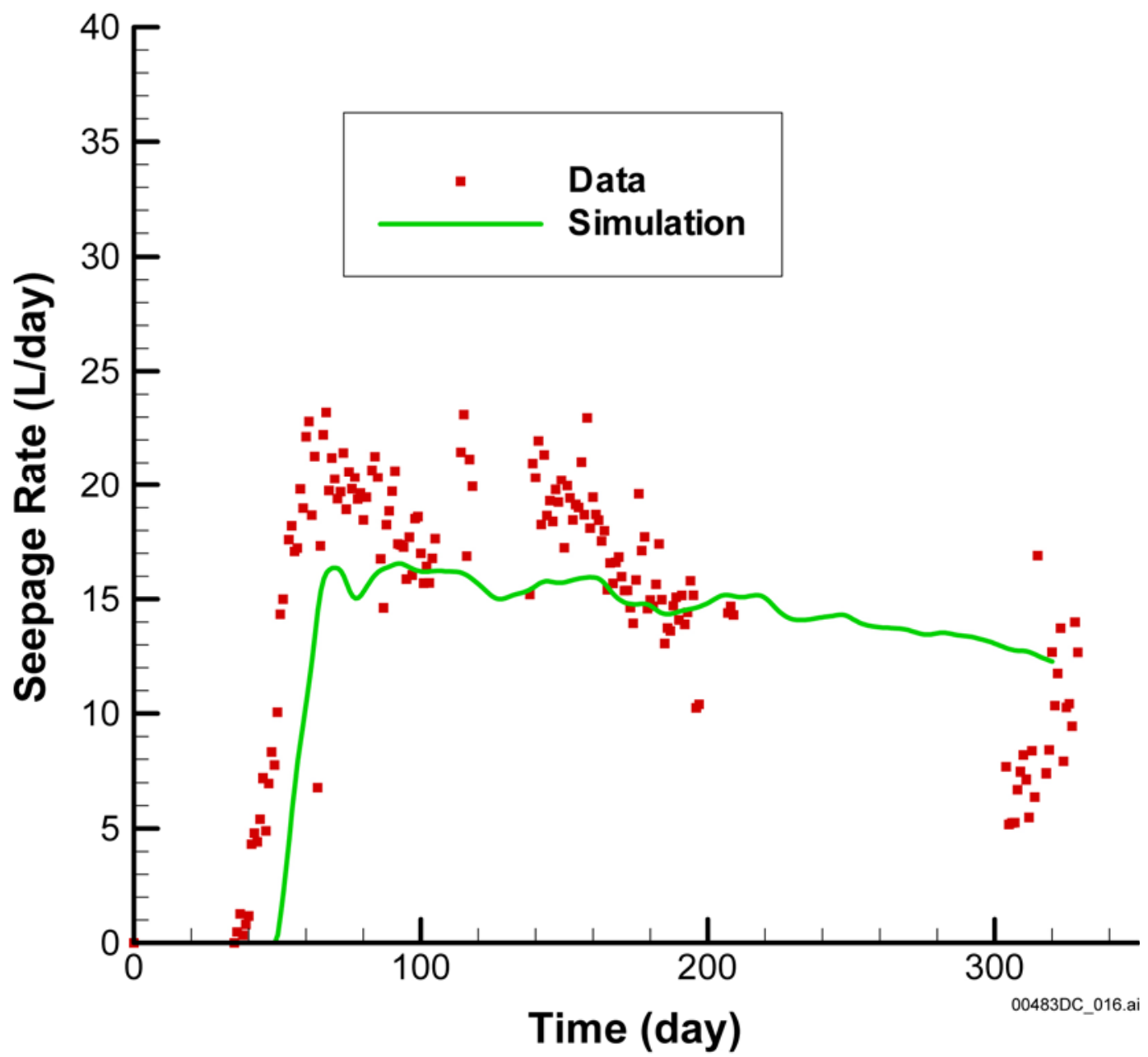

Source DTN: LB0303A8N3LIQR.001 (DIRS 162570) (file: All_seepage.dat).

Output DTN: LB0303A8N3MDLG.001 (file: Irun4Ni.tec).

Figure 7.6-8. A Comparison between Simulated Seepage Rates as a Function of Time (Run \#2) and Field Observations

\subsubsection{Effects of Matrix Diffusion}

Tracer transport within the fault is controlled by several processes, including advection, diffusion into the matrix blocks (matrix diffusion), mass exchange between the fault and the surrounding fracture networks, and dispersion. Our special attention in this study is given to evaluating the relative importance of matrix diffusion. To do so, we used the flow field obtained from calibration Run \#2 to simulate tracer transport processes and compare simulation results with field observations (Figure 7.6-4). The breakthrough curve is obtained from the output of T2R3D V1.4 (LBNL 1999 [DIRS 146654]) using a software routine Bkread.f V1.0 (LBNL 2002 [DIRS 162143]).

Two conservative tracers with different molecular diffusion coefficients $\left(2.08 \mathrm{E}-9 \mathrm{~m}^{2} / \mathrm{s}\right.$ for $\mathrm{Br}$ (Lide 2002 [DIRS 160832]) and 7.60E-10 m² for pentafluorobenzoic acid (Benson and Bowman 1996 [DIRS 153427]) were used in the fault test. Based on analyses of the relevant 
diffusion experiment results, Moridis et al. (2003 [DIRS 161902], Table 1) reported that the tortuosity factor for the tuff matrix can be approximated by the corresponding matrix porosity. Therefore, the average matrix porosity for tsw33 and tsw34 (0.13) was used as the tortuosity factor. The effective diffusion coefficient for the matrix diffusion process is the product of the molecular diffusion coefficient and tortuosity factor.

Figure 7.6-9 shows comparisons between simulated breakthrough curves at the niche for two different fault-matrix interface areas and the observed data. One simulation corresponds to an interface area defined in the original numerical grid, which considers the fault as a fracture with two vertical walls. The criterion for validation is that the predicted results for the time required for a conservative tracer to reach a given concentration (e.g., peak concentration) are within a factor of five of the observed time (BSC 2002 [DIRS 160819], Attachment Section I-1-2-1). Note that this criterion is met (Figure 7.6-9). The other sensitivity simulation corresponds to an interface area increased by 45 times over that in the first simulation. In these two simulations, the dispersivity is assumed to be zero. (The relative importance of the dispersion will be discussed later.) Since the diffusive flux from the fault to the matrix is proportional to the product of the tortuosity factor and the fault-matrix interface area, changes in the interface area for a given tortuosity factor are equivalent to changes in tortuosity factor for a given interface area. For simplicity, the tortuosity factor value was changed in actual simulations, but the numerical grid (defining the interface area) was kept unchanged. Note that changes in the interface area do not significantly alter the flow field during the period of the tracer test. Tracers were introduced into infiltrating water at about 200 days after infiltration started, resulting in the matrix near the fault being almost saturated during the tracer test and the matrix imbibition being insignificant. As shown in Figure 7.6-9, the simulated breakthrough curve with the original interface area is very different from the observed data. It exhibits much larger concentration peak values and much earlier arrival times for these peaks. The observed data are favorably matched by the simulated result with increased interface area, indicating that matrix diffusion significantly affects the overall solute transport behavior and is underestimated by the simulation using the original interface area.

The need to increase interface areas between fractures (or faults) and the matrix in matching the field observations of tracer transport in fractured rock has been recently reported by several researchers. Shapiro (2001 [DIRS 162132]) interpreted concentration measurements for tritium and dichlorodifluoromethane collected from a glacial drift and fractured crystalline rock over $4 \mathrm{~km}^{2}$ in central New Hampshire. He found that the effective diffusion coefficient at the kilometer scale is at least three orders of magnitude greater than laboratory estimates of diffusion in crystalline rock. Neretnieks (2002 [DIRS 162140]) presented comparisons between several analytical solutions and tracer test results at the Äspö site and reported a need for a factor 30 to 50 times larger for the fracture-matrix interface area than expected. He also indicated that nine other research groups reached a similar conclusion in their interpretation of the same test data set. Our results in this study are consistent with these previous findings. 


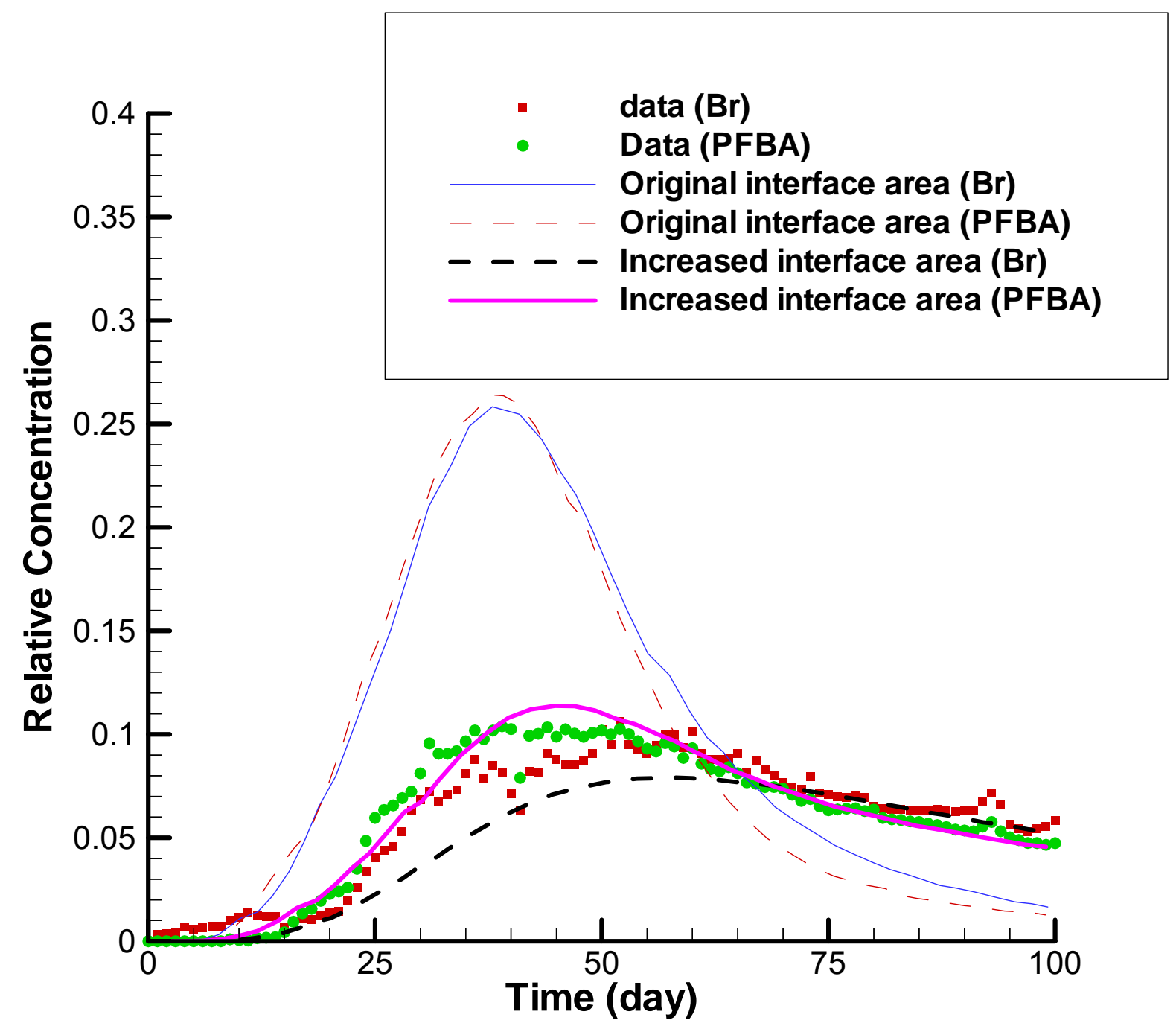

Output DTN: LB0303A8N3MDLG.001 (files: BTC.dat; BTC_odis.dat).

Figure 7.6-9. Comparisons between Simulated Breakthrough Curves at the Niche for Two Different Fault-Matrix Interface Areas and the Observed Data 
Several mechanisms regarding the increase in the interface area have been reported in the literature. They include (1) advective mass exchanges from high-permeability fractures to low-permeability fractures (Shapiro 2001 [DIRS 162132], Section 7), (2) diffusion into stagnant water zones (Neretnieks 2002 [DIRS 162140]), and (3) enhanced fracture-matrix interface areas for fractures with small-trace lengths that do not contribute to global flow and are not considered in the survey data (and, therefore, not included in the numerical grid). In addition to these potential mechanisms, two other factors also contribute to the increase in the interface area. First, in the relevant analytical and numerical solutions to tracer transport, fracture walls are assumed to be flat surfaces. However, it is now well known that fracture walls are rough and characterized by fractal geometry (National Research Council 1996 [DIRS 139151], pp. 105 to 111). Consequently, the actual interface areas between fractures (and faults) and the matrix are larger than what are calculated using flat fracture walls. Second, a fault zone may include a great number of crushed matrix blocks that have smaller sizes than the fracture spacing in a non-fault zone. These crushed matrix blocks can make a significant contribution to the matrix diffusion within the fault, but are not considered in our numerical grid, where the fault is simply treated as a vertical fracture. To compensate for the effects of these mechanisms mentioned above, an increase in fault-matrix interface areas is obviously needed.

Although simulation results with the increased interface area reasonably match the observed data (Figure 7.6-9), the concentration difference at a given time for the two tracers is generally overestimated by the model. One plausible explanation is that the crushed matrix blocks within the fault zone have much smaller sizes than the fracture spacing. This, however, is not considered in our model, in which the matrix block size is characterized by fracture spacing. The smaller sizes correspond to the shorter times needed by the equilibrating tracer concentration at the center and outer surface of a matrix block, reducing the difference between the effects of matrix diffusion on overall solute transport behavior for different molecular-diffusion coefficients. This can be further illustrated by an extreme case: an infinitely small block size within the fault and without mass exchange between the fault and nonfault fractured rock. In this case, the concentrations of the matrix block within the fault can be equilibrated simultaneously with those at the outer surface of the block for two tracers with different molecular diffusion coefficients. Consequently, although the existence of this kind of matrix block can still significantly retard tracer transport within the fault, identical breakthrough curves may be observed at Niche 3 for the two tracers. This issue was not further explored in the current modeling study because the matrix block size distribution within the fault cannot be independently estimated or observed.

Compared with matrix diffusion, the macrodispersion process is not considered to be significant within the fault for this particular test. Field measurements indicate that water travel-velocity distribution is quite uniform within and near the fault (Figure 7.6-3), whereas macrodispersion results from variability in water velocity. These experimental observations are consistent with the findings from our model analyses: the observed data were very difficult to match when a considerable degree of dispersion was included in the model. For example, Figure 7.6-10 shows simulated breakthrough curves with a longitudinal dispersivity value of $1 \mathrm{~m}$ and a transverse dispersivity value of $0.1 \mathrm{~m}$ (and with the increased fault-matrix interface area), compared to results in Figure 7.6-9 (without considering dispersion). Larger dispersivity values generally correspond to earlier arrival times of peak concentrations and to a larger difference between these peak concentrations for the two different tracers. 


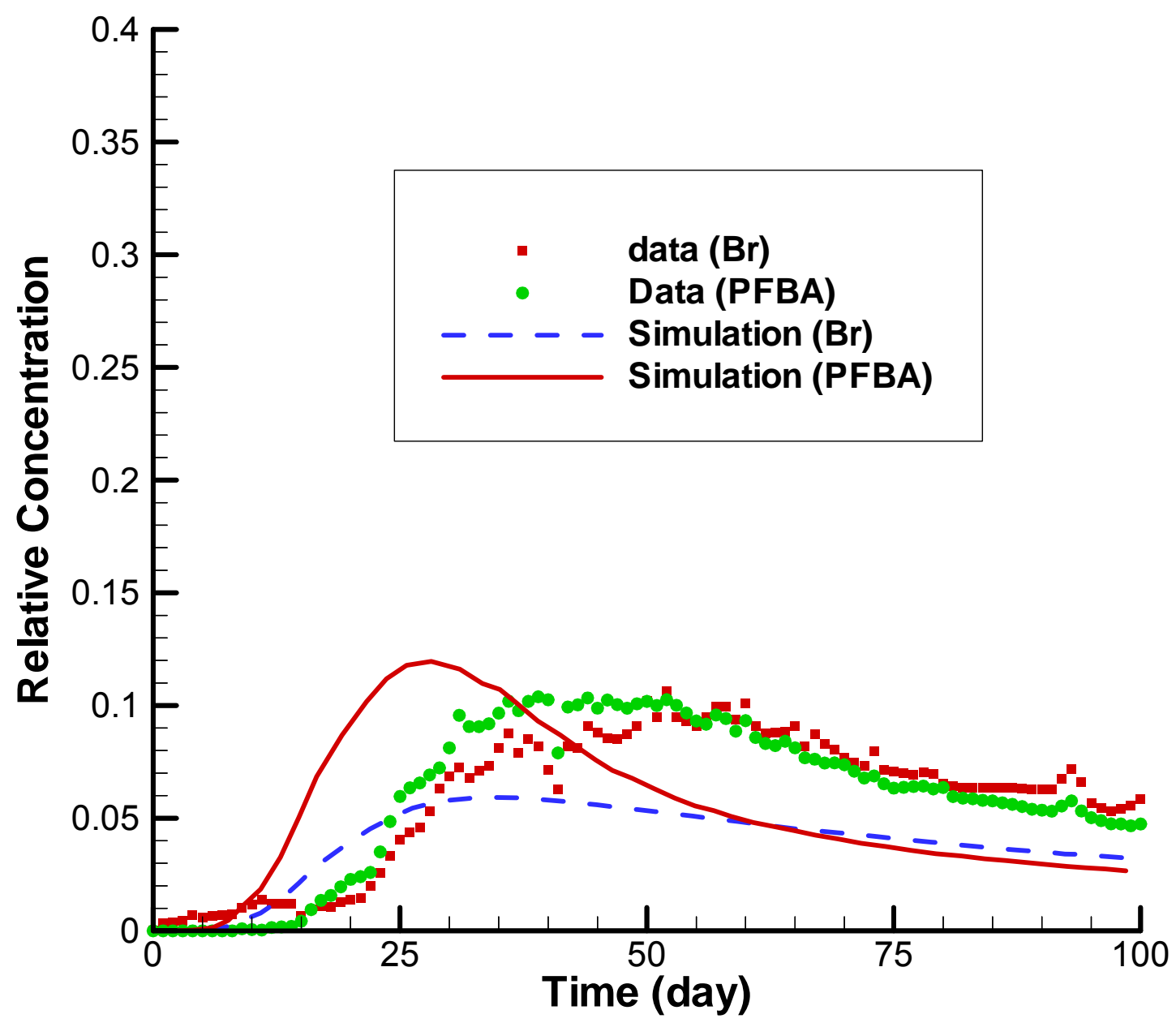

Output DTN: LB0303A8N3MDLG.001 (files: BTC.dat; BTC_dis.dat).

Figure 7.6-10. Comparisons between Simulated Breakthrough Curves (Considering Dispersion) at the Niche for the Increased Fault-Matrix Interface Areas and the Observed Data

\subsubsection{Implication for Radionuclide Transport in the Yucca Mountain UZ}

Matrix diffusion has been identified as a key mechanism for retarding radionuclide transport in both unsaturated and saturated fractured rock (e.g., Bodvarsson et al. 2001 [DIRS 160133]; Neretnieks 2002 [DIRS 162140]). The enhancement of the fracture (fault)-matrix interface area (or effective matrix diffusion coefficient) seems to be common for matching field-scale solute transport observations, as suggested by this study and previous studies (Shapiro 2001 [DIRS 162132]; Neretnieks 2002 [DIRS 162140]). The current site-scale model for the Yucca Mountain UZ does not include the effects of this enhancement. Consequently, the estimated performance of the repository, estimated based on the site-scale model, may be conservative.

The other related issue is the effects of cavities (existing in several geological layers at the Yucca Mountain site) on water flow and radionuclide transport processes. One may intuitively expect the cavities connected to fractures to act as capillary barriers under unsaturated conditions, because the cavity openings are much larger than fracture apertures. However, both this study and analyses of water-release tests performed in the related geological units at the Yucca 
Mountain site suggest that cavities are accessible by water within fracture networks, and, therefore, are retarding the downward water flow and radionuclide transport processes. This is also supported by field observation that mineral coatings exist in many cavities (BSC 2004 [DIRS 169734], Section 5.2.2.5.4). The coating is a signature for liquid-water flow paths. Although the cavity openings are larger than fracture apertures, the roughness of cavity walls may result in film flow (along cavity walls) from fractures to the cavities (Tokunaga and Wan 1997 [DIRS 139195]).

\subsection{AMBIENT THERMAL MODEL}

A site-scale model of heat flow and geothermal conditions in the Yucca Mountain UZ was developed in the report by Wu et al. (1999 [DIRS 117161]). Percolation flux was estimated from temperature data (Bodvarsson et al. 2003 [DIRS 162477]). This ambient thermal model simulates large-scale UZ geothermal and heat flow conditions,. and also provides thermal, gas, and moisture boundaries, and initial conditions for the mountain-scale and drift-scale thermal-hydrological (TH), thermal-hydrological-chemical (THC), and thermal-hydrologicalmechanical (THM) coupled process models. The three-dimensional ambient thermal model, as discussed in Section 6.3, has been calibrated against qualified temperature data measured from five boreholes. The model uses the three-dimensional UZ flow model and the base-case, mean infiltration property set as input parameters, and simulates advective and conductive heat transfer processes within the UZ at ambient, steady-state conditions.

To validate the ambient thermal model, modelers use borehole-measured temperature as corroborative evidence in this section. Based on the validation plan (BSC 2002 [DIRS 160819], Attachment Section I-1-2-2), ECRB temperature data, if available in the TDMS, would be used for the validation. Since no ECRB temperature measurements are currently available from the TDMS, the temperature data measured from Boreholes H-5, H-4, and WT-18 (Sass et al. 1988 [DIRS 100644]; with DTN: GS950408318523.001 [DIRS 107244]) are used instead in the following validation. The criterion is the same as planned for ECRB data: agreement within $\pm 3{ }^{\circ} \mathrm{C}$. These boreholes were not used for calibration in Section 6.3.

The locations of Boreholes H-5, H-4, and WT-18 are plotted in Figure 6.3-1. These boreholes penetrate the repository block and the entire UZ. The comparisons of simulated and observed temperature profiles along this borehole are shown in Figures 7.7-1, 7.7-2, and 7.7-3, indicating a good match between the three-dimensional model prediction and observed data. Borehole H-5 is close by the ECRB, and Figures 7.7-1 and 7.7-2 show that the simulated temperatures differ from observed values by less than $1.5^{\circ} \mathrm{C}$ in all elevations. In Borehole WT-18, the simulated results again prove to be a reasonable match with field-measured data. All these simulation results are within $2^{\circ} \mathrm{C}$ of the measured temperature, which is smaller than the criterion of validation of $3^{\circ} \mathrm{C}$ in the TWP. Therefore, the validation criterion is satisfied. 


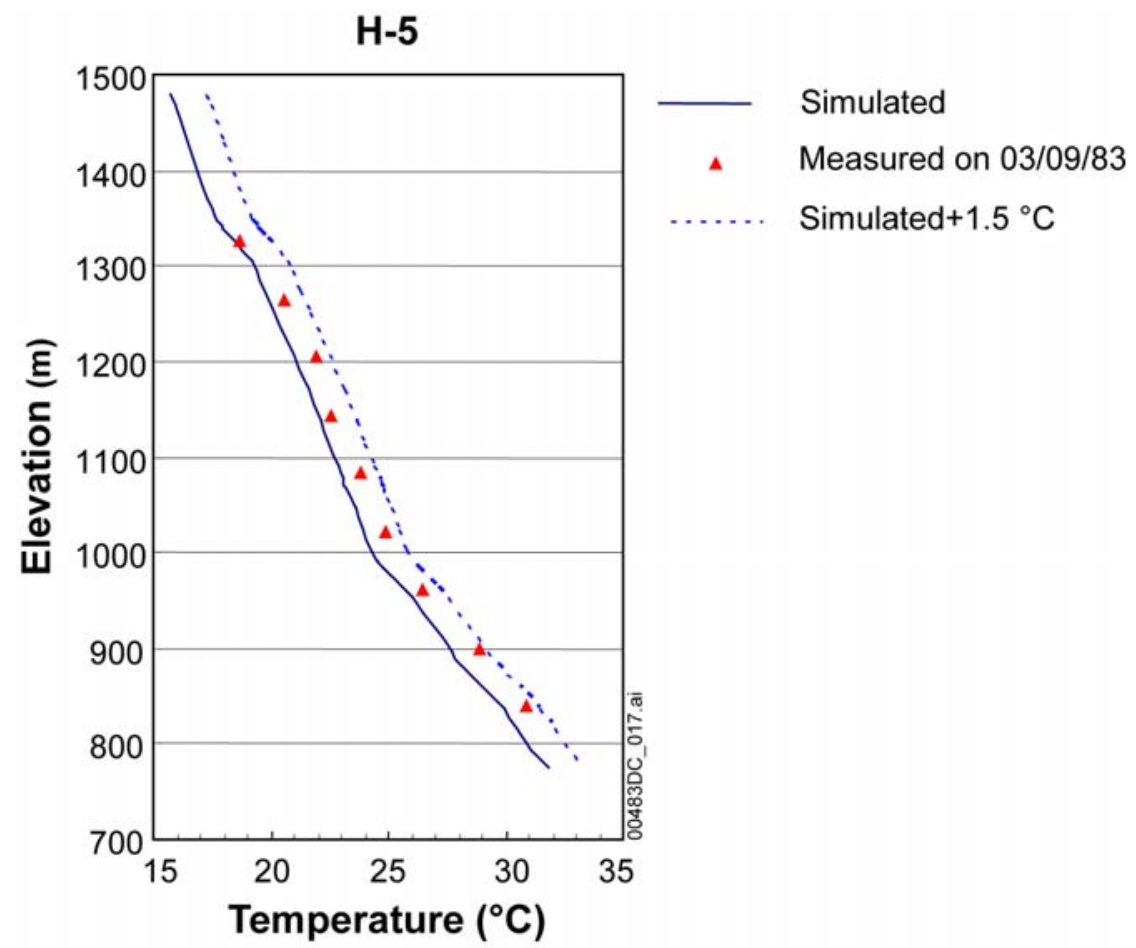

Source DTN: GS950408318523.001 (DIRS 107244).

Output DTN: LB0303THERMSIM.001.

Figure 7.7-1. Comparison of Simulated and Observed Temperature Profiles for Borehole H-5

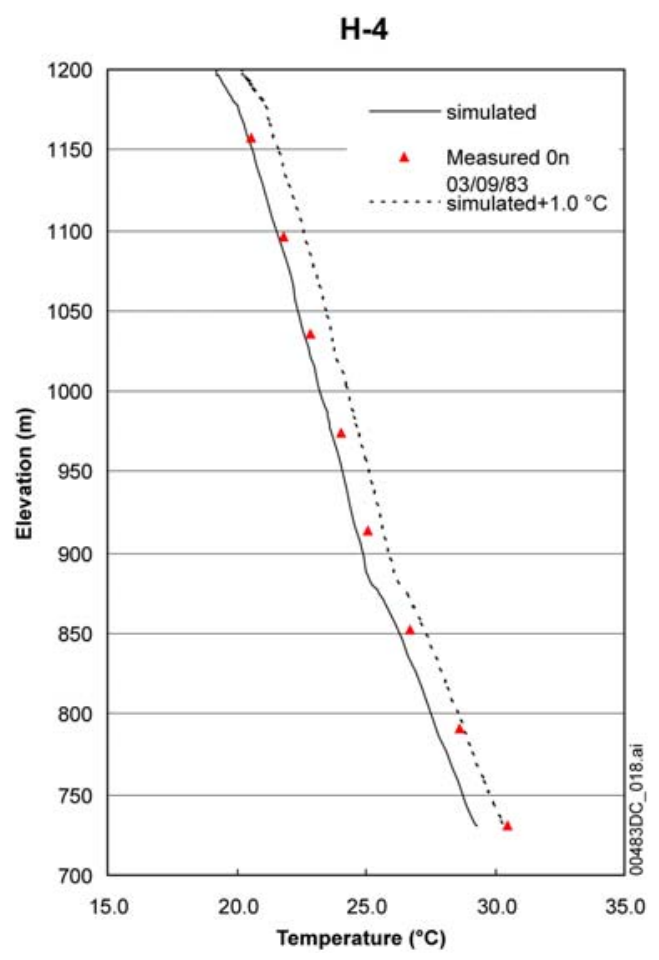

Source DTN: GS950408318523.001 (DIRS 107244).

Output DTN: LB0303THERMSIM.001.

Figure 7.7-2. Comparison of Simulated and Observed Temperature Profiles for Borehole H-4 


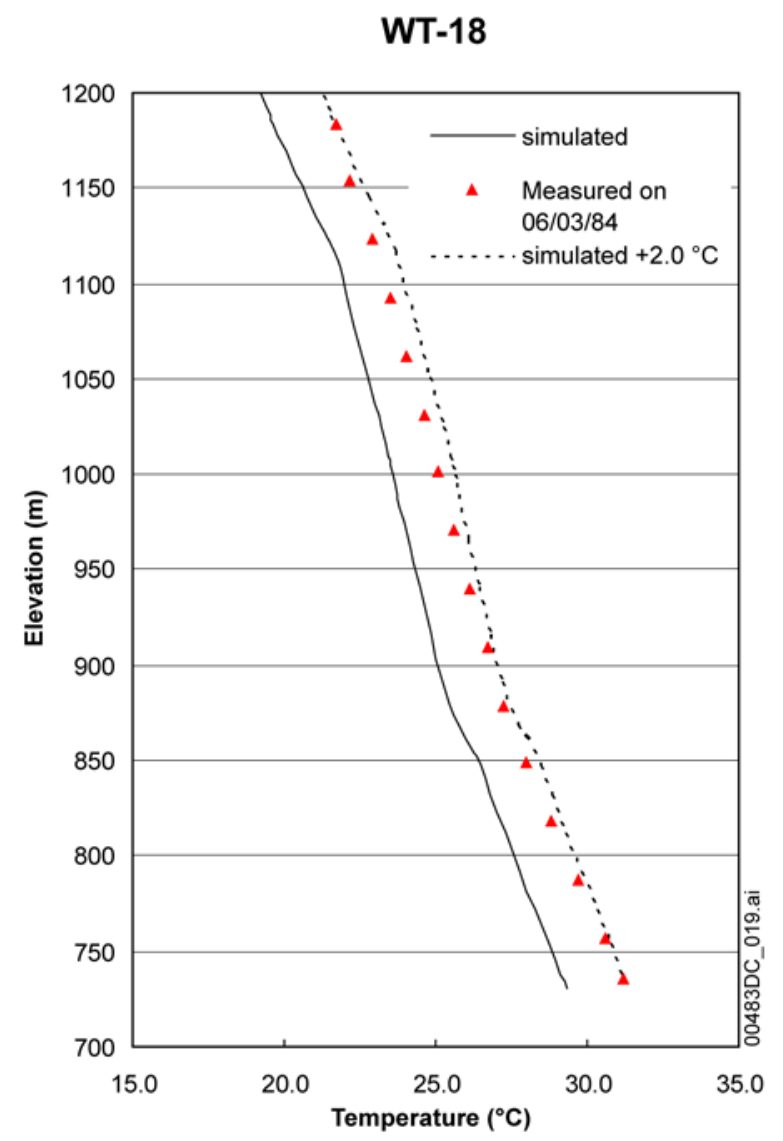

Source DTN: GS950408318523.001 (DIRS 107244).

Output DTN: LB0303THERMSIM.001.

Figure 7.7-3. Comparison of Simulated and Observed Temperature Profiles for Borehole WT-18

\subsection{VALIDATION USING CHLORIDE MEASUREMENTS ALONG ESF}

Natural chemical tracers in subsurface systems can be useful tools in examining water flow and solute transport and their history. Chloride is hydrologically very mobile and chemically inert, and a nearly ideal natural tracer for the study of water movement in the liquid phase in geological systems. Chloride has been used already in some relevant applications to flow and transport modeling of Yucca Mountain UZ, and has been used to calculate infiltration rates along the ESF (Fabryka-Martin et al. 1998 [DIRS 146355]). Liu et al. (2003 [DIRS 162478]) calibrated infiltration rates using chloride data in conjunction with hydrostructural and hydrogeological features, and demonstrated that the impact of infiltration alteration on percolation fluxes is less than that on chloride concentration. Chloride has been used in this report to calibrate UZ flow model predictions of percolation fluxes and moisture distributions within the UZ system, as discussed in Section 6.5.

The chloride model simulates large-scale UZ chloride transport processes. It uses the three-dimensional flow fields calculated by the UZ flow model and incorporates chloride-in-precipitation data to model advective and diffusive chloride transport in the UZ. Its purpose is to validate the UZ flow model by testing it with data not used in the development or calibration of the UZ flow model. The simulated pore-water chloride concentration is compared 
with analysis of samples collected along the ESF. Chloride concentrations of the ESF at different infiltration scenarios are plotted in Figure 7.8-1. The range of the simulated chloride concentration of the base case flow field (preq $\mathrm{mA}$ ) in the ESF fall, in general, within the range for measured concentrations, which satisfies the validation criterion. The figure also indicates that the trend of chloride concentrations in samples is preserved in the calculated chloride concentrations. Note that measured chloride data are clustered around three areas with distances of about 1,000; 3,600; and greater than $6,800 \mathrm{~m}$. For the first two locations, at 1,000 and $3,600 \mathrm{~m}$, the simulated (preq $\mathrm{mA}$ ) results are either within or at the range of measurements. For the last portion, however, the simulations are well within the range of measurement for greater than 7,000 $\mathrm{m}$ and are close to (but a little higher than) the measurement.

\section{ESF}

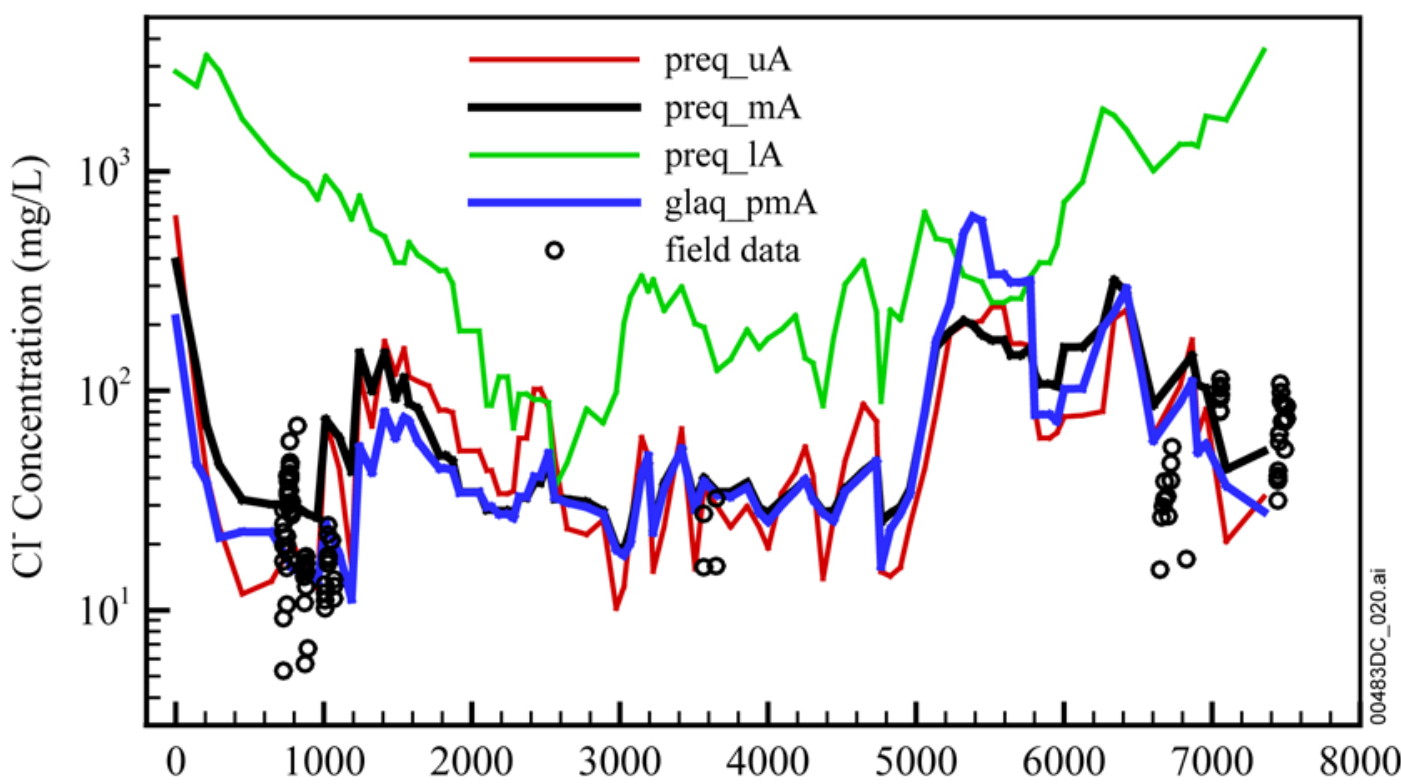

Distance from the North Portal Entrance (m)

Source DTNs: GS961108312261.006 (DIRS 107293); LA0002JF12213U.002 (DIRS 156281); LA9909JF831222.010 (DIRS 122733).

Output DTN: LB0303CLINFL3D.001.

Figure 7.8-1. Comparison of Chloride Concentration (mg/L) Profiles under Present-Day Recharges with Mean, Upper, and Lower Bounds and Glacial-transition Recharge at the ESF

\subsection{CALCITE MODEL RESULTS}

\subsubsection{Introduction}

The percolation flux in the UZ is an important parameter because it controls seepage into drifts that may contact waste packages. As shown in Section 6.6, it depends strongly on the infiltration flux, which is a boundary condition of the UZ flow model. Observations of precipitated calcite in the UZ constrain the infiltration flux. Therefore, comparing observed hydrogenic calcite deposits to simulations increased confidence in the model's ability to capture this boundary condition. Because direct measurements of infiltration flux is not possible, this confirmation of 
the boundary condition generally builds confidence in the UZ flow model. Hydrogenic calcite deposits in fractures and lithophysal cavities at Yucca Mountain have been studied to estimate past percolation fluxes (Carlos et al. 1995 [DIRS 162118]; Marshall et al. 1998 [DIRS 107415]; BSC 2004 [DIRS 169734], Section 7.7.1).

One objective of these previous studies was to investigate the relationship between percolation flux and measured calcite abundances. The U.S. Geological Survey (USGS) determined calcite abundances from a deep surface-based borehole (WT-24) (DTN: GS021008315215.007 [DIRS 162127]). Geochronology work performed by the USGS (Neymark et al. 2001 [DIRS 156889]) indicates that this calcite formed over approximately 10 million years. Hydrogenic mineral coatings in the UZ are nonuniformly distributed and located almost entirely on fracture footwalls and cavity floors - in contrast to saturated environments, in which vein and cavity deposits usually coat all surfaces.

A one-dimensional model column corresponding to the location of a deep borehole (WT-24) was chosen for modeling calcite deposition because measured calcite abundances (DTN: GS021008315215.007 [DIRS 162127]) were available for comparison. Here, the results of a reactive transport numerical model for calcite deposition under different infiltration conditions are presented. The setup and results of the problem are cited from the report by Xu et al. (2003 [DIRS 162124]). The reactive transport model used here considers the following essential factors affecting calcite precipitation: (1) infiltration, (2) the ambient geothermal gradient, (3) gaseous $\mathrm{CO}_{2}$ diffusive transport and partitioning in liquid and gas phases, (4) fracture-matrix interaction for water flow and chemical constituents (dual permeability), and (5) water-rock interaction. Any water-rock interaction effects (e.g., $\mathrm{pH}$ modification) also affect the calcite solubility, hence, its abundance in each rock unit. The dual-permeability model allows us to address not only the abundances of calcite with depth, but also its relative abundance in fractures and in the rock matrix as a function of the hydrological/geochemical processes in each medium, as well as the interaction of water flowing between fractures and matrix.

\subsubsection{Calcite Precipitation Mechanisms}

Along with wind-blown dust, precipitation carries much of the calcium to the surface (Vaniman et al. 2001 [DIRS 157427]). In the soil zone, strong evapotranspiration, along with some water-rock interaction and root-zone biological processes, leads to saturation with respect to calcite. The depth to reach calcite equilibrium depends on climate and infiltration variations over time, episodic water flow, and near-surface biogeochemical conditions. During more typical smaller infiltration events, calcite may reach equilibrium close to the surface. However, large infiltration pulses of calcite-undersaturated water can dissolve near-surface calcite and reach equilibrium at a greater depth. This model validation activity concerns calcite deposition in a deep geological unit, the TSw, where the repository is located. Uncertainty in the infiltrating water composition near the surface is, thus, insignificant because calcite reaches saturation well above this unit. In addition, the constant infiltration rate and steady-state water flow conditions over geological time used in our simulations are also justified by evidence that the rate of calcite growth in the UZ has remained approximately constant over at least the past 8 million years (Paces et al. 1998 [DIRS 107408]). 
The primary driving force for calcite precipitation from percolating waters in the UZ is its decreasing solubility with increasing temperature; calcite precipitates as water flows downward because of the geothermal gradient. Therefore, consideration of the ambient geothermal gradient is very important for calcite precipitation. The temperature distribution is a function of the crustal heat flow and the effect of infiltration. The modeled temperature distributions in Borehole WT-24 are discussed later in Section 7.9.5.2. Pore waters extracted from deep locations of the Yucca Mountain rock matrix are close to equilibrium with respect to calcite (BSC 2004 [DIRS 169734], Section 7.7.1), and no measurements of aqueous concentrations are available from fractures because they generally have low liquid saturations.

The calcium concentration and $\mathrm{CO}_{2}$ partial pressure in percolating water is a major factor controlling the abundances of calcite and its stability. This is a result of the decreasing solubility of $\mathrm{CO}_{2}$ gas in water with increasing temperature, which in turn causes the following degassing process: $\mathrm{HCO}_{3}^{-}+\mathrm{H}^{+} \rightarrow \mathrm{CO}_{2}(\mathrm{~g})+\mathrm{H}_{2} \mathrm{O}$. Gaseous $\mathrm{CO}_{2}$ is also redistributed by gas-phase diffusive transport. Degassing increases the $\mathrm{pH}$, and then contributes to calcite precipitation: $\mathrm{Ca}^{2+}+\mathrm{HCO}_{3}^{-} \rightarrow \mathrm{CaCO}_{3}$ (calcite) $+\mathrm{H}^{+}$. Water and gas flow between fractures and the adjacent matrix governs the resulting calcite distribution within each medium. Calcite precipitation is also affected by other factors, such as the dissolution and precipitation of aluminosilicate minerals (mainly through modifying the $\mathrm{pH}$ and the $\mathrm{CO}_{2}$ partial pressure).

\subsubsection{Reactive-Transport Model}

Modeling of calcite deposition in the Yucca Mountain UZ was performed using the reactive transport computer code TOUGHREACT (Xu and Pruess 1998 [DIRS 117170]; 2001 [DIRS 156280]). (This version of the code has not been qualified under LP-SI.11Q-BSC, but its use for corroboration is appropriate.) The code uses a sequential iteration approach similar to the report by Yeh and Tripathi (1991 [DIRS 162125]), Walter et al. (1994 [DIRS 162122]), and Xu et al. (1999 [DIRS 162123]), which solve the transport and reaction equations separately. Flow and transport are based on space discretization by means of integral finite differences. An implicit time-weighting scheme is used for individual components of the model: flow, transport, and kinetic geochemical reaction. The chemical transport equations are solved independently for each component, whereas the reaction equations are solved on a gridblock basis using Newton-Raphson iteration. Full details of the code are given in reports by Xu and Pruess (1998 [DIRS 117170]; 2001 [DIRS 156280]).

In the model, advective and diffusive transport of aqueous chemical species is considered in the liquid phase. Molecular diffusive transport of gaseous species $\left(\mathrm{CO}_{2}\right)$ is considered in the gas phase. Aqueous chemical complexation and gas dissolution/exsolution are accounted for under local equilibrium, whereas mineral dissolution/precipitation can proceed at equilibrium and/or can be kinetically controlled. Gas species in the chemical computations are assumed to behave as ideal gases (i.e., fugacity equals partial pressure). Temperature effects are considered for geochemical reaction calculations, because equilibrium and kinetic data are functions of temperature.

Changes in porosity and permeability from mineral dissolution and precipitation of water flow are not considered for the present modeling. This feedback between transport and chemistry can be important, but a rather large computational time penalty has to be paid if this is modeled 
explicitly. By neglecting porosity and permeability change, modelers obtain quasi-steady flow conditions. This makes it possible to consider geochemistry in great detail for a simulation period of 10 million years.

A dual-permeability approach, in which fractures and matrix are treated as two separate continua, was employed for water flow and chemical transport in the unsaturated fractured tuff. In this approach, interflow (water and chemicals) is allowed between fractures and the adjacent matrix, and global flow occurs within both fracture and matrix continua. The AFM developed by Liu et al. (1998 [DIRS 105729]) was used to describe fracture-matrix interaction and preferential liquid flow in fractures.

\subsubsection{Hydrogeological and Geochemical Conditions}

\subsubsection{Hydrogeological Conditions}

As discussed in the geological model of Section 6.1, the Yucca Mountain UZ consists of layers of welded and nonwelded volcanic tuffs. The welded and nonwelded tuffs have vastly different hydrological properties. Welded units are characterized by relatively low porosity, low matrix permeability, and high fracture density, whereas the nonwelded tuffs have higher matrix porosity and permeability, and lower fracture density (Liu et al. 1998 [DIRS 105729]). Montazer and Wilson (1984 [DIRS 100161]) developed a conceptual model for the UZ at Yucca Mountain that identified five main hydrogeological units based on the degree of welding and on the associated relationships to fracture intensity. This model has formed the basis for modeling flow in the UZ at Yucca Mountain. Table 7.9-1 describes each unit, which is further divided into a number of model layers with different hydrogeological and geochemical properties (BSC 2004 [DIRS 169857]; BSC 2004 [DIRS 169856]). The CHn unit is comprised of zeolitic and vitric nonwelded tuffs underlying the basal vitrophyre of the Topopah Spring Tuff. Below the CHn are the Crater Flat undifferentiated units, consisting of the lower Bullfrog and Tram Tuffs of the Crater Flat Group. The hydrogeological units below the TSw were not considered in geochemical transport simulations, so details regarding these units are not given in Table 7.9-1. We are primarily interested in calcite deposition within the TSw unit, where the repository is located (tsw4 and tsw5 model layers in Table 7.9-1). The exclusion of the underlying hydrogeological units does not affect the results in the TSw unit because flow is predominantly gravity driven, and upward chemical diffusion is subordinate to downward advective transport. 
Table 7.9-1. Hydrogeologic Units, Model Layers, and Hydrogeological Properties for the Yucca Mountain Unsaturated Zone Flow and Transport Model, as Given by the Calibrated Properties Model

\begin{tabular}{|c|c|c|c|c|c|c|}
\hline \multirow[b]{2}{*}{$\begin{array}{c}\text { Hydrogeologic } \\
\text { Unit }\end{array}$} & \multirow[b]{2}{*}{ Description } & \multirow[b]{2}{*}{$\begin{array}{l}\text { Model } \\
\text { Layer }\end{array}$} & \multicolumn{2}{|c|}{ Fracture } & \multicolumn{2}{|c|}{ Matrix } \\
\hline & & & $\begin{array}{c}\text { Permeability } \\
\left(\mathrm{m}^{2}\right)\end{array}$ & Porosity & $\begin{array}{c}\text { Permeability } \\
\left(\mathrm{m}^{2}\right)\end{array}$ & Porosity \\
\hline \multirow{3}{*}{$\begin{array}{l}\text { TCw: } \\
\text { Tiva Canyon } \\
\text { Welded unit }\end{array}$} & \multirow{3}{*}{$\begin{array}{l}\text { Moderately to } \\
\text { densely welded } \\
\text { portions of the Tiva } \\
\text { Canyon Tuff of the } \\
\text { Paintbrush Group }\end{array}$} & tcw1 & $2.41 \times 10^{-12}$ & $3.7 \times 10^{-2}$ & $3.86 \times 10^{-15}$ & 0.253 \\
\hline & & tcw2 & $1.00 \times 10^{-10}$ & $2.6 \times 10^{-2}$ & $2.74 \times 10^{-19}$ & 0.082 \\
\hline & & tcw3 & $5.42 \times 10^{-12}$ & $1.9 \times 10^{-2}$ & $9.23 \times 10^{-17}$ & 0.203 \\
\hline \multirow{6}{*}{$\begin{array}{l}\text { PTn: } \\
\text { Paintbrush } \\
\text { Nonwelded unit }\end{array}$} & \multirow{6}{*}{$\begin{array}{l}\text { Variably welded } \\
\text { Paintbrush Tuff and } \\
\text { its associated } \\
\text { bedded tuffs, } \\
\text { including those } \\
\text { located at the } \\
\text { bottom of the Tiva } \\
\text { Canyon and top of } \\
\text { the Topopah Spring } \\
\text { Tuffs }\end{array}$} & ptn1 & $1.86 \times 10^{-12}$ & $1.4 \times 10^{-2}$ & $9.90 \times 10^{-13}$ & 0.387 \\
\hline & & ptn2 & $2.00 \times 10^{-11}$ & $1.5 \times 10^{-2}$ & $2.65 \times 10^{-12}$ & 0.439 \\
\hline & & ptn3 & $2.60 \times 10^{-13}$ & $3.2 \times 10^{-3}$ & $1.23 \times 10^{-13}$ & 0.254 \\
\hline & & ptn4 & $4.67 \times 10^{-13}$ & $1.5 \times 10^{-2}$ & $7.86 \times 10^{-14}$ & 0.411 \\
\hline & & ptn5 & $7.03 \times 10^{-13}$ & $7.9 \times 10^{-3}$ & $7.00 \times 10^{-14}$ & 0.499 \\
\hline & & ptn6 & $4.44 \times 10^{-13}$ & $4.6 \times 10^{-3}$ & $2.21 \times 10^{-13}$ & 0.492 \\
\hline \multirow{9}{*}{$\begin{array}{l}\text { TSw: } \\
\text { Topopah Spring } \\
\text { welded unit }\end{array}$} & \multirow{9}{*}{$\begin{array}{l}\text { Moderately to } \\
\text { densely welded } \\
\text { portions of the } \\
\text { Topopah Spring Tuff } \\
\text { down to, and } \\
\text { including, the } \\
\text { densely welded } \\
\text { basal vitrophyre }\end{array}$} & tsw1 & $3.21 \times 10^{-11}$ & $7.1 \times 10^{-3}$ & $6.32 \times 10^{-17}$ & 0.053 \\
\hline & & tsw2 & $3.56 \times 10^{-11}$ & $1.2 \times 10^{-2}$ & $5.83 \times 10^{-16}$ & 0.157 \\
\hline & & tsw3 & $3.86 \times 10^{-11}$ & $8.5 \times 10^{-3}$ & $3.08 \times 10^{-17}$ & 0.154 \\
\hline & & tsw4 & $1.70 \times 10^{-11}$ & $1.0 \times 10^{-2}$ & $4.07 \times 10^{-18}$ & 0.110 \\
\hline & & tsw5 & $4.51 \times 10^{-11}$ & $1.5 \times 10^{-2}$ & $3.04 \times 10^{-17}$ & 0.131 \\
\hline & & tsw6 & $7.01 \times 10^{-11}$ & $2.0 \times 10^{-2}$ & $5.71 \times 10^{-18}$ & 0.112 \\
\hline & & tsw7 & $7.01 \times 10^{-11}$ & $2.0 \times 10^{-2}$ & $4.49 \times 10^{-18}$ & 0.094 \\
\hline & & tsw8 & $5.92 \times 10^{-13}$ & $1.6 \times 10^{-2}$ & $4.53 \times 10^{-18}$ & 0.037 \\
\hline & & tsw9 & $4.57 \times 10^{-13}$ & $5.9 \times 10^{-3}$ & $5.46 \times 10^{-17}$ & 0.173 \\
\hline
\end{tabular}

DTN: LB997141233129.001 (DIRS 104055).

\subsubsection{Geochemical Model}

Minerals considered in the simulations are calcite, gypsum, goethite, tridymite, cristobalite- $\alpha$, quartz, amorphous silica, hematite, fluorite, albite, K-feldspar, anorthite, Ca-smectite, Mg-smectite, Na-smectite, illite, kaolinite, opal-CT, stellerite, heulandite, mordenite, clinoptilolite, and glass (Xu et al. 2003 [DIRS 162124]). This full assemblage of minerals and the corresponding aqueous species are hereafter termed the "extended-case geochemical system." This assemblage has complexities and uncertainties in terms of thermodynamics and kinetics of mineral solid solutions (clays, zeolites, and feldspars), effects on $\mathrm{pH}$, and the partial pressure of $\mathrm{CO}_{2}$. A simpler set of minerals and aqueous species (base-case geochemical system) disregards all aluminosilicates, as well as Fe- and Mg-bearing minerals.

Calcite and gypsum dissolution and precipitation were assumed to take place under geochemical equilibrium, whereas dissolution and precipitation of the other minerals were treated under kinetic constraints. Initial mineral abundances were taken from DTN: LB991200DSTTHC.003 
(DIRS 161276). Potential secondary minerals (i.e., those allowed to precipitate but which may not necessarily form) were determined from field and experimental observations of water-rock interaction, and from equilibrium geochemical model calculations. Reactive surface areas of minerals on fracture walls were calculated from the fracture-matrix interface area/volume ratio, the fracture porosity, and the derived mineral volume fractions (DTN: LB0101DSTTHCR1.003 [DIRS 161278]). These areas were based on the fracture densities, fracture porosities, and mean fracture diameter. Mineral surface areas in the rock matrix were calculated using the geometric area of a cubic array of truncated spheres that make up the framework of the rock and reductions to those areas, owing to the presence of alteration phases such as clays and zeolites.

Initial pore water chemical concentrations were based on analyses of ultracentrifuged water and chemical speciation calculations presented in the report by BSC (2004 [DIRS 169856]). Except for perched water that lies well below the repository horizon, water has not been observed in fractures in the UZ. Therefore, the initial composition of water in the fractures was set to be the same as the matrix pore water (Table 7.9-2). The same water composition, re-equilibrated at the temperature of the top model boundary, was assumed for infiltrating water. Oxidizing conditions were considered for this water because the fracture permeability of the rock is high and the system is unsaturated (air phase is present everywhere). The $\mathrm{CO}_{2}$ gas partial pressures used for initial and top boundary conditions of the gas transport are in equilibrium with the corresponding aqueous chemical composition. An elevated gas partial pressure (relative to an atmospheric value of $0.344 \times 10^{-3}$ bar) at the upper boundary can be attributed to soil-zone $\mathrm{CO}_{2}$ production.

Table 7.9-2. Water and Gas Chemistry Used for Initial and Boundary Conditions of the Reaction-Transport Simulations

\begin{tabular}{|l|c|l|}
\hline \multicolumn{1}{|c|}{ Component } & Concentration & \multicolumn{1}{c|}{ Unit } \\
\hline $\mathrm{Ca}$ & 101 & $\mathrm{mg} / \mathrm{L}$ \\
\hline $\mathrm{Mg}$ & 17 & $\mathrm{mg} / \mathrm{L}$ \\
\hline $\mathrm{Na}$ & 61.3 & $\mathrm{mg} / \mathrm{L}$ \\
\hline $\mathrm{K}$ & 8 & $\mathrm{mg} / \mathrm{L}$ \\
\hline $\mathrm{SiO}_{2}(\mathrm{aq})$ & 70.5 & $\mathrm{mg} / \mathrm{L}$ \\
\hline $\mathrm{Al}$ & $1.67 \times 10^{-5}$ & $\mathrm{mg} / \mathrm{L}$ \\
\hline $\mathrm{HCO}_{3}$ & 200 & $\mathrm{mg} / \mathrm{L}$ \\
\hline $\mathrm{Cl}$ & 117 & $\mathrm{mg} / \mathrm{L}$ \\
\hline $\mathrm{SO}_{4}$ & 116 & $\mathrm{mg} / \mathrm{L}$ \\
\hline $\mathrm{F}$ & 0.86 & $\mathrm{mg} / \mathrm{L}$ \\
\hline $\mathrm{Fe}$ & $6.46 \times 10^{-8}$ & $\mathrm{mg} / \mathrm{L}$ \\
\hline & & \\
\hline $\mathrm{pH}$ & $8.32\left(\right.$ at $\left.25^{\circ} \mathrm{C}\right)$ & \\
& $7.75\left(\right.$ at $\left.17^{\circ} \mathrm{C}\right)$ & \\
\hline $\mathrm{PCO}_{2}$ & $2.726 \times 10^{-3}$ at $17^{\circ} \mathrm{C}$ & $\mathrm{bar}$ \\
\hline
\end{tabular}

Source: Xu et al. 2003 (DIRS 162124). 


\subsubsection{Simulation Setup}

Simulations with the one-dimensional model were performed using three infiltration rates, a base-case rate of $5.92 \mathrm{~mm} /$ year (BSC 2004 [DIRS 169857]), and bounding rates of $2 \mathrm{~mm} /$ year and $20 \mathrm{~mm} /$ year. The corresponding (to infiltration rates) steady-state water flow conditions were used for geochemical transport simulations. Steady-state water saturation distribution is presented in Figure 7.9-1. Steady-state temperature distributions corresponding to the same three infiltration rates are shown in Figure 7.9-2. These were obtained using a top temperature of $15.6^{\circ} \mathrm{C}$ at the land surface and a bottom temperature of $28^{\circ} \mathrm{C}$ at the water table. For the three infiltration rates, the same water and gas chemistry was used for the top boundary condition. As discussed in Section 7.9.2, the infiltrating water composition applied here is considered to be the water chemistry after transformation by soil-zone processes (evapotranspiration predominantly). Calcite precipitation in the TSw unit is not sensitive to uncertainties in the infiltrating water chemistry because it is well below the region where calcite becomes saturated. Moreover, episodic flow, likely, has been strongly dampened by the overlying weakly fractured bedded tuffs in the PTn hydrogeological unit.

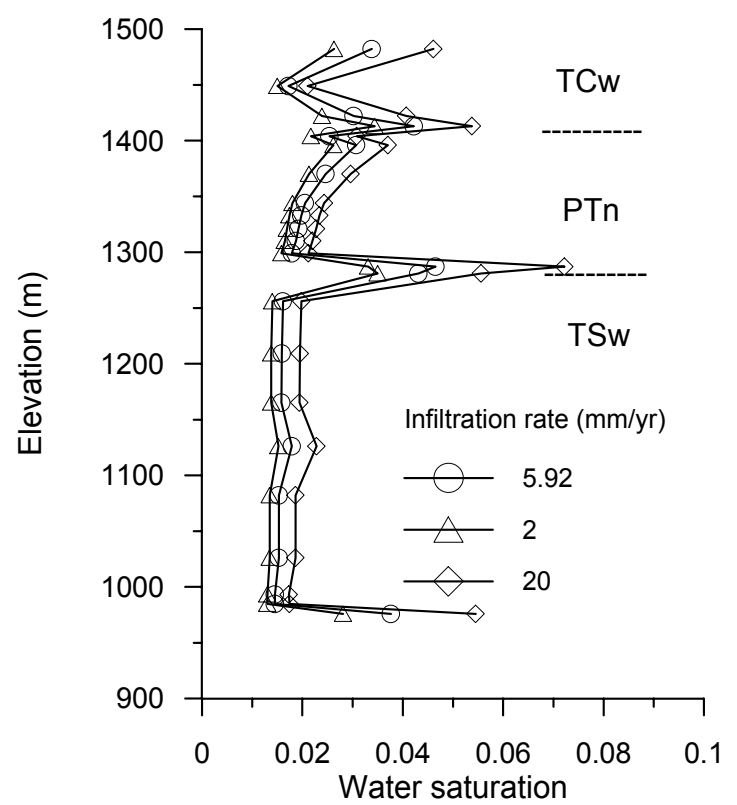

(a) Fracture

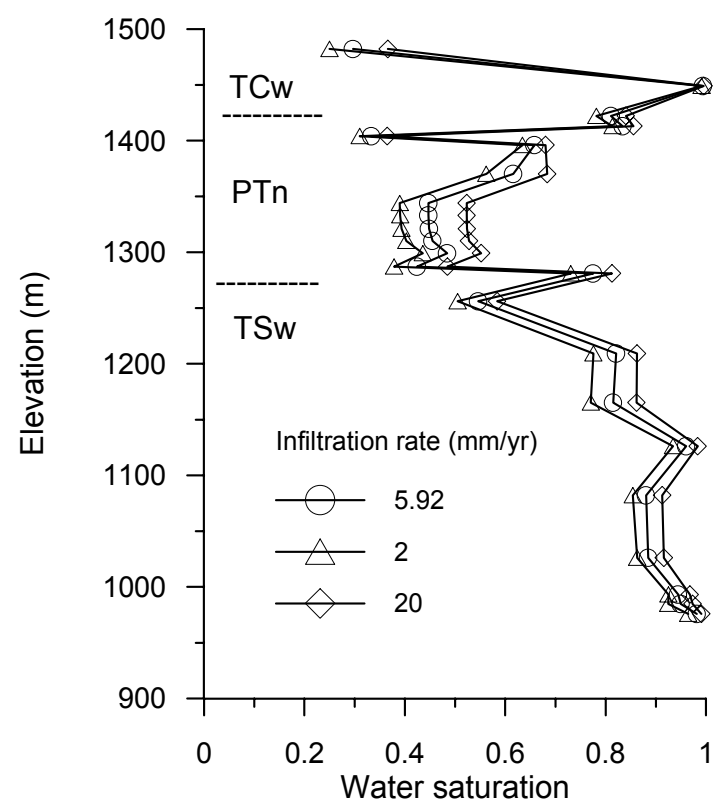

(b) Matrix

Source: Xu et al. 2003 (DIRS 162124).

PTn=Paintbrush nonwelded hydrogeologic unit; TCw=Tiva Canyon welded hydrogeologic unit; TSw=Topopah Spring welded hydrogeologic unit

Figure 7.9-1. Modeled Steady-State Water Saturations for the WT-24 Column Using Infiltration Rates: 2, 5.92, and $20 \mathrm{~mm} /$ year 


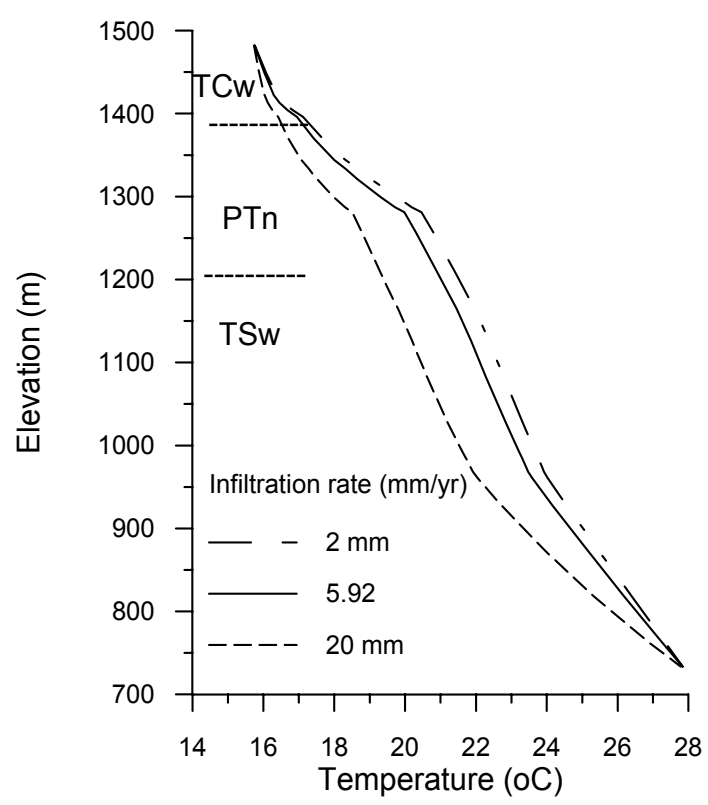

Source: Xu et al. 2003 (DIRS 162124).

PTn=Paintbrush nonwelded hydrogeologic unit; TCw=Tiva Canyon welded hydrogeologic unit; TSw=Topopah Spring welded hydrogeologic unit

Figure 7.9-2. Modeled Temperature Profiles in Borehole WT-24 as a Function of Depth for Three Infiltration Rates

For the reactive transport simulations of calcite precipitation, a simulation time of 10 million years was selected because this calcite formed over approximately 10 million years (Neymark et al. 2001 [DIRS 156889]). Infiltration rates and temperatures were held constant throughout the time of the simulation; therefore, the results reflect the average conditions over this period of time.

\subsubsection{Results and Discussion}

\subsubsection{Comparison with Measured Data}

The simulated total (fracture plus matrix) calcite abundances in the WT-24 column obtained using the three different infiltration rates are presented together with measured data in Figure 7.9-3a (extended-case geochemical system) and Figure 7.9-3b (base-case geochemical system). Generally, the results obtained using the base-case infiltration rate $(5.92 \mathrm{~mm} / \mathrm{year})$ agree better with the measured WT-24 mineral abundances than those obtained using the other infiltration rates, especially for the PTn unit. The extended-case geochemical system gives a better match to the total calcite abundances, especially for the TSw unit, indicating that some contribution of $\mathrm{Ca}$ from the rock is required. 


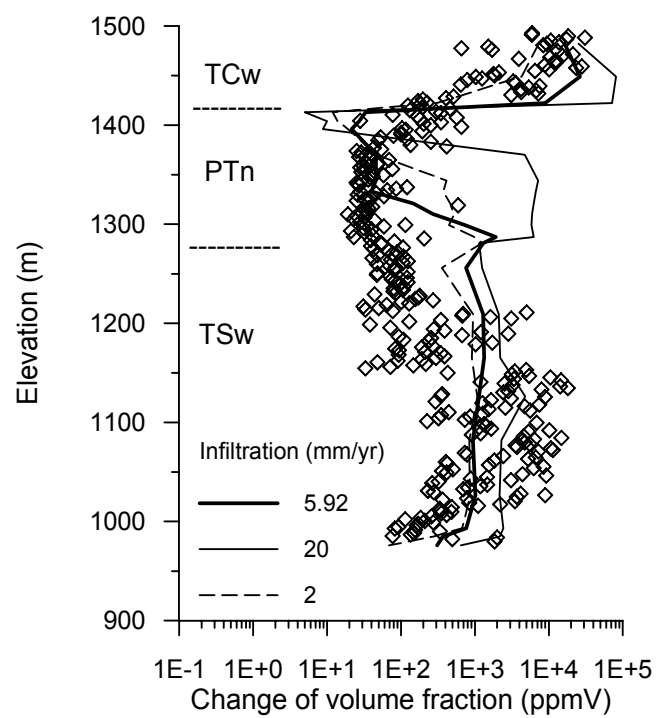

(a) Extended case

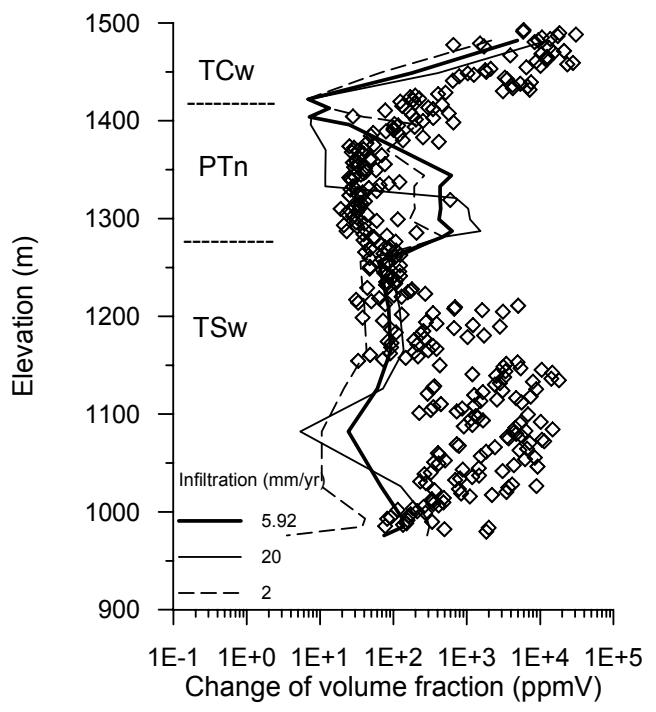

(b) Base case

Source: Simulated results are from Xu et al. 2003 (DIRS 162124).

NOTE: Diamonds represent bulk rock calcite abundances measured by the U.S. Geological Survey (GS021008315215.007 [DIRS 162127]).

PTn=Paintbrush nonwelded hydrogeologic unit; TCw=Tiva Canyon welded hydrogeologic unit; TSw=Topopah Spring welded hydrogeologic unit

Figure 7.9-3. Simulated Total (Fracture Plus Matrix) Calcite Abundances (in ppmV or $10^{-6}$ Volume Fraction) in the WT-24 Column for Different Infiltration Rates after 10 Million Years: (a) Extended-Case Geochemical System, (b) Base-Case Geochemical System

The simulated calcite abundances in the basal PTn layer for the three infiltration simulations are higher than that measured in WT-24. This results from an increase in the temperature gradient (Figure 7.9-2), resulting in a concomitant decrease in calcite solubility. The relatively larger calcite abundances in the bottom layer of the PTn have been observed at other locations such as in another deep borehole, USW G-2 (Carey et al. 1998 [DIRS 109051]). The lower measured calcite abundances may also result from lateral flow or by-passing of percolation, which is not captured in the one-dimensional simulations.

As shown in Figure 7.9-3, model results for the welded TSw unit (of the most interest to the YMP) generally fall in the wide range of measured calcite data with the extended case, while the base-case geochemical system model presents a better match only for the upper portion TSw, but underestimates calcite abundances in the lower TSw. Calcite deposition values obtained from the highest infiltration rate $(20 \mathrm{~mm} /$ year $)$ are closer to the high bound of measured values. Those values from the base case $(5.92 \mathrm{~mm} /$ year) fall in the middle of the TSw measured data range. This may imply that the $20 \mathrm{~mm} /$ year percolation rate is the high bound for the WT-24 location, whereas the base infiltration $(5.92 \mathrm{~mm} /$ year) from the flow property calibration (used for the flow model) may be close to the long-term mean infiltration rate for this location. The extended-case geochemical system provides the closest match to the measured data in the TSw unit because of the contribution of $\mathrm{Ca}$ from feldspars. 


\subsubsection{Calcite Precipitation in Fractures and Matrix}

Modeled calcite abundances in the fracture and matrix continua are very different for the various hydrogeological units (Figures 7.9-4 and 7.9-5). Figure 7.9-4 shows calcite abundances in fractures and matrix for the three infiltration rates with the extended-case geochemical system. In the PTn unit (Figures 7.9-5a and 7.9-5b), the matrix shows a similar or larger proportion of calcite than the fractures, except near the contact with the TSw, where the distribution reverses. In the uppermost part of the TSw unit (just above the repository horizon), calcite precipitation in fractures is dominant, indicating that flow is enhanced in the fractures. Calcite coatings are frequently found in fractures and lithophysal cavities (intersected with fractures) in the TSw tuffs (Paces et al. 1998 [DIRS 107408]).

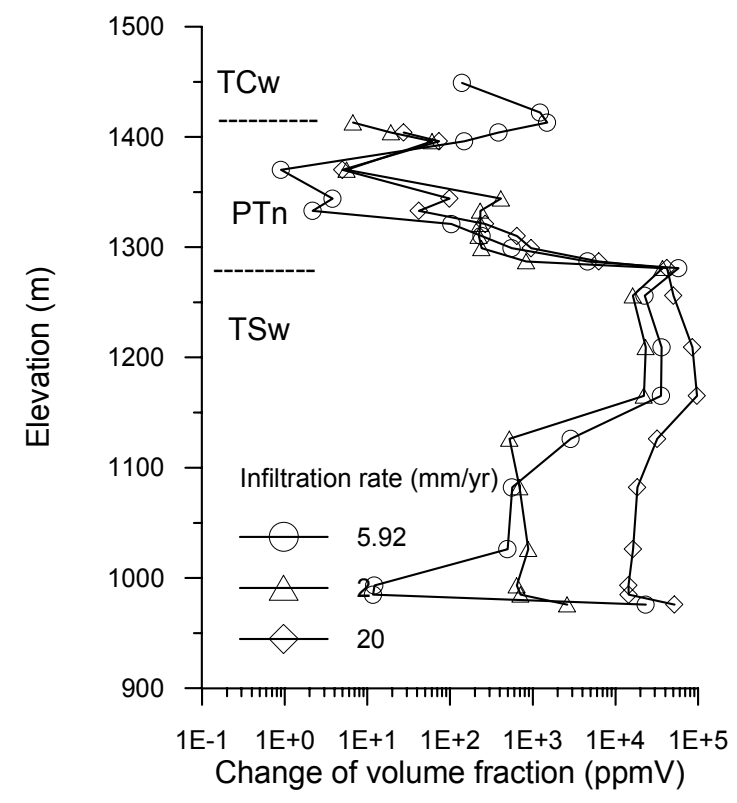

(a) Fracture

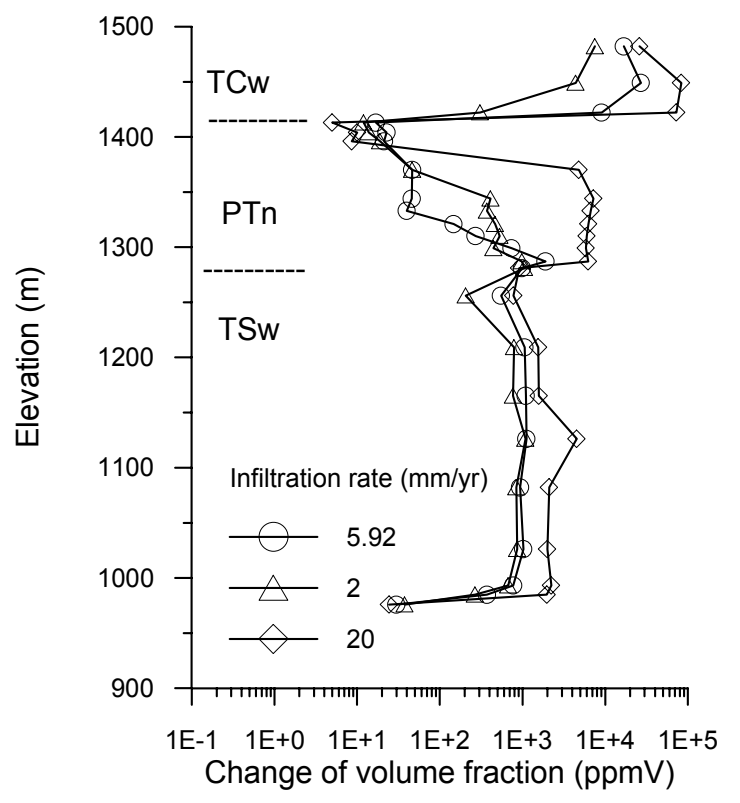

(b) Matrix

Source: Xu et al. 2003 (DIRS 162124).

PTn=Paintbrush nonwelded hydrogeologic unit; TCw=Tiva Canyon welded hydrogeologic unit; TSw=Topopah Spring welded hydrogeologic unit

Figure 7.9-4. Modeled Calcite Abundances (in ppmV or 10-6 Volume Fraction) in Fractures and in the Matrix after 10 Million Years for Differing Infiltration Rates Using the Extended-Case Geochemical System 


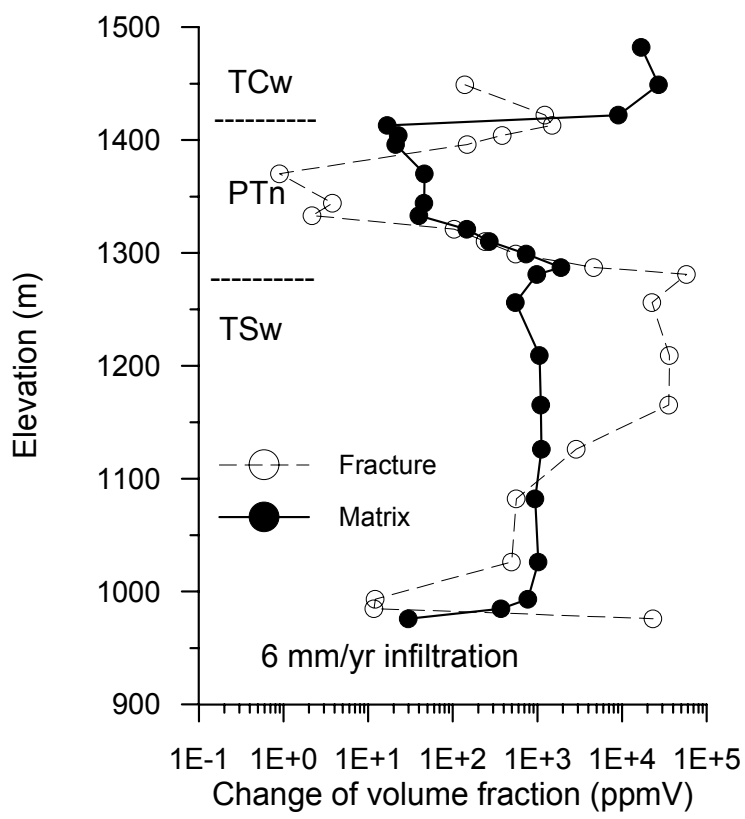

(a) Extended case

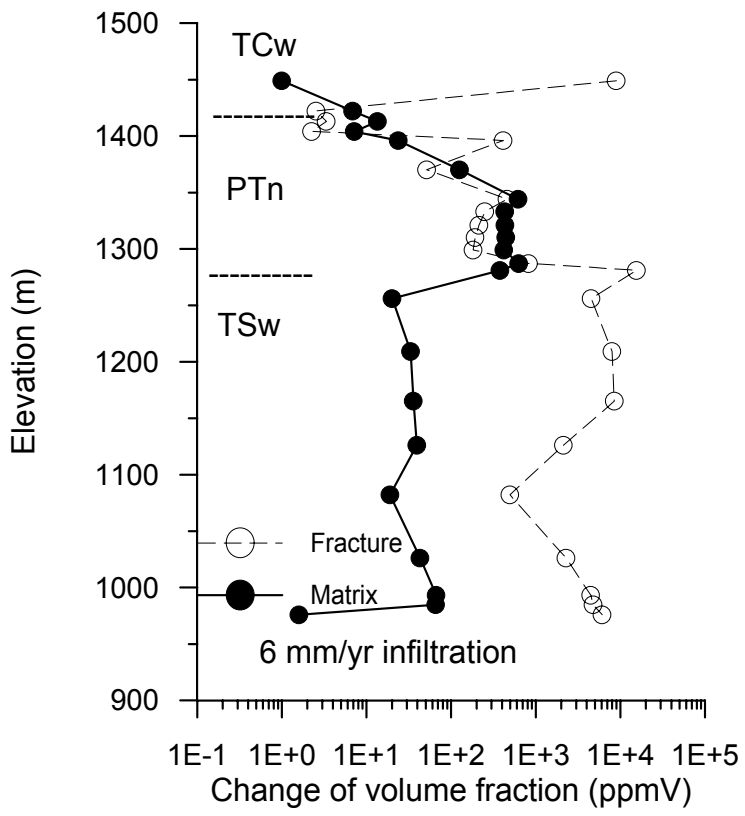

(b) Base case

Source: Xu et al. 2003 (DIRS 162124).

PTn=Paintbrush nonwelded hydrogeologic unit; TCw=Tiva Canyon welded hydrogeologic unit; TSw=Topopah Spring welded hydrogeologic unit

Figure 7.9-5. Modeled Calcite Abundances (in ppmV or $10^{-6}$ Volume Fraction) in Fractures and in the Matrix for (a) the Extended-Case and (b) Base-Case Geochemical Systems

However, the abundances in Figures 7.9-4 and 7.9-5 reflect only the proportion of calcite within the fracture and the matrix volumes individually. Figure 7.9-6 shows changes of calcite volume fraction versus infiltration rate for layer tsw4 (at an elevation of 1,126 m). In the extended case (Figure 7.9-6a), there are about equal total amounts of calcite in the matrix and fractures (the total is about twice that in the matrix, which makes up most of the volume of the rock), even though the fractures show a much larger proportion of calcite (Figure 7.9-5a). For the base-case system (Figure 7.9-6b), calcite in the fractures is about three-fourths of the total calcite in the rock, owing to the limited amount of $\mathrm{Ca}$ coming from the rock matrix and forming calcite. Greater simulated calcite abundances in the fractures result from the fractures carrying higher water fluxes in these strongly fractured, densely welded rocks.

The extended-case and base-case geochemical system simulations also show that from about 2 to $5.92 \mathrm{~mm} /$ year, the amount of calcite precipitated in the welded Topopah Spring tuff is sensitive to the infiltration rate (Figures 7.9-6a and 7.9-6b). This dependence decreases at higher infiltration rates $(5.92 \mathrm{~mm} /$ year infiltration rate to $20 \mathrm{~mm} / \mathrm{year})$, owing to a modification of the geothermal gradient from the increased percolation flux (Figure 7.9-2). The decrease in temperature at this level is about $2^{\circ} \mathrm{C}$, which resulted in less calcite precipitating in the $\mathrm{TSw}$, and more calcite being transported below the TSw. 

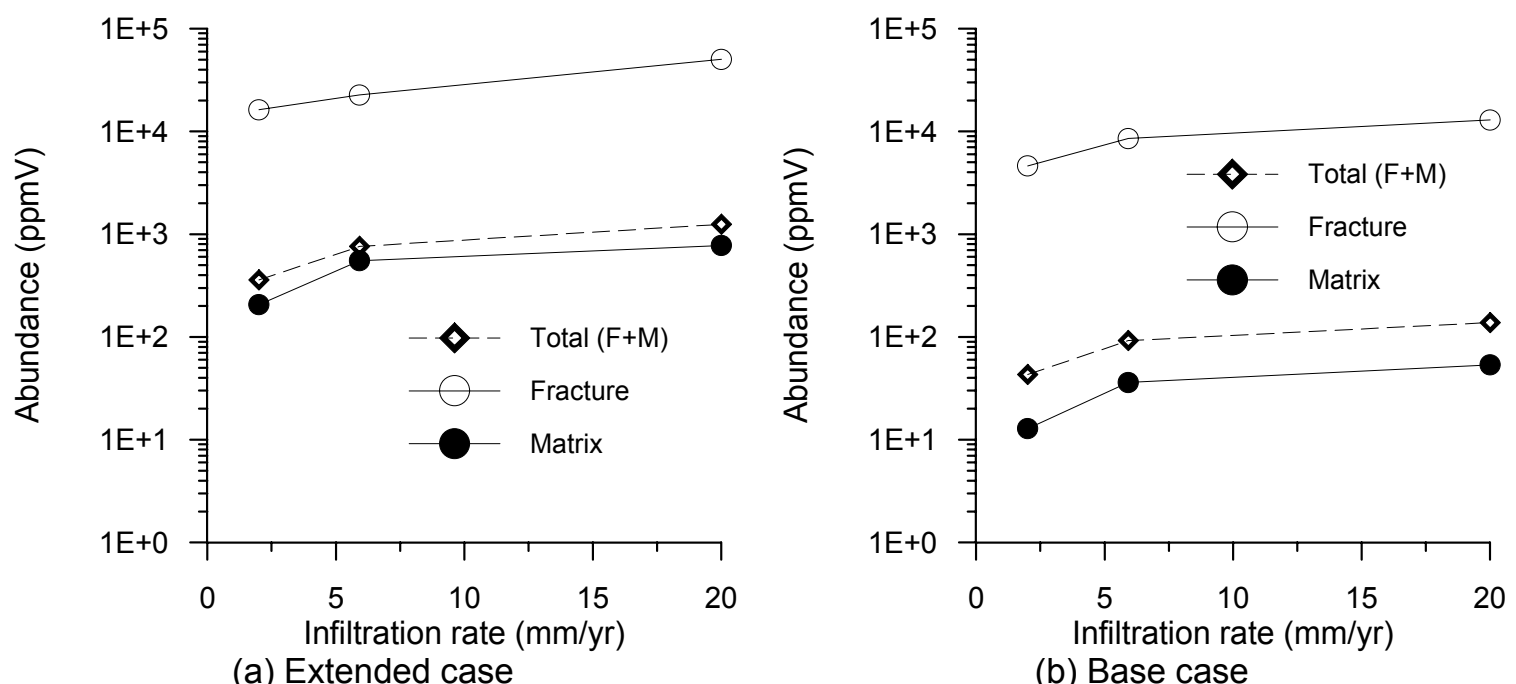

Source: Xu et al. 2003 (DIRS 162124).

Figure 7.9-6. Changes in Calcite Volume Fraction (ppmV) vs. Infiltration Rates for tsw4 Layer (at an Elevation of 1,126 m) for (a) the Extended-Case and (b) Base-Case Geochemical Systems

\subsubsection{Spatial Variation in Calcite Deposition}

Observed calcite abundances vary significantly in space and as a function of depth. Studies for the WT-24 column can give some general insight into calcite deposition conditions, but cannot represent the entire picture at Yucca Mountain. Calcite abundance data for Borehole USW SD-6 were later released by USGS in 2002 (DTN: GS020608315215.002 [DIRS 162126]), but modeling of calcite deposition for SD-6 has not been performed. Measured calcite data have a wide range of values (orders from $10^{2}$ to $10^{4} \mathrm{ppmV}$ ). To compare the two columns, which show large variability, the geometric means over a specified depth range were compared. The calcite data were grouped according to (1) every $10 \mathrm{~m}$ in depth (if possible) and (2) within one geologic unit. The calculation of calcite geometric means (in Microsoft Excel) are documented in the report by Wang (2003 [DIRS 162417], SN-LBNL-SCI-160-V1, pp. 89 to 92). The original measured calcite data and calculated geometric means versus depth are presented in Figure 7.9-7. To better compare WT-24 with SD-6, we plot both geometric means in Figure 7.9-8. For the PTn, SD-6 has much more calcite deposition than WT-24. The thickness of the PTn unit for SD-6 is thinner than that of WT-24. For the TSw, calcite abundances in SD-6 fall in a range similar to those in WT-24. In the three-dimensional UZ flow model, a mean infiltration of $19.6 \mathrm{~mm} /$ year is used in SD-6, which is higher than the $5.9 \mathrm{~mm} /$ year in WT-24. This once again indicates that between a 5.92 and $20 \mathrm{~mm} /$ year infiltration rate, the amount of calcite is not expected to be significantly different in the TSw. 


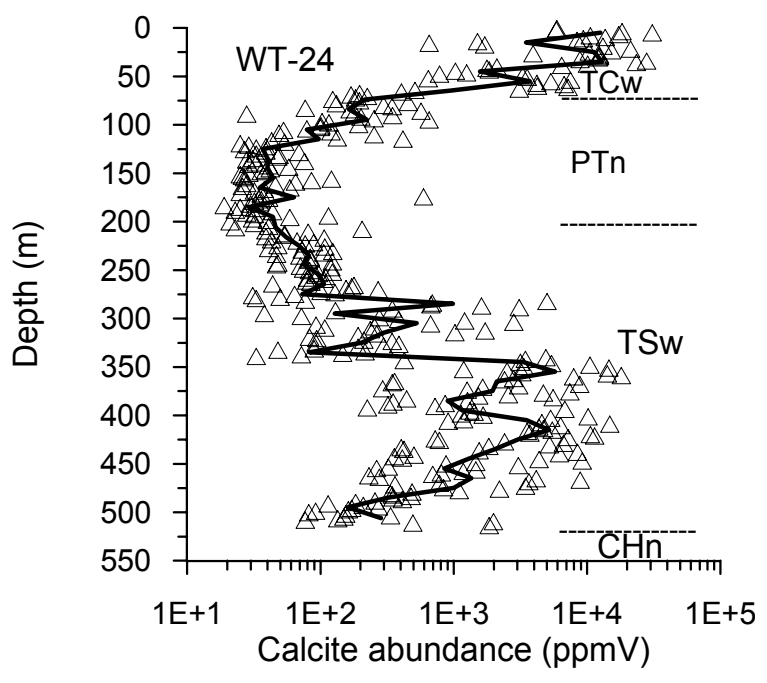

(a) WT-24

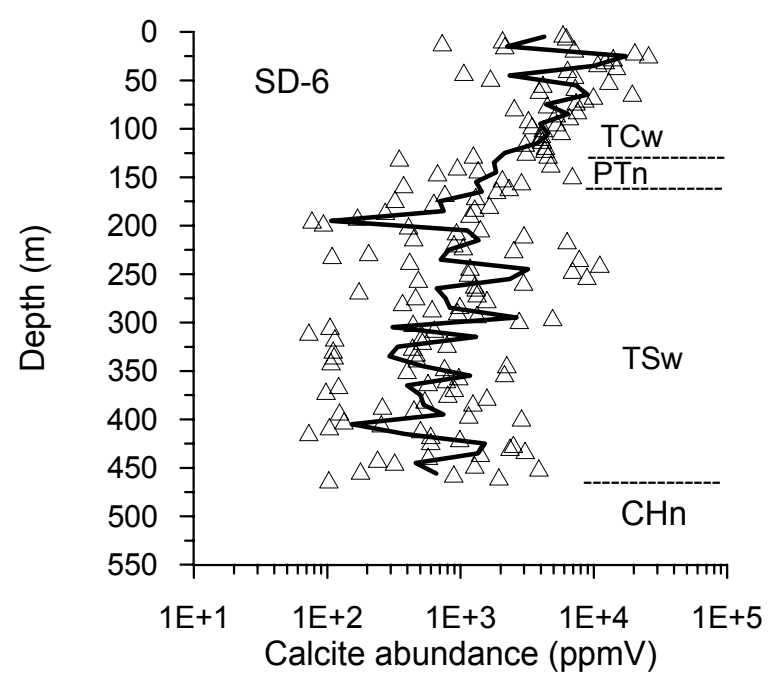

(b) SD-6

Source DTNs: GS021008315215.007 (DIRS 162127) for WT-24; GS020608315215.002 (DIRS 162126) for SD-6. NOTE: Symbols represent USGS-measured calcite abundances. Solid lines represent geometric means. PTn=Paintbrush nonwelded hydrogeologic unit; TCw=Tiva Canyon welded hydrogeologic unit; TSw=Topopah Spring welded hydrogeologic unit

Figure 7.9-7. Calcite Abundances (in ppmV or $10^{-6}$ Volume Fraction) with Depth in Boreholes WT-24 and SD-6

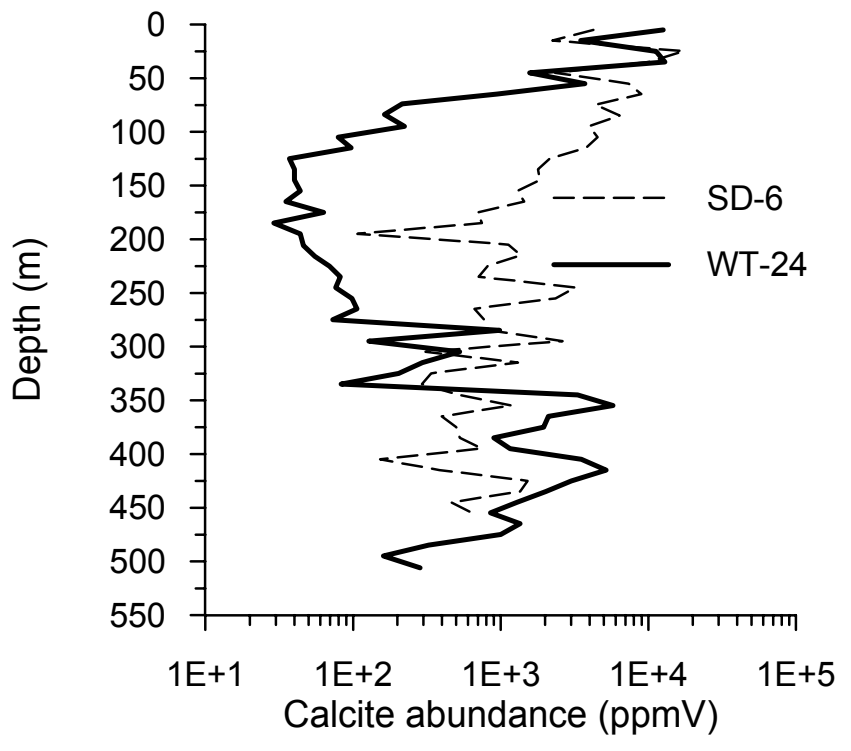

Source: Wang 2003 (DIRS 162417), SN-LBNL-SCI-160-V1, p. 92.

Figure 7.9-8. Geometric Means of Calcite Abundances with Depth for Boreholes WT-24 and SD-6 


\subsubsection{Concluding Remarks}

Modeling calcite deposition provides additional evidence for validation of the UZ model. For the mean infiltration rate $(5.92 \mathrm{~mm} / \mathrm{yr})$, simulations in Figure $7.9-3$ are within the range of data for each unit except at the PTn-TSw contact for the more realistic extended-case geochemical system. The contact between two units is where lateral flow may occur, which is not included in the 1-D model. The comparison in Figure 7.9-3 indicates that the validation criterion is to be met. This is because the acceptance criterion is applied only to the mean infiltration rate that is the expected rate and the other rates, representing extremes, would not be expected to simulate actual mean behavior. In addition, the validation is focused on the extended-case geochemical system. The excursion in the model results at the PTn-TSw contact is not important because it is an artifact of the lack of lateral flow in the 1-D model and would not occur in the 3D UZ flow model.

Over a range of 2 to $20 \mathrm{~mm} /$ year infiltration rates, the simulated calcite abundances generally fall within the range of calcite observed in the field, which satisfies the validation criterion. The simulated calcite distributions capture the USGS-measured data from the WT-24 well cuttings (DTN: GS021008315215.007 [DIRS 162127]). The 20-mm/year infiltration rate may be the upper bound for WT-24 location, whereas the base-case infiltration rate $(5.92 \mathrm{~mm} / \mathrm{year})$ used for the flow model gives the closest match to the data. The observed calcite precipitation for the top of TSw occurs mostly in the fractures, which is also captured. The modeling results can provide useful insight into process mechanisms such as fracture-matrix interaction, as well as conditions and parameters controlling calcite deposition. The modeled calcite abundances generally increase with increasing infiltration rate, but become less sensitive to infiltration at higher rates as a result of changes to the geothermal gradient. Between a 5.92 and $20-\mathrm{mm} /$ year infiltration rate, the amount of calcite is not expected to be significantly different in the TSw, a conclusion supported by the similar abundances in WT-24 and SD-6 in the TSw.

One-dimensional simulation is appropriate because both flow and geothermal gradient are primarily vertical. The current observed calcite is formed cumulatively over about 10 million years. A number of uncertainties are involved in the numerical simulation results; the most influential of which are variations of geothermal gradient and infiltration over time. Differences between one-dimensional and three-dimensional flow are much less than the differences in geothermal gradient and infiltration over 10 million years. Agreement between simulated and measured calcite abundance could work to establish the validity of the flow field from and infiltration rates used in the UZ flow model.

\subsection{MODEL VALIDATION USING STRONTIUM GEOCHEMISTRY AND ISOTOPIC RATIOS}

This section describes the use of strontium ( $\mathrm{Sr})$ and strontium isotopic ratios $\left({ }^{87} \mathrm{Sr} /{ }^{86} \mathrm{Sr}\right)$ for validation of the UZ flow model. Validation methodology consists of work presented in peer-reviewed journals, as well as comparison of model results to data collected for pore waters. The criterion for the validation is a qualitative agreement between simulated Sr concentrations and the average of the observations at the same elevation, and an agreement with vertical trends (BSC 2002 [DIRS 160819], Attachment Section I-1-2-5). 


\subsubsection{Background}

Strontium concentrations and the ${ }^{87} \mathrm{Sr} /{ }^{86} \mathrm{Sr}$ ratio in pore fluids and secondary minerals can provide important constraints on infiltration rates, flow paths, residence times, and degrees of water-rock and fracture-matrix interaction at Yucca Mountain (Stuckless et al. 1991 [DIRS 106947]; Marshall et al. 1991 [DIRS 106335]; Peterman et al. 1992 [DIRS 147110]; Peterman and Stuckless 1993 [DIRS 101149]; Johnson and DePaolo 1994 [DIRS 162560]; Vaniman and Chipera 1996 [DIRS 100089]; Sonnenthal and Bodvarsson 1999 [DIRS 117127]; and Paces et al. 2001 [DIRS 156507]). Strontium concentrations in pore waters are related to the infiltration rate (through evaporation), the dissolution of minerals in surface deposits, reaction with minerals or glass in the tuffs, precipitation of calcite, and exchange with clays and zeolites (Vaniman et al. 2001 [DIRS 157427]; Vaniman and Chipera 1996 [DIRS 100089]; Sonnenthal and Bodvarsson 1999 [DIRS 117127]). The similarity of $\mathrm{Sr}$ to $\mathrm{Ca}$ in charge and ionic radius results in $\mathrm{Sr}$ incorporation into Ca-bearing minerals, such as plagioclase feldspar, and secondary minerals, such as Ca-zeolites and Ca-rich smectite.

The ${ }^{87} \mathrm{Sr} /{ }^{86} \mathrm{Sr}$ ratio in pore waters depends on its initial ratio and is affected along a flow path by dissolution of Sr-bearing phases (e.g., calcite, feldspars, volcanic glass), exchange with clays or zeolites, and the mixing of waters having differing isotopic ratios (Johnson and DePaolo 1994 [DIRS 162560], p. 1571). If such fluids have differing strontium concentrations, mixing will result in hyperbolic curves of ${ }^{87} \mathrm{Sr} /{ }^{86} \mathrm{Sr}$ versus total $\mathrm{Sr}$ (Faure 1986 [DIRS 105559], p. 143), making them more complex chemically, but adding additional constraints to understanding the hydrological system. In nature, almost no fractionation of $\mathrm{Sr}$ isotopes occurs; however, fractionation of $\mathrm{Rb}$ from $\mathrm{Sr}$ leads to variations in ${ }^{87} \mathrm{Sr} /{ }^{86} \mathrm{Sr}$ because of the decay of ${ }^{87} \mathrm{Rb}$ to ${ }^{87} \mathrm{Sr}$. Because the half-life of ${ }^{87} \mathrm{Rb}$ is about $5 \times 10^{10}$ years, this decay effect is insignificant over the few hundred thousand years of interest for the UZ flow system.

The effect of the rock on the isotopic composition of water, thus, depends on the Sr content as well as on its isotopic ratio. The amount of rock dissolution and mineral precipitation depends on the degree to which the mineral assemblage is in disequilibrium with the water. Unaltered volcanic glass is more reactive than minerals, so that the rate of reaction of devitrified tuff with water is lower than that with glass. However, several factors can result in reduced apparent rates of reaction. The development of amorphous silica saturation in the soil zone has been proposed as a strong inhibitor of water-rock reaction in the underlying tuffs at Yucca Mountain (Meijer 2002 [DIRS 158813], pp. 803 to 804). Alteration products on the surface of fractures or on mineral grains would also lead to rates limited by diffusion through such films rather than by reaction, retarding the dissolution rate (Sonnenthal and Ortoleva 1994 [DIRS 117914], p. 407). Incongruent dissolution of volcanic glass has also been proposed as a cause for lower quantities of $\mathrm{Sr}$ dissolved into pore fluids in the PTn bedded tuffs (Vaniman and Chipera 1996 [DIRS 100089], p. 4421).

\subsubsection{Validation of Conceptual and Numerical Models of UZ Transport Based on Corroborative Information from Published Works}

Based on $\mathrm{Cl} / \mathrm{Sr}$ ratios in a relatively few number of pore-water samples that were similar to those of an estimated effective precipitation composition, and the lack of a substantial shift in ${ }^{87} \mathrm{Sr} /{ }^{86} \mathrm{Sr}$ ratio in pore salts and calcite, Sonnenthal and Bodvarsson (1999 [DIRS 117127], pp. 111, 151) 
suggested that the Sr concentrations in the UZ above the zeolitic units were, in large part, inherited from surface evapotranspiration processes, with only a minor contribution from water-rock interaction. Three-dimensional UZ transport modeling, including ion exchange, showed relatively high pore-water $\mathrm{Sr}$ concentrations in nonzeolitic units and a strong shift to lower concentrations (by a few orders of magnitude) in zeolitic units, which was consistent with pore-water and perched-water compositions in contact with the respective rock units. This comparison of modeled Sr pore water concentrations was good supporting evidence for the approximately $5 \mathrm{~mm} /$ year mean infiltration rate at Yucca Mountain based on $\mathrm{Cl}$ concentrations in pore water (Sonnenthal and Bodvarsson 1999 [DIRS 117127], p. 107). The model also produced Sr compositions at perched-water locations that were high where the perching was on the basal vitrophyre of the Topopah Spring tuff and very low where the perched water contacted zeolitic rocks. The results were consistent with several measurements made in the various boreholes that had intersected perched water bodies.

Extensive exchange of $\mathrm{Sr}$ with $\mathrm{Ca}$ in clinoptilolite, other Ca-rich zeolites, and clays is well documented in the Yucca Mountain UZ (Vaniman et al. 2001 [DIRS 157427]; Vaniman and Chipera 1996 [DIRS 100089], p. 4431). An analysis performed by Vaniman et al. (2001 [DIRS 157427], p. 3409) showed that the excess Sr in the zeolitic rocks from the UZ-16 borehole, produced by ion exchange, was consistent with 10 million years of infiltration at about $5 \mathrm{~mm} /$ year. Therefore, this published work provides independent corroboration of the results obtained by Sonnenthal and Bodvarsson (1999 [DIRS 117127], p. 107), based on conceptual and numerical models that form the basis for the UZ model presented in this report. Support for the $5 \mathrm{~mm}$ /year being a long-term maximum is the observation that the ${ }^{87} \mathrm{Sr} /{ }^{86} \mathrm{Sr}$ ratios in calcite are shifted to slightly higher values in calcite precipitated more recently compared to early formed calcite, indicating some contribution of Sr from water-rock interaction (Paces et al. 2001 [DIRS 156507], p. 75). Therefore, some of the $\mathrm{Sr}$ in the zeolitic units must have been derived from dissolution of tuff. An increase in the ${ }^{87} \mathrm{Sr} /{ }^{86} \mathrm{Sr}$ ratio in pore water at lower infiltration rates is a result of the longer residence time that the water has in contact with rock having a much higher ${ }^{87} \mathrm{Sr} /{ }^{86} \mathrm{Sr}$ ratio.

This evidence, and the generally high Sr concentrations through the UZ above zeolitic rocks, suggests that, although some $\mathrm{Sr}$ is lost to precipitating calcite, a comparable amount is gained by tuff dissolution. If some of the $\mathrm{Sr}$ in the zeolitic rocks is in excess of that produced by infiltration, then the estimated infiltration rate, based on Sr concentrations in the zeolitic rocks, would be an upper limit.

Another piece of corroborating evidence comes from the compositions of calcite in fracture coatings. An excellent long-term record of the loss of $\mathrm{Sr}$ through ion exchange in the zeolites is given by the Sr concentrations in coexisting calcite, which are a few hundred ppm through much of the UZ, and then drop to a few ppm below zeolitic layers in the Calico Hills unit (Vaniman and Chipera 1996 [DIRS 100089], pp. 4428 to 4429, Table 3). This corroborates the model results showing flow through the zeolitic units and $\mathrm{Sr}$ exchange with $\mathrm{Ca}$ in zeolites, resulting in waters having very low Sr concentrations. 


\subsubsection{Model for Three-Dimensional Sr Concentrations}

A first approximation to modeling $\mathrm{Sr}$ concentrations in the $\mathrm{UZ}$ is to consider $\mathrm{Sr}$ as a conservative species in the nonzeolitic units and an exchangeable species in the zeolitic units (Sonnenthal and Bodvarsson 1999 [DIRS 117127], p. 143). Simulations were run based on the model for Cl used in Section 6.5 employing the base-case, present-day infiltration rate (scenario "preq $\mathrm{mA}$ " in Table 6.5-2). The only modifications to this model were for the $\mathrm{Sr}$ diffusion coefficient $(7.94 \times$ $10^{-10} \mathrm{~m}^{2} / \mathrm{s}$ at $25^{\circ} \mathrm{C}$; Lasaga 1998 [DIRS 117091 ], p. 315$)$ and the Sr distribution coefficient $\left(\mathrm{K}_{\mathrm{d}}\right)$ in zeolitic rocks $\left(1.0 \mathrm{~m}^{3} / \mathrm{kg}\right.$; DTN: LA0302AM831341.002 [DIRS 162575]). The latter value for the $K_{d}$ is the approximate mean based on a range from 0.05 to $2.0 \mathrm{~m}^{3} / \mathrm{kg}$ provided in the data tracking number. Because all the $\mathrm{K}_{\mathrm{d}}$ values in this range would result in a moderate to strong shift in pore water Sr concentrations from nonzeolitic to zeolitic rocks, the effect of assuming a uniform $\mathrm{K}_{\mathrm{d}}$ only results in uncertainty in the degree to which concentrations within and below the zeolitic units are shifted to lower values.

Strontium input at the surface was assumed to be wholly from precipitation, using an approximate $\mathrm{Cl} / \mathrm{Sr}$ concentration ratio in precipitation of approximately 100 (Sonnenthal and Bodvarsson 1999 [DIRS 117127], p. 147). The lower boundary condition (saturated zone) was set to zero concentration. Although this is less than the potential $\mathrm{Sr}$ concentrations in the saturated zone, the effect on the UZ would be limited to gridblocks adjacent to the lower boundary only, where few samples have been collected. The simulation was run for 4 million years using T2R3D V1.4 (LBNL 1999 [DIRS 146654]), which resulted in a steady state concentration distribution. Simulations run for 1 and 2 m.y. showed some deviation from steady-state in low permeability gridblocks near the base of the domain, but not in most of the UZ locations where samples were collected. Although the 4 m.y. simulation may still show slight deviation from steady-state in the bottom gridblocks where concentrations are very low, the differences do not impact the model validation.

Modeled Sr concentrations are compared to measured values for pore salts extracted (by leaching) from two surface-based boreholes (SD-9 and SD-12; DTN: GS990308315215.004 [DIRS 145711]), perched waters, and pore waters obtained by ultracentrifugation of core samples from the ECRB (DTN: GS020408312272.003 [DIRS 160899]). Comparison of measured and modeled Sr concentrations as a function of elevation for the surface-based boreholes is shown in Figure 7.10-1( $\mathrm{a}$ and $\mathrm{b}$ ). Inputs and outputs for the three-dimensional $\mathrm{Sr}$ model simulations have been submitted to the TDMS under DTN: LB0304UZSRTRAN.001. Measured concentrations in the UZ above the perched water show a range of concentrations from about 0.1 to $2 \mathrm{mg} / \mathrm{L}$, with perched-water concentrations (and pore-water concentrations at a similar depth) closer to $0.01 \mathrm{mg} / \mathrm{L}$. This sharp reduction in $\mathrm{Sr}$ concentrations is greater than the equivalent drop in $\mathrm{Cl}$ concentrations in the perched-water bodies and is consistent with ion exchange in zeolitic rocks. Strong variations exist in the measured $\mathrm{Sr}$ concentrations as a function of depth in the UZ. However, no distinct trends can be discerned. The steady-state modeled concentrations above the perched water are very close to the mean values in Boreholes SD-9 and SD-12. Where perched water samples were collected in SD-9, the model results capture the drop in concentration quite closely. In SD-12, the measured and modeled concentrations below 900 meters exhibit a reversal to higher concentrations. This reversal is consistent with lateral flow in the vitric units, rather than simple vertical flow through the zeolitic units that would result in consistently low concentrations below them. The criterion for 
validation is qualitative agreement between the simulated strontium concentrations and the average of the observations at the same elevation, and agreement with the vertical trends (BSC 2002 [DIRS 160819], Attachment Section I-1-2-5). The comparisons shown for the surface-based boreholes meet the validation criteria.

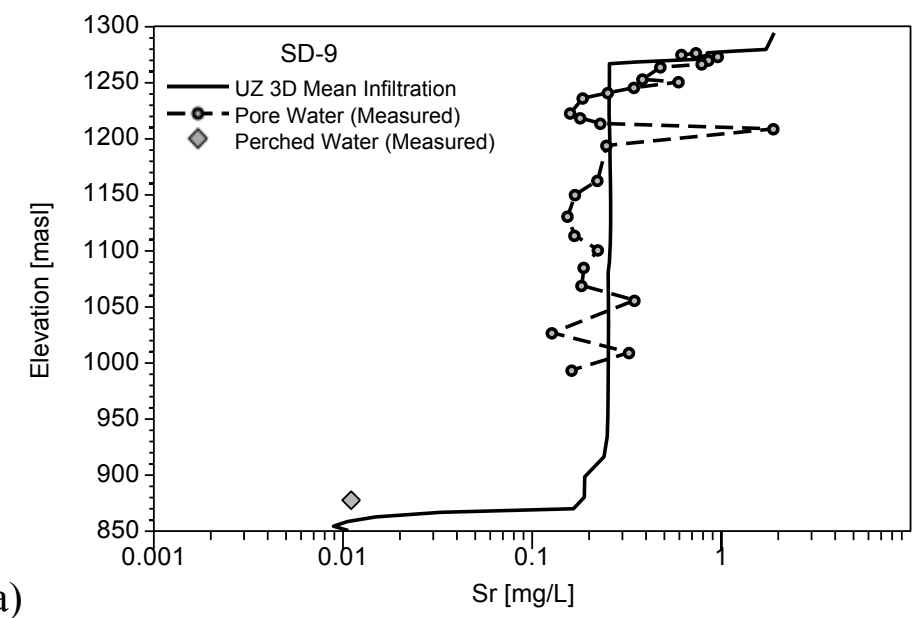

(a)

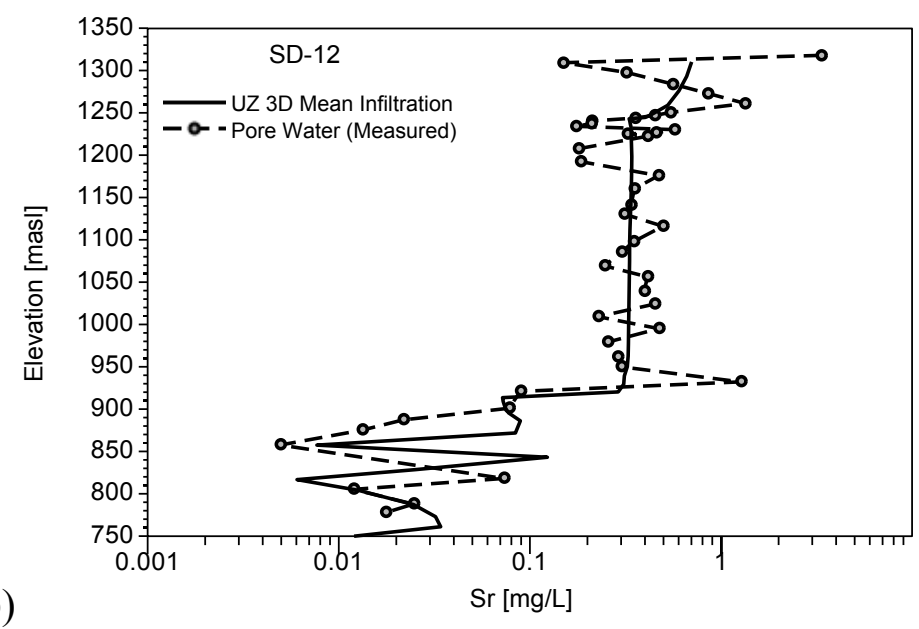

Source DTN: GS990308315215.004 (DIRS 145711).

Model Input and Output DTN: LB0304UZSRTRAN.001.

3-D=three-dimensional; $U Z=$ =unsaturated zone; masl=meters above sea level

Figure 7.10-1. Comparison of Measured and Modeled Sr Concentrations as a Function of Elevation for the Surface-Based Boreholes (a) SD-9 and (b) SD-12

Measured and modeled Sr concentrations in pore waters extracted from cores taken in the ECRB are shown in Figure 7.10-2. Measured concentrations are nearly all between 1 and $2 \mathrm{mg} / \mathrm{L}$, with one sample having a concentration of about $3.6 \mathrm{mg} / \mathrm{L}$. These concentrations are generally much higher than those measured in the surface-based boreholes. It is not clear if the different techniques used (leaching in the surface-based samples and ultracentrifugation in the ECRB) have resulted in any systematic bias in the Sr concentrations. Consistent with the lower $\mathrm{Cl}$ concentrations in most ECRB samples, compared to areas to the east where the infiltration rates are expected to be lower, most of the modeled $\mathrm{Sr}$ concentrations are also lower. Although the 
comparison of measured and modeled concentrations generally meet the order-of-magnitude criterion, the deviations are mostly greater than that for the surface-based boreholes. Ratios for ${ }^{87} \mathrm{Sr} /{ }^{86} \mathrm{Sr}$ are not available for these samples, and, therefore, the degree to which $\mathrm{Sr}$ concentrations may have been shifted to higher values by water-rock interaction cannot be assessed. Bulk-rock compositions for major and trace elements for tuffs in the ECRB are virtually identical to samples collected elsewhere (Peterman and Cloke 2002 [DIRS 162576], p. 696). Consequently, a shift caused by locally greater water-rock interaction in the welded tuffs is not likely, although enhanced reaction above is possible.

Based on the agreement between modeled and measured borehole data, the Sr model has been validated sufficiently.

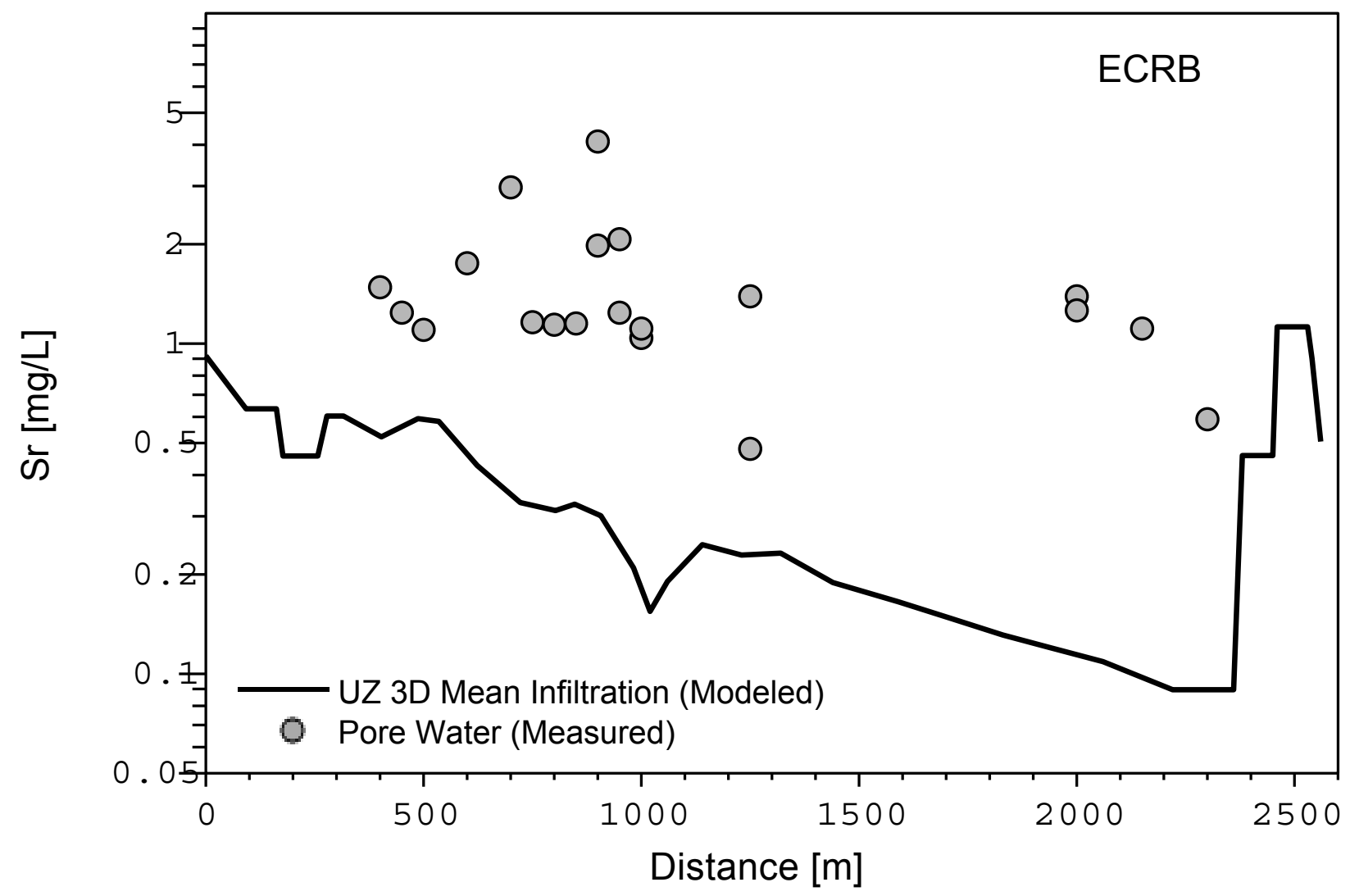

Source DTN: GS020408312272.003 (DIRS 160899).

Model Input and Output DTN: LB0304UZSRTRAN.001.

3-D=three-dimensional; ECRB=Enhanced Characterization of the Repository Block; UZ=unsaturated zone

Figure 7.10-2. Measured and Modeled Sr Concentrations in Pore Waters Extracted from Cores Taken in the ECRB

\subsection{REPRESENTATION OF THE UZ FLOW FIELDS WITH A HIGHER WATER TABLE}

In the absence of direct hydrological data to validate the future UZ flow fields with a higher water table, justification of the simulated future flow fields must rely on the conceptual and 
mathematical validity of models. As described in Section 6.6.3, these future UZ flow fields were generated based on the three-dimensional UZ flow model, which was developed using a fixed water table representing the current, ambient condition. The flow fields with the current water table can also be used to extract flow fields for a rising-water-table case in the future; i.e., a water-rise situation can be handled by simply transecting the flow fields vertically at a new water table elevation.

The use of these truncated steady-state UZ flow fields can be justified by considering the fundamentals in model formulation, i.e., the mathematical model of Richards' equation, or, more specifically, Darcy's law for description of UZ flow under a future high water table condition. UZ flow is simulated using Richards' equation as well as Darcy's law and the impact of a future water table rising is limited mainly to the lower unit of the CHn below the repository horizon. Note that the water table boundary is handled as a sink term in the UZ flow model. Near or at the future elevated water table, which is within the model domain of the UZ flow model, UZ flow is vertically dominant. The flow is determined primarily by the upstream or upper-layer conditions in the UZ flow model. According to the Darcy's law, in particular, the vertical flow is decided by two factors: hydraulic conductivity and hydraulic gradient. Since the hydraulic conductivity is upstream weighted in the model and vertical hydraulic gradient is dominated by gravity term, a constant, inserting a future water table boundary into the current UZ flow model will provide a good approximation for obtaining the future flow fields with an elevated water table. In addition, certain lateral flow may exist at or near a future water table, which is caused by intersecting perched water low-permeability zones. These intersected perched water or low-permeability zones will have liquid saturation near 100 percent, as predicted by the UZ flow model, which is approximately the same condition needed for representing a future water table boundary. Therefore, truncated flow fields at a future higher water table using the current UZ flow fields will provide a reasonable representation for UZ flow fields under future climates for both vertical and lateral flow components.

\subsection{SUMMARY OF VALIDATION}

This section summarizes the validation activities and results for the UZ flow model and its submodels. The validation is carried out according to the Technical Work Plan (BSC 2004 [DIRS 169654], Section 2.2.1.1). The model validation efforts in this section consists of (1) confidence building during model development; (2) corroboration with experimental data and modeling studies; (3) corroboration with information published in referred journals and literature; (4) analysis of model uncertaities; and (5) corroboration with natural analogues. As demonstrated in this section, the model validation criteria have been met and the UZ flow model is valid for its intended use in TSPA-LA. 


\section{CONCLUSIONS}

This report documents the development, results, and analyses of the UZ flow model and its submodels. These models and modeling analyses include the following:

- Three-dimensional UZ calibration and flow model for generating nine base-case flow fields

- Three-dimensional UZ alternative flow model for generating nine alternative flow fields

- Mountain-scale, ambient TH model

- Three-dimensional gas flow model

- Chloride submodel

- Calcite analysis

- Tracer transport analysis

- Modeling analysis of AFM

- Model validation activities and results.

The UZ flow model and its submodels are developed to simulate past, present, and future hydrogeological, geothermal, and geochemical conditions and processes within the Yucca Mountain UZ to support various TSPA-LA activities. In particular, as part of the output of this report, nine three-dimensional, base-case steady-state flow fields of the Yucca Mountain UZ system have been generated for TSPA-LA calculations. This report has documented the UZ flow model and its submodels in terms of modeling approaches, hydrogeological conceptual models, data source and incorporation, methodology of model calibrations, model parameter estimation and modifications, and model results and analysis of the 18 flow fields (nine base-case + nine alternative). This report also includes associated analyses on tracer transport with the 18 flow fields. The development and calibration of the mountain-scale ambient thermal, gas flow, chloride, calcite, and strontium submodels are mainly for building confidence in the UZ flow model, with the output data and tracking numbers listed in Table 8-1. 
Table 8-1. Output Data and Data Tracking Numbers

\begin{tabular}{|c|c|c|c|c|}
\hline \multirow[b]{2}{*}{ Data Tracking Number } & \multicolumn{3}{|c|}{ Location in this report } & \multirow[b]{2}{*}{ Remarks } \\
\hline & Text & Figure & Table & \\
\hline LB03023DSSCP9I.001 & $\begin{array}{l}\text { 6.6.2, 6.8.1, } \\
6.8 .2 .1,7.2 \\
7.3,7.5,9.4\end{array}$ & $\begin{array}{l}\text { Figures } 6.2-2 \text { to } \\
6.2-4,6.6-1 \text { to } \\
6.6-4,6.6-6, \\
6.6-8,6.6-10, \\
6.6-12,6.6-14, \\
6.6-16,6.6-18, \\
6.6-20,6.6-22, \\
6.6-23,7.2-1, \\
7.3-1\end{array}$ & $\begin{array}{l}\text { Tables 6.2-10, } \\
6.6-3,6.7-2\end{array}$ & $\begin{array}{l}\text { Results of nine flow fields } \\
\text { (base case), input/output } \\
\text { files, and simulations } \\
\text { results to be used by } \\
\text { TSPA-LA }\end{array}$ \\
\hline LB03033DSSFF9I.001 & $6.6,9.4$ & $\begin{array}{l}\text { Figures } \\
6.6-5,6.6-7 \\
6.6-9,6.6-11 \\
6.6-13,6.6-15 \\
6.6-17,6.6-19 \\
6.6-21,6.6-23\end{array}$ & $\begin{array}{l}\text { Tables } \\
6.6-2,6.6 .3 \\
6.6-4,6.7-3\end{array}$ & $\begin{array}{l}\text { Results of nine flow fields } \\
\text { (alternative and } \\
\text { supporting files for both } \\
\text { base case and alternative } \\
\text { flow fields), input/output } \\
\text { files, and simulation } \\
\text { results }\end{array}$ \\
\hline LB03033DUZTRAN.001 & $7.7,9.4$ & $\begin{array}{l}\text { Figures: } \\
6.7-1 \text { to } 6.7-8\end{array}$ & $\begin{array}{l}\text { Tables: } \\
6.7-2 \text { to } 6.7-5\end{array}$ & $\begin{array}{l}\text { Tc and Np Transport } \\
\text { simulation scenarios, } \\
\text { input/output files; using } \\
\text { nine base-case and nine } \\
\text { alternative flow fields }\end{array}$ \\
\hline LB0303THERMSIM.001 & $6.3,7.7,9.4$ & $\begin{array}{l}\text { Figures } 6.3-2 \text { to } \\
6.3-4,7.7-1 \text { to } \\
7.7-3\end{array}$ & & $\begin{array}{l}\text { Three-Dimensional UZ } \\
\text { ambient thermal model, } \\
\text { Input/output, supporting } \\
\text { files, and simulation } \\
\text { results }\end{array}$ \\
\hline LB0303THERMESH.001 & $\begin{array}{l}6.3 .4 \\
9.4 \\
\end{array}$ & Figure 6.3-1 & Table 6.3-1 & $\begin{array}{l}\text { Three-Dimensional UZ } \\
\text { thermal model grid }\end{array}$ \\
\hline LB0303GASFLW3D.001 & $6.4 .3,7.49 .4$ & $\begin{array}{l}\text { Figures } 6.4-1, \\
6.4-2,7.4-1, \\
7.4-2\end{array}$ & & $\begin{array}{l}\text { Three-Dimensional gas } \\
\text { flow model, input/out, } \\
\text { supporting files, and } \\
\text { simulation results }\end{array}$ \\
\hline LB0303C14INF3D.001 & $7.5,9.4$ & $\begin{array}{l}\text { Figures } 7.5-1 \\
7.5-2\end{array}$ & & $\begin{array}{l}\text { C-14 simulations, } \\
\text { input/output files, and } \\
\text { simulation results }\end{array}$ \\
\hline LB03013DSSCP3I.001 & $\begin{array}{l}\text { 6.3.4, 6.4.1, } \\
7.2,9.4\end{array}$ & & $\begin{array}{l}\text { Tables } 6.2-5 \text { to } \\
6.2-9,6.6-1 \\
\text { Appendix A } \\
\text { Tables A-1 to } \\
\text { A-6 }\end{array}$ & $\begin{array}{l}\text { Three-Dimensional site } \\
\text { scale model calibrated } \\
\text { property sets: Data } \\
\text { Summaries }\end{array}$ \\
\hline LB0303CLINFL3D.001 & $6.5 .2,9.4$ & $\begin{array}{l}\text { Figures } 6.5-1 \text { to } \\
6.5-4,7.8-1\end{array}$ & & $\begin{array}{l}\mathrm{Cl} \text { transport simulation } \\
\text { results, input/output files }\end{array}$ \\
\hline LB0304RDTRNSNS.001 & $6.8,9.4$ & $\begin{array}{l}\text { Figures } 6.8-1 \text { to } \\
6.8-4\end{array}$ & $\begin{array}{l}\text { Tables 6.8-1, } \\
6.8-2\end{array}$ & $\begin{array}{l}\text { Three-Dimensional flow } \\
\text { and transport sensitivity } \\
\text { analysis with active } \\
\text { fracture model parameter, } \\
\text { input/output, supporting } \\
\text { files, and simulation } \\
\text { results }\end{array}$ \\
\hline
\end{tabular}


Table 8-1. Output Data and Data Tracking Numbers (Continued)

\begin{tabular}{|c|c|c|c|c|}
\hline \multirow[b]{2}{*}{ Data Tracking Number } & \multicolumn{3}{|c|}{ Location in this report } & \multirow[b]{2}{*}{ Remarks } \\
\hline & Text & $\begin{array}{l}\text { Figure } \\
\end{array}$ & Table & \\
\hline LB0304UZSRTRAN.001 & $7.10 .3,9.4$ & $\begin{array}{l}\text { Figures } 7.10-1, \\
7.10-2\end{array}$ & & $\begin{array}{l}\text { UZ strontium transport } \\
\text { model, input/output files, } \\
\text { and simulation results }\end{array}$ \\
\hline LB0303A8N3MDLG.001 & $7.6,9.4$ & $\begin{array}{l}\text { Figures } 7.6-1 \text {, } \\
7.6-4,7.6-6 \text {, } \\
7.6-7,7.6-8, \\
7.6-9,7.6-10\end{array}$ & $\begin{array}{l}\text { Tables 7.6-2, } \\
7.6-3\end{array}$ & $\begin{array}{l}\text { Alcove 8/Niche } 3 \text { Seepage } \\
\text { Modeling: } \\
\text { Simulation files and } \\
\text { results }\end{array}$ \\
\hline LB0305TSPA18FF.001 & & & Table $6.2-11$ & $\begin{array}{l}\text { Eighteen three- } \\
\text { dimensional Site Scale UZ } \\
\text { Flow Fields Converted } \\
\text { from TOUGH2 to } \\
\text { T2FEHM format (See } \\
\text { Appendix D.2) }\end{array}$ \\
\hline LB0305PTNTSW9I.001 & $\begin{array}{l}\text { Appendix D } \\
\text { D.1 }\end{array}$ & & & $\begin{array}{l}\text { PTn/TSw Interface } \\
\text { Percolation Flux Maps for } \\
9 \text { Alternative Infiltration } \\
\text { Scenarios }\end{array}$ \\
\hline LB0302PTNTSW9I.001 & $\begin{array}{l}\text { Appendix D } \\
\text { D.1 }\end{array}$ & & & $\begin{array}{l}\text { PTn/TSw Interface } \\
\text { Percolation Flux Maps for } \\
9 \text { base case Infiltration } \\
\text { Scenarios }\end{array}$ \\
\hline LB0312TSPA06FF.001 & 6.6 .3 & & & $\begin{array}{l}6 \text { UZ flow fields, converted } \\
\text { for future water table } \\
\text { rising }\end{array}$ \\
\hline $\begin{array}{l}\text { LB0408RITSSCPF.001 } \\
\text { (TDIF: } 316734 \text { ) }\end{array}$ & $\begin{array}{l}\text { Appendix G, } \\
\text { Appendix I }\end{array}$ & & & $\begin{array}{l}\text { One-Dimensional } \\
\text { simulations for PTn } \\
\text { damping effect on } \\
\text { percolation fluxes; and } \\
\text { three-dimensional Site } \\
\text { Scale UZ Flow Simulation } \\
\text { for new RIT Infiltration } \\
\text { Scenario. }\end{array}$ \\
\hline
\end{tabular}

${ }^{a}$ The nine base-case flow fields will be directly used for TSPA-LA.

PTn=Paintbrush nonwelded hydrogeologic unit; RIT=Repository Integration Team; TSPA-LA=Total System Performance Assessment for License Application; TSw=Topopah Spring welded hydrogeologic unit; UZ=unsaturated zone

\subsection{UZ FLOW MODEL CALIBRATION}

As a critical step, field-measured saturation, water potential, and perched-water data have been used to calibrate the UZ flow model. Such calibrations are part of the important iterative processes of model development to increase confidence in model predictions of site conditions. This report continues this model calibration effort using the one-dimensional inversions reported by BSC (2004 [DIRS 169857]) and in the previous three-dimensional modeling effort (BSC 2001 [DIRS 158726]). This work focuses particularly on the PTn unit and potential perched-water layers using a three-dimensional forward calibration approach.

Calibration was conducted using three sets of rock-property parameters (BSC 2004 [DIRS 169857]) associated with present-day lower, mean, and upper infiltration rates, and the current geological model and numerical grid (BSC 2004 [DIRS 169855]). Two sets of rock properties were examined for the PTn units, with one set selected to be included in the base case 
and the other for the alternative set, based on analysis of chloride data. In addition, a permeability-barrier conceptual model was adopted for modeling water-perching occurrences. Under the permeability barrier concept, rock properties were locally modified to better match data in several grid layers near the observed perched zones.

The model calibration efforts conclude that the UZ flow model can reproduce moisture conditions in the Yucca Mountain UZ in terms of liquid saturations and water potentials, as verified by observations. In general, the modeled results from the nine base-case flow-field simulations using the perched-water conceptual model are in good agreement with the measured water-perching elevations at seven boreholes for upper-bound and mean present-day infiltration scenarios. However, under the lower-bound present-day infiltration rate, the models did not match the perched-water data very well in Boreholes SD-7, SD-9, NRG-7a, and UZ- 14 because of the low percolation fluxes at these locations. This will have little effect on flow fields.

The UZ flow model provides results of steady-state fluid and heat flow as well as transient tracer transport. Flow processes for model layers above the TSw and PTn units may be subject to episodic infiltration. Since the model results with these layers may not reflect actual conditions, which are time- and scale-dependent, therefore, the results may be directly applicable to studies on a much smaller scale, such as the emplacement drift. In this report, the uncertainties in the results, owing to input-parameter and model-gridding uncertainties, are evaluated by generating a number of flow fields with various parameter sets, infiltration maps, and conceptual models.

\subsection{GEOTHERMAL MODEL CALIBRATION}

The ambient geothermal model simulates large-scale UZ geothermal and heat flow conditions. The three-dimensional ambient thermal model was calibrated against qualified temperature data measured from five boreholes, using the base-case, present-day infiltration parameter set with a three-dimensional dual-permeability thermal grid. Simulated temperature results are in good agreement with the observed temperature profiles from the boreholes. Such results provide the ambient temperature distributions that determine boundary and initial conditions for the mountain-scale and drift-scale TH, THC, and THM coupled-process models.

\subsection{GAS FLOW MODEL}

A three-dimensional pneumatic simulation has been performed as a part of the UZ flow model calibration effort. Results of gas flow simulations are compared to the measured pneumatic data from three boreholes, including SD-7, SD-12, and UZ-7a, for the purposes of calibration and validation. As a result of calibration, fracture permeability in several TSw layers were reduced by a factor of 15 , leading to an overall good match between the three-dimensional model prediction and measurement of pneumatic data under three-dimensional flow conditions. The gas flow calibration results add confidence that the UZ flow model is reliable and appropriate for modeling gas flow in the UZ.

\subsection{CHLORIDE SUBMODEL}

Chloride is a naturally occurring conservative tracer. It enters the groundwater system as a solute in the infiltration flux. Thus, chloride data can be used to examine the long-term infiltration rate in the flow model. The chloride flux to the UZ at Yucca Mountain is calculated based on the precipitation, runon, and runoff at the ground surface of the mountain. 
The chloride transport modeling considered four scenarios of infiltration rates, including present-day (or modern) mean, upper, and lower bounds, as well as glacial-transition mean infiltration. Each scenario compares the results of two sets of flow fields with different PTn properties, one set denoted as a base-case flow field and the other as an alternative set, in order to study the effect of potential lateral flow in the PTn unit. The base case incorporates a property set of the PTn that would more likely cause lateral flow diversion, with the alternative less likely. Results show that the chloride transport model with the base case in the present-day, mean infiltration yields the closest and most consistent match with field data. In other words, the property set of the PTn that would favor lateral flow diversion (in the PTn unit) yields more reasonable results in matching the chloride concentration in the field samples. It indicates that lateral diversion may occur in the PTn unit at Yucca Mountain.

\subsection{CALCITE SUBMODEL}

Calcite precipitation has been modeled in unsaturated fractured rocks, considering several essential factors: (1) infiltration rate, (2) ambient geothermal gradient, (3) gaseous $\mathrm{CO}_{2}$ diffusive transport and partitioning between liquid and gas phases, (4) fracture-matrix interaction for water flow and chemical constituents, and (5) water-rock interaction.

Modeling calcite deposition can be used to build some constraints on the infiltration-percolation flux. The modeling also provides additional evidence for validation of the UZ model. Over a range of 2-20 mm/year infiltration rates, the simulated calcite distributions capture the measured data from the WT-24 well cuttings. The $20 \mathrm{~mm} /$ year infiltration rate may be the upper bound for the WT-24 location, whereas the base-case infiltration rate $(5.92 \mathrm{~mm} / \mathrm{year})$ used for the flow model gives the closest match to the data. The observed calcite precipitation for the top of TSw occurs mostly in the fractures, which is also captured by the modeling. The modeled results can provide useful insight into process mechanisms such as fracture-matrix interaction, as well as conditions and parameters controlling calcite deposition. The modeled calcite abundances generally increase with increasing infiltration rate, but become less sensitive to infiltration at higher rates as a result of its impact to the geothermal gradient. Data from Borehole SD-6 are roughly consistent with the relation between infiltration rate and calcite abundances, although a locally higher thermal gradient in the PTn can also be a factor in the calcite distribution.

\subsection{TSPA FLOW FIELDS}

Eighteen three-dimensional UZ flow fields (nine for the base case and nine for the alternative ones) were generated for TSPA-LA calculations. The nine base-case flow fields were produced for use by FEHM in the TSPA-LA calculations. These flow fields were based on (1) the TSPA-LA grid (BSC 2004 [DIRS 169855]), (2) nine infiltration maps representing three climates, (3) the six parameter sets, and (4) the two conceptual models of PTn flow and a perched-water conceptual model with the calibrated perched-water parameters. The purpose of studying a large number of flow fields for various modeling scenarios was to cover the TSPA-LA scenarios and to account for possible current and future site conditions. Alternative parameter sets for the PTn were used to investigate conceptual model uncertainty. The main uncertainties currently considered in the UZ flow model included fracture-matrix properties, present-day and future net infiltration rates over the mountain, conceptual models for perched water occurrence, and the role of PTn for lateral flow. 
A detailed analysis of simulated percolation fluxes at the repository level and at the water table was conducted for all simulation scenarios of 18 flow fields. These percolation fluxes and their distributions at the repository level indicated that there exists a certain amount of large-scale lateral flow or diversion by the PTn unit (on the order of several hundreds of meters) for the nine base-case simulations. In comparison, the nine alternative flow fields predict smaller lateral diversion when flowing through the PTn unit. In both models, however, significant flow diversion and redistribution into faults within the PTn unit is predicted. On the other hand, a comparison of simulated percolation fluxes at the repository level with those at the water table indicated that significant lateral flow occurs at perched or zeolitic layers when traveling through the CHn layers.

Fracture-matrix flow components at the repository horizon and at the water table were also analyzed for the 18 simulations. The statistics show that fracture flow is dominant in the welded tuffs, both at the repository horizon and at the water table, in the 18 flow fields. For three present-day infiltration scenarios - fracture-matrix flow components simulated at the repository level-fracture flow contributes more than 90 percent of total flow, and at the water table, 70 to 80 percent of the total flow. Furthermore, faults provide major flow pathways for focused percolation fluxes. Fault flow percentage increases with depth from 30 to 40 percent at the repository level, to 60 percent at the water table (Section 6.6.3, Tables 6.6-3 and 6.6-4).

\subsection{TRACER TRANSPORT TIMES}

A total of 40 tracer transport simulations were conducted to obtain insight into the impacts of infiltration rates, perched-water and PTn conceptual models, and retardation effects on tracer migration from the repository to the water table (Section 6.7). The 18 TSPA-LA flow fields were incorporated into these 40 transport runs. For each flow field, there were two tracer transport runs; one for conservative (or nonadsorbing) and the other for reactive (or adsorbing) tracer transport, respectively, with tracer release from repository fracture blocks. For the two present-day mean infiltration cases, tracer release from repository matrix blocks was also investigated, resulting in four additional transport runs. These tracer-transport studies indicate that there exist a wide range of tracer transport times associated with different infiltration rates, type of tracers, and PTn water conceptual models. The most important factors for tracer-transport times are found to be (1) surface infiltration rates; (2) adsorption effects in the $\mathrm{CHn}$ unit; and (3) release from repository fracture or matrix blocks.

Statistics of tracer transport times at 10 percent and 50 percent mass breakthrough at the water table from the 40 simulations show that tracer-transport times are inversely proportional to average surface infiltration. When the average infiltration rate increases from 5 to 35 (mm/year), average tracer transport (50 percent breakthrough) times decrease by two to three orders of magnitude. Nonadsorbing tracers migrate one to two orders of magnitude faster than adsorbing tracers when traveling from the repository to the water table under the same infiltration conditions. The base-case flow fields predict a little shorter or more conservative tracer transport times than the alternative ones, in general. The simulation results show that the two different PTn models have an insignificant impact on tracer transport at the lower units, i.e., from the repository to the water table. 


\subsection{SENSITIVITY ANALYSIS OF ACTIVE-FRACTURE-MODEL PARAMETER}

The impacts of uncertainty in the active fracture parameter $(\gamma)$ on the simulated flow and transport were evaluated by sensitivity analyses of flow and transport simulation results (Section 6.8). Two additional three-dimensional flow simulations, using reduced values of active fracture parameter $\gamma$ for TSw units and all units below the repository (including the units where the repository is located), respectively, were performed to carry out the analyses. By comparing liquid saturation, water potential, and the percolation flux obtained by these two simulations with those obtained by simulations using unmodified (calibrated) $\gamma$ values, we found that the changes in liquid saturation, water potential, and percolation flux are rather small. In general, the flow fields are not very sensitive to the active fracture parameter $\gamma$. On the other hand, tracer transport times were found to be sensitive to the value.

\subsection{MODEL VALIDATION}

Model validation efforts have been documented in this report. Validation activities for the UZ flow model mainly include corroboration with experimental data and modeling studies, using the following corroboration with experimental data: (1) ECRB observation data; (2) WT-24 perched-water data; (3) gas flow data from Boreholes SD-12 and UZ-7a; (4) borehole measured ${ }^{14} \mathrm{C}$ data; and (5) Alcove 8 flow and seepage test results. In addition, validation efforts are also performed for the ambient thermal model, chloride model, calcite model, and strontium model using field observed data from surface-based boreholes or from the ESF.

In these validation examples, the simulation results of the UZ flow model and Submodels are shown to be able to match different types of available observation data, such as water potentials, perched-water locations, tracer and geochemical concentrations, temperatures, and pneumatic pressures. The criteria of the model validation of the TWP are, in general, satisfied. These efforts have provided validation of the UZ flow model and its submodels for their accuracy and reliability in describing hydrological, thermal, and chemical conditions, and predicting flow and transport processes in the UZ system of Yucca Mountain.

\subsection{BARRIER CAPABILITY OF THE UZ}

The 500 to $700 \mathrm{~m}$ thick UZ consists of surficial soils and the TCw, PTn, TSw, and CHn units above and below the repository. The thick UZ formation itself is a natural barrier to downward water percolation and transport. The flow model documented in this report quantitatively describes the barrier capabilities of the UZ. The surficial soils function as a barrier by diverting (as runoff) some of the water that arrives as precipitation and runon, and by storing the remainder so that some of it is evaporated as evapotranspiration. A substantial amount of water thus diverted or evaporated cannot percolate as net infiltration (BSC 2004 [DIRS 170007], p. 23). The surficial soils are shown to be an effective natural barrier to water recharge and surface infiltration using the statistics of Tables $6.5-2$ and 6.1-2 for the present-day climates. Table 8-2 lists the estimated percentage of net infiltration (Table 6.1-2) over net recharge (=precipitation+run-on-runoff, Table 6.5-2), indicating that only 0.63 percent, 1.95 percent, and 2.5 percent of net water recharge on the model top boundary penetrates the top soil layer and becomes net infiltration, respectively, for the lower-, mean, and upper-bound infiltration scenarios. More than 97 percent of net recharge returns to the atmosphere by evapotranspiration. 
Table 8-2. Percentage of Net Infiltration over Net Recharge after Evapotranspiration for PresentDay/Modern Climates over the Model Domain)

\begin{tabular}{|c|c|c|c|c|}
\hline $\begin{array}{l}\text { Present-Day/Modern } \\
\text { Infiltration Scenarios }\end{array}$ & $\begin{array}{l}\text { Precipitation }^{\mathrm{a}} \\
\text { (mm/year) }\end{array}$ & $\begin{array}{l}\text { Net Recharge } \\
\text { (mm/year) }\end{array}$ & $\begin{array}{l}\text { Net Infiltration } \\
\text { (mm/year) }\end{array}$ & $\begin{array}{c}\text { Net Infiltration } \\
\%\end{array}$ \\
\hline Low & 185.9 & 198.5 & 1.25 & 0.63 \\
\hline Mean & 189.5 & 227.1 & 4.43 & 1.95 \\
\hline Upper & 267.1 & 429.9 & 10.74 & 2.50 \\
\hline
\end{tabular}

${ }^{\mathrm{a}}$ from Table 6.5-2.

${ }^{\mathrm{b}}$ from Table 6.1-2.

Barrier capability of the UZ below the surficial soils is the subject of the present report. We first consider UZ tuffs above and below the repository: water not diverted or evaporated by surficial soils and evapotranspiration entering the UZ formation as net infiltration, which is set as the surface boundary recharge condition for the UZ flow model. The UZ formation units above the repository serve as a barrier by storage and diversion. Percolating water flow through the PTn is matrix-dominated flow rather than fracture-dominated flow, which has been shown in Section 6.6-3 to subject to strong capillary barrier effects and lateral diversion. Therefore, the PTn unit buffers the repository from sudden changes in percolation flux and from episodic surface infiltration pulses. Because of predicted climate changes, the Yucca Mountain region as well as the UZ is expected to receive more precipitation and more infiltration in the future than at present, so that percolation flux at the repository horizon will increase. Storage in the UZ above the repository, particularly in the PTn unit, will significantly delay the increase in percolation flux below the PTn. However, the modeling approach adopted here ignores that delay because the flow field is modeled as changing instantly to the long-term steady state. This ignores the lower net infiltration during the transitional period and results in more conservative model predictions.

Lateral flow diversion within the PTn due to the capillary barrier effect is demonstrated in this report by two conceptual models. This lateral diversion diverts a large amount of percolation flux into faults, which becomes fast and focused flow pathways, which may bypass repository drifts. For example, the UZ model predicts with the present-day mean infiltration that more than 25 percent of percolation is diverted to faults by the units above the repository, mainly by the PTn. This will, on average, reduce percolation fluxes at the repository horizon, which is the driving force for potential seepage into drifts. Lateral diversion in the PTn thus reduces the amount of water seeping into drifts, which may transport radionuclides to the saturated zone.

Below the repository horizon, the UZ also has a barrier capability of delaying radionuclide transport to the saturation zone. The UZ does this by retarding the water flow and by removing some of the radionuclides by sorption. The flow in the UZ below the repository horizon is partially through perched water bodies and low-permeability zeolitic zones of the CHn. Flow through perched water bodies or zeolitic zones is slow because of the permeability in these areas. Percolation flux may also be diverted horizontally over perched water bodies caused by permeability barriers. This laterally diverted flow through perched water bodies travels slowly because of the longer distance and the smaller driving force (gravity gradient). Overall, low-permeability zeolitic zones and perched-water bodies retard downward percolation flux and increase tracer transport times. This increased residence time enhances adsorption and matrix diffusion effects while radionuclides are transported through these regions. 
The other portion of the flow below the repository goes through unfractured $\mathrm{CHn}$ vitric zones of the Calico Hills formation, and is retarded by low matrix permeability and large pore storage. This will also promote diffusion of radionuclides from fractures to matrix, and delay overall transport times. Furthermore, all UZ tuffs, even in faults, have some adsorptive capacity for radionuclides, regardless of zeolitic or vitric units of the $\mathrm{CHn}$. Adsorbing effect of radionuclides on unsaturated tuffs not only delays its arrival at the water table, but reduces the transported mass by radioactive decay.

\subsection{LIMITATIONS}

The UZ flow model and submodels are appropriate tools for characterizing flow and transport processes in the UZ of Yucca Mountain. The accuracy and reliability of the UZ flow model predictions are critically dependent on the accuracy of estimated model properties, other types of input data, and hydrogeological conceptual models. These models are limited mainly by the current understanding of the mountain system, including the geological and conceptual models, the volume-average modeling approach, and the available field and laboratory data.

Past site investigations have shown that large variabilities exists in the flow and transport parameters over the spatial and temporal scales of the mountain. Even though considerable progress has been made in this area, uncertainty associated with the UZ flow model input parameters exists. The major uncertainties in the UZ model parameters are: (1) accuracy of estimated current, past, and future net infiltration rates over the mountain; (2) quantitative descriptions of the heterogeneity of welded and nonwelded tuffs, their flow properties, and detailed spatial distributions within the mountain, especially below the repository; (3) fracture properties in zeolitic units and faults from field studies; (4) evidence of lateral diversion caused by zeolites in the CHn units and within the PTn units; and (5) transport properties (e.g., adsorption or $\mathrm{K}_{\mathrm{d}}$ coefficients in different rock types, matrix molecular diffusion coefficients in different units for different radionuclides, dispersivities in fracture and matrix systems). These uncertainties exist, but they have been addressed with the modeling studies in this report. In particular, most uncertainties are captured in the range of flow field generated.

This document and its conclusions may be affected by technical product input information However, the results and conclusions of the UZ flow fields will not be affected by the status of temperature and geochemistry data used in the calibration or validation studies because these flow fields are based on flow simulations under isothermal and different climate conditions.

\subsection{HOW ACCEPTANCE CRITERIA ARE ADDRESSED}

The following information describes how this analysis addresses the acceptance criteria in the Yucca Mountain Review Plan (NRC 2003 [DIRS 163274], Section 2.2.1.3.6.3). Only those acceptance criteria that are applicable to this report (see Section 4.2) are discussed. In most cases, the applicable acceptance criteria are not addressed solely by this report; rather, the acceptance criteria are fully addressed when this report is considered in conjunction with other analysis and model reports that describe flow in the UZ. Where a subcriterion includes several components, only some of those components may be addressed. How these components are addressed is summarized below. 


\section{Acceptance Criteria from Section 2.2.1.3.6, Flow Paths in the Unsaturated Zone}

\section{Acceptance Criterion 1: System Description and Model Integration Are Adequate.}

Subcriterion (1): The UZ flow model and submodels described in this report support the TSPA-LA. This model adequately incorporates important design features (drift layout and spacing), physical phenomena (geologic, hydrologic, geochemical, and thermal properties of the Yucca Mountain unsaturated zone strata), and couplings (ambient thermal-hydrological and hydrological-chemical) (Sections 6.1 through 6.8). The UZ flow model uses assumptions that are consistent with related UZ abstractions and analysis reports (Section 5).

Subcriterion (2): The models adequately incorporate the aspects of geology, hydrology, geochemistry, physical phenomena, and couplings important for determining flow paths in the unsaturated zone through use of Yucca Mountain field data, calibration to site-specific data, and verification via a number of physical processes and tests (Sections 6.2 through 6.8, and 7.1 through 7.10). Conditions and assumptions supporting the related abstraction of flow paths in the unsaturated zone are identified in Section 5. These assumptions are consistent with the system and model description in Sections 6.1, 6.3, and related abstractions.

Subcriterion (3): The process-level model of flow in the UZ uses assumptions, technical bases, data and models that are appropriate and consistent with other abstractions. Specifically, the TSPA-LA uses the UZ flow model simulations to provide input to other models such as ambient and thermal drift-scale models, the mountain-scale thermal-hydrological model, and the radionuclide transport model. And the UZ flow model applies other upstream models that form the project basis for climate projections, infiltration, hydrology, and geology in the unsaturated and saturated zones (Section 6.1). This model and submodels simulate ambient conditions and perform predictive studies of changes in the mountain caused by climatic, ambient thermal, and geochemical perturbations based on Yucca Mountain data collected over the last decade (Sections 6.1-6.5). The descriptions and technical basis are transparent and traceable to the data sources and references provided in Section 4.1.

Subcriterion (4): Parameters and properties employed in the UZ flow model were obtained from the same documents that provided the parameters and properties used for the UZ transport model (e.g., Calibrated Properties Model (BSC 2004 [DIRS 169857]) and (Geologic Framework Model (GFM2000) (BSC 2004 [170029]); DTN: MO0012MWDGFM02.002 [DIRS 153777])) (Section 6.1); therefore, their bases and justification are consistent. Ambient thermal-hydrologic effects are incorporated in this model and are consistent with the approach taken for these effects in the radionuclide transport model (Sections 6.1, 6.3, and 6.5). Similar numerical model approaches were used for the flow and transport models as described in Conceptual Model and Numerical Approaches for Unsaturated Zone Flow and Transport (BSC 2004 [DIRS 170035]) (Section 6).

Subcriterion (6): The infiltration boundary condition is output from an approved model that considers future climate changes. Parameter estimates used in this process-level model are representative of the temporal (time-related climate changes) and spatial (geologic strata and linear variations over the grid defined by the Geologic Framework Model) discretizations considered in the model (Sections 6.1 and 6.2). 
Subcriterion (7): Average parameter estimates are consistent with the temporal (time-related climate changes) and spatial discretizations adopted by the UZ flow model (Sections 6.1.1 and 6.1.5).

Subcriterion (8): Section 7.11 describes the representation of the UZ flow fields after a climate-induced water table rise.

Subcriterion (9): This report was developed in accordance with the QARD, which commits to NUREGs 1297 and 1298. Moreover, compliance with the DOE procedures, which are designed to ensure compliance with the QARD, is verified by audits by QA and other oversight activities. Accordingly, the guidance in NUREGs 1297 and 1298 has been followed as appropriate.

\section{Acceptance Criterion 2: Data Are Sufficient for Model Justification.}

Subcriterion (1): Hydrological and ambient thermal-hydrological or hydrological-chemical values used in the models discussed in this report are adequately justified in Sections 4.1, 6.1.3, $6.1 .4,6.1 .5,6.2 .3,6.3,6.4,6.8,6.9$, and, in the validation sections, 7.1 through 7.11. These sections provide adequate descriptions of how the data were used, interpreted, and synthesized into the parameters.

Subcriterion (2): The quality of the data used in this report is assured by the QA program (Section 2). Approved QA procedures identified in the TWP (BSC 2004 [DIRS 169654], Section 4) have been used to conduct and document the activities described in this analysis report.

Subcriterion (3): The UZ flow model, temperature model, and geochemistry submodels have been developed to simulate past, present, and future hydrological, geothermal, and geochemical conditions in the UZ of Yucca Mountain. Flow fields are computed using six parameter sets and nine infiltration maps with relevant spatial variability, such as, future climate states that influence net infiltration amounts (Sections 6.0, 6.1, 6.2 and 6.7). As demonstrated by results of calculations for the 18 flow fields (nine base cases and nine alternatives), representative values for deep-percolation flux rates are determined through use of the base case median or maximum climate scenarios (summarized in Section 8). The 3-D UZ flow model was calibrated using field-measured liquid saturation, water potential, perched-water, pneumatic, and isotopic tracer data (Section 6.2). Both the top and bottom boundaries of the model are treated as Dirichlet-type conditions with specified constant but spatially varying temperature and gas pressure (Section 6.1.3). Surface infiltration, as discussed in Section 6.1.4, is applied using a source term, accounting for varying climate scenarios, in the fracture gridblocks on the top boundary.

Subcriterion (6): Approved QA procedures identified in the TWP (BSC 2004 [DIRS 169654], Section 4) have been used to conduct and document the activities described in this model report.

Subcriterion (7): The conceptual model used in this report incorporates processes to describe subsurface flow and transport in the UZ in a heterogeneous system of layered, anisotropic, fractured volcanic rocks. Understanding of such processes has been promoted by a continuous effort of data collection and analysis as well as modeling studies (BSC 2001 [DIRS 158726]) (Section 6.2.2). Mathematical models used in the UZ flow model are TOUGH2 V1.4 (LBNL 2000 [DIRS 146496]) and T2R3D V1.4 (LBNL 1999 [DIRS 146654]). These codes were selected because they have been baselined through YMP QA procedure AP-SI.1Q for modeling flow and transport in heterogeneous fractured rock (e.g., BSC 2001 [DIRS 158726]; Wu et al. 2002 [DIRS 160195]) (Section 6.1.2). The robustness of results is demonstrated through the 
calibration and validation processes and comparison to alternative models as described in Sections 6.2 through 6.9 and 7.1 through 7.11 .

\section{Acceptance Criterion 3: Data Uncertainty is Characterized and Propagated Through the Model Abstraction.}

Subcriterion (1): The multiple flow fields generated by the UZ model capture the uncertainties in the parameter values and boundary conditions, as summarized in Sections 6.9 and 8.11. By choosing flow fields that consistently match site data and analog models, model and parametric uncertainties are reasonably accounted for and do not result in an under-representation of the risk estimate (Section 6.9).

Subcriterion (4): Boundary conditions (ground surface, and water table) applied to this model and sensitivity analyses performed on this model are representative of climate projections for nine base cases (present day, monsoon, and glacial climates means, maximums, and minimums) (Section 6.1.3). Surface infiltration as a function of climate scenario, as discussed in Section 6.1.4, is applied using a source term in the surface fracture gridblocks. These boundary conditions are used for both sensitivity analyses with the alternative model parameters and base case flow field calculations.

Subcriterion (5): Coupled thermal-hydrological or hydrological-chemical processes at the ambient condition are incorporated in the model by consideration of geothermal gradient in the thermal-hydrologic model initialization and by geochemical submodel prediction of chemical migration (e.g., chloride concentrations) (Sections 6.3 and 6.5). The geothermal gradient is determined by the ground surface temperature, the water table temperature, and the thermal conductivity from layer to layer under ambient flow conditions. Borehole-measured temperature was used to validate the ambient thermal model in Section 6.3.

Subcriterion (6): Uncertainties in the characteristics of the natural system are considered through the parametric studies performed on $\gamma$ values in conjunction with consideration of the nine climate scenarios (Sections 6.8 and 6.9).

\section{Acceptance Criterion 4: Model Uncertainty is Characterized and Propagated Through the Model Abstraction.}

Subcriterion (1): The UZ flow model report includes investigation of alternative modeling approaches of features, events and processes that might be important to describe UZ flow (see the list of included FEPs in Section 6.2.6, Table 6.2-11 and Section 6.6.2). Alternative approaches include climate and climate related changes (Section 6.1.4 and throughout the report) and water table rise (Section 7.11).

Subcriterion (3): The model uncertainties have been discussed, investigated or quantified in this report using field observation data, modeling sensitivity analyses, natural analog information and other arguments (Sections 6.2 through 6.8). Model uncertainty is reasonably captured by computations using alternative parameter sets as discussed in Section 6.9. The effects of parameter and data uncertainties on UZ flow are sufficiently covered in the model results for the 18 3-D flow fields so that no under-representation of the risk estimate will occur (Section 6.9.1). 


\section{INPUTS AND REFERENCES}

The following is a list of the references cited in this document. Column 2 represents the unique six digit numerical identifier (the Document Input Reference System number), which is placed in the text following the reference callout (e.g., BSC 2002 [DIRS 160819]). The purpose of these numbers is to assist in locating a specific reference. Within the reference list, multiple sources by the same author (e.g., BSC 2002) are sorted alphabetically by title.

\subsection{DOCUMENTS CITED}

Ahlers, C.F.; Bandurraga, T.M.; Bodvarsson, G.S.; Chen, G.; Finsterle, S.; and Wu, 101180 Y-S. 1995. Summary of Model Calibration and Sensitivity Studies Using the LBNL/USGS Three-Dimensional Unsaturated Zone Site-Scale Model. Milestone 3GLM107M. Berkeley, California: Lawrence Berkeley National Laboratory. ACC: MOL.19960208.0092.

Ahlers, C.F.; Finsterle, S.; and Bodvarsson, G.S. 1999. "Characterization and Prediction of Subsurface Pneumatic Response at Yucca Mountain, Nevada." Journal 109715 of Contaminant Hydrology, 38, (1-3), 47-68. New York, New York: Elsevier. TIC: 244160.

Altman, W.D.; Donnelly, J.P.; and Kennedy, J.E. 1988. Qualification of Existing Data for High-Level Nuclear Waste Repositories: Generic Technical Position. NUREG-1298. Washington, D.C.: U.S. Nuclear Regulatory Commission. TIC: 200652.

Altman, W.D.; Donnelly, J.P.; and Kennedy, J.E. 1988. Peer Review for High-Level 103597 Nuclear Waste Repositories: Generic Technical Position. NUREG-1297.

Washington, D.C.: U.S. Nuclear Regulatory Commission. TIC: 200651.

Bandurraga, T.M. and Bodvarsson, G.S. 1999. "Calibrating Hydrogeologic Parameters for the 3-D Site-Scale Unsaturated Zone Model of Yucca Mountain, Nevada." Journal of Contaminant Hydrology, 38, (1-3), 25-46. New York, New York: Elsevier. TIC: 244160.

Bear, J. 1972. Dynamics of Fluids in Porous Media. Environmental Science Series. Biswas, A.K., ed. New York, New York: Elsevier. TIC: 217356.

Benson, C.F. and Bowman, R.S. 1996. "Erratum, Tri- and Tetrafluorobenzoates as Nonreactive Tracers in Soil and Groundwater." Soil Science Society of America Journal, 60, 1780. Madison, Wisconsin: Soil Science Society of America. TIC: 246741.

Birkholzer, J.; Li, G.; Tsang, C-F.; and Tsang, Y. 1999. "Modeling Studies and Analysis of Seepage into Drifts at Yucca Mountain." Journal of Contaminant Hydrology, 38, (1-3), 349-384. New York, New York: Elsevier. TIC: 244160. 
Bodvarsson, G.S.; Bandurraga, T.M.; and Wu, Y.S., eds. 1997. The Site-Scale 100103 Unsaturated Zone Model of Yucca Mountain, Nevada, for the Viability Assessment. LBNL-40376. Berkeley, California: Lawrence Berkeley National Laboratory. ACC: MOL.19971014.0232.

Bodvarsson, G.S.; Boyle, W.; Patterson, R.; and Williams, D. 1999. "Overview of 120055 Scientific Investigations at Yucca Mountain-The Potential Repository for HighLevel Nuclear Waste." Journal of Contaminant Hydrology, 38, (1-3), 3-24. New York, New York: Elsevier. TIC: 244160.

Bodvarsson, G.S.; Kwicklis, E.; Shan, C.; and Wu, Y.S. 2003. "Estimation of Percolation Flux from Borehole Temperature Data at Yucca Mountain, Nevada." Journal of Contaminant Hydrology, 62-63, 3-22. New York,

New York: Elsevier. TIC: 254205.

Bodvarsson, G.S.; Liu, H.H.; Ahlers, C.F.; Wu, Y-S.; and Sonnenthal, S. 2001. "Parameterization and Upscaling in Modeling Flow and Transport in the Unsaturated Zone of Yucca Mountain." Chapter 11 of Conceptual Models of Flow and Transport in the Fractured Vadose Zone. Washington, D.C.: National Academy Press.

TIC: 252777.

BSC (Bechtel SAIC Company) 2001. UZ Flow Models and Submodels. MDL-NBS-HS-000006 REV 00 ICN 01. Las Vegas, Nevada: Bechtel SAIC Company. ACC: MOL.20020417.0382.

BSC 2002. Technical Work Plan for: Performance Assessment Unsaturated Zone. 160819 TWP-NBS-HS-000003 REV 02. Las Vegas, Nevada: Bechtel SAIC Company. ACC: MOL.20030102.0108.

BSC 2002. Total System Performance Assessment-License Application Methods and Approach. TDR-WIS-PA-000006 REV 00. Las Vegas, Nevada: Bechtel SAIC Company. ACC: MOL.20020923.0175.

BSC 2003. Repository Design, Repository/PA IED Subsurface Facilities. 161727 800-IED-EBS0-00402-000-00B. Las Vegas, Nevada: Bechtel SAIC Company. ACC: MOL.20030109.0146.

BSC 2003. Underground Layout Configuration. 800-P0C-MGR0-00100-000-00E. Las Vegas, Nevada: Bechtel SAIC Company. ACC: ENG.20031002.0007.

BSC 2004. Analysis of Hydrologic Properties Data. ANL-NBS-HS-000042 REV 00. 170038 Las Vegas, Nevada: Bechtel SAIC Company. ACC: DOC.20041005.0004.

BSC 2004. Calibrated Properties Model. MDL-NBS-HS-000003 REV 02. Las Vegas, Nevada: Bechtel SAIC Company. ACC: DOC.20041006.0004. 
BSC 2004. Conceptual Model and Numerical Approaches for Unsaturated Zone Flow

170035 and Transport. MDL-NBS-HS-000005 REV 01. Las Vegas, Nevada: Bechtel SAIC Company. ACC: DOC.20040922.0006.

BSC 2004. Development of Numerical Grids for UZ Flow and Transport Modeling. 169855 ANL-NBS-HS-000015 REV 02. Las Vegas, Nevada: Bechtel SAIC Company. ACC: DOC.20040901.0001.

BSC 2004. Drift-Scale THC Seepage Model. MDL-NBS-HS-000001, Rev. 03. Las Vegas, Nevada: Bechtel SAIC Company.

BSC 2004. Features, Events, and Processes in UZ Flow and Transport. ANL-NBS-MD-000001, Rev. 03. Las Vegas, Nevada: Bechtel SAIC Company.

BSC 2004. Future Climate Analysis. ANL-NBS-GS-000008 REV 01. 170002 Las Vegas, Nevada: Bechtel SAIC Company. ACC: DOC.20040908.0005.

BSC 2004. Geologic Framework Model (GFM2000). MDL-NBS-GS-000002 REV 02. Las Vegas, Nevada: Bechtel SAIC Company. ACC: DOC.20040827.0008.

BSC 2004. In Situ Field Testing of Processes. ANL-NBS-HS-000005, 170004 Rev. 03. Las Vegas, Nevada: Bechtel SAIC Company.

BSC 2004. Mineralogic Model (MM3.0) Report. MDL-NBS-GS-000003 REV 01. 170031 Las Vegas, Nevada: Bechtel SAIC Company. ACC: DOC.20040908.0006. BSC 2004. Mountain-Scale Coupled Processes (TH/THC/THM). MDL-NBS-HS-000007 REV 02. Las Vegas, Nevada: Bechtel SAIC Company.

BSC 2004. Natural Analogue Synthesis Report. TDR-NBS-GS-000027 REV 01. Las Vegas, Nevada: Bechtel SAIC Company. ACC: DOC.20040524.0008.

BSC 2004. Particle Tracking Model and Abstraction of Transport Processes. MDL-NBS-HS-000020 REV 01. Las Vegas, Nevada: Bechtel SAIC Company. ACC: DOC.20041020.0016.

BSC 2004. Q-List. 000-30R-MGR0-00500-000-000 REV 00. Las Vegas, Nevada: Bechtel SAIC Company. ACC: ENG.20040721.0007.

BSC 2004. Radionuclide Transport Models Under Ambient Conditions. 164500 MDL-NBS-HS-000008, Rev. 02. Las Vegas, Nevada: Bechtel SAIC Company.

BSC 2004. Saturated Zone Site-Scale Flow Model. MDL-NBS-HS-000011, Rev. $02 . \quad 170037$ Las Vegas, Nevada: Bechtel SAIC Company.

BSC 2004. Simulation of Net Infiltration for Present-Day and Potential Future 170007 Climates. MDL-NBS-HS-000023, Rev. 00. Las Vegas, Nevada: Bechtel SAIC Company. 
BSC 2004. Technical Work Plan for: Unsaturated Zone Flow Analysis and Model

Report Integration. TWP-MGR-HS-000001 REV 00. Las Vegas, Nevada: Bechtel

SAIC Company. ACC: DOC.20040701.0005.

BSC 2004. UZ Flow Models and Submodels. MDL-NBS-HS-000006

168027

REV 01 Errata 001. Las Vegas, Nevada: Bechtel SAIC Company.

ACC: DOC.20030818.0002; DOC.20040211.0008.

BSC 2004. Yucca Mountain Site Description. TDR-CRW-GS-000001

169734

REV 02 ICN 01. Two volumes. Las Vegas, Nevada: Bechtel SAIC Company.

ACC: DOC.20040504.0008.

Campbell, K.; Wolfsberg, A.; Fabryka-Martin, J.; and Sweetkind, D. 2003.

162745

"Chlorine-36 Data at Yucca Mountain: Statistical Tests of Conceptual Models for

Unsaturated-Zone Flow." Journal of Contaminant Hydrology, 62-63, 43-61.

New York, New York: Elsevier. TIC: 254205.

Canori, G.F. and Leitner, M.M. 2003. Project Requirements Document.

166275

TER-MGR-MD-000001 REV 02. Las Vegas, Nevada: Bechtel SAIC Company.

ACC: DOC.20031222.0006.

Carey, J.W.; Chipera, S.J.; Vaniman, D.T.; and Bish, D.L. 1998. Three-Dimensional

109051

Mineralogic Model of Yucca Mountain, Nevada: Rev 2.0. Deliverable SP32BSM4.

Los Alamos, New Mexico: Los Alamos National Laboratory, Earth and

Environmental Sciences Division. ACC: MOL.20000110.0159.

Carlos, B.A.; Chipera, S.J.; and Bish, D.L. 1995. "Calcite and Zeolite Fracture

162118

Coatings in Topopah Spring Tuff Along Drill Hole Wash, Yucca Mountain, Nevada."

High Level Radioactive Waste Management, Proceedings of the Sixth Annual

International Conference, Las Vegas, Nevada, April 30-May 5, 1995. Pages 100-102.

La Grange Park, Illinois: American Nuclear Society. TIC: 215781.

Codell, R.B. and Murphy, W.M. 1992. "Geochemical Model for 14C Transport in

100719

Unsaturated Rock." High Level Radioactive Waste Management, Proceedings of the

Third International Conference, Las Vegas, Nevada, April 12-16, 1992. 2, 1959-1965.

La Grange Park, Illinois: American Nuclear Society. TIC: 204231.

CRWMS (Civilian Radioactive Waste Management System) M\&O (Management and Operating Contractor) 2000. Conceptual and Numerical Models for UZ Flow and Transport. MDL-NBS-HS-000005 REV 00.

Las Vegas, Nevada: CRWMS M\&O. ACC: MOL.19990721.0526.

CRWMS M\&O 2000. Natural Analogs for the Unsaturated Zone.

ANL-NBS-HS-000007 REV 00. Las Vegas, Nevada: CRWMS M\&O.

ACC: MOL.19990721.0524. 
D’Agnese, F.A.; O’Brien, G.M.; Faunt, C.C.; and San Juan, C.A. 1999. Simulated Effects of Climate Change on the Death Valley Regional Ground-Water Flow System, Nevada and California. Water-Resources Investigations Report 98-4041. Denver, Colorado: U.S. Geological Survey. TIC: 243555.

Doughty, C. 1999. "Investigation of Conceptual and Numerical Approaches for 135997 Evaluating Moisture, Gas, Chemical, and Heat Transport in Fractured Unsaturated Rock." Journal of Contaminant Hydrology, 38, (1-3), 69-106. New York, New York: Elsevier. TIC: 244160.

Driscoll, F.G. 1986. Groundwater and Wells. 2nd Edition. St. Paul, Minnesota: 116801 Johnson Filtration Systems. TIC: 217555.

Fabryka-Martin, J.T.; Turin, H.J.; Wolfsberg, A.V.; Brenner, D.; Dixon, P.R.; and Musgrave, J.A. 1996. Summary Report of Chlorine-36 Studies.

LA-CST-TIP-96-003. Draft. Los Alamos, New Mexico: Los Alamos National Laboratory. ACC: MOL.19970103.0037.

Fabryka-Martin, J.T.; Turin, H.J.; Wolfsberg, A.V.; Brenner, D.L.; Dixon, P.R.; and 162737 Musgrave, J.A. 1998. Summary Report of Chlorine-36 Studies as of August 1996. LA-13458-MS. Los Alamos, New Mexico: Los Alamos National Laboratory. ACC: MOL.20031119.0395.

Fabryka-Martin, J.T.; Wolfsberg, A.V.; Dixon, P.R.; Levy, S.S.; Musgrave, J.A.; and 100145 Turin, H.J. 1997. Summary Report of Chlorine-36 Studies: Sampling, Analysis, and Simulation of Chlorine-36 in the Exploratory Studies Facility. LA-13352-MS. Los Alamos, New Mexico: Los Alamos National Laboratory. ACC: MOL.19980812.0254.

Fabryka-Martin, J.T.; Wolfsberg, A.V.; Roach, J.L.; Winters, S.T.; and Wolfsberg, L.E. 1998. "Using Chloride to Trace Water Movement in the Unsaturated Zone at Yucca Mountain." High-Level Radioactive Waste Management, Proceedings of the Eighth International Conference, Las Vegas, Nevada, May 11-14, 1998.

Pages 264-268. La Grange Park, Illinois: American Nuclear Society. TIC: 237082.

Faure, G. 1986. Principles of Isotope Geology. 2nd Edition. New York, New York: John Wiley \& Sons. TIC: 237212.

Finsterle, S. 1999. ITOUGH2 User's Guide. LBNL-40040. Berkeley, California: Lawrence Berkeley National Laboratory. TIC: 243018.

Flint, A.L. and Flint, L.E. 1994. "Spatial Distribution of Potential Near Surface Moisture Flux at Yucca Mountain." High Level Radioactive Waste Management, Proceedings of the Fifth Annual International Conference, Las Vegas, Nevada, May 22-26, 1994. 4, 2352-2358. La Grange Park, Illinois: American Nuclear Society. TIC: 210984. 
Flint, A.L.; Flint, L.E.; Bodvarsson, G.S.; Kwicklis, E.M.; and Fabryka-Martin, J. 2001. "Evolution of the Conceptual Model of Unsaturated Zone Hydrology at Yucca Mountain, Nevada." Journal of Hydrology, 247, (1-2), 1-30. New York, New York: Elsevier. TIC: 250932.

Flint, A.L.; Flint, L.E.; Kwicklis, E.M.; Bodvarsson, G.S.; and Fabryka-Martin, J.M. 2001. "Hydrology of Yucca Mountain, Nevada." Reviews of Geophysics, 39, (4), 447-470. Washington, D.C.: American Geophysical Union. TIC: 254964.

Flint, A.L.; Hevesi, J.A.; and Flint, L.E. 1996. Conceptual and Numerical Model of Infiltration for the Yucca Mountain Area, Nevada. Milestone 3GUI623M. Denver, Colorado: U.S. Geological Survey.

ACC: MOL.19970409.0087.

Flint, L.E. 1998. Characterization of Hydrogeologic Units Using Matrix Properties, Yucca Mountain, Nevada. Water-Resources Investigations Report 97-4243. Denver, Colorado: U.S. Geological Survey.

ACC: MOL.19980429.0512.

Flint, L.E.; Flint, A.L.; and Selker, J.S. 2003. "Influence of Transitional Volcanic 163967 Strata on Lateral Diversion at Yucca Mountain, Nevada." Water Resources Research, 39, (4), 4-1 to 4-17. Washington, D.C.: American Geophysical Union. TIC: 254439.

Forester, R.M.; Bradbury, J.P.; Carter, C.; Elvidge, A.B.; Hemphill, M.L.; Lundstrom, 100148 S.C.; Mahan, S.A.; Marshall, B.D.; Neymark, L.A.; Paces, J.B.; Sharpe, S.E.; Whelan, J.F.; and Wigand, P.E. 1996. Synthesis of Quaternary Response of the Yucca Mountain Unsaturated and Saturated Zone Hydrology to Climate Change. Milestone 3GCA102M. Las Vegas, Nevada: U.S. Geological Survey.

ACC: MOL.19970211.0026.

Fridrich, C.J.; Dudley, W.W., Jr.; and Stuckless, J.S. 1994. "Hydrogeologic Analysis of the Saturated-Zone Ground-Water System, Under Yucca Mountain, Nevada." Journal of Hydrology, 154, 133-168. Amsterdam, The Netherlands: Elsevier. TIC: 224606.

Goode, D.J. 1996. "Direct Simulation of Groundwater Age." Water Resources Research, 32, (2), 289-296. Washington, D.C.: American Geophysical Union. TIC: 252291.

Grathwohl, P. 2000. Diffusion in Natural Porous Media: Contaminant Transport, Sorption/Desorption and Dissolution Kinetics. Boston, Massachusetts: Kluwer Academic Publishers. TIC: 247983.

Hevesi, J.A.; Flint, A.L.; and Istok, J.D. 1992. "Precipitation Estimation in Mountainous Terrain Using Multivariate Geostatistics. Part II: Isohyetal Maps." Journal of Applied Meteorology, 31, (7), 677-688. Boston, Massachusetts: American Meteorological Society. TIC: 225248. 
Johnson, T.M. and DePaolo, D.J. 1994. "Interpretation of Isotopic Data in

Groundwater-Rock Systems: Model Development and Application to Sr Isotope Data from Yucca Mountain.” Water Resources Research, 30, (5), 1571-1587. Washington, D.C.: American Geophysical Union. TIC: 252320.

Lasaga, A.C. 1998. Kinetic Theory in the Earth Sciences. Princeton,

New Jersey: Princeton University Press. TIC: 246279.

Lide, D.R., ed. 2002. CRC Handbook of Chemistry and Physics. 83rd Edition.

160832

Boca Raton, Florida: CRC Press. TIC: 253582.

Liu, H-H.; Haukwa, C.B.; Ahlers, C.F.; Bodvarsson, G.S.; Flint, A.L.; and Guertal,

162470

W.B. 2003. "Modeling Flow and Transport in Unsaturated Fractured Rock: An Evaluation of the Continuum Approach." Journal of Contaminant Hydrology, 62-63, 173-188. New York, New York: Elsevier. TIC: 254205.

Liu, H.H.; Bodvarsson, G.S.; and Finsterle, S. 2002. "A Note on Unsaturated Flow in 160230 Two-Dimensional Fracture Networks." Water Resources Research, 38, (9), 15-1 to 15-9. Washington, D.C.: American Geophysical Union. TIC: 253307.

Liu, H.H.; Doughty, C.; and Bodvarsson, G.S. 1998. "An Active Fracture Model for 105729 Unsaturated Flow and Transport in Fractured Rocks." Water Resources Research, 34, (10), 2633-2646. Washington, D.C.: American Geophysical Union. TIC: 243012.

Liu, J.; Sonnenthal, E.L.; and Bodvarsson, G.S. 2003. "Calibration of Yucca Mountain Unsaturated Zone Flow and Transport Model Using Porewater Chloride Data." Journal of Contaminant Hydrology, 62-63, 213-235. New York, New York: Elsevier. TIC: 254205.

Lu, G.; Sonnenthal, E.L.; and Bodvarsson, G.S. 2003. "Implications of Halide Leaching on ${ }^{36} \mathrm{Cl}$ Studies at Yucca Mountain, Nevada." Water Resources Research, 39, (12), 3-1 through 3-15. Washington, D.C.: American Geophysical Union.

TIC: 255498.

Marshall, B.D.; Paces, J.B.; Neymark, L.A.; Whelan, J.F.; and Peterman, Z.E. 1998. 107415 "Secondary Minerals Record Past Percolation Flux at Yucca Mountain, Nevada." High-Level Radioactive Waste Management, Proceedings of the Eighth International Conference, Las Vegas, Nevada, May 11-14, 1998. Pages 127-129. La Grange Park, Illinois: American Nuclear Society. TIC: 237082.

Marshall, B.D.; Peterman, Z.E.; Futa, K.; and Stuckless, J.S. 1991. "Strontium Isotopes in Carbonate Deposits at Crater Flat, Nevada." High Level Radioactive Waste Management, Proceedings of the Second Annual International Conference, Las Vegas, Nevada, April 28-May 3, 1991. 2, 1423-1428. La Grange Park, Illinois: American Nuclear Society. TIC: 204272. 
Meijer, A. 2002. "Conceptual Model of the Controls on Natural Water Chemistry at 158813 Yucca Mountain, Nevada.” Applied Geochemistry, 17, (6), 793-805. New York, New York: Elsevier. TIC: 252808.

Montazer, P. and Wilson, W.E. 1984. Conceptual Hydrologic Model of Flow in the 100161 Unsaturated Zone, Yucca Mountain, Nevada. Water-Resources Investigations Report 84-4345. Lakewood, Colorado: U.S. Geological Survey.

ACC: NNA.19890327.0051.

Moridis, G.J.; Hu, Q.; Wu, Y-S.; and Bodvarsson, G.S. 2003. "Preliminary 3-D 161902 Site-Scale Studies of Radioactive Colloid Transport in the Unsaturated Zone at Yucca Mountain, Nevada." Journal of Contaminant Hydrology, 60, (3-4), 251-286.

New York, New York: Elsevier. TIC: 253921.

Murphy, E.M.; Ginn, T.R.; and Phillips, J.L. 1996. "Geochemical Estimates of Paleorecharge in the Pasco Basin: Evaluation of the Chloride Mass Balance Technique." Water Resources Research, 32, (9), 2853-2868. Washington, D.C.: American Geophysical Union. TIC: 252291.

National Research Council. 1996. Rock Fractures and Fluid Flow, Contemporary 139151 Understanding and Applications. Washington, D.C.: National Academy Press. TIC: 235913.

Neretnieks, I. 2002. "A Stochastic Multi-Channel Model for Solute Transport-Analysis of Tracer Tests in Fractured Rock." Journal of Contaminant Hydrology, 55, (3-4), 175-211. New York, New York: Elsevier. TIC: 253977.

Neuman, S.P. 1994. "Generalized Scaling of Permeabilities: Validation and Effect of 105731 Support Scale.” Geophysical Research Letters, 21, (5), 349-352. Washington, D.C.: American Geophysical Union. TIC: 240142.

Neymark, L.A.; Amelin, Y.V.; Paces, J.B.; Peterman, Z.E.; and Whelan, J.F. 2001. "Age Constraints on Fluid Inclusions in Calcite at Yucca Mountain." "Back to the Future - Managing the Back End of the Nuclear Fuel Cycle to Create a More Secure Energy Future," Proceedings of the 9th International High-Level Radioactive Waste Management Conference (IHLRWM), Las Vegas, Nevada, April 29, May 3, 2001. La Grange Park, Illinois: American Nuclear Society. TIC: 247873.

NRC (U.S. Nuclear Regulatory Commission) 2003. Yucca Mountain Review Plan, Final Report. NUREG-1804, Rev. 2. Washington, D.C.: U.S. Nuclear Regulatory Commission, Office of Nuclear Material Safety and Safeguards. TIC: 254568.

Paces, J.B.; Neymark, L.A.; Marshall, B.D.; Whelan, J.F.; and Peterman, Z.E. 1998. "Inferences for Yucca Mountain Unsaturated-Zone Hydrology from Secondary Minerals." High-Level Radioactive Waste Management, Proceedings of the Eighth International Conference, Las Vegas, Nevada, May 11-14, 1998. Pages 36-39. La Grange Park, Illinois: American Nuclear Society. TIC: 237082. 
Paces, J.B.; Neymark, L.A.; Marshall, B.D.; Whelan, J.F.; and Peterman, Z.E. 2001.

Ages and Origins of Calcite and Opal in the Exploratory Studies Facility Tunnel,

Yucca Mountain, Nevada. Water-Resources Investigations Report 01-4049. Denver,

Colorado: U.S. Geological Survey. TIC: 251284.

Paces, J.B.; Peterman, Z.E.; Neymark, L.A.; Nimz, G.J.; Gascoyne, M.; and Marshall, 162738 B.D. 2003. "Summary of Chlorine-36 Validation Studies at Yucca Mountain, Nevada." Proceedings of the 10th International High-Level Radioactive Waste Management Conference (IHLRWM), March 30-April 2, 2003, Las Vegas, Nevada. Pages 348-356. La Grange Park, Illinois: American Nuclear Society. TIC: 254253.

Pan, L.; Warrick, A.W.; and Wierenga, P.J. 1997. "Downward Water Flow Through Sloping Layers in the Vadose Zone: Time-Dependence and Effect of Slope Length." Journal of Hydrology, 199, (1-2), 36-52. New York,

New York: Elsevier. TIC: 254555.

Pan, L.; Wu, Y-S.; and Zhang, K. 2004. "A Modeling Study of Flow Diversion and 169760 Focusing in Unsaturated Fractured Rock." Vadose Zone Journal, 3, 233-246. Madison, Wisconsin: Soil Science Society of America. TIC: 256135.

Peterman, Z.E. and Cloke, P.L. 2002. "Geochemistry of Rock Units at the Potential Repository Level, Yucca Mountain, Nevada (includes Erratum).” Applied Geochemistry, 17, $(6,7), 683-698,955-958$. New York, New York: Pergamon. TIC: $252516 ; 252517$.

Peterman, Z.E. and Stuckless, J.S. 1993. "Isotopic Evidence of Complex Ground101149 Water Flow at Yucca Mountain, Nevada, USA." High Level Radioactive Waste Management, Proceedings of the Fourth Annual International Conference, Las Vegas, Nevada, April 26-30, 1993. 2, 1559-1566. La Grange Park, Illinois: American Nuclear Society. TIC: 208542.

Peterman, Z.E.; Stuckless, J.S.; Marshall, B.D.; Mahan, S.A.; and Futa, K. 1992. "Strontium Isotope Geochemistry of Calcite Fracture Fillings in Deep Core, Yucca Mountain, Nevada -- A Progress Report." High Level Radioactive Waste Management, Proceedings of the Third International Conference, Las Vegas, Nevada, April 12-16, 1992. 2, 1582-1586. La Grange Park, Illinois: American Nuclear Society. TIC: 204231.

Philip, J.R.; Knight, J.H.; and Waechter, R.T. 1989. "Unsaturated Seepage and Subterranean Holes: Conspectus, and Exclusion Problem for Circular Cylindrical Cavities." Water Resources Research, 25, (1), 16-28. Washington, D.C.: American Geophysical Union. TIC: 239117.

Pruess, K. and Narasimhan, T.N. 1985. "A Practical Method for Modeling Fluid and 101707 Heat Flow in Fractured Porous Media." Society of Petroleum Engineers Journal, 25, (1), 14-26. Dallas, Texas: Society of Petroleum Engineers. TIC: 221917. 
Pruess, K.; Oldenburg, C.; and Moridis, G. 1999. TOUGH2 User's Guide, Version 160778 2.0. LBNL-43134. Berkeley, California: Lawrence Berkeley National Laboratory. TIC: 253038.

Richards, L.A. 1931. "Capillary Conduction of Liquids Through Porous Mediums." 104252 Physics, 1, 318-333. New York, New York: American Physical Society. TIC: 225383.

Rousseau, J.P.; Kwicklis, E.M.; and Gillies, D.C., eds. 1999. Hydrogeology of the 102097 Unsaturated Zone, North Ramp Area of the Exploratory Studies Facility, Yucca Mountain, Nevada. Water-Resources Investigations Report 98-4050. Denver, Colorado: U.S. Geological Survey.

ACC: MOL.19990419.0335.

Rousseau, J.P.; Loskot, C.L.; Thamir, F.; and Lu, N. 1997. Results of Borehole Monitoring in the Unsaturated Zone Within the Main Drift Area of the Exploratory Studies Facility, Yucca Mountain, Nevada. Milestone SPH22M3. Denver, Colorado: U.S. Geological Survey. ACC: MOL.19970626.0351.

Sass, J.H.; Lachenbruch, A.H.; Dudley, W.W., Jr.; Priest, S.S.; and Munroe, R.J. 100644 1988. Temperature, Thermal Conductivity, and Heat Flow Near Yucca Mountain, Nevada: Some Tectonic and Hydrologic Implications. Open-File Report 87-649. Denver, Colorado: U.S. Geological Survey. TIC: 203195.

Shapiro, A.M. 2001. "Effective Matrix Diffusion in Kilometer-Scale Transport in Fractured Crystalline Rock." Water Resources Research, 37, (3), 507-522.

Washington, D.C.: American Geophysical Union. TIC: 253979.

Sonnenthal, E. and Ortoleva, P.J. 1994. "Numerical Simulations of Overpressured Compartments in Sedimentary Basins." Basin Compartments and Seals. Ortoleva, P.J., ed. AAPG Memoir 61. 403-416. Tulsa, Oklahoma: American Association of Petroleum Geologists. TIC: 235940.

Sonnenthal, E.L. and Bodvarsson, G.S. 1999. "Constraints on the Hydrology of the 117127 Unsaturated Zone at Yucca Mountain, NV from Three-Dimensional Models of Chloride and Strontium Geochemistry." Journal of Contaminant Hydrology, 38, (1-3), 107-156. New York, New York: Elsevier. TIC: 244160.

Stuckless, J.S.; Peterman, Z.E.; and Muhs, D.R. 1991. "U and Sr in Ground Water 106947 and Calcite, Yucca Mountain, Nevada: Evidence Against Upwelling Water." Science, 254, 551-554. Washington, D.C.: American Association for the Advancement of Science. TIC: 224423.

Tokunaga, T.K. and Wan, J. 1997. "Water Film Flow Along Fracture Surfaces of Porous Rock." Water Resources Research, 33, (6), 1287-1295. Washington, D.C.: American Geophysical Union. TIC: 242739. 
Triay, I.R.; Meijer, A.; Conca, J.L.; Kung, K.S.; Rundberg, R.S.; and Strietelmeier,

101014 B.A. 1996. Summary and Synthesis Report on Radionuclide Retardation for the Yucca Mountain Site Characterization Project. Milestone 3784. Los Alamos, New Mexico: Los Alamos National Laboratory. ACC: MOL.19961231.0099.

Tyler, S.W.; Chapman, J.B.; Conrad, S.H.; Hammermeister, D.P.; Blout, D.O.; Miller, J.J.; Sully, M.J.; and Ginanni, J.M. 1996. "Soil-Water Flux in the Southern Great Basin, United States: Temporal and Spatial Variations Over the Last 120,000 Years." Water Resources Research, 32, (6), 1481-1499. Washington, D.C.: American Geophysical Union. TIC: 235938.

USGS (U.S. Geological Survey) 2000. Future Climate Analysis. 136368 ANL-NBS-GS-000008 REV 00. Denver, Colorado: U.S. Geological Survey. ACC: MOL.20000629.0907.

van Genuchten, M.T. 1980. "A Closed-Form Equation for Predicting the Hydraulic Conductivity of Unsaturated Soils." Soil Science Society of America Journal, 44, (5), 892-898. Madison, Wisconsin: Soil Science Society of America. TIC: 217327.

Vaniman, D.T. and Chipera, S.J. 1996. "Paleotransport of Lanthanides and Strontium Recorded in Calcite Compositions from Tuffs at Yucca Mountain, Nevada, USA." Geochimica et Cosmochimica Acta, 60, (22), 4417-4433. New York, New York: Pergamon Press. TIC: 231351.

Vaniman, D.T.; Chipera, S.J.; Bish, D.L.; Carey, J.W.; and Levy, S.S. 2001. 157427 "Quantification of Unsaturated-Zone Alteration and Cation Exchange in Zeolitized Tuffs at Yucca Mountain, Nevada, USA." Geochimica et Cosmochimica Acta, 65, (20), 3409-3433. New York, New York: Elsevier. TIC: 251574.

Walter, A.L.; Frind, E.O.; Blowes, D.W.; Ptacek, C.J.; and Molson, J.W. 1994. "Modeling of Multicomponent Reactive Transport in Groundwater. 1. Model Development and Evaluation." Water Resources Research, 30, (11), 3137-3148. Washington, D.C.: American Geophysical Union. TIC: 252320.

Wang, J.S. 2003. "Scientific Notebooks Referenced in Model Report U0050, UZ Flow Models and Submodels, MDL-NBS-HS-000006 REV 01." Memorandum from J.S. Wang (BSC) to File, June 6, 2003, with attachments.

ACC: MOL.20030611.0227.

Wang, J.S.Y. and Narasimhan, T.N. 1985. "Hydrologic Mechanisms Governing Fluid 108835 Flow in a Partially Saturated, Fractured, Porous Medium." Water Resources Research, 21, (12), 1861-1874. Washington, D.C.: American Geophysical Union. TIC: 225290.

Wang, J.S.Y. and Narasimhan, T.N. 1993. "Unsaturated Flow in Fractured Porous 106793 Media." Chapter 7 of Flow and Contaminant Transport in Fractured Rock. Bear, J.; Tsang, C-F.; and de Marsily, G., eds. San Diego, California: Academic Press. TIC: 235461 
Wu, Y-S. and Pruess, K. 2000. "Numerical Simulation of Non-Isothermal Multiphase

Tracer Transport in Heterogeneous Fractured Porous Media." Advances in Water

Resources, 23, (7), 699-723. New York, New York: Elsevier. TIC: 249626.

Wu, Y-S.; Pan, L.; Zhang, W.; and Bodvarsson, G.S. 2002. "Characterization of

160195

Flow and Transport Processes within the Unsaturated Zone of Yucca Mountain, Nevada, Under Current and Future Climates." Journal of Contaminant Hydrology, 54, (3-4), 215-247. New York,

New York: Elsevier. TIC: 253316.

Wu, Y-S.; Zhang, W.; Pan, L.; Hinds, J.; and Bodvarsson, G.S. 2000. Capillary

154918

Barriers in Unsaturated Fractured Rocks of Yucca Mountain, Nevada. LBNL-46876.

Berkeley, California: Lawrence Berkeley National Laboratory. TIC: 249912.

Wu, Y-S.; Zhang, W.; Pan, L.; Hinds, J.; and Bodvarsson, G.S. 2002. "Modeling Capillary Barriers in Unsaturated Fractured Rock." Water Resources Research, 38, (11), 35-1 through 35-12. Washington, D.C.: American Geophysical Union.

TIC: 253854.

Wu, Y.S.; Haukwa, C.; and Bodvarsson, G.S. 1999. "A Site-Scale Model for Fluid and Heat Flow in the Unsaturated Zone of Yucca Mountain, Nevada." Journal of Contaminant Hydrology, 38, (1-3), 185-215. New York, New York: Elsevier. TIC: 244160.

Wu, Y.S.; Ritcey, A.C.; and Bodvarsson, G.S. 1999. "A Modeling Study of Perched 117167 Water Phenomena in the Unsaturated Zone at Yucca Mountain." Journal of Contaminant Hydrology, 38, (1-3), 157-184. New York, New York: Elsevier. TIC: 244160.

$\mathrm{Xu}, \mathrm{T}$. and Pruess, K. 1998. Coupled Modeling of Non-Isothermal Multi-Phase Flow, Solute Transport and Reactive Chemistry in Porous and Fractured Media: 1. Model Development and Validation. LBNL-42050. Berkeley, California: Lawrence Berkeley National Laboratory. TIC: 243735.

Xu, T. and Pruess, K. 2001. "Modeling Multiphase Non-Isothermal Fluid Flow and Reactive Geochemical Transport in Variably Saturated Fractured Rocks: 1. Methodology." American Journal of Science, 301, 16-33. New Haven, Connecticut: Yale University, Kline Geology Laboratory. TIC: 251482.

Xu, T.; Samper, J.; Ayora, C.; Manzano, M.; and Custodio, E. 1999. "Modeling of 162123 Non-isothermal Multi-component Reactive Transport in Field Scale Porous Media Flow Systems." Journal of Hydrology, 214, (1-4), 144-164. New York, New York: Elsevier. TIC: 254290.

Xu, T.; Sonnenthal, E.; and Bodvarsson, G. 2003. "A Reaction-Transport Model for 162124 Calcite Precipitation and Evaluation of Infiltration Fluxes in Unsaturated Fractured Rock." Journal of Contaminant Hydrology, 64, (1-2), 113-127. New York, New York: Elsevier. TIC: 254008. 
Yang, I.C. 2002. "Percolation Flux and Transport Velocity in the Unsaturated Zone, 160839

Yucca Mountain, Nevada." Applied Geochemistry, 17, (6), 807-817. New York, New York: Elsevier. TIC: 253605.

Yang, I.C.; Rattray, G.W.; and Yu, P. 1996. Interpretation of Chemical 100194 and Isotopic Data from Boreholes in the Unsaturated Zone at Yucca Mountain, Nevada. Water-Resources Investigations Report 96-4058. Denver, Colorado: U.S. Geological Survey. ACC: MOL.19980528.0216.

Yeh, G-T. and Tripathi, V.S. 1991. "A Model for Simulating Transport of Reactive Multispecies Components: Model Development and Demonstration." Water Resources Research, 27, (12), 3075-3094. Washington, D.C.: American Geophysical Union. TIC: 236255.

Zhou, Q.; Liu, H-H.; Bodvarsson, G.S.; and Oldenburg, C.M. 2003. "Flow and Transport in Unsaturated Fractured Rock: Effects of Multiscale Heterogeneity of Hydrogeologic Properties." Journal of Contaminant Hydrology, 60, (1-2), 1-30. New York, New York: Elsevier. TIC: 253978.

\subsection{CODES, STANDARDS, REGULATIONS, AND PROCEDURES}

10 CFR 63. Energy: Disposal of High-Level Radioactive Wastes in a Geologic

Repository at Yucca Mountain, Nevada. Readily available.

AP-2.22Q, Rev. 1, ICN 1. Classification Analyses and Maintenance of the Q-List. Washington, D.C.: U.S. Department of Energy, Office of Civilian Radioactive Waste Management. ACC: DOC.20040714.0002.

AP-2.27Q, Rev. 1, ICN 4. Planning for Science Activities. Washington, D.C.: U.S. Department of Energy, Office of Civilian Radioactive Waste Management.

ACC: DOC.20040610.0006.

AP-SIII.10Q, Rev. 1, ICN 7. Models. Washington, D.C.: U.S. Department of Energy, Office of Civilian Radioactive Waste Management. ACC: DOC.20040920.0002.

LP-SI.11Q-BSC, Rev. 0, ICN 1. Software Management. Washington, D.C.: U.S. Department of Energy, Office of Civilian Radioactive Waste Management. ACC: DOC.20041005.0008.

\subsection{SOURCE DATA, LISTED BY DATA TRACKING NUMBER}

GS000308311221.005. Net Infiltration Modeling Results for 3 Climate Scenarios for 147613 FY99. Submittal date: 03/01/2000.

GS000608312271.001. Pore-Water Hydrochemistry and Isotopic Data for Boreholes 153407 USW NRG-6, USW NRG-7A, USW SD-7, USW SD-9, USW SD-12, USW UZ-14 and UE-25 UZ\#16 from 10/1/96 to 1/31/97.

Submittal date: 06/23/2000. 
GS010708312272.002. Chemical Data for Pore Water from Tuff Cores of USW

NRG-6, USW NRG-7/7A, USW UZ-14, USW UZ-N55 and UE-25 UZ\#16.

Submittal date: 09/05/2001.

GS020408312272.003. Collection and Analysis of Pore Water Samples for the

160899

Period from April 2001 to February 2002. Submittal date: 04/24/2002.

GS020508312242.001. Trench Fault Infiltration in Alcove 8 Using Permeameters from March 5, 2001 to June 1, 2001.

Submittal date: 05/22/2002.

GS020608315215.002. Carbon Dioxide Abundances, Carbon Dioxide

162126

Concentrations, and Normative Calcite Concentrations for Cuttings from Borehole USW SD-6, USW WT-24, and ECRB Cross Drift Boreholes, Determined by Carbon Dioxide Evolution, May 25, 2000 and

September 8, 2000. Submittal date: 06/26/2002.

GS020908312242.002. Trenched Fault Infiltration in Alcove 8 Using Permeameters

162141 from June 1, 2001 to March 26, 2002.

Submittal date: 09/17/2002.

GS021008315215.007. Carbon Dioxide and Normative Calcite Concentrations in

Powdered Cuttings from Borehole USW WT-24 Determined by CO2 Evolution between July 1998 and August 1999. Submittal date: 11/07/2002.

GS030108314224.001. Geotechnical Data for Alcove 8 (ECRB) and Niche 3 (ESF):

162131

Full Periphery Geologic Map (Drawing OA-46-356).

Submittal date: 02/05/2003.

GS030608312242.005. Surface Infiltration in a Large Plot in Alcove 8 Using 166200 Permeameters from November 19, 2002 to March 24, 2003. Submittal date: 06/24/2003.

GS031008312242.007. Surface Infiltration in a Large Plot in Alcove 8 Using 166089 Permeameters from August 20, 2002 to November 19, 2002. Submittal date: $10 / 31 / 2003$.

GS031208312232.003. Deep Unsaturated Zone Surface-Based Borehole Instrumentation Program Data from Boreholes USW NRG-7A, UE-25 UZ \#4, USW NRG-6, UE-25 UZ \#5, USW UZ-7A and USW SD-12 for the Time Period 10/01/97 - 03/31/98. Submittal date: 07/29/2004.

GS950208312232.003. Data, Including Water Potential, Pressure and Temperature, 105572 Collected from Boreholes USW NRG-6 and USW NRG-7A from Instrumentation through March 31, 1995. Submittal date: 02/13/1995.

GS950408318523.001. Temperature, Thermal Conductivity, and Heat Flow Near 107244 Yucca Mountain, Nevada. Submittal date: 04/21/1995. 
GS951108312232.008. Data, Including Water Potential, Pressure and Temperature, 106756 Collected from Boreholes UE-25 UZ\#4 \& UZ\#5 from Instrumentation through September 30, 1995, and from USW NRG-6 \& NRG-7A from April 1 through September 30, 1995.

Submittal date: 11/21/1995.

GS960308312232.001. Deep Unsaturated Zone Surface-Based Borehole 105573 Instrumentation Program Data from Boreholes USW NRG-7A, USW NRG-6, UE-25 UZ\#4, UE-25 UZ\#5, USW UZ-7A, and USW SD-12 for the Time Period 10/01/95 through 3/31/96. Submittal date: 04/04/1996.

GS960308312312.005. Water-Level, Discharge Rate and Related Data from the 107230 Pump Tests Conducted at Well USW UZ-14, August 17 through August 30, 1993. Submittal date: 03/15/1996.

GS960808312232.004. Deep Unsaturated Zone Surface-Based Borehole 105974 Instrumentation Program Data for Boreholes USW NRG-7A, USW NRG-6, UE-25 UZ\#4, UE-25 UZ\#5, USW UZ-7A and USW SD-12 for the Time Period 4/1/96 through 8/15/96. Submittal date: 08/30/1996.

GS960908312261.004. Shut-in Pressure Test Data from UE-25 NRG\#5 and USW SD-7 from November, 1995 to July, 1996.

Submittal date: 09/24/1996.

GS961108312261.006. Gas Chemistry, ESF Alcoves 2 and 3, 11/95 - 4/96; Water 107293 Chemistry, Alcove 2 (Tritium), Alcove 3, and ESF Tunnel; and Pneumatic Pressure Response from Boreholes in Exploratory Studies Facility Alcoves 2 and 3, 10/95 - 5/96. Submittal date: 11/12/1996.

GS961108312271.002. Chemical and Isotopic Composition of Pore Water and Pore Gas, 1994-96, from Boreholes USW UZ-1, USW UZ-14, UE-25 UZ\#16, USW NRG-6, USW NRG-7A, USW SD-7, USW SD-9, ESF-AL\#3-RBT\#1, and ESF-AL\#3-RBT\#4, and ESF Rubble.

Submittal date: 12/04/1996.

GS970108312232.002. Deep Unsaturated Zone, Surface-Based Borehole Instrumentation Program - Raw Data Submittal for Boreholes USW NRG-7A, USW NRG-6, UE-25 UZ\#4, UE-25 UZ\#5, USW UZ-7A, and USW SD-12, for the Period 8/16/96 through 12/31/96.

Submittal date: $01 / 22 / 1997$.

GS970808312232.005. Deep Unsaturated Zone Surface-Based Borehole 105978 Instrumentation Program Data from Boreholes USW NRG-7A, UE-25 UZ\#4, UE-25 UZ\#5, USW UZ-7A and USW SD-12 for the Time Period 1/1/97 - 6/30/97. Submittal date: $08 / 28 / 1997$. 
GS970908312271.003. Unsaturated Zone Hydrochemistry Data, 2-1-97 to 8-31-97, 111467 Including Chemical Composition and Carbon, Oxygen, and Hydrogen Isotopic Composition: Porewater from USW NRG-7A, SD-7, SD-9, SD-12 and UZ-14; and Gas from USW UZ-14.

Submittal date: 09/08/1997.

GS971108312232.007. Deep Unsaturated Zone Surface-Based Borehole Instrumentation Program Data from Boreholes USW NRG-7A, UE-25 UZ \#4, UE-25 105980 UZ \#5, USW UZ-7A and USW SD-12 for the Time Period 7/1/97 - 9/30/97.

Submittal date: 11/18/1997.

GS980408312232.001. Deep Unsaturated Zone Surface-Based Borehole Instrumentation Program Data from Boreholes USW NRG-7A, UE-25 UZ \#4, USW NRG-6, UE-25 UZ \#5, USW UZ-7A and USW SD-12 for the Time Period 10/01/97 - 03/31/98. Submittal date: 04/16/1998.

GS980508312313.001. Water-Level and Related Data Collected in Support of 109746 Perched-Water Testing in Borehole USW WT-24, September 10, 1997 through February 3, 1998. Submittal date: 05/07/1998.

GS980708312242.010. Physical Properties of Borehole Core Samples, and Water Potential Measurements Using the Filter Paper Technique, for Borehole Samples from USW WT-24. Submittal date: 07/27/1998.

GS980808312242.014. Physical Properties of Borehole Core Samples and Water 106748 Potential Measurements Using the Filter Paper Technique for Borehole Samples from USW SD-6. Submittal date: 08/11/1998.

GS980908312242.036. Water Potentials Measured with Heat Dissipation Probes in ECRB Holes from 4/23/98 to 7/31/98. Submittal date: 09/22/1998.

GS981008312272.004. Analysis for Chemical Composition of Pore Water from Boreholes USW UZ-7A, USW WT-24, USW SD-6, USW SD-7, and USW SD-12 During FY 1997 and 1998. Submittal date: 10/28/1998.

GS990208312272.001. Analysis for Chemical Composition of Pore Water from Borehole USW UZ-14 and UE-25 UZ\#16 and Groundwater from UE-25 UZ\#16. Submittal date: 02/23/1999.

GS990308315215.004. Strontium Isotope Ratios and Strontium Concentrations in 145711 Rock Core Samples and Leachates from USW SD-9 and USW SD-12. Submittal date: 03/25/1999.

LA000000000034.002. Diffusion of Sorbing and Non-Sorbing Radionuclides. 148603 Submittal date: 06/22/1993. 
LA0002JF12213U.001. Chemistry Data for Porewater Extracted from Drillcore from

154760 Surface-Based Boreholes USW NRG-6, USW NRG-7A, USW UZ-7A, USW UZ-14, UE-25 UZ\#16, USW UZ-N55, USW SD-6, USW SD-7, USW SD-9, USW SD-12, and USW WT-24.

Submittal date: $02 / 15 / 2000$.

LA0002JF12213U.002. Chemistry Data for Porewater Extracted from ESF, Cross Drift and Busted Butte Drill Core. Submittal date: 02/15/2000.

156281

LA0003JC831362.001. Preliminary Matrix Diffusion Coefficients for Yucca 149557 Mountain Tuffs. Submittal date: 4/10/2000.

LA0010JC831341.001. Radionuclide Retardation Measurements of Sorption 162476

Distribution Coefficients for Barium. Submittal date: 10/19/2000.

LA0010JC831341.002. Radionuclide Retardation Measurements of Sorption Distribution Coefficients for Cesium. Submittal date: 10/19/2000.

LA0010JC831341.003. Radionuclide Retardation Measurements of Sorption Distribution Coefficients for Strontium. Submittal date: 10/19/2000.

LA0010JC831341.004. Radionuclide Retardation Measurements of Sorption Distribution Coefficients for Selenium. Submittal date: 10/19/2000.

LA0010JC831341.005. Radionuclide Retardation Measurements of Sorption Distribution Coefficients for Uranium. Submittal date: 10/19/2000.

LA0010JC831341.006. Radionuclide Retardation Measurements of Sorption 153318 Distribution Coefficients for Plutonium. Submittal date: 10/19/2000.

LA0010JC831341.007. Radionuclide Retardation Measurements of Sorption

Distribution Coefficients for Neptunium. Submittal date: 10/19/2000.

LA0302AM831341.002. Unsaturated Zone Distribution Coefficients (Kds) for U, 162575 $\mathrm{Np}, \mathrm{Pu}, \mathrm{Am}, \mathrm{Pa}, \mathrm{Cs}, \mathrm{Sr}, \mathrm{Ra}$, and Th. Submittal date: 02/04/2003.

LA9909JF831222.004. Chloride, Bromide, and Sulfate Analyses of Busted Butte and 145598 Cross Drift Tunnel Porewaters in FY99. Submittal date: 09/29/1999.

LA9909JF831222.010. Chloride, Bromide, Sulfate, and Chlorine-36 Analyses of 122733 ESF Porewaters. Submittal date: 09/29/1999.

LAJF831222AQ98.011. Chloride, Bromide, Sulfate and Chlorine-36 Analyses of 145402 Springs, Groundwater, Porewater, Perched Water and Surface Runoff. Submittal date: $09 / 10 / 1998$. 
LB0101DSTTHCR1.003. Attachment III - Mineral Reactive Surface Areas:

161278

TPTPMN and DST THC Models for AMR N0120/U0110 REV01,

"Drift-Scale Coupled Processes (Drift-Scale Test and THC Seepage) Models.".

Submittal date: 01/26/2001.

LB0205REVUZPRP.001. Fracture Properties for UZ Model Layers Developed from

159525

Field Data. Submittal date: 05/14/2002.

LB0208UZDSCPMI.001. Drift-Scale Calibrated Property Sets: Mean Infiltration

161285

Supporting Files. Submittal date: 08/27/2002.

LB0208UZDSCPMI.002. Drift-Scale Calibrated Property Sets: Mean Infiltration

161243

Data Summary. Submittal date: 08/26/2002.

LB02091DSSCP3I.002. 1-D Site Scale Calibrated Properties: Data Summary.

161433

Submittal date: 09/18/2002.

LB02092DSSCFPR.001. 2-D Site Scale Calibrated Fault Properties: Supporting

162422

Files. Submittal date: 09/18/2002.

LB02092DSSCFPR.002. 2-D Site Scale Calibrated Fault Properties: Data Summary. 162128 Submittal date: 09/18/2002.

LB0210THRMLPRP.001. Thermal Properties of UZ Model Layers: Data Summary. 160799 Submittal date: 10/25/2002.

LB0301N3SURDAT.001. Niche 3107 Measurements and Elevations Used for Grid

162130 Generation. Submittal date: 01/29/2003.

LB03023DKMGRID.001. UZ 3-D Site Scale Model Grids.

162354

Submittal date: 02/26/2003.

LB0302AMRU0035.001. Model Validation and Parameter Uncertainty: Supporting Files. Submittal date: 02/07/2003.

LB0303A8N3LIQR.001. Alcove 8 - Niche 3 Seepage Data Compilation. Submittal 162570 date: $03 / 19 / 2003$.

LB0306A8N3LIQR.001. Fault Infiltration Test from Alcoves to Niche3 (9/18/2002 165405 10/16/2002). Submittal date: 06/19/2003.

LB0308A8N3SEEP.001. Niche 3 Seepage (10/16/2002-04/02/2003). Submittal date: 166090 08/29/2003.

LB0312A8N3MDLG.001. Pre-Test Prediction Results for 169761 Alcove 8/Niche 3: Simulations. Submittal date: 12/17/2003. 
LB980901233124.101. Pneumatic Pressure and Air Permeability Data from Niche 3107 and Niche 4788 in the ESF from Chapter 2 of Report SP33PBM4: Fracture Flow and Seepage Testing in the ESF, FY98. Submittal date: 11/23/1999.

LB990501233129.001. Fracture Properties for the UZ Model Grids and Uncalibrated 106787 Fracture and Matrix Properties for the UZ Model Layers for AMR U0090, "Analysis of Hydrologic Properties Data".

Submittal date: 08/25/1999.

LB990861233129.001. Drift Scale Calibrated 1-D Property Set, FY99. Submittal 110226 date: $08 / 06 / 1999$.

LB991091233129.001. One-Dimensional, Mountain-Scale Calibration for AMR 125868 U0035, "Calibrated Properties Model”. Submittal date: 10/22/1999.

LB991121233129.001. Calibrated Parameters for the Present-Day, Mean Infiltration Scenario, Used for Simulations With Perched Water Conceptual Model \#1 (Flow Through) for the Mean Infiltration Scenarios of the Present-Day, Monsoon and Glacial Transition Climates.

Submittal date: 03/11/2000.

LB991121233129.003. Calibrated Parameters for the Present-Day, Upper-Bound 147335 Infiltration Scenario, Used for Simulations with Perched Water Conceptual Model \#1 for the Upper-Bound Infiltration Scenarios of the Present-Day, Monsoon and Glacial Transition Climates.

Submittal date: 03/11/2000.

LB991121233129.005. Calibrated Parameters for the Present-Day, Lower-Bound 147346 Infiltration Scenario, Used for Simulations with Perched Water Conceptual Model \#1 for the Lower-Bound Infiltration Scenarios of the Present-Day, Monsoon and Glacial Transition Climates.

Submittal date: 03/11/2000.

LB991200DSTTHC.003. Mineral Initial Volume Fractions: Attachment II of AMR 161276 N0120/U0110, "Drift-Scale Coupled Processes (Drift-Scale Test and THC Seepage) Models.”. Submittal date: 03/11/2000.

LB997141233129.001. Calibrated Basecase Infiltration 1-D Parameter Set for the 104055 UZ Flow and Transport Model, FY99. Submittal date: 07/21/1999.

MO0004QGFMPICK.000. Lithostratigraphic Contacts from 152554 MO9811MWDGFM03.000 to be Qualified Under the Data Qualification Plan, TDP-NBS-GS-000001. Submittal date: 04/04/2000.

MO0012CARB1314.000. Water - Carbon 13 and Carbon 14 Abundance. Submittal 153398 date: $12 / 01 / 2000$. 
MO0012MWDGFM02.002. Geologic Framework Model (GFM2000). Submittal date: $12 / 18 / 2000$.

MO0109HYMXPROP.001. Matrix Hydrologic Properties Data.

Submittal date: 09/17/2001.

MO0407SEPFEPLA.000. LA FEP List. Submittal date: 07/20/2004.

SN0408T0507804.003. Output Flux Files Calculated Using INFIL V A_2.A1,

Submodel Denoted H104. Submittal date: 08/17/2004.

SNT02110894001.002. Geologic Core Logs for USW SD-7.

Submittal date: Submittal date: 07/15/1996.

\subsection{OUTPUT DATA, LISTED BY DATA TRACKING NUMBER}

LB03013DSSCP3I.001. 3-D Site Scale Calibrated Properties: Data Summaries. Submittal date: 01/27/2003.

LB03023DSSCP9I.001. 3-D Site Scale UZ Flow Field Simulations for 9 Infiltration Scenarios. Submittal date: 02/28/2003.

LB0302PTNTSW9I.001. PTn/TSw Interface Percolation Flux Maps for 9 Infiltration Scenarios. Submittal date: 02/28/2003.

LB03033DSSFF9I.001. 3-D Site Scale UZ Flow Fields for 9 Infiltration Scenarios. Simulations. Submittal date: 03/28/2003.

LB03033DUZTRAN.001. Tc and Np distributions/transport in UZ flow-fields. Submittal date: 03/28/2003.

LB0303A8N3MDLG.001. Alcove 8 - Niche 3 Seepage Modeling: Simulations. Submittal date: 03/31/2003.

LB0303C14INF3D.001. Carbon-14 isotope distributions in UZ flow-fields. Submittal date: $03 / 28 / 2003$.

LB0303CLINFL3D.001. Chloride ion distributions in UZ flow-fields.

Submittal date: $03 / 28 / 2003$.

LB0303GASFLW3D.001. Time-dependent gas pressure distributions in UZ flowfields. Submittal date: 03/28/2003.

LB0303THERMESH.001. Thermal Model Mesh. Submittal date: 03/28/2003.

LB0303THERMSIM.001. UZ Thermal Modeling: Simulations.

Submittal date: 03/28/2003. 
LB030432DGRIDS.001. Three 2-D Cross-section Grids.

Submittal date: 04/29/2003.

LB0304GASFLW3D.001. Time-dependent gas pressure distributions in UZ

flow-fields (using a 5-character element thermal mesh). Submittal date: 04/29/2003.

LB0304RDTRNSNS.001. Supporting Files of 3D Flow and Transport Sensitivity Analyses. Submittal date: 04/29/2003.

LB0304UZSRTRAN.001. UZ strontium transport modeling: Simulations.

Submittal date: 04/29/2003.

LB0305PTNTSW9I.001. PTn/TSw Interface Percolation Flux Maps for

9 Alternative Infiltration Scenarios. Submittal date: 05/12/2003.

LB0305TSPA18FF.001. Eighteen 3-D Site Scale UZ Flow Fields Converted from TOUGH2 to T2FEHM format. Submittal date: 05/09/2003.

LB0312TSPA06FF.001. Six Flow Fields With Raised Water Tables, upper, middle, and lower bound infiltration scenarios for glacial and monsoonal climates (6 flow fields) with wtrise v2.0 processing for a water table rise (conversion of saturation and flux at previously unsaturated nodes). Submittal date: 12/23/2003.

LB0408RITSSCPF.001. 3-D Site Scale Uz Flow Simulation For RIT Infiltration Scenario, one 3-D flow field based on present day climate (for RIT).

Submittal date: 08/18/2004.

\subsection{SOFTWARE CODES}

LBNL (Lawrence Berkeley National Laboratory) 1999. Software Code: infil2grid.

134754 V1.6. PC with Windows/95 or 98. Sun or DEC Workstation with Unix OS. 10077-1.6-00.

LBNL 1999. Software Code: iTOUGH2. V4.0. SUN, DEC. 10003-4.0-00.

LBNL 1999. Software Code: T2R3D. V1.4. FORTRAN 77, SUN, DEC/ALPHA. 146654 10006-1.4-00.

LBNL 2000. Software Code: TOUGH2. V1.4. Sun Ultra Sparc, SUN O.S. 5.5.2, and DEC/ALPHA, OSF 2 V4.0, OSF1 V5.1. 10007-1.4-01.

LBNL 2000.

Software Routine: bot_sum.f. V1.0. SUN AND DEC. 10349-1.0-00.

LBNL 2000. Software Routine: get_temp_v0.f. V1.0. DEC Alpha w/OSF1 V4.0. 10222-1.0-00.

LBNL 2000. Software Routine: toptemp_v0.f. V1.0. DEC Alpha w/OSF1 V4.0. 10224-1.0-00. 
LBNL 2001. Software Routine: vf_con.for. V1.0. PC w/Windows.

154345 10466-1.0-00.

LBNL 2002.

162143

Software Code: Bkread.f. V1.0. SunOS 5.5.1. 10894-1.0-00.

LBNL 2002. Software Code: infil2grid. V1.7. DEC-Alpha, PC. 10077-1.7-00.

154793

LBNL 2002. Software Code: iTOUGH2. V5.0. SUN UltraSparc.,

160106 DEC ALPHA, LINUX. 10003-5.0-00.

LBNL 2002. Software Code: Smesh.f. V1.0. SunOS 5.5.1. 10896-1.0-00.

162142

LBNL 2002. Software Code: TBgas3D. V2.0. SUN UltraSparc.

160107 10882-2.0-00.

LBNL 2002. Software Code: TOUGHREACT. V3.0. DEC ALPHA/OSF1 V5.1, 161256 DEC ALPHA/OSF1 V5.0, Sun UltraSparc/Sun OS 5.5.1, PC/Linux Redhat 7.2. 10396-3.0-00.

LBNL 2002. Software Code: WINGRIDDER. V2.0. PC. 10024-2.0-00.

LBNL 2002. Software Routine: 2kgrid8.for. V1.0. DEC-Alpha, PC. 10503-1.0-00.

LBNL 2003. Software Code: flow-con. V1.0. PC/ WINDOWS 95/98

LBNL 2003. Software Code: T2FEHM. V4.0. DEC ALPHA / OSF1 V4.0/ V5.1. 10997-4.0-00.

LBNL 2003. Software Code: TOUGH2. V1.6. PC/MS-DOS Windows 98, Sun 161491 UltraSparc/Sun OS 5.5.1, DEC-Alpha OSF1 V4.0. 10007-1.6-01.

LBNL 2003. Software Code: WTRISE. V2.0. PC/WINDOWS 2000/98; DEC 163453 ALPHA/OSF1 V5.1. 10537-2.0-00. 


\section{APPENDIX A}

CALIBRATED PARAMETER SETS, COMBINING ONE-DIMENSIONAL INVERSIONS AND THREE-DIMENSIONAL PERCHED-WATER AND CHLORIDE-TRANSPORT MODELING USED IN GENERATING THE NINE FLOW FIELDS, AND TRACER TRANSPORT TIMES 
This appendix presents the six parameter sets for the UZ flow model. The first three sets of Tables A-1, A-2 and A-3 are the calibrated 3-D UZ flow model parameters and used for generating the nine base case UZ flow fields. The second three sets of Table A-4, A-5 and A-6 are used as alternative parameters and used for sensitivity modeling studies and for generating alternative UZ flow fields.

Table A-1. Calibrated Parameters for the Present-Day, Mean Infiltration Scenario, Used for Simulations with the Mean Infiltration Scenarios of the Present-Day, Monsoon, and Glacial-Transition Climates

\begin{tabular}{|c|c|c|c|c|c|c|c|}
\hline Model Layer & $\begin{array}{c}k_{M} \\
\left(m^{2}\right)\end{array}$ & $\begin{array}{c}\alpha_{M} \\
(1 / P a)\end{array}$ & $\begin{array}{c}m_{M} \\
(-)\end{array}$ & $\begin{array}{c}k_{F} \\
\left(m^{2}\right)\end{array}$ & $\begin{array}{c}\alpha_{F} \\
(1 / \mathrm{Pa})\end{array}$ & $\begin{array}{c}m_{F} \\
(-)\end{array}$ & $\begin{array}{c}\gamma \\
(-)\end{array}$ \\
\hline tcw11 & $3.74 \mathrm{E}-15$ & $1.01 \mathrm{E}-5$ & 0.388 & $4.24 \mathrm{E}-11$ & $5.27 \mathrm{E}-3$ & 0.633 & 0.587 \\
\hline tcw12 & $5.52 \mathrm{E}-20$ & $3.11 \mathrm{E}-6$ & 0.280 & $9.53 \mathrm{E}-11$ & $1.57 \mathrm{E}-3$ & 0.633 & 0.587 \\
\hline tcw13 & $5.65 \mathrm{E}-17$ & $3.26 \mathrm{E}-6$ & 0.259 & $1.32 \mathrm{E}-11$ & $1.24 \mathrm{E}-3$ & 0.633 & 0.587 \\
\hline ptn21 & $9.90 \mathrm{E}-13$ & $1.01 \mathrm{E}-5$ & 0.176 & 1.86E-12 & $1.68 \mathrm{E}-3$ & 0.580 & 0.09 \\
\hline ptn22 & $2.65 \mathrm{E}-12$ & 1.60E-4 & 0.326 & $2.00 \mathrm{E}-11$ & $7.68 \mathrm{E}-4$ & 0.580 & 0.09 \\
\hline ptn23 & $1.23 \mathrm{E}-13$ & $5.58 \mathrm{E}-6$ & 0.397 & $2.60 \mathrm{E}-13$ & $9.23 \mathrm{E}-4$ & 0.610 & 0.09 \\
\hline ptn24 & $7.86 \mathrm{E}-14$ & $1.53 \mathrm{E}-4$ & 0.225 & 4.67E-13 & 3.37E-3 & 0.623 & 0.09 \\
\hline ptn25 & 7.00E-14 & $5.27 \mathrm{E}-5$ & 0.323 & 7.03E-13 & $6.33 \mathrm{E}-4$ & 0.644 & 0.09 \\
\hline ptn26 & $2.21 \mathrm{E}-13$ & 2.49E-4 & 0.285 & $4.44 \mathrm{E}-13$ & 2.79E-4 & 0.552 & 0.09 \\
\hline tsw31 & $2.95 \mathrm{E}-17$ & $8.70 \mathrm{E}-5$ & 0.218 & $5.42 \mathrm{E}-12$ & $1.00 \mathrm{E}-4$ & 0.633 & 0.129 \\
\hline tsw32 & $2.23 \mathrm{E}-16$ & $1.14 \mathrm{E}-5$ & 0.290 & $4.72 \mathrm{E}-12$ & $1.00 \mathrm{E}-4$ & 0.633 & 0.600 \\
\hline tsw33 & $6.57 \mathrm{E}-18$ & $6.17 \mathrm{E}-6$ & 0.283 & $5.18 \mathrm{E}-12$ & $1.59 \mathrm{E}-3$ & 0.633 & 0.600 \\
\hline tsw34 & 1.77E-19 & $8.45 \mathrm{E}-6$ & 0.317 & $2.21 \mathrm{E}-12$ & $1.04 \mathrm{E}-4$ & 0.633 & 0.569 \\
\hline tsw35 & $4.48 \mathrm{E}-18$ & $1.08 \mathrm{E}-5$ & 0.216 & $6.08 \mathrm{E}-12$ & $1.02 \mathrm{E}-4$ & 0.633 & 0.569 \\
\hline tsw36 & $2.00 \mathrm{E}-19$ & $8.32 \mathrm{E}-6$ & 0.442 & 8.99E-12 & $7.44 \mathrm{E}-4$ & 0.633 & 0.569 \\
\hline tsw37 & $2.00 \mathrm{E}-19$ & $8.32 \mathrm{E}-6$ & 0.442 & 8.99E-12 & $7.44 \mathrm{E}-4$ & 0.633 & 0.569 \\
\hline tsw38 & $2.00 \mathrm{E}-18$ & $6.23 \mathrm{E}-6$ & 0.286 & $8.10 \mathrm{E}-13$ & $2.12 \mathrm{E}-3$ & 0.633 & 0.569 \\
\hline tswz (zeolitic portion of tsw39) & $3.50 \mathrm{E}-17$ & $4.61 \mathrm{E}-6$ & 0.059 & $8.10 \mathrm{E}-13$ & $1.50 \mathrm{E}-3$ & 0.633 & 0.370 \\
\hline tswv (vitric portion of tsw39) & 1.49E-13 & $4.86 \mathrm{E}-5$ & 0.293 & $\mathrm{a}$ & $\mathrm{a}$ & $\mathrm{a}$ & $\mathrm{a}$ \\
\hline $\operatorname{ch} 1 z$ & $3.50 \mathrm{E}-17$ & $2.12 \mathrm{E}-7$ & 0.349 & $2.50 \mathrm{E}-14$ & $1.40 \mathrm{E}-3$ & 0.633 & 0.370 \\
\hline $\operatorname{ch} 1 v$ & $6.65 \mathrm{E}-13$ & $8.73 \mathrm{E}-5$ & 0.240 & a & a & a & a \\
\hline $\operatorname{ch} 2 v$ & $2.97 \mathrm{E}-11$ & $2.59 \mathrm{E}-4$ & 0.158 & a & a & $\mathrm{a}$ & a \\
\hline $\operatorname{ch} 3 v$ & 2.97E-11 & 2.59E-4 & 0.158 & $\mathrm{a}$ & a & $\mathrm{a}$ & a \\
\hline $\operatorname{ch} 4 v$ & 2.97E-11 & $2.59 \mathrm{E}-4$ & 0.158 & a & a & a & a \\
\hline $\operatorname{ch} 5 \mathrm{v}$ & $2.97 \mathrm{E}-11$ & $2.59 \mathrm{E}-4$ & 0.158 & $a$ & $a$ & $\mathrm{a}$ & $a$ \\
\hline ch6v & $2.35 \mathrm{E}-13$ & $1.57 \mathrm{E}-5$ & 0.147 & $a$ & $a$ & $\mathrm{a}$ & $a$ \\
\hline $\operatorname{ch} 2 z$ & $5.20 \mathrm{E}-18$ & $2.25 \mathrm{E}-6$ & 0.257 & $2.50 \mathrm{E}-14$ & $8.90 \mathrm{E}-4$ & 0.633 & 0.370 \\
\hline $\operatorname{ch} 3 z$ & $5.20 \mathrm{E}-18$ & $2.25 \mathrm{E}-6$ & 0.257 & $2.50 \mathrm{E}-14$ & $8.90 \mathrm{E}-4$ & 0.633 & 0.370 \\
\hline $\operatorname{ch} 4 z$ & $5.20 \mathrm{E}-18$ & $2.25 \mathrm{E}-6$ & 0.257 & $2.50 \mathrm{E}-14$ & $8.90 \mathrm{E}-4$ & 0.633 & 0.370 \\
\hline $\operatorname{ch} 5 z$ & $5.20 \mathrm{E}-18$ & $2.25 \mathrm{E}-6$ & 0.257 & $2.50 \mathrm{E}-14$ & $8.90 \mathrm{E}-4$ & 0.633 & 0.370 \\
\hline ch6z & $8.20 \mathrm{E}-19$ & $1.56 \mathrm{E}-7$ & 0.499 & $2.50 \mathrm{E}-14$ & $1.40 \mathrm{E}-3$ & 0.633 & 0.370 \\
\hline pp4 & $8.77 \mathrm{E}-17$ & 4.49E-7 & 0.474 & $2.50 \mathrm{E}-14$ & $1.83 \mathrm{E}-3$ & 0.633 & 0.370 \\
\hline
\end{tabular}


Table A-1. Calibrated Parameters for the Present-Day, Mean Infiltration Scenario, Used for Simulations with the Mean Infiltration Scenarios of the Present-Day, Monsoon, and Glacial-Transition Climates (Continued)

\begin{tabular}{|l|c|c|c|c|c|c|c|}
\hline \multicolumn{1}{|c|}{ Model Layer } & $\begin{array}{c}\boldsymbol{k}_{\mathbf{M}} \\
\left(\mathbf{m}^{2}\right)\end{array}$ & $\begin{array}{c}\alpha_{M} \\
(\mathbf{1} / \mathbf{P a})\end{array}$ & $\begin{array}{c}\boldsymbol{m}_{M} \\
(-)\end{array}$ & $\begin{array}{c}\boldsymbol{k}_{F} \\
\left(\mathbf{m}^{2}\right)\end{array}$ & $\begin{array}{c}\alpha_{F} \\
(\mathbf{1} / \mathbf{P a})\end{array}$ & $\begin{array}{c}\boldsymbol{m}_{F} \\
(-)\end{array}$ & $\begin{array}{c}\gamma \\
(-)\end{array}$ \\
\hline pp3 & $7.14 \mathrm{E}-14$ & $8.83 \mathrm{E}-6$ & 0.407 & $2.20 \mathrm{E}-13$ & $2.47 \mathrm{E}-3$ & 0.633 & 0.199 \\
\hline pp2 & $1.68 \mathrm{E}-15$ & $2.39 \mathrm{E}-6$ & 0.309 & $2.20 \mathrm{E}-13$ & $3.17 \mathrm{E}-3$ & 0.633 & 0.199 \\
\hline pp1 & $2.35 \mathrm{E}-15$ & $9.19 \mathrm{E}-7$ & 0.272 & $2.50 \mathrm{E}-14$ & $1.83 \mathrm{E}-3$ & 0.633 & 0.370 \\
\hline $\mathrm{bf3}$ & $4.34 \mathrm{E}-13$ & $1.26 \mathrm{E}-5$ & 0.193 & $2.20 \mathrm{E}-13$ & $2.93 \mathrm{E}-3$ & 0.633 & 0.199 \\
\hline $\mathrm{bf2}$ & $8.10 \mathrm{E}-17$ & $1.18 \mathrm{E}-7$ & 0.617 & $2.50 \mathrm{E}-14$ & $8.90 \mathrm{E}-4$ & 0.633 & 0.370 \\
\hline pcM38/ pcF38 & $3.00 \mathrm{E}-19$ & $6.23 \mathrm{E}-6$ & 0.286 & $3.00 \mathrm{E}-18$ & $6.23 \mathrm{E}-6$ & 0.286 & 0.00 \\
\hline pcM39/ pcF39 & $6.20 \mathrm{E}-18$ & $4.61 \mathrm{E}-6$ & 0.059 & $6.20 \mathrm{E}-17$ & $4.61 \mathrm{E}-6$ & 0.059 & 0.00 \\
\hline pcM1z/ pcF1z & $9.30 \mathrm{E}-20$ & $2.12 \mathrm{E}-7$ & 0.349 & $9.30 \mathrm{E}-19$ & $2.12 \mathrm{E}-7$ & 0.349 & 0.00 \\
\hline pcM2z/ pcF2z & $2.40 \mathrm{E}-18$ & $2.25 \mathrm{E}-6$ & 0.257 & $2.40 \mathrm{E}-17$ & $2.25 \mathrm{E}-6$ & 0.257 & 0.00 \\
\hline pcM5z/ pcF5z & $2.40 \mathrm{E}-18$ & $2.25 \mathrm{E}-6$ & 0.257 & $2.40 \mathrm{E}-18$ & $2.25 \mathrm{E}-6$ & 0.257 & 0.00 \\
\hline pcM6z/ pcF6z & $1.10 \mathrm{E}-19$ & $1.56 \mathrm{E}-7$ & 0.499 & $1.10 \mathrm{E}-19$ & $1.56 \mathrm{E}-7$ & 0.499 & 0.00 \\
\hline pcM4p/ pcF4p & $7.70 \mathrm{E}-19$ & $4.49 \mathrm{E}-7$ & 0.474 & $7.70 \mathrm{E}-19$ & $4.49 \mathrm{E}-7$ & 0.474 & 0.00 \\
\hline
\end{tabular}

NOTE: These data have been developed as documented in this report and submitted under Output DTN: LB03013DSSCP3I.001.

${ }^{a}$ Conceptual model for calibrated properties model does not include fractures in these model layers.

Table A-2. Calibrated Parameters for the Present-Day, Upper-Bound Infiltration Scenario, Used for Simulations with the Upper-Bound Infiltration Scenarios of the Present-Day, Monsoon, and Glacial-Transition Climates

\begin{tabular}{|l|c|c|c|c|c|c|c|}
\hline \multicolumn{1}{|c|}{ Model Layer } & $\begin{array}{c}\boldsymbol{k}_{\mathbf{M}} \\
\left(\mathbf{m}^{2}\right)\end{array}$ & $\begin{array}{c}\alpha_{M} \\
(\mathbf{1} / \mathrm{Pa})\end{array}$ & $\begin{array}{c}\boldsymbol{m}_{M} \\
(-)\end{array}$ & $\begin{array}{c}\boldsymbol{k}_{F} \\
\left(\mathbf{m}^{2}\right)\end{array}$ & $\begin{array}{c}\alpha_{F} \\
(\mathbf{1} / \mathrm{Pa})\end{array}$ & $\begin{array}{c}\boldsymbol{m}_{F} \\
(-)\end{array}$ & $\begin{array}{c}\gamma \\
(-)\end{array}$ \\
\hline tcw11 & $3.90 \mathrm{E}-15$ & $1.23 \mathrm{E}-5$ & 0.388 & $3.16 \mathrm{E}-12$ & $5.01 \mathrm{E}-3$ & 0.633 & 0.500 \\
\hline tcw12 & $1.16 \mathrm{E}-19$ & $3.39 \mathrm{E}-6$ & 0.280 & $1.00 \mathrm{E}-10$ & $2.19 \mathrm{E}-3$ & 0.633 & 0.500 \\
\hline tcw13 & $4.41 \mathrm{E}-16$ & $3.25 \mathrm{E}-6$ & 0.259 & $9.67 \mathrm{E}-13$ & $1.86 \mathrm{E}-3$ & 0.633 & 0.500 \\
\hline ptn21 & $1.26 \mathrm{E}-13$ & $1.84 \mathrm{E}-4$ & 0.199 & $1.00 \mathrm{E}-11$ & $2.38 \mathrm{E}-3$ & 0.611 & 0.08 \\
\hline ptn22 & $5.98 \mathrm{E}-12$ & $2.42 \mathrm{E}-5$ & 0.473 & $1.00 \mathrm{E}-11$ & $1.26 \mathrm{E}-3$ & 0.665 & 0.08 \\
\hline ptn23 & $3.43 \mathrm{E}-13$ & $4.06 \mathrm{E}-6$ & 0.407 & $1.96 \mathrm{E}-13$ & $1.25 \mathrm{E}-3$ & 0.627 & 0.08 \\
\hline ptn24 & $3.93 \mathrm{E}-13$ & $5.27 \mathrm{E}-5$ & 0.271 & $4.38 \mathrm{E}-13$ & $2.25 \mathrm{E}-3$ & 0.631 & 0.08 \\
\hline ptn25 & $1.85 \mathrm{E}-13$ & $2.95 \mathrm{E}-5$ & 0.378 & $6.14 \mathrm{E}-13$ & $1.00 \mathrm{E}-3$ & 0.637 & 0.08 \\
\hline ptn26 & $6.39 \mathrm{E}-13$ & $3.54 \mathrm{E}-4$ & 0.265 & $3.48 \mathrm{E}-13$ & $3.98 \mathrm{E}-4$ & 0.367 & 0.08 \\
\hline tsw31 & $1.77 \mathrm{E}-17$ & $4.85 \mathrm{E}-5$ & 0.218 & $6.46 \mathrm{E}-11$ & $1.00 \mathrm{E}-4$ & 0.633 & 0.100 \\
\hline tsw32 & $2.13 \mathrm{E}-16$ & $1.96 \mathrm{E}-5$ & 0.290 & $5.62 \mathrm{E}-11$ & $1.00 \mathrm{E}-4$ & 0.633 & 0.561 \\
\hline tsw33 & $2.39 \mathrm{E}-17$ & $5.22 \mathrm{E}-6$ & 0.283 & $6.17 \mathrm{E}-11$ & $1.58 \mathrm{E}-3$ & 0.633 & 0.561 \\
\hline tsw34 & $2.96 \mathrm{E}-19$ & $1.65 \mathrm{E}-6$ & 0.317 & $2.63 \mathrm{E}-11$ & $1.00 \mathrm{E}-4$ & 0.633 & 0.570 \\
\hline tsw35 & $8.55 \mathrm{E}-18$ & $5.03 \mathrm{E}-6$ & 0.216 & $7.24 \mathrm{E}-11$ & $5.78 \mathrm{E}-4$ & 0.633 & 0.570 \\
\hline tsw36 & $7.41 \mathrm{E}-19$ & $1.08 \mathrm{E}-6$ & 0.442 & $1.07 \mathrm{E}-10$ & $1.10 \mathrm{E}-3$ & 0.633 & 0.570 \\
\hline tsw37 & $7.41 \mathrm{E}-19$ & $1.08 \mathrm{E}-6$ & 0.442 & $1.07 \mathrm{E}-10$ & $1.10 \mathrm{E}-3$ & 0.633 & 0.570 \\
\hline tsw38 & $7.40 \mathrm{E}-18$ & $5.58 \mathrm{E}-6$ & 0.286 & $8.10 \mathrm{E}-13$ & $8.91 \mathrm{E}-4$ & 0.633 & 0.570 \\
\hline tswz (zeolitic portion of tsw39) & $3.50 \mathrm{E}-17$ & $4.61 \mathrm{E}-6$ & 0.059 & $8.10 \mathrm{E}-13$ & $1.50 \mathrm{E}-3$ & 0.633 & 0.500 \\
\hline
\end{tabular}


Table A-2. Calibrated Parameters for the Present-Day, Upper-Bound Infiltration Scenario, Used for Simulations with the Upper-Bound Infiltration Scenarios of the Present-Day, Monsoon, and Glacial-Transition Climates (Continued)

\begin{tabular}{|c|c|c|c|c|c|c|c|}
\hline Model Layer & $\begin{array}{c}k_{M} \\
\left(m^{2}\right)\end{array}$ & $\begin{array}{c}\alpha_{M} \\
(1 / \mathrm{Pa})\end{array}$ & $\begin{array}{c}m_{M} \\
(-)\end{array}$ & $\begin{array}{c}k_{F} \\
\left(m^{2}\right)\end{array}$ & $\begin{array}{c}\alpha_{F} \\
(1 / P a)\end{array}$ & $\begin{array}{c}m_{F} \\
(-) \\
\end{array}$ & $\begin{array}{c}\gamma \\
(-)\end{array}$ \\
\hline tswv (vitric portion of tsw39) & $2.24 \mathrm{E}-13$ & $4.86 \mathrm{E}-5$ & 0.293 & $a$ & $a$ & $\mathrm{a}$ & $\mathrm{a}$ \\
\hline $\operatorname{ch} 1 \mathrm{z}$ & $3.50 \mathrm{E}-17$ & $2.12 \mathrm{E}-7$ & 0.349 & $2.50 \mathrm{E}-14$ & $1.40 \mathrm{E}-3$ & 0.633 & 0.500 \\
\hline ch1v & $1.39 \mathrm{E}-12$ & $8.82 \mathrm{E}-5$ & 0.240 & $\mathrm{a}$ & $a$ & $\mathrm{a}$ & $\mathrm{a}$ \\
\hline $\operatorname{ch} 2 v$ & $4.90 \mathrm{E}-11$ & $2.73 \mathrm{E}-4$ & 0.158 & $a$ & $\mathrm{a}$ & $a$ & $a$ \\
\hline $\operatorname{ch} 3 v$ & $4.90 \mathrm{E}-11$ & $2.73 \mathrm{E}-4$ & 0.158 & $\mathrm{a}$ & $\bar{a}$ & $\mathrm{a}$ & $\mathrm{a}$ \\
\hline $\operatorname{ch} 4 v$ & $4.90 \mathrm{E}-11$ & $2.73 \mathrm{E}-4$ & 0.158 & $\mathrm{a}$ & $\mathrm{a}$ & $\mathrm{a}$ & $\mathrm{a}$ \\
\hline ch5v & $4.90 \mathrm{E}-11$ & $2.73 \mathrm{E}-4$ & 0.158 & $\mathrm{a}$ & a & a & $\mathrm{a}$ \\
\hline ch6v & $2.72 \mathrm{E}-13$ & $1.67 \mathrm{E}-5$ & 0.147 & $\mathrm{a}$ & $\mathrm{a}$ & $\mathrm{a}$ & $\mathrm{a}$ \\
\hline $\operatorname{ch} 2 z$ & $5.20 \mathrm{E}-18$ & $2.25 \mathrm{E}-6$ & 0.257 & $2.50 \mathrm{E}-14$ & $8.90 \mathrm{E}-4$ & 0.633 & 0.500 \\
\hline ch3z & $5.20 \mathrm{E}-18$ & $2.25 \mathrm{E}-6$ & 0.257 & $2.50 \mathrm{E}-14$ & $8.90 \mathrm{E}-4$ & 0.633 & 0.500 \\
\hline $\operatorname{ch} 4 z$ & $5.20 \mathrm{E}-18$ & $2.25 \mathrm{E}-6$ & 0.257 & $2.50 \mathrm{E}-14$ & $8.90 \mathrm{E}-4$ & 0.633 & 0.500 \\
\hline $\operatorname{ch} 5 z$ & $5.20 \mathrm{E}-18$ & $2.25 \mathrm{E}-6$ & 0.257 & $2.50 \mathrm{E}-14$ & $8.90 \mathrm{E}-4$ & 0.633 & 0.500 \\
\hline ch6z & $8.20 \mathrm{E}-19$ & $1.56 \mathrm{E}-7$ & 0.499 & $2.50 \mathrm{E}-14$ & $1.40 \mathrm{E}-3$ & 0.633 & 0.500 \\
\hline pp4 & $1.02 \mathrm{E}-15$ & $4.57 \mathrm{E}-7$ & 0.474 & $2.50 \mathrm{E}-12$ & 8.91E-4 & 0.633 & 0.500 \\
\hline pp3 & $1.26 \mathrm{E}-13$ & $9.50 \mathrm{E}-6$ & 0.407 & $2.20 \mathrm{E}-12$ & $1.66 \mathrm{E}-3$ & 0.633 & 0.500 \\
\hline pp2 & $1.70 \mathrm{E}-15$ & $2.25 \mathrm{E}-6$ & 0.309 & $2.20 \mathrm{E}-13$ & $1.66 \mathrm{E}-3$ & 0.633 & 0.500 \\
\hline pp1 & $2.57 \mathrm{E}-15$ & $8.77 \mathrm{E}-7$ & 0.272 & $2.50 \mathrm{E}-14$ & $8.91 \mathrm{E}-4$ & 0.633 & 0.500 \\
\hline bf3 & $3.55 \mathrm{E}-14$ & $3.48 \mathrm{E}-5$ & 0.193 & $2.20 \mathrm{E}-13$ & $1.66 \mathrm{E}-3$ & 0.633 & 0.500 \\
\hline bf2 & $8.10 \mathrm{E}-17$ & $1.18 \mathrm{E}-7$ & 0.617 & $2.50 \mathrm{E}-14$ & $8.90 \mathrm{E}-4$ & 0.633 & 0.500 \\
\hline pcM38/ pcF38 & $3.00 \mathrm{E}-19$ & $5.58 \mathrm{E}-6$ & 0.286 & $3.00 \mathrm{E}-18$ & $5.58 \mathrm{E}-6$ & 0.286 & 0.00 \\
\hline pcM39/ pcF39 & $6.20 \mathrm{E}-18$ & $4.61 \mathrm{E}-6$ & 0.059 & $6.20 \mathrm{E}-17$ & $4.61 \mathrm{E}-6$ & 0.059 & 0.00 \\
\hline pcM1z/ pcF1z & $9.30 \mathrm{E}-20$ & $2.12 \mathrm{E}-7$ & 0.349 & $9.30 \mathrm{E}-19$ & $2.12 \mathrm{E}-7$ & 0.349 & 0.00 \\
\hline pcM2z/ pcF2z & $2.40 \mathrm{E}-18$ & 2.25E-6 & 0.257 & $2.40 \mathrm{E}-17$ & $2.25 \mathrm{E}-6$ & 0.257 & 0.00 \\
\hline pcM5z/ pcF5z & $2.40 \mathrm{E}-18$ & $2.25 \mathrm{E}-6$ & 0.257 & $2.40 \mathrm{E}-18$ & $2.25 \mathrm{E}-6$ & 0.257 & 0.00 \\
\hline pcM6z/ pcF6z & 1.10E-19 & $1.56 \mathrm{E}-7$ & 0.499 & 1.10E-19 & 1.56E-7 & 0.499 & 0.00 \\
\hline $\mathrm{pcM} 4 \mathrm{p} / \mathrm{pcF} 4 \mathrm{p}$ & $7.70 \mathrm{E}-19$ & $4.57 \mathrm{E}-7$ & 0.474 & 7.70E-19 & $4.57 \mathrm{E}-7$ & 0.474 & 0.00 \\
\hline
\end{tabular}

NOTE: These data have been developed as documented in this report and submitted under Output DTN: LB03013DSSCP3I.001.

${ }^{a}$ Conceptual model for calibrated properties model does not include fractures in these model layers.

Table A-3. Calibrated Parameters for the Present-Day, Lower-Bound Infiltration Scenario, Used for Simulations with the Lower-Bound Infiltration Scenarios of the Present-Day, Monsoon, and Glacial-Transition Climates

\begin{tabular}{|l|c|c|c|c|c|c|c|}
\hline Model Layer & $\begin{array}{c}\boldsymbol{k}_{\mathbf{M}} \\
\left(\mathbf{m}^{2}\right)\end{array}$ & $\begin{array}{c}\alpha_{M} \\
(\mathbf{1} / \mathbf{P a})\end{array}$ & $\begin{array}{c}\boldsymbol{M}_{\boldsymbol{M}} \\
(-)\end{array}$ & $\begin{array}{c}\boldsymbol{k}_{F} \\
\left(\mathbf{m}^{2}\right)\end{array}$ & $\begin{array}{c}\alpha_{F} \\
(\mathbf{1} / \mathbf{P a})\end{array}$ & $\begin{array}{c}\boldsymbol{m}_{\boldsymbol{F}} \\
(-)\end{array}$ & $\begin{array}{c}\gamma \\
(-)\end{array}$ \\
\hline tcw11 & $3.44 \mathrm{E}-15$ & $1.16 \mathrm{E}-5$ & 0.388 & $3.16 \mathrm{E}-12$ & $4.68 \mathrm{E}-3$ & 0.633 & 0.483 \\
\hline tcw12 & $3.00 \mathrm{E}-20$ & $2.67 \mathrm{E}-6$ & 0.280 & $9.73 \mathrm{E}-11$ & $3.20 \mathrm{E}-3$ & 0.633 & 0.483 \\
\hline tcw13 & $3.96 \mathrm{E}-17$ & $1.64 \mathrm{E}-6$ & 0.259 & $9.47 \mathrm{E}-13$ & $2.13 \mathrm{E}-3$ & 0.633 & 0.483 \\
\hline ptn21 & $1.86 \mathrm{E}-13$ & $6.13 \mathrm{E}-5$ & 0.165 & $1.00 \mathrm{E}-11$ & $1.66 \mathrm{E}-3$ & 0.503 & 0.01 \\
\hline ptn22 & $3.27 \mathrm{E}-12$ & $1.51 \mathrm{E}-5$ & 0.390 & $1.00 \mathrm{E}-11$ & $9.39 \mathrm{E}-4$ & 0.651 & 0.01 \\
\hline
\end{tabular}


Table A-3. Calibrated Parameters for the Present-Day, Lower-Bound Infiltration Scenario, Used for Simulations with the Lower-Bound Infiltration Scenarios of the Present-Day, Monsoon, and Glacial-Transition Climates (Continued)

\begin{tabular}{|c|c|c|c|c|c|c|c|}
\hline Model Layer & $\begin{array}{c}k_{M} \\
\left(m^{2}\right)\end{array}$ & $\begin{array}{c}\alpha_{M} \\
(1 / \mathrm{Pa})\end{array}$ & $\begin{array}{c}M_{M} \\
(-)\end{array}$ & $\begin{array}{c}k_{F} \\
\left(\mathrm{~m}^{2}\right)\end{array}$ & $\begin{array}{c}\alpha_{F} \\
(1 / P a)\end{array}$ & $\begin{array}{c}m_{F} \\
(-)\end{array}$ & $\begin{array}{c}\gamma \\
(-)\end{array}$ \\
\hline ptn23 & $4.20 \mathrm{E}-13$ & 2.04E-6 & 0.388 & $1.84 \mathrm{E}-13$ & $1.28 \mathrm{E}-3$ & 0.518 & 0.01 \\
\hline ptn24 & $3.94 \mathrm{E}-13$ & 2.32E-5 & 0.210 & $4.31 \mathrm{E}-13$ & 2.02E-3 & 0.594 & 0.01 \\
\hline ptn25 & $2.22 \mathrm{E}-13$ & $2.04 \mathrm{E}-5$ & 0.296 & 7.12E-13 & 7.42E-4 & 0.555 & 0.01 \\
\hline ptn26 & $5.43 \mathrm{E}-13$ & $1.82 \mathrm{E}-4$ & 0.264 & $3.08 \mathrm{E}-13$ & 2.00E-4 & 0.401 & 0.01 \\
\hline tsw31 & $1.42 \mathrm{E}-17$ & $8.02 \mathrm{E}-5$ & 0.218 & $5.13 \mathrm{E}-11$ & $1.00 \mathrm{E}-4$ & 0.633 & 0.037 \\
\hline tsw32 & $3.96 \mathrm{E}-16$ & $9.46 \mathrm{E}-6$ & 0.290 & 4.47E-11 & $1.31 \mathrm{E}-4$ & 0.633 & 0.528 \\
\hline tsw33 & $1.60 \mathrm{E}-18$ & $4.25 \mathrm{E}-6$ & 0.283 & $4.90 \mathrm{E}-11$ & $1.94 \mathrm{E}-3$ & 0.633 & 0.528 \\
\hline tsw34 & $1.38 \mathrm{E}-19$ & $1.19 \mathrm{E}-6$ & 0.317 & $2.09 \mathrm{E}-11$ & $6.55 \mathrm{E}-4$ & 0.633 & 0.476 \\
\hline tsw35 & $2.33 \mathrm{E}-18$ & $1.97 \mathrm{E}-6$ & 0.216 & $5.75 \mathrm{E}-11$ & $1.35 \mathrm{E}-3$ & 0.633 & 0.476 \\
\hline tsw36 & $5.58 \mathrm{E}-19$ & $4.22 \mathrm{E}-7$ & 0.442 & $8.51 \mathrm{E}-11$ & $1.31 \mathrm{E}-3$ & 0.633 & 0.476 \\
\hline tsw37 & $5.58 \mathrm{E}-19$ & $4.22 \mathrm{E}-7$ & 0.442 & $8.51 \mathrm{E}-11$ & $1.31 \mathrm{E}-3$ & 0.633 & 0.476 \\
\hline tsw38 & 2.93E-18 & $1.43 \mathrm{E}-6$ & 0.286 & $8.10 \mathrm{E}-13$ & $1.75 \mathrm{E}-3$ & 0.633 & 0.476 \\
\hline tswz (zeolitic portion of tsw39) & $3.50 \mathrm{E}-17$ & $4.61 \mathrm{E}-6$ & 0.059 & $8.10 \mathrm{E}-13$ & $1.50 \mathrm{E}-3$ & 0.633 & 0.276 \\
\hline tswv (vitric portion of tsw39) & $3.15 \mathrm{E}-13$ & $1.86 \mathrm{E}-5$ & 0.293 & $\mathrm{a}$ & $\mathrm{a}$ & a & $\mathrm{a}$ \\
\hline $\operatorname{ch} 1 \mathrm{z}$ & $3.50 \mathrm{E}-17$ & $2.12 \mathrm{E}-7$ & 0.349 & $2.50 \mathrm{E}-14$ & $1.40 \mathrm{E}-3$ & 0.633 & 0.276 \\
\hline $\operatorname{ch} 1 v$ & $3.15 \mathrm{E}-14$ & $4.50 \mathrm{E}-5$ & 0.240 & $a$ & 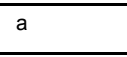 & $\mathrm{a}$ & $\mathrm{a}$ \\
\hline $\operatorname{ch} 2 v$ & $1.13 \mathrm{E}-11$ & $1.22 \mathrm{E}-4$ & 0.158 & $\mathrm{a}$ & $\mathrm{a}$ & $\mathrm{a}$ & $\mathrm{a}$ \\
\hline $\operatorname{ch} 3 v$ & $1.13 \mathrm{E}-11$ & $1.22 \mathrm{E}-4$ & 0.158 & $\mathrm{a}$ & $\mathrm{a}$ & $\mathrm{a}$ & $a$ \\
\hline $\operatorname{ch} 4 v$ & $1.13 \mathrm{E}-11$ & $1.22 \mathrm{E}-4$ & 0.158 & $\mathrm{a}$ & $\mathrm{a}$ & $a$ & $\mathrm{a}$ \\
\hline $\operatorname{ch} 5 \mathrm{v}$ & $1.13 \mathrm{E}-11$ & $1.22 \mathrm{E}-4$ & 0.158 & $\mathrm{a}$ & $\mathrm{a}$ & $\mathrm{a}$ & $\mathrm{a}$ \\
\hline ch6v & $2.54 \mathrm{E}-13$ & $9.05 \mathrm{E}-6$ & 0.147 & $a$ & a & $a$ & a \\
\hline $\operatorname{ch} 2 z$ & $5.20 \mathrm{E}-18$ & 2.25E-6 & 0.257 & $2.50 \mathrm{E}-14$ & $8.90 \mathrm{E}-4$ & 0.633 & 0.276 \\
\hline $\operatorname{ch} 3 z$ & $5.20 \mathrm{E}-18$ & $2.25 \mathrm{E}-6$ & 0.257 & $2.50 \mathrm{E}-14$ & $8.90 \mathrm{E}-4$ & 0.633 & 0.276 \\
\hline $\operatorname{ch} 4 z$ & $5.20 \mathrm{E}-18$ & $2.25 \mathrm{E}-6$ & 0.257 & $2.50 \mathrm{E}-14$ & $8.90 \mathrm{E}-4$ & 0.633 & 0.276 \\
\hline $\operatorname{ch} 5 z$ & $5.20 \mathrm{E}-18$ & $2.25 \mathrm{E}-6$ & 0.257 & $2.50 \mathrm{E}-14$ & $8.90 \mathrm{E}-4$ & 0.633 & 0.276 \\
\hline $\operatorname{ch} 6 z$ & $8.20 \mathrm{E}-19$ & $1.56 \mathrm{E}-7$ & 0.499 & $2.50 \mathrm{E}-14$ & 1.40E-3 & 0.633 & 0.276 \\
\hline $\mathrm{pp} 4$ & $2.98 \mathrm{E}-16$ & $2.88 \mathrm{E}-7$ & 0.474 & $2.50 \mathrm{E}-14$ & $1.88 \mathrm{E}-3$ & 0.633 & 0.276 \\
\hline pp3 & $5.37 \mathrm{E}-14$ & $7.97 \mathrm{E}-6$ & 0.407 & $2.20 \mathrm{E}-13$ & $1.32 \mathrm{E}-3$ & 0.633 & 0.248 \\
\hline pp2 & $4.24 \mathrm{E}-16$ & $2.41 \mathrm{E}-6$ & 0.309 & $2.20 \mathrm{E}-13$ & $2.80 \mathrm{E}-3$ & 0.633 & 0.248 \\
\hline $\mathrm{pp} 1$ & $7.02 \mathrm{E}-16$ & $1.36 \mathrm{E}-6$ & 0.272 & $2.50 \mathrm{E}-14$ & $6.39 \mathrm{E}-4$ & 0.633 & 0.276 \\
\hline bf3 & $2.97 \mathrm{E}-14$ & $1.32 \mathrm{E}-5$ & 0.193 & $2.20 \mathrm{E}-13$ & $1.92 \mathrm{E}-3$ & 0.633 & 0.248 \\
\hline bf2 & $8.1 \mathrm{E}-17$ & $1.18 \mathrm{E}-7$ & 0.617 & $2.50 \mathrm{E}-14$ & $8.9 \mathrm{E}-4$ & 0.633 & 0.276 \\
\hline pcM38/ pcF38 & $3.00 \mathrm{E}-19$ & $1.43 \mathrm{E}-6$ & 0.286 & $3.00 \mathrm{E}-19$ & $1.43 \mathrm{E}-6$ & 0.286 & 0.00 \\
\hline pcM39/ pcF39 & $6.20 \mathrm{E}-18$ & $4.61 \mathrm{E}-6$ & 0.059 & $6.20 \mathrm{E}-18$ & $4.61 \mathrm{E}-6$ & 0.059 & 0.00 \\
\hline pcM1z/ pcF1z & $9.30 \mathrm{E}-20$ & $2.12 \mathrm{E}-7$ & 0.349 & $9.30 \mathrm{E}-20$ & $2.12 \mathrm{E}-7$ & 0.349 & 0.00 \\
\hline pcM2z/ pcF2z & $2.40 \mathrm{E}-18$ & $2.25 \mathrm{E}-6$ & 0.257 & $2.40 \mathrm{E}-18$ & $2.25 \mathrm{E}-6$ & 0.257 & 0.00 \\
\hline
\end{tabular}


Table A-3. Calibrated Parameters for the Present-Day, Lower-Bound Infiltration Scenario, Used for Simulations with the Lower-Bound Infiltration Scenarios of the Present-Day, Monsoon, and Glacial-Transition Climates (Continued)

\begin{tabular}{|l|c|c|c|c|c|c|c|}
\hline \multicolumn{1}{|c|}{ Model Layer } & $\begin{array}{c}\boldsymbol{k}_{\mathrm{M}} \\
\left(\mathbf{m}^{2}\right)\end{array}$ & $\begin{array}{c}\alpha_{M} \\
(\mathbf{1} / \mathbf{P a})\end{array}$ & $\begin{array}{c}\boldsymbol{M}_{M} \\
(-)\end{array}$ & $\begin{array}{c}\boldsymbol{k}_{F} \\
\left(\mathbf{m}^{2}\right)\end{array}$ & $\begin{array}{c}\alpha_{F} \\
(\mathbf{1} / \mathbf{P a})\end{array}$ & $\begin{array}{c}\boldsymbol{m}_{\boldsymbol{F}} \\
(-)\end{array}$ & $\begin{array}{c}\gamma \\
(-)\end{array}$ \\
\hline pcM5z/pcF5z & $2.40 \mathrm{E}-18$ & $2.25 \mathrm{E}-6$ & 0.257 & $2.40 \mathrm{E}-18$ & $2.25 \mathrm{E}-6$ & 0.257 & 0.00 \\
\hline pcM6z/pcF6z & $1.10 \mathrm{E}-19$ & $1.56 \mathrm{E}-7$ & 0.499 & $1.10 \mathrm{E}-19$ & $1.56 \mathrm{E}-7$ & 0.499 & 0.00 \\
\hline pcM4p/pcF4p & $7.70 \mathrm{E}-19$ & $2.88 \mathrm{E}-7$ & 0.474 & $7.70 \mathrm{E}-19$ & $2.88 \mathrm{E}-7$ & 0.474 & 0.00 \\
\hline
\end{tabular}

NOTE: These data have been developed as documented in this report and submitted under Output DTN: LB03013DSSCP3I.001.

${ }^{\text {a }}$ Conceptual model for calibrated properties model does not include fractures in these model layers (Section 5).

Table A-4. Calibrated Parameters for the Alternative Modeling Studies of the Present-Day, Mean Infiltration Scenario, Used for Simulations with the Mean Infiltration Scenarios of the PresentDay, Monsoon, and Glacial-transition Climates

\begin{tabular}{|c|c|c|c|c|c|c|c|}
\hline Model Layer & $\begin{array}{c}k_{M} \\
\left(m^{2}\right) \\
\end{array}$ & $\begin{array}{c}\alpha_{M} \\
(1 / \mathrm{Pa})\end{array}$ & $\begin{array}{c}m_{M} \\
(-)\end{array}$ & $\begin{array}{c}k_{F} \\
\left(\mathrm{~m}^{2}\right)\end{array}$ & $\begin{array}{c}\alpha_{F} \\
(1 / P a)\end{array}$ & $\begin{array}{c}m_{F} \\
(-)\end{array}$ & $\begin{array}{c}\gamma \\
(-) \\
\end{array}$ \\
\hline tcw11 & $3.74 \mathrm{E}-15$ & $1.01 \mathrm{E}-5$ & 0.388 & $4.24 \mathrm{E}-11$ & $5.27 \mathrm{E}-3$ & 0.633 & 0.587 \\
\hline tcw12 & $5.52 \mathrm{E}-20$ & $3.11 \mathrm{E}-6$ & 0.280 & $9.53 E-11$ & $1.57 \mathrm{E}-3$ & 0.633 & 0.587 \\
\hline tcw13 & $5.65 \mathrm{E}-17$ & $3.26 \mathrm{E}-6$ & 0.259 & $1.32 \mathrm{E}-11$ & $1.24 \mathrm{E}-3$ & 0.633 & 0.587 \\
\hline ptn21 & 4.60E-15 & 1.62E-4 & 0.245 & $2.11 \mathrm{E}-12$ & $8.70 \mathrm{E}-4$ & 0.633 & 0.232 \\
\hline ptn22 & 4.43E-12 & 1.46E-4 & 0.219 & $9.41 \mathrm{E}-12$ & $1.57 \mathrm{E}-3$ & 0.633 & 0.232 \\
\hline ptn23 & $9.20 \mathrm{E}-15$ & $2.47 \mathrm{E}-5$ & 0.247 & 5.35E-13 & $5.18 \mathrm{E}-3$ & 0.633 & 0.232 \\
\hline ptn24 & $2.35 \mathrm{E}-12$ & $7.90 \mathrm{E}-4$ & 0.182 & $1.00 \mathrm{E}-11$ & $1.86 \mathrm{E}-3$ & 0.633 & 0.232 \\
\hline ptn25 & $2.15 \mathrm{E}-13$ & $1.04 \mathrm{E}-4$ & 0.300 & $1.24 \mathrm{E}-12$ & $1.33 \mathrm{E}-3$ & 0.633 & 0.232 \\
\hline ptn26 & $1.00 \mathrm{E}-11$ & $9.83 \mathrm{E}-4$ & 0.126 & $3.17 \mathrm{E}-13$ & $1.34 \mathrm{E}-3$ & 0.633 & 0.232 \\
\hline tsw31 & $2.95 \mathrm{E}-17$ & $8.70 \mathrm{E}-5$ & 0.218 & $5.42 \mathrm{E}-12$ & $1.00 \mathrm{E}-4$ & 0.633 & 0.129 \\
\hline tsw32 & $2.23 \mathrm{E}-16$ & $1.14 \mathrm{E}-5$ & 0.290 & $4.72 \mathrm{E}-12$ & $1.00 \mathrm{E}-4$ & 0.633 & 0.600 \\
\hline tsw33 & $6.57 \mathrm{E}-18$ & $6.17 \mathrm{E}-6$ & 0.283 & $5.18 \mathrm{E}-12$ & $1.59 \mathrm{E}-3$ & 0.633 & 0.600 \\
\hline tsw34 & 1.77E-19 & $8.45 \mathrm{E}-6$ & 0.317 & $2.21 \mathrm{E}-12$ & $1.04 \mathrm{E}-4$ & 0.633 & 0.569 \\
\hline tsw35 & $4.48 \mathrm{E}-18$ & $1.08 \mathrm{E}-5$ & 0.216 & $6.08 \mathrm{E}-12$ & $1.02 \mathrm{E}-4$ & 0.633 & 0.569 \\
\hline tsw36 & $2.00 \mathrm{E}-19$ & $8.32 \mathrm{E}-6$ & 0.442 & $8.99 \mathrm{E}-12$ & 7.44E-4 & 0.633 & 0.569 \\
\hline tsw37 & $2.00 \mathrm{E}-19$ & $8.32 \mathrm{E}-6$ & 0.442 & $8.99 \mathrm{E}-12$ & $7.44 \mathrm{E}-4$ & 0.633 & 0.569 \\
\hline tsw38 & $2.00 \mathrm{E}-18$ & $6.23 \mathrm{E}-6$ & 0.286 & $8.10 \mathrm{E}-13$ & $2.12 \mathrm{E}-3$ & 0.633 & 0.569 \\
\hline tswz (zeolitic portion of tsw39) & $3.50 \mathrm{E}-17$ & $4.61 \mathrm{E}-6$ & 0.059 & 8.10E-13 & $1.5 \mathrm{E}-3$ & 0.633 & 0.370 \\
\hline tswv (vitric portion of tsw39) & 1.49E-13 & $4.86 \mathrm{E}-5$ & 0.293 & $\mathrm{a}$ & $a$ & a & a \\
\hline Ch1z & $3.50 \mathrm{E}-17$ & $2.12 \mathrm{E}-7$ & 0.349 & $2.50 \mathrm{E}-14$ & $1.4 \mathrm{E}-3$ & 0.633 & 0.370 \\
\hline Ch1v & $6.65 \mathrm{E}-13$ & $8.73 \mathrm{E}-5$ & 0.240 & $\mathrm{a}$ & $\mathrm{a}$ & a & a \\
\hline $\mathrm{Ch} 2 \mathrm{v}$ & $2.97 \mathrm{E}-11$ & $2.59 \mathrm{E}-4$ & 0.158 & a & a & a & a \\
\hline Ch3v & 2.97E-11 & $2.59 \mathrm{E}-4$ & 0.158 & a & $\mathrm{a}$ & $a$ & $a$ \\
\hline Ch4v & $2.97 \mathrm{E}-11$ & $2.59 \mathrm{E}-4$ & 0.158 & $a$ & $a$ & $\mathrm{a}$ & $a$ \\
\hline Ch5v & $2.97 \mathrm{E}-11$ & $2.59 \mathrm{E}-4$ & 0.158 & a & a & a & a \\
\hline
\end{tabular}


Table A-4. Calibrated Parameters for the Alternative Modeling Studies of the Present-Day, Mean Infiltration Scenario, Used for Simulations with the Mean Infiltration Scenarios of the Present-Day, Monsoon, and Glacial-Transition Climates (Continued)

\begin{tabular}{|c|c|c|c|c|c|c|c|}
\hline Model Layer & $\begin{array}{c}k_{M} \\
\left(m^{2}\right)\end{array}$ & $\begin{array}{c}\alpha_{M} \\
(1 / \mathrm{Pa})\end{array}$ & $\begin{array}{c}m_{M} \\
(-)\end{array}$ & $\begin{array}{c}k_{F} \\
\left(\mathbf{m}^{2}\right)\end{array}$ & $\begin{array}{c}\alpha_{F} \\
(1 / P a)\end{array}$ & $\begin{array}{c}m_{F} \\
(-)\end{array}$ & $\begin{array}{c}\gamma \\
(-)\end{array}$ \\
\hline Ch6v & $2.35 E-13$ & $1.57 \mathrm{E}-5$ & 0.147 & $a$ & $\mathrm{a}$ & $\mathrm{a}$ & $\mathrm{a}$ \\
\hline $\mathrm{Ch} 2 \mathrm{z}$ & $5.20 \mathrm{E}-18$ & $2.25 \mathrm{E}-6$ & 0.257 & $2.50 \mathrm{E}-14$ & $8.90 \mathrm{E}-4$ & 0.633 & 0.370 \\
\hline Ch3z & $5.20 \mathrm{E}-18$ & $2.25 \mathrm{E}-6$ & 0.257 & $2.50 \mathrm{E}-14$ & $8.90 \mathrm{E}-4$ & 0.633 & 0.370 \\
\hline $\mathrm{Ch} 4 \mathrm{z}$ & $5.20 \mathrm{E}-18$ & $2.25 \mathrm{E}-6$ & 0.257 & $2.50 \mathrm{E}-14$ & $8.90 \mathrm{E}-4$ & 0.633 & 0.370 \\
\hline Ch5z & $5.20 \mathrm{E}-18$ & $2.25 \mathrm{E}-6$ & 0.257 & $2.50 \mathrm{E}-14$ & $8.90 \mathrm{E}-4$ & 0.633 & 0.370 \\
\hline Ch6z & $8.20 E-19$ & $1.56 \mathrm{E}-7$ & 0.499 & $2.50 \mathrm{E}-14$ & $1.40 \mathrm{E}-3$ & 0.633 & 0.370 \\
\hline $\mathrm{Pp} 4$ & 8.77E-17 & $4.49 \mathrm{E}-7$ & 0.474 & $2.50 \mathrm{E}-14$ & $1.83 \mathrm{E}-3$ & 0.633 & 0.370 \\
\hline Pp3 & $7.14 \mathrm{E}-14$ & $8.83 \mathrm{E}-6$ & 0.407 & $2.20 \mathrm{E}-13$ & $2.47 \mathrm{E}-3$ & 0.633 & 0.199 \\
\hline Pp2 & $1.68 \mathrm{E}-15$ & $2.39 \mathrm{E}-6$ & 0.309 & $2.20 \mathrm{E}-13$ & 3.17E-3 & 0.633 & 0.199 \\
\hline Pp1 & $2.35 E-15$ & $9.19 \mathrm{E}-7$ & 0.272 & $2.50 \mathrm{E}-14$ & $1.83 \mathrm{E}-3$ & 0.633 & 0.370 \\
\hline $\mathrm{Bf3}$ & $4.34 \mathrm{E}-13$ & $1.26 \mathrm{E}-5$ & 0.193 & $2.20 \mathrm{E}-13$ & $2.93 E-3$ & 0.633 & 0.199 \\
\hline bf2 & $8.10 \mathrm{E}-17$ & $1.18 \mathrm{E}-7$ & 0.617 & $2.50 \mathrm{E}-14$ & $8.90 \mathrm{E}-4$ & 0.633 & 0.370 \\
\hline pcM38/ pcF38 & $3.00 E-19$ & $6.23 \mathrm{E}-6$ & 0.286 & $3.00 \mathrm{E}-18$ & $6.23 \mathrm{E}-6$ & 0.286 & 0.00 \\
\hline pcM39/ pcF39 & $6.20 \mathrm{E}-18$ & $4.61 \mathrm{E}-6$ & 0.059 & $6.20 \mathrm{E}-17$ & $4.61 \mathrm{E}-6$ & 0.059 & 0.00 \\
\hline pcM1z/ pcF1z & 9.30E-20 & $2.12 \mathrm{E}-7$ & 0.349 & 9.30E-19 & $2.12 \mathrm{E}-7$ & 0.349 & 0.00 \\
\hline pcM2z/ pcF2z & $2.40 \mathrm{E}-18$ & $2.25 \mathrm{E}-6$ & 0.257 & $2.40 \mathrm{E}-17$ & $2.25 \mathrm{E}-6$ & 0.257 & 0.00 \\
\hline pcM5z/ pcF5z & $2.40 \mathrm{E}-18$ & $2.25 \mathrm{E}-6$ & 0.257 & $2.40 \mathrm{E}-18$ & $2.25 \mathrm{E}-6$ & 0.257 & 0.00 \\
\hline pcM6z/ pcF6z & 1.10E-19 & $1.56 \mathrm{E}-7$ & 0.499 & 1.10E-19 & $1.56 \mathrm{E}-7$ & 0.499 & 0.00 \\
\hline $\mathrm{pcM} 4 \mathrm{p} / \mathrm{pcF} 4 \mathrm{p}$ & 7.70E-19 & $4.49 \mathrm{E}-7$ & 0.474 & 7.70E-19 & $4.49 \mathrm{E}-7$ & 0.474 & 0.00 \\
\hline
\end{tabular}

NOTE: These data have been developed as documented in this report and submitted under Output DTN: LB03013DSSCP3I.001.

${ }^{\text {a }}$ Conceptual model for calibrated properties model does not include fractures in these model layers.

Table A-5. Calibrated Parameters for the Alternative Modeling Studies of the Present-Day, Upper-Bound Infiltration Scenario, Used for Simulations with the Upper-Bound Infiltration Scenarios of the Present-Day, Monsoon, and Glacial-Transition Climates

\begin{tabular}{|l|c|c|c|c|c|c|c|}
\hline \multicolumn{1}{|c|}{ Model Layer } & $\begin{array}{c}\boldsymbol{k}_{\mathbf{M}} \\
\left(\mathbf{m}^{2}\right)\end{array}$ & $\begin{array}{c}\alpha_{M} \\
(\mathbf{1} / \mathbf{P a})\end{array}$ & $\begin{array}{c}\boldsymbol{m}_{\boldsymbol{M}} \\
(-)\end{array}$ & $\begin{array}{c}\boldsymbol{k}_{\boldsymbol{F}} \\
\left(\mathbf{m}^{2}\right)\end{array}$ & $\begin{array}{c}\alpha_{F} \\
(\mathbf{1} / \mathbf{P a})\end{array}$ & $\begin{array}{c}\boldsymbol{m}_{\boldsymbol{F}} \\
(-)\end{array}$ & $\begin{array}{c}\gamma \\
(-)\end{array}$ \\
\hline tcw11 & $3.90 \mathrm{E}-15$ & $1.23 \mathrm{E}-5$ & 0.388 & $3.16 \mathrm{E}-12$ & $5.01 \mathrm{E}-3$ & 0.633 & 0.500 \\
\hline tcw12 & $1.16 \mathrm{E}-19$ & $3.39 \mathrm{E}-6$ & 0.280 & $1.00 \mathrm{E}-10$ & $2.19 \mathrm{E}-3$ & 0.633 & 0.500 \\
\hline tcw13 & $4.41 \mathrm{E}-16$ & $3.25 \mathrm{E}-6$ & 0.259 & $9.67 \mathrm{E}-13$ & $1.86 \mathrm{E}-3$ & 0.633 & 0.500 \\
\hline ptn21 & $2.14 \mathrm{E}-14$ & $1.56 \mathrm{E}-4$ & 0.245 & $1.00 \mathrm{E}-11$ & $2.69 \mathrm{E}-3$ & 0.633 & 0.100 \\
\hline ptn22 & $1.29 \mathrm{E}-11$ & $1.33 \mathrm{E}-4$ & 0.219 & $3.85 \mathrm{E}-13$ & $1.38 \mathrm{E}-3$ & 0.633 & 0.100 \\
\hline ptn23 & $4.07 \mathrm{E}-14$ & $2.39 \mathrm{E}-5$ & 0.247 & $9.04 \mathrm{E}-14$ & $1.23 \mathrm{E}-3$ & 0.633 & 0.100 \\
\hline ptn24 & $4.27 \mathrm{E}-12$ & $5.62 \mathrm{E}-4$ & 0.182 & $3.16 \mathrm{E}-13$ & $2.95 \mathrm{E}-3$ & 0.633 & 0.100 \\
\hline ptn25 & $1.01 \mathrm{E}-12$ & $9.48 \mathrm{E}-5$ & 0.300 & $1.59 \mathrm{E}-13$ & $1.10 \mathrm{E}-3$ & 0.633 & 0.100 \\
\hline ptn26 & $1.00 \mathrm{E}-11$ & $5.23 \mathrm{E}-4$ & 0.126 & $9.23 \mathrm{E}-13$ & $9.55 \mathrm{E}-4$ & 0.633 & 0.100 \\
\hline tsw31 & $1.77 \mathrm{E}-17$ & $4.85 \mathrm{E}-5$ & 0.218 & $6.46 \mathrm{E}-11$ & $1.00 \mathrm{E}-4$ & 0.633 & 0.100 \\
\hline
\end{tabular}


Table A-5. Calibrated Parameters for the Alternative Modeling Studies of the Present-Day, Upper-Bound Infiltration Scenario, Used for Simulations with the Upper-Bound Infiltration Scenarios of the Present-Day, Monsoon, and Glacial-transition Climates (Continued)

\begin{tabular}{|c|c|c|c|c|c|c|c|}
\hline Model Layer & $\begin{array}{c}k_{M} \\
\left(m^{2}\right)\end{array}$ & $\begin{array}{c}\alpha_{M} \\
(1 / \mathrm{Pa})\end{array}$ & $\begin{array}{c}\boldsymbol{m}_{M} \\
(-)\end{array}$ & $\begin{array}{c}k_{F} \\
\left(\mathbf{m}^{2}\right)\end{array}$ & $\begin{array}{c}\alpha_{F} \\
(1 / P a)\end{array}$ & $\begin{array}{c}m_{F} \\
(-)\end{array}$ & $\begin{array}{c}\gamma \\
(-)\end{array}$ \\
\hline tsw32 & $2.13 E-16$ & $1.96 \mathrm{E}-5$ & 0.290 & $5.62 \mathrm{E}-11$ & $1.00 \mathrm{E}-4$ & 0.633 & 0.561 \\
\hline tsw33 & $2.39 \mathrm{E}-17$ & $5.22 \mathrm{E}-6$ & 0.283 & $6.17 \mathrm{E}-11$ & $1.58 \mathrm{E}-3$ & 0.633 & 0.561 \\
\hline tsw34 & $2.96 \mathrm{E}-19$ & $1.65 \mathrm{E}-6$ & 0.317 & $2.63 \mathrm{E}-11$ & 1.00E-4 & 0.633 & 0.570 \\
\hline tsw35 & $8.55 \mathrm{E}-18$ & $5.03 \mathrm{E}-6$ & 0.216 & $7.24 \mathrm{E}-11$ & $5.78 \mathrm{E}-4$ & 0.633 & 0.570 \\
\hline tsw36 & $7.41 \mathrm{E}-19$ & $1.08 \mathrm{E}-6$ & 0.442 & $1.07 \mathrm{E}-10$ & $1.10 \mathrm{E}-3$ & 0.633 & 0.570 \\
\hline tsw37 & $7.41 \mathrm{E}-19$ & $1.08 \mathrm{E}-6$ & 0.442 & $1.07 \mathrm{E}-10$ & $1.10 \mathrm{E}-3$ & 0.633 & 0.570 \\
\hline tsw38 & $7.40 \mathrm{E}-18$ & $5.58 \mathrm{E}-6$ & 0.286 & $8.10 \mathrm{E}-13$ & 8.91E-4 & 0.633 & 0.570 \\
\hline tswz (zeolitic portion of tsw39) & $3.50 \mathrm{E}-17$ & $4.61 \mathrm{E}-6$ & 0.059 & $8.10 \mathrm{E}-13$ & $1.50 \mathrm{E}-3$ & 0.633 & 0.500 \\
\hline tswv (vitric portion of tsw39) & $2.24 \mathrm{E}-13$ & $4.86 \mathrm{E}-5$ & 0.293 & $\mathrm{a}$ & $\mathrm{a}$ & $\mathrm{a}$ & $\mathrm{a}$ \\
\hline $\operatorname{ch} 1 z$ & $3.50 \mathrm{E}-17$ & $2.12 \mathrm{E}-7$ & 0.349 & $2.50 \mathrm{E}-14$ & $1.40 \mathrm{E}-3$ & 0.633 & 0.500 \\
\hline $\operatorname{ch} 1 v$ & $1.39 \mathrm{E}-12$ & $8.82 \mathrm{E}-5$ & 0.240 & $a$ & $\mathrm{a}$ & $\mathrm{a}$ & $a$ \\
\hline $\operatorname{ch} 2 v$ & $4.90 \mathrm{E}-11$ & $2.73 \mathrm{E}-4$ & 0.158 & $a$ & $\mathrm{a}$ & $a$ & $\mathrm{a}$ \\
\hline $\operatorname{ch} 3 v$ & $4.90 \mathrm{E}-11$ & $2.73 \mathrm{E}-4$ & 0.158 & $\mathrm{a}$ & $\mathrm{a}$ & $a$ & $a$ \\
\hline $\operatorname{ch} 4 v$ & $4.90 \mathrm{E}-11$ & $2.73 \mathrm{E}-4$ & 0.158 & $a$ & $\mathrm{a}$ & $a$ & $\mathrm{a}$ \\
\hline $\operatorname{ch} 5 v$ & $4.90 \mathrm{E}-11$ & $2.73 \mathrm{E}-4$ & 0.158 & $\bar{a}$ & $\mathrm{a}$ & $\mathrm{a}$ & $\bar{a}$ \\
\hline $\operatorname{ch6v}$ & $2.72 \mathrm{E}-13$ & $1.67 \mathrm{E}-5$ & 0.147 & $\mathrm{a}$ & $\mathrm{a}$ & $a$ & $\mathrm{a}$ \\
\hline $\operatorname{ch} 2 z$ & $5.20 \mathrm{E}-18$ & $2.25 \mathrm{E}-6$ & 0.257 & $2.50 \mathrm{E}-14$ & $8.90 \mathrm{E}-4$ & 0.633 & 0.500 \\
\hline $\operatorname{ch} 3 z$ & $5.20 \mathrm{E}-18$ & $2.25 \mathrm{E}-6$ & 0.257 & $2.50 \mathrm{E}-14$ & $8.90 \mathrm{E}-4$ & 0.633 & 0.500 \\
\hline$\overline{\operatorname{ch} 4 z}$ & $5.20 \mathrm{E}-18$ & $2.25 \mathrm{E}-6$ & 0.257 & $2.50 \mathrm{E}-14$ & $8.90 \mathrm{E}-4$ & 0.633 & 0.500 \\
\hline $\operatorname{ch} 5 z$ & $5.20 \mathrm{E}-18$ & $2.25 \mathrm{E}-6$ & 0.257 & $2.50 \mathrm{E}-14$ & $8.90 \mathrm{E}-4$ & 0.633 & 0.500 \\
\hline $\operatorname{ch} 6 z$ & $8.20 \mathrm{E}-19$ & $1.56 \mathrm{E}-7$ & 0.499 & $2.50 \mathrm{E}-14$ & $1.40 \mathrm{E}-3$ & 0.633 & 0.500 \\
\hline pp4 & $1.02 \mathrm{E}-15$ & $4.57 \mathrm{E}-7$ & 0.474 & $2.50 \mathrm{E}-12$ & $8.91 \mathrm{E}-4$ & 0.633 & 0.500 \\
\hline pp3 & $1.26 \mathrm{E}-13$ & $9.50 \mathrm{E}-6$ & 0.407 & $2.20 \mathrm{E}-12$ & $1.66 \mathrm{E}-3$ & 0.633 & 0.500 \\
\hline pp2 & $1.70 \mathrm{E}-15$ & $2.25 \mathrm{E}-6$ & 0.309 & $2.20 \mathrm{E}-13$ & $1.66 \mathrm{E}-3$ & 0.633 & 0.500 \\
\hline $\mathrm{pp} 1$ & $2.57 \mathrm{E}-15$ & $8.77 \mathrm{E}-7$ & 0.272 & $2.50 \mathrm{E}-14$ & $8.91 \mathrm{E}-4$ & 0.633 & 0.500 \\
\hline bf3 & $3.55 \mathrm{E}-14$ & $3.48 \mathrm{E}-5$ & 0.193 & $2.20 \mathrm{E}-13$ & $1.66 \mathrm{E}-3$ & 0.633 & 0.500 \\
\hline bf2 & $8.10 \mathrm{E}-17$ & $1.18 \mathrm{E}-7$ & 0.617 & $2.50 \mathrm{E}-14$ & $8.90 \mathrm{E}-4$ & 0.633 & 0.500 \\
\hline pcM38/ pcF38 & $3.00 \mathrm{E}-19$ & $5.58 \mathrm{E}-6$ & 0.286 & $3.00 \mathrm{E}-18$ & $5.58 \mathrm{E}-6$ & 0.286 & 0.00 \\
\hline pcM39/ pcF39 & $6.20 \mathrm{E}-18$ & $4.61 \mathrm{E}-6$ & 0.059 & $6.20 \mathrm{E}-17$ & $4.61 \mathrm{E}-6$ & 0.059 & 0.00 \\
\hline pcM1z/ pcF1z & $9.30 \mathrm{E}-20$ & $2.12 \mathrm{E}-7$ & 0.349 & 9.30E-19 & 2.12E-7 & 0.349 & 0.00 \\
\hline pcM2z/ pcF2z & $2.40 \mathrm{E}-18$ & $2.25 \mathrm{E}-6$ & 0.257 & $2.40 \mathrm{E}-17$ & $2.25 \mathrm{E}-6$ & 0.257 & 0.00 \\
\hline pcM5z/ pcF5z & $2.40 \mathrm{E}-18$ & $2.25 \mathrm{E}-6$ & 0.257 & $2.40 \mathrm{E}-18$ & $2.25 \mathrm{E}-6$ & 0.257 & 0.00 \\
\hline pcM6z/ pcF6z & 1.10E-19 & $1.56 \mathrm{E}-7$ & 0.499 & 1.10E-19 & $1.56 \mathrm{E}-7$ & 0.499 & 0.00 \\
\hline pcM4p/pcF4p & 7.70E-19 & $4.57 \mathrm{E}-7$ & 0.474 & $7.70 \mathrm{E}-19$ & $4.57 \mathrm{E}-7$ & 0.474 & 0.00 \\
\hline
\end{tabular}

NOTE: These data have been developed as documented in this report and submitted under OutputDTN: LB03013DSSCP3I.001.

${ }^{a}$ Conceptual model for calibrated properties model does not include fractures in these model layers. 
Table A-6. Calibrated Parameters for the Alternative Modeling Studies of the Present-Day, Lower-Bound Infiltration Scenario, Used for Simulations with the Lower-Bound Infiltration Scenarios of the Present-Day, Monsoon, and Glacial-transition Climates

\begin{tabular}{|c|c|c|c|c|c|c|c|}
\hline Model Layer & $\begin{array}{c}k_{M} \\
\left(m^{2}\right)\end{array}$ & $\begin{array}{c}\alpha_{M} \\
(1 / \mathrm{Pa})\end{array}$ & $\begin{array}{c}m_{M} \\
(-)\end{array}$ & $\begin{array}{c}k_{F} \\
\left(\mathrm{~m}^{2}\right)\end{array}$ & $\begin{array}{c}\alpha_{F} \\
(1 / P a)\end{array}$ & $\begin{array}{c}m_{F} \\
(-)\end{array}$ & $\begin{array}{c}\gamma \\
(-)\end{array}$ \\
\hline tcw11 & $3.44 \mathrm{E}-15$ & $1.16 \mathrm{E}-5$ & 0.388 & $3.16 \mathrm{E}-12$ & $4.68 \mathrm{E}-3$ & 0.633 & 0.483 \\
\hline tcw12 & 3.00E-20 & $2.67 \mathrm{E}-6$ & 0.280 & 9.73E-11 & 3.20E-3 & 0.633 & 0.483 \\
\hline tcw13 & 3.96E-17 & $1.64 \mathrm{E}-6$ & 0.259 & $9.47 E-13$ & $2.13 \mathrm{E}-3$ & 0.633 & 0.483 \\
\hline ptn21 & $5.55 \mathrm{E}-15$ & $6.38 \mathrm{E}-5$ & 0.245 & $1.00 \mathrm{E}-11$ & $2.93 \mathrm{E}-3$ & 0.633 & 0.065 \\
\hline ptn22 & 8.40E-12 & 1.67E-4 & 0.219 & $1.00 \mathrm{E}-11$ & $6.76 \mathrm{E}-4$ & 0.633 & 0.065 \\
\hline ptn23 & $1.92 \mathrm{E}-14$ & $4.51 \mathrm{E}-5$ & 0.247 & 1.16E-13 & 3.96E-3 & 0.633 & 0.065 \\
\hline ptn24 & $6.66 \mathrm{E}-13$ & $2.52 \mathrm{E}-3$ & 0.182 & $1.00 \mathrm{E}-11$ & $2.51 \mathrm{E}-3$ & 0.633 & 0.065 \\
\hline ptn25 & $1.96 \mathrm{E}-14$ & $1.24 \mathrm{E}-4$ & 0.300 & 4.37E-13 & $1.53 \mathrm{E}-3$ & 0.633 & 0.065 \\
\hline ptn26 & $1.00 \mathrm{E}-11$ & $1.63 \mathrm{E}-3$ & 0.126 & 8.29E-14 & $1.52 \mathrm{E}-3$ & 0.633 & 0.065 \\
\hline tsw31 & $1.42 \mathrm{E}-17$ & $8.02 \mathrm{E}-5$ & 0.218 & $5.13 \mathrm{E}-11$ & $1.00 \mathrm{E}-4$ & 0.633 & 0.037 \\
\hline tsw32 & 3.96E-16 & $9.46 \mathrm{E}-6$ & 0.290 & 4.47E-11 & $1.31 \mathrm{E}-4$ & 0.633 & 0.528 \\
\hline tsw33 & $1.60 \mathrm{E}-18$ & $4.25 \mathrm{E}-6$ & 0.283 & $4.90 \mathrm{E}-11$ & $1.94 \mathrm{E}-3$ & 0.633 & 0.528 \\
\hline tsw34 & $1.38 \mathrm{E}-19$ & $1.19 \mathrm{E}-6$ & 0.317 & $2.09 \mathrm{E}-11$ & $6.55 \mathrm{E}-4$ & 0.633 & 0.476 \\
\hline tsw35 & 2.33E-18 & $1.97 \mathrm{E}-6$ & 0.216 & $5.75 \mathrm{E}-11$ & $1.35 \mathrm{E}-3$ & 0.633 & 0.476 \\
\hline tsw36 & $5.58 \mathrm{E}-19$ & $4.22 \mathrm{E}-7$ & 0.442 & $8.51 \mathrm{E}-11$ & $1.31 \mathrm{E}-3$ & 0.633 & 0.476 \\
\hline tsw37 & $5.58 \mathrm{E}-19$ & $4.22 \mathrm{E}-7$ & 0.442 & $8.51 \mathrm{E}-11$ & $1.31 \mathrm{E}-3$ & 0.633 & 0.476 \\
\hline tsw38 & 2.93E-18 & $1.43 \mathrm{E}-6$ & 0.286 & 8.10E-13 & $1.75 \mathrm{E}-3$ & 0.633 & 0.476 \\
\hline tswz (zeolitic portion of tsw39) & $3.50 \mathrm{E}-17$ & $4.61 \mathrm{E}-6$ & 0.059 & 8.10E-13 & $1.50 \mathrm{E}-3$ & 0.633 & 0.276 \\
\hline tswv (vitric portion of tsw39) & $3.15 \mathrm{E}-13$ & $1.86 \mathrm{E}-5$ & 0.293 & $\mathrm{a}$ & a & $\mathrm{a}$ & $\mathrm{a}$ \\
\hline ch1z & $3.50 \mathrm{E}-17$ & $2.12 \mathrm{E}-7$ & 0.349 & $2.50 \mathrm{E}-14$ & $1.40 \mathrm{E}-3$ & 0.633 & 0.276 \\
\hline $\operatorname{ch} 1 \mathrm{v}$ & $3.15 \mathrm{E}-14$ & $4.50 \mathrm{E}-5$ & 0.240 & $a$ & a & $a$ & a \\
\hline $\operatorname{ch} 2 v$ & $1.13 \mathrm{E}-11$ & $1.22 \mathrm{E}-4$ & 0.158 & $\mathrm{a}$ & a & $\bar{a}$ & $\bar{a}$ \\
\hline $\operatorname{ch} 3 v$ & $1.13 \mathrm{E}-11$ & $1.22 \mathrm{E}-4$ & 0.158 & $a$ & $a$ & $a$ & $\mathrm{a}$ \\
\hline $\operatorname{ch} 4 v$ & 1.13E-11 & $1.22 \mathrm{E}-4$ & 0.158 & a & a & $a$ & $a$ \\
\hline $\operatorname{ch} 5 \mathrm{v}$ & $1.13 \mathrm{E}-11$ & $1.22 \mathrm{E}-4$ & 0.158 & $a$ & $a$ & $\mathrm{a}$ & $a^{a}$ \\
\hline $\operatorname{ch} 6 \mathrm{v}$ & $2.54 \mathrm{E}-13$ & $9.05 \mathrm{E}-6$ & 0.147 & $a$ & a & $a$ & $a$ \\
\hline $\operatorname{ch} 2 z$ & $5.20 \mathrm{E}-18$ & $2.25 \mathrm{E}-6$ & 0.257 & $2.50 \mathrm{E}-14$ & 8.90E-4 & 0.633 & 0.276 \\
\hline ch3z & $5.20 \mathrm{E}-18$ & $2.25 \mathrm{E}-6$ & 0.257 & $2.50 \mathrm{E}-14$ & $8.90 \mathrm{E}-4$ & 0.633 & 0.276 \\
\hline $\operatorname{ch} 4 z$ & $5.20 \mathrm{E}-18$ & $2.25 \mathrm{E}-6$ & 0.257 & $2.50 \mathrm{E}-14$ & $8.90 \mathrm{E}-4$ & 0.633 & 0.276 \\
\hline $\operatorname{ch} 5 z$ & $5.20 \mathrm{E}-18$ & $2.25 \mathrm{E}-6$ & 0.257 & $2.50 \mathrm{E}-14$ & $8.90 \mathrm{E}-4$ & 0.633 & 0.276 \\
\hline ch6z & $8.20 \mathrm{E}-19$ & $1.56 \mathrm{E}-7$ & 0.499 & $2.50 \mathrm{E}-14$ & $1.40 \mathrm{E}-3$ & 0.633 & 0.276 \\
\hline $\mathrm{pp} 4$ & $2.98 \mathrm{E}-16$ & $2.88 \mathrm{E}-7$ & 0.474 & $2.50 \mathrm{E}-14$ & $1.88 \mathrm{E}-3$ & 0.633 & 0.276 \\
\hline pp3 & $5.37 \mathrm{E}-14$ & $7.97 \mathrm{E}-6$ & 0.407 & $2.20 \mathrm{E}-13$ & $1.32 \mathrm{E}-3$ & 0.633 & 0.248 \\
\hline pp2 & 4.24E-16 & $2.41 \mathrm{E}-6$ & 0.309 & $2.20 \mathrm{E}-13$ & $2.80 \mathrm{E}-3$ & 0.633 & 0.248 \\
\hline $\mathrm{pp} 1$ & 7.02E-16 & $1.36 \mathrm{E}-6$ & 0.272 & $2.50 \mathrm{E}-14$ & $6.39 \mathrm{E}-4$ & 0.633 & 0.276 \\
\hline
\end{tabular}


Table A-6. Calibrated Parameters for the Alternative Modeling Studies of the Present-Day, Lower-Bound Infiltration Scenario, Used for Simulations with the Lower-Bound Infiltration Scenarios of the Present-Day, Monsoon, and Glacial-transition Climates (Continued)

\begin{tabular}{|l|c|c|c|c|c|c|c|}
\hline \multicolumn{1}{|c|}{ Model Layer } & $\begin{array}{c}\boldsymbol{k}_{\mathbf{M}} \\
\left(\mathbf{m}^{2}\right)\end{array}$ & $\begin{array}{c}\alpha_{M} \\
(\mathbf{1} / \mathrm{Pa})\end{array}$ & $\begin{array}{c}\boldsymbol{m}_{\boldsymbol{M}} \\
(-)\end{array}$ & $\begin{array}{c}\boldsymbol{k}_{F} \\
\left(\mathbf{m}^{2}\right)\end{array}$ & $\begin{array}{c}\alpha_{F} \\
(\mathbf{1} / \mathbf{P a})\end{array}$ & $\begin{array}{c}\boldsymbol{m}_{\boldsymbol{F}} \\
(-)\end{array}$ & $\begin{array}{c}\gamma \\
(-)\end{array}$ \\
\hline bf3 & $2.97 \mathrm{E}-14$ & $1.32 \mathrm{E}-5$ & 0.193 & $2.20 \mathrm{E}-13$ & $1.92 \mathrm{E}-3$ & 0.633 & 0.248 \\
\hline bf2 & $8.10 \mathrm{E}-17$ & $1.18 \mathrm{E}-7$ & 0.617 & $2.50 \mathrm{E}-14$ & $8.90 \mathrm{E}-4$ & 0.633 & 0.276 \\
\hline pcM38/ pcF38 & $3.00 \mathrm{E}-19$ & $1.43 \mathrm{E}-6$ & 0.286 & $3.00 \mathrm{E}-19$ & $1.43 \mathrm{E}-6$ & 0.286 & 0.00 \\
\hline pcM39/ pcF39 & $6.20 \mathrm{E}-18$ & $4.61 \mathrm{E}-6$ & 0.059 & $6.20 \mathrm{E}-18$ & $4.61 \mathrm{E}-6$ & 0.059 & 0.00 \\
\hline pcM1z/ pcF1z & $9.30 \mathrm{E}-20$ & $2.12 \mathrm{E}-7$ & 0.349 & $9.30 \mathrm{E}-20$ & $2.12 \mathrm{E}-7$ & 0.349 & 0.00 \\
\hline pcM2z/ pcF2z & $2.40 \mathrm{E}-18$ & $2.25 \mathrm{E}-6$ & 0.257 & $2.40 \mathrm{E}-18$ & $2.25 \mathrm{E}-6$ & 0.257 & 0.00 \\
\hline pcM5z/ pcF5z & $2.40 \mathrm{E}-18$ & $2.25 \mathrm{E}-6$ & 0.257 & $2.40 \mathrm{E}-18$ & $2.25 \mathrm{E}-6$ & 0.257 & 0.00 \\
\hline pcM6z/ pcF6z & $1.10 \mathrm{E}-19$ & $1.56 \mathrm{E}-7$ & 0.499 & $1.10 \mathrm{E}-19$ & $1.56 \mathrm{E}-7$ & 0.499 & 0.00 \\
\hline pcM4p/ pcF4p & $7.70 \mathrm{E}-19$ & $2.88 \mathrm{E}-7$ & 0.474 & $7.70 \mathrm{E}-19$ & $2.88 \mathrm{E}-7$ & 0.474 & 0.00 \\
\hline
\end{tabular}

NOTE: These data have been developed as documented in this report and submitted under OutputDTN: LB03013DSSCP3I.001.

${ }^{\text {a }}$ Conceptual model for calibrated properties model does not include fractures in these model layers (Section 5). 


\section{INTENTIONALLY LEFT BLANK}


APPENDIX B

LOCATION COORDINATES AND SURFACE ELEVATIONS OF SELECTED BOREHOLES USED IN MODEL CALIBRATION AND STUDIES 
Table B-1. Coordinates and Surface Elevations of Selected Boreholes

\begin{tabular}{|l|c|c|c|c|c|c|}
\hline \multicolumn{1}{|c|}{ Borehole } & Easting (ft) & Northing (ft) & Elevation (ft) & Easting (m) & Northing (m) & Elevation (m) \\
\hline NRG-6 & 564187 & 766726 & 4093 & 171964.2 & 233698.1 & 1247.5 \\
\hline NRG-7A & 562984 & 768880 & 4209 & 171597.5 & 234354.6 & 1282.9 \\
\hline SD-6 & 558608 & 762421 & 4906 & 170263.7 & 232385.9 & 1495.3 \\
\hline SD-7 & 561240 & 758950 & 4475 & 171066.0 & 231328.0 & 1364.0 \\
\hline SD-9 & 561818 & 767998 & 4275 & 171242.1 & 234085.8 & 1303.0 \\
\hline SD-12 & 561606 & 761957 & 4343 & 171177.5 & 232244.5 & 1323.8 \\
\hline UZ\#4 & 566140 & 768716 & 3941 & 172559.5 & 234304.6 & 1201.2 \\
\hline UZ\#5 & 566136 & 768593 & 3954 & 172558.3 & 234267.1 & 1205.2 \\
\hline UZ-7a & 562270 & 760693 & 4230 & 171379.9 & 231859.2 & 1289.3 \\
\hline UZ-14 & 560142 & 771310 & 4427 & 170731.3 & 235095.3 & 1349.4 \\
\hline UZ\#16 & 564857 & 760535 & 4002 & 172168.4 & 231811.3 & 1219.8 \\
\hline H-5 & 558908 & 766634 & 4852 & 170355.2 & 233670.0 & 1478.9 \\
\hline G-2 & 560504 & 778826 & 5098 & 170841.6 & 237386.2 & 1553.9 \\
\hline G-3 & 558483 & 752780 & 4858 & 170225.6 & 229447.3 & 1480.7 \\
\hline WT-24 & 562329 & 776703 & 4900 & 171397.9 & 236739.1 & 1493.5 \\
\hline
\end{tabular}

Source DTN: MO0012MWDGFM02.002 (DIRS 153777), file contacts00el.dat. 


\section{INTENTIONALLY LEFT BLANK}


APPENDIX C

COMPUTATIONS IN INPUT DATA PREPARATIONS AND SIMULATION RESULT ANALYSES 


\section{C1. CALCULATING THE CHLORIDE FLUX OF SECTION 6.5}

This appendix presents the details of calculations in postprocessing of the simulation results and data analyses of Sections 6.5, 6.6, and 6.8. The working files are saved in the attached CD labeled as Files of Appendix C for model report MDL-NBS-HS-000006 REV02.

\section{C1.1 FORMULATION}

The chloride flux is calculated using the following formulation:

$$
F_{C l}=C_{C l, p} \times 10^{-6}\left(F_{\text {prec }}+F_{\text {runon }}-F_{\text {runoff }}\right)
$$

where $F_{C l}$ is chloride flux ( $\mathrm{kg} \mathrm{Cl} /$ second); $F_{\text {prec }}$ is precipitation flux ( $\mathrm{kg}$ water/second); $F_{\text {runon }}$ is runon (kg water/second); and $F_{\text {runoff }}$ is runoff flux ( $\mathrm{kg}$ water/second). $C_{C l, p}$ is chloride concentration in precipitation, and was assumed to be $0.55 \mathrm{mg} / 1 \mathrm{Cl}^{-}$(Sonnenthal and Bodvarsson 1999 [DIRS 117127], p. 148). These flux terms are generated using software routine infil2grid V1.7 (LBNL 2002 [DIRS 154793]), employing the net infiltration data listed below:

Table C.1.1-1. Infiltration Data Files

\begin{tabular}{|l|l|}
\hline $\begin{array}{l}\text { modern upper bound } \\
\text { infiltration }\end{array}$ & modernu.dat \\
\hline $\begin{array}{l}\text { modern mean } \\
\text { infiltration }\end{array}$ & modernm.dat \\
\hline $\begin{array}{l}\text { modern low bound } \\
\text { infiltration }\end{array}$ & modernl.dat \\
\hline glacial mean infiltration & glacialm.dat \\
\hline \multicolumn{2}{|l|}{ Source DTN: GS00308311221.005 (DIRS 147613). } \\
NOTE: Attached CD (Files of Appendix C for model report MDL-NBS- \\
HS-000006 REV 02): II.1/files in Table II.1.1-1/.
\end{tabular}

\section{C1.2 INPUT AND OUTPUT FILES USED IN THE CALCULATIONS}

All of the input files for the calculations are in the GENER format of the TOUGH2 code. Chloride $(\mathrm{Cl})$ fluxes to be calculated are defined as mass recharge rates on the surface with infiltration, and are represented also in terms of GENER. The input file uses the following format:

Line 1: NGENER (an integer for the total number of GENER terms)

Line 2: Notation giving mean flux

Lines from 3 to NGENER:

Format (A8, 28x, A5, F10.4, F10.4)

ELEMENT, COMPONENT, FLUX, ENTHALPY.

The input and output files used in the calculation are listed in Tables C.1.2-1 to C.1.2-4 for the three present-day infiltration scenarios and one glacial transition infiltration scenario, respectively. 
Table C.1.2-1. Cl Flux Calculation for Present-Day, Upper-Bound Infiltration

\begin{tabular}{|c|l|l|}
\hline \multirow{2}{*}{\begin{tabular}{c} 
Input files $\begin{array}{c}\text { (GENER } \\
\text { files) }\end{array}$ \\
\cline { 2 - 3 }
\end{tabular}} & Precipitation flux & modernugenprec.dat \\
\cline { 2 - 3 } & Runon flux & modernugenrunon.dat \\
\hline \multicolumn{2}{|c|}{ Output file (Cl flux) } & modernugenrunoff.dat \\
\hline \multicolumn{2}{|c|}{ modernu_GENER_Cl } \\
\hline
\end{tabular}

NOTE: Attached CD (Files of Appendix C for model report, MDL-NBS-HS-000006 REV 02): II.1/files in Table IIC.1.2-1/.

Table C.1.2-2. Cl Flux Calculation for Present-Day, Mean Infiltration

\begin{tabular}{|c|l|l|}
\hline \multirow{3}{*}{$\begin{array}{c}\text { Input files } \\
\text { (GENER } \\
\text { files) }\end{array}$} & Precipitation flux & genmmprec \\
\cline { 2 - 3 } & Runon flux & genmmrunon \\
\cline { 2 - 3 } & Runoff flux & genmmrunoff \\
\hline \multicolumn{2}{|c|}{ Output file (Cl flux) } & Gen_mm_Cl \\
\hline
\end{tabular}

NOTE: Attached CD (Files of Appendix C for model report, MDL-NBS-HS-000006 REV 02): II.1/files in Table II.1.2-2/.

Table C.1.2-3. Cl Flux Calculation for Present-Day Lower-Bound Infiltration

\begin{tabular}{|c|l|l|}
\hline \multirow{2}{*}{$\begin{array}{c}\text { Input files } \\
\text { (GENER } \\
\text { files) }\end{array}$} & Precipitation flux & modernlgenprec \\
\cline { 2 - 3 } & Runon flux & modernlgenrunon \\
\cline { 2 - 3 } & Runoff flux & modernlgenrunoff \\
\hline \multicolumn{2}{|c|}{ Output file (Cl flux) } & modern__GENER_Cl \\
\hline
\end{tabular}

NOTE: Attached CD (Files of Appendix C for model report, MDL-NBS-HS-000006 REV 02): II.1/files in Table II.1.2-3/.

Table C.1.2-4. Cl Flux Calculation for Glacial Infiltration

\begin{tabular}{|c|l|l|}
\hline \multirow{2}{*}{$\begin{array}{c}\text { Input files } \\
\text { (GENER } \\
\text { files) }\end{array}$} & Precipitation flux & glacmgenprec \\
\cline { 2 - 3 } & Runon flux & glacmgenrunon \\
\cline { 2 - 3 } & Runoff flux & glacmgenrunoff \\
\hline \multicolumn{2}{|c|}{ Output file (Cl flux) } & glacm_GENER_Cl \\
\hline
\end{tabular}

NOTE: Attached CD (Files of Appendix C for model report, MDL-NBS-HS-000006 REV 02): II.1/files in Table C.1.2-4/.

\section{C1.3 CALCULATION PROCEDURES}

$\mathrm{Cl}$ flux is calculated by taking the following steps:

Step 1: Open three input files using EXCEL. Then copy/paste the files into one worksheet in the order of precipitation, runon, and runoff.

Step 2: Identify columns representing precipitation (column C), runon (column G), and runoff (column K). 
Step 3: Use Equation (C.1.1-1) to calculate $\mathrm{Cl}$ flux by typing:

- $=0.55^{*} 1 \mathrm{E}-6 *(\mathrm{C} 3+\mathrm{E} 3-\mathrm{K} 3)$ in Column M, Row 3. Then press $<$ ENTER $>$ key to get $\mathrm{Cl}$ flux for the cell of Column $\mathrm{M}$ and Row 3.

- Calculate $\mathrm{Cl}$ fluxes for the rest of the elements by highlighting and dragging down the cursor from the lower right-hand corner until Row (NGENER+2) appears.

Details of the calculation are documented in a Scientific Notebook (see Wang 2003 [DIRS 162417], SN-LBNL-SCI-219-V1, pp. 122, 135 to 140).

\section{C2. CALCULATING VERTICAL FLUXES, DISTRIBUTION, AND PERCENTAGE OF FRACTURE-MATRIX FLOW FOR SECTION 6.6}

\section{C2.1 EXTRACTION OF VERTICAL FLUX AT THE PAINTBRUSH NONWELDED HYDROGEOLOGIC (PTN) BOTTOM}

Extracting vertical fluxes at the PTn bottom or the Topopah Spring welded hydrogeologic (TSw) top requires two files: (1) model mesh file of the three-dimensional Total System Performance Assessment for License Application model grid ("MESH_2KN.VI", Output-DTN: LB03023DSSCP9I.001), and an output file of the base-case flow fields or any other cases of interest (e.g. "preq_mA.out", Output-DTN: LB03023DSSCP9I.001).

In addition, the following are the four mesh-related files of identifying gridblocks, element coordinates, and connection areas of the PTn bottom and TSw top layers. They have the names "PTN_BOT.XY," "PTN.BOT," and "TSW.TOP," and "CONN.area", respectively.

"PTN_BOT.XY" contains three columns and 2,042 rows. The three columns are gridblock name, $\mathrm{x}$ coordinate, and y coordinate. Each row corresponds to one gridblock located at the bottom layer of the PTn unit.

"PTN.BOT": contains 2042 columns and only one row containing the names of the gridblocks located at the bottom layer of the PTn unit.

"TSW.TOP": contains 2042 columns and only one row containing the names of the gridblocks located at the top layer of the TSw unit.

"CONN.area": contains connection areas for all PTn bottom/TSw top vertical connections.

These four files will be used for extracting all vertical fluxes at the PTn bottom for different infiltration scenarios and flow fields. The extracting steps are as follows:

Step 1: Extracting flow components:

Find vertical fracture-fracture (F-F) flux, matrix-matrix (M-M) flux, and fracture-matrix (F-M) flux using UNIX commends (with flow field of "preq_mA.out" as an example): 
fgrep $-f$ TSW.TOP preq_mA.out $>$ tsw_top.conn

fgrep $-f \quad$ PTN.BOT tsw_top.conn $>$ ptn-tsw.conn

grep-v 'F0' ptn-tsw.conn > ptn-tsw_M.conn

The nonvertical connections (data rows 1,993-2,377) are then deleted from the file "ptn-tsw_M.conn." Now, file "ptn-tsw_M.conn" contains only vertical matrix-matrix flux at the PTn bottom.

The vertical fracture-fracture flux at the PTn bottom is obtained in the following form:

grep -v 'M0' ptn-tsw.conn>ptn-tsw_F.conn

Delete data rows 1,993-2,377 from "ptn-tsw_F.conn" to exclude nonvertical connections.

The vertical fracture-matrix flux at the PTn bottom is obtained as:

grep 'M0' ptn-tsw.conn > tem.conn

grep 'F0' tem.conn > ptn-tsw_FM.conn

Step 2: Importing flow components to the spreadsheet

Use Microsoft Excel to sum the vertical fluxes from the three types of vertical connections as follows:

Open file "ptn-tsw_M.conn," "ptn-tsw_F.conn," and "ptn-tsw_FM.conn."

Copy the columns for the gridblock name of connected pairs and the fluxes in these files to a working spreadsheet ("total_ptn_flux.xls"). Note that the connections in the above three files are written in the same sequence.

Step 3: Handling PTn absence:

In the unsaturated zone flow model grid, Tiva Canyon welded hydrogeologic and PTn units are absent in a number of grid columns. For these columns, infiltration rates are directly added to the top layers of the TSw. Therefore, these infiltration rates are considered as bottom PTn fluxes.

Use command "fgrep - $\mathrm{f}$ TSW.TOP GENER>preq_m.inf" to extract infiltration data, and then edit "preq_m.inf" using a PC MS DOS editor. File "preq_m.inf" consists of two columns: column 1 is the name of gridblocks directly connected to the model top boundary; the second column is its corresponding infiltration rate (in $\mathrm{kg} / \mathrm{s}$ ). Note the "GENER" file is different for different infiltration scenarios.

There are a total of 110 direct connections to the top boundary from the TSw unit. 
Step 4: Incorporation of additional files and summation Import preq_m.inf to the working spreadsheet ("total_ptn_flux.xls").

Import “PTN_BOT.XY” to the working spreadsheet.

Import "CONN.area" to the spreadsheet. (Note that all connections in different files should be in the same sequence.)

Sum fluxes along fracture-fracture (F-F), matrix-matrix (M-M), and fracture-matrix (F-M) connections for the same column and infiltration corrections.

Transform the unit of total vertical flux from $\mathrm{kg} / \mathrm{s}$ to $\mathrm{mm} / \mathrm{y}$ by performing $\mathrm{q}_{\mathrm{n}}=\mathrm{q}_{\mathrm{o}} * 31557600.0$ /area, where $\mathrm{q}_{\mathrm{n}}$ is the vertical flux in mm/year, $\mathrm{q}_{\mathrm{o}}$ is the vertical flux in $\mathrm{kg} / \mathrm{s}$, and area is the corresponding connection area.

The calculations are all done using the Excel standard formula function.

Export the columns of $\mathrm{x}$ and $\mathrm{y}$ coordinates and total fluxes $(\mathrm{mm} / \mathrm{y})$ to a text file, "preq_mA_ptn.q".

Use Tecplot to plot the vertical flux distribution map at the PTn bottom using the data file "preq_mA_ptn.q".

Table C.2.1-1 lists the files used to extract vertical fluxes at the PTn bottom.

Table C.2.1-1. Files Used in Extracting Vertical Flux at the PTn Bottom

\begin{tabular}{|c|l|l|}
\hline \multirow{3}{*}{ Input Files } & Mesh file & MESH_2KN.V1 \\
\cline { 2 - 3 } & Model output & preq_mA.out \\
\cline { 2 - 3 } & Processing used files & $\begin{array}{l}\text { PTN_BOT.XY, PTN.BOT,TSW.TOP } \\
\text { CONN.area, GENER }\end{array}$ \\
\hline \multirow{2}{*}{ Working Files } & $\begin{array}{l}\text { tsw_top.conn, ptn_tsw.conn, } \\
\text { ptn_tsw_F.conn, ptn_tsw_M.conn, } \\
\text { ptn_tsw_FM.conn, preq_m.inf, tem.conn }\end{array}$ \\
\hline \multicolumn{2}{|c|}{$\begin{array}{l}\text { Working Spreadsheet and } \\
\text { Output Files }\end{array}$} & total_ptn_flux.xls, preq_mA_ptn.q \\
\hline
\end{tabular}

NOTE: Attached CD (Files of Appendix C for model report MDL-NBS-HS-000006 REV 02): II.2/files in Table II.2.1-1/.

\section{C2.2 EXTRACTION OF VERTICAL FLUX AT THE REPOSITORY LAYER}

Extracting vertical fluxes at the repository layer requires the three-dimensional Total System Performance Assessment for license application model grid ("MESH_2KN.VI", Output DTN: LB03023DSSCP9I.001) and an output file of the base-case flow fields or any other case of interest (e.g., "preq_mA.out", Output DTN: LB03023DSSCP9I.001). 
In addition, we need the following four mesh-related files of identifying gridblocks, their coordinates, and connection areas: "REPO.XY" "REPO.DAT," "REPO+1.DAT," and "CONN_rep.area", respectively:

"REPO.XY": this file contains three columns: grid block name, $\mathrm{x}$, and $\mathrm{y}$. There are a total of 2,042 rows for all the grid blocks located at the entire repository horizon.

"REPO.DAT": this file contains 2042 rows and only one column listing the names of the gridblocks located at the entire repository horizon.

"REPO+1.DAT": this file contains 2042 rows and only one column listing the names of the gridblocks located at the layer just above the repository horizon.

"CONN_rep.area": this file contains connection areas for all vertical connections at the repository layer.

These four files will be used to extract all vertical fluxes through the repository horizon with different infiltration scenarios.

Step 1: Find vertical fracture-fracture flux, matrix-matrix flux, and fracture-matrix flux using the following Unix commands:

- fgrep -f REPO+1.DAT preq_mA.out>repo+1.conn

- fgrep -f REPO.DAT repo+1.conn>repo.conn

- grep -v 'F0' repo.conn>repo_M.conn

- grep -v 'M' repo.conn>repo_F.conn

- grep 'M' repo.conn>tem.conn

- grep 'F0' tem.conn>repo_FM.conn.

Step 2: Remove data rows of nonvertical connections

Using a text editor, remove rows of nonvertical connections from "repo_F.conn" and "repo_M.conn". For vertical connections, the last three characters in the block names of two connected blocks are the same. The vertical connections are the first 2,042 connections in "repo_M.conn" and "repo_F.conn."

Step 3: Import flow components to spreadsheet:

Open three files: "repo_M.conn," "repo_F.conn," and "repo_FM.conn" in Excel, and then copy the columns for gridblock name of connected cells and flux in these files to a working spreadsheet ("total_rep_flux.xls"). Make sure all connections are in the same sequence. 
Step 4: Incorporate additional files and summation

- Import "CONN_rep.area" and "REPO.XY" to the spreadsheet.

- Transform unit of flux from $\mathrm{kg} / \mathrm{s}$ to $\mathrm{mm} / \mathrm{y}$ by performing:

$$
\mathrm{q}_{\mathrm{n}}=\mathrm{q}_{\mathrm{o}} * 31557600.0 / \text { area }
$$

where $\mathrm{q}_{\mathrm{n}}$ is vertical flux in $\mathrm{mm} / \mathrm{year}, \mathrm{q}_{\mathrm{o}}$ is vertical flux in $\mathrm{kg} / \mathrm{s}$, and area is corresponding connection area.

The above calculations are performed using the Excel formulas function.

- Export the columns of $\mathrm{x}$ and y coordinates and total flux $(\mathrm{mm} / \mathrm{y})$ to a text file "preq_mA_rep.q."

- Use Tecplot to plot the vertical flux distribution map at repository horizon, using the data file "preq_mA_rep.q."

Table C.2.2-1 lists the files used to extract vertical fluxes at the repository layer:

Table C.2.2-1. Files Used to Extract Vertical Fluxes at the Repository Layer

\begin{tabular}{|c|l|l|}
\hline \multirow{3}{*}{ Input Files } & Mesh file & MESH_2KN.V1 \\
\cline { 2 - 3 } & Model output & preq_mA.out \\
\cline { 2 - 3 } & Processing used files & $\begin{array}{l}\text { REPO.XY, REPO.DAT, REPO+1.DAT } \\
\text { CONN_rep.area }\end{array}$ \\
\hline \multicolumn{2}{|c|}{ Working Files } & $\begin{array}{l}\text { repo+1.conn, repo.conn, repo_M.conn, repo_F.conn, } \\
\text { repo_FM.conn, tem.conn }\end{array}$ \\
\hline \multirow{2}{*}{$\begin{array}{c}\text { Working Spreadsheet and Output } \\
\text { Files }\end{array}$} & total_rep_flux.xls,preq_mA_rep.q \\
\hline
\end{tabular}

NOTE: Attached CD (Files of Appendix C for model report MDL-NBS-HS-000006 REV 02):

II.2/files in Table II.2.2-1/.

\section{C2.3 EXTRACTION OF VERTICAL FLUX AT THE DOMAIN BOTTOM}

In addition to the unsaturated zone grid mesh file and a TOUGH2 output file of the flow field of interest, we also need two files containing the bottom grid coordinates and vertical connection area: "BT.XY" and "CONN_bt.area," respectively. "BT.XY" contains three columns: grid block

name, $\mathrm{x}$, and $\mathrm{y}$. There are a total of 2,042 rows for all of the gridblocks located at the domain bottom. "CONN_bt.area" contains connection areas along all vertical connections at the domain bottom. 
These two files will be used to extract all vertical fluxes through the bottom of different infiltration scenarios.

Step 1: Find vertical fracture-fracture flux and matrix-matrix flux using the following Unix commands:

- grep 'BT' preq_mA.out $>$ bt.conn

- grep 'F0' bt.conn>bt_F.conn

- grep 'M0' bt.conn>bt_M.conn.

Step 2: Sum the F-F and M-M vertical fluxes.

Use Microsoft Excel to open files " $b t_{-}$M.conn" and " $b t_{-} F$.conn," and then copy the columns for gridblock name of connected cells and flux in the two files to a working spreadsheet ("total_bt_flux.xls"). Note that "bt_M.conn" contains 2,042 M-M connections and " $b t_{-}$F.con" has 2,042 F-F connections.

- Import "CONN_bt.area" and "BT.XY” to the spreadsheet.

- Transform unit of flux from $\mathrm{kg} / \mathrm{s}$ to $\mathrm{mm} / \mathrm{y}$ by performing $\mathrm{q}_{\mathrm{n}}=\mathrm{q}_{\mathrm{o}} * 31557600.0$ /area, where $\mathrm{q}_{\mathrm{n}}$ is vertical flux in $\mathrm{mm} /$ year, $\mathrm{q}_{\mathrm{o}}$ is vertical flux in $\mathrm{kg} / \mathrm{s}$, and area is the corresponding connection area.

All of the above calculations are done using the Excel standard formula function.

- Export the columns of $\mathrm{x}, \mathrm{y}$, and total flux $(\mathrm{mm} / \mathrm{y})$ to a text file "preq_mA_bt.q."

- Use Tecplot to plot the vertical flux distribution map at domain bottom using the data file "preq_mA_bt.q."

Table C.2.3-1 lists the files used in extracting the vertical fluxes at the domain bottom:

Table C.2.3-1. Files Used to Extract Vertical Fluxes at the Domain Bottom

\begin{tabular}{|c|l|l|}
\hline \multirow{3}{*}{ Input Files } & Mesh file & MESH_2KN.V1 \\
\cline { 2 - 3 } & Model output & preq_mA.out \\
\cline { 2 - 3 } & Processing used files & BT.XY, CONN_bt.area \\
\hline Working Files & bt.conn, bt_F.conn, bt_M.conn \\
\hline Working Spreadsheet and Output Files & total_bt_flux.xls, preq_mA_bt.q \\
\hline
\end{tabular}

NOTE: Attached CD (Files of Appendix C for model report MDL-NBS-HS-000006 REV 02):

II.2/files in Table II.2.3-1/. 


\section{C2.4 CALCULATION OF PERCENTAGE OF FLUX IN FRACTURES, MATRIX, AND FAULTS}

Step 1: Calculate the total flux in fractures at the entire repository horizon as follows:

- Copy the columns of F-F flux, F-M flux, and total flux and paste them onto a working spreadsheet ("compu_frac_q_percentage.xls") from "total_rep_flux.xls" (see Section C.2.2 of this appendix for more information about this file).

- In accounting for F-M flux, note that some connections are F-M and others are M-F (matrix-fracture). Delete F-M connections from this column (i.e., F-M flux is not treated as fracture flux).

- Sum the cells in columns of F-F flux and M-F flux, and total fracture flux is obtained (qf).

- Sum the cells in the column of total flux, and total vertical flux at the repository horizon is obtained $(\mathrm{q})$.

- Percentage is computed by qf/q*100 percent.

Step 2: Calculate total flux in the matrix at the repository layer:

- Total matrix flux (qm), qm =q-qf. Its percentage is $\mathrm{qm} / \mathrm{q} * 100$ percent.

Step 3: Calculate total flux in faults at the repository layer.

- Export the columns of the connected gridblock names and total flux to a text file ("fault_rep_q.dat") from "total_rep_flux.xls."

- Edit the "fault_rep_q.dat" by deleting characters at columns 1-5 and columns $7-8$ from data column of gridblock names. Those gridblocks with upper-case letters in their names at column 6 are fault blocks.

- Import "fault_rep_q.dat" to a working spreadsheet ("compu_fault_q.xls"). Use the Excel sort function to sort the data by the sixth character of the gridblock name.

- Delete the lines with lower-case letters at column 6 of the gridblock names.

- Sum the total flux column. Total fault flux is obtained as qfa.

- Its percentage is calculated by qfa/q*100 percent. 
Step 4: Calculate the total vertical flux in fractures and the matrix at water table

- Sum the columns of F-F flux and total flux in working file "total_bt_flux.xls" (Section C.2.3, Step 2). Total F-F flux (qf) and total flux (q) are obtained.

- Fracture flux percentage is computed by qf/q*100 percent.

- Matrix flux percentage is computed by (1-qf/q)*100 percent.

Step 5: Calculate the total flux in faults at the water table

Total flux in faults at the water table is calculated in the same way as the calculation of total flux in faults at the repository horizon, except the flux data is from "total_bt_flux.xls." See the working file "compu_bt_fault_q.xls" and "fault_bt_q. dat."

Table C.2.4-1 lists all the files used in this section (C.2.4).

Table C.2.4-1. Files Used in Calculation of Percentage of Flux in Fractures, Matrix, and Faults

\begin{tabular}{|c|l|}
\hline Input Files & total_rep_flux.xls, total_bt_flux.xls \\
\hline $\begin{array}{c}\text { Working Spreadsheet and } \\
\text { Output Files }\end{array}$ & $\begin{array}{l}\text { compu_frac_q_percentage.xls,fault_rep_q.dat, compu_fault_q.xls, } \\
\text { compu_bt_falut_q.xls, fault_bt_q.dat }\end{array}$ \\
\hline
\end{tabular}

NOTE: Attached CD (Files of Appendix C for model report MDL-NBS-HS-000006 REV 02):

II.2/files in Table II.2.4-1/.

\section{C2.5 EXTRACTION OF VERTICAL FLUX WITHIN THE REPOSITORY FOR CUMULATIVE FLUX DISTRIBUTION}

The list of gridblock names is needed for extracting the vertical flux through the repository zone from file "total_rep_q.dat." There are a total of 469 blocks within the repository zone; their names are listed in file "REPO_Z."

- Export flux data at repository horizon from the spreadsheet "total_rep_flux.xls" (C.2.2, Step 3) to a text file "total_rep_q.dat."

- Use Unix command:

$$
\text { fgrep-f REPO_Ztotal_rep_q.dat }>r e p \_z o n e \_q . d a t
$$

to extract fluxes through gridblocks within the repository zone.

- Import "rep_zone_q.dat" to a spreadsheet and copy the columns of fluxes to a working spreadsheet "preq_ma_rep.xls."

- Calculate flux frequency using the histogram function under the Data Analysis menu of Excel, and plot the frequency distribution using the Graph function. 
Table C.2.5-1 lists all of the files used in this section (C.2.4).

Table C.2.5-1. Files Used in Extracting Vertical Flux at the Repository Zone

\begin{tabular}{|c|l|}
\hline Input Files & REPO_Z, total_rep_flux.xls \\
\hline Working Files and Output Files & total_rep_q.dat, rep_zone_q.dat, preq_ma_rep.xls \\
\hline
\end{tabular}

NOTE: Attached CD (Files of Appendix C for model report MDL-NBS-HS-000006 REV02):

II.2/files in Table II.2.5-1/.

\section{C2.6 CUMULATIVE FLUX DISTRIBUTION}

- Copy all cumulative flux distribution frequency data to a working spreadsheet ("cumu_flux.xls", see Attached CD, Files of Appendix C for model report MDL-NBS-HS-000006 REV01: C.2/files in Section C.2.6) from the flux data of different climate scenario (e.g., "preq_ma_rep.xls").

- Plot the cumulative flux distribution curve using the Excel graph function.

\section{C3. POSTPROCESSING FLOW FIELDS IN SENSITIVITY ANALYSES OF SECTION 6.8}

\section{C3.1 FORMULATION}

The equation for calculating the relative changes of percolation flux is

$$
\mathrm{R}_{\mathrm{c}}=\frac{\mathrm{F}_{\mathrm{c}}-\mathrm{F}_{0}}{\mathrm{~F}_{0}}
$$

where $R_{c}$ is the relative change, $F_{c}$ is the percolation flux calculated in the sensitivity simulations, and $\mathrm{F}_{0}$ is the base-case percolation flux.

\section{C3.2 INPUT/OUTPUT FILES}

The percolation fluxes through the gridblocks within the repository area and the entire repository horizon are extracted from TOUGH 2 output files (Table C.3.2-1): 
Table C.3.2-1. Postprocessing Input Files (Simulation Output Files)

\begin{tabular}{|l|l|l|}
\hline \multicolumn{1}{|c|}{ File name } & \multicolumn{1}{c|}{ Description } & \multicolumn{1}{c|}{ DTN } \\
\hline flow9.dat_preq_mA.dat & Base-case flow field output & LB0304RDTRNSNS.001 \\
\hline flow9.dat_TSw & $\begin{array}{l}\text { Flow-field output for the case with reduced } \\
\text { gamma for TSw units }\end{array}$ & LB0304RDTRNSNS.001 \\
\hline flow9.dat_Urepo & $\begin{array}{l}\text { Flow-field output for the case with reduced } \\
\text { gamma for units below the repository (including } \\
\text { units at where the repository is located) }\end{array}$ & LB0304RDTRNSNS.001 \\
\hline REPO_ZONE.cell & Names of gridblocks within the repository area & LB03033DSSFF9I.001 \\
\hline REPO_layer.cell & $\begin{array}{l}\text { Names of gridblocks within the entire repository } \\
\text { horizon. }\end{array}$ & LB03033DSSFF9I.001 \\
\hline
\end{tabular}

TSw=Topopah Spring welded hydrogeologic unit

File REPO_ZONE.cell and REPO_layer.cell list the names of the gridblocks within the repository zone and within the entire repository horizon, respectively.

Data extraction and calculation produce the following final results and intermediate data files in which the matrix and fracture percolation flux through gridblocks within the repository area and the entire repository horizon are saved (Table C.3.2-2).

Table C.3.2-2. Working Files of Percolation Flux Data Extraction

\begin{tabular}{|l|l|}
\hline \multicolumn{1}{|c|}{ File name } & \multicolumn{1}{c|}{ Description } \\
\hline FLOW9_BM.out & Repository area matrix percolation flux, base-case. \\
\hline FLOW9_BF.out & Repository area fracture percolation flux, base-case. \\
\hline FLOW9BM.out & Matrix percolation flux of the entire repository horizon, base-case. \\
\hline FLOW9BF.out & $\begin{array}{l}\text { Fracture percolation flux of the entire repository horizon, } \\
\text { base-case. }\end{array}$ \\
\hline FLOW9_TM.out & $\begin{array}{l}\text { Matrix percolation flux of the repository area, the case with } \\
\text { reduced gamma for TSw units. }\end{array}$ \\
\hline FLOW9_TF.out & $\begin{array}{l}\text { Fracture percolation flux of the repository area, the case with } \\
\text { reduced gamma for TSw units. }\end{array}$ \\
\hline FLOW9TM.out & $\begin{array}{l}\text { Matrix percolation flux of the entire repository horizon, the case } \\
\text { with reduced gamma for TSw units. }\end{array}$ \\
\hline FLOW9TF.out & $\begin{array}{l}\text { Fracture percolation flux of the entire repository horizon, the case } \\
\text { with reduced gamma for TSw units. }\end{array}$ \\
\hline FLOW9_UM.out & $\begin{array}{l}\text { Matrix percolation flux of the repository area, the case reduced } \\
\text { gamma for units below the repository (including units at where the } \\
\text { repository is located). }\end{array}$ \\
\hline FLOW9_UF.out & $\begin{array}{l}\text { Fracture percolation flux of the repository area, the case reduced } \\
\text { gamma for units below the repository (including units at where the } \\
\text { repository is located). }\end{array}$ \\
\hline FLOW9UM.out & $\begin{array}{l}\text { Matrix percolation flux of entire repository horizon, the case } \\
\text { reduced gamma for units below the repository (including units at } \\
\text { where the repository is located). }\end{array}$ \\
\hline
\end{tabular}


Table C.3.2-2. Working Files of Percolation Flux Data Extraction (Continued)

\begin{tabular}{|l|l|}
\hline \multicolumn{1}{|c|}{ File name } & \multicolumn{1}{c|}{ Description } \\
\hline FLOW9UF.out & $\begin{array}{l}\text { Fracture percolation flux of the entire repository horizon, the case } \\
\text { reduced gamma for units below the repository (including units at } \\
\text { where the repository is located). }\end{array}$ \\
\hline Relative_changes_of_flux_in_repo.dat & $\begin{array}{l}\text { Matrix, fracture, and total percolation flux of the repository area for } \\
\text { base-case, the case reduced gamma for TSw units and the case } \\
\text { reduced gamma for units below the repository (including units at } \\
\text { where the repository is located), and the relative changes of the } \\
\text { flux due to gamma change. }\end{array}$ \\
\hline Relative_changes_of_flux_repo_layer.dat & $\begin{array}{l}\text { Matrix, fracture, and total percolation flux of the entire repository } \\
\text { horizon for base-case, the case reduced gamma for TSw units } \\
\text { and the case reduced gamma for units below the repository } \\
\text { (including units at where the repository is located), and the relative } \\
\text { changes of the flux due to gamma change. }\end{array}$ \\
\hline
\end{tabular}

NOTE: Attached CD (Files of Appendix C for model report MDL-NBS-HS-000006 REV02): II.3/files in Table II.3.2-2/.

TSw=Topopah Spring welded hydrogeologic unit

\section{C3.3 PROCEDURE FOR EXTRACTING AND CALCULATING THE RELATIVE CHANGES IN PERCOLATION FLUX}

The matrix and fracture percolation flux data are extracted by the following steps:

Step 1: Use the following Unix commands to extract the data related to the gridblocks listed in REPO_ZONE.cell and REPO_layer.cell, respectively:

fgrep -f REPO_ZONE.cell flow9.dat_preq_mA.dat $>a 1$

fgrep $-f$ REPO_layer.cell flow9.dat_preq_mA.dat $>a 2$

fgrep $-f$ REPO_ZONE.cell flow9.dat_TSw.dat $>a 3$

fgrep $-f$ REPO_layer.cell flow9.dat_TSw.dat $>a 4$

FGREP -F REPO_ZONE.CELL FLOW9.DAT_UREPO.DAT >A5

fgrep $-f$ REPO_layer.cell flow9.dat_Urepo.dat $>a 6$.

Before applying these commands, make sure that the first column (before the block names) in REPO_ZONE.cell and REPO_layer.cell is deleted if it is blank.

Step 2: Split the matrix data and fracture data as follows:

$$
\begin{aligned}
& \text { grep 'M0'al> FLOW9_BM.out } \\
& \text { grep 'F0' a1>FLOW9_BF.out } \\
& \text { GREP 'M0' A2> FLOW9BM.OUT } \\
& \text { grep 'F0' a2> FLOW9BF.out } \\
& \text { grep 'M0' a3> FLOW9_TM.out } \\
& \text { grep 'F0' a3>FLOW9_TF.out } \\
& \text { grep 'M0'a4>FLOW9TM.out } \\
& \text { grep 'F0' a4>FLOW9TF.out }
\end{aligned}
$$


grep 'MO' a5> FLOW9_UM.out

grep 'F0' a5> FLOW9_UF.out

grep 'MO' a6> FLOWŌUM.out

grep 'F0' a6> FLOW9UF.out.

Step 3: Extract the connection data by manually deleting the gridblock data rows:

Manually delete the gridblock data rows (should be the first 469 rows) from FLOW9_BM.out, FLOW9_BF.out, FLOW9_TM.out, FLOW9_TF.out, FLOW9_UM.out, and FLOW9_UF.out.

Manually delete the gridblock data rows (should be the first 2,042 rows) from FLOW9BM.out, FLOW9BF.out, FLOW9TM.out, FLOW9TF.out, FLOW9UM.out, and FLOW9UF.out. Then save the files.

Step 4: Manually delete data rows related to the fracture-matrix connections:

Manually delete data rows related to fracture-matrix and matrix-fracture connection data from files FLOW9_BM.out, FLOW9_BF.out, FLOW9_TM.out, FLOW9_TF.out, FLOW9_UM.out, FLOW9_UF.out (should be data rows 939-the end), and from data files: FLOW9BM.out, FLOW9BF.out, FLOW9TM.out, FLOW9TF.out, FLOW9UM.out, and FLOW9UF.out (should be data rows 4095-the end).

Step 5: Manually select one vertical connection related to each gridblock:

Manually select one vertical connection related to each gridblock by deleting the other connections related to the gridblock from files FLOW9_BM.out, FLOW9_BF.out, FLOW9BM.out, FLOW9BF.out, FLOW9_TM.out, FLOW9_TF.out, FLOW9TM.out, FLOW9TF.out, FLOW9_UM.out, FLOW9_UF.out, FLOW9UM.out, and FLOW9UF.out.

The selected vertical connections are constantly in the same direction (upward or downward).

Step 6: Combine the fracture and matrix percolation flux and calculate the relative changes of the percolation flux:

Copy the third data column from FLOW9_BM.out and FLOW9_BF.out, and paste them onto column $\mathrm{A}$ and column $\mathrm{B}$ in an Excel spread sheet. Use the standard function column $\mathrm{C}=$ column $\mathrm{A}+$ column $\mathrm{B}$ to combine the matrix and fracture percolation flux for gridblocks within the repository area (base case), where Column $\mathrm{C}$ is the total percolation flux of the gridblocks, column $\mathrm{A}$ is the fracture flux of the gridblocks, and column B is the matrix flux of the gridblocks. 
The same operation is also applied to the following couples of files:

FLOW9BM.out and FLOW9BF.out

FLOW9 TM.out and FLOW9 TF.out

FLOW9TM.out and FLOW9TF.out

FLOW9 UM.out and FLOW9 UF.out

FLOW9UM.out and FLOW9UF.out.

Doing this yields the percolation fluxes through the gridblocks within the repository area and the gridblocks within the entire repository horizon in the base-case, the case with reduced gamma for TSw units and the case with reduced gamma for units below the repository (including the repository units).

The data columns for percolation flux of gridblocks within the repository area are stored in the file called Relative_changes_of_flux_in_repo.dat. Data columns in the file are described in Table C.3.3-1.

Table C.3.3-1. Definition of Data Columns in the File Called Relative_changes_of_flux_in_repo.dat and Relative_changes_of_flux_repo_layer.dat

\begin{tabular}{|l|l|l|}
\hline \multicolumn{1}{|c|}{ Column Name } & \multicolumn{1}{|c|}{ Simulation } & \multicolumn{1}{c|}{ Content } \\
\hline Column A: base_F & Base case & Fracture fluxes \\
\hline Column B: base_M & Base case & Matrix fluxes \\
\hline Column C: base_total & Base case & Total fluxes \\
\hline Column D: TSw_F & Reduced gamma for TSw units & Fracture fluxes \\
\hline Column E: TSw_M & Reduced gamma for TSw units & Matrix fluxes \\
\hline Column F: Tsw_total & Reduced gamma for TSw units & Total fluxes \\
\hline $\begin{array}{l}\text { Column G: } \\
\text { TSw_re_change }\end{array}$ & Reduced gamma for TSw units & $\begin{array}{l}\text { Relative flux } \\
\text { changes }\end{array}$ \\
\hline Column H: Urepo_F & $\begin{array}{l}\text { Reduced gamma for units below the repository, } \\
\text { including the repository units }\end{array}$ & Fracture fluxes \\
\hline Column I: Urepo_M & $\begin{array}{l}\text { Reduced gamma for units below the repository, } \\
\text { including the repository units }\end{array}$ & Matrix fluxes \\
\hline Column J: Urepo_total & $\begin{array}{l}\text { Reduced gamma for units below the repository, } \\
\text { including the repository units }\end{array}$ & Total fluxes \\
\hline $\begin{array}{l}\text { Column K: } \\
\text { Urepo_re_change }\end{array}$ & $\begin{array}{l}\text { Reduced gamma for units below the repository, } \\
\text { including the repository units }\end{array}$ & $\begin{array}{l}\text { Relative flux } \\
\text { changes }\end{array}$ \\
\hline
\end{tabular}

TSw=Topopah Spring welded hydrogeologic unit

The relative changes of each gridblock within the repository area are calculated as follows:

$$
\text { column } \mathrm{G}=(\text { column } \mathrm{F}-\text { column } \mathrm{C}) / \text { column } \mathrm{C}
$$

where column $G$ is the relative change in the percolation flux caused by the changes of gamma value for TSw units, and

$$
\text { column } \mathrm{K}=(\text { column } \mathrm{J}-\text { column } \mathrm{C}) / \text { column } \mathrm{C}
$$


where column $\mathrm{K}$ is the relative change in the percolation flux caused by the changes of gamma value for units below the repository (including the unit where the repository is located).

The same operation is also applied to the extracted percolation flux of the gridblocks within the entire repository horizon, and the data are saved in the file called Relative_changes_of_flux_repo_layer.dat.

Step 7: Calculate the average changes as follows:

Use a standard function to calculate: $A=\frac{\sum \text { columnG }}{469}$ where column $G$, in file Relative_changes_of_flux_in_repo.dat, contains the relative changes in the percolation flux of every gridbock within the repository area (due to changes of gamma for TSw units), A is the average relative change of the percolation flux, and 469 is the total number of repository blocks.

The same operation is also applied to column $\mathrm{K}$. This yields the average of the relative changes in the percolation fluxes of the gridblocks within the repository area (in response to the gamma changes of units below the repository, including units where the repository is located).

The same operation is also applied to column $\mathrm{G}$ and column $\mathrm{K}$ in the file called Relative_changes_of_flux_repo_layer.dat. Note that the number of the gridblocks within the entire repository horizon is 2,042 . The average of the relative changes in the percolation-fluxes through the gridblocks within the entire repository horizon (in response to the gamma changes of TSw units and units below the repository, including the units at where the repository is located) are then obtained (Table C.3.3-2, file name table_relative_flux_change.doc).

Table C.3.3-2. Relative Changes of Percolation Flux in Response to the Changes of $\gamma$

\begin{tabular}{|l|l|l|}
\hline \multicolumn{1}{|c|}{ Simulation ID } & \multicolumn{1}{c|}{$\begin{array}{c}\text { Within the } \\
\text { Repository Area }\end{array}$} & $\begin{array}{c}\text { The Whole } \\
\text { Repository Layer }\end{array}$ \\
\hline TSw & $-4.478 \mathrm{E}-3$ & $-1.450 \mathrm{E}-2$ \\
\hline UnderRepo & $-5.655 \mathrm{E}-3$ & -0.016 \\
\hline
\end{tabular}

ID=identification; TSw=Topopah Spring welded hydrogeologic unit 


\section{C4. ATTACHED DATA FILES (CD: FILES OF APPENDIX C FOR MODEL REPORT, MDL-NBS-HS-000006 REV 01)}

This CD has been submitted to the Records Processing Center with the report and can be accessed through the Records Processing Center. All files mentioned above except for the files from the Technical Data Management System (submitted with DTN) are attached in the CD called "Files of Appendix C for model report MDL-NBS-HS-000006 REV 01." The files are organized in the $\mathrm{CD}$ in the order in which they appear above and are described below:

\section{CD label:}

\section{Files of Appendix C for Model Report MDL-NBS-HS-000006 REV 01}

\section{List of the Contents:}

The folder structure, file names, file size, and dates stored in the subfolders of the CD are described in the following table (Table C4-1) and screen captures.

Table C.4-1. List of the File Contents of the Attached CD, Files of Appendix C for Model Report MDL-NBS-HS-000006 REV 01

\begin{tabular}{|c|c|c|}
\hline Folder & Subfolder & Files \\
\hline \multirow[t]{5}{*}{ C. 1} & Files in Table C.1.1-1 & $\begin{array}{l}\text { modernu.dat } \\
\text { modernm.dat } \\
\text { modernl.dat } \\
\text { glacialm.dat }\end{array}$ \\
\hline & Files in Table C.1.2-1 & $\begin{array}{l}\text { modernugenprec.dat } \\
\text { modernugenrunon.dat } \\
\text { modernugenrunoff.dat } \\
\text { modernu_GENER_C }\end{array}$ \\
\hline & Files in Table C.1.2-2 & $\begin{array}{l}\text { genmmprec } \\
\text { genmmrunon } \\
\text { genmmrunoff } \\
\text { Gen_mm_Cl }\end{array}$ \\
\hline & Files In Table C.1.2-3 & $\begin{array}{l}\text { modernlgenprec } \\
\text { modernlgenrunon } \\
\text { modernlgenrunoff } \\
\text { modernl_GENER_Cl }\end{array}$ \\
\hline & Files In Table C.1.2-4 & $\begin{array}{l}\text { glacmgenprec } \\
\text { glacmgenrunon } \\
\text { glacmgenrunoff } \\
\text { glacm_GENER_Cl }\end{array}$ \\
\hline C.2 & Files in Table C.2.1-1 & $\begin{array}{l}P T N \_B O T . X Y \\
P T N . B O T \\
\text { TSW.TOP } \\
\text { CONN.area } \\
\text { tsw_top.conn } \\
\text { ptn_tsw.conn, } \\
\text { ptn_tsw_F.conn } \\
\text { ptn_tsw_M.conn } \\
\text { ptn_tsw_FM.conn } \\
\text { preq_m.inf } \\
\text { total_ptn_flux.xls } \\
\text { preq_mA_ptn.q } \\
\text { tem.conn }\end{array}$ \\
\hline
\end{tabular}


Table C.4-1. List of the File Contents of the Attached CD, Files of Appendix C for Model Report MDL-NBS-HS-000006 REV01 (Continued)

\begin{tabular}{|c|c|c|}
\hline Folder & Subfolder & Files \\
\hline C.2 (Continued) & Files in Table C.2.2-1 & $\begin{array}{l}\text { REPO.XY } \\
\text { REPO.DAT } \\
\text { REPO+1.DAT } \\
\text { CONN_rep.area } \\
\text { repo+1.conn } \\
\text { repo.conn } \\
\text { repo_M.conn } \\
\text { repo_F.conn } \\
\text { repo_FM.conn } \\
\text { tem.conn } \\
\text { total_rep_flux.xls } \\
\text { preq_mA rep.q }\end{array}$ \\
\hline \multirow[t]{4}{*}{ C.2 (Continued) } & Files in Table C.2.3-1 & $\begin{array}{l}\text { BT.XY } \\
\text { CONN_bt.area } \\
\text { bt.conn } \\
\text { bt_F.conn } \\
\text { bt_M.conn } \\
\text { total_bt_flux.xls } \\
\text { preq_mA_bt.q }\end{array}$ \\
\hline & Files in Table C.2.4-1 & $\begin{array}{l}\text { total_rep_flux.xls } \\
\text { total_bt_flux.xls } \\
\text { compu_frac_q_percentage.xls } \\
\text { fault_rep_q.dat } \\
\text { compu_faultq.xls } \\
\text { compu_bt_falut_q.xls } \\
\text { fault_bt_q.dat }\end{array}$ \\
\hline & Files in Table C.2.5-1 & $\begin{array}{l}\text { REPO_Z } \\
\text { total_rep_flux.xls } \\
\text { total_rep_q.dat } \\
\text { rep_zone_q.dat } \\
\text { preq_ma_rep.xls }\end{array}$ \\
\hline & File in Section C.2.6 & cumu_flux.xls \\
\hline C.3 & Files in Table C.3.2-2 & $\begin{array}{l}\text { FLOW9_BM.out } \\
\text { FLOW9_BF.out } \\
\text { FLOW9BM.out } \\
\text { FLOW9BF.out } \\
\text { FLOW9_TM.out } \\
\text { FLOW9_TF.out } \\
\text { FLOW9TM.out } \\
\text { FLOW9TF.out } \\
\text { FLOW9_UM.out } \\
\text { FLOW9_UF.out } \\
\text { FLOW9UM.out } \\
\text { FLOW9UF.out } \\
\text { Relative_changes_of_flux_in_repo.dat } \\
\text { Relative_changes_of_flux_repo_layer.dat }\end{array}$ \\
\hline
\end{tabular}




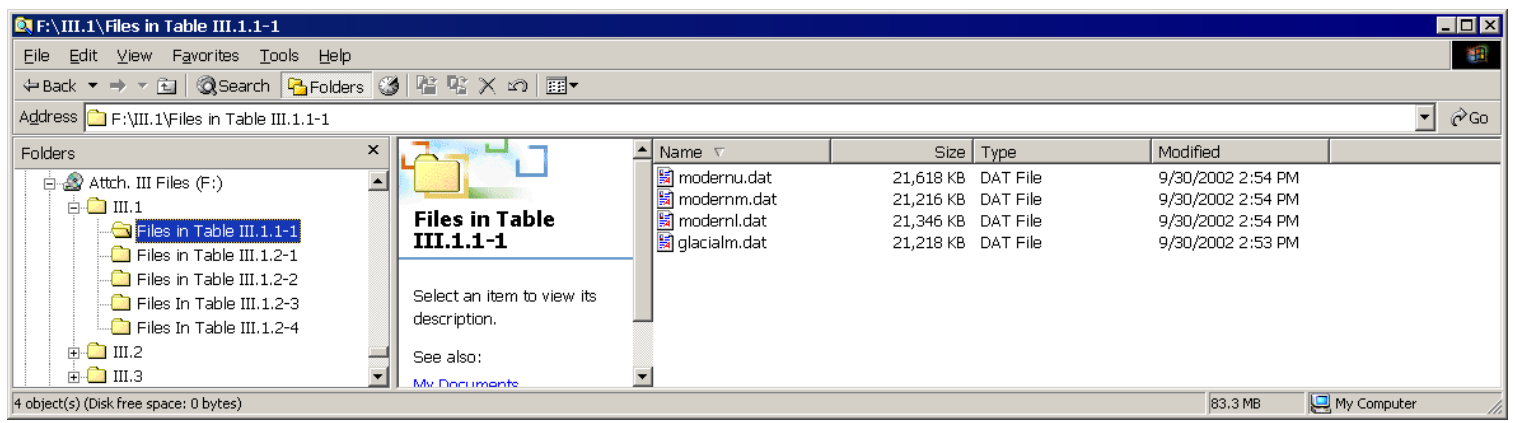

NOTE: In this and following screen pictures, "III" is used to represent "C" (e.g., Table III.1.1-1 denotes Table C.1.1-1).

Figure C.4-1 The File Names, File Size, and Dates Stored in the Subfolders of the CD for Data Files in Table C.1.1-1

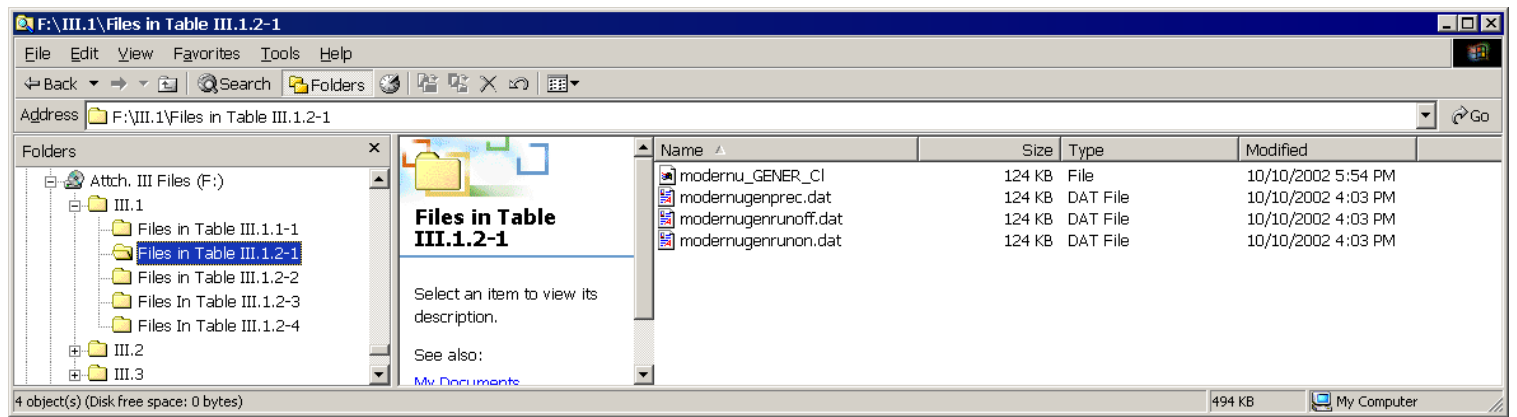

Figure C.4-2 The File Names, File Size, and Dates Stored in the Subfolders of the CD for Data Files in Table C.1.2-1

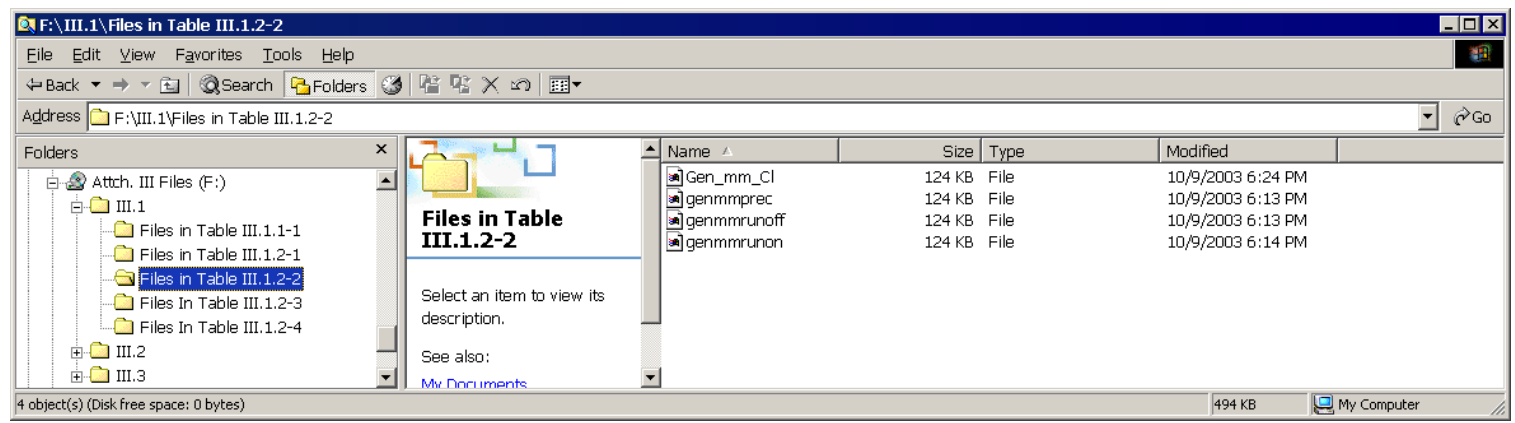

Figure C.4-3 The File Names, File Size, and Dates Stored in the Subfolders of the CD for Data Files in Table C.1.2-2 


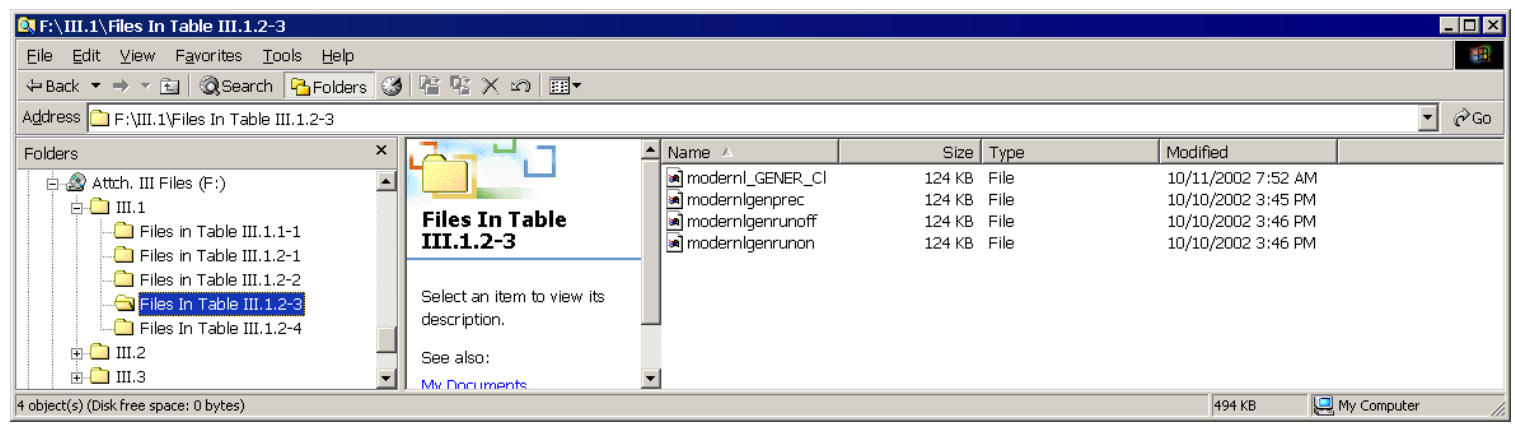

Figure C.4-4 The File Names, File Size, and Dates Stored in the Subfolders of the CD for Data Files in Table C.1.2-3

\begin{tabular}{|c|c|c|c|c|c|c|c|c|}
\hline \multicolumn{8}{|l|}{ QF:\III.1\Files In Table III.1.2-4 } & $-\sigma_{0}$ \\
\hline \multicolumn{8}{|c|}{ Eile Edit View Fagvorites Iools Help } & 畑 \\
\hline \multicolumn{9}{|c|}{ 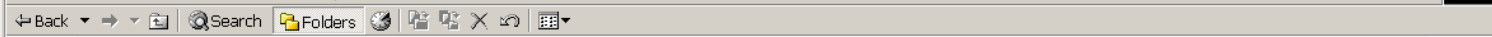 } \\
\hline \multicolumn{8}{|c|}{ Address 0 F:VIII.1YFiles In Table III.1.2-4 } & $\overrightarrow{G_{0}}$ \\
\hline \multicolumn{2}{|l|}{ Folders } & 7,47 & $\Delta$ Name 1 & Size & Type & Modified & & \\
\hline Attch. III Files (F:) & $\Delta$ & & 清glacm_GENER_Cl & $124 \mathrm{~KB}$ & File & $10 / 11 / 20037: 39 \mathrm{AM}$ & & \\
\hline 曰 III.1 & & riln $T=0$ & [-1) glacmgenprec & $124 \mathrm{~KB}$ & & 10/10/2002 4:04 PM & & \\
\hline \multirow{2}{*}{$\exists$ Files in Table III.1.1-1 } & & $\begin{array}{l}\text { Files In Table } \\
\text { III,1.2-4 }\end{array}$ & glacmgenrunoff & $124 \mathrm{~KB}$ & & 10/10/2002 4:04 PM & & \\
\hline & & $111.1 .2^{-4}$ & 国 glacmgenrunon & $124 \mathrm{~KB}$ & & 10/10/2002 4:04 PM & & \\
\hline $\begin{array}{l}\text { Files in Table III.1.2-1 } \\
\text { Files in Table III.1.2-2 }\end{array}$ & & & & & & & & \\
\hline $\begin{array}{l}\text { Files in Table III.1.2-2 } \\
\text { Files In Table III.1.2-3 }\end{array}$ & & $\begin{array}{l}\text { Select an item to view its } \\
\text { description. }\end{array}$ & - & & & & & \\
\hline \multirow{2}{*}{$\begin{array}{l}+9 \text { III.2 } \\
+7 \text { II.3 }\end{array}$} & - & See also: & & & & & & \\
\hline & 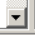 & Mur norruments. & \pm & & & & & \\
\hline 4 object(s) (Disk free space: 0 bytes) & & & & & & $494 \mathrm{~KB}$ & My Computer & \\
\hline
\end{tabular}

Figure C.4-5 The File Names, File Size, and Dates Stored in the Subfolders of the CD for Data Files in Table C.1.2-4

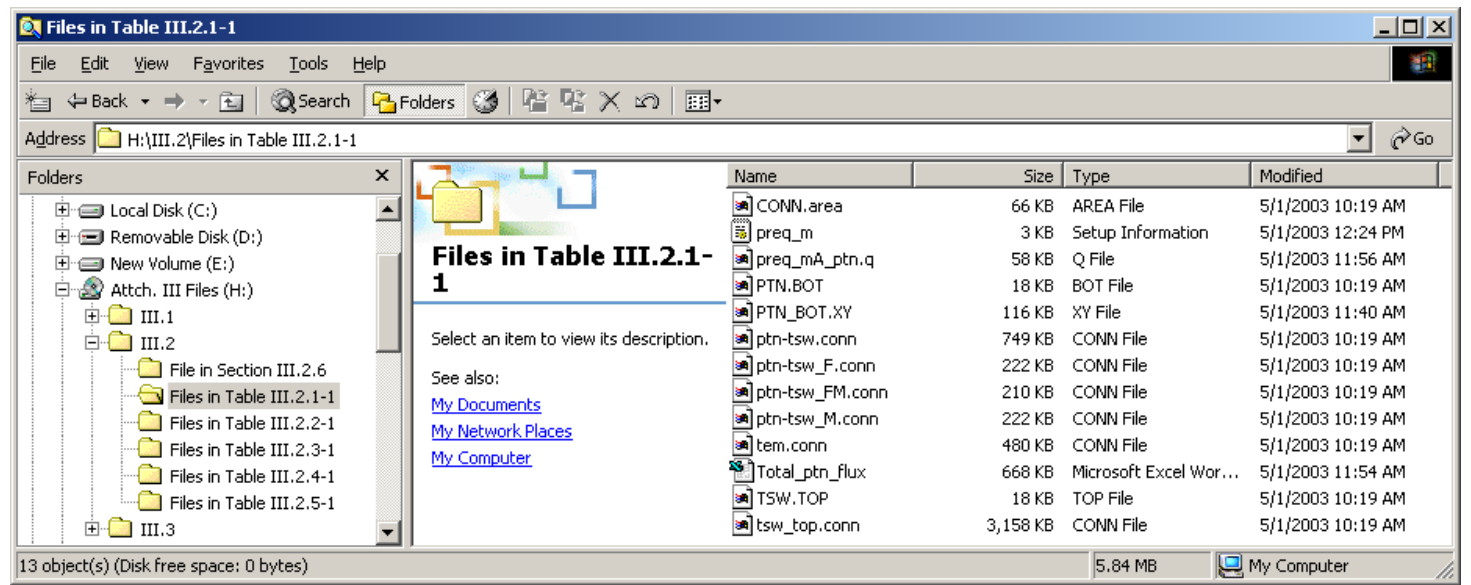

Figure C.4-6 The File Names, File Size, and Dates Stored in the Subfolders of the CD for Data Files in Table C.2.1-1 


\begin{tabular}{|c|c|c|c|c|c|c|}
\hline \multicolumn{4}{|l|}{ 2. Files in Table III.2.2-1 } & \multicolumn{3}{|r|}{$-\mid(\square) x$} \\
\hline \multicolumn{4}{|l|}{ File Édit View Favorites Iools Help } & \multicolumn{3}{|r|}{ 为 } \\
\hline \multicolumn{4}{|c|}{ 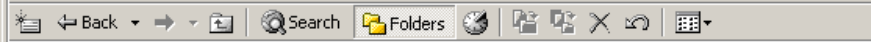 } & \multirow{2}{*}{\multicolumn{3}{|c|}{$\nabla$ ले०o }} \\
\hline \multicolumn{4}{|c|}{ Address $\bigcirc$ H:III.2!Files in Table III.2.2-1 } & & & \\
\hline Folders & $x$ & $21=$ & Name & \multicolumn{3}{|r|}{\begin{tabular}{|l|l} 
Modified \\
\end{tabular}} \\
\hline † & $\Delta$ & \multirow{2}{*}{$\begin{array}{l}\text { Files in Table III.2.2- } \\
1\end{array}$} & CONN_rep.area & $80 \mathrm{~KB}$ & AREA File & $5 / 1 / 20034: 13 \mathrm{PM}$ \\
\hline$\bigoplus$ Removable Disk (D:) & & & Dreq_mA_rep.q & $58 \mathrm{~KB}$ & Q File & $5 / 1 / 20034: 21 \mathrm{PM}$ \\
\hline † III.1 & & \multirow[b]{2}{*}{ Select an item to view its description. } & REPO.XY & $211 \mathrm{~KB}$ & XY File & $5 / 1 / 20034: 09 \mathrm{PM}$ \\
\hline \multicolumn{2}{|l|}{ III.2 } & & repo_F.conn & $222 \mathrm{~KB}$ & CONN File & 5/1/2003 3:44 PM \\
\hline$\square$ File in Section III.2.6 & & \multirow{4}{*}{$\begin{array}{l}\text { See also: } \\
\text { My Documents } \\
\text { My Network Places } \\
\text { My Computer }\end{array}$} & repo_FM.conn & $4 \mathrm{~KB}$ & CONN File & $5 / 1 / 20033: 44 \mathrm{PM}$ \\
\hline$\square$ Files in Table III.2.1-1 & & & repo_M.conn & $222 \mathrm{~KB}$ & CONN File & $5 / 1 / 20033: 44 \mathrm{PM}$ \\
\hline Files in Table III.2.2-1 & & & repo+1.conn & $3,266 \mathrm{~KB}$ & CONN File & 5/1/2003 3:44 PM \\
\hline$\square$ Files in Table III.2.3-1 & & & REPO+1 & $18 \mathrm{~KB}$ & DAT File & $5 / 1 / 20033: 44 \mathrm{PM}$ \\
\hline
\end{tabular}

Figure C.4-7 The File Names, File Size, and Dates Stored in the Subfolders of the CD for Data Files in Table C.2.2-1

\begin{tabular}{|c|c|c|c|c|c|c|c|c|}
\hline QNF:\III.2\Files in Table III.2.3-1 & & & & & & & & $-10 x$ \\
\hline Eile Edit Yiew Fagvorites Iools & & & & & & & & 头 \\
\hline$\leftrightarrow$ Back $\rightarrow \rightarrow$ i & 3 & 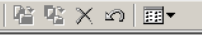 & & & & & & \\
\hline Address F:ViII.2YFiles in Table III.2.3 & & & & & & & $\exists$ & लेo \\
\hline Folders & $x$ & 4 & $\Delta$ Name $\triangle$ & Size & Type & Modified & & \\
\hline Attch. III Files (F:) & $\Delta$ & & ibt.conn & $627 \mathrm{~KB}$ & CONN File & 5/2/2003 9:05 AM & & \\
\hline † III.1 & & & BT.XY & $74 \mathrm{~KB}$ & XYFile & 11/20/2002 1:40 PM & & \\
\hline III.2 & & $\begin{array}{l}\text { Files in Table } \\
\text { III.2.3-1 }\end{array}$ & $\begin{array}{l}\text { bit_f.conn } \\
\text { b. M.conn }\end{array}$ & $\begin{array}{l}222 \mathrm{~KB} \\
222 \mathrm{~KB}\end{array}$ & CONN File & 5/2/20039:05 AM & & \\
\hline File in Section III.2.6 & & & CONN_bt.area & $\begin{array}{r}222 \mathrm{~KB} \\
66 \mathrm{~KB}\end{array}$ & AREA File & $11 / 20 / 20021: 38 \mathrm{PM}$ & & \\
\hline Files in Table III.2.1-1 & & & ispreq_ma_bt.q & $54 \mathrm{~KB}$ & Q File & 5/2/2003 9:17 AM & & \\
\hline $\begin{array}{l}9 \text { Files in Table III.2.2-1 } \\
\text { GFiles in Table III.2.3-1 }\end{array}$ & & $\begin{array}{l}\text { Select an item to view its } \\
\text { description. }\end{array}$ & Q total_bt_flux,xls & $593 \mathrm{~KB}$ & Microsoft Excel Wor... & $5 / 2 / 20032: 35 \mathrm{PM}$ & & \\
\hline & & & & & & & & \\
\hline $\begin{array}{l}\text { Files in Table III.2.4-1 } \\
\text { Files in Table III.2.5-1 }\end{array}$ & 1 & See also: & & & & & & \\
\hline 由 III.3 & $\vec{\nabla}$ & My Documents & -1 & & & & & \\
\hline 7 object(s) (Disk free space: 0 bytes) & & & & & & $1.81 \mathrm{MB}$ & (ㅁ⿺ㄴ My Computer & \\
\hline
\end{tabular}

Figure C.4-8 The File Names, File Size, and Dates Stored in the Subfolders of the CD for Data Files in Table C.2.3-1

\begin{tabular}{|c|c|c|c|c|c|c|c|c|}
\hline \multicolumn{9}{|l|}{ QF: \III.2\Files in Table III.2.4-1 } \\
\hline \multicolumn{9}{|c|}{ Eile Edit View Fagvorites Iools Help } \\
\hline \multicolumn{9}{|c|}{$\hookleftarrow$ Back $\rightarrow+$ a } \\
\hline \multicolumn{8}{|c|}{ Address 1 F:WIII.2YFiles in Table III.2.4-1 } & लGo \\
\hline \multicolumn{2}{|l|}{ Folders } & \multirow{2}{*}{$\overrightarrow{4}$ प } & $\triangle$ Name & Size & Type & Modified & & \\
\hline Attch. III Files (F:) & \multirow{3}{*}{\multicolumn{2}{|c|}{ Files in Table }} & \multirow{9}{*}{ 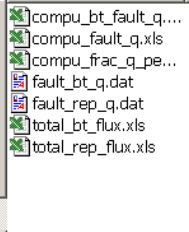 } & $41 \mathrm{~KB}$ & Microsoft Excel Wor... & $5 / 2 / 20032: 50 \mathrm{PM}$ & & \\
\hline †曰 III.1 & & & & $44 \mathrm{~KB}$ & Microsoft Excel Wor... & 5/2/2003 2:39 PM & & \\
\hline III.2 & & & & $232 \mathrm{~KB}$ & Microsoft Excel Wor... & $5 / 2 / 200310: 44 \mathrm{AM}$ & & \\
\hline File in Section III.2.6 & & \multirow{4}{*}{$\begin{array}{l}\text { Select an item to view its } \\
\text { description. }\end{array}$} & & $\begin{array}{l}52 \mathrm{~KB} \\
54 \mathrm{~KB}\end{array}$ & $\begin{array}{l}\text { DAT File } \\
\text { DAT File }\end{array}$ & $\begin{array}{l}\text { 5/6/2003 8:51 AM } \\
5 / 2 / 200311: 22 \text { AM }\end{array}$ & & \\
\hline Files in Table III.2.1-1 & & & & $593 \mathrm{~KB}$ & Microsoft Excel Wor... & $5 / 2 / 20032: 35 \mathrm{PM}$ & & \\
\hline Files in Table III.2.2-1 & & & & $649 \mathrm{~KB}$ & Microsoft Excel Wor... & 5/1/2003 4:22 PM & & \\
\hline Files in Table III.2.3-1 & & & & & & & & \\
\hline Files in Table III.2.4-1 & \multirow{2}{*}{\multicolumn{2}{|c|}{$\begin{array}{l}\text { See also: } \\
\text { My Documents }\end{array}$}} & & & & & & \\
\hline Files in Table III.2.5-1 & & & & & & & & \\
\hline \multicolumn{4}{|l|}{7 object(s) (Disk free space: 0 bytes) } & & & $162 \mathrm{MB}$ & [(口) Mv Comouter & \\
\hline
\end{tabular}

Figure C.4-9 The File Names, File Size, and Dates Stored in the Subfolders of the CD for Data Files in Table C.2.4-1 


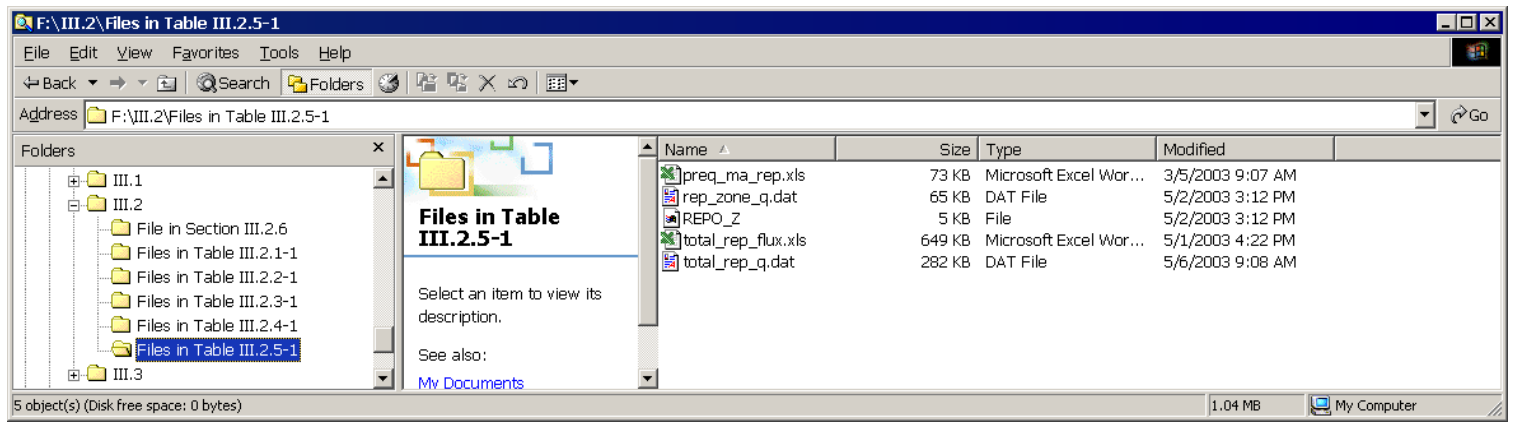

Figure C.4-10 The File Names, File Size, and Dates Stored in the Subfolders of the CD for Data Files in Table C.2.5-1

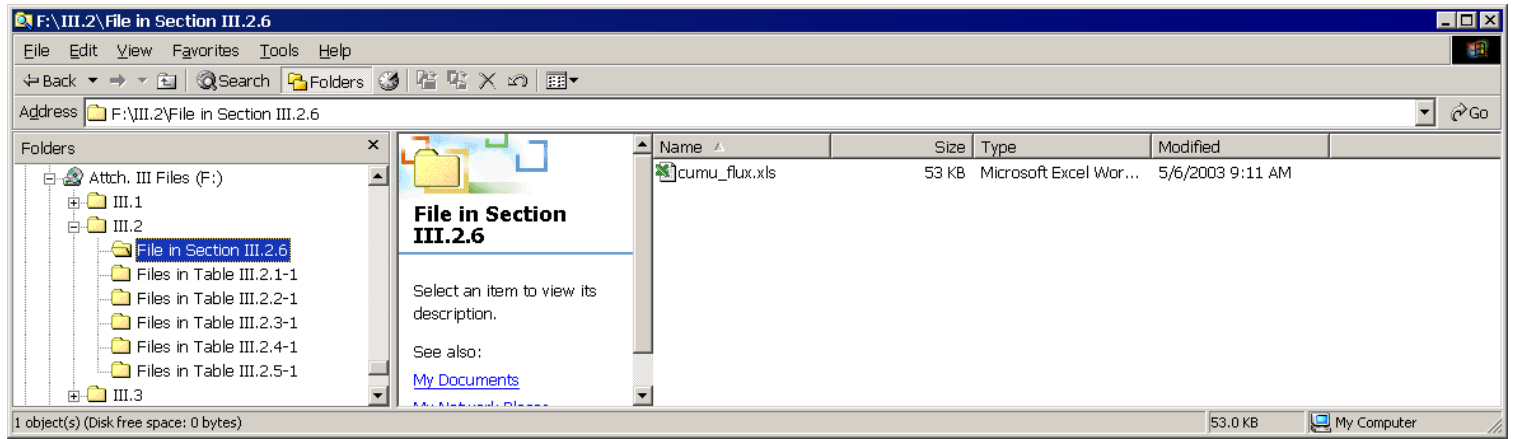

Figure C.4-11 The File Names, File Size, and Dates Stored in the Subfolders of the CD for Data Files in Table C2.6

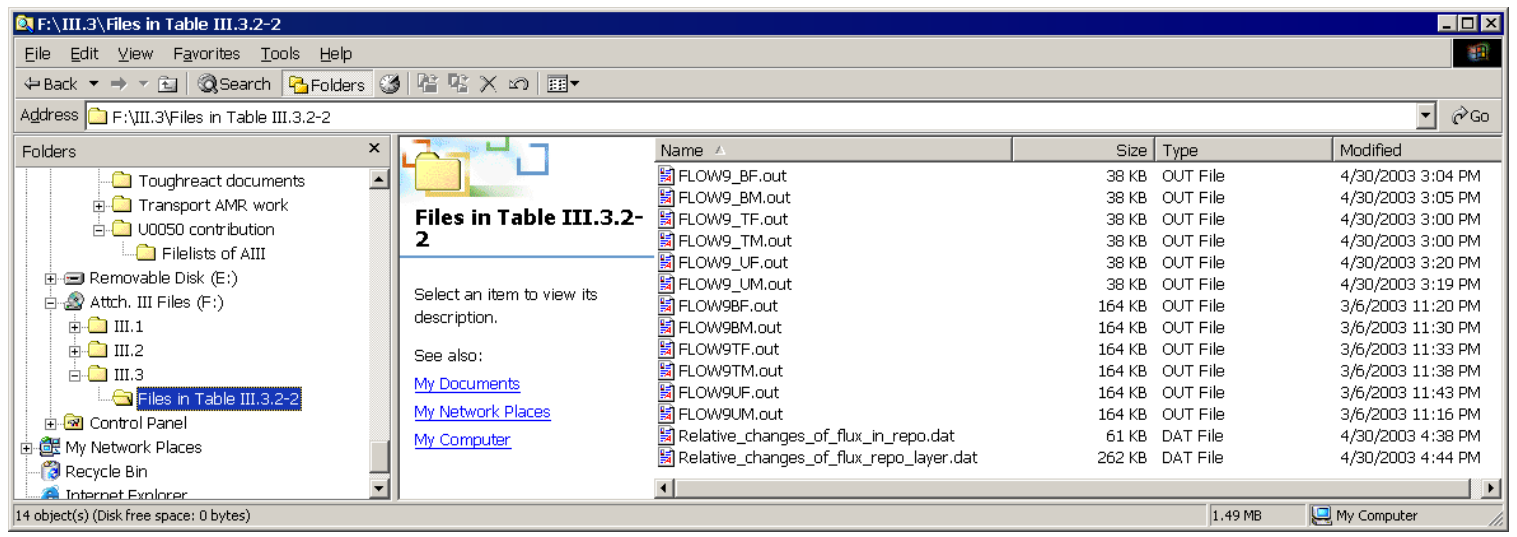

Figure C.4-12 The File Names, File Size, and Dates Stored in the Subfolders of the CD for Data Files in Table C.3.2-2 
APPENDIX D

PAINTBRUSH NONWELDED HYDROGEOLOGIC UNIT/TOPOPAH SPRING WELDED HYDROGEOLOGIC UNIT (PTN/TSW) FLUX AND FLOW-FIELD CONVERSION 


\section{D1. INTRODUCTION}

To use the simulated three-dimensional unsaturated zone percolation fluxes for other modeling studies, vertical percolation fluxes at PTn/TSw interfaces are extracted (procedures given in Appendix C.2.1) for the 18 flow fields of nine base cases and nine alternatives. The PTn/TSw percolation data for the nine base case flow fields are submitted to the Technical Data Management System with DTN: LB0302PTNTSW9I.001, while the PTn/TSw percolation data for the nine alternative flow fields are submitted with DTN: LB0305PTNTSW9I.001.

\section{D2. FLOW FIELD CONVERSION}

The 18 three-dimensional unsaturated zone flow fields are generated using a dual-permeability model with extra global fracture-matrix connections, which cannot be directly used by the Finite Element Heat and Mass code in total system performance assessment calculations. Therefore, the 18 TOUGH2 flow fields need to be converted using the routine flow-con V1.0 (STN: 10993-1.0-00; LBNL 2003 [DIRS 163162]), into flow fields on the dual-permeability mesh (mesh_2kb.dkm), which does not have the extra fracture-matrix connections. The output-flow field files of flow-con V1.0 (LBNL 2003 [DIRS 163162]) are then used as input files to the routine: T2FEHM V4.0 (STN: 10997-4.0-00, LBNL 2003 [DIRS 163161]), which converts TOUGH2 files in the format of "flow9.dat" into files readable to Finite Element Heat and Mass.

These converted 18 flow fields are submitted to the Technical Data Management System for the use of the Total System Performance Assessment for License Application with DTN: LB0305TSPA18FF.001. 


\section{INTENTIONALLY LEFT BLANK}




\section{APPENDIX E}

\section{MATHEMATICAL EQUATIONS}




\section{E1. EQUATIONS USED IN THIS UZ MODEL}

This appendix lists the equations used in this unsaturated zone flow model for unsaturated liquid flow under isothermal conditions. They include Darcy's law (Bear 1972 [DIRS 156269]), Richard's equation (Richards 1931 [DIRS 104252], van Genuchten model (1980 [DIRS 100610]), and active fracture model (Liu et al. 1998 [DIRS 105729]).

For fracture continuum or matrix continuum in the dual continuum system, the basic mass balance equations solved by TOUGH 2 can be written in the following form:

$$
\begin{aligned}
& \frac{d}{d t} \int_{V_{n}} M_{f} d V_{n}=\int_{\Gamma_{n}} \mathbf{F}_{f} \bullet \mathbf{n} d \Gamma_{n}+\int_{V_{n}}\left(q_{f}+q_{f m}\right) d V_{n} \\
& \frac{d}{d t} \int_{V_{n}} M_{m} d V_{n}=\int_{\Gamma_{n}} \mathbf{F}_{m} \bullet \mathbf{n} d \Gamma_{n}+\int_{V_{n}}\left(q_{m}-q_{f m}\right) d V_{n}
\end{aligned}
$$

where subscripts $f, m$ stand for fracture continuum and matrix continuum, respectively. (We denote $p=f$ or $m$ in the following discussion). The integration is over an arbitrary subdomain $\mathrm{V}_{n}$ of the flow system under study, which is bounded by the closed surface $\Gamma_{n}$. F denotes mass flux. $\mathbf{n}$ is a normal vector on surface element $\Gamma_{n}$, pointing inward into $\mathrm{V}_{n}$. The quantity $M$ represents mass per volume with $M_{p}=\phi_{p} S_{p} \rho$ (where $\phi_{p}$ is porosity, $S_{p}$ is saturation, and $\rho$ is liquid density). $q_{p}$ denotes sinks and sources per unit volume. $q_{f m}$ is fracture-matrix exchange flux per unit volume, a coupling term for describing fluid flow between the fracture and the matrix continuum. The $q_{f m}$ takes positive values if the exchange flux is from matrix to fracture, and negative if from fracture to matrix; see Equation E-13.

Darcy's law is expressed as:

$$
\mathrm{F}_{p}=\rho \mathrm{u}_{p}=-k_{p} \frac{k_{r p} \rho}{\mu}\left(\nabla P_{p}-\rho g\right)
$$

where $\mathbf{u}_{p}$ is the Darcy velocity (volume flux), $k_{p}$ is absolute permeability, $k_{r p}$ is relative permeability, $\mu$ is viscosity, $g$ is gravity acceleration constant, and $P_{p}$ is capillary pressure. In the Darcy's law written in this form, the variation of gas pressure is neglected. The capillary pressure is related to the gas pressure by the following equation:

$$
P_{p}=-P_{p g}+P_{p l}
$$

where $P_{p l}$ is water phase pressure and $P_{p g}$ is the gas pressure. 
By combining mass balance equations (Equations E-1 to E-2) with Darcy's law (Equation E-3), we have Richard's equation (Richards 1931 [DIRS 104252]; Pruess et al. 1999 [DIRS 160778], Equation A.17, p. 147) for both the fracture and matrix continuum described as:

$$
\begin{aligned}
& \frac{\partial}{\partial t} \theta_{f}=\operatorname{div}\left[K_{f} \nabla \psi_{f}\right]+q_{f}+q_{f m} \\
& \frac{\partial}{\partial t} \theta_{m}=\operatorname{div}\left[K_{m} \nabla \psi_{m}\right]+q_{m}-q_{f m}
\end{aligned}
$$

where $K_{p}=k_{p} k_{r p} \rho g / \mu$ is hydraulic conductivity, $\psi_{p}=z+P_{p} /(\rho g)$ is the total water potential, $z$ is elevation, and $\theta_{p}=\phi_{p} S_{p}$ is specific volumetric moisture content for fracture or matrix.

The water capillary pressure for the matrix continuum is described by the well-known van Genuchten relation (van Genuchten 1980 [DIRS 100610]), described as:

$$
P_{m}\left(S_{e m}\right)=\frac{1}{\alpha_{m}}\left[S_{e m}^{-1 / m_{m}}-1\right]^{1 / n_{m}}
$$

where $P_{m}$ is matrix capillary pressure; $\alpha_{m}\left(\mathrm{~Pa}^{-1}\right), n_{m}$, and $m_{m}=1-1 / n_{m}$ are van Genuchten parameters for the matrix continuum; and $S_{e m}$ is the effective matrix water saturation. Together with effective fracture water saturation, $S_{e f}$ discussed below:

$$
S_{e p}=\frac{S_{p}-S_{r p}}{1-S_{r p}}
$$

where $S_{p}$ is the water saturation of fracture or matrix and $S_{r p}$ is the residual fracture or matrix saturation.

The relative permeability $k_{r m}$ for the matrix continuum is given as:

$$
k_{r m}=S_{e m}{ }^{1 / 2}\left[1-\left\{1-S_{e m}{ }^{1 / m}\right\}^{m}\right]^{2}
$$

The water capillary pressure $P_{f}$ for the fracture continuum is determined by:

$$
P_{f}\left(S_{e f}\right)=\frac{1}{\alpha_{f}}\left[S_{e f}^{(\gamma-1) / m_{f}}-1\right]^{1 / n_{f}}
$$

where $S_{e f}$ is the effective water saturation of all connected fractures (defined in Equation E-8); $\alpha_{f}$ $\left(\mathrm{Pa}^{-1}\right), n_{f}$, and $m_{f}=1-1 / n_{f}$ are van Genuchten parameters for the fracture continuum; and $\gamma$ is the active fracture parameter (Liu et al. 1998 [DIRS 105729]). 
The relative permeability $k_{r f}$ for the fracture continuum is given as:

$$
k_{r f}=S_{e f}^{(1+\gamma) / 2}\left[1-\left\{1-S_{e f}^{(1-\gamma) / m_{f}}\right\}^{m_{f}}\right]^{2}
$$

In an unsaturated fracture network, the ratio of the interface area contributing to flow and transport between fractures and the matrix to the total interface area determined geometrically from the fracture network is called the fracture-matrix interface area reduction factor. The reduction factor $R$ is introduced by Liu et al. (1998 [DIRS 105729]) with the following expression:

$$
R \cong S_{e f}^{1+\gamma}
$$

The interface area between fracture continuum and matrix continuum, used to calculate $q_{f m}$, is multiplied by the factor $R$ in the active fracture model (Liu et al. 1998 [DIRS 105729]).

The fracture-matrix exchange flux introduced in Equations E-1 to E-2 can be approximated as quasi-steady, with the rate of matrix-fracture flux proportional to the difference in (local) average pressure:

$$
q_{f m} \propto R A \frac{\psi_{m}-\psi_{f}}{l_{f}}
$$

where $A$ is the total interface area between fracture-matrix (area/volume), and $l_{f}$ is the characteristic distance for fracture-matrix flow (BSC 2004 [DIRS 169855]). 


\section{INTENTIONALLY LEFT BLANK}


APPENDIX F

JUSTIFICATION OF THE USE OF PARAMETER SETS FOR MODELING FUTURE CLIMATE CONDITION 


\section{F1. PROPERTY CALIBRATION ON PRESENT-DAY CLIMATE CONDITIONS}

The consistency of rock-property sets obtained by model calibrations at different infiltration rate ranges is demonstrated by comparing calibrated rock property data from the drift-scale model under present-day climate conditions to the corresponding property data from models analyzing field infiltration tests. The consistency of two sets of rock property is defined as the difference between log values of the corresponding parameters and assuring that it is smaller than the standard deviation of the calibrated parameter distribution under the current climate condition. The field tests discussed below include the fault test and large plot test at Alcove 8-Niche 3 (also referred to as Niche 3107) (BSC 2004 [DIRS 170004]), and the infiltration test at Alcove 1 (Liu et al. 2003 [DIRS 162470]). These tests with high infiltration rates are expected to represent flow conditions under future climates. In addition, the uncertainties of models calibrated on current climate conditions to predict future flow fields will be addressed through theoretical discussion and analysis of data uncertainties.

Because hydrologic parameters are spatially scale-dependent, drift-scale model parameters and mountain-scale model parameters are used for different model scales. In the following discussion, emphasis is placed on the calibration of drift-scale model parameters because the field tests took place at scales corresponding to the drift scale. Uncertainties of the calibrated hydrologic parameters are also discussed. Calibration results will be used for evaluating the consistency of rock-property sets calibrated on different infiltration conditions (BSC 2004 [DIRS 169857]).

It is noted in the literature that large-scale effective permeabilities are generally larger than smaller-scale ones (Neuman 1994 [DIRS 105731]). An intuitive explanation for this scale-dependent behavior is that a larger observation scale, in an average sense, corresponds to a larger opportunity to encounter more permeable zones or paths when observations are made, which considerably increases values of the observed permeability. Although it is expected that estimated large-scale matrix permeabilities should also be larger than those measured on a core scale, no evidence exists to indicate that matrix properties should be very different on both the mountain and drift scales. Only fracture permeabilities for the mountain-scale property sets may demonstrate large differences from drift-scale data, whereas other properties are the same as or close to those in the corresponding drift-scale properties. Even though fracture permeabilities at drift-scale and mountain-scale may be different, we can find that the effects of changes in infiltration on the parameter for both scales are similar by comparing the calibration results (BSC 2004 [DIRS 169857], Tables 6-8 to 6-10 and 6-12). Only the calibration of drift-scale model parameters will be discussed.

\section{F1.1 CALIBRATION OF DRIFT-SCALE PARAMETERS}

One-dimensional inversion of the matrix-saturation and water-potential data is carried out for determining drift-scale parameters. The one-dimensional submodels correspond to surface-based boreholes from which saturation and water potential have been measured. In the calibration procedure, steady-state water flow is simulated simultaneously in all columns. Layer-averaged effective parameters are estimated (i.e., the same set of parameter values is used for each geologic layer in all columns, or each geological layer is considered to be homogeneous) (see Table 6.1-1). 
Three calibrated parameter sets are produced, one for each present-day infiltration case (lower-bound, mean, and upper-bound) (see Section 6.1.4). Uncalibrated rock-property data (BSC 2004 [DIRS 169857], Tables 6-2 and 6-3) are used as the initial guesses. Uncalibrated rock-property data here are defined as the layer averaged properties determined from field measurement data. The infiltration scenarios are key inputs to the unsaturated zone model because flow and transport are dependent on the amount of water infiltrating into the mountain. The base-case infiltration scenario gives the expected spatially varying infiltration rates over Yucca Mountain, and parameters calibrated using this scenario are the base-case parameter set. The upper- and lower-bound infiltration scenarios give bounds to the uncertainty of the base-case infiltration scenario. Parameters calibrated using the bounding scenarios are also provided; this gives the parameter sets that consider underestimation and overestimation of the present-day infiltration by the base-case scenario.

Model parameters to be estimated are matrix permeability $k_{M}$, matrix van Genuchten parameter $\alpha_{M}$ (van Genuchten 1980 [DIRS 100610], pp. 892 to 893), fracture van Genuchten parameters $\alpha_{F}$, and an active-fracture-model parameter $\gamma$ (Liu et al. 1998 [DIRS 105729]). Parameters are calibrated for model layers, though in some cases a common parameter value is estimated for groups of layers. Other parameters, such as fracture permeability $\left(k_{F}\right)$ and van Genuchten $m$ parameters for fracture $\left(m_{F}\right)$ and matrix $\left(m_{M}\right)$, are not changed in the calibration. These parameters may be insensitive to model performance or can be well constrained. A detailed discussion of sensitivities of rock properties to the relevant simulation conditions is provided by Bandurraga and Bodvarsson (1999 [DIRS 103949], Section 5).

The one-dimensional calibrated drift-scale parameter sets for the base-case (mean), upper-bound, and lower-bound infiltration scenarios can be found in Tables 6-8, 6-9, and 6-10 of the report by BSC (2004 [DIRS 169857]), respectively. By comparing the calibration results in these tables, it can be seen that the calibrated parameters do not vary much between different infiltration scenarios.

\section{F1.2 CALIBRATION OF FAULT PARAMETERS}

The fault property for the unsaturated zone is obtained by calibrating a two-dimensional model. Two-dimensional flow (vertical and east-west) is used to describe the flow patterns around Borehole USW UZ-7a for fault-property calibration. Data from USW UZ-7a are the most comprehensive with respect to faults. Liquid saturation, water potential, and pneumatic pressure data are available within the Ghost Dance fault zone from the surface to the upper layers of the Topopah Spring welded hydrogeologic unit (TSw). Because the data on faults are so limited, they are separated into four units/layers to reduce the number of parameters used to characterize the fault zones. The four units/layers are the Tiva Canyon welded hydrogeologic, Paintbrush nonwelded hydrogeologic, TSw, and Calico Hills nonwelded hydrogeologic/Crater Flat undifferentiated hydrogeologic units. Data for inversion are available for only the first three layers, so only the parameters of these layers are calibrated. Minimization of the inversion function is the only criterion used for a successful calibration. 
Fault properties to be calibrated are fracture properties, whereas matrix properties within fault zones are taken as the same as those in the adjacent nonfault zones (DTN: LB02081DKMGKID.001). Fracture permeabilities are fixed during the saturation and water potential inversion, and are the only parameters calibrated to the pneumatic data. Parameters to be calibrated against saturation and water potential data are fracture $\alpha$ and active-fracture-model parameter $\gamma$. The fault parameters calibrated for the base-case infiltration scenario are checked to determine whether they are satisfactory for the other two infiltration scenarios. The objective function values for the two infiltration scenarios, determined with forward runs of iTOUGH2 V5.0 (LBNL 2002 [DIRS 160106]), are even smaller than that for the base-case infiltration scenario. Therefore, a single calibrated fault parameter set is applied to all three infiltration scenarios. The calibrated fault parameter set is presented in Table F-1.

Table F-1. Calibrated Fault Parameters from Two-Dimensional Inversions of Saturation, Water Potential, and Pneumatic Data

\begin{tabular}{|c|c|c|c|c|}
\hline Model Layer & $\begin{array}{c}\boldsymbol{k}_{\boldsymbol{F}} \\
\left(\mathbf{m}^{2}\right)\end{array}$ & $\begin{array}{c}\boldsymbol{\alpha}_{\boldsymbol{F}} \\
(\mathbf{1} / \mathbf{P a})\end{array}$ & $\boldsymbol{m}_{\boldsymbol{F}}$ & $\boldsymbol{\gamma}$ \\
\hline tcwf & $9.77 \times 10^{-10}$ & $3.89 \times 10^{-3}$ & 0.633 & 0.40 \\
\hline ptnf & $1.00 \times 10^{-10}$ & $2.80 \times 10^{-3}$ & 0.633 & 0.11 \\
\hline tswf & $2.51 \times 10^{-11}$ & $3.16 \times 10^{-4}$ & 0.633 & 0.30 \\
\hline chnf & $3.70 \times 10^{-13}$ & $2.30 \times 10^{-3}$ & 0.633 & 0.30 \\
\hline
\end{tabular}

Source: BSC 2004 (DIRS 169857), Table 6-14.

NOTE: tcwf, ptnf, tswf, and chnf represent faults at the four units of Tiva Canyon welded hydrogeologic, Paintbrush nonwelded hydrogeologic, Topopah Spring welded hydrogeologic, and Calico Hills nonwelded hydrogeologic unit, respectively.

\section{F1.3 UNCERTAINTIES OF HYDROLOGIC PROPERTY DATA}

This section discusses sources and quantification of uncertainties for the calibrated parameters. The uncertainty information provided in this section will be used later to assess the uncertainty of using calibrated models (on current climate conditions) to forecast flow conditions under future climates.

\section{F1.3.1 Sources of Parameter Uncertainty}

A major source of parameter uncertainty is the conceptual model (e.g. different continuum approaches). Parameter calibration is based on the conceptual model for unsaturated zone flow and transport (CRWMS M\&O 2000 [DIRS 141187]). Model simplifications will also contribute to parameter uncertainty. For example, one-dimensional models are used for calibrating drift-scale property sets. As a result, lateral flow behavior in the unsaturated zone may not be captured by the property sets determined from one-dimensional models.

Infiltration-rate uncertainty also contributes to parameter uncertainty because flow processes in the unsaturated zone are largely determined by top boundary conditions. Using the three infiltration scenarios for the parameter calibration documented in this study captures this uncertainty (BSC 2004 [DIRS 169857]). Other sources of certainty may include field measurement uncertainty (e.g., the uncertainty in the measurement data of saturation, water potential, and pneumatic pressure). The measurement uncertainty is propagated to parameter 
uncertainty in the calibration procedure. Compared to other uncertainty sources, measurement uncertainty contributes little to the parameter uncertainty because measurement data can be constrained in a small range.

In addition, scale effects are a well-known source of parameter uncertainty. This is especially true for determination of the unsaturated zone model parameters. For example, matrix parameters are measured in the unsaturated zone at core scale on the order of several centimeters, whereas in the unsaturated zone flow and transport model, numerical gridblocks are on the order of a few meters to hundreds of meters. The scale-dependence of hydrologic parameters has been widely recognized in the scientific community (Neuman 1994 [DIRS 105731]). Although upscaling is partially considered in developing uncalibrated matrix properties, the calibrated matrix permeabilities are, on average, higher than uncalibrated ones for the three infiltration scenarios (Table F-2). The general increase in permeability with scale is consistent with reported findings (Neuman 1994 [DIRS 105731]). Consequently, the calibrated matrix $\alpha$ values are, on average, also higher than uncalibrated ones. A higher permeability is generally expected to correspond to a higher van Genuchten $\alpha$. For example, fracture $\alpha$ values are significantly higher than matrix values. The residuals for each layer (uncalibrated $\log x$ minus calibrated $\log x$, where $x=k_{M}$ or $\alpha_{M}$ ) were averaged to calculate the values shown in Table F-2. Because of the difference between measurement scale and modeling scale, uncalibrated properties are not directly measured, but are estimated values by averaging the measurements from the layer for the scales used in the unsaturated zone model. As a result, residuals cannot be used to evaluate the uncertainty as to the true parameter value, although they may be used to bound this uncertainty (as will be discussed below).

Table F-2. Average Residual for Calibrated Matrix Properties for Three Infiltration Scenarios

\begin{tabular}{|l|c|c|}
\hline & Residual for $\log \left(k_{M}\right)$ & Residual for $\log \left(\alpha_{M}\right)$ \\
\hline Base-case & -0.37 & -0.25 \\
\hline Upper bound & -0.65 & -0.17 \\
\hline Lower bound & -0.17 & -0.06 \\
\hline
\end{tabular}

Source: BSC 2004 (DIRS 169857), Table 6-15.

NOTE: The residual refers to an uncalibrated matrix property minus the corresponding calibrated property.

Calibrated properties are nonunique because of data limitation. For example, in drift-scale parameter calibration, 78 parameters are calibrated to about 300 data points. This is, therefore, a poorly constrained problem. Further complicating the calibrating process, many of the parameters are cross-correlated; that is, variations in two or more parameters may have the same effect on predicted system response. Because the inversion problem is poorly constrained, there is no well-defined global minimum in the objective function. Rather, there are likely to be many equivalent local minima. With respect to moisture and water potential data, any of these minima provide an equally good parameter set. To provide better initial values, uncalibrated parameters are used as initial guesses and prior information in most inversions.

Table F-3 shows the average absolute residuals, which refer to an absolute difference between uncalibrated property and its corresponding calibrated property for calibrated matrix properties for three infiltration scenarios. The absolute value of the residual is always positive, and the 
average absolute residual is, therefore, greater than the average residual, as shown in Table F-2. The average standard deviation of $\log \left(k_{M}\right)$ for uncalibrated matrix property sets is 1.61 . Average standard deviation (calculated by hand) for $\log \left(\alpha_{M}\right)$ for the uncalibrated matrix property set is 0.81 . The residual values for $\log \left(\alpha_{F}\right)$ are also given in Table F-3. They are close to or smaller than the average standard deviation of $\log \left(\alpha_{F}\right)$, which is 0.30 , determined from uncalibrated fracture property sets (BSC 2004 [DIRS 169857], Table 4-3).

Table F-3. Average Absolute Residual for Calibrated Matrix Properties for Three Infiltration Scenarios

\begin{tabular}{|l|c|c|c|}
\hline & $\begin{array}{c}\text { Average Absolute } \\
\text { Residual for } \log \left(k_{M}\right)\end{array}$ & $\begin{array}{c}\text { Average Absolute } \\
\text { Residual for } \log \left(\alpha_{M}\right)\end{array}$ & $\begin{array}{c}\text { Average Absolute } \\
\text { Residual for } \log \left(\alpha_{F}\right)\end{array}$ \\
\hline Base case & 0.75 & 0.44 & 0.41 \\
\hline Upper bound & 0.81 & 0.38 & 0.19 \\
\hline Lower bound & 0.74 & 0.43 & 0.28 \\
\hline
\end{tabular}

Source: BSC 2004 (DIRS 169857), Table 6-16.

NOTE: The absolute residual refers to an absolute difference between uncalibrated matrix property and the corresponding calibrated property.

\section{F1.3.2 Quantification of Parameter Uncertainty}

Quantifying parameter uncertainties is difficult to establish for the estimated parameter sets. In principle, these uncertainties could be evaluated either by Monte Carlo simulation or by linear error analysis, both of which are capabilities of iTOUGH2 V5.0 (LBNL 2002 [DIRS 160106]). Because of the large numbers of parameters and the high nonlinearity of the unsaturated flow process, the linear error analysis may not be reliable (Finsterle 1999 [DIRS 104367]). Alternatively, Monte Carlo-type methods (such as the bootstrap method) would be required. However, the large number of parameters make uncertainty analysis by Monte Carlo simulation prohibitively time consuming. Based on these considerations, the uncertainty information from prior information is believed to be more reliable (and practical) for determining uncertainties for the calibrated property sets.

In this study, parameter uncertainties (standard deviations) for the uncalibrated parameter sets are directly used for the calibrated parameter sets because these uncertainties are determined from measurements. The parameter uncertainty of the uncalibrated property sets is largely a result of small-scale spatial variability. Because the degree of spatial variability decreases with scale (spatial variability is averaged at a large scale), it is likely to provide upper limits of uncertainty on calibrated parameters for the given conceptual model and infiltration rates (BSC 2004 [DIRS 169857]).

Table F-4 gives the uncertainties of the parameters $k_{M}, \alpha_{M}, k_{F}$, and $\alpha_{F}$ (BSC 2004 [DIRS 169857], Table 6-17). When a $\log \left(k_{F}\right)$ uncertainty is not available in these two tables (BSC 2004 [DIRS 169857]) for a model layer, the largest value among the uncertainties (standard deviations) in all of the layers for which uncertainty values are available is used. Uncertainties for $\log \left(\alpha_{M}\right)$ and $\log \left(\alpha_{F}\right)$ are approximated from uncertainty values of the corresponding permeability. Uncertainties of the active-fracture-model parameter $\gamma$ are difficult to obtain here and have not been calculated because prior information for $\gamma$ is not available. A sensitivity analysis on the uncertainties of $\gamma$ is provided in this model report. In addition, no 
information is available for quantifying uncertainties for $m_{F}$ that are not calibrated parameters. Flow model results are not sensitive to neither $\gamma$ nor $m_{F}$, nor can they be constrained in a small range (Section 6.8.1). Therefore, uncertainty of these two parameters may have limited influence on model results.

Table F-4 also shows estimated uncertainties for calibrated fault properties. Because fault properties are calibrated with limited data points, the parameter uncertainties are expected to be relatively large. For each parameter type, the largest parameter uncertainty within the corresponding hydrogeologic unit for the nonfault property set is used as the corresponding fault parameter uncertainty. The fault property set does not include matrix parameters. Use of large uncertainty for a parameter may lead to relatively large uncertainty of model results, and provide conservative ranges of simulation results. This treatment should not have adverse effects on risk estimation for the repository.

Table F-4. Uncertainties of Calibrated Parameters

\begin{tabular}{|c|c|c|c|c|}
\hline \multirow[b]{2}{*}{ Model Layer } & \multicolumn{2}{|c|}{ Matrix Property } & \multicolumn{2}{|c|}{ Fracture Property } \\
\hline & $\log \left(k_{M}\right)$ & $\log \left(\alpha_{M}\right)$ & $\log \left(k_{F}\right)$ & $\log \left(\alpha_{F}\right)$ \\
\hline tcw11 & 0.47 & 0.24 & 1.15 & 0.58 \\
\hline tcw12 & 2.74 & 1.37 & 0.78 & 0.39 \\
\hline tcw13 & 2.38 & 1.19 & 1.15 & 0.58 \\
\hline ptn21 & 2.05 & 1.03 & 0.88 & 0.44 \\
\hline ptn22 & 1.41 & 0.71 & 0.20 & 0.10 \\
\hline ptn23 & 0.64 & 0.32 & 0.20 & 0.10 \\
\hline ptn24 & 1.09 & 0.55 & 1.15 & 0.58 \\
\hline ptn25 & 0.39 & 0.20 & 0.10 & 0.05 \\
\hline ptn26 & 1.12 & 0.56 & 1.15 & 0.58 \\
\hline tsw31 & 3.02 & 1.51 & 1.15 & 0.58 \\
\hline tsw32 & 0.94 & 0.47 & 0.66 & 0.33 \\
\hline tsw33 & 1.61 & 0.81 & 0.61 & 0.31 \\
\hline tsw34 & 0.97 & 0.49 & 0.47 & 0.24 \\
\hline tsw35 & 1.65 & 0.83 & 0.75 & 0.38 \\
\hline tsw36 & 3.67 & 1.84 & 0.54 & 0.27 \\
\hline tsw37 & 3.67 & 1.84 & 0.28 & 0.14 \\
\hline tsw38 & 1.57 & 0.79 & 1.15 & 0.58 \\
\hline tswz (zeolitic portion of tsw39) & 2.74 & 1.37 & 1.15 & 0.58 \\
\hline tswv (vitric portion of tsw39) & 1.38 & 0.69 & a & a \\
\hline $\operatorname{ch} 1 z$ & 2.74 & 1.37 & 1.15 & 0.58 \\
\hline $\operatorname{ch} 1 \mathrm{v}$ & 1.11 & 0.56 & ${ }^{a}$ & ${ }^{a}$ \\
\hline $\operatorname{ch} 2 v$ & 1.62 & 0.81 & a & a \\
\hline $\operatorname{ch} 3 v$ & 1.62 & 0.81 & $\mathrm{a}$ & $\mathrm{a}$ \\
\hline $\operatorname{ch} 4 v$ & 1.62 & 0.81 & a & a \\
\hline $\operatorname{ch} 5 v$ & 1.62 & 0.81 & $\mathrm{a}$ & $\mathrm{a}$ \\
\hline ch6v & 1.11 & 0.56 & a & a \\
\hline
\end{tabular}


Table F-4. Uncertainties of Calibrated Parameters (Continued)

\begin{tabular}{|c|c|c|c|c|}
\hline \multirow[b]{2}{*}{ Model Layer } & \multicolumn{2}{|c|}{ Matrix Property } & \multicolumn{2}{|c|}{ Fracture Property } \\
\hline & $\log \left(k_{M}\right)$ & $\log \left(\alpha_{M}\right)$ & $\log \left(k_{F}\right)$ & $\log \left(\alpha_{F}\right)$ \\
\hline $\operatorname{ch} 2 z$ & 0.91 & 0.46 & 1.15 & 0.58 \\
\hline $\operatorname{ch} 3 z$ & 0.91 & 0.46 & 1.15 & 0.58 \\
\hline $\operatorname{ch} 4 \mathrm{z}$ & 0.91 & 0.46 & 1.15 & 0.58 \\
\hline $\operatorname{ch} 5 z$ & 0.91 & 0.46 & 1.15 & 0.58 \\
\hline ch6z & 2.05 & 1.03 & 1.15 & 0.58 \\
\hline pp4 & 2.74 & 1.37 & 1.15 & 0.58 \\
\hline pp3 & 0.75 & 0.38 & 1.15 & 0.58 \\
\hline pp2 & 1.18 & 0.59 & 1.15 & 0.58 \\
\hline pp1 & 1.52 & 0.76 & 1.15 & 0.58 \\
\hline bf3 & 1.64 & 0.82 & 1.15 & 0.58 \\
\hline bf2 & 1.52 & 0.76 & 1.15 & 0.58 \\
\hline tcwf & $\mathrm{b}$ & $\mathrm{b}$ & 1.15 & 0.58 \\
\hline ptnf & b & b & 1.15 & 0.58 \\
\hline tswf & $\mathrm{b}$ & $\mathrm{b}$ & 1.15 & 0.58 \\
\hline chnf & b & $\mathrm{b}$ & 1.15 & 0.58 \\
\hline
\end{tabular}

Source: BSC 2004 (DIRS 169857), Table 6-17.

a The calibrated properties conceptual model does not include fractures in these layers.

b Fault property set does not include matrix properties.

The propagation of uncertainty in model calibration is addressed in this study. The uncertainty data for measurements are used as inputs into inversions. The uncertainty in boundary conditions is reflected by developing property sets for different infiltration scenarios. The uncertainty in prior information has been used for characterizing uncertainties for calibrated properties.

\section{F2. PROPERTY CALIBRATION ON HIGHER INFILTRATION CONDITIONS}

The field tests at Alcove 8 -Niche 3 and Alcove 1 conducted at high infiltration rates are expected to encompass flow behavior representative of future climates. The numerical models developed for these tests are calibrated based on the high infiltration rates. The calibrated rock properties for these models are compared to rock properties from the calibrated drift-scale model (BSC 2004 [DIRS 169857]). If these two data sets are consistent, one can conclude that the models calibrated based on the current climate conditions can be used for forecasting flow in future climate conditions.

\section{F2.1 ALCOVE 8-NICHE 3 TESTS}

The information in this section is based on In Situ Field Testing of Processes (BSC 2004 [DIRS 170004]) for the Alcove 8-Niche 3 tests (Section 7.6) and "Modeling Flow and Transport in Unsaturated Fractured Rock: An Evaluation of the Continuum Approach," Journal of Contaminant (Liu et al. 2003 [DIRS 162470]) for the Alcove 1 test. 
Two types of tests were conducted at the site. One is a fault test and the other is a large-plot test. Alcove 8 has been excavated for liquid releases through a fault (fault tests) and a network of fractures (large-plot tests). Niche 3 serves as the site for monitoring wetting-front migration of seepage originating from water applied to either the fault or infiltration plot in Alcove 8, and for the collection and subsequent analysis of tracer concentrations of the seeping water. Alcove 8 is located within the upper lithophysal zone of the TSw. Niche 3 is located in the middle nonlithophysal zone of the TSw.

Both fault tests and large-plot tests were planned to include two phases involving water release with and without tracers. Phase I corresponds to an experimental condition characterized by positive water pressure head $(2 \mathrm{~cm})$ at the infiltration plots. In this case, the fault or fracture network is saturated (at least near the infiltration plots). Phase II corresponds to an experimental condition characterized by much smaller infiltration rates (or more negative water pressure heads) than phase I. The planned phase II fault tests were not performed due to time constraints and conflicting experimental test schedules. Results of phase II testing (large-plot) are not yet available, and, subsequently, are not used in the calibration.

Water was applied at infiltration plots in Alcove 8. For the fault tests, initially, the application area was over a small section of the fault. This was increased from $0.3 \mathrm{~m}$ to $1.0 \mathrm{~m}$ and then to $5.15 \mathrm{~m}$. Water was first released from the smallest injection zone, which is a cylinder $0.30 \mathrm{~cm}$ in diameter. During the second release, the cylinder zone was replaced with a box that measured $70 \mathrm{~cm} \times 70 \mathrm{~cm}$. For the third set of water releases (along $5.15 \mathrm{~m}$ ), the fault was divided into four sections with each section serving as a separate release point. In each of these applications, water along the release zone was ponded to a head of about $0.02 \mathrm{~m}$.

The large-plot tests involve the release of water (without and with tracers) under both ponded and nonponded conditions in a $3 \mathrm{~m} \times 4 \mathrm{~m}$ plot. The infiltration zone was divided into 12 sections each $1 \times 1 \mathrm{~m}$ (Figure F-1). Observations from this phase of testing include the seepage rates measured at Niche 3. Infiltration was initiated in the large-plot on the floor of Alcove 8 by maintaining an approximately $2 \mathrm{~cm}$ head of ponded water (for phase I). The amount of water necessary to maintain the $2 \mathrm{~cm}$ of ponding was recorded, and, thus, the infiltration rates (liters/day) over time were also known for all plots (1-12 in Figure F-1) (BSC 2004 [DIRS 170004], Section 6.12). 


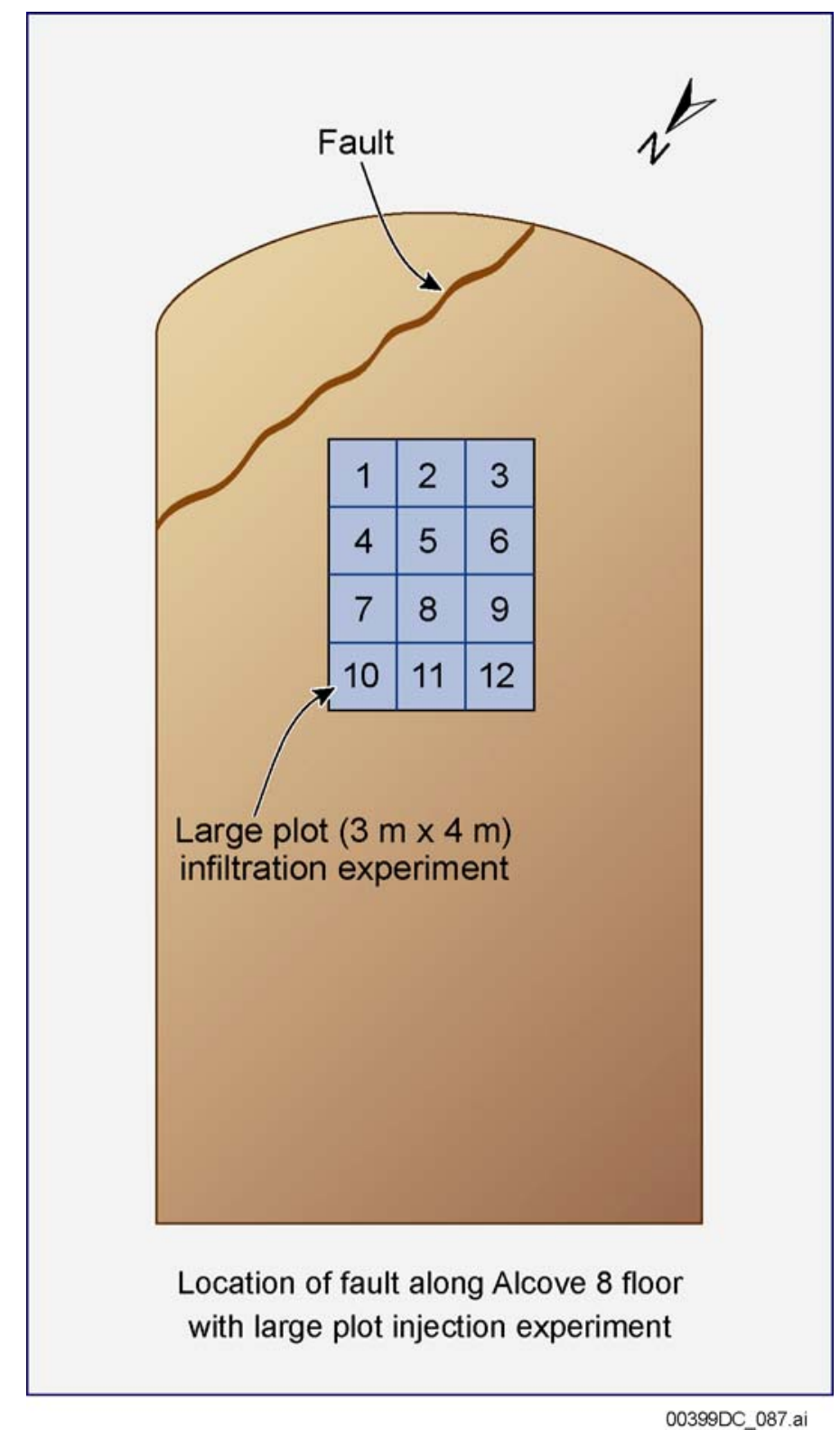

Source: BSC 2004 (DIRS 170004), Figure 6.12.4-1.

NOTE: Plot numbers are added here.

Figure F-1. Illustration of the Infiltration Zones along the Floor of Alcove 8 Large-Plot Test with the Numbers Identifying the 12 Infiltration Subplots

\section{F2.2 MODEL ANALYSIS OF THE FAULT TEST AT ALCOVE 8-NICHE 3}

Model Development-A numerical model was developed to simulate the fault test. Simulation results are compared to the relevant field observations. This model is calibrated to the higher infiltration rates used in the field test. Detailed discussion of the numerical model development was presented at Section 7.6.2. 
Model Calibration Based on Higher Infiltration-The numerical model was calibrated against the seepage and water-travel-velocity data to obtain the calibrated rock properties and the corresponding water flow field. Calibration procedure and results were presented at Section 7.6.3.

\section{F2.3 MODEL ANALYSIS OF THE LARGE PLOT TEST AT ALCOVE 8-NICHE 3}

Model Development-A numerical model was developed to simulate and better understand results from the large-plot tests (phase I). The seepage and infiltration-rate data were used to calibrate the model to obtain the site-specific rock properties. A three-dimensional numerical grid was constructed for modeling the large-plot tests (Figure F-2). The top of the grid corresponds to the floor of Alcove 8, where infiltration occurred. The 12 infiltration plots and the projected outline boundary of Niche 3 ceiling (under which seepage trays were installed) are also shown on the top of the grid in Figure F-2. Small grid sizes were used above the niche ceiling and near the interface between model layers tsw33 and tsw34 to capture diverted water flow around the niche and rock property transition at the interface between model layers. The dips of the contact between tsw33 and tsw34 are ignored because flow in fractures is expected to occur mainly in the vertical direction. For simplicity, the niche ceiling was approximated as a flat surface. To capture the transient flow and transport behavior, the multiple interacting continua model (Pruess and Narasimhan 1985 [DIRS 101707]) was used, a model that can handle steep pressure and concentration gradients. In the numerical grid shown in Figure F-2, each gridblock includes a fracture element and five matrix elements.

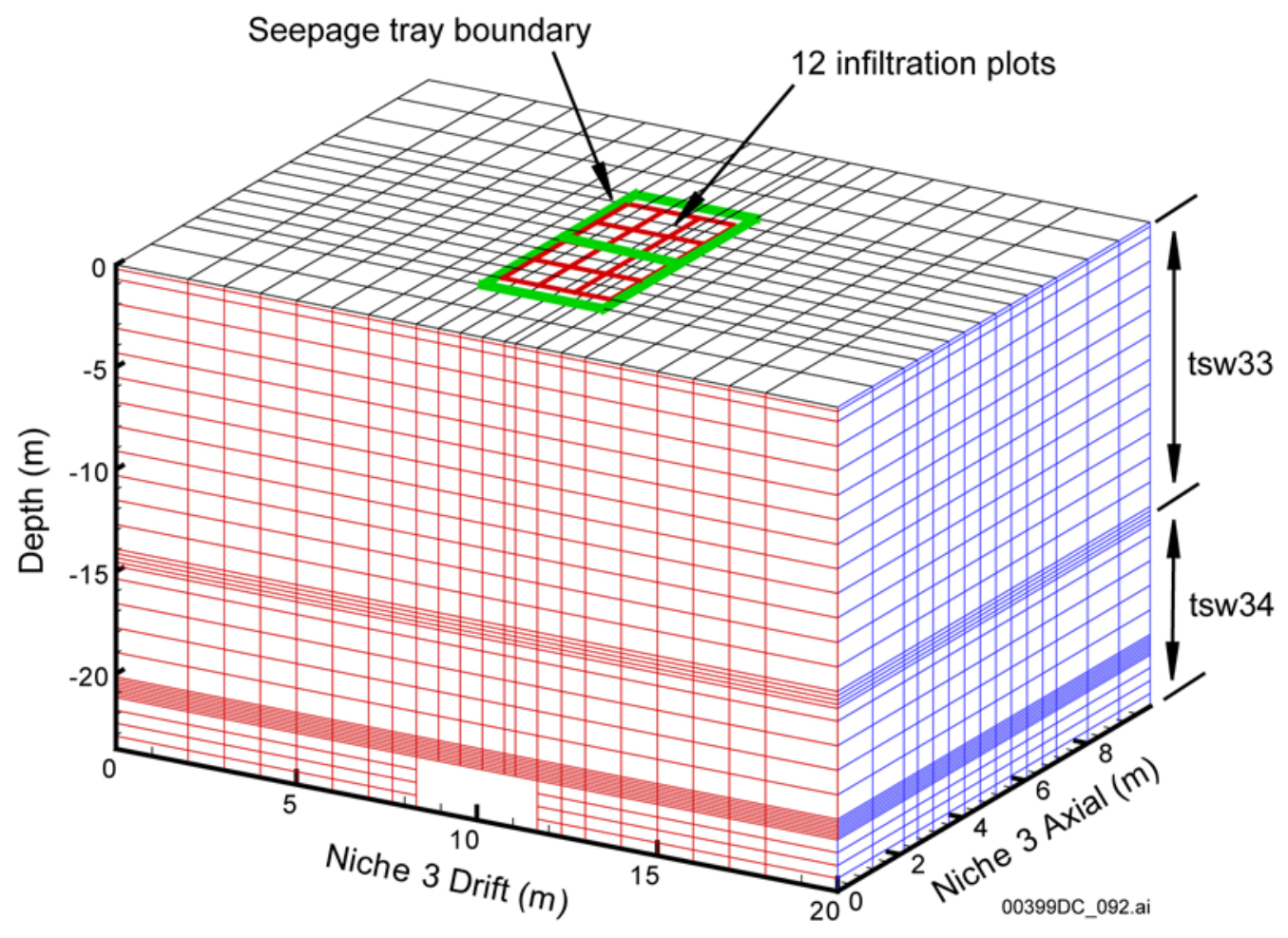

Source: DTN: LB0312A8N3MDLG.001 (DIRS 169761).

Figure F-2. Three-Dimensional Numerical Grids for the Large-Plot Tests 
To handle the spatial variabilities observed from the infiltration rates in Alcove 8 and seepage rates in Niche 3, heterogeneous distributions of fracture properties within a given model layer were considered in the three-dimensional model. Within a model layer, fractured rock is divided into a number of vertical columns within zones below the infiltration plots (for tsw33) or above the ceiling of Niche 3 (for tsw34). Therefore, there are two sets of vertical columns that are located in tsw33 and tsw34, respectively. Each column in the upper layer (tsw33) corresponds to an infiltration plot, and each column in the lower layer (tsw34) corresponds to one seepage tray. The rest of the rock was considered to have homogeneous property distributions within each model layer. Generally, the homogeneous property distributions were also used for each column.

Considerable temporal variability in the infiltration rate was observed during the large-plot tests, although a constant water-pressure head $(2 \mathrm{~cm})$ was applied at the infiltration plot. This may result from in-filled materials within the fractures just below the infiltration plots. In other words, the effective permeability of fractures just below the plot changed with time, although fracture properties may not change for zones away from the infiltration plots. Given these considerations, infiltration rates (that are both spatially and temporally variable, based on Figure F-3) at Alcove 8, rather than the pressure head, were used as the boundary condition at the large infiltration plot. The side boundary corresponds to zero-flow conditions (in the direction perpendicular to the simulation domain). The niche wall boundary was again modeled by a zero-capillary-pressure condition, representing capillary barrier effects. The bottom boundary corresponds to free drainage conditions. Under ambient conditions, matrix liquid saturation is 0.72 for tsw33 and 0.85 for tsw34 (Flint 1998 [DIRS 100033], p. 44, Table 6-4). Because of the disturbance of nearby fault tests, the actual matrix saturations are expected to be higher than these values. In the model, a value of 1.0 averaged with the saturation value reported by Flint (1998 [DIRS 100033], p. 44, Table 7) was used as the initial matrix saturation value for each model layer. Because of this approximation, a larger degree of uncertainty is expected to exist for initial conditions assigned in the model. Other initial conditions for the rock mass within the model domain are that the rock is solute-free and has a small water saturation $\left(1.05 \times 10^{-2}\right)$ in fractures. 

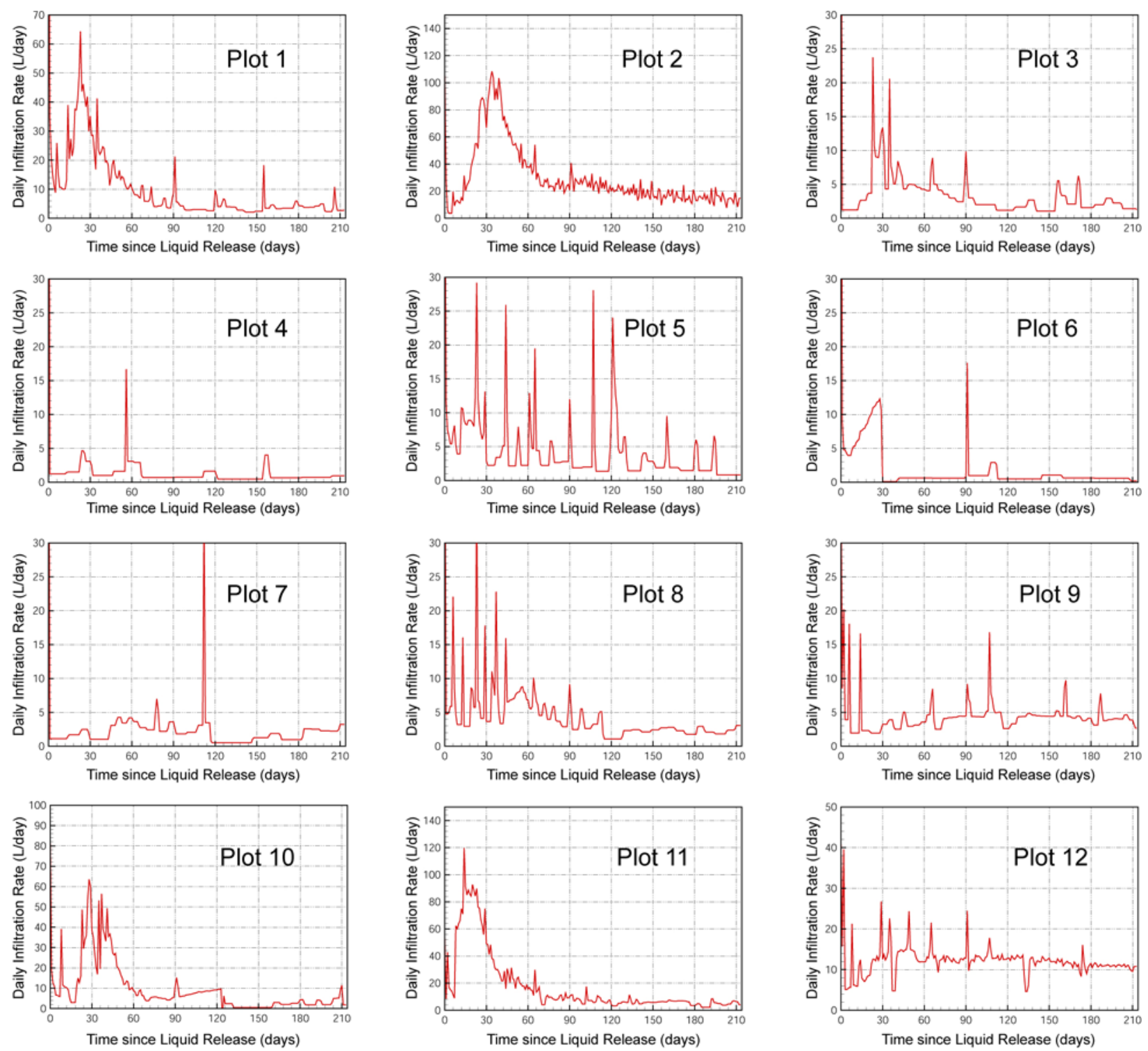

00399DC_093.eps

Source: DTNs: GS031008312242.007 (DIRS 166089) from 8/20/02 to 11/19/02; GS030608312242.005 (DIRS 166200) from $11 / 19 / 02$ to $3 / 21 / 03$.

NOTE: Plot numbers correspond to those in Figure F-1.

Figure F-3. Infiltration Rates for Each Plot in the Large-Plots Test in Alcove 8 from 9/16/02 to 3/16/03

Calibration Based on Higher Infiltration Rates-Model calibration is carried out to determine site-specific rock properties. The observed spatial distribution of seepage rate on the ceiling of Niche 3 was explicitly considered. In addition to the observed total seepage rate as a function of time, the seepage rates from individual intersections between the niche ceiling and the vertical columns in tsw34 were matched in the model calibration procedure.

To reduce the total number of rock parameters to be calibrated, only the most sensitive parameters to the infiltration rate and measured seepage rate are considered in the calibration. In this case, fracture permeability and fracture van Genuchten parameter $\alpha$ are the most important 
rock properties for water redistribution. The other parameters are assumed to be homogeneous within each hydrogeologic unit. For tsw34, there are seepage rate data for over 215 days to be used as calibration data and two unknowns for each rock column. However, for tsw33, the infiltration rate is sensitive to the saturated hydraulic conductivity beneath an infiltration subplot, but not sensitive to the van Genuchten parameter $\alpha$ in the rock column. For simplicity, van Genuchten parameter $\alpha$ in the tsw33 unit is assumed to be uniform for all of the columns.

Model calibration adjusts rock properties such that modeling results match field observations. For model layer tsw33, calibrated rock properties are fracture permeabilities and van Genuchten $\alpha$ for vertical columns (corresponding to individual infiltration plots) and for the rest of the rock mass. An initial guess of fracture permeability for a column was determined by the largest infiltration rate (for time $t$ greater than 1 day) at the infiltration plot under water pressure head of $2 \mathrm{~cm}$. The largest infiltration rate (per unit area) is considered to be the saturated hydraulic conductivity for the column. A scale factor was used to calibrate all these fracture permeability values for the columns in tsw33, such that calibrated fracture permeability for a vertical column is equal to its initial guess, multiplied by the calibrated scale factor. In this way, the effects of observed spatial variability of infiltration rate were approximately captured by the model calibration. (A vertical column in tsw33 has a uniform property distribution.)

For model layer tsw34, calibrated rock properties are again fracture permeabilities and van Genuchten $\alpha$ for vertical columns (corresponding to seepage trays) and for the rest of rock mass. While most vertical columns have uniform distributions in this model layer, Columns 1, 6, 11, and 12 were further divided into two parts: upper and lower. These two parts have different rock properties for each of the columns mentioned above in order to consider rock-damage effects on rock properties near the niche ceiling. The lower parts correspond to rock between the niche ceiling and $0.4 \mathrm{~m}$ above the ceiling. Fracture porosity calibrated from the fault tests and matrix properties used in fault-test modeling studies are used here. These properties were not varied during model calibration.

Matches between the simulated and observed seepage rates associated with different vertical columns are shown in Figure F-4. Fairly good matches were obtained except for a few columns (e.g., Columns 1, 4, and 7). Figure F-5 shows a comparison between simulated and observed total seepage rate as a function of time. In general, matches shown in the two figures are reasonable. Table F-5 lists calibrated rock properties. 

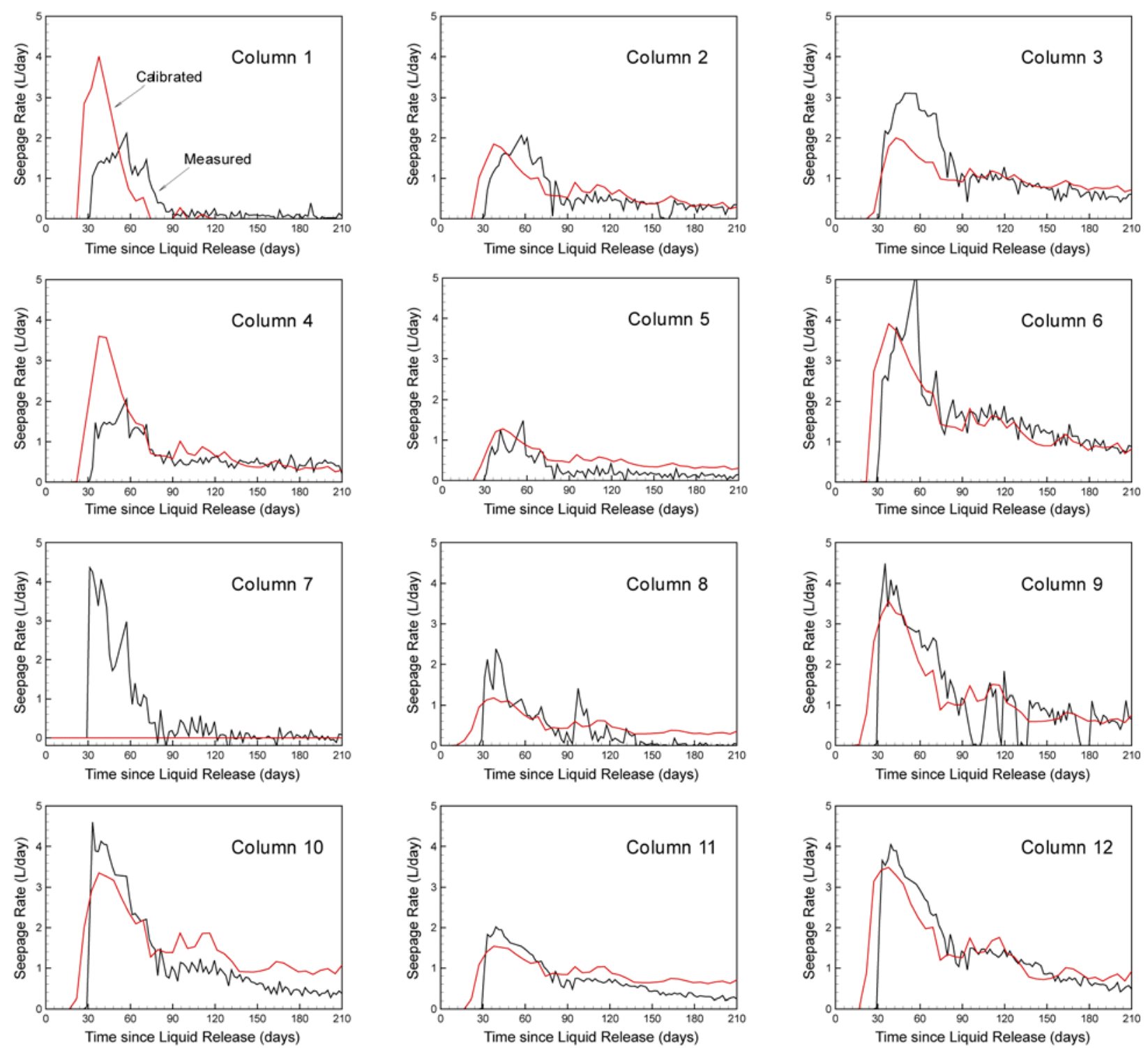

00399DC_094.ai

Source: Observed data: DTN: LB0306A8N3LIQR.001 (DIRS 165405) from 9/18/02 to 10/16/02;

DTN: LB0308A8N3SEEP.001 (DIRS 166090) from 10/16/02 to 4/2/03; Model results:

DTN: LB0312A8N3MDLG.001 (DIRS 169761).

Figure F-4. Matches between the Simulated and Observed Seepage Rates Associated with Different Vertical Columns 


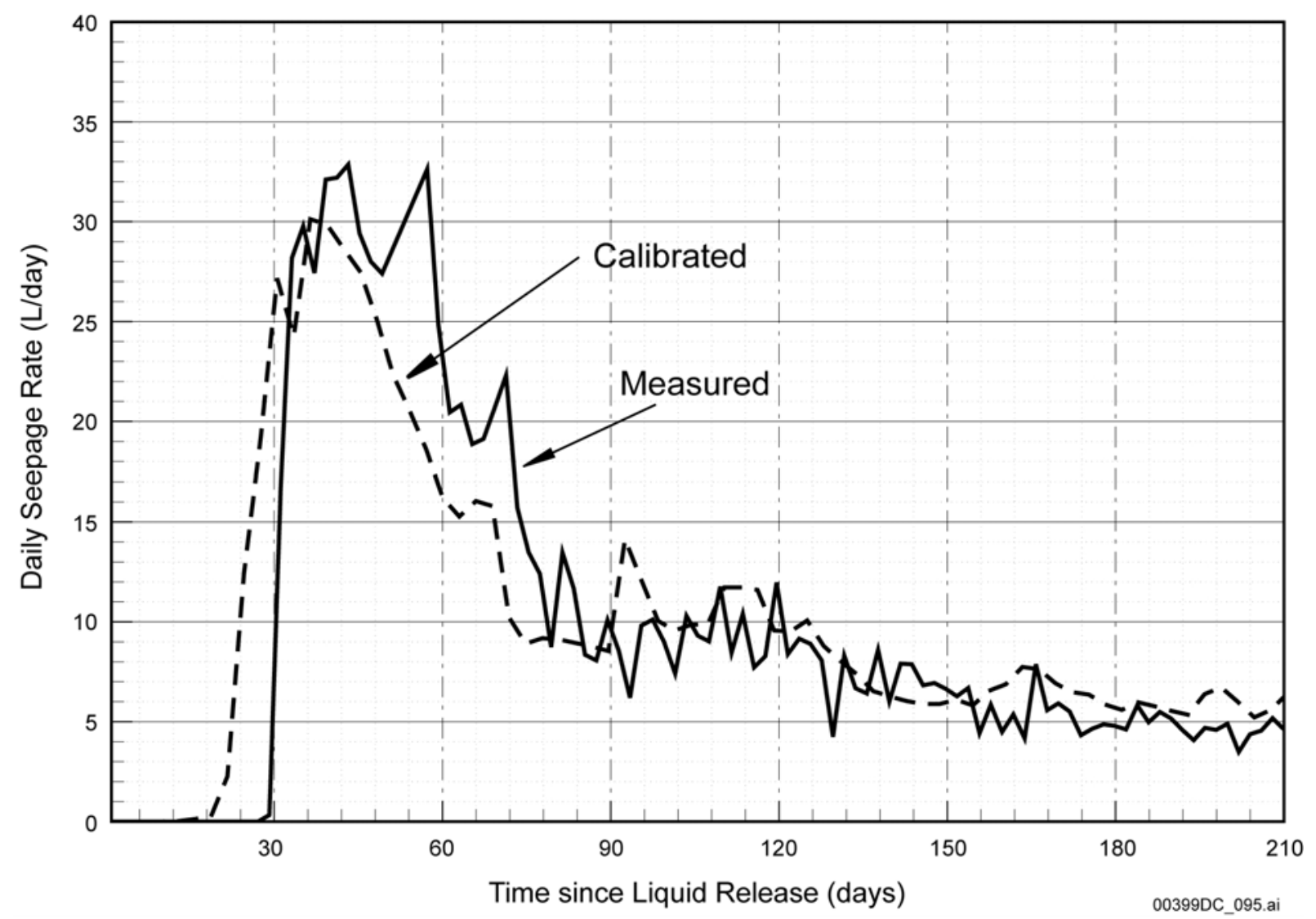

Source: $\quad$ Observed data: DTN: LB0306A8N3LIQR.001 (DIRS 165405) from 9/18/02 to 10/16/02; DTN: LB0308A8N3SEEP.001 (DIRS 166090) from 10/16/02 to 4/2/03; Model results: DTN: LB0312A8N3MDLG.001 (DIRS 169761).

Figure F-5. A Comparison between Simulated and Observed Total Seepage Rate as a Function of TimeTable

Table F-5. Calibrated Rock Properties

\begin{tabular}{|c|c|c|c|c|c|}
\hline \multicolumn{2}{|r|}{ Model Layer } & Permeability & $\begin{array}{c}\text { van Genuchten } \\
\alpha\end{array}$ & $\underset{m}{\operatorname{van} \text { Genuchten }}$ & Porosity \\
\hline \multirow[t]{13}{*}{ tsw33 } & Column 1 & $0.9926 \times 10^{-13}$ & \multirow[t]{12}{*}{$0.2453 \times 10^{-3}$} & \multirow[t]{13}{*}{$0.608^{a}$} & \multirow[t]{13}{*}{$0.066^{\mathrm{a}}$} \\
\hline & Column 2 & $0.1685 \times 10^{-12}$ & & & \\
\hline & Column 3 & $0.2959 \times 10^{-13}$ & & & \\
\hline & Column 4 & $0.3146 \times 10^{-13}$ & & & \\
\hline & Column 5 & $0.5569 \times 10^{-13}$ & & & \\
\hline & Column 6 & $0.1845 \times 10^{-13}$ & & & \\
\hline & Column 7 & $0.1314 \times 10^{-13}$ & & & \\
\hline & Column 8 & $0.6757 \times 10^{-13}$ & & & \\
\hline & Column 9 & $0.2470 \times 10^{-13}$ & & & \\
\hline & Column 10 & $0.9786 \times 10^{-13}$ & & & \\
\hline & Column 11 & $0.1864 \times 10^{-12}$ & & & \\
\hline & Column 12 & $0.3332 \times 10^{-13}$ & & & \\
\hline & Rest rock mass & $0.1190 \times 10^{-11}$ & $0.4787 \times 10^{-3}$ & & \\
\hline
\end{tabular}


Table F-5. Calibrated Rock Properties (Continued)

\begin{tabular}{|c|c|c|c|c|c|}
\hline \multicolumn{2}{|r|}{ Model Layer } & Permeability & $\begin{array}{c}\text { van Genuchten } \\
\alpha \\
\end{array}$ & $\begin{array}{c}\text { van Genuchten } \\
\boldsymbol{m}\end{array}$ & Porosity \\
\hline \multirow[t]{17}{*}{ tsw34 } & Column 1 (upper) & $0.225 \times 10^{-11}$ & $0.5677 \times 10^{-3}$ & \multirow[t]{17}{*}{$0.608^{a}$} & \multirow[t]{17}{*}{$0.010^{a}$} \\
\hline & Column 2 & $0.704 \times 10^{-12}$ & $0.1480 \times 10^{-2}$ & & \\
\hline & Column 3 & $0.448 \times 10^{-14}$ & $0.1152 \times 10^{-2}$ & & \\
\hline & Column 4 & $0.171 \times 10^{-13}$ & $0.3857 \times 10^{-2}$ & & \\
\hline & Column 5 & $0.304 \times 10^{-14}$ & $0.8647 \times 10^{-3}$ & & \\
\hline & Column 6 (upper) & $0.149 \times 10^{-13}$ & $0.2932 \times 10^{-3}$ & & \\
\hline & Column 7 & $0.434 \times 10^{-11}$ & $0.1891 \times 10^{-2}$ & & \\
\hline & Column 8 & $0.614 \times 10^{-13}$ & $0.3208 \times 10^{-2}$ & & \\
\hline & Column 9 & $0.104 \times 10^{-13}$ & $0.5316 \times 10^{-2}$ & & \\
\hline & Column 10 & $0.616 \times 10^{-14}$ & $0.9825 \times 10^{-3}$ & & \\
\hline & Column 11 (upper) & $0.189 \times 10^{-14}$ & $0.3107 \times 10^{-3}$ & & \\
\hline & Column 12 (upper) & $0.143 \times 10^{-13}$ & $0.2424 \times 10^{-3}$ & & \\
\hline & Rest rock mass & $0.495 \times 10^{-12}$ & $0.7399 \times 10^{-3}$ & & \\
\hline & Column 1 (lower) & $0.5012 \times 10^{-12 a}$ & $0.1275 \times 10^{-2}$ & & \\
\hline & Column 6 (lower) & $0.5012 \times 10^{-12 a}$ & $0.2052 \times 10^{-2}$ & & \\
\hline & Column 11 (lower) & $0.5012 \times 10^{-12 a}$ & $0.2360 \times 10^{-2}$ & & \\
\hline & Column 12 (lower) & $0.5012 \times 10^{-12 a}$ & $0.1721 \times 10^{-2}$ & & \\
\hline
\end{tabular}

Source DTN: LB0312A8N3MDLG.001 (DIRS 169761).

a These properties are not varied during model calibration.

\section{F2.4 INFILTRATION TEST AT ALCOVE 1 AND MODEL ANALYSIS}

The infiltration test site is located in Alcove 1 near the North Portal of the Exploratory Studies Facility. Alcove 1, about $30 \mathrm{~m}$ below the ground surface, was constructed for collecting seepage water originating from an infiltration plot located at the ground surface. During the infiltration test, water was applied at the ground surface directly above the end of the alcove. The infiltration test started on March 9, 1998 (time $\mathrm{t}=0$ ), and was conducted in two phases (Liu et al. 2003 [DIRS 162470]). Alcove 1 data used in the infiltration test are documented in In Situ Field Testing of Processes (BSC 2004 [DIRS 170004]).

Infiltration rates in phase I exhibited a greater degree of temporal variability than those in phase II. During the late stage of phase II, bromide was introduced into the infiltrating water as a tracer. Seepage into the alcove was collected as a function of time, with tracer concentrations obtained by analyzing the seepage water (Liu et al. 2003 [DIRS 162470]).

A numerical model was developed to simulate the test, and a cylindrical grid was constructed for the model using a dual-continuum approach (Liu et al. 2003 [DIRS 162470]). Both fracture and matrix were treated as homogeneous continua. The grid extended $45 \mathrm{~m}$ in the vertical and $30 \mathrm{~m}$ in the radial direction (the diameter was $60 \mathrm{~m}$ ). The ground surface was approximated as horizontal. The model domain was considered to be large enough in comparison with size of the alcove and infiltration application area, such that side boundaries had an insignificant effect on flow and transport near the alcove. On the basis of the site data, a square opening representing 
the alcove was created in the grid 30 to $35.5 \mathrm{~m}$ below the ground surface. The grid was regular with $10 \mathrm{~cm}$ grid spacing around the alcove and $1 \mathrm{~m}$ grid spacing away from the alcove.

The temporally variable inflow rates are imposed on the top boundary, representing the infiltration condition (Figure F-6). The side boundary corresponds to a zero-flow condition in the radial direction. The alcove wall boundary is modeled by a zero-capillary-pressure condition, representing a relative humidity of 100 percent in the alcove (Birkholzer et al. 1999 [DIRS 105170]). The bottom boundary was assigned a constant matrix saturation of 0.61 , which is consistent with field observations under ambient conditions (Flint 1998 [DIRS 100033]).

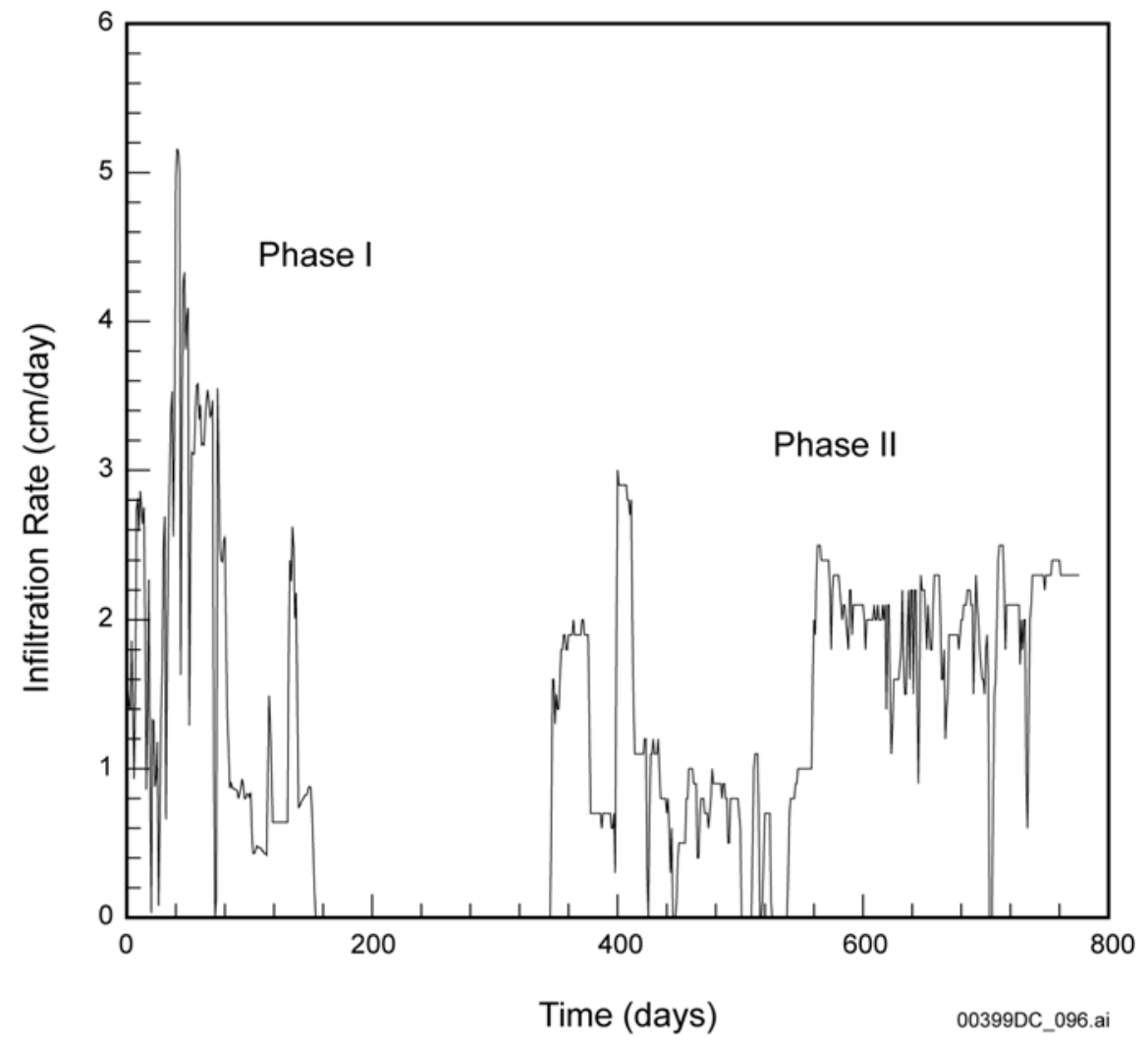

Source: $\quad$ Liu et al. 2003 (DIRS 162470), Figure 1.

Figure F-6. Infiltration Rates Used for the Alcove 1 Infiltration Test

The model was calibrated to the seepage data measured at Alcove 1 during the infiltration test. Calibration results are presented in Table F-6 (Liu et. al. 2003 [DIRS 162470]). The model calibration was determined by adjusting rock hydraulic parameters to make simulation results match the corresponding data. The match of the inversion is measured using the standard least squares approach, which minimizes the sum of the squared residuals weighted by the inverse of variances of the data.

Rock hydraulic properties needed as inputs into the model include fracture spacing, fracture and matrix permeabilities, porosities, van Genuchten parameters, and the parameter of the active fracture model, $\gamma$. Both fracture and matrix properties were assumed to be homogeneously distributed within the model domain, although heterogeneities do exist at the test site. The 
fracture porosity and spacing were estimated from fracture map data obtained in the ESF. Note that these fracture properties are important for determining internal node connections between the fracture and matrix continua within a gridblock. Fracture permeability was estimated based on air injection tests performed in the same geologic unit as that of the test site. These average matrix properties were obtained by averaging the corresponding property data obtained from core measurements, given in Table F-6.

Table F-6. Hydrologic Properties for the Fracture and Matrix Continua

\begin{tabular}{|c|c|c|}
\hline Property & Fracture & Matrix \\
\hline Porosity & $\begin{array}{l}\text { Initial Guess: } 0.01 \\
\text { First Calibration: } 0.028 \\
\text { Second Calibration: } 0.03\end{array}$ & $0.164^{a}$ \\
\hline Vertical permeability $\left(\mathrm{m}^{2}\right)$ & $\begin{array}{l}\text { Initial Guess: } 2.29 \times 10^{-11} \\
\text { First Calibration: } 2.90 \times 10^{-11} \\
\text { Second Calibration: } 3.08 \times 10^{-11}\end{array}$ & $\begin{array}{l}\text { Initial Guess: } 1.2 \times 10^{-15} \\
\text { First Calibration: } 3.64 \times 10^{-16} \\
\text { Second Calibration: } 1.01 \times 10^{-15}\end{array}$ \\
\hline Horizontal permeability $\left(\mathrm{m}^{2}\right)$ & $\begin{array}{l}\text { Initial Guess: } 2.29 \times 10^{-11} \\
\text { First Calibration: } 3.14 \times 10^{-11} \\
\text { Second Calibration: } 2.99 \times 10^{-11}\end{array}$ & $\begin{array}{l}\text { Initial Guess: } 1.2 \times 10^{-15} \\
\text { First Calibration: } 9.35 \times 10^{-16} \\
\text { Second Calibration: } 3.42 \times 10^{-16}\end{array}$ \\
\hline$\alpha(1 / \mathrm{Pa})$ & $\begin{array}{l}\text { Initial Guess: } 2.37 \times 10^{-3} \\
\text { First Calibration: } 2.07 \times 10^{-3} \\
\text { Second Calibration: } 2.34 \times 10^{-3}\end{array}$ & $\begin{array}{l}\text { Initial Guess: } 7.12 \times 10^{-6} \\
\text { First Calibration: } 1.84 \times 10^{-5} \\
\text { Second Calibration: } 1.90 \times 10^{-5}\end{array}$ \\
\hline $\mathrm{m}$ & $0.633^{a}$ & $0.346^{\mathrm{a}}$ \\
\hline Fracture spacing (m) & $0.377^{\mathrm{a}}$ & \\
\hline Residual saturation & $0.01^{a}$ & $0.06^{a}$ \\
\hline$\gamma$ & $\begin{array}{l}\text { Initial Guess: } 0.15 \\
\text { First Calibration: } 0.28 \\
\text { Second Calibration: } 0.21\end{array}$ & \\
\hline
\end{tabular}

Source: Liu et al. 2003 (DIRS 162470), Table 1.

a These properties are fixed during model calibrations.

\section{F3. COMPARISON OF HYDROLOGIC PROPERTY DATA CALIBRATED UNDER DIFFERENT INFILTRATION CONDITIONS}

Model analyses of the field tests corresponding to high infiltration conditions are discussed in previous sections. Several sets of hydrologic property data are obtained from these analyses. The models with high infiltration rates are expected to encompass flow behavior representative of future climates. Rock property sets obtained for high infiltration rates are consistent with those from the calibrated drift-scale model under present-day climate conditions. This indicates that extrapolation of a model calibrated to present-day climate conditions to predict unsaturated flow under future climate conditions is appropriate.

Table F-7 gives average infiltration rates for current and future climate conditions, estimated infiltration rates for the fault test and large plot tests at Alcove 8-Niche 3, and the test at Alcove 1. Infiltration rates for the tests are approximately estimated from infiltration plots (Figures 7.6-1, F-3, and F-6) of these tests. The infiltration rates in millimeters per year are calculated by reading infiltration rates in liters per day from infiltration plots and transforming to 
millimeters per year based on the information of applied area of infiltration water. As shown in the table, the infiltration rates for field tests are all much higher than those for future climate conditions. For example, the highest peak infiltration for the tests is $43,800 \mathrm{~mm} /$ year, which is about 1,500 times the average infiltration rate for the upper bound of the glacial transition period. The highest average infiltration rate (employed in Plot 2 of the Alcove 8 test) is 7,300 mm/year. This rate is about 250 times the average infiltration rate for the upper bound of the glacial transition climate. The use of these tests to represent future climate conditions is conservative.

Table F-7. Infiltration Rate Information

\begin{tabular}{|l|c|c|c|c|}
\hline \multirow{2}{*}{$\begin{array}{c}\text { Climate Conditions } \\
\text { or Testing Schemes }\end{array}$} & \multicolumn{2}{c|}{ Peak Infiltration Rate } & \multicolumn{2}{c|}{ Average Infiltration Rate } \\
\cline { 2 - 5 } & L/day & mm/year & L/day & mm/year \\
\hline Present-day mean & & & & 4.43 \\
\hline Present-day upper bound & & & & 10.74 \\
\hline Present-day lower bound & & & & 11.25 \\
\hline Monsoon mean & & & & 19.23 \\
\hline Monsoon upper bound & & & & 4.43 \\
\hline Monsoon lower bound & & & & 17.02 \\
\hline Glacial transition mean & & & & 31.69 \\
\hline Glacial transition upper bound & & & & 2.35 \\
\hline Glacial transition lower bound & 400 & 4,000 & 180 & 1,800 \\
\hline Fault test at Alcove 8-Niche 3 & 65 & 23,735 & 6 & 2,190 \\
\hline Plot 1, Large plot test at Alcove 8 & 105 & 38,325 & 20 & 7,300 \\
\hline Plot 2, Large plot test at Alcove 8 & 24 & 8,700 & 3 & 1,095 \\
\hline Plot 3, Large plot test at Alcove 8 & 16 & 5,800 & 1 & 365 \\
\hline Plot 4, Large plot test at Alcove 8 & 29 & 10,585 & 3 & 1,095 \\
\hline Plot 5, Large plot test at Alcove 8 & 17 & 6,205 & 0.5 & 183 \\
\hline Plot 6, Large plot test at Alcove 8 & 30 & 10,905 & 2 & 730 \\
\hline Plot 7, Large plot test at Alcove 8 & 30 & 10,950 & 4 & 1,460 \\
\hline Plot 8, Large plot test at Alcove 8 & 18 & 6,570 & 4 & 1,460 \\
\hline Plot 9, Large plot test at Alcove 8 & 62 & 22,630 & 5 & 1,825 \\
\hline Plot 10, Large plot test at Alcove 8 & 120 & 43,800 & 8 & 2,920 \\
\hline Plot 11, Large plot test at Alcove 8 & 40 & 14,600 & 11 & 4,015 \\
\hline Plot 12, Large plot test at Alcove 8 & & 18,250 & & 2,190 \\
\hline Infiltration test at Alcove 1 & & & & \\
\hline Sourc: Average & & & \\
\hline
\end{tabular}

Source: Average infiltration rates for current and future climates are from Table 6.1-2. Infiltration rates for the tests are estimated from the infiltration plots of the tests, Figures 7.6-1, F-3, and F-6.

\section{F3.1 COMPARISON FOR ALCOVE 8-NICHE 3 TEST}

Table F-8 shows a comparison of calibrated fracture permeability for the unit tsw33, tsw34, and the fault from different infiltration conditions. The three present-day infiltration scenarios give identical fracture permeability for the tsw33 and tsw34 unit. Calibrated results on higher infiltration for tsw33 have a maximum value of $1.23 \times 10^{-12} \mathrm{~m}^{2}$ and minimum value of $1.314 \times 10^{-14} \mathrm{~m}^{2}$, with an average of $2.11 \times 10^{-13} \mathrm{~m}^{2}$. Calibrated results for tsw34 has a maximum value of $4.34 \times 10^{-12} \mathrm{~m}^{2}$ and minimum value of $1.89 \times 10^{-15} \mathrm{~m}^{2}$ with an average of $5.69 \times 10^{-13} \mathrm{~m}^{2}$. Differences between calibration results for tests may be caused by local 
heterogeneity within geologic units. The corresponding calibrated results from current climate conditions are in the range of the higher infiltration calibration results and close to their average values. As discussed in Section F.1.3.2, the parameter uncertainties (standard deviations) for the uncalibrated parameter sets can be directly used for the calibrated parameter sets. From Table F-4, one sees that the standard deviation (uncertainty) for $\log \left(K_{f}\right)$ is 0.61 for tsw33 and 0.47 for tsw34. The differences between averaged $\log \left(K_{f}\right)$ for the tests and results of calibrated drift-scale models are 0.57 and 0.24 for tsw33 and tsw34, respectively. Both are smaller than their standard deviations. Therefore, calibrated fracture permeabilities for tsw33 and tsw34 from different climate conditions can be considered consistent. The results from drift-scale model calibration are the average value of entire layers at the Yucca Mountain site, and the results from the calibration of infiltration tests represent the value at the specific test location.

Calibrated fault permeability for the TSw unit under the present-day mean infiltration and the corresponding results of the two runs of the fault test at Alcove 8 are in the same order of magnitude. The average of the two runs is $8.94 \times 10^{-11} \mathrm{~m}^{2}$. The $\log \left(K_{f}\right)$ difference between average value for fault test and calibration result of drift-scale model is 0.55 , which is, again, smaller than the uncertainty (standard deviation) of that unit (1.15, see Table F-4).

Table F-8. Comparison of Calibrated Fracture Permeabilities

\begin{tabular}{|l|l|l|l|}
\hline \multicolumn{1}{|c|}{ Data Sources } & Fault $\left(\mathbf{m}^{2}\right)$ & tsw33 $\left(\mathbf{m}^{2}\right)$ & tsw34 $\left(\mathbf{m}^{2}\right)$ \\
\hline Calibrated on fault test (run 1) & $6.67 \times 10^{-11}$ & $8.93 \times 10^{-13}$ & $3.16 \times 10^{-14}$ \\
\hline Calibrated on fault test (run 2) & $1.12 \times 10^{-10}$ & $1.23 \times 10^{-12}$ & $5.01 \times 10^{-13}$ \\
\hline Calibrated on large plot test, plot 1 & & $9.93 \times 10^{-14}$ & $2.25 \times 10^{-12}$ \\
\hline Calibrated on large plot test, plot 2 & & $1.69 \times 10^{-13}$ & $7.04 \times 10^{-13}$ \\
\hline Calibrated on large plot test, plot 3 & & $2.96 \times 10^{-14}$ & $4.48 \times 10^{-15}$ \\
\hline Calibrated on large plot test, plot 4 & & $3.15 \times 10^{-14}$ & $1.71 \times 10^{-14}$ \\
\hline Calibrated on large plot test, plot 5 & & $5.57 \times 10^{-14}$ & $3.04 \times 10^{-15}$ \\
\hline Calibrated on large plot test, plot 6 & & $1.85 \times 10^{-14}$ & $1.49 \times 10^{-14}$ \\
\hline Calibrated on large plot test, plot 7 & & $1.31 \times 10^{-14}$ & $4.34 \times 10^{-12}$ \\
\hline Calibrated on large plot test, plot 8 & & $6.76 \times 10^{-14}$ & $6.14 \times 10^{-14}$ \\
\hline Calibrated on large plot test, plot 9 & & $2.47 \times 10^{-14}$ & $1.04 \times 10^{-14}$ \\
\hline Calibrated on large plot test, plot 10 & & $9.77 \times 10^{-14}$ & $6.16 \times 10^{-15}$ \\
\hline Calibrated on large plot test, plot 11 & & $1.86 \times 10^{-13}$ & $1.89 \times 10^{-15}$ \\
\hline Calibrated on large plot test, plot 12 & & $3.33 \times 10^{-14}$ & $1.43 \times 10^{-14}$ \\
\hline Calibrated on present-day mean infiltration & $2.51 \times 10^{-11}$ & $7.80 \times 10^{-13}$ & $3.30 \times 10^{-13}$ \\
\hline Calibrated on present-day lower-bound infiltration & & $7.80 \times 10^{-13}$ & $3.30 \times 10^{-13}$ \\
\hline Calibrated on present-day upper-bound infiltration & & $7.80 \times 10^{-13}$ & $3.30 \times 10^{-13}$ \\
\hline
\end{tabular}

Source: Tables F-1, F-5, 7.6.2, 7.6.3, and Tables 6-8, 6-9, and 6-10 of the report by BSC (2004 [DIRS 169857]).

TSw=Topopah Spring welded hydrogeologic unit

The values for the calibrated fracture van Genuchten parameter $\alpha$ from different infiltration conditions are listed in Table F-9. The calibration results from fault tests are close to the results from the calibrated property set on current climate conditions. The results from large plot tests show little deviation from the results of current climates. The $\log \left(\alpha_{\mathrm{f}}\right)$ differences between 
average values for the large plot test and drift-scale calibrated properties for both units are larger than their corresponding uncertainties provided in Table F-4. This could be caused by the local heterogeneity of the unit; however, they are still in the same order of magnitude. The calibrated results on higher infiltration for tsw33 have a maximum value of $2.19 \times 10^{-3} \mathrm{~Pa}^{-1}$ and minimum value of $2.45 \times 10^{-4} \mathrm{~Pa}^{-1}$, with an average of $4.86 \times 10^{-4} \mathrm{~Pa}^{-1}$. Those results for tsw34 have a maximum value of $5.32 \times 10^{-3} \mathrm{~Pa}^{-1}$ and minimum value of $2.42 \times 10^{-4} \mathrm{~Pa}^{-1}$, with an average of $1.55 \times 10^{-3} \mathrm{~Pa}^{-1}$. The corresponding calibrated results from current climate conditions are in the range of the higher infiltration calibration results.

Table F-9. Comparison of Calibrated Fracture van Genuchten Parameters $\alpha$

\begin{tabular}{|l|c|c|c|}
\hline \multicolumn{1}{|c|}{ Data Sources } & Fault $\left(\mathbf{P a}^{-1}\right)$ & Tsw33 $\left(\mathbf{P a}^{-1}\right)$ & tsw34 $\left(\mathbf{P a}^{-1}\right)$ \\
\hline Calibrated on fault test (run 1) & $1.15 \times 10^{-3}$ & $1.67 \times 10^{-3}$ & $4.59 \times 10^{-4}$ \\
\hline Calibrated on fault test (run 2) & $1.24 \times 10^{-3}$ & $2.19 \times 10^{-3}$ & $1.09 \times 10^{-3}$ \\
\hline Calibrated on large plot test, plot 1 & & $2.45 \times 10^{-4}$ & $5.68 \times 10^{-4}$ \\
\hline Calibrated on large plot test, plot 2 & & $2.45 \times 10^{-4}$ & $1.48 \times 10^{-3}$ \\
\hline Calibrated on large plot test, plot 3 & & $2.45 \times 10^{-4}$ & $1.15 \times 10^{-3}$ \\
\hline Calibrated on large plot test, plot 4 & & $2.45 \times 10^{-4}$ & $3.86 \times 10^{-3}$ \\
\hline Calibrated on large plot test, plot 5 & & $2.45 \times 10^{-4}$ & $8.65 \times 10^{-4}$ \\
\hline Calibrated on large plot test, plot 6 & & $2.45 \times 10^{-4}$ & $2.93 \times 10^{-4}$ \\
\hline Calibrated on large plot test, plot 7 & & $2.45 \times 10^{-4}$ & $1.89 \times 10^{-3}$ \\
\hline Calibrated on large plot test, plot 8 & & $2.45 \times 10^{-4}$ & $3.21 \times 10^{-3}$ \\
\hline Calibrated on large plot test, plot 9 & & $2.45 \times 10^{-4}$ & $5.32 \times 10^{-3}$ \\
\hline Calibrated on large plot test, plot 10 & & $2.45 \times 10^{-4}$ & $9.83 \times 10^{-4}$ \\
\hline Calibrated on large plot test, plot 11 & & $2.45 \times 10^{-4}$ & $3.11 \times 10^{-4}$ \\
\hline Calibrated on large plot test, plot 12 & & $2.45 \times 10^{-4}$ & $2.42 \times 10^{-4}$ \\
\hline Calibrated on present-day mean infiltration & $3.16 \times 10^{-4}$ & $1.59 \times 10^{-3}$ & $1.04 \times 10^{-4}$ \\
\hline Calibrated on present-day lower-bound infiltration & & $1.94 \times 10^{-3}$ & $6.55 \times 10^{-4}$ \\
\hline Calibrated on present-day upper-bound infiltration & & $1.58 \times 10^{-3}$ & $1.00 \times 10^{-4}$ \\
\hline
\end{tabular}

Source: Tables F-1, F-5, 7.6.2, 7.6.3, and Tables 6-8, 6-9, and 6-10 of the report by BSC (2004 [DIRS 169857]).

TSw=Topopah Spring welded hydrogeologic unit

An examination of Tables F-7, F-8, and F-9 reveals that the calibrated results do not show clear evidence of dependence on the infiltration rates.

\section{F3.2 COMPARISON FOR ALCOVE 1 TEST}

Table F-10 presents the comparison of calibrated rock properties for the tcw11 unit in which the Alcove 1 infiltration test was conducted. The infiltration test at Alcove 1 occurred mainly in tcw11. The table shows that fracture permeability is almost identical from calibration on higher infiltration and current climate conditions. Other parameters all have quite close values. The differences in $\log$ value for matrix permeability, fracture $\alpha$, and matrix $\alpha$ are $0.57,0.35$, and 0.27 , respectively. They are all close to or smaller than their corresponding standard deviations $(0.47$, 0.58 , and 0.24$)$. 
Table F-10. Comparison of Calibrated Rock-Property Data for tcw11

\begin{tabular}{|l|l|l|l|l|}
\hline \multicolumn{1}{|c|}{ Data Sources } & \multicolumn{1}{|c|}{$\begin{array}{c}\text { Fracture Permeability } \\
\left(\mathbf{m}^{2}\right)\end{array}$} & \multicolumn{1}{c|}{$\begin{array}{c}\text { Matrix Permeability } \\
\left(\mathbf{m}^{2}\right)\end{array}$} & $\begin{array}{c}\text { Fracture } \mathbf{\alpha} \\
\left(\mathbf{P a}^{-1}\right)\end{array}$ & $\begin{array}{c}\text { Matrix } \mathbf{\alpha} \\
\left(\mathbf{P a}^{-1}\right)\end{array}$ \\
\hline $\begin{array}{l}\text { Calibrated on infiltration } \\
\text { test at Alcove 1 }\end{array}$ & $\begin{array}{l}2.99 \times 10^{-11} \text { (horizontal) } \\
3.08 \times 10^{-11}(\text { vertical) }\end{array}$ & $\begin{array}{l}3.42 \times 10^{-16} \text { (horizontal) } \\
1.01 \times 10^{-15}(\text { vertical) }\end{array}$ & $2.34 \times 10^{-3}$ & $1.90 \times 10^{-5}$ \\
\hline $\begin{array}{l}\text { Calibrated on present-day } \\
\text { mean infiltration }\end{array}$ & $3.0 \times 10^{-11}$ & $3.74 \times 10^{-15}$ & $5.27 \times 10^{-3}$ & $1.01 \times 10^{-5}$ \\
\hline $\begin{array}{l}\text { Calibrated on present-day } \\
\text { lower-bound infiltration }\end{array}$ & $3.0 \times 10^{-11}$ & $3.44 \times 10^{-15}$ & $4.68 \times 10^{-3}$ & $1.16 \times 10^{-5}$ \\
\hline $\begin{array}{l}\text { Calibrated on present-day } \\
\text { upper-bound infiltration }\end{array}$ & $3.0 \times 10^{-11}$ & $3.90 \times 10^{-15}$ & $5.01 \times 10^{-3}$ & $1.23 \times 10^{-5}$ \\
\hline
\end{tabular}

Source: Table F-6, and Tables 6-8, 6-9, and 6-10 of the report by BSC (2004 [DIRS 169857]).

\section{F4. SUMMARY}

The uncertainty involved in hydrologic properties obtained by model calibration under present-day climate conditions and used to forecast flow for future climate conditions results, mainly, from the uncertainties of the hydrologic property set. The major sources of calibrated parameter uncertainty may include the numerical model uncertainty, infiltration rate uncertainty, scale effects, and field measurement uncertainty. These uncertainties can be propagated to the model for forecasting flow and transport in future climate conditions.

Theoretically speaking, the actual hydrologic parameters are in general independent of infiltration rates under normal flow and transport conditions. They remain the same under different climate conditions and, therefore, it is reasonable to use the same rock properties under current and future climate conditions. Although the future climate is expected to be wetter, it is not substantially wetter than the present-day climate, and the future infiltration rate will be much lower than the infiltration rates encountered in Alcove 8-Niche 3 tests and Alcove 1 tests.

The consistency between property sets calibrated under different infiltration indicates it is appropriate to use calibrated rock properties on present-day climate conditions in the model for predicting future flow and transport condition, based on information provided in previous sections. 


\section{APPENDIX G}

JUSTIFICATION OF LATERAL FLOW AND SPATIAL SMOOTHING AND TEMPORAL DAMPING EFFECTS IN THE PAINTBRUSH NONWELDED HYDROGEOLOGIC UNIT 


\section{G1. EFFECT OF PAINTBRUSH NONWELDED HYDROGEOLOGIC UNIT ON UNSATURATED ZONE FLOW}

Conceptual models used in the study of the role played by the Paintbrush nonwelded hydrogeologic unit (PTn) are discussed in Section 6.2.2 as well as Conceptual and Numerical Models for UZ Flow and Transport (BSC 2004 [DIRS 170035]). As illustrated in Figure 6.2-1, because the PTn unit has very different and highly contrasting hydrogeologic properties from the Tiva Canyon welded hydrogeologic (TCw) (a unit above) and Topopah Spring welded hydrogeologic (TSw) (a unit below) units, potential lateral flow exists in the PTn unit, which laterally divert the percolating water into faults. In addition, with high matrix porosity and low fracture intensity, the PTn matrix system has a large capacity for storing groundwater from transient surface net infiltration. Therefore, the PTn unit has also been conceptualized to damp temporal variations in percolation flux so that water flow below the PTn unit may be modeled as occurring under steady-state conditions.

\section{G2. SPATIAL DISTRIBUTION OF PERCOLATION FLUXES IN THE PTN UNIT}

\section{G2.1 EVIDENCE FROM TWO-DIMENSIONAL MODELS}

The spatial redistribution and focusing effect of the PTn unit on percolation fluxes are demonstrated through two-dimensional models. Figure G-1 shows the location of the two-dimensional cross-sectional models. The numerical modeling studies investigate the hydrogeologic conditions required to form capillary barriers and the effect that capillary barriers have on fluid flow. The following information is based upon the simulation results of two cross-sectional, two-dimensional steady-state models discussed by $\mathrm{Wu}$ et al. (2002 [DIRS 161058]). These models investigate the development of capillary barriers and their associated flow behavior within the PTn unit. The first cross-sectional model (A-A') (Figure G-1) is used to analyze the fundamentals of capillary barrier phenomena in fractured formation. The second model (B-B') is for larger, mountain scale behavior as well as the effects of major faults on the Yucca Mountain site.

The modeling approach is also the dual-continuum formulation of coupled multiphase fluid and tracer transport through fractured porous rock. The input parameters for the rock and fluid properties of the model layers are estimated from several related studies. A detailed discussion of the two models, including meshes, boundary conditions, input parameters, and numerical approaches, is given by Wu et al. (2002 [DIRS 161058]). 


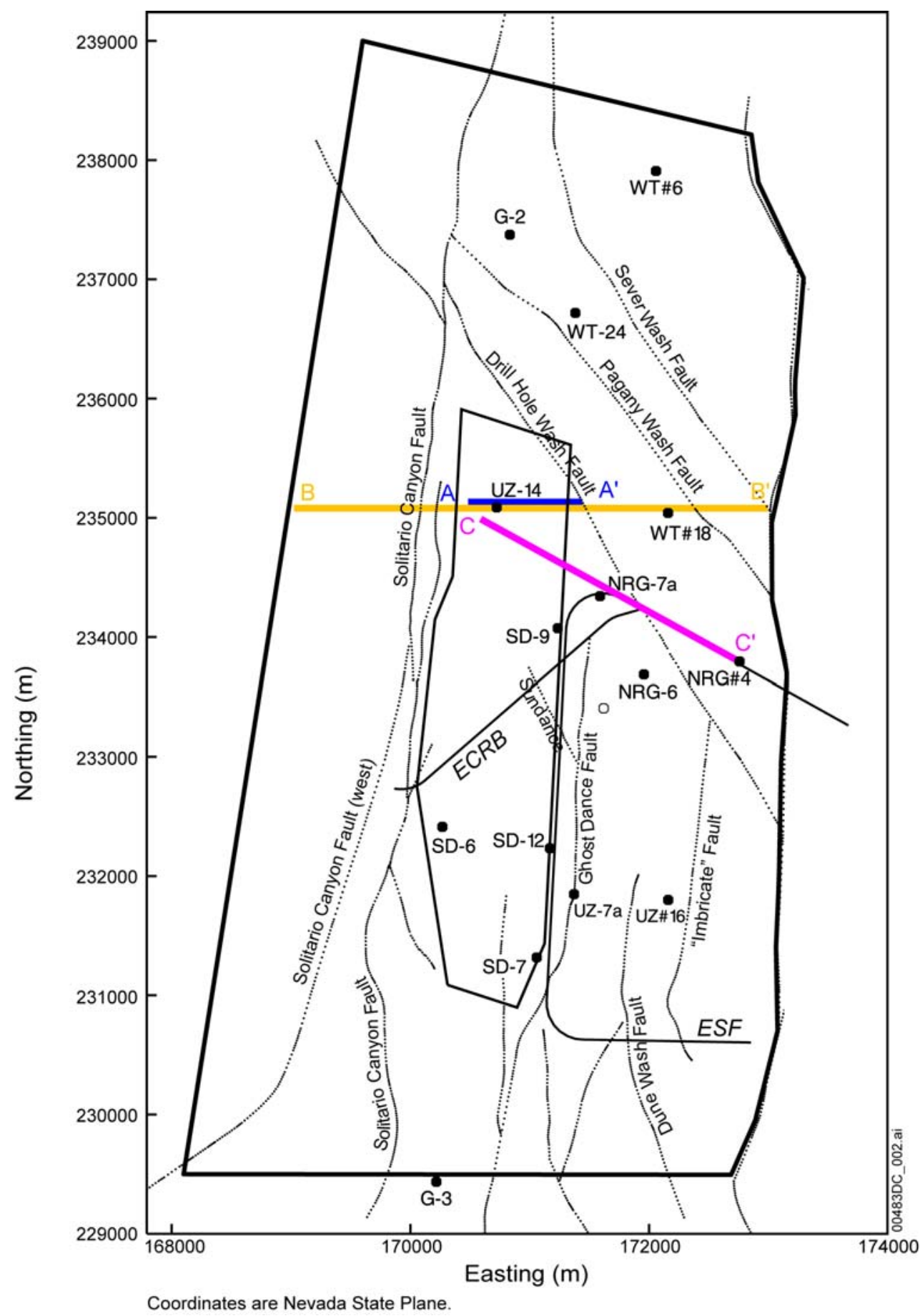

Source: Wu et al. 2002 (DIRS 161058), Figure 1.

Figure G-1. Plan View of the Unsaturated Zone Model Domain Showing the Model Boundary, Repository Outline, Major Faults, Selected Boreholes, and Vertical Cross Sections A-A', B$\mathrm{B}^{\prime}$, and C-C' 


\section{G2.2 RESULTS USING THE CROSS-SECTIONAL MODEL ALONG A-A'}

Figure G-2 presents the two-dimensional, steady-state, mass flux vector magnitude distribution for the $1,000 \mathrm{~m}$ wide $\mathrm{A}-\mathrm{A}^{\prime}$ cross section. In the figure, dark blue zones indicate high flow rates. The modeling results shown in Figure G-2 illustrate the importance of the ptn21 (uppermost) and ptn23 layers. Significant lateral flow occurs along these two layers within the PTn unit because strong capillary barriers have developed directly below these units. A large amount of the percolation flux is diverted into a narrow zone near the down slope, right-hand boundaries due to the artificial effect of a no-flow boundary there. When lateral flow reaches the no-flow boundary at the right-hand side, it is blocked by the boundary and forced to flow down trend. This artificial effect does not affect simulation results of the other part of the cross section.

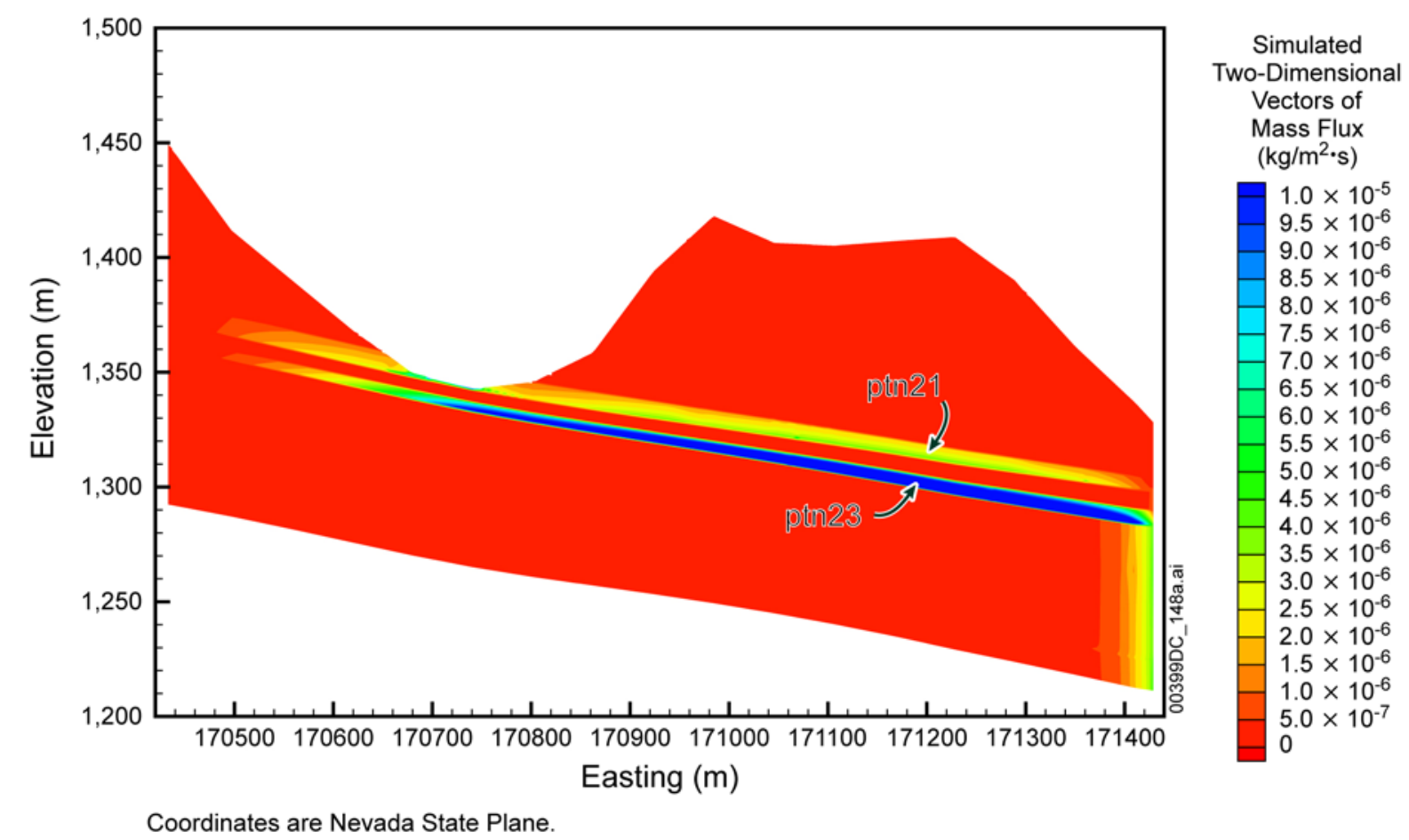

Source: Wu et al. 2002 (DIRS 161058), Figure 3.

Figure G-2. Magnitude of Simulated Two-Dimensional Vectors of Mass Fluxes for the $1,000 \mathrm{~m}$ Scale Cross Section A-A'

Capillary barriers in either fractured rock or unfractured soils depend on contrasting hydraulic properties between two contacted layers. However, the formation of capillary barriers in fractured rock is dependent not only on the interaction of vertical capillary gradients in both fracture and matrix systems of the layer, but also on the flow between the two continua. Under steady-state flow conditions, local capillary gradients between the fractures and matrix tend to be at a minimum (relative to transient flow) or near equilibrium. These gradients have little effect on global fracture to fracture or matrix to matrix flow. Thus, lateral flow is primarily controlled by the net effect of competing downward gravitational forces and upward capillary gradients in both fracture and matrix systems. 
Figure G-3 further illustrates the effect that the interactions of the two continua have on the development of capillary barriers. In this figure, vertical capillary gradients at an Easting coordinate of $171,140 \mathrm{~m}$ of the A-A' cross section are plotted for the fracture and matrix continua of the model. In addition, the two layers (ptn21 and ptn23) previously shown to exhibit a strong potential capillary-barrier effect are indicated (see Figure G-2). Negative capillary pressure gradients shown in Figure G-3 imply upward vertical flow and positive capillary pressure gradients indicate downward vertical flow, as would be driven by capillary gradients alone. Both capillary gradients and gravitational forces drive actual flow. The upward vertical matrix flow within layers ptn21 and ptn23 exhibits capillary-pressure gradients of approximately 0.1 (bar/m). These upward gradients are balanced by the gravity gradient $\left(\rho_{\mathrm{w}} \times \mathrm{g} \approx 0.1 \mathrm{bar} / \mathrm{m}\right)$, such that matrix flow can occur only in the horizontal direction within these two layers. In a similar manner, capillary barrier effects in the fracture continuum are expected at the base of layer ptn23, where upward vertical fracture flow (i.e., a negative capillary pressure gradient) is again balanced by the downward gravitational gradients. Layer ptn21, on the other hand, exhibits an unbalanced downward flow by capillary gradients in the fracture continuum and, thus, the capillary-barrier effect in this layer is diminished (see Figure G-2). Strong fracture-matrix counter flow is also seen at a lower elevation of $1,240 \mathrm{~m}$, which explains why no lateral flow occurs at that level (see Figure G-2).

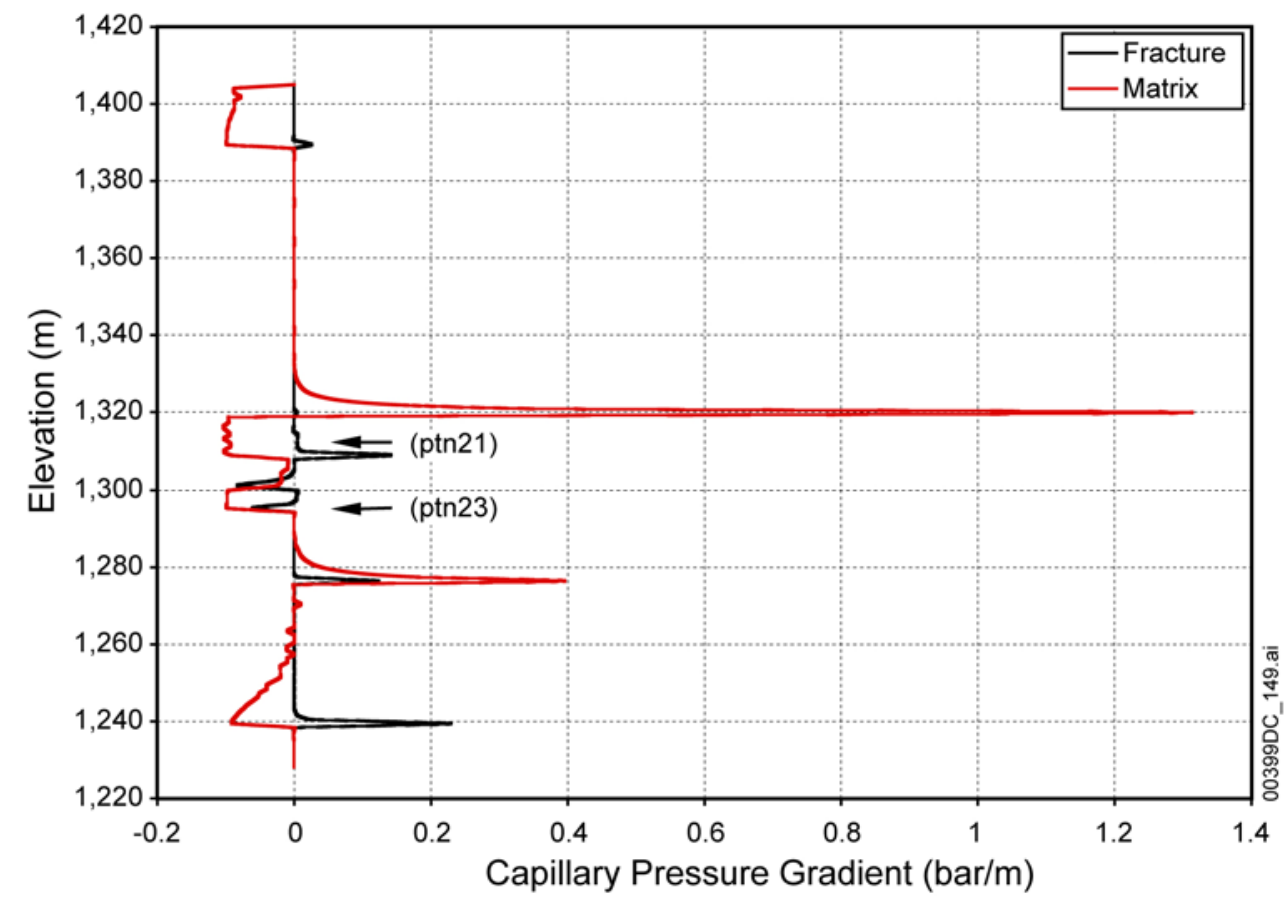

Source: Wu et al. 2002 (DIRS 161058), Figure 4.

Figure G-3. Vertical Capillary Pressure Gradients at an Easting Coordinate of $171,200 \mathrm{~m}$ from the $1,000 \mathrm{~m}$ Scale Cross Section A-A' Using the Refined Grid

The two-dimensional flow field shown in Figure G-4 predicts that large lateral flow is indeed occurring along the ptn21 and ptn23 model layers and reaching maximum flow velocities within ptn23. Both the fracture and matrix van Genuchten $\alpha$ parameter $\left(5.58 \times 10^{-6}\right.$ and $9.23 \times 10^{-4}$, which describes capillary functions) used for model layer ptn23 are much lower than that for the 
underlying ptn24 unit $\left(1.53 \times 10^{-4}\right.$ and $\left.3.37 \times 10^{-3}\right)$. This simulation indicates that ptn23 is expected to have a strong capillary suction, as indicated by the large capillary pressure contrast shown along the ptn23-ptn24 boundary in Figure G-4.

The simulation results for the A-A' cross section indicate the development of capillary barriers in the PTn. These capillary barriers cause formation of lateral flow and dampen episodic flow.

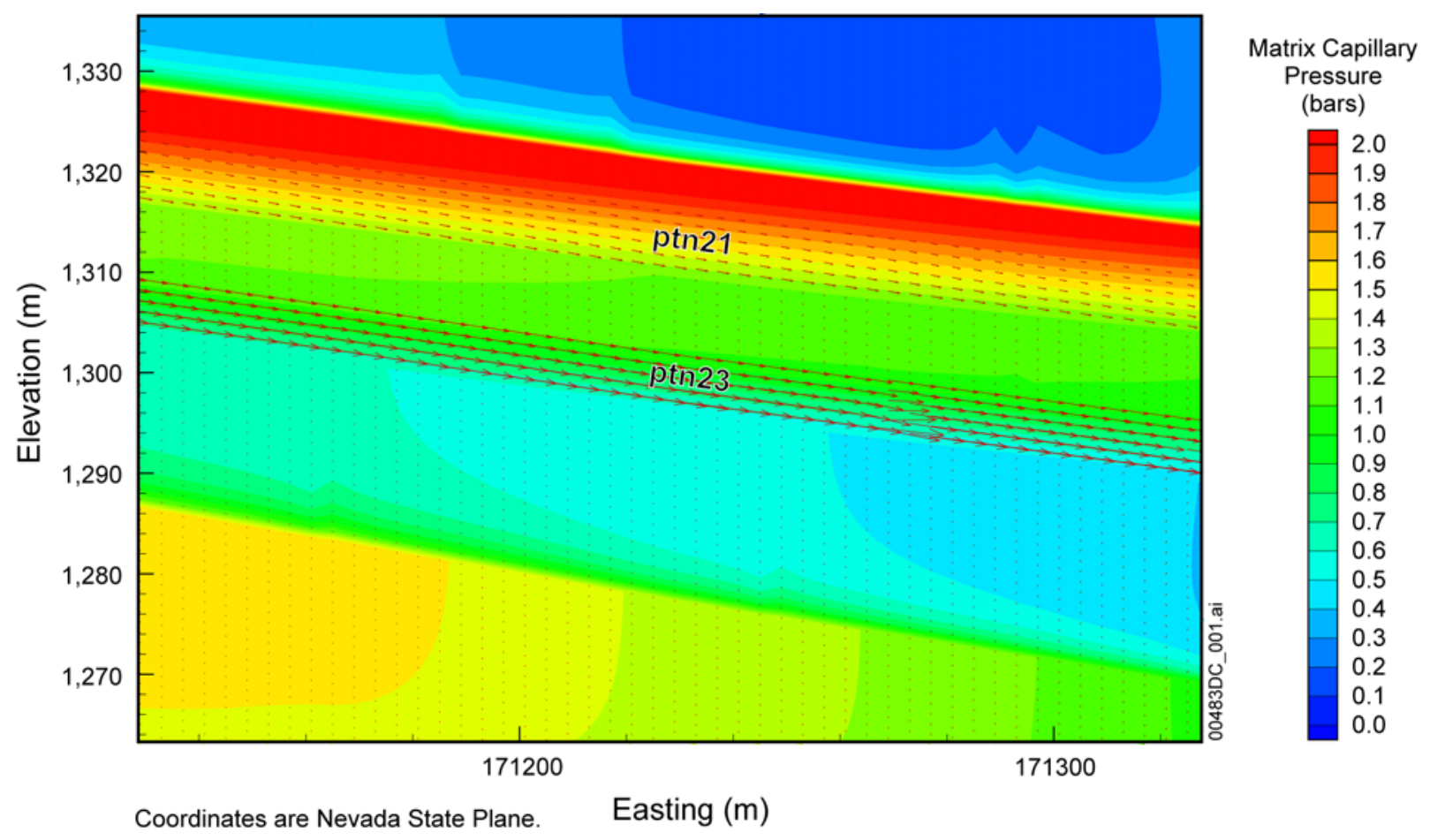

Source: Wu et al. 2002 (DIRS 161058), Figure 5.

Figure G-4. Simulated Two-Dimensional Flow Field within the 1,000 m Scale Cross Section A-A'

\section{G2.3 RESULTS USING THE CROSS-SECTIONAL MODEL ALONG B-B'}

Cross section B-B' is considered more representative than cross section $A-A^{\prime}$ in modeling large-scale flow behavior because B-B' includes several major faults and covers the entire thickness of the unsaturated zone.

Comparison of percolation flux values at the top and the bottom of the PTn allows for an estimation of the amount of lateral flow occurring within the unit. Model results show that percolation patterns along the top of the PTn are essentially the same as surface infiltration. Consequently, the analyses simply use surface infiltration values as proxy for the actual percolation occurring at the top of the PTn. Figure G-5 compares these distributed surface infiltration values with the modeled percolation flux at the PTn-TSw interface (bottom of the PTn) along B-B' for both the coarse and refined grids. Figure G-5 shows that significant lateral flow diversion is occurring within the PTn and that a large amount of the water is being diverted down-slope to the Solitario Canyon, Ghost Dance, and Drill Hole Wash faults. Figure G-5 also shows that the simulated percolation flux directly above the repository (in the area between the Solitario Canyon and Ghost Dance faults) is significantly reduced by the lateral diversion of 
water into faults. In addition, the percolation values become more uniform in the unfaulted zones after passing through the PTn. When a uniform surface infiltration is used, both the coarse and fine model results along the PTn-TSw boundary are similar to those shown in Figure G-5. Therefore, detailed spatial distributions of surface net infiltration may not be critical once percolating waters have traveled to the base of the PTn unit.

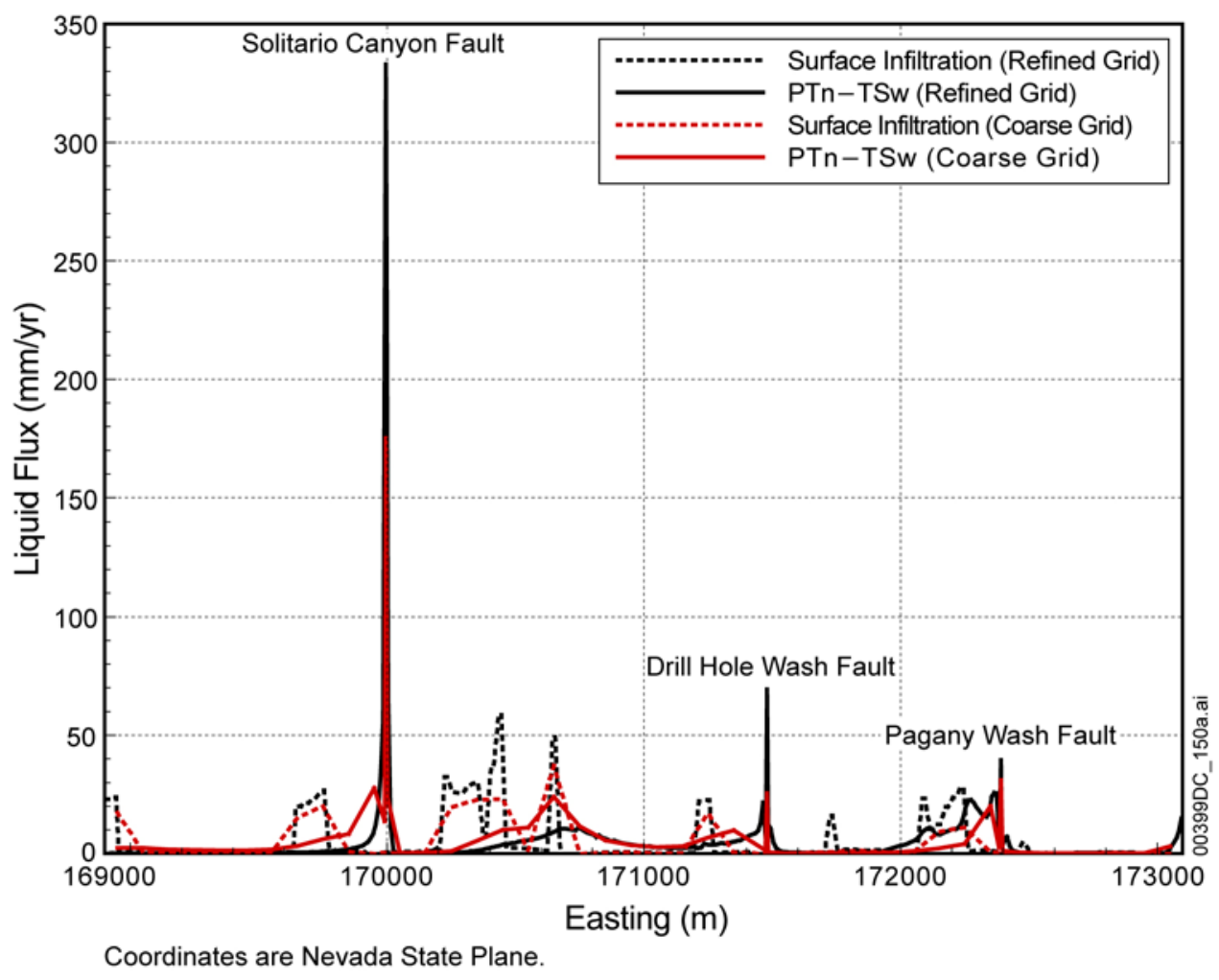

Source: Wu et al. 2002 (DIRS 161058), Figure 7.

Figure G-5. Simulated Vertical Percolation Flux at the PTn-TSw Interface along B-B' Using Refined and Coarse Grids with Distributed Surface Net Infiltration (Averaging $5 \mathrm{~mm} /$ year)

The effects of capillary barriers and faults on flux values along B-B' are evident in Figure G-6, which plots the magnitude of the two-dimensional steady-state mass flux vectors for the entire cross section. Layers ptn 23 and ptn21 are controlling the lateral flow within the PTn unit. Figure G-6 further shows that major faults are providing the main flow pathways for vertical percolation flux (see also Figure G-5). Only one moderate vertical flux zone at an Easting coordinate of approximately 172,000 m (between Ghost Dance and Drill Hole Wash faults) is not related to fault infiltration. In this area, layers $p \operatorname{tn} 21$ and $\operatorname{ptn} 23$ become thin (approximately $2 \mathrm{~m}$ ) and a weaker capillary-barrier effect exists in this region. 


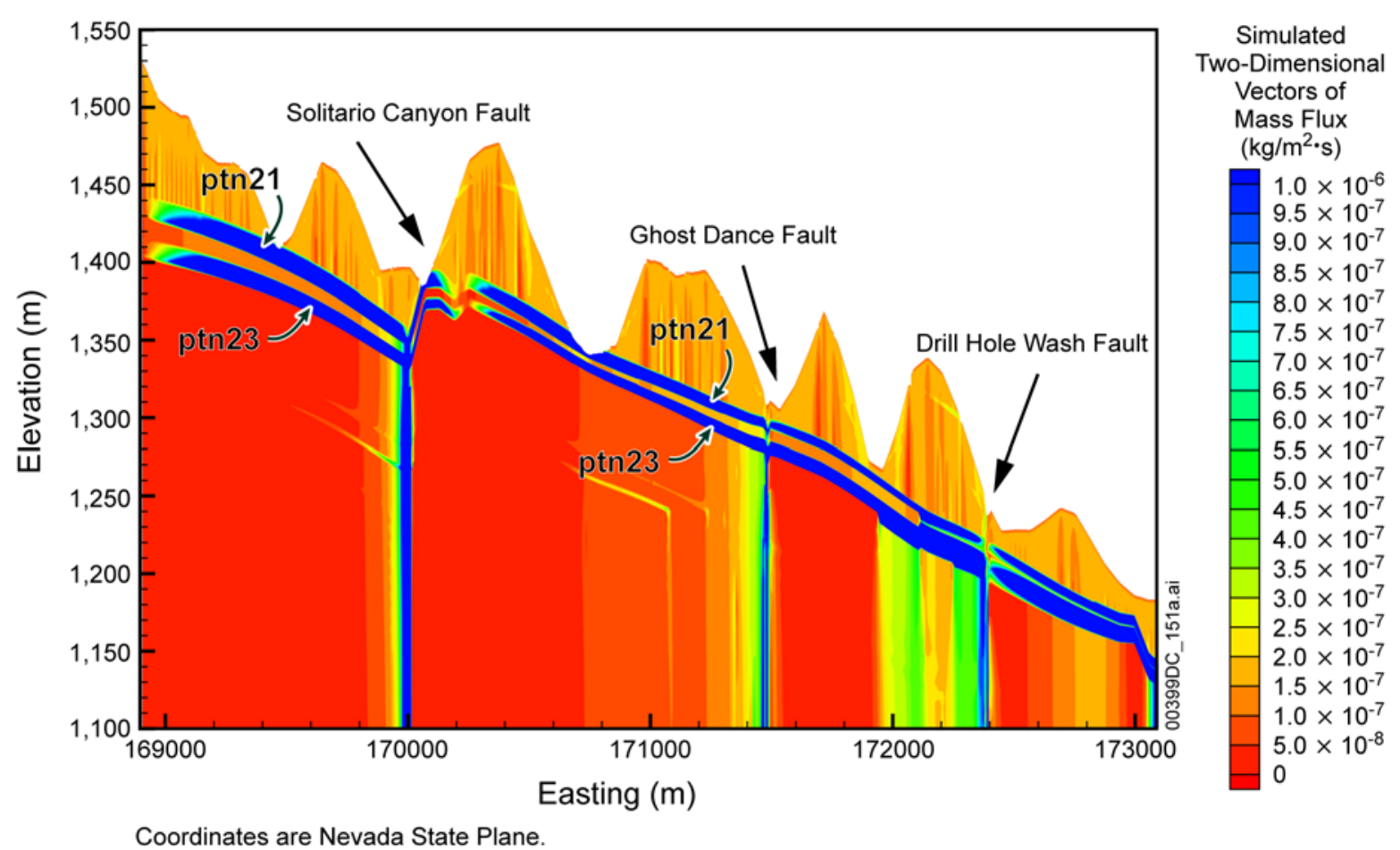

Source: Wu et al. 2002 (DIRS 161058), Figure 8.

Figure G-6. Magnitude of Simulated Two-Dimensional Vectors of Mass Flux along B-B' Uniform Surface Infiltration

Although the spatial distribution of surface infiltration has little or no impact on the distribution of flow at the base of the PTn, simulation results indicate that net infiltration values have more of an overall impact on capillary barriers (and lateral flow). As net infiltration increases, the percentage of fault flow decreases because both fractures and matrix in the unfaulted areas become more saturated, the more saturated the system, the generally weaker the capillary barriers between rock layers. Consequently, there is less percentage of moisture lateral diversion into fault zones. For section B-B', the model results show that an average of approximately 20 percent of the total percolation flux has been laterally diverted into faults or fault zones in high infiltration scenarios, and fault flow consists of approximately 40 percent of the total flow at lower-infiltration rates.

The lateral flow distribution in the rock layers depended significantly on the particular layer hydrogeological properties and infiltration rates (Pan et al. 2004 [DIRS 169760]). In general, higher infiltration on top boundary (wetter condition) will lead to lower capillary barrier effect. With the increase of infiltration rate, the percentage of lateral flow will reduce.

From the above discussion, we can conclude that the spatial damping effect of percolation fluxes in PTn unit is mainly caused by the capillary barriers. For certain infiltration rate, the spatial distribution of surface infiltration has little or no impact on the distribution of fluxes at the base of the PTn, as supported by two-dimensional models. However, damping effect could be either spatial or temporal. 


\section{G3. EVIDENCE FROM THREE-DIMENSIONAL MODEL RESULTS}

The spatial redistribution and focusing effect of the PTn unit on percolation flux is examined by comparing the infiltration distribution on the land surface to the vertical flux distribution at the repository layer.

Figures 6.6-1, 6.6-2, and 6.6-3 show percolation fluxes along the repository layer for the three mean infiltration scenarios of the climates of present-day, monsoon, and glacial transition, respectively. Comparisons of the calculated repository percolation fluxes of Figures 6.6-1, 6.6-2, and 6.6-3 with those of the surface infiltration maps (Figures 6.1-2, 6.1-3, and 6.1-4, respectively) indicate that percolation fluxes at the repository are very different from surface infiltration patterns. These differences could be reasonable due to capillary effect. Comparison results also indicate that within the PTn unit, lateral flow has a significant damping effect on percolation flux distribution in the repository layer. In Figures 6.6-1, 6.6-2, and 6.6-3, the large-scale lateral flow from west to east (in general) is illustrated by "Lateral Flow Scale". The "Lateral Flow Scale" was determined by shifting distance of the high infiltration ridge by comparing infiltration map and simulated percolation flux distribution at the repository horizon. Detailed discussion of the comparisons and lateral flow distributions are presented at Section 6.6.3.

The above analysis is based on comparisons between the infiltration distribution on the repository surface to vertical flux distribution at the repository level. Through comparison of vertical flux distribution at the interface of PTn-TSw and the repository layer it can be further concluded that the lateral flow occurs in the PTn unit, not the upper part of TSw unit. Figure G-7 shows simulated percolation fluxes at the PTn-TSw interface under the present-day, mean infiltration scenario for the base case. A comparison of Figures 6.6-1 and G-7 shows that the two figures have a similar pattern except in a small part at the northwest corner of the modeling domain. This is because there is no overlaid layer at this part and infiltration occurs at the PTn-TSw interface. The similar pattern of percolation fluxes at the two layers suggests that the damping effect of flux indeed occurs in the PTn unit.

Figure G-8 presents an example of the simulation results (present-day mean infiltration scenario) with the alternative flow model of using a different PTn property set. A comparison between Figure G-8 and the surface infiltration map (Figure 6.1-2) of the present-day climate shows very similar flux patterns. This indicates that the alternative unsaturated zone flow model predicts small lateral flow occurrence in the PTn in most model areas, except in the north of the model domain and the intermediate area next to the Solitario Canyon fault. 


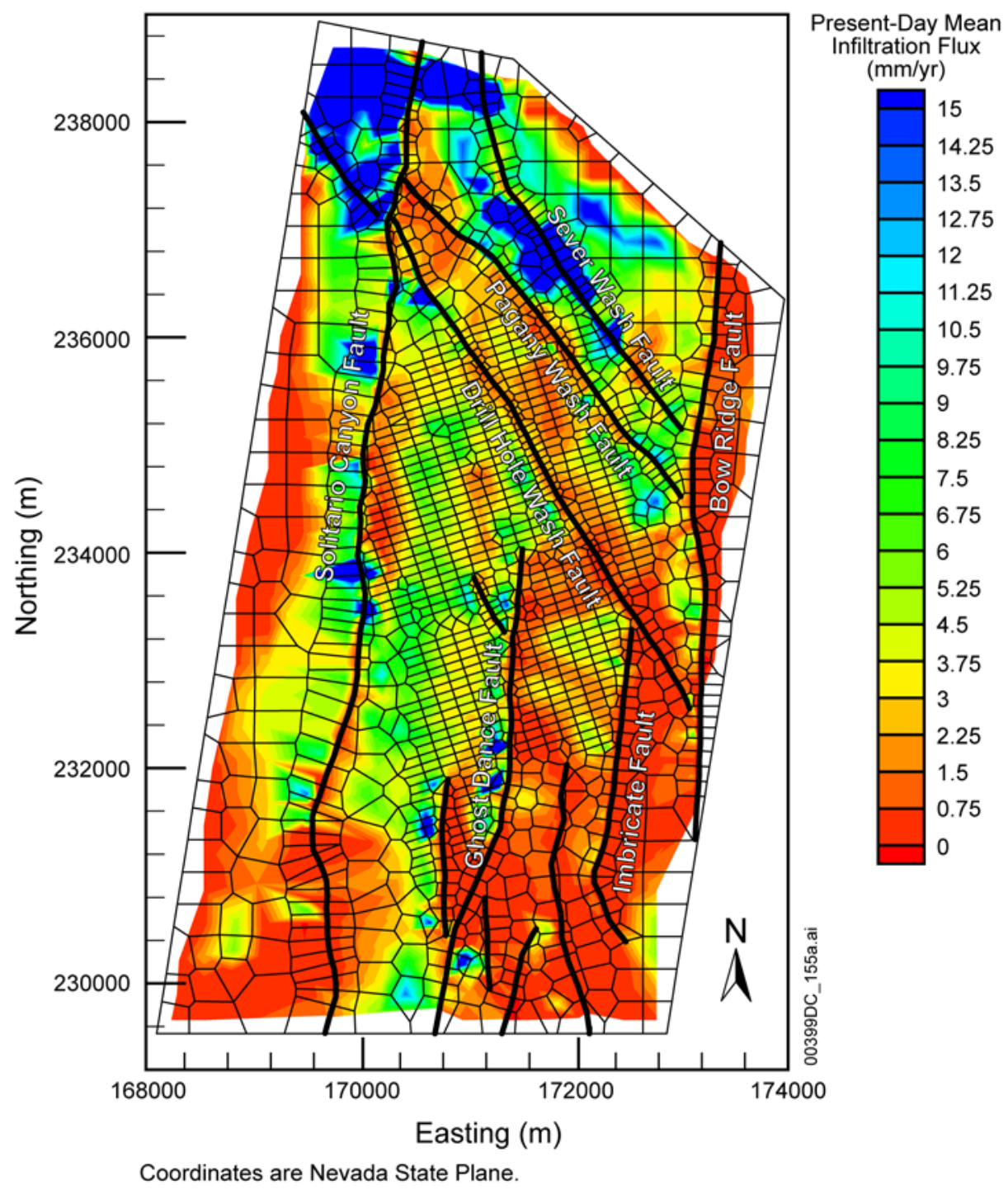

Source Output: DTN: LB03023DSSCP9I.001.

Figure G-7. Simulated Percolation Fluxes at the PTn-TSw Interface under the Present-Day Mean Infiltration Scenario Using the Results of Simulation preq_mA 


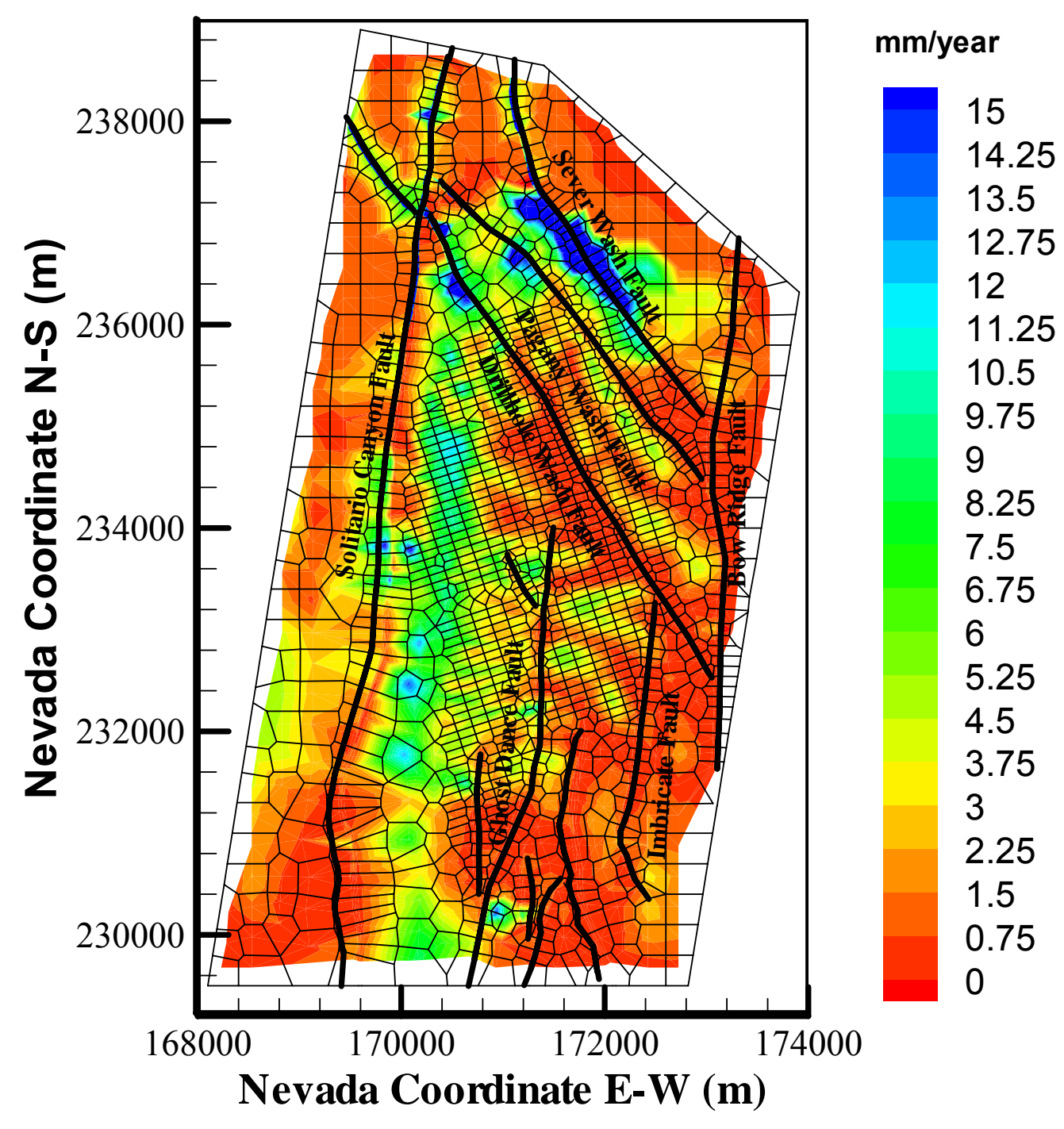

Source: Output: DTN: LB03023DSSCP9I.001.

Figure G-8. Simulated Percolation Fluxes at the Repository Horizon under the Present-Day Mean Infiltration Scenario Using the Results of Simulation preq_mB of the Alternative Flow Model 


\section{G4. TEMPORAL DAMPING OF EPISODIC INFILTRATION PULSES}

The temporal damping effect of the PTn unit on percolation fluxes is examined through models with episodic infiltration pulses on the top boundary of the repository. The information in this section is based on the study by Wu et al. (2000 [DIRS 154918]) and simulation results of a one-dimensional model.

The net surface infiltration at the bedrock surface (on top of the TCw unit) is conceptualized as episodic with significant pulses occurring only once every few years (USGS 2000 [DIRS 136368]). Spatially and temporally variable pulses of moisture percolate rapidly through the highly fractured tuffs of the TCw. However, at the TCw-PTn interface where welded tuffs grade sharply into nonwelded tuffs, flow behavior changes from fracture-dominated to matrix-dominated flow (BSC 2001 [DIRS 158726]). The highly porous PTn unit attenuates the episodic infiltration flux significantly such that the net episodic surface infiltration, once crossing the PTn, can be approximated as steady state.

Effects of surface transient infiltration on capillary barriers and percolation are analyzed below using numerical models. The model development is documented in the report by Wang (2003 [DIRS 162417], SN-LBNL-SCI-199-V1, pp. 147 to 155). Wu et al. (2000 [DIRS 154918]) use a 50-m-long two-dimensional section model (part of the A-A' cross section) and a one-dimensional model at the Easting coordinate of $170906 \mathrm{~m}$ (see Section G.2.1 and Figure G-1). Surface infiltration pulses are assumed to be uniformly distributed spatially with a one-week infiltration cycle of 50 years (i.e., the model top boundary is subject to nonzero infiltration for only one week every 50 years, infiltration rate for the week is about $13,045 \mathrm{~mm} /$ year). The net infiltration value of the week averaged over the 50 years is also $5 \mathrm{~mm} /$ year. The initial conditions for both the two-dimensional and one-dimensional models correspond to steady-state status under $5 \mathrm{~mm} /$ year infiltration.

Figure G-9 presents simulated bottom vertical percolation fluxes at different times as compared with the steady-state, initial results. Figure G-9 indicates that simulated percolation fluxes at the PTn-TSw interface varies with times under transient pulses of infiltration, but the magnitude of the transient variation of the bottom fluxes is relatively small as compared with pulses on the surface. Strong effects of capillary barriers on transient percolating fluxes can be seen because similar flow patterns resulted for all of the times. Figure G-10 shows the variations of total fluxes at the bottom of the PTn and surface infiltration pulses versus time from the two-dimensional and one-dimensional models. Results in Figure G-10 demonstrate the strong time damping effects of the PTn unit. Surface infiltration or pulses can be effectively smoothed temporally after the early transient period of several hundred years. Figure G-10 presents the results for up to 1,000 years following the steady-state flow of the initial condition. After rapid changes during the first several hundred years, the total fluxes at the bottom boundaries gradually approach the average value of $5 \mathrm{~mm} /$ year, and eventually the system should reach a dynamic equilibrium condition under the uniform pulses of infiltration. 


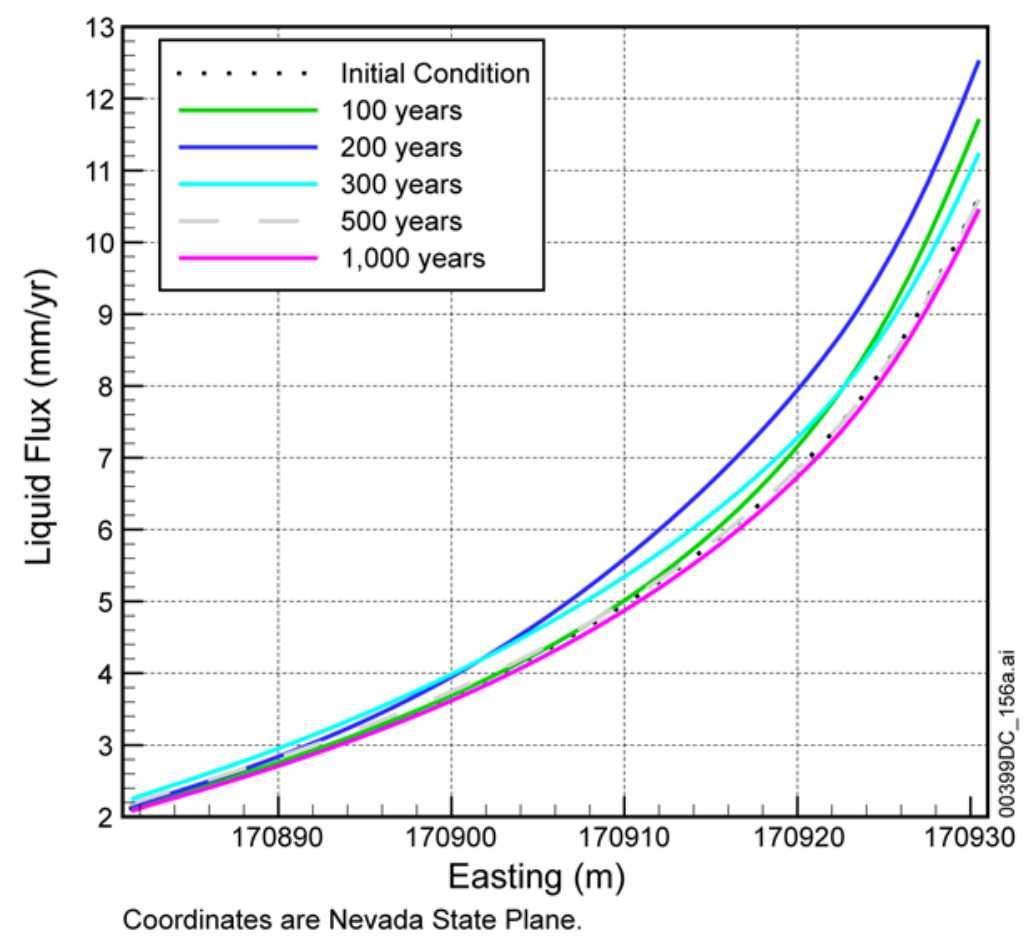

Source: Wu et al. 2000 (DIRS 154918), Figure 4.1-10.

Figure G-9. Simulated Vertical Percolation Fluxes at Different Times across the PTn-TSw Interface along a 50-m-Long Cross Section

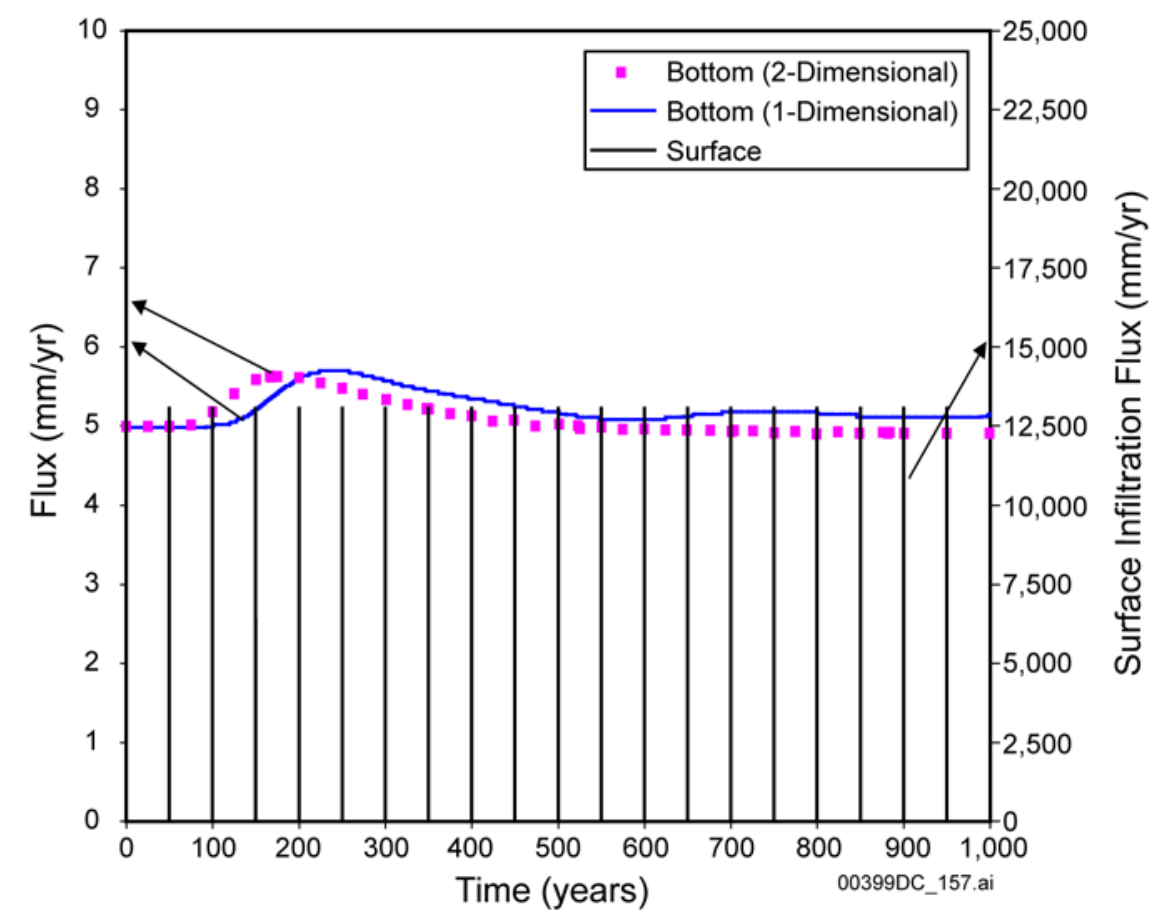

Source: Wu et al. 2000 (DIRS 154918), Figure 4.1-11.

Figure G-10. Simulated Variations in Total Percolation Fluxes Versus Times at the Bottom PTn Unit of the Two-Dimensional and One-Dimensional Models 
A one-dimensional model was developed to further demonstrate the temporal damping effect of the PTn unit on percolation fluxes with longer simulation periods and higher infiltration rates. This model consists of a single vertical column, which is extracted directly from the three-dimensional mountain scale unsaturated zone model (see Section 6.1). The representative column is located at coordinates $171250.5,236250$. The current model uses two different infiltration pulses, 5 and $20 \mathrm{~mm} /$ year (covering the range of ambient condition). In this model, surface infiltration pulses are also assumed to be uniformly distributed spatially with a one-week infiltration cycle of 50 years (i.e., the model top boundary is subject to nonzero infiltration for only one week every 50 years). The net infiltration value of the week, averaged over the 50 years, is 5 or $20 \mathrm{~mm} /$ year, which is about 13,045 mm/year or $52,179 \mathrm{~mm} /$ year for the week.

Figures G-11 and G-12 show variations of total fluxes at the bottom of the PTn for the two different infiltration pulses, respectively. These figures are created using simulation output from the model documented by Wang (2003 [DIRS 162417], SN-LBNL-SCI-199-V1, pp.147 to 155). The patterns of flux distribution for these two cases are similar to the results presented on Figure G-10. Figures G-11 and G-12 also show flux changes during the first several hundred years. The total fluxes at the bottom boundaries of the PTn gradually approach their average values, and, eventually, the system reaches a dynamic equilibrium condition under the uniform pulses of infiltration for time greater than 1,000 years. These results show the significance of temporal damping effects of the PTn unit, and that surface infiltration or pulses can be smoothed temporally after the early transient period of several hundred years. The two different infiltration pulses produce a similar damping effect. This may indicate that the damping effect will not be weakened by higher infiltration. The use of averaged infiltration rate of $20 \mathrm{~mm} /$ year is sufficient to represent future climate conditions.

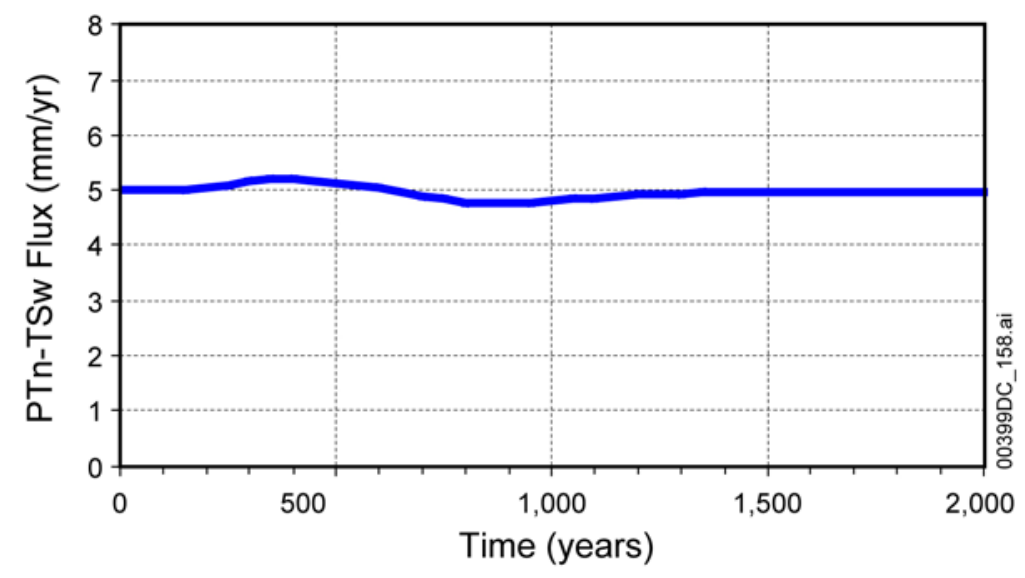

Source: Wang 2003 (DIRS 162417) SN-LBNL-SCI-199-V1, pp.147 to 155.

NOTE: Subject to one-week transient infiltration pulses every 50 years, equivalent to $5 \mathrm{~mm} /$ year averaged infiltration rate.

Figure G-11. Simulated Variations in Total Percolation Fluxes Versus Times at the Bottom PTn Unit of the One-Dimensional Model 


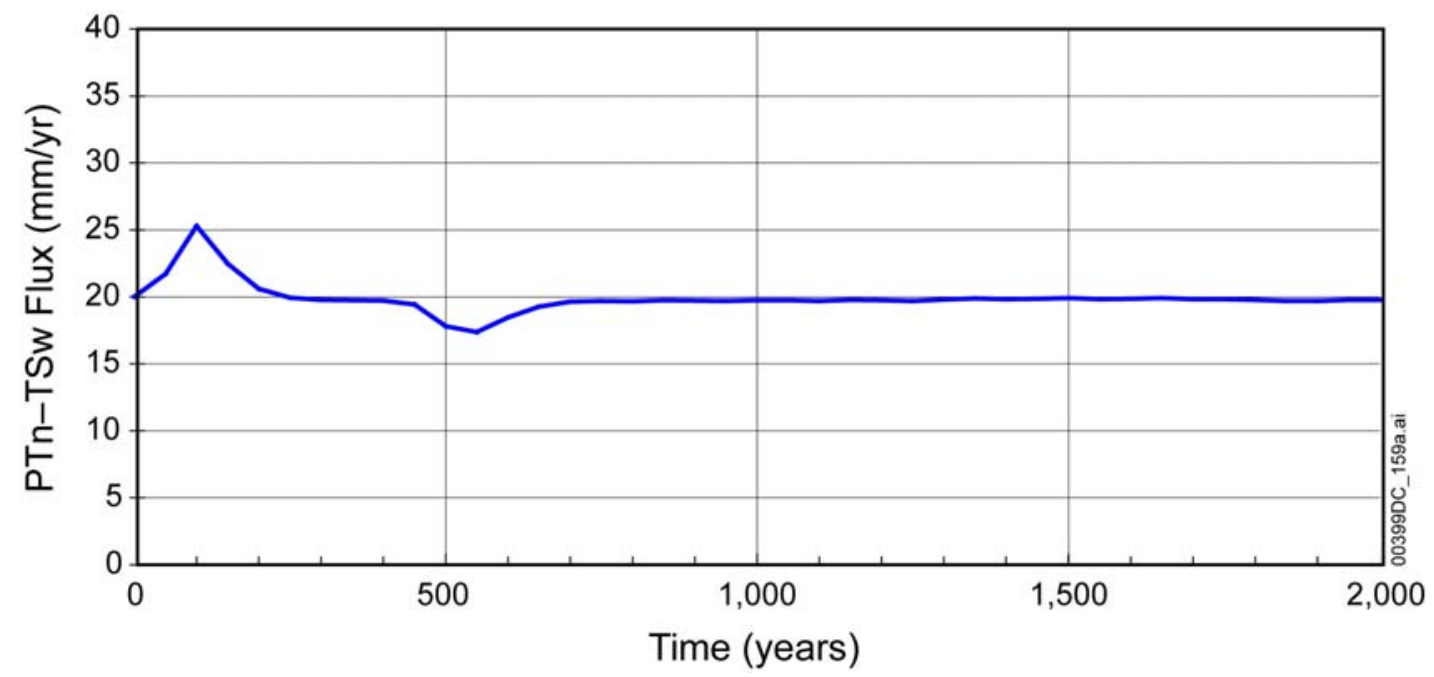

Source: Wang 2003 (DIRS 162417) SN-LBNL-SCI-199-V1, pp.147 to 155.

NOTE: Subject to one-week transient infiltration pulses every 50 years, equivalent to $20 \mathrm{~mm} /$ year averaged infiltration rate.

Figure G-12. Simulated Variations in Total Percolation Fluxes Versus Times at the Bottom PTn Unit of the One-Dimensional Model

\section{G5. DAMPING EFFECT ON TRACER TRANSPORT}

The information in this section is based on the study by Wu et al. (2002 [DIRS 161058]).

A cross-sectional model is used to investigate tracer or groundwater transport times under strong lateral flow conditions. The model simulation results further demonstrate the damping effect of the PTn unit on the contaminant transport. The cross section is oriented from northwest to southeast (see cross section C-C' in Figure G-1), which, in general, follows the dipping direction of the PTn unit in this area (Wu et al. 2002 [DIRS 161058]). The geologic model indicates that the cross section intersects seven small faults (defined as vertical faults with small, up to 1-m offsets) in addition to one major fault (Drill Hole Wash). A numerical grid is generated for this cross section, which explicitly includes the one large fault and seven small faults. In the model, both large and small faults are treated as vertical zones with a $2 \mathrm{~m}$ width. The difference is in assignment of fracture-matrix properties to fault zones, in which the major fault uses calibrated fault fracture-matrix properties while small faults incorporate only calibrated fault fracture properties whose matrices have the same properties as those of the adjacent unfaulted matrix blocks.

In the cross-sectional model, transport simulations of a tracer are presented for further insight into the capillary-barrier effect on groundwater and tracer transport times in the PTn unit. The tracer is treated as a conservative (nonabsorbing) component transported through the model. The mechanical dispersion effect through the fracture-matrix system was previously found to be insensitive to modeled results (Wu et al. 2002 [DIRS 161058]), and is ignored in this study (A constant molecular diffusion coefficient of $3.2 \times 10^{-11} \mathrm{~m}^{2} / \mathrm{s}$ is used for matrix diffusion.) Two transport simulation scenarios of different tracer releases are run to 100,000 years under steady-state flow fields. The first scenario released a tracer with an initial constant source 
concentration in fracture blocks along the entire top model boundary, and the second released a tracer with an initial constant source concentration at only one fracture block of the top $(\mathrm{x}=200 \mathrm{~m})$.

For the first scenario, the tracer or groundwater transport times are analyzed using breakthrough curves of concentrations (shown in Figure G-13) monitored at several elevations within the PTn at $\mathrm{x}=1,300 \mathrm{~m}$ in the middle of the cross-sectional model. Figure G-13 shows that it takes from 2,000 to 3,000 years for percolation water to reach these depths, as indicated by peak values of concentration breakthrough curves. In Figure G-13, the first peak at $\operatorname{ptn} 25(\mathrm{z}=1,210 \mathrm{~m})$ corresponds to transport times of the tracer released from the top boundary area directly above the observation point, while the second, higher peak is the result of combined downward and laterally diverted transport. Carbon composition $\left({ }^{14} \mathrm{C}\right)$ data collected within the bedded tuffs of the PTn unit near this cross section from 1984 to 1994 (Yang et al. 1996 [DIRS 100194]) reveal average activity values of 70 percent modern carbon (pmc). This corresponds to a water age of approximately 2,900 years in the PTn, similar to that predicted by the model. This result supports the model prediction that significant lateral movement and mixing occurs in the PTn. This large lateral flow phenomenon is consistent with the observation in an underground seepage test of flow in the PTn unit (BSC 2004 [DIRS 170004], Section 6.7).

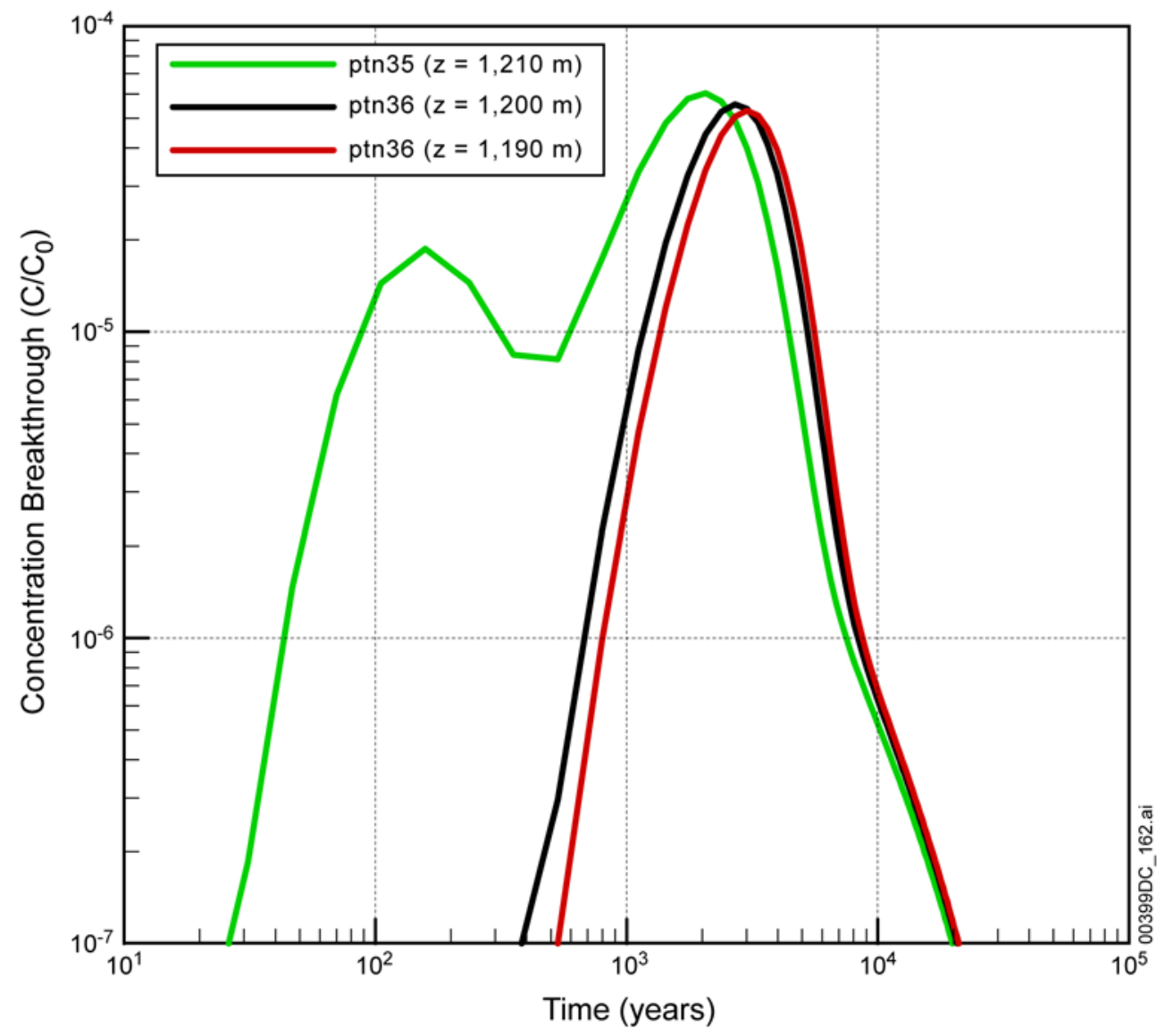

Source: Wu et al. 2002 (DIRS 161058), Figure 10.

Figure G-13. Simulated Normalized Tracer Concentration Breakthrough Curves at Three Elevations of $\mathrm{x}=1,300 \mathrm{~m}$ along the Middle of the $\mathrm{C}-\mathrm{C}^{\prime}$ Cross Section 
Figure G-14 displays a snapshot of normalized tracer concentration (relative to initial source concentration $\mathrm{C}_{0}$ ) distributions in fractures after 1,000 years of tracer release, indicating significant lateral flow or transport along the cross section from the second transport simulation. At the same time, the simulated matrix concentration plume is similar to the one shown in Figure G-14, but a little delayed in transport distance. The results of the second simulation indicate that the center of the tracer plume, upon reaching the PTn-TSw interface, moved laterally about $1,000 \mathrm{~m}$ along the cross section, with the plume front laterally crossing several faults. The average water transport times to the bottom boundary estimated from the second, one-point-tracer-release simulation is much longer than those from the first simulation with uniform tracer release on the top. This is because the one-point-tracer-release result predicts a much longer transport distance than the average results of the uniform tracer release scenario under the same flow conditions.

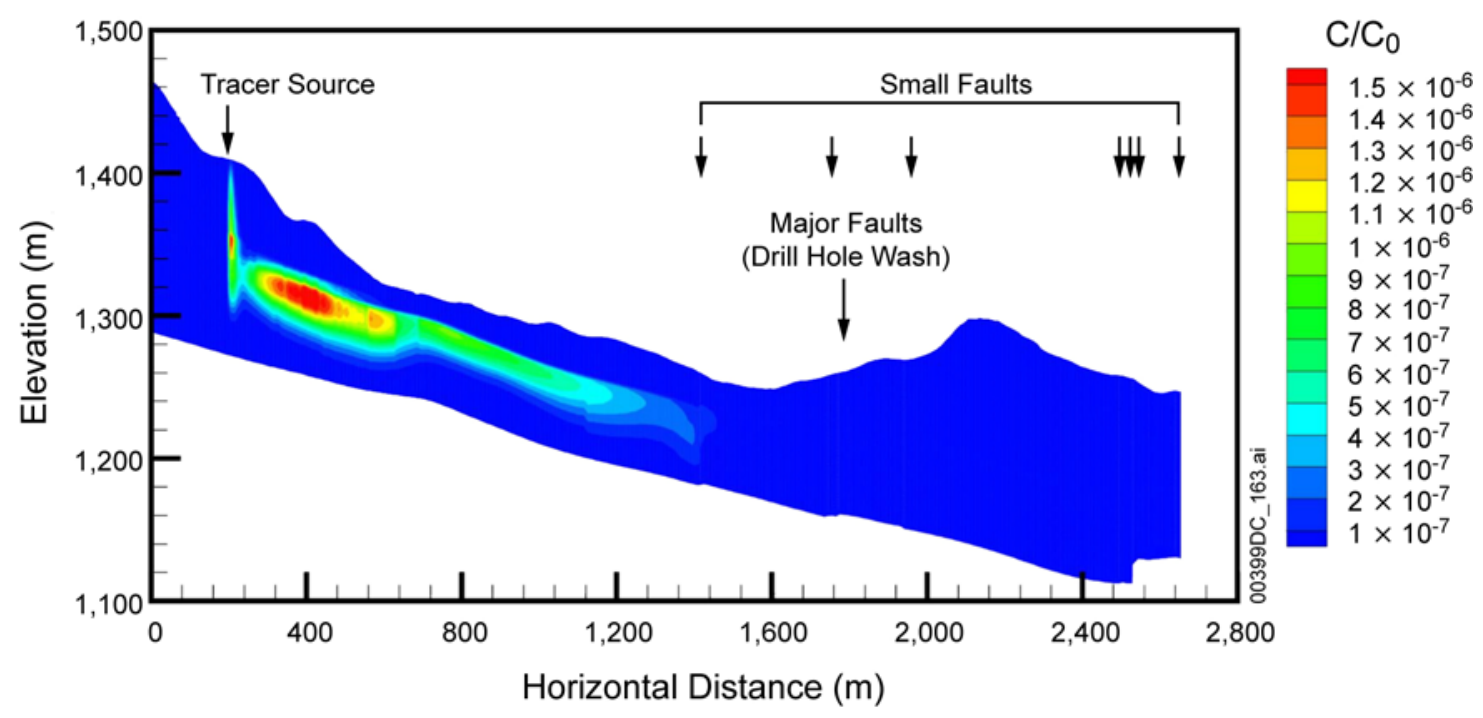

Source: Wu et al. 2002 (DIRS 161058), Figure 11.

Figure G-14. Distribution of Normalized Tracer Concentrations within the C-C' Cross-Sectional Percolation after 1,000 Years of Tracer Release from the One-Point Source

\section{G6. SUMMARY}

This appendix has demonstrated the effectiveness of the PTn unit in damping percolation flow. First, the effect of the capillary barrier on the PTn was discussed using results of two-dimensional cross-sectional models and three-dimensional mountain-scale models for its spatial redistribution and focusing capacity. The modeling results indicate that significant capillary-barrier effects exist and result in large-scale lateral flow within the PTn unit. Secondly, it was demonstrated that the PTn is efficient in smoothing rapid transient infiltration pulses from surface infiltration and the $\mathrm{TCw}$ unit using one-dimensional and two-dimensional model simulations with two extremely episodic infiltration scenarios. Third, the damping effect of the PTn unit was demonstrated through a tracer transport model. The PTn spatial smoothing effect is also confirmed by the results of previous modeling study. 


\section{APPENDIX H}

\section{${ }^{36}$ CL STUDIES AT YUCCA MOUNTAIN}




\section{H1. BACKGROUND INFORMATION}

This appendix provides information, review and analysis regarding Chlorine-36 $\left({ }^{36} \mathrm{Cl}\right)$ previous field and modeling studies.

The information in this section is based on work by Lu et al. (2003 [DIRS 168915]).

To assess the movement of groundwater through the upper portions Yucca Mountain, studies in the mid to late 1990's focused on the use of Chlorine-36 as an anthropogenic tracer to detect the rapid movement of surface waters to the depth of the repository horizon. The results of the Chlorine-36 studies can be found in documents by BSC (2004 [DIRS 169734], Section 5.2.2.5.3), Fabryka-Martin et al. (1996 [DIRS 101003]), and Flint et al. (2001 [DIRS 156351]). Understanding potential fast pathways into the repository horizon will help identify likely areas of seeps into repository drifts under wetter climatic conditions in the future.

Chlorine, a conservative water movement tracer, has a radioactive isotope Chlorine-36, which has a 301,000-year half-life. Chlorine-36 is produced naturally by interaction of cosmic rays with argon in the atmosphere. Because the amount of Chlorine-36 generated has changed over time, the ratio of Chlorine-36 to stable chlorine $\left({ }^{36} \mathrm{Cl} / \mathrm{Cl}\right)$ is a measure of a groundwater age.

Over the past tens of thousands of years, the ${ }^{36} \mathrm{Cl} / \mathrm{Cl}$ ratio has varied because of variations in chloride deposition rates and variations in the production rate (A broad-brush picture shows a bi-modal distribution: a fairly constant ${ }^{36} \mathrm{Cl} / \mathrm{Cl}$ ratio of about $5 \times 10^{-13}$ (Holocene signal) over the last 10,000 years and a somewhat elevated ration of about $12 \times 10^{-13}$ (Pliestocene signal) before that period. This bimodal distribution has been verified by analyzing fossilized pack-rat middens (BSC 2004 [DIRS 169734], Section 5.2.2.5.3). From 1952 to 1963, a Chlorine-36 spike (ratios of ${ }^{36} \mathrm{Cl} / \mathrm{Cl}$ in excess of $10 \times 10^{-8}$ ) was introduced into the atmosphere due to weapons testing in the South Pacific. This "bomb pulse" spike can be used to test for recent groundwater from the surface at Yucca Mountain to the level of the repository via fast pathways (faults and fractures).

During the initial investigation of Chlorine-36 in the Exploratory Studies Facility (ESF) and Enhanced Characterization of the Repository Block Cross-Drift, over 250 crushed rock samples were collected. When these samples were leached, four distinct sets of ${ }^{36} \mathrm{Cl} / \mathrm{Cl}$ ratios were statistically determined. The two main sets of ratios were the expected Holocene and Pliestocene signals. In addition, a similar number of samples had low ${ }^{36} \mathrm{Cl} / \mathrm{Cl}$ ratios, indicating the presence of greater than 300,000-year-old waters. Finally, a small set of the collected samples (about 13 percent) had elevated ${ }^{36} \mathrm{Cl} / \mathrm{Cl}$ ratios indicating the potential presence of young "bomb-pulse" waters at the repository horizon level. As shown in Figure H-1, these apparent "bomb-pulse" signals are associated with faults that cut through all of the units overlying the repository, and where thin alluvial cover at the surface allows for rapid movement of waters from the surface to the repository horizon.

${ }^{36} \mathrm{Cl}$ has been successfully used to date very old groundwater. ${ }^{36} \mathrm{Cl}$ is generated naturally in the atmosphere, washes out by precipitation, and, subsequently, enters the ground. Before ${ }^{36} \mathrm{Cl}$ enters the ground, however, its concentrations are affected by a number of different physical 
processes, especially evapotranspiration. To account for the effect of these processes on ${ }^{36} \mathrm{Cl}$ concentrations, ${ }^{36} \mathrm{Cl}$ signatures are usually expressed as ${ }^{36} \mathrm{Cl} / \mathrm{Cl}$ ratios.

Another important use of ${ }^{36} \mathrm{Cl}$ is in identifying the movement of young water, taking advantage of ${ }^{36} \mathrm{Cl}$ bomb-pulse input from nuclear tests. The lower limit of bomb-pulse inputs $\left({ }^{36} \mathrm{Cl} / \mathrm{Cl}\right.$ ratios) is set to $1,250 \times 10^{-15}$, which is about the upper limit of input for the Pleistocene (Fabryka-Martin et al. 1997 [DIRS 100145]; 1998 [DIRS 162737]). This is based on the meteoric ${ }^{36} \mathrm{Cl} / \mathrm{Cl}$ ratios of recent geological time, which are approximately $550 \times 10^{-15}$ throughout the Holocene, and average $900 \times 10^{-15}$ for the late Pleistocene (with peak values as high as $1,100 \times 10^{-15}$ ) at Yucca Mountain. On the other hand, there are sources of chlorine with low ${ }^{36} \mathrm{Cl} / \mathrm{Cl}$ ratios in the tuffs at Yucca Mountain. They include a small component of ${ }^{36} \mathrm{Cl}$ produced by radioactive decay in the rock, and chlorine in equilibrium with subsurface production rates from natural neutron fluxes within the host tuffs $\left({ }^{36} \mathrm{Cl} / \mathrm{Cl}\right.$ ratios about $\left.35 \times 10^{-15}\right) \quad($ Fabryka-Martin et al. 1997 [DIRS 100145]; 1998 [DIRS 162737]). The identification of bomb-pulse input is challenging because of the presence and subsequent dilution of chlorine sources having low ${ }^{36} \mathrm{Cl} / \mathrm{Cl}$ ratios.

Because bomb-pulse signals indicate relatively young input, they are used to identify fast flow paths in relatively impermeable media (matrix). A study of ${ }^{36} \mathrm{Cl}$ at Yucca Mountain conducted in the mid-to-late $1990 \mathrm{~s}$ by Los Alamos National Laboratory (LANL) reported elevated ${ }^{36} \mathrm{Cl} / \mathrm{Cl}$ ratios attributed to atmospheric nuclear testing (Fabryka-Martin et al. 1997 [DIRS 100145]; 1998 [DIRS 162737]). The finding of bomb-pulse ${ }^{36} \mathrm{Cl}$ in the ESF within 50 years of nuclear testing (Fabryka-Martin et al. 1997 [DIRS 100145]; 1998 [DIRS 162737]) indicated the potential presence of fast flow paths extending $300 \mathrm{~m}$ from the surface to the repository depth through unsaturated fractured rock in 50 years. This may have led to the conclusion that at least some meteoric water is capable of percolating rapidly through the thick zones of unsaturated rock, even crossing several strata with contrasting hydrologic properties.

\section{H1.1 SAMPLING AND LEACHING EXPERIMENT}

For the LANL ${ }^{36} \mathrm{Cl}$ analyses, rock samples were collected mainly from tunnel walls of the Yucca Mountain ESF, primarily by dry chipping and drilling methods (Fabryka-Martin et al. 1997 [DIRS 100145]), with the chloride leached from samples for isotopic analysis. Typical sample sizes for leaching were 1 to $5 \mathrm{~kg}$ of rock. Unconsolidated or poorly consolidated material (such as fault gouge) was leached in the same form as it was received. For most other samples, the rock was crushed with a hammer to create chips of approximately 1 to $2 \mathrm{~cm}$ prior to leaching. These samples were then placed in a pot and immersed with an equal mass of deionized water for 48 hours. The leachate was used to obtain $\mathrm{AgCl}$ by adding $\mathrm{AgNO}_{3}$. $\mathrm{AgCl}$ precipitates were, subsequently, sent to the Purdue Rare Isotope Measurement Laboratory at Purdue University for chlorine isotope analysis by accelerator mass spectrometry (Fabryka-Martin et al. 1997 [DIRS 100145]; 1998 [DIRS 162737]). 


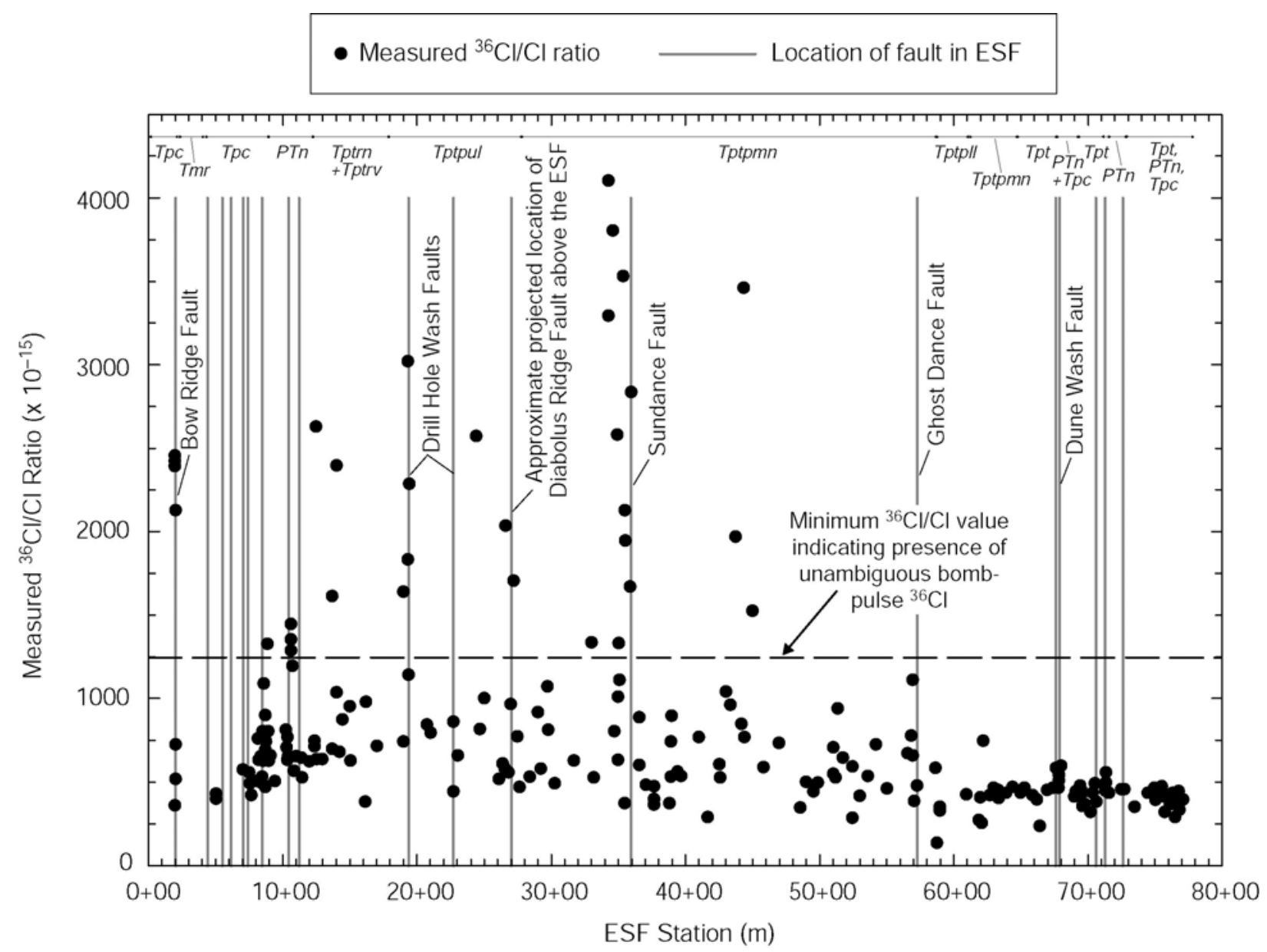

Source: Based on BSC 2004 [DIRS 170004], Figure 6.14.2-1.

NOTE: This plot shows the distribution of ${ }^{36} \mathrm{Cl} / \mathrm{Cl}$ ratios measured for rock samples in the Exploratory Studies Facility. Faults in the Exploratory Studies Facility that correlated with mapped faults at the surface are shown [2004 [DIRS 170004]).

Figure $\mathrm{H}-1$. Early Data Distribution of ${ }^{36} \mathrm{Cl} / \mathrm{Cl}$ in the Exploratory Studies Facility

Whereas LANL samples were collected mostly from tunnel walls, the validation study samples (36 of them) were obtained from cores of forty 4-10 m long, dry-drilled boreholes between stations 3,389 $\mathrm{m}$ and 3,690 $\mathrm{m}$ (distance from the North Portal entrance) around Sundance fault. In addition, six samples of the core from a borehole in Niche 1 (also referred to as Niche 3566) were taken and initially analyzed at Lawrence Livermore National Laboratory (LLNL). These validation study samples were crushed, and the 6 to $13 \mathrm{~mm}$ size fractions were leached in a slowly rotating tumbler for 7 hours. This method yielded leachate with high chlorine concentrations (approximately 1 to $4.6 \mathrm{mg} / \mathrm{kg}$ rock) and $l o w{ }^{36} \mathrm{Cl} / \mathrm{Cl}$ ratio (approximately $40 \times 10^{-15}$ to $275 \times 10^{-15}$ ), as a result of potential over-extracting rock chlorine with negligible ${ }^{36} \mathrm{Cl}$ (Paces et al. 2003 [DIRS 162738]).

The validation study leaching experiment at LLNL was performed on smaller rock-chip sizes than those at LANL, and the validation study samples were actively disturbed (rotated). In the next phase of the LLNL validation study, different leaching protocols were adopted. The 
validation study samples were prepared at the U.S. Geological Survey (USGS) facilities in Denver and analyzed at the LLNL Center for Accelerator Mass Spectrometry. Samples were hand- or machine-crushed and sieved to 2 to $19 \mathrm{~mm}$ sized fractions. USGS used 1 to $2 \mathrm{~kg}$ of crushed rock placed in stainless-steel wire baskets and immersed in stainless-steel stockpots containing an equal weight of deionized water. After soaking for 1 hour, the rock was removed and the leachate was filtered $(0.45 \mu \mathrm{m})$ (Paces et al. 2003 [DIRS 162738]). These samples were found to have no elevated ${ }^{36} \mathrm{Cl} / \mathrm{Cl}$ (Paces et al. 2003 [DIRS 162738]).

Based on these results, the reproducibility of the bomb-pulse measurements would seem to be problematic. The protocols of the leaching experiments have not been consistent, even though the sample processing was meant to be performed under conditions similar to the passive-leaching methods used in earlier LANL studies. The validation study samples were crushed manually (hammer) or machine, and subsequently sieved to obtain a larger fraction of the sample. This treatment created significantly smaller chip sizes in the validation study than those in the previous LANL study.

\section{H1.2 DISCREPANCY IN LEACHING RESULTS}

As indicated in the previous section, the interpretation that the ${ }^{36} \mathrm{Cl} / \mathrm{Cl}$ ratios at Yucca Mountain indicate the presence of bomb-pulse signals is open to question. This is because the ${ }^{36} \mathrm{Cl}$ bomb-pulse component on the fracture surfaces-presumably where bomb-pulse ${ }^{36} \mathrm{Cl}$ would reside, if present-can be overwhelmed by chlorine from other sources in the rock. Variability in results may also result from the difference in methods used for chlorine leaching.

The dependence of leaching results on the protocol used was demonstrated in a study of sediments from Pasco Basin, Washington, in which chloride extraction was shown to be sensitive to grain size (Murphy et al. 1996 [DIRS 169762]). A similar observation was made for Yucca Mountain rock samples. Samples pulverized by the ream bit during borehole drilling have consistently lower ${ }^{36} \mathrm{Cl} / \mathrm{Cl}$ ratios than samples from the same stratigraphic intervals collected by less destructive methods (Fabryka-Martin et al. 1998 [DIRS 162737]). Bomb-pulse ${ }^{36} \mathrm{Cl}$ concentrations (and hence ${ }^{36} \mathrm{Cl} / \mathrm{Cl}$ ratios) in borehole samples were diluted to a higher extent for finer samples, by the leaching of chloride incorporated into the rock matrix at the time of its formation (Fabryka-Martin et al. 1998 [DIRS 162737]). This explanation was supported by $\mathrm{Br} / \mathrm{Cl}$ data (Fabryka-Martin et al. 1997 [DIRS 100145]; 1998 [DIRS 162737]). Such dilution is also confirmed through review of the existing ${ }^{36} \mathrm{Cl}$ data (Fabryka-Martin et al. 1997 [DIRS 100145]), showing that the ${ }^{36} \mathrm{Cl} / \mathrm{Cl}$ ratios are approximately inversely proportional to the increase in chlorine concentration (Sonnenthal and Bodvarsson 1999 [DIRS 117127]). This finding indicates that ${ }^{36} \mathrm{Cl} / \mathrm{Cl}$ ratios may, in fact, be a function of the chloride dissolution from the rock matrix.

The results from the LANL studies (Fabryka-Martin et al. 1997 [DIRS 100145]) show that the bomb pulse ${ }^{36} \mathrm{Cl} / \mathrm{Cl}$ ratios are not only present at fault zones but also in fractured zones between faults. However, bomb-pulse ${ }^{36} \mathrm{Cl} / \mathrm{Cl}$ ratios were not identified in some locations where they could be expected. For example, given the LANL studies' findings, the south ramp of the ESF might be expected to have bomb-pulse chloride, due to the thinness of the overlying PTn. However, the measured data do not clearly indicate the presence of any bomb-pulse ${ }^{36} \mathrm{Cl} / \mathrm{Cl}$ ratios in this area (Fabryka-Martin et al. 1997 [DIRS 100145]). Statistical analysis shows that 
several of the ${ }^{36} \mathrm{Cl} / \mathrm{Cl}$ ratios for the south ramp are likely to contain bomb-pulse ${ }^{36} \mathrm{Cl}$, a conclusion that is only revealed once the lower background in this area is taken into account (Campbell et al. 2003 [DIRS 162745]).

\section{H1.3 CONCLUSIONS FROM MODELING STUDIES}

To understand how sample extraction might affect ${ }^{36} \mathrm{Cl} / \mathrm{Cl}$ ratios, Lu et al. (2003 [DIRS 168915]) developed a leaching model to simulate the effects from a variety of factors in the leaching process, including time, rock-chip sizes, and the gravitational settlement of the rock-water mixtures (active and passive leaching). The model also evaluates the effect of pore-water chlorine concentration and bomb-pulse strength on the observed bomb-pulse ratios.

The model results of the report by Lu et al. (2003 [DIRS 168915]) show that bomb-pulse signals can be most likely recovered within 1 to 10 hours of leaching as the leachate concentration increases with time. The peak time for bomb-pulse ratios mainly depends on the strength of the bomb-pulse layer thickness. Moreover, bomb-pulse ratios are influenced by the difference between active and passive leaching. Active leaching yields more chlorine than passive leaching, and produces lower bomb-pulse ratios. The bomb-pulse ratios are also influenced by the different sizes of rock chips, especially in TSw samples. More chlorine is leached out as sample sizes decrease, leading to a decrease in bomb-pulse ratios. The effect of size may have impacted the validation study samples. The validation study by USGS-LLNL attempted to follow the protocol used in the previous study by LANL. But the validation study samples included chips as small as $0.2 \mathrm{~cm}$, which significantly diminished the ability to reproduce leachate of elevated ${ }^{36} \mathrm{Cl} / \mathrm{Cl}$ because the size effect is greater on samples with smaller rock-chip sizes.

Their results indicate that bomb-pulse ratios are masked in the Tiva Canyon welded hydrogeologic and Paintbrush nonwelded hydrogeologic units when using the ${ }^{36} \mathrm{Cl} / \mathrm{Cl}$ ratios to measure the bomb-pulse signature, because of high chlorine concentration and relatively high porosity. This corroborates the masking effect observed by Sonnenthal and Bodvarsson (1999 [DIRS 117127]).

The bomb-pulses reported by Fabryka-Martin et al. (1997 [DIRS 100145]; 1998 [DIRS 162737]) in the ESF main drift (TSw) are associated with very low pore-water chlorine concentration roughly in the range of 3 to $21 \mathrm{mg} / \mathrm{L}$. The LANL samples with bomb pulse ${ }^{36} \mathrm{Cl} / \mathrm{Cl}$ are correlated with the signatures of construction water. Samples with low pore-water chloride are found to have a greater fraction of water and chlorine from construction sources (Lu et al. 2003 [DIRS 168915]). This result is because at this low concentration level, bomb-pulse ratio ${ }^{36} \mathrm{Cl}$ are less diluted during leaching and, thus, possibly more easily detected by leaching.

In conclusion, the USGS validation studies and LANL studies were performed under different leaching protocols. Specifically, the USGS validation samples were consistently in smaller chip size than the samples used by LANL. Based on the size effect of the ${ }^{36} \mathrm{Cl} / \mathrm{Cl}$ signatures, the general lower concentration value of the USGS samples are reasonably explained because of the smaller size, while the higher value of the LANL samples are also validated for their larger chip size. Both the USGS validation studies and the LANL studies produced reasonable results under their respective leaching conditions. Besides, those LANL samples with bomb-pulse signatures 
are associated with pore water with very low chlorine concentration (Lu et al. 2003 [DIRS 168915], Section 4.4), at which the size effect of the leaching is expected to be more severe.

\section{H2. GROUNDWATER AND ${ }^{36}$ CL TRANSPORT TIMES FROM THE LAND SURFACE}

The information in this section is based on the previous model studies of UZ Flow Models and Submodels (BSC 2001 [DIRS 158726]). ${ }^{36} \mathrm{Cl}$ groundwater transport times were modeled using the three-dimensional model grid with the present-day, mean infiltration rate. Detailed information for the model development can be found in UZ Flow Models and Submodels (BSC 2001 [DIRS 158726]).

The model was developed to investigate groundwater transport times from the ground surface to the repository level, as well as ${ }^{36} \mathrm{Cl}$ transport phenomena under steady-state unsaturated zone flow conditions. A tracer with ${ }^{36} \mathrm{Cl}$ transport properties was introduced into the top grid or infiltration layer of the calibration grid with the climate scenario of the present-day, mean infiltration for the modeling studies. Four simulation scenarios with different surface tracer boundary conditions were specified within a small area directly above the repository and for the entire model domain, respectively. Use of the small area of the tracer source boundary condition on the land surface reduces the possible effects of lateral boundaries and focuses transport behavior on the immediate vicinity above the repository. The small tracer-source area is defined as an area directly above the repository bounded by the Solitario Canyon, Drill Hole Wash, and Ghost Dance faults in the west, north, and east, with the southern boundary in alignment with the south ramp of the ESF.

Two types of boundary conditions were specified for the tracer, one being a constant initial tracer concentration and the other a constant tracer mass injection rate in the fracture gridblocks of the boundary. In the four simulations, the tracer was treated as a conservative (nonabsorbing) and decaying component. For all cases, the hydrodynamic dispersion effect through the fracture-matrix system was included with longitudinal dispersivities of 20 and $5 \mathrm{~m}$, and transverse dispersivities of 4 and $1 \mathrm{~m}$, respectively, for the fracture and matrix systems. Transport simulations were conducted for 1,000,000 years.

Among the four simulation scenarios: (1) cam1_CL1 uses a constant initial tracer concentration boundary condition within the small source area (the area directly above the repository); (2) cam1_CL2 uses a constant tracer mass flux boundary condition proportional to the net infiltration rate for each fracture block within the small source area; (3) cam1_CL3 uses a constant initial tracer concentration boundary condition over the entire top model area; and (4) cam1_CL4 uses a constant tracer mass flux boundary condition with each fracture block over the entire top model area.

Groundwater or ${ }^{36} \mathrm{Cl}$ transport times to the repository following release from the ground surface can be estimated using a cumulative or fractional breakthrough curve (shown in Figure $\mathrm{H}-2$ for the four simulation scenarios). Figure H-2 shows a similar range of groundwater tracer transport times for the four different surface source conditions with the same present-day, mean infiltration rate. Except for the scenario with a constant initial concentration within the small surface source area (cam1_CL1), there is about 1 percent mass breakthrough during 10 to 100 years after tracer release on the ground. 
This indicates the existence of possible fast flow pathways (with a transport time of 50 years) from the ground surface to the repository level under the steady-state unsaturated zone flow condition. However, the cumulative mass breakthrough is small (approximately 1 percent of the total mass released on the ground) for the early breakthrough at 50 years. The average groundwater transport times from the surface to the repository level are estimated to be between 5,000 to 20,000 years using the 50 percent mass breakthrough curves of Figure $\mathrm{H}-2$ from the four simulation results.

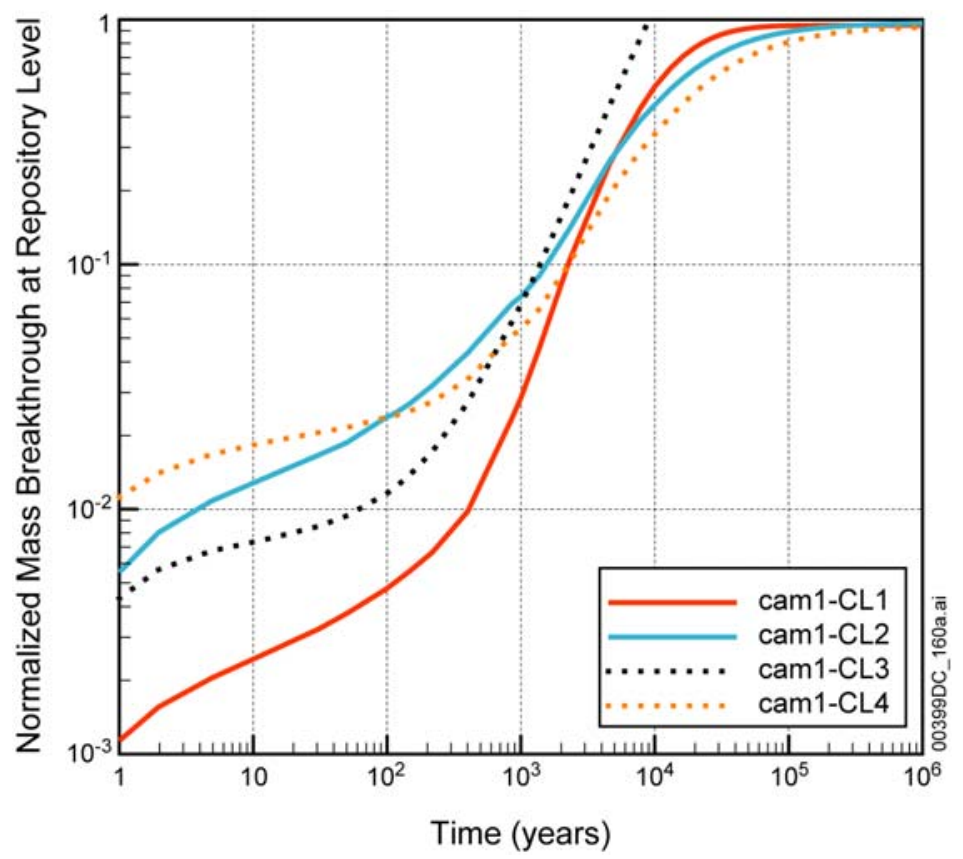

Source: $\quad$ BSC 2001 (DIRS 158726), Figure 6-60.

Figure $\mathrm{H}-2$. Simulated Breakthrough Curve of Cumulative $\left({ }^{36} \mathrm{Cl}\right)$ Mass Arriving at the Repository Level, Since Release from the Ground Surface Using Present-Day Mean Infiltration and Four Simulation Scenarios (Note: Normalized Mss Breakthrough for the instantaneous release cases of cam1-CL1 and cam1-CL3 is calculated using total accumulative mass flux at the repository level, divided by the total initial source mass; while Normalized Mss Breakthrough for the continuous release cases of cam1-CL2 and cam-CL4 is determined using total mass flux at the repository level, divided by the recharge mass rate)

Figure H-3 shows spatial profiles of tracer mass fraction or concentrations in the unsaturated zone model at 50 years after release from the small source area of the top boundary. Figure H-3 indicates, in plan view, localized breakthrough at the repository level showing all high mass fraction and concentration zones associated with faults. Examination of the simulated tracer concentration distributions along vertical cross sections, the ESF, and Enhanced Characterization of the Repository Block indicates that in the vertical direction, tracer plumes penetrate faster only along high-permeability faults during the earlier transport times of 50 to 1000 years.

The ${ }^{36} \mathrm{Cl}$ transport simulation results using the unsaturated zone flow model suggest that fast flow pathways may exist in PTn unit, and that only a small percentage of ${ }^{36} \mathrm{Cl}$ mass breaks through in 50 years along the repository layers. Unsaturated flow modeling indicates that only a very small percentage (approximately 1 percent) of water entering Yucca Mountain is transmitted via these "fast-pathways". While the existence of these "fast-paths" remains to be 
confirmed (see BSC 2004 [DIRS 170004], Section 6.14), a model including them would be a more conservative approach for estimating unsaturated zone flow. For this reason, this appendix has conservatively compared simulated results to the ${ }^{36} \mathrm{Cl} / \mathrm{Cl}$ results that indicate "fast paths". The small portion flux through fast flow path is not expected to affect the repository performance. This indicates that the model results are consistent with observed ${ }^{36} \mathrm{Cl}$ data.

\section{H3. SUMMARY}

${ }^{36} \mathrm{Cl}$ studies for the Yucca Mountain site were discussed and transport simulation results were presented to show that only a small percentage of ${ }^{36} \mathrm{Cl}$ mass breaks through in 50 years along the repository layers. This indicates that the unsaturated zone flow model results are consistent with observed ${ }^{36} \mathrm{Cl}$ data. Because of the significance of these reported ${ }^{36} \mathrm{Cl}$ findings, a ${ }^{36} \mathrm{Cl}$ validation study was initiated at the direction of the U.S. Department of Energy to independently substantiate these findings by project researchers (BSC 2004 [DIRS 170004]). 


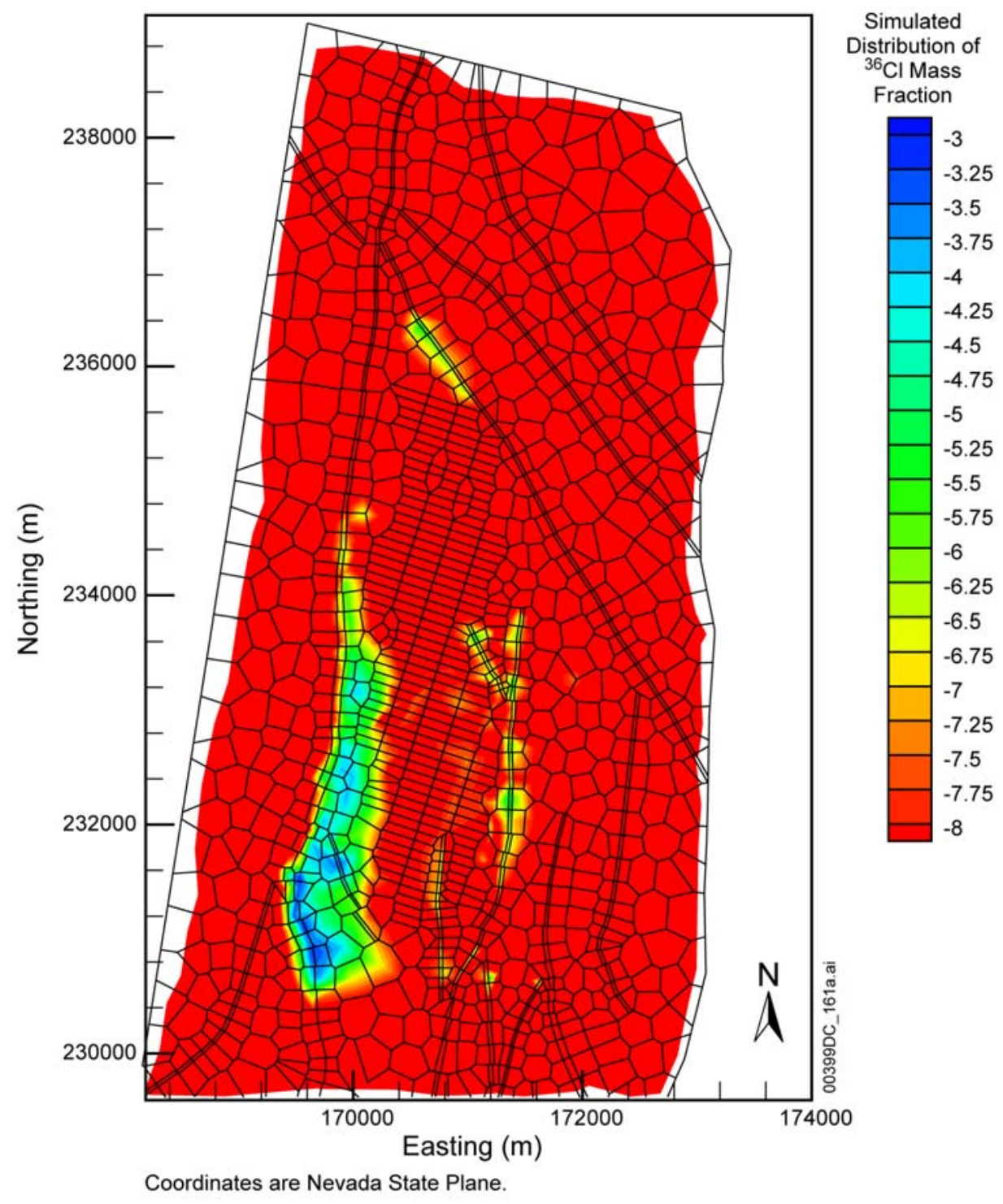

Source: $\quad$ BSC 2001 (DIRS 158726), Figure 6-61.

NOTE: $\quad$ Shown mass fraction is normalized to mass fraction values at source.

Figure H-3 Simulated Distributions of Logarithmic Values of Normalized ${ }^{36} \mathrm{Cl}$ Mass Fraction in the Matrix Blocks along the Repository Layers at 50 years of Release from Surface Fractures 


\section{INTENTIONALLY LEFT BLANK}




\section{APPENDIX I}

\section{EVALUATION OF THE NEW INFILTRATION MAP}


This appendix provides evaluation of the newly estimated, alternative net surface infiltration map (BSC 2004 [DIRS 170007], DTN: SN0408T0507804.003 [DIRS 171350]) for its effect on unsaturated zone (UZ) flow model results. The evaluation is conducted using the current three-dimensional UZ flow model with incorporation of the alternative infiltration data.

\section{I1. NEW INFILTRATION MAP}

The new net infiltration map (DTN: SN0408T0507804.003 [DIRS 171350]) is provided for sensitivity analyses of present-day, mean infiltration rates on UZ flow model results in this Appendix. A plan view of the spatial distribution in the new infiltration map, as interpolated onto the Total System Performance Assessment for license application (TSPA-LA) grid, is shown in Figure I-1 for this alternative, present-day, mean infiltration scenario. For a better comparison with the current, present-day, mean infiltration patterns (Figure 6.1-2), Figure I-2 presents a contour map of net difference between the two present-day infiltration maps, and the differences are calculated with the infiltration values from the new map, subtracted column by column by the corresponding values from the current infiltration map (Figure 6.1-2). Negative values or red colors in Figure I-2 indicate the areas with decrease in net infiltration for the new infiltration map. As compared with the current present-day, mean infiltration patterns (Figure 6.1-2), Figures I-1 and I-2 show a generally similar, but very different recharge flux distribution. The main difference are: (1) there is a wider high infiltration zone along the middle of the model domain from the Drill Hole Wash fault down to the south, bounded by the Solitario Canyon and Ghost Dance faults in the west and east, respectively; (2) significant decrease in the very north of the model domain with some decrease along the crest of the mountain near the middle of the model domain; and (3) large increase in the area west to Solitario Canyon and south to the Drill Hole Wash fault.

Table I-1 presents the statistics of both the new and current present-day infiltration maps for their average values over the UZ model domain. As shown in Table I-1, the average rate over the entire UZ model domain for the new present-day mean infiltration is $5.25 \mathrm{~mm} / \mathrm{year}$, as comparing to $4.43 \mathrm{~mm} / \mathrm{year}$ (Wang 2003 [DIRS 162417], SN-LBNL-SCI-199-V1, pp. 159 to 173), indicating a 18.5 percent net increase in infiltration rate. Within the repository footprint at the center of the model domain, however, Table I-1 shows that the average infiltration rate changes from 4.13 to $7.14 \mathrm{~mm} / \mathrm{year}$, or a 73 percent net increase.

Table I-1. Comparison of Infiltration Rates and Statistics of Current and New Present-Day Infiltration Maps, Averaged over the UZ Model Domain

\begin{tabular}{|l|c|c|}
\hline \multicolumn{1}{|c|}{ Scenario } & $\begin{array}{c}\text { Mean Infiltration (mm/year) } \\
\text { Over UZ Model Domain }\end{array}$ & $\begin{array}{c}\text { Mean Infiltration (mm/year) } \\
\text { Within Repository Footprint }\end{array}$ \\
\hline $\begin{array}{l}\text { Infiltration used in UZ flow } \\
\text { model for TSPA }\end{array}$ & 4.43 & 4.13 \\
\hline New, alternative Infiltration & 5.25 & 7.14 \\
\hline
\end{tabular}

Output DTNs: LB03023DSSCP9I.001 and LB0408RITSSCPF.001. 


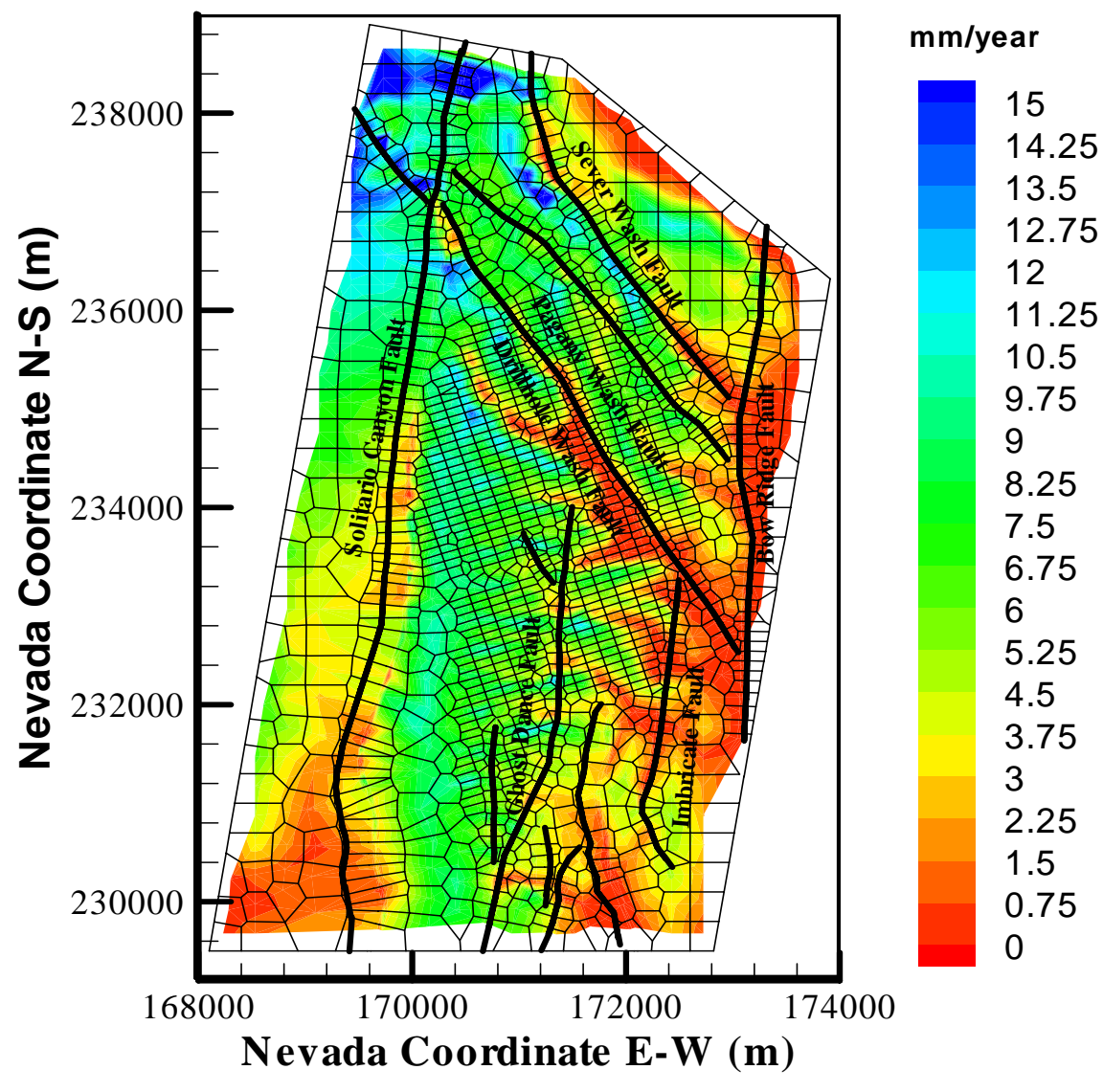

Output DTN: LB0408RITSSCPF.001.

Figure I-1. Plan View of New, Alternative Net Infiltration Distributed over the Three-Dimensional UZ TSPA-LA Model Grid for an Alternative Present-Day Mean Infiltration Scenario 


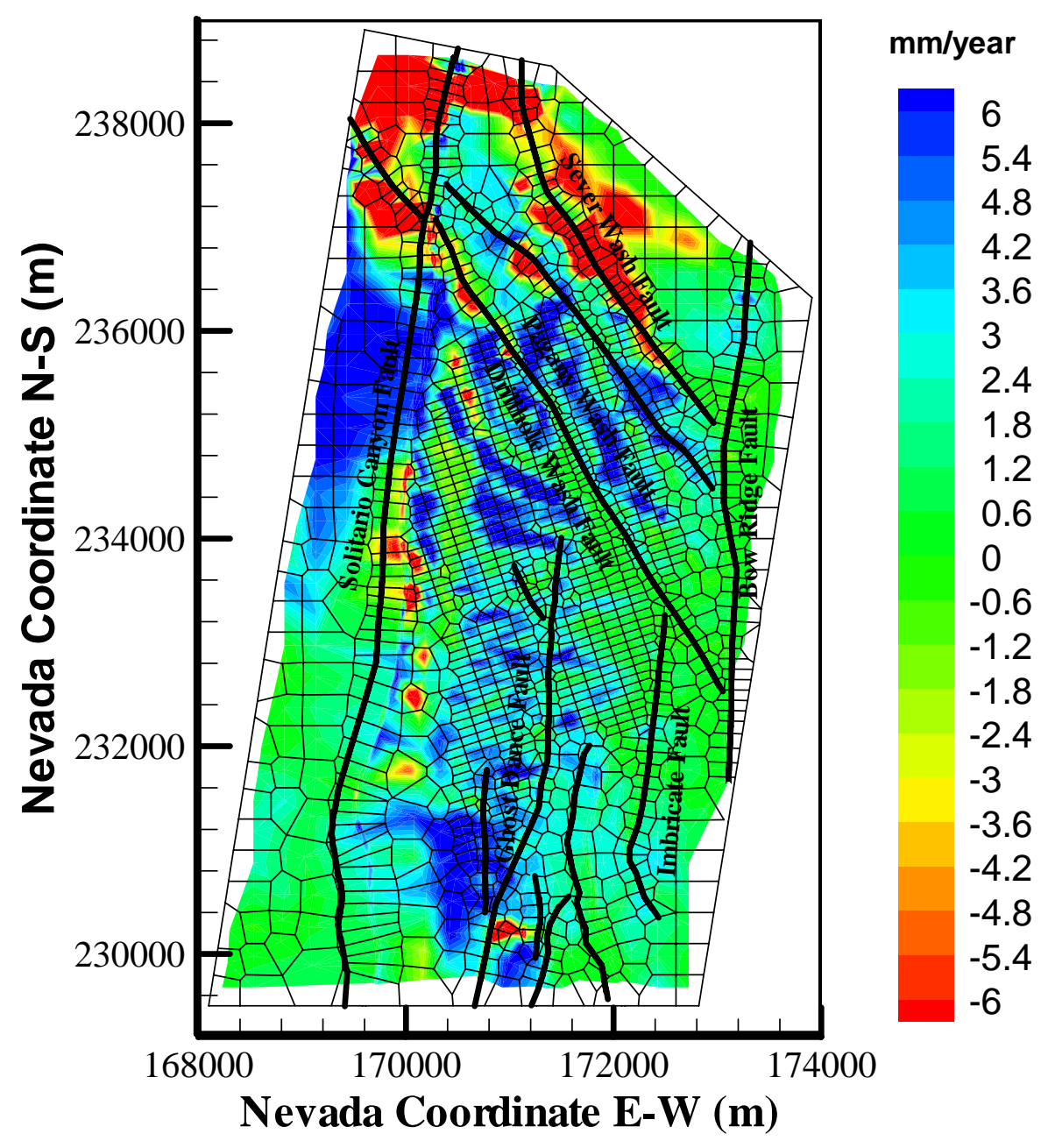

Output DTNS: LB03023DSSCP9I.001 and LB0408RITSSCPF.001.

Figure 1-2. Differences in Net Infiltration between the New, Alternative Infiltration Map and the Current Present-Day, Mean Infiltration Map (Figure 6.1-2) over the Three-Dimensional UZ TSPA-LA Model Grid Domain 


\section{I2. MODEL SIMULATION RESULTS WITH NEW INFILTRATION MAP}

The three-dimensional model simulation is carried out using the UZ flow model of this model report with incorporation of the new infiltration map. The simulation input parameters, model grid, specification of boundary, and initial conditions are exactly the same as the base-case, present-day mean case of the UZ flow model (preq_mA), as discussed in Sections 6.1, 6.2, and 6.6, except the new infiltration rate is used for surface water recharge. The three-dimensional UZ flow simulation is run using the TOUGH2 V1.6 code (LBNL 2003 [DIRS 161491]) to a steady-state, which is confirmed by a global mass-balance error of less than 0.1 percent. The new simulation using the new infiltration map is designated as scenario of "preq_RIT' in this appendix and in figures.

Model Results and Their Comparison with Observed Moisture Data as Well as Previous Simulation Results: Figures I-3, I-4, and I-5 show comparisons between the new three-dimensional model results with field observed matrix liquid saturation, water potential, and perched water data along the vertical column representing Boreholes UZ-14 and SD-12, as well as the model simulation results with the current infiltration rate. The locations of these two boreholes are shown in Figure 6.1-1. Figures I-3, I-4, and I-5 show that, in general, the modeled results from the new simulation (preq_RIT) with the new surface infiltration map are almost identical to those of the simulations with the current infiltration rate (preq_mA), reasonably in agreement with the measured saturation and water-potential profiles, and perched water elevations. 


\section{UZ-14}

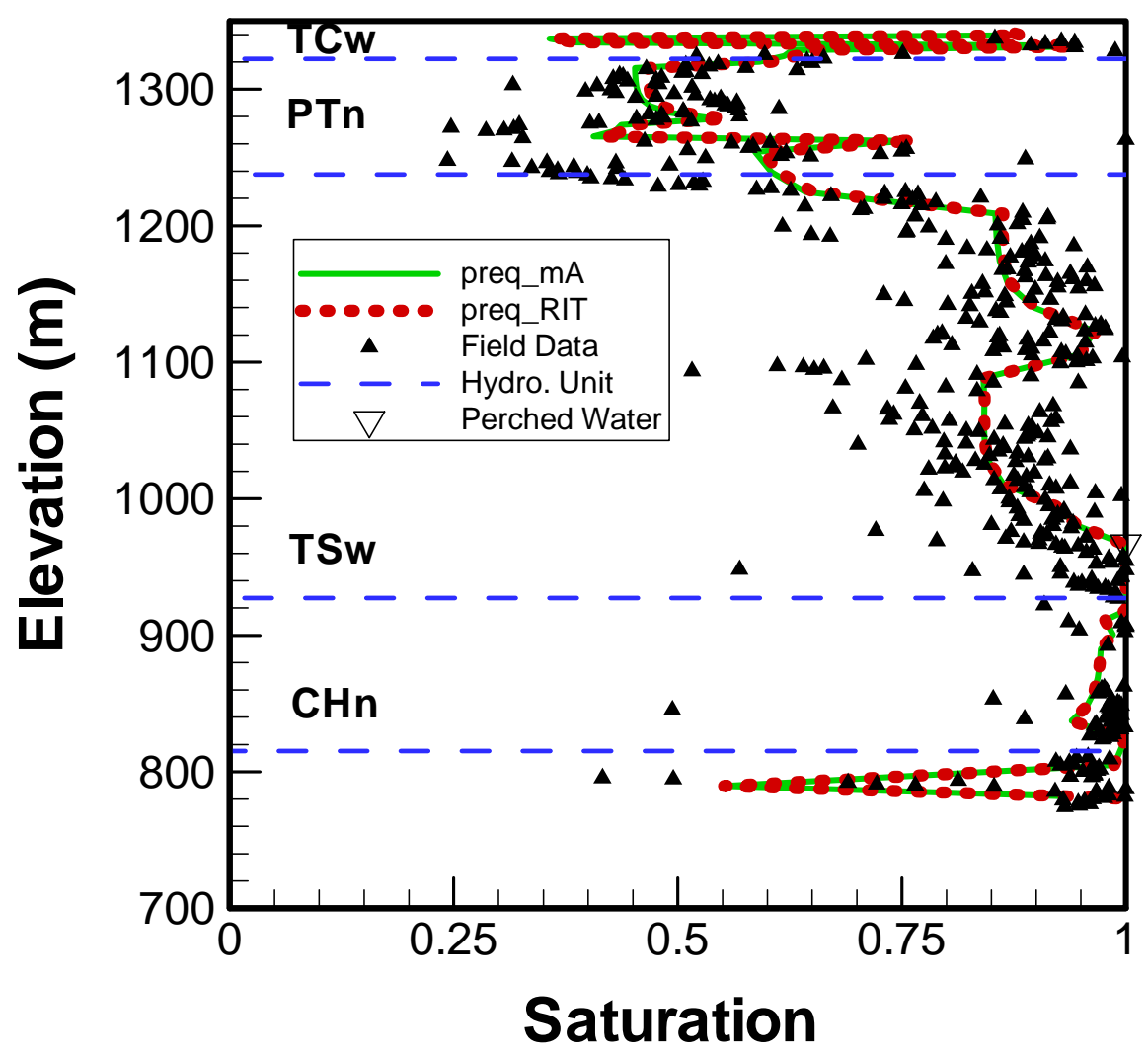

Source DTNs: GS960308312312.005 (DIRS 107230); MO0109HYMXPROP.001 (DIRS 155989); MO0004QGFMPICK.000 (DIRS 152554).

Output DTNs: LB03023DSSCP9I.001 and LB0408RITSSCPF.001.

Figure I-3. Comparison to the Simulated and Observed Matrix Liquid Saturations and Perched-Water Elevations for Borehole UZ-14, Using the Results of the Simulations of preq_mA and preq_RIT of Two Present-Day Mean Infiltration Rates 


\section{SD-12}

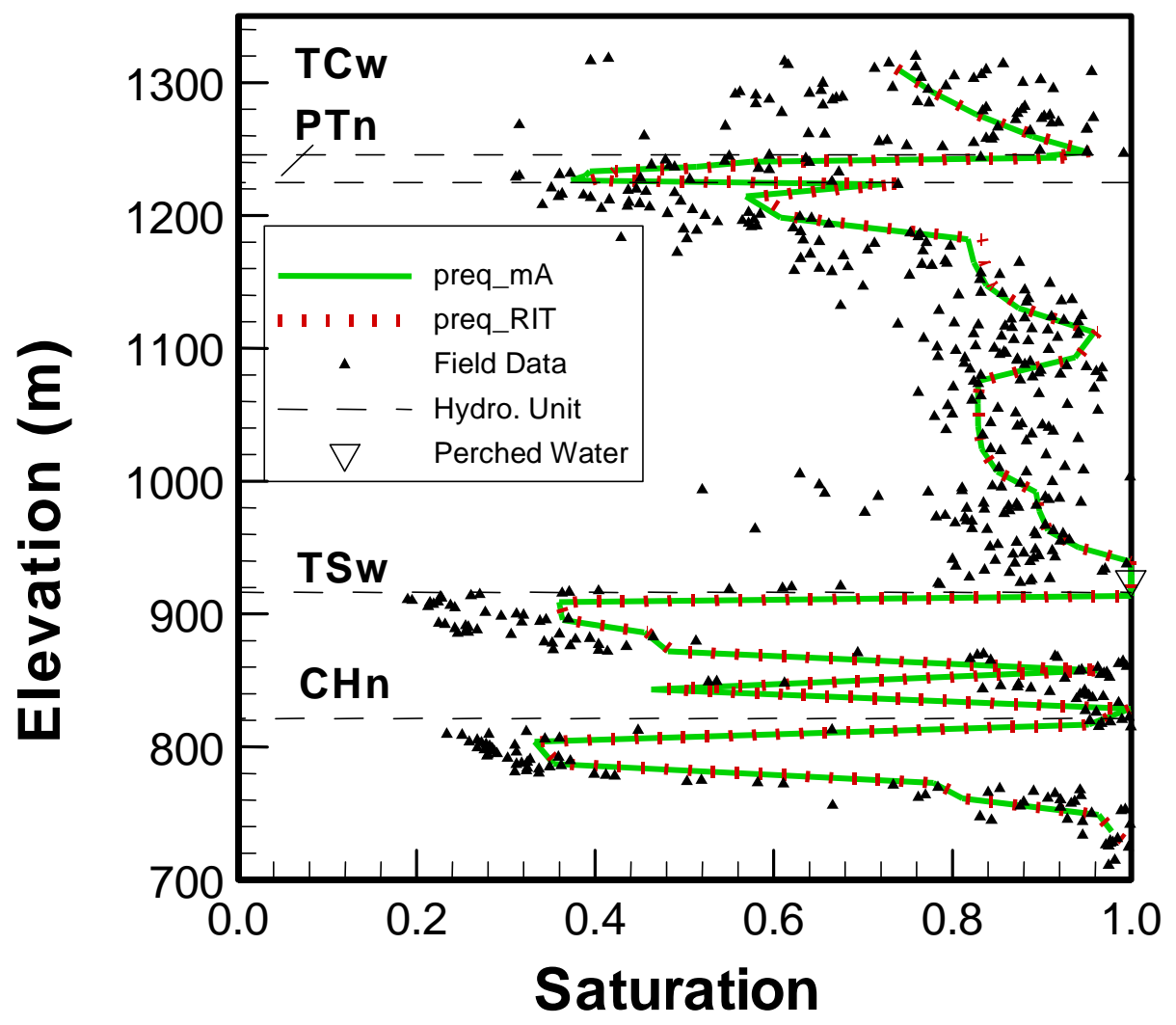

Source: $\quad$ Rousseau et al. 1997 (DIRS 100178); DTNs: MO0109HYMXPROP.001 (DIRS 155989); MO0004QGFMPICK.000 (DIRS 152554).

Output DTNs: LB03023DSSCP9I.001 and LB0408RITSSCPF.001.

Figure I-4. Comparison to the Simulated and Observed Matrix Liquid Saturations and Perched-Water Elevations for Borehole SD-12, Using the Results of the Simulations of preq_mA and preq_RIT of Two Present-Day Mean Infiltration Rates 


\section{SD-12}

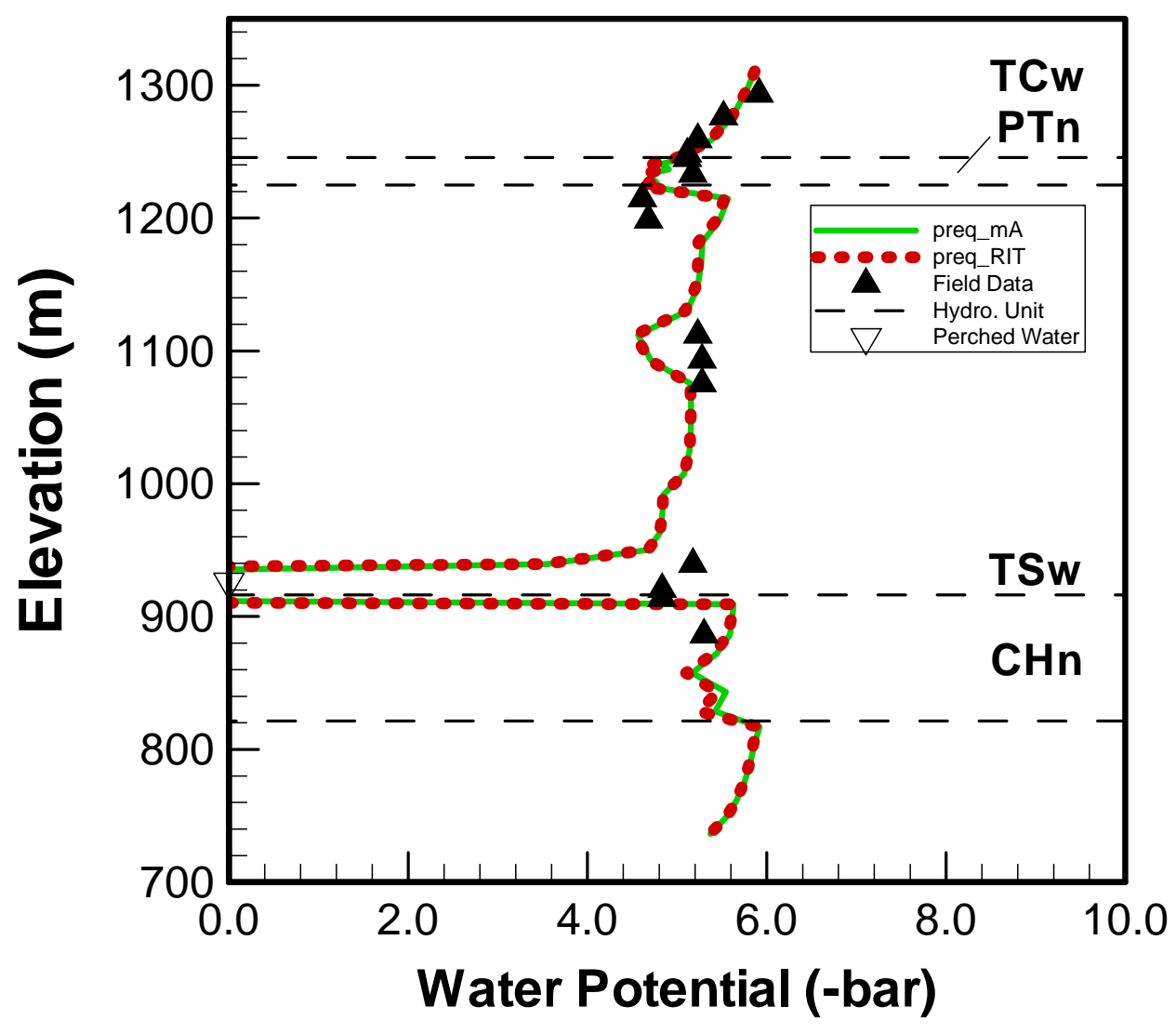

Source DTN: MO0004QGFMPICK.000 (DIRS 152554).

Output DTNs: LB03023DSSCP9I.001 and LB0408RITSSCPF.001.

NOTE: Field data shown in figure are from DTN: LB991091233129.001 (DIRS 125868), based on measured water potentials in DTNs: GS970808312232.005 [DIRS 105978] and GS980408312232.001 (DIRS 105982).

Figure I-5. Comparison to the Simulated and Averaged Observed Water Potentials and Perched-Water Elevations for Borehole SD-12, Using the Results of the Simulations of preq_mA and preq_RIT of Two Present-Day Mean Infiltration Rates 


\section{I3. FLOW RESULTS AND ANALYSES}

Percolation fluxes simulated with the new infiltration are shown in Figure I-6 for the repository horizon and in Figure I-7 for the water table. The new percolation patterns at the repository level of Figure I-6 seem similar to those of Figure 6.6-1 from the model prediction with the current present-day infiltration. The main difference between the two percolation maps of Figures I-6 and 6.6-1 is that there is a wider high percolation zone along the middle of the model domain from the Drill Hole Wash fault to the southern model boundary with the new infiltration model results. When compared with the new surface infiltration map of Figure I-1, Figure I-6 shows a general trend of high flux zones shafting to east along the central model domain from the Drill Hole Wash fault until the southern boundary. This indicates considerable amount of lateral flow occurring while traveling through the Paintbrush nonwelded hydrogeologic unit.

Once traveled down to the water table, Figure I-7 shows a small difference from its counterpart of Figure 6.6-6. Only in the very south, middle part of the model domain, does the new infiltration model predict a larger flux at the water table. 


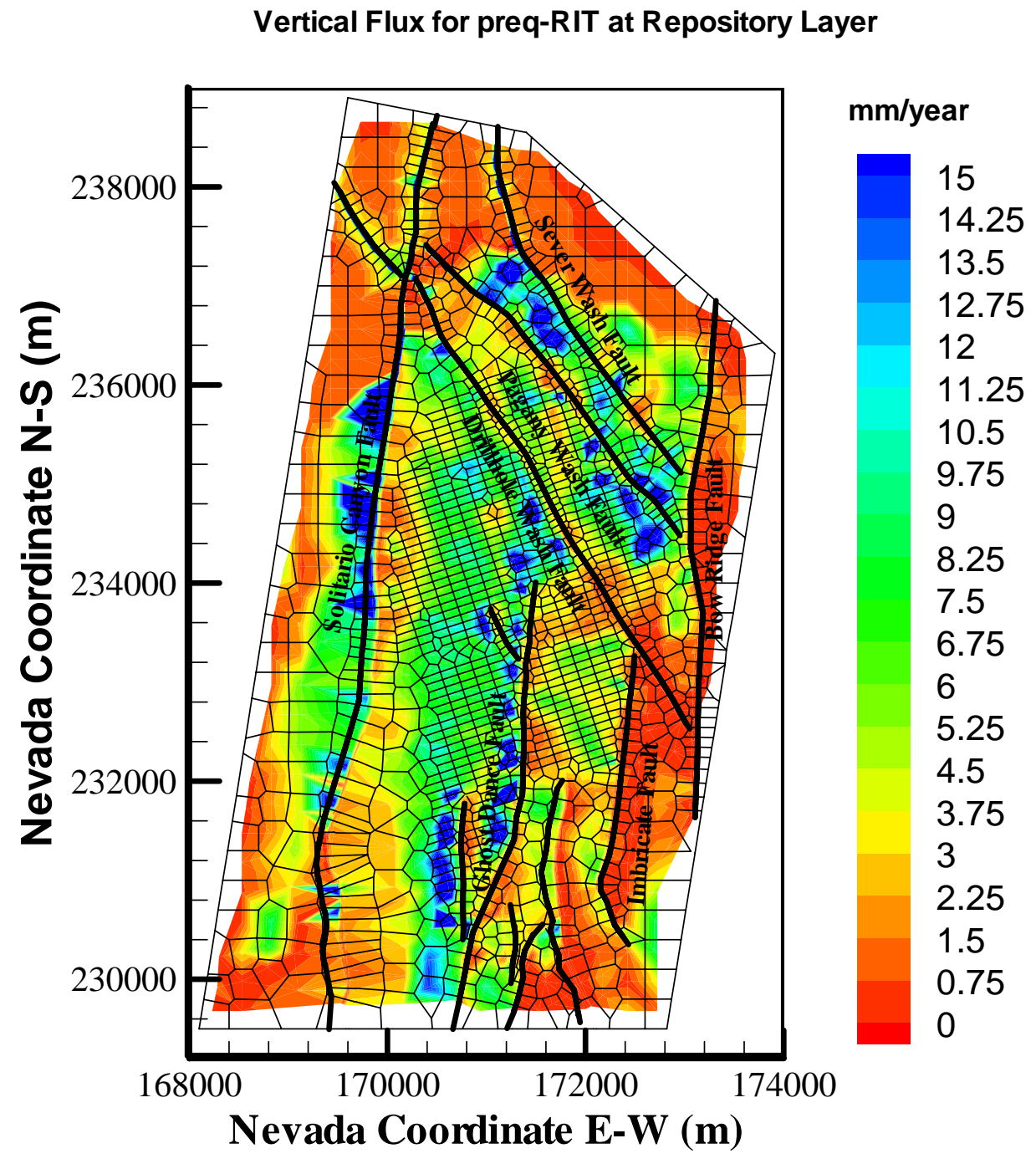

Output DTN: LB0408RITSSCPF.001.

Figure I-6. Simulated Percolation Fluxes at the Repository Horizon under the New, Alternative Present-Day, Mean Infiltration Scenario Using the Results of Simulation: preq_RIT 


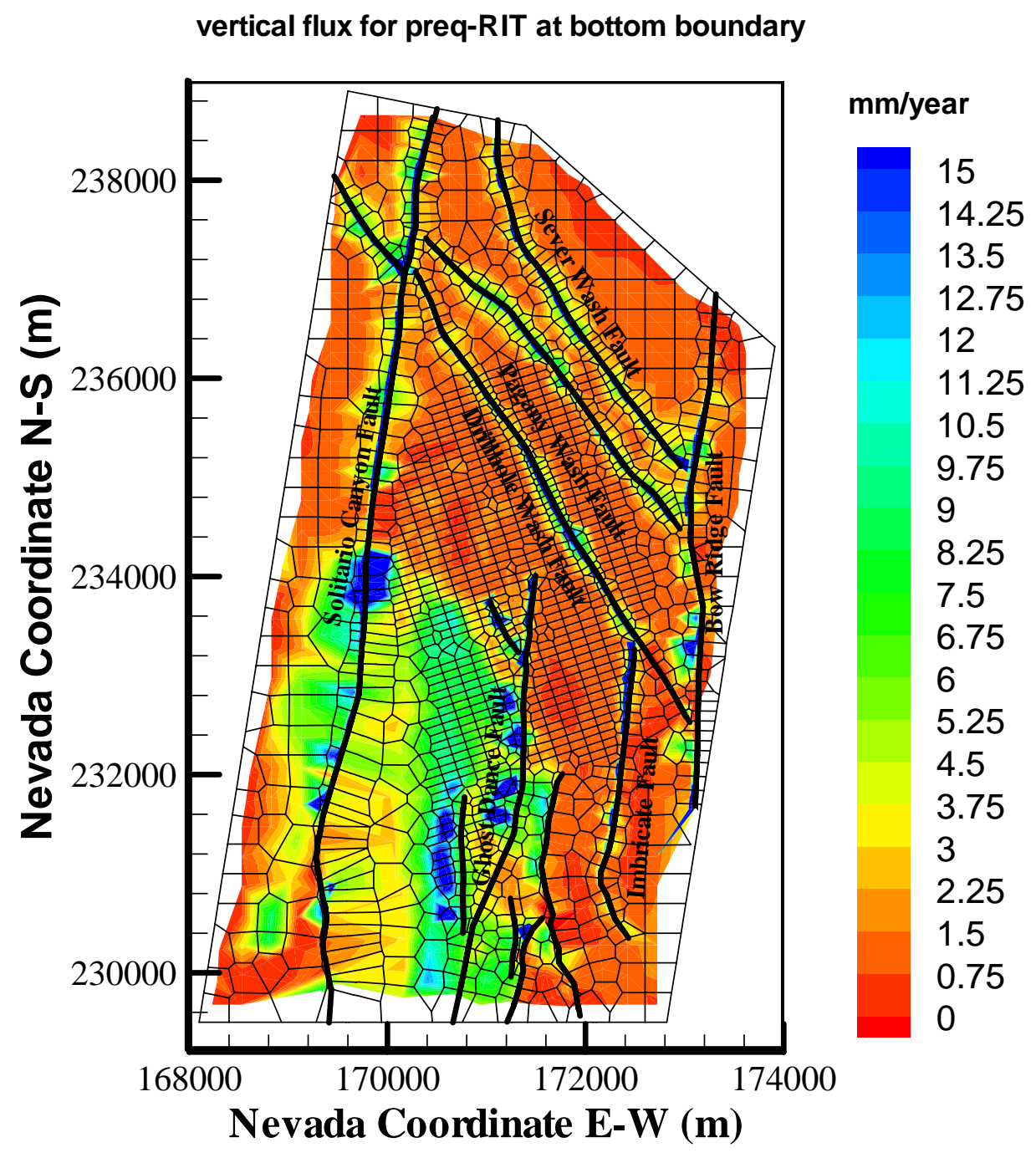

Output DTN: LB0408RITSSCPF.001.

Figure I-7. Simulated Percolation Fluxes at the Water Table under the New, Alternative Present-Day, Mean Infiltration Scenario Using the Results of Simulation: preq_RIT 
Table I-2 lists statistics of percentages of fracture-matrix flow components of non-fault zones and fault flow over the entire model domain and within the repository footprint at the three horizons of the Tiva Canyon welded hydrogeologic/Paintbrush nonwelded hydrogeologic interface (TCw/PTn), the repository level, and the water table for the new infiltration model results as well as comparisons with the current, present-day mean infiltration model results. While Table I-2 shows that there are very similar percentages of fracture, matrix, and fault flow within the repository footprint, a smaller area, the significant difference in these statistics between the two simulation results is a large decrease in fault flow percentage at repository and water table levels, which are reduced from 29 percent to 12 percent and 54 percent to 45 percent, respectively, for the new infiltration model results.

Table I-2. Comparison of the Water Flux through Matrix, Fractures of Non-fault Zones, and Faults as a Percentage of the Total Flux over the Entire Model Domain and within the Repository Footprint at Three Different Horizons: (1) at the Tiva Canyon Welded Hydrogeologic/Paintbrush Nonwelded Hydrogeologic Interface, (2) at the Repository Level, and (3) at the Water Table for the Two Present-Day Mean Infiltration Rates

\begin{tabular}{|l|l|c|c|c|c|c|c|}
\hline \multicolumn{2}{|c|}{ Simulation Designation } & \multicolumn{2}{c|}{ Flux over Entire Model Domain } & \multicolumn{2}{c|}{ Flux within Repository Footprint } \\
(\%)
\end{tabular}

Output DTNs: LB03023DSSCP9I.001 and LB0408RITSSCPF.001.

Frequency distribution of normalized flux values within the repository footprint is shown in Figure I-8. This area flux frequency plot displays the average percentage of the repository area subject to a particular percolation rate for the new infiltration model results. Figure I- 8 indicates wider high-frequency flux ranges around unit normalized flux, somehow a different distribution pattern as compared to Figure 6.6-22 (a) for the model results with the current infiltration map.

\section{I4. SUMMARY}

This appendix provides modeling evaluation and sensitivity studies of the newly estimated surface infiltration map for the present-day climate. The modeling studies are conducted by incorporating the new present-day infiltration map into the current three-dimensional UZ flow of this model report, and the resulting steady-state three-dimensional flow UZ flow field is compared with the current present-day infiltration model results. 
present day, mean infiltration (preq_RIT)

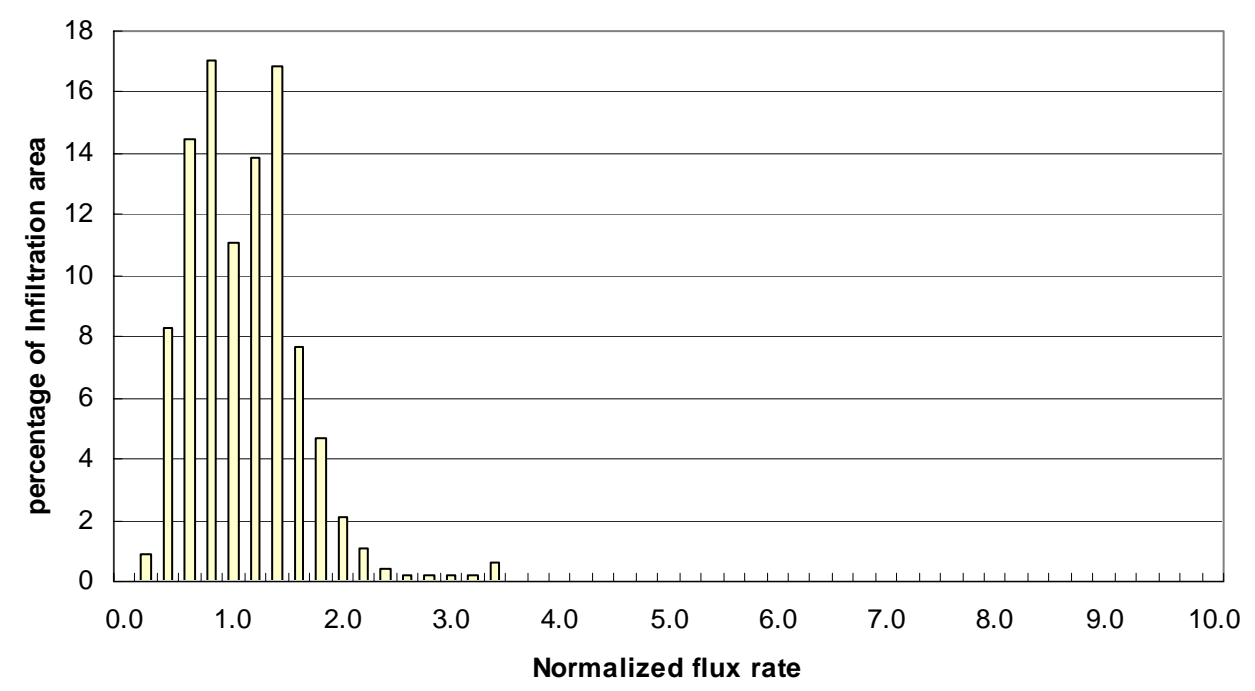

Output DTN: LB0408RITSSCPF.00.

Figure I-8. Areal Frequency and Distribution of Simulated Percolation Fluxes within the Repository Domain Normalized to the Mean Infiltration Rate, Simulation: preq_RIT

The studies of this appendix show that, on average, the new infiltration map provides an 18 percent increases in net infiltration; however, the new infiltration within the repository footprint near the center of the UZ model domain is increased by 73 percent. The main difference of the new infiltration map from the current one is the large decrease in net recharge in the very northern part, and some increase along the middle from the Drill Hole Wash fault to the south. On the other hand, the UZ moisture conditions predicted using the new infiltration map are very similar to those by the current present-day, mean infiltration map, in terms of matching matrix liquid saturation, water potential, and perched water data. The statistics of simulated percolation fluxes, and the fracture, matrix, and fault flow components for the new infiltration map are similar to those for the current infiltration map, except that fault flow percentage at the repository and water table levels are noticeably lower when averaged over the entire model domain. 